\author{
UNIVERSIDADE DE SÃO PAULO \\ ESCOLA DE ENGENHARIA DE SÃO CARLOS \\ PROGRAMA DE PÓS-GRADUAÇÃO EM GEOTECNIA
}

IRAYDES TÁlitA DE SENA NOLA

Avaliação de dados geológico-geotécnicos prévios para elaboração de carta de eventos perigosos de movimentos de massa gravitacionais por meio de redes neurais artificiais e probabilidade 


\section{Avaliação de dados geológico-geotécnicos prévios para elaboração de carta de eventos perigosos de movimentos de massa gravitacionais por meio de redes neurais artificiais e probabilidade}

\section{VOLUME 1}

Dissertação apresentada à Escola de Engenharia de São Carlos da Universidade de São Paulo como parte dos requisitos para obtenção do título de Mestre em Ciências, Programa de Pós-graduação em Geotecnia.

Versão Corrigida

Orientador:

Prof. Dr. Lázaro Valentin Zuquette 
AUTORIZO A REPRODUÇÃO TOTAL OU PARCIAL DESTE TRABALHO, POR QUALQUER MEIO CONVENCIONAL OU ELETRÔNICO, PARA FINS DE ESTUDO E PESQUISA, DESDE QUE CITADA A FONTE.

Nola, Iraydes Tálita de Sena

Avaliação de dados geológico-geotécnicos prévios para elaboração de carta de eventos perigosos de movimentos de massa gravitacionais por meio de redes neurais artificiais e probabilidade / Iraydes Tálita de Sena Nola; orientador Lázaro Valentin Zuquette. São Carlos, 2015.

Dissertação (Mestrado) - Programa de Pós-Graduação e Área de Concentração em Geotecnia -- Escola de Engenharia de São Carlos da Universidade de São Paulo, 2015.

1. movimentos de massa gravitacionais. 2. carta de eventos perigosos. 3. redes neurais artificiais. 4. probabilidade. I. Título. 


\section{FOLHA DE JULGAMENTO}

Candidata: Geóloga IRAYDES TÁLITA DE SENA NOLA.

Título da dissertação: "Avaliação de dados geológico-geotécnicos prévios para elaboração de carta de eventos perigosos de movimentos de massa gravitacionais por meio de redes neurais artificiais e probabilidade ".

Data da defesa: 20/08/2015

Comissão Julgadora:

Prof. Titular Lázaro Valentin Zuquette (Orientador) (Escola de Engenharia de São Carlos/EESC)

Prof. Dr. Edilson Pissato

(Instituto de Geociências/IG-USP)

Prof. Dr. Rogério Pinto Ribeiro

(Escola de Engenharia de São Carlos/EESC)

\section{Resultado:}
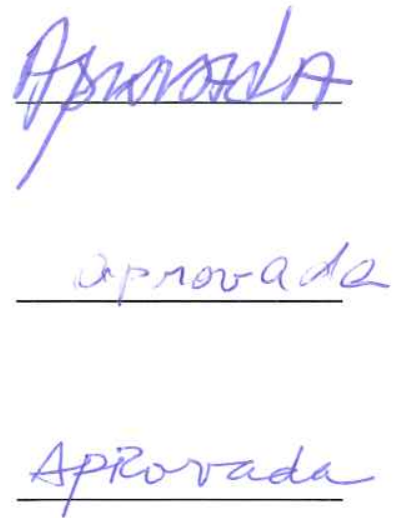

Coordenador do Programa de Pós-Graduação em Geotecnia:

Prof. Dr. Edmundo Rogério Esquivel

Presidente da Comissão de Pós-Graduação:

Prof. Associado Paulo César Lima Segantine 
À minha querida e amada Vovó Tina (in memoriam), pelo orgulho que sempre teve de mim. 



\section{AGRADECIMENTOS}

Ao Prof. Dr. Lázaro Valentin Zuquette pela orientação tão dedicada, pela atenção, pelo apoio, carinho fraterno e pelos longos momentos de descontração.

À Universidade de São Paulo, pela oportunidade de realização do curso de mestrado. E ao Conselho Nacional de Desenvolvimento Científico e Tecnológico (CNPq), pela bolsa concedida.

Ao Departamento de Geotecnia da Escola de Engenharia de São Carlos, igualmente ao quadro de docentes e demais funcionários, pela infraestrutura e auxílios técnicoadministrativos oferecidos, em especial ao Profa Valéria, Profa. Cristina, Prof. Osni, Prof. Bortolucci (Çula), Prof. Orêncio, ao Álvaro, Maristela, Neiva e Oscar.

Aos geólogos, Prof. Edézio Teixeira de Carvalho, Profa. Maria Giovana Parizzi, e Cláudia de Sanctis Viana, pelos ensinamentos geotécnicos, amizade e apoio na decisão de realizar o meu sonho de ser mestre.

Aos professores Ricardo Augusto Fernandes e Danilo Hernane Spatti pelas orientações e aprendizados em redes neurais.

Ao Instituto Geotécnico de Ouro Preto - IGEO - que, por meio do Engenheiro Geotécnico Michel Moreira Fontes e do Geólogo Bruno Novais, gentilmente cedeu-me os dados levantados por este instituto. E também a Coordenadoria Municipal de Defesa Civil através do seu coordenador Sr. Sebastião Bonifácio e do Geólogo Flávio Brandão.

Aos amigos da sala de mapeamento: Bianca Kancelkis, Bruno Medeiros, Camila Almeida, Cláudia Rotta, Diego Ruiz, Lucas Schettini, Maria Paula Oliveira e Moisés Failache. Aos demais colegas da Geotecnia, em especial a Amanda Almeida, Breno Rocha, Camila Eberle, Christopher Fonseca, Denis Watashi, Isabela Monici, João Manoel, João Parizotto, Jussara Michette, Katerin Guerrero, Larissa Vieira, Phillipe Almeida, Rafaela Machado e Thaise Morais.

Ao meu querido Roberto, por transformar os momentos escuros em claros como um dia ensolarado de verão. Seu apoio geotécnico, ideias, brincadeiras, carinho e atenção, fizeram toda a diferença.

Às meninas do "Apê 14": Bruna Correia, Giovana Matos, Larissa Gabrielle e Letícia Duarte pela boa convivência, amizade e divertimento, e ao Homer (Tarcísio Marinelli) também pelos auxílios computacionais.

Aos queridos amigos: Ligia Sampaio, Chien Tseng e demais componentes do grupo de estudos do TAO, por me proporcionarem momentos de tranquilidade e por me darem a oportunidade de conhecer pessoas tão especiais. 
Às amizades tão valiosas de Minas, por não se esquecerem de mim e por me fazer não esquecer também: Alessandra Souza, Flávia Cristina, Flávia de Faria, Karin Voll, Rafael Avelino e Carlos Cunha.

A minha família Sena e Nola (tios, primos e agregados) pelo amor que vocês têm por mim e porque sei que as minhas realizações são também de cada um de vocês. Em especial à Tia Marli, Tio Zé Guilherme, Vanessa e Igor que me receberem em São Paulo de braços abertos.

E por fim, agradeço a Deus por este trabalho e pela magnífica família que ele me deu. Suporte e apoio nos momentos ruins (que não foram poucos), e, alegria, festa e diversão nos momentos felizes. Não me senti sozinha em nenhum dos dias que passei longe de vocês. Obrigada aos meus pais, Luiz Nola e Irayde Sena, aos meus irmãos Luiz Henrique, Luciana e Ana Paula e aos cunhados Cléria e Marcello! 
"... A um quilômetro dali havia um morro com grande desbarrancado - a "barreira", como se dizia no sítio. O Visconde levou-os para lá. Diante da barreira, parou e sorriu.

Os meninos entreolharam-se. Não compreendiam que o Visconde encontrasse matéria para sorriso num barranco feio como todos os mais. — Que gosto é esse, Visconde? - perguntou Emília. - Ah, o sorriso que tenho nos lábios é um sorriso geológico, o sorriso de quem sabe, olha, vê e compreende. Este barranco é para mim um livro aberto, uma página da história da terra na qual leio mil coisas interessantíssimas."

O poço do Visconde Monteiro Lobato 



\section{RESUMO}

NOLA, I. T. S. Avaliação de dados geológico-geotécnicos prévios para elaboração de Carta de Eventos Perigosos de movimentos de massa gravitacionais por meio de redes neurais artificiais e probabilidade. 2015. Dissertação (Mestrado em Geotecnia) Escola de Engenharia de São Carlos, Universidade de São Paulo, São Carlos, 2015.

Este trabalho contempla os estudos realizados para elaboração de uma carta de eventos perigosos (hazard) de uma área de aproximadamente $45 \mathrm{~km}^{2}$, no município de Ouro Preto/MG, a partir de dados geológicos e geotécnicos, gerados em trabalhos de mapeamento geotécnico, com o uso dos recursos de redes neurais artificiais e da probabilidade condicional. Os dados prévios foram tratados e um conjunto de 15 mapas e cartas elaborado, a saber: topográfico, de substrato rochoso, material inconsolidado, de uso e ocupação, de inventário dos movimentos de massa gravitacionais (escorregamentos translacionais, escorregamentos translacionais - tipo de material), de declividade, de rumo da inclinação das encostas, das unidades geológico-geotécnicas, das seções típicas das unidades geológico-geotécnicas, da resistência ao cisalhamento, do contraste de permeabilidade e da superfície potencial de ruptura, associado a uma tabela com as características das unidades geológicogeotécnicas. Os modelos de redes neurais artificiais e probabilidade condicional foram desenvolvidos para o uso em MATLAB utilizando um conjunto de 11 mapas e cartas dentre os citados anteriormente. A análise dos dados prévios frente aos modelos foi desenvolvida no sentido de avaliar a sua qualidade e a sua adequação ao modelo proposto. Concluiu-se sobre a necessidade de dados específicos que nem sempre são gerados em trabalhos rotineiros, como: levantamento da atividade, velocidade, volume e data de ocorrência, entre outros para caracterização das feições de movimentos de massa gravitacionais; estudo detalhado dos parâmetros de resistência dos materiais e das descontinuidades presentes no substrato rochoso; dados de estações pluviométricas para estudos da intensidade e distribuição da chuva na região, entre outras informações.

Palavras-chave: movimentos de massa gravitacionais, carta de eventos perigosos, redes neurais artificiais, probabilidade, Ouro Preto, Brasil. 



\begin{abstract}
NOLA, I. T. S. Assessment of the Previous Geological and Geotechnical data for elaboration of the landslides hazard map using artificial neural network and probability. 2015. Dissertação (Mestrado em Geotecnia) - Escola de Engenharia de São Carlos, Universidade de São Paulo, São Carlos, 2015.
\end{abstract}

This work shows the studies developed for elaboration of the landslide hazard map of the area of $45 \mathrm{~km}^{2}$, approximately, in the municipality of Ouro Preto, in the state of Minas Gerais, Brazil, from data generated in geotechnical mapping, with the use of artificial neural networks and conditional probability methods. The previous data were processed and was elaborated a set of 15 maps and charts: topographic, lithologies, unconsolidated material, land uses, inventory (landslides, translational slides, translational inventory - type of geological material, slope, slope inclination direction, geological - geotechnical units, typical topographic profile of the geological and geotechnical units, the shear strength categories, hydraulic conductivity contrasts, potential failure surfaces and a table with characteristic of the geological and geotechnical units. The procedures of the artificial neural networks and conditional probability were developed for use in MATLAB using a set of 11 maps among the 15 elaborated. A analysis of the previous data prepared and the data necessary for models was developed to evaluate its suitability. The main conclusion is that the routine mapping and inventories do not consider important attributes, such as activity, movement rate, volume, landslide date and others aspects of the features; detailed study about shear strength of geological materials and discontinuities and rainfall data.

Keywords: Landslides, hazard map, artificial neural network, probability, Ouro Preto, Brazil. 



\section{LISTA DE FIGURAS}

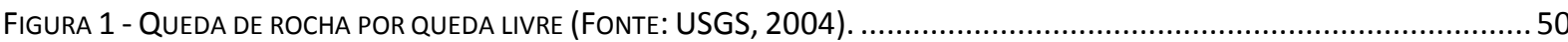

FIGURA 2 - EXEMPLO DE QUEDA DE BLOCOS DE ROCHA OCORRIDO EM STUPICA NA CROÁCIA............................................5 51

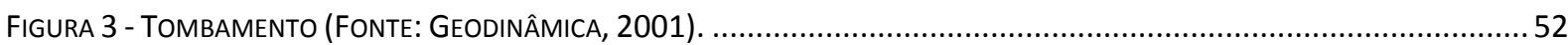

FIGURA 4 - EXEMPLO DE TOMBAMENTO DE ROCHA OCORRIDO EM ALBERTA/CANADÁ. ..................................................... 52

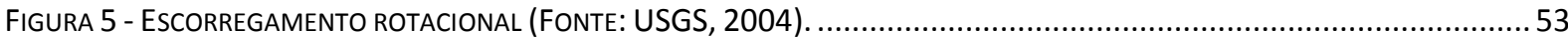

FIGURA 6 - EsCoRREGAMENTO ROTACIONAL DE GRANDES DIMENSÕES OCORRIDO EM LA CONCHITA, CALIFÓRNIA/EUA................54

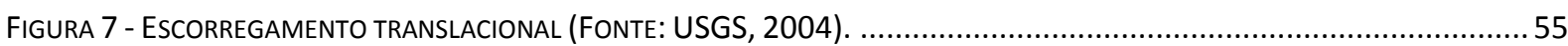

FIGURA 8 - ESCORREGAMENTO TRANSLACIONAL OCORRIDO EM 2008 NA CIDADE DE BLUMENAU, SANTA CATARINA. ....................55

FIGURA 9 - EXEMPLO DE FLUXO DE LAMA OCORRIDO EM BLUMENAU, SANTA CATARINA EM 2008.......................................58

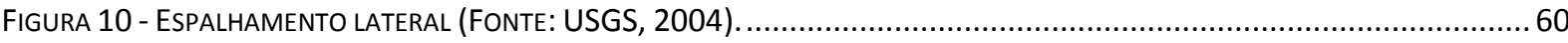

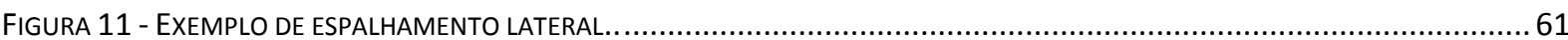

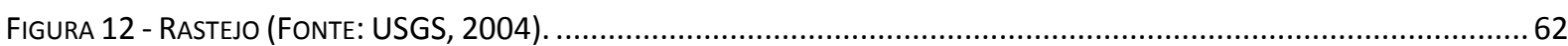

FIGURA 13 - EXEMPLO DE RASTEJO EM ENCOSTA CUJOS INDÍCIOS SÃO VISTOS ATRAVÉS DOS TRONCOS CURVOS, BUSCANDO O

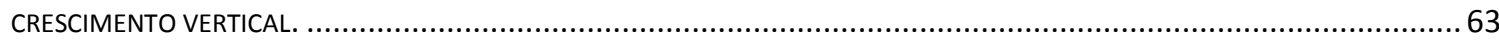

FIGURA 14 - TIPOS DE MOVIMENTOS DE VERTENTES DE MONTANHAS (MODIFICADO DE HUTCHINSON, 1988). ..........................67

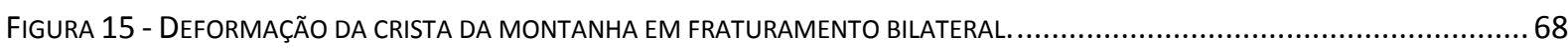

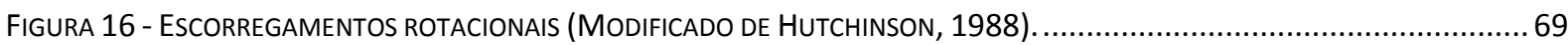

FIGURA 17 - ESCORREGAMENTOS TRANSLACIONAIS (MODIFICADO DE HUTCHINSON, 1988). ..........................................69

FigURA 18 - TIPOS DE MOVIMENTOS DE DETRITOS EM FORMA DE FLUXO (MODIFICADO DE HUTCHINSON, 1988).......................70

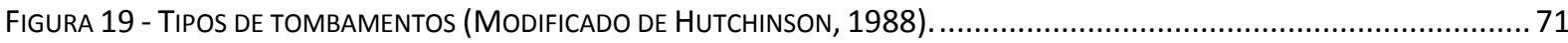

FIGURA 20 - TIPOS DE QUEDAS DE BLOCOS (MODIFICADO DE HUTCHINSON, 1988)......................................................... 72

FIGURA 21 - ETAPAS DO MODELO DE AVALIAÇÃO dOS MOVIMENTOS DE MASSA DE UMA ÁREA, ORGANIZADOS EM ORDEM DE

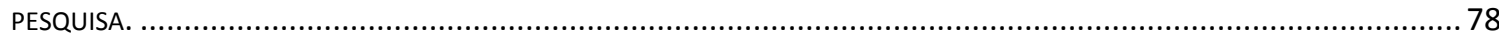

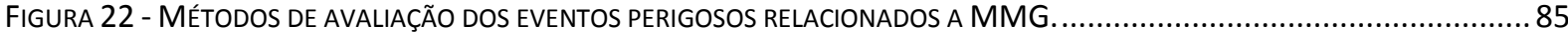

FIGURA 23 - PARTE DO MAPA DE EVENTOS PERIGOSOS ELABORADO ATRAVÉS DA ANÁLISE .................................................8 87

Figura 24 - CARTA DE EVENTOS PERIgOSOS DE NAMASIGUE, HONDURAS: A) ANTES DA ADIÇÃO dO RESULTAdO dO FATOR USO E OCUPAÇÃO E, B) DEPOIS DA ADIÇÃO DE TOdOS OS FATORES (PEROTTO-BALDIVIEZO ET AL., 2004). ..................................89

Figura 25 - Carta de eVentos Perigosos de Selangor, MalÁsia (Pradhan, 2010)..............................................91

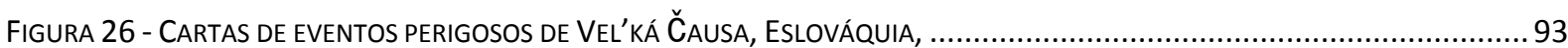

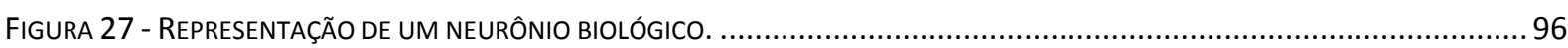

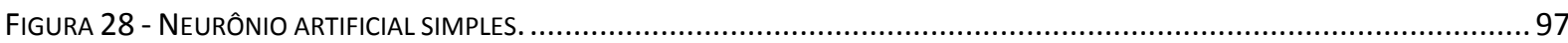

FIGURA 29 - ALGUNS PESQUISADORES NO ESTUDO DAS REDES NEURAIS ARTIFICIAIS. DA ESQUERDA PARA DIREITA: WARREN

McCulloch, Walter Pitts, Donald Hebb, Marvin Minsky, Bernard Widrow, Seymour Papert e John Hopfield (ADAPTADO DE KRIESEL 2005). 
FIGURA 30 - REDE UNIDIRECIONAL COM ÚNICA CAMAdA DE NEURÔNIOS (MODIFICADO DE HAYKIN, 2001).. .104

FIGURA 31 - REDE UNIDIRECIONAL COM MULTICAMAdAS DE NEURÔNIOS (MODIFICADO DE HAYKIN, 2001). .104

Figura 32 - Rede RECORRENTE COM NEURÔNIOS OCULtos (MOdIFICAdO DE HAYKIN, 2001). 105

FIGURA 33 - GRÁFICO ILUSTRANDO A FRONTEIRA DE SEPARAÇão ENTRE AS DUAS CLASSES DE SAÍDA (MODIFICADO de SILVA, SPATTI E FLAUZINO, 2010). 109

Figura 34 - REPRESENTAÇÕES GRÁFICAS dA SEPARAÇÃo LINEAR dOS DAdOS USANDO PERCEPTRON PARA: A) FUnÇÃo AND,

B)FUNÇÃO OR E C)FUNÇÃO XOR...... 111

FIGURA 35 - REPRESENTAÇÃO DE UMA REDE SIMPLES DO TIPO MLP COM CAMADAS INTERMEDIÁRIAS OU OCULTAS... .112

FIGURA 36 - REPRESENTAÇÃO DE UM NEURÔNIO (J) DA CAMADA (L) DE UMA REDE 114

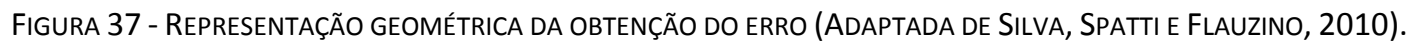
.115

FIGURA 38 - FLUXOGRAMA DE ESTUDO. .119

FIGURA 39 - EVENTO A E SEU EVENTO COMPLEMENTAR Ā NUM ESPAÇO AMOSTRAL $\Omega$. 122

FiguRA 40 - Diagrama de VENN PARA $\boldsymbol{A} \cup \boldsymbol{B}$ NUM ESPAÇO AMOSTRAL $\Omega$. .122

FIGURA 41 - DiagRAMA DE VENN PARA EVENTOS MUTUAMENTE EXCLUSIVOS EM UM ESPAÇO AMOSTRAL $\Omega$. .123

Figura 42 - Diagrama de VenN PARA OS EVENTOS A E B, CUJA INTERSEÇÃO, ...........................................................124

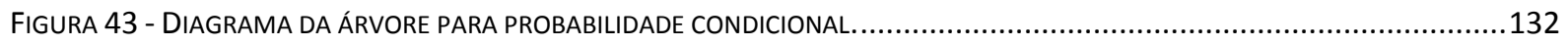

FIGURA 44 - DIAGRAMA DE ÁRVORE COM AS POSSIBILIDADES EXISTENTES AO LANÇAR UM DADO E UMA MOEDA.........................132

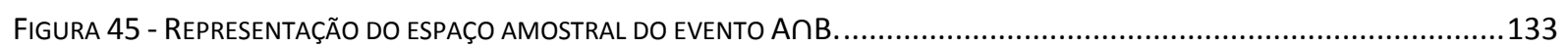

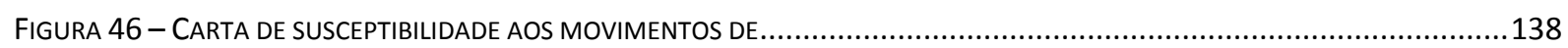

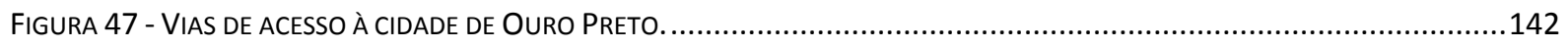

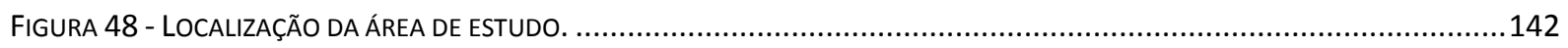

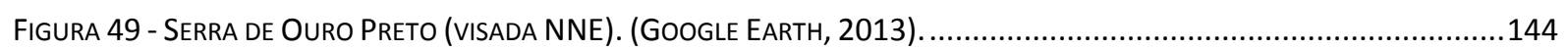

FIGURA 50 - SERRA DE ITACOLOMI AO FUNDO E OCUPAÇÃO URBANA A DIREITA DA IMAGEM...............................................145

FIgURA 51 - CICATRIZES DE MOVIMENTAÇÃO DE MASSA EM ENCOSTA NA CIDADE DE OURO PRETO......................................146

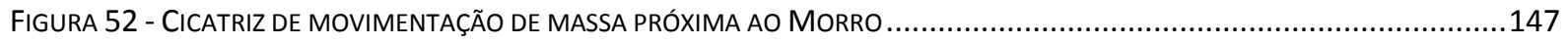

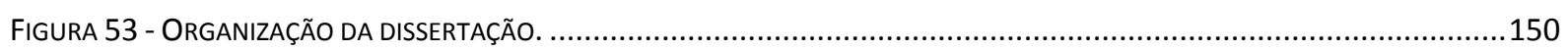

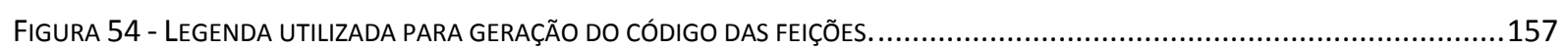

FIGURA 55 - DETALHE dA PORÇÃo LESTE do MAPA de ÁreAS de RISCO E REGISTROS .....................................................179

FIGURA 56 - REPRODUÇÃO DE PARTE DA TABELA DE DAdOS APRESENTADA POR FONTES(2011)........................................181

FIGURA 57 - PoRÇÃo LESTE do MAPA DE INVENTÁRIO DE OCORRÊNCIAS APRESENTADO POR FONTES(2011)...........................182

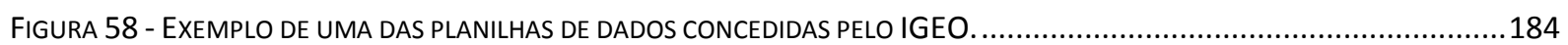

FIGURA 59 - FREQUÊNCIA DAS OCORRÊNCIAS QUANTO AO TIPO DE MOVIMENTO, QUE SÃO: A) ESCORREGAMENTO ROTACIONAL; B) ESCORREGAMENTO E CORRIDA; C) ESCORREGAMENTO E EROSÃO; D) CORRIDAS E ROLAMENTOS; E) ESCORREGAMENTO TRANSLACIONAL E CORRIDA; F) CORRIDAS; G) ÁREA DE MÚLTIPLAS FEIÇÕES; H) ESCORREGAMENTO; I) ESCORREGAMENTO TRANSLACIONAL; J) QUEDAS E ROLAMENTOS; K) COMPLEXO.

FIGURA 60 - ANÁLISE DAS FEIÇÕES INVENTARIADAS: A)TIPO DE MATERIAL; B)ATIVIDADE; C)PROFUNDIDADE DA SUPERFíCIE DE RUPTURA. 
FIGURA 61 - ANÁLISE DAS FEIÇÕES CLASSIFICADAS COMO ESCORREGAMENTO TRANSLACIONAL: A)TIPO DE MATERIAL; B)ATIVIDADE;

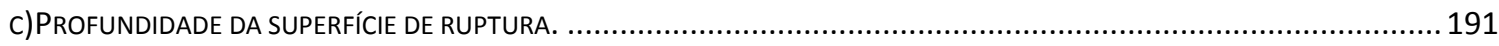

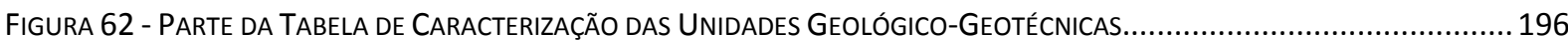

FiguRA 63 - ForÇAS ATUANTES EM UMA FATIA GENÉRICA, SEGUNDO o MÉTOdO DE TALUdE INFINITO. (MOdiFICAdO DE GERSCOVICH, 2012) 206

FIGURA 64 - REPRESENTAÇÃO DA CONVERSÃO DAS CLASSES DE VETORIAIS PARA MATRICIAIS. ...........................................209

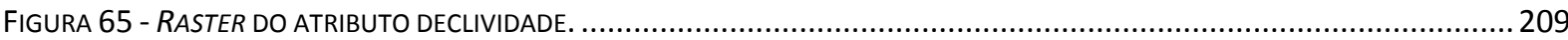

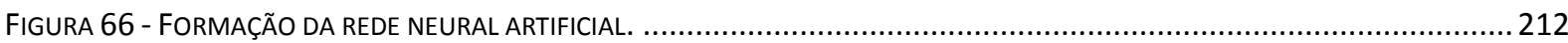

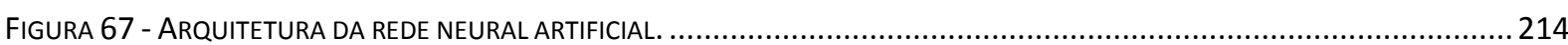

FIGURA 68 - FORMA DE REPRESENTAÇÃO DA CARTA DE EVENTOS PERIGOSOS: A) MAPA DE VERTENTES, B)GRADE COM VALORES DE

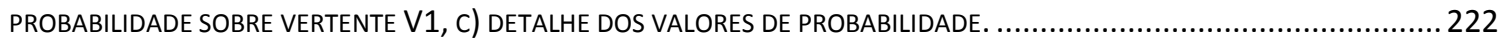

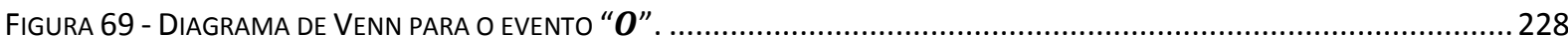

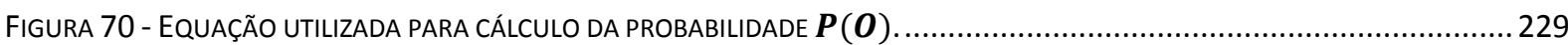





\section{LISTA DE TABELAS}

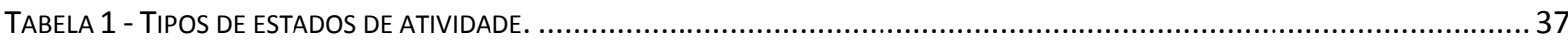

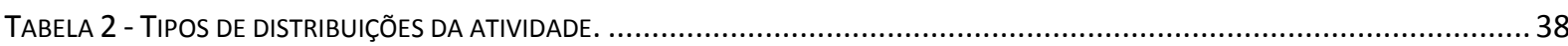

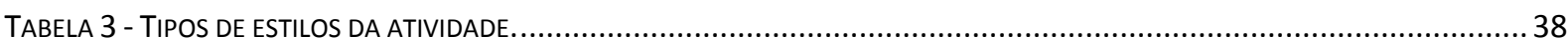

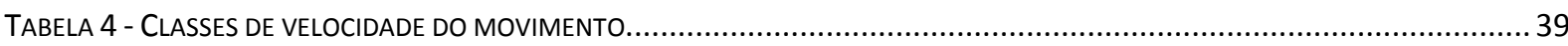

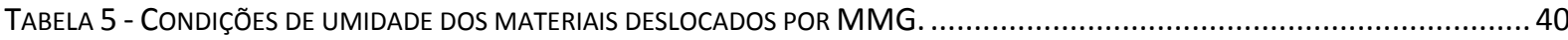

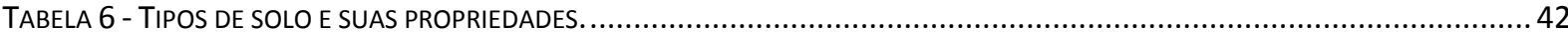

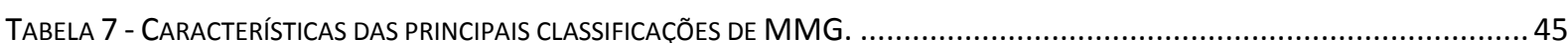

TABELA 8 - VANTAGENS E DESVANTAGENS DAS PRINCIPAIS CLASSIFICAÇÕES DOS MOVIMENTOS DE MASSA GRAVITACIONAIS. ........... 47

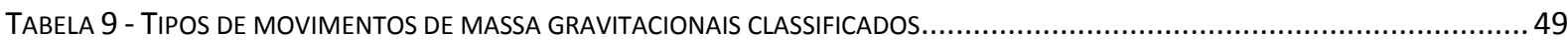

TABELA 10 - TIPOS DE MOVIMENTOS DE MASSA GRAVITACIONAIS CLASSIFICADOS POR HUTCHINSON (1988). ............................66

TABELA 11 - LISTA DAS CAUSAS QUE GERAM MMG (CRUDEN E LAN, 2015) ............................................................... 74

TABELA 12 - DESCRIÇÃO DOS ELEMENTOS QUE COMPÕEM UM NEURÔNIO ARTIFICIAL. ...................................................... 98

TABELA 13 - FunçÕES DE ATIVAÇÃo EM Redes NeURAis ARTIFICIAIS.........................................................................99

TABELA 14 - DADOS DE TREINAMENTO PARA DIAGNÓSTICO DE DOENÇAS.................................................................. 106

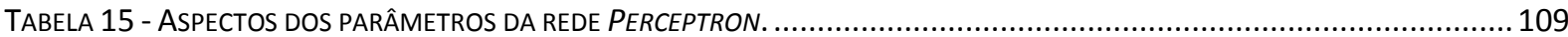

TABELA 16 - VALORES DE ENTRAdA E SAÍDA PARA REPRESENTAÇÃO DAS FUnÇÕES AND, OR E XOR. ..................................... 110

TABELA 17 - TABELA DE INFORMAÇÕES DOS FUNCIONÁRIOS DE UMA EMPRESA........................................................... 126

TABELA 18 - RESULTAdOS PARA LANÇAMENTO DE UMA MOEDA E UM DADO.......................................................... 131

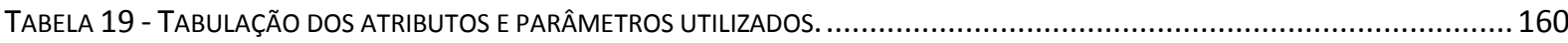

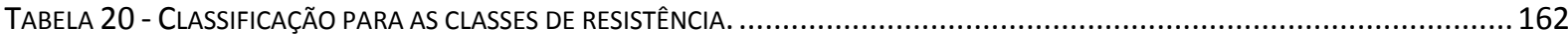

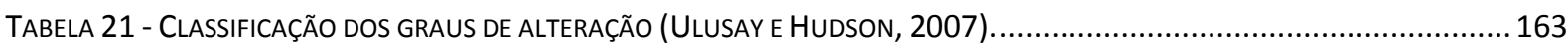

TABELA 22 - INTERVALOS DE PERMEABILIDADE DOS MATERIAIS EXISTENTES NA ÁREA DE ESTUDO........................................ 164

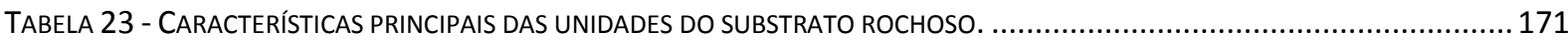

TABELA 24 - CARACTERÍSTICAS PRINCIPAIS DAS UNIDADES DO MATERIAL INCONSOLIDADO. ........................................... 173

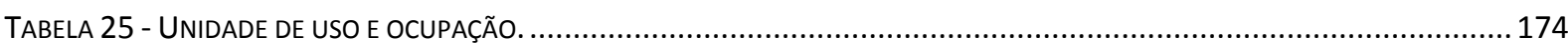

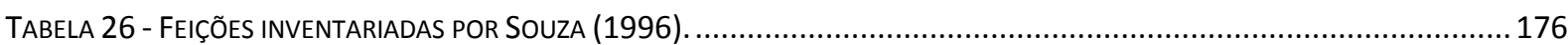

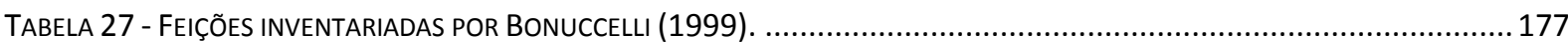

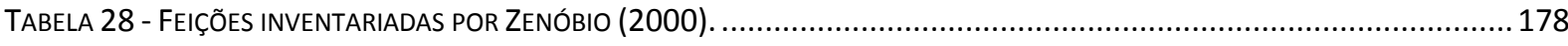

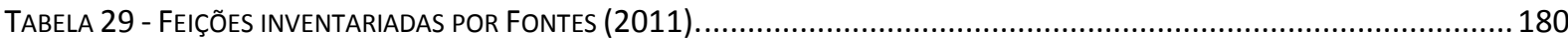

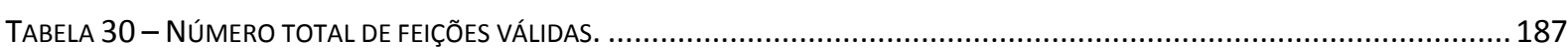

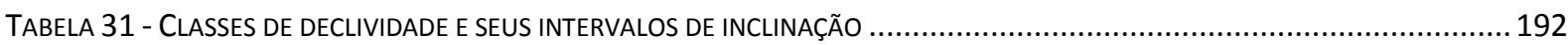

TABELA 32 - CLASSES DO RUMO DE INCLINAÇÃO DAS ENCOSTAS E SEUS INTERVALOS.................................................... 193

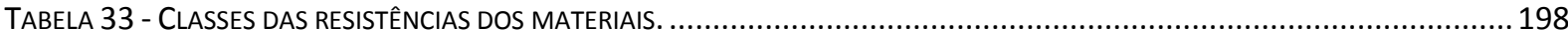

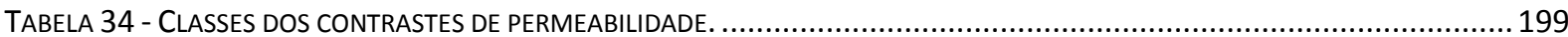


TABELA 35 - CLASSES DA SUPERFÍCIE POTENCIAL DE RUPTURA.

TABELA 36 - CONDIÇÕES PARA OCORRÊNCIA DE ESCORREGAMENTO TRANSLACIONAL.

TABELA 37 - CONDIÇÕES PARA OCORRÊNCIA DE ESCORREGAMENTO TRANSLACIONAL. .....................................................204

TABELA 38 - VALORES DE PROBABILIDADE PARA AS CLASSES DO ATRIBUTO UNIDADE GEOLÓGICO-GEOTÉCNICAS. . 


\section{LISTA DE SIGLAS}

$\begin{array}{ll}\text { APA } & \text { Área de Proteção Ambiental } \\ \text { ASCII } & \text { American Standard Code for Information Interchange } \\ \text { BGS } & \text { British Geological Survey } \\ \text { IAEG } & \text { International Association for Engineering Geology and the Environment } \\ \text { IGEO } & \text { Instituto Geotécnico } \\ \text { IPT } & \text { Instituto de Pesquisas Tecnológicas } \\ \text { ISRM } & \text { International Society of Rock Mechanics } \\ \text { MDT } & \text { Modelo Digital de Terreno } \\ \text { MMG } & \text { Movimento de Massa Gravitacional } \\ \text { MPL } & \text { Multilayer Perceptron } \\ \text { RNA } & \text { Rede Neural Artificial } \\ \text { TIN } & \text { Triangulated Irregular Network } \\ \text { UNESCO } & \text { United Nations Educational, Scientific and Cultural Organization } \\ \text { UCS } & \text { Uniaxial Compressive Strength } \\ \text { URCS } & \text { Unified Classification Rock System } \\ \text { USGS } & \text { United States Geological Survey } \\ \text { UTM } & \text { Universal Transversa de Mercator } \\ \text { WP/WLI } & \text { Working Party on World Landslides Inventory } \\ \text { ZERMOS } & \text { Zones Exposed to Risk of Soil Movements }\end{array}$





\section{SUMÁRIO}

\section{VOLUME 1}

1 INTRODUÇÃO

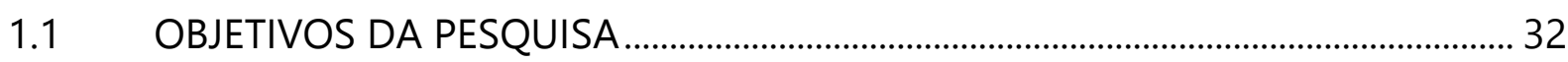

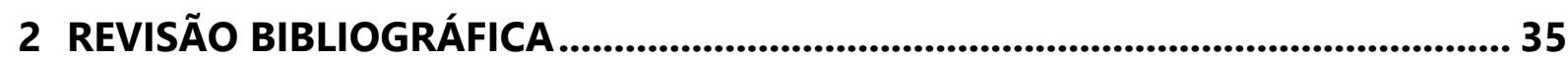

2.1 MOVIMENTO DE MASSA GRAVITACIONAL ............................................................... 35

2.1.1 Informações adicionais para descrição do MMG ...................................................... 36

2.1.1.1 Atividade do Movimento................................................................................................. 36

2.1.1.2 Velocidade do movimento ................................................................................................ 39

2.1.1.3 Condições de umidade ............................................................................................ 39

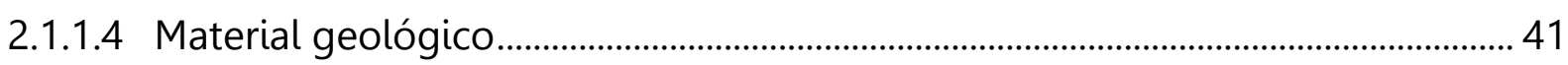

2.1.2 Comparação entre as classificações.............................................................................. 43

2.1.3 Principais classificações ............................................................................................ 48

2.1.3.1 Classificação de Varnes (1978) .............................................................................. 48

2.1.3.2 Classificação de Hutchinson (1988)............................................................................ 65

2.1.4 Fatores que influenciam o MMG ……………………………………………..... 72

2.2 ESTUDO SOBRE MOVIMENTOS DE MASSA GRAVITACIONAIS ............................ 76

2.2.1 Conceitos gerais ..................................................................................................

2.2.2 Tipos de mapas e cartas de movimentos de massa gravitacionais..................... 77

2.2.2.1 Inventário …………………………………………………………………………….... 79

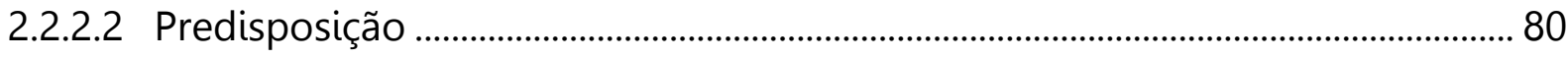

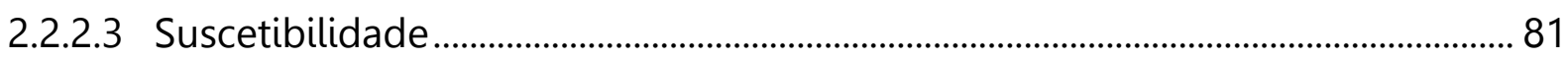

2.2.2.4 Eventos Perigosos (Hazard) ……………………………………………………….... 81

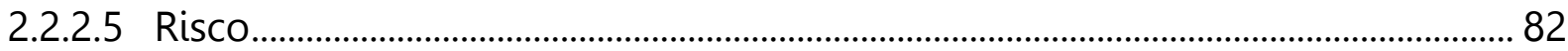

2.3 CARTA DE EVENTOS PERIGOSOS (HAZARD) ...................................................... 84

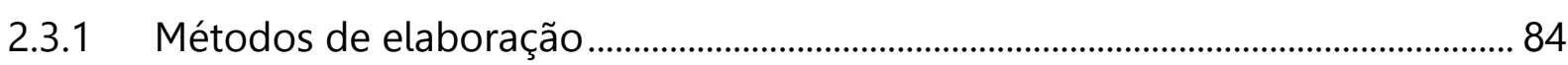

2.3.1.1 Métodos qualitativos ............................................................................................... 85

2.3.1.2 Métodos quantitativos .............................................................................................. 89

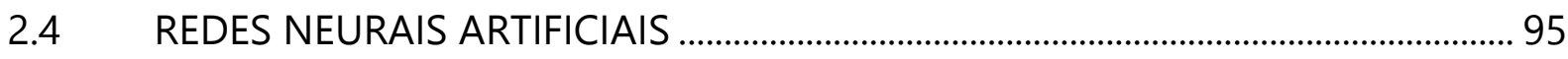

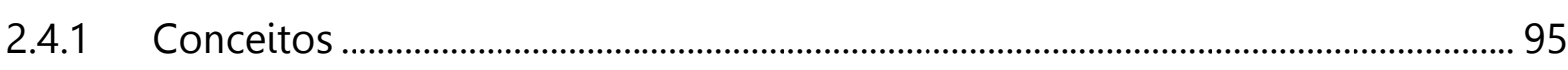

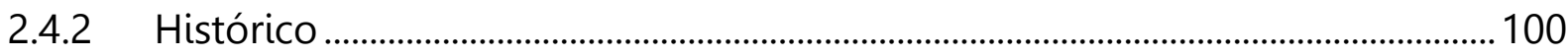


2.4.3 Arquitetura de RNA …………………………………………………………...... 102

2.4.4 Treinamento e aprendizagem .................................................................................. 105

2.4.5 Tipos de redes................................................................................................................. 107

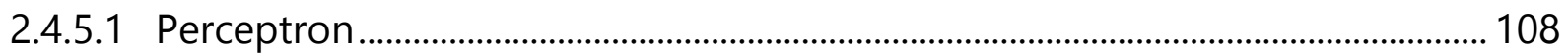

2.4.5.2 Perceptron de Multicamadas....................................................................................... 111

2.4.6 Área de aplicação ......................................................................................................... 116

2.4.7 Uso das redes neurais no estudo de MMG......................................................... 118

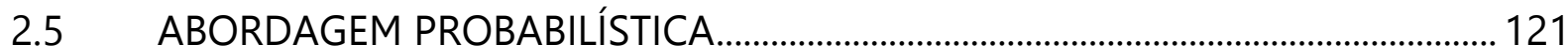

2.5.1 Principais conceitos …………………………………………………………..... 121

2.5.2 Abordagens probabilísticas .............................................................................. 125

2.5.2.1 Abordagem clássica ................................................................................................ 125

2.5.2.2 Abordagem frequentista ............................................................................................ 126

2.5.2.3 Abordagem subjetiva ........................................................................................ 127

2.5.3 Eventos dependentes e independentes ............................................................. 128

2.5.4 Eventos compostos ...................................................................................................... 130

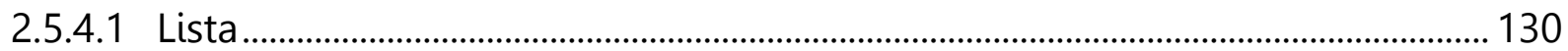

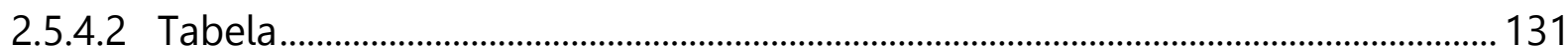

2.5.4.3 Diagrama de Árvore................................................................................................. 131

2.5.5 Probabilidade condicional.......................................................................................... 133

2.5.6 Teorema da Probabilidade Total............................................................................. 136

2.5.7 Teorema de Bayes ................................................................................................ 136

2.5.8 Uso de análise probabilística no estudo de MMG ................................................. 137

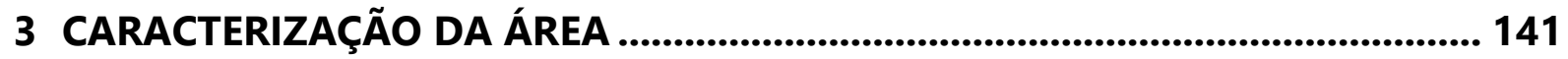

3.1 CONSIDERAÇÕES GERAIS................................................................................... 141

3.1.1 Localização ................................................................................................................. 141

3.2 ASPECTOS GERAIS ........................................................................................... 143

3.2.1 Geologia......................................................................................................... 143

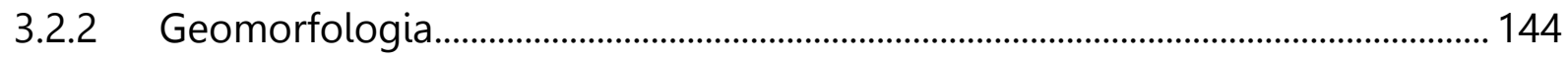

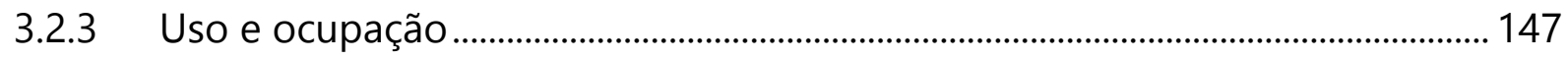

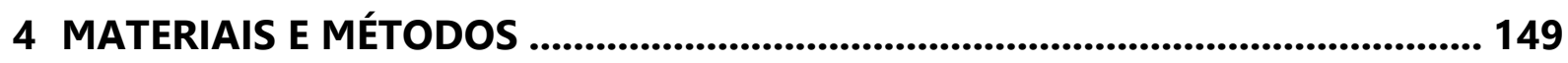

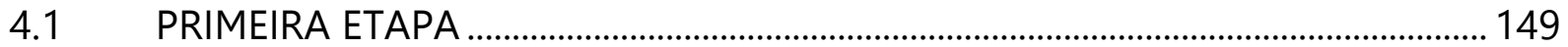


4.1.1 Documentos e dados prévios.................................................................................... 151

4.1.1.1 Souza (1996) ........................................................................................................... 151

4.1.1.2 Bonuccelli (1999) .............................................................................................................. 151

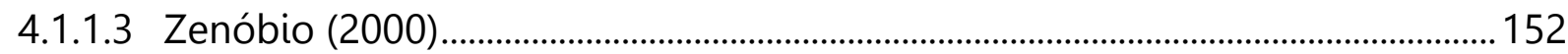

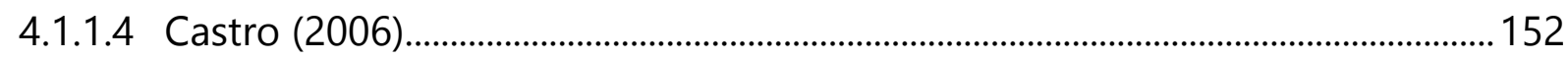

4.1.1.5 Fontes (2011) ............................................................................................................ 153

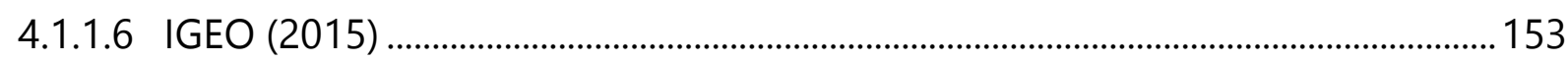

4.1.2 Definição do mapa básico .....................................................................................154

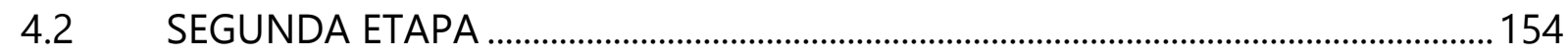

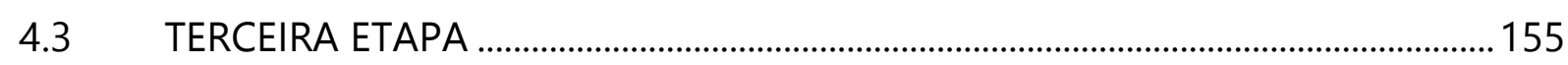

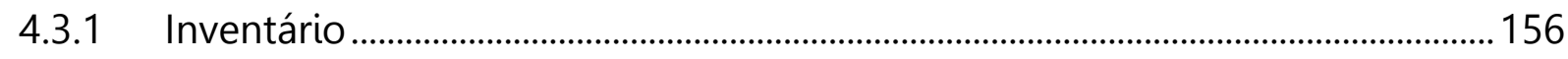

4.3.2 Elaboração do modelo e definição dos atributos....................................................158

4.3.3 Dados prévios.................................................................................................... 158

4.3.4 Dados gerados ......................................................................................................... 159

4.3.4.1 Tabulação dos atributos e parâmetros ……………………………………………....159

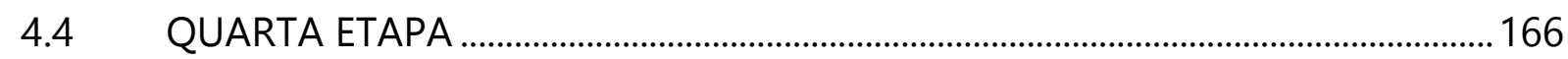

4.4.1 Aplicação em Redes Neurais Artificiais.................................................................... 166

4.4.2 Aplicação em Probabilidade ..................................................................................... 167

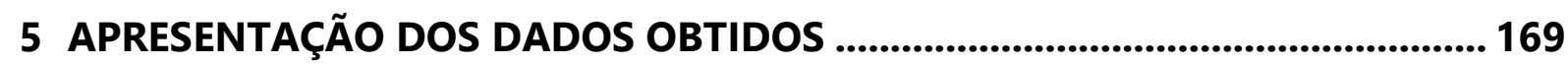

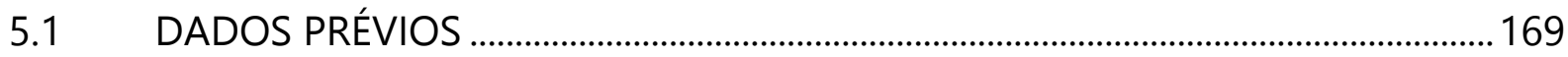

5.1.1 Mapa topográfico ................................................................................................... 169

5.1.2 Mapa de Substrato Rochoso .......................................................................................... 170

5.1.3 Mapa de Material Inconsolidado .............................................................................. 172

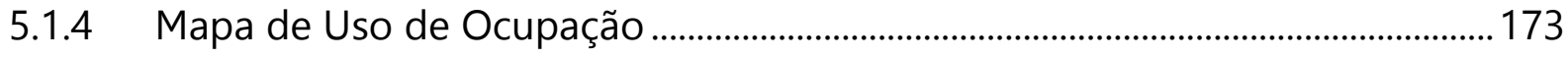

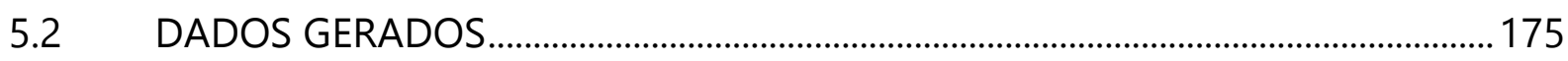

5.2.1 Mapa de Inventário dos Movimentos de Massa Gravitacionais......................... 175

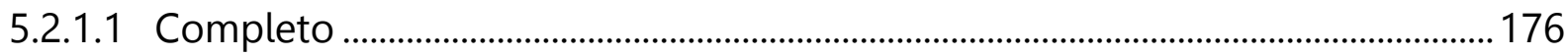

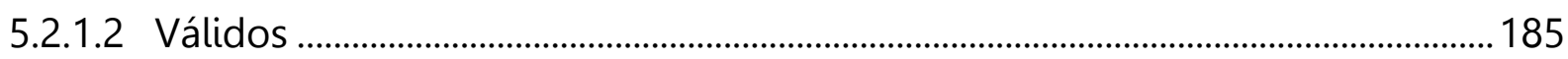

5.2.1.3 Mapa de Inventário dos escorregamentos translacionais....................................190

5.2.2 Carta de Declividade.................................................................................................. 192

5.2.3 Carta de Rumo da Inclinação da Encosta....................................................................193 
5.2.4 Carta Geotécnica - Unidades geológico-geotécnicas ........................................... 194

5.2.5 Carta de Resistência ao Cisalhamento ..................................................................... 197

5.2.6 Carta de Contraste de Permeabilidade ........................................................................ 199

5.2.7 Carta de Superfície Potencial de Ruptura.................................................................. 200

5.2.8 Resultados ausentes ......................................................................................................2 202

6 ANÁLISE CRÍTICA DOS DADOS PARA USO EM RNA E PROBABILIDADE........ 203

6.1 DEFINIÇÃO DO MODELO PARA ESTUDO DO MMG ...............................................203

6.1.1 Modelo conceitual adotado......................................................................................2 203

6.1.2 Modelo físico e matemático adotado ………………………………………………...... 206

6.2 CONDIÇÕES PARA USO DOS DADOS EM REDES NEURAIS ARTIFICIAIS .......208

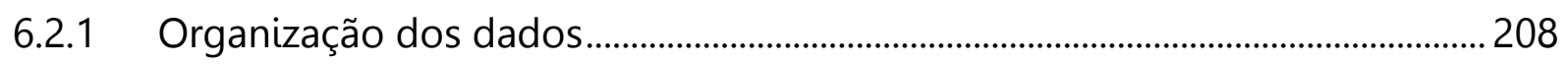

6.2.2 Implementação de um modelo de RNA …………………………………………......213

6.2.2.1 Estruturação da RNA ..................................................................................... 213

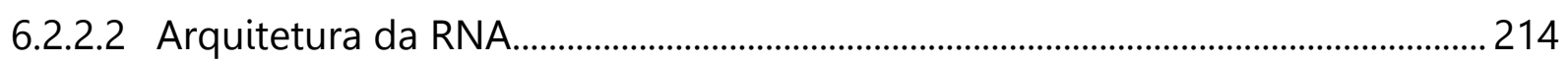

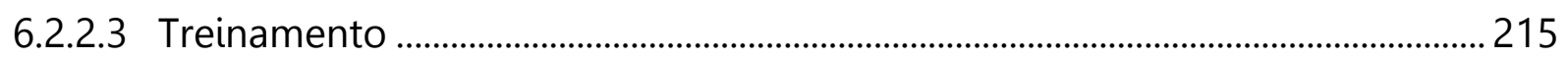

6.2.2.4 Validação e execução final ........................................................................................220

6.2.3 Carta de Eventos Perigosos aplicando RNA …………………………………….... 221

6.3 CONDIÇÕES PARA USO DOS DADOS EM PROBABILIDADE ............................... 224

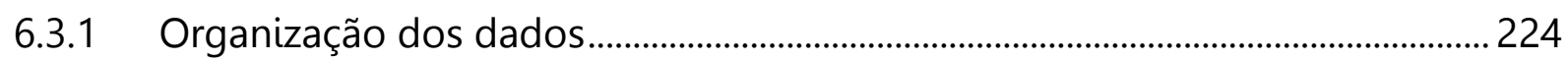

6.3.2 Método probabilístico...............................................................................................22

6.3.2.1 Descrição do método ....................................................................................................225

6.3.3 Implementação do método ......................................................................................... 227

6.3.3.1 Relação atributo $x$ inventário .....................................................................................2229

6.3.4 Carta de Eventos Perigosos aplicando probabilidade ..........................................2 231

7 CONCLUSÕES E RECOMENDAÇÕES................................................................. 233

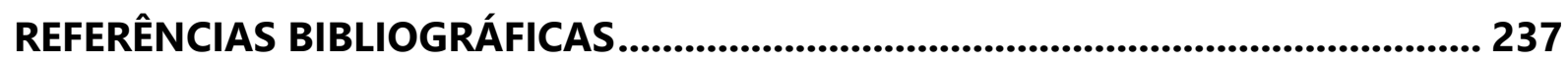




\section{ANEXOS}

ANEXO I - Ocorrências utilizadas para Análise de Correlação (Castro, 2006)

ANEXO II - Mapa com Zoneamento das Áreas de Risco (Castro, 2006)

ANEXO III - Lista das Ocorrências Mapeadas (Fontes, 2011)

ANEXO IV - Mapa de Inventário de Ocorrências (Fontes, 2011)

ANEXO V - Ficha de campo - STC4 (Fontes, 2011)

ANEXO VI - Parecer técnico - IG-1404-DEC-E-LT01-00 (IGEO, 2015) 



\section{APÊNDICES}

APÊNDICE A - Tabela de dados cedidos pelo IGEO.

APÊNDICE B - Banco de dados do inventário de movimentos de massa gravitacionais. 



\section{VOLUME 2}

APÊNDICE I - Mapa Topográfico

APÊNDICE II - Mapa de Substrato Rochoso

APÊNDICE III - Mapa de Material Inconsolidado

APÊNDICE IV - Mapa de Uso e Ocupação

APÊNDICE V - Mapa das Ocorrências Inventariadas

APÊNDICE VI - Mapa de Inventário dos Movimentos de Massa Gravitacionais

APÊNDICE VII - Mapa de Inventário dos Escorregamentos Translacionais

APÊNDICE VIII - Mapa de Inventário dos Escorregamentos Translacionais - Tipo de Material

APÊNDICE IX - Carta de declividade

APÊNDICE X - Carta do Rumo da Inclinação das Encostas

APÊNDICE XI - Tabela de Caracterização das Unidades Geológico-Geotécnicas

APÊNDICE XII - Carta das Unidades Geológico-Geotécnicas

APÊNDICE XIII - Mapa das Seções Típicas das Unidades Geológico-Geotécnicas

APÊNDICE XIV - Carta da Resistência ao Cisalhamento

APÊNDICE XV - Carta de Contraste de Permeabilidade

APÊNDICE XVI - Carta de Superfície Potencial de Ruptura 



\section{INTRODUÇÃO}

Os movimentos de massa gravitacionais possuem grande relevância como evento natural juntamente com terremotos, erupções vulcânicas, inundações e furacões, como geradores de desastres. Apesar de serem menos catastróficos, eles vêm sendo reconhecidos pela população como causadores de várias perdas e danos.

A investigação deste processo ganhou mais destaque devido ao aumento dos investimentos dos países mais desenvolvidos em planejamento e gestão da ocupação, principalmente nos perímetros urbanos, e pelo despertar dos países menos desenvolvidos para a necessidade de investigar estes processos. Por isso, tornou-se fundamental a determinação e avaliação de áreas propícias à ocorrência de movimentos de massa gravitacionais no sentido de evitar desastres e elaborar um ordenamento territorial mais adequado.

No Brasil, muitas são as regiões atingidas por movimentos de massa gravitacionais gerando perdas econômicas e humanas, inclusive com centenas de vítimas fatais. Um caso brasileiro com destaque internacional aconteceu em janeiro de 2011, na Região Serrana do estado do Rio de Janeiro, causando centenas de mortes e vários desaparecimentos.

Visando identificar, avaliar, minimizar ou solucionar os problemas relacionados à ocorrência dos movimentos de massa gravitacionais devem ser analisados os processos, fatores condicionantes e a relação entre eles, de maneira que seja possível caracterizar a área de forma integrada.

Os procedimentos de análise se iniciam a partir do levantamento das feições dos movimentos de massa gravitacionais, passando pela caracterização geológicogeotécnica da área, zoneamento das regiões mais predispostas à movimentação, a avaliação da suscetibilidade, as condições de eventos perigosos e o risco.

Sem os estudos dos movimentos de massa gravitacionais com mapas adequados, as estratégias de mitigação e prevenção de desastres podem não ser corretamente implementadas. Por isso, é necessário investir na aquisição de dados de alta qualidade, gerando bons resultados a fim de dar confiabilidade ao trabalho. 
Diante deste panorama, buscou-se elaborar uma pesquisa que contribuísse para a compreensão da problemática dos movimentos de massa gravitacionais, a começar pela escolha da área de estudo que se encontrasse inserida no cenário brasileiro de desastres naturais.

A área escolhida corresponde a $45 \mathrm{~km}^{2}$ do território municipal de Ouro Preto e ocupa grande parte do perímetro urbano da cidade. As ocorrências de movimentos de massa gravitacionais são constantes na região, tanto na área urbana como na rural, principalmente nas estações chuvosas. Estes eventos geram perdas e danos à população, às edificações históricas da cidade e às atividades econômicas relacionadas, em especial, ao turismo.

Sob a perspectiva de que a região estudada é frequentemente atingida por movimentos de massa gravitacionais, procurou-se desenvolver este trabalho a partir de um conjunto de informações obtidas através de trabalhos anteriores e também elaboradas por este estudo. Estas informações compõem um banco de dados que foi analisado e avaliado quanto à sua utilização em redes neurais artificiais e probabilidade, a fim de gerar uma carta de eventos perigosos relacionada aos movimentos de massas gravitacionais.

\subsection{OBJETIVOS DA PESQUISA}

Este trabalho tem como objetivo principal o levantamento de dados geológico-geotécnicos para análise crítica quanto às possibilidades de uso em métodos probabilísticos e redes neurais artificiais para elaboração de uma carta de eventos perigosos. Espera-se que o resultado responda às seguintes perguntas, a saber:

- Quais os atributos mais importantes para elaboração de uma carta de eventos perigosos?

- Qual o grau de detalhamento, precisão e confiabilidade destas informações? 
- Quais mapas e cartas podem ser elaborados a partir das informações?

- De que modo e forma devem estar às informações para elaboração de um mapa de inventário?

- Quais os requisitos básicos para o desenvolvimento de um banco de dados destinado à aplicação em probabilidade e redes neurais artificiais com a finalidade de elaborar uma carta de eventos perigosos?

- Qual a metodologia para aplicação em probabilidade?

- Qual a metodologia para aplicação em redes neurais artificiais?

- Qual o grau de detalhamento satisfatório para um bom resultado a partir de redes neurais artificiais e probabilidade?

Para alcançar o objetivo principal e responder às perguntas que conduzem esta pesquisa, foram definidos objetivos específicos como:

- Elaboração de mapa de inventário da área estudada;

- Elaboração de cartas geotécnicas;

- Análise dos dados frente as condições para aplicação de métodos probabilísticos e redes neurais artificiais para elaboração de carta de eventos perigosos.

- Propor recomendações para realizar um trabalho satisfatório quando aplicado redes neurais artificiais e probabilidade. 



\section{REVISÃO BIBLIOGRÁFICA}

\subsection{MOVIMENTO DE MASSA GRAVITACIONAL}

O movimento de massa gravitacional (MMG) é definido como sendo o deslocamento dos materiais que formam as encostas, incluindo rocha, solo, preenchimento, ou quaisquer combinações destes, no sentido para baixo e para fora da encosta, sob influência da gravidade (Varnes, 1978). Os movimentos podem ser induzidos por meio de um agente deflagrador como a água, o gelo, a neve e o ar, tombando, deslizando, espalhando-se ou fluindo (Cruden e Varnes, 1996).

Segundo Hutchinson (1988) classificar os tipos de movimentos de massa gravitacionais é importante, em primeiro lugar, para definir e estruturar o campo de estudo, facilitando o intercâmbio de ideias em desenvolvimento e, na medida do possível, promover uma clara e consensual terminologia. Por isso é de fundamental importância a adoção de uma classificação que seja efetiva para a finalidade da pesquisa (Rodrigues, 1998).

Visto a necessidade de definir uma classificação de movimentos de massa gravitacionais a ser usada, apresenta-se uma breve comparação entre as classificações existentes (Seção 2.1.2) e em seguida, as principais classificações são exibidas de forma detalhada (Seção 2.1.3).

Antes disso, são apresentados alguns termos que fazem parte da classificação do tipo de movimento e que podem ser adicionadas à descrição, para que o resultado da pesquisa seja integralizado e, futuramente, de ampla utilização. 


\subsubsection{Informações adicionais para descrição do MMG}

A caracterização dos movimentos de massa gravitacionais torna-se mais completa se consideradas todas as informações que descrevem o movimento. Estes termos são apresentados em diversos estudos relacionados à classificação de movimentos de massa como Varnes (1978), Cruden (1993), Cruden e Varnes (1996), Guthrie (2013), Hungr, Leroueill e Picarelli (2014) e, Cruden e Lan (2015).

Sugere-se determinar a atividade do movimento, seu estado, estilo e distribuição, a velocidade do movimento, as condições de umidade e, principalmente, o tipo de material envolvido.

A sequência recomendada, segundo Cruden e Lan (2015), para nomear o movimento analisado é: atividade, velocidade do movimento, condições de umidade, material e tipo de movimento, respectivamente. Em seguida, tem-se uma breve explicação de cada um destes termos.

\subsubsection{Atividade do Movimento}

A atividade do movimento pode ser examinada durante o reconhecimento inicial do movimento de massa gravitacional e antes de determinar mais detalhadamente quais materiais foram deslocados (Cruden e Varnes, 1996 e Cruden e Lan, 2015). Os termos relativos à atividade foram inicialmente descritos por Varnes (1978) e estão agrupados em três categorias: atividade, distribuiç̧ão e estilo da atividade. As expressões em português das tabelas 1, 2 e 3 foram traduzidas por Bonuccelli (1999).

\section{A. Estado de atividade}

Esta categoria descreve o que se sabe sobre o atual estado do movimento. Existem 4 tipos de estado de atividade conforme a Tabela 1. O estado inativo 
significa que o movimento não ocorreu nos últimos 12 meses e, ele é subdivido em outros 4 estados: dormente, estabilizado naturalmente, estabilizado artificialmente e remanescente.

Tabela 1 - Tipos de estados de atividade.

\begin{tabular}{|c|c|c|c|c|}
\hline \multicolumn{4}{|c|}{ Estado da atividade } & \multirow{2}{*}{ Descrição } \\
\hline & Inglês & & Português & \\
\hline \multirow{7}{*}{ 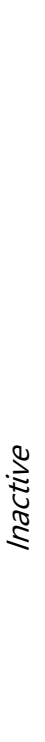 } & Active & & Ativo & O movimento está atualmente em movimento. \\
\hline & Suspended & & Suspenso & $\begin{array}{l}\text { O movimento ocorreu dentro dos últimos } 12 \\
\text { meses, mas que não está se movendo no } \\
\text { momento. }\end{array}$ \\
\hline & Reativated & & Reativado & O movimento estava inativo e se tornou ativo. \\
\hline & Dormant & & Dormente & $\begin{array}{l}\text { O movimento está inativo, mas pode ser } \\
\text { reativado pela causa original ou outra qualquer. }\end{array}$ \\
\hline & Abandoned & $\stackrel{*}{\circ}$ & $\begin{array}{l}\text { Estabilizado } \\
\text { naturalmente }\end{array}$ & $\begin{array}{l}\text { O movimento está inativo e não será reativado } \\
\text { pela sua causa original. }\end{array}$ \\
\hline & Stabilized & & $\begin{array}{l}\text { Estabilizado } \\
\text { artificialmente }\end{array}$ & $\begin{array}{l}\text { O movimento está inativo e foi protegido contra } \\
\text { causas originais por medidas corretivas. }\end{array}$ \\
\hline & Relict & & Remanescente & $\begin{array}{l}\text { O movimento ocorreu em condições climáticas e } \\
\text { geomorfológicas diferentes das condições } \\
\text { naturais. }\end{array}$ \\
\hline
\end{tabular}

*Inativo: O movimento não ocorreu nos últimos 12 meses. Adaptado de Cruden e Lan (2015).

\section{B. Distribuição da atividade}

Esta categoria descreve onde e como a feição está se movendo. A distribuição é setorizada em termos de alteração da superfície de ruptura com o tempo e da mudança de volume do material deslocado, também com o tempo. As classes desta categoria estão descritas na Tabela 2. 
Tabela 2 - Tipos de distribuições da atividade.

\begin{tabular}{|c|c|c|}
\hline \multicolumn{2}{|c|}{ Distribuição da atividade } & \multirow{2}{*}{ Descrição } \\
\hline Inglês & Português & \\
\hline Advancing & Progressivo & $\begin{array}{l}\text { A superfície de ruptura progride no mesmo sentido } \\
\text { do movimento. }\end{array}$ \\
\hline Retrogressing & Retrogressivo & $\begin{array}{l}\text { A superfície de ruptura progride no sentido oposto } \\
\text { ao movimento da massa deslocada. }\end{array}$ \\
\hline Enlarging & $\begin{array}{l}\text { Ampliado em } \\
\text { várias direções }\end{array}$ & $\begin{array}{l}\text { A superfície de ruptura progride em } 2 \text { ou mais } \\
\text { direções. }\end{array}$ \\
\hline Widening & $\begin{array}{l}\text { Ampliado } \\
\text { lateralmente }\end{array}$ & $\begin{array}{l}\text { A superfície de ruptura se desloca para uma ou para } \\
\text { as duas margens laterais. }\end{array}$ \\
\hline Confined & Confinado & $\begin{array}{l}\text { Possui uma escarpa, mas a superfície de ruptura não } \\
\text { é visível no pé da massa deslocada. }\end{array}$ \\
\hline Diminishing & Regressivo & O volume do material deslocado diminui. \\
\hline Moving & Em movimento & $\begin{array}{l}\text { A massa deslocada continua se movimentando sem } \\
\text { alteração visível da superfície de ruptura ou do } \\
\text { volume deslocado. }\end{array}$ \\
\hline
\end{tabular}

\section{Estilo da atividade}

Esta categoria indica como movimentos diferentes contribuem para a ocorrência de movimentos de massa gravitacionais em geral. As classes desta categoria estão descritas na Tabela 3.

Tabela 3 - Tipos de estilos da atividade.

\begin{tabular}{ccl}
\hline \multicolumn{2}{c}{ Estilo da atividade } & \\
\cline { 1 - 2 } Inglês & Português & Descrição \\
\hline Complex & Complexo & $\begin{array}{l}\text { Apresenta pelo menos dois tipos de movimentos em } \\
\text { sequência. }\end{array}$ \\
Multiple & Múltiplo & $\begin{array}{l}\text { Apresenta pelo menos dois tipos de movimentos } \\
\text { simultâneos em partes diferentes da massa deslocada. }\end{array}$ \\
Successive & Sucessivo & $\begin{array}{l}\text { Movimento do mesmo tipo de outro ocorrido próximo a } \\
\text { ele, porém sem compartilhar a mesma superfície de } \\
\text { ruptura e massa deslocada. }\end{array}$ \\
Single & Simples & A massa deslocada resulta de um só tipo de movimento. \\
\hline Adaptado de Cruden e Lan (2015).
\end{tabular}




\subsubsection{Velocidade do movimento}

A velocidade do movimento pode ser estimada por diferentes técnicas (Cruden e Lan, 2015): por sondagens repetidas em várias posições do objeto deslocado; por reconstrução das trajetórias da massa deslocada; por observações de testemunhas oculares, e por instrumentação.

O grupo de pesquisa Terrain (1995), propôs uma modificação dos intervalos de velocidade do movimento, anteriormente definidos por Varnes (1978). O objetivo desta alteração foi ajustar as divisões para aumentar em múltiplos de 100. Isto causou uma pequena elevação do limite superior da escala e diminuição do limite inferior. As classes de velocidade do movimento, propostas por Terrain (1995) estão expostas na Tabela 4.

Tabela 4 - Classes de velocidade do movimento.

\begin{aligned} \hline Velocidade & Valores limites \\ \hline Extremamente rápido & $>5 \mathrm{~m} / \mathrm{s} \\$ Muito rápido & $3 \mathrm{~m} / \mathrm{min} \\$ Rápido & $1,8 \mathrm{~m} / \mathrm{h} \\$ Moderadamente rápido & $3 \mathrm{~m} / \mathrm{semana} \\$ Lento & $1,6 \mathrm{~m} / \mathrm{ano} \\$ Muito lento & $16 \mathrm{~mm} / \mathrm{ano} \\$ Extremamente lento & $<16 \mathrm{~mm} / \mathrm{ano} \\$\hline Adaptado de Terrain (1995). & \end{aligned}

\subsubsection{Condições de umidade}

As condições de umidade foram descritas por Varnes (1978) sob o nome de teor de água (Water Content). Entretanto, para que esse nome tenha o real significado, a descrição deveria considerar os limites de Atterberg (limites de consistência) (Cruden e Lan, 2015). Assim, a opção sugerida por Hungr et al. (2001) 
foi modificá-lo para condições de umidade, que se refere à caracterização do estado do material. As condições de umidade presentes no material estão descritas na Tabela 5.

Tabela 5 - Condições de umidade dos materiais deslocados por MMG.

\begin{aligned} & \hline Condições Descrição \\ & \hline Seco Nenhuma umidade visível. \\ & Parcialmente $\begin{array}{l}\text { Contém um pouco de água, mas não livre. O } \\ \text { material pode se comportar como um sólido } \\ \text { plástico, mas a água não flui livremente. }\end{array} \\ & \begin{array}{l}\text { Possui água o suficiente para se comportar } \\ \text { como líquido. Parte da água pode fluir ou } \\ \text { permanecer represada. }\end{array} \\ &$ Muito úmido $\begin{array}{l}\text { Possui água o suficiente para fluir em baixo } \\ \text { gradiente hidráulico. }\end{array} \\ &$\hline Adaptado de Cruden e Lan (2015). \end{aligned}

Outros dois termos foram propostos por (Cruden e Couture, $2010^{1}$ apud Cruden e Lan, 2015), são eles:

i. Congelado: a água presente no material está em forma de gelo. É geralmente usado para descrever movimentos de massa próximos às geleiras, em áreas com permafrost. Este solo é encontrado na região do Ártico, constituído por solo, rocha e gelo, estando permanentemente congelado.

ii. Descongelado: a água presente no material origina-se do degelo. A instabilidade dos terrenos de permafrost é consequência direta da mudança de estado da água de sólida para líquida, por isso a importância de se adicionar a condição descongelada.

\footnotetext{
${ }^{1}$ CRUDEN, D M; COUTURE, R More comprehensive characterization of landslides: Review and addition. In Geologically Active: Proceedings of the 11th IAEG Congress. Auckland, New Zealand, 2010. p. 1033-1042.
} 


\subsubsection{Material geológico}

A descrição do material é uma das categorias mais importantes para se conhecer o movimento e classificá-lo de forma certa, principalmente porque ele está diretamente ligado aos tipos de movimento de massa que podem ocorrer.

Varnes (1978) separa os materiais que podem se movimentar em substrato rochoso e solo. O substrato rochoso é o termo usado para designar uma rocha resistente ou firme, que estava intacta ou em seu lugar natural antes de iniciar o movimento. O solo é qualquer material inconsolidado ou agregado de partículas sólidas pobremente cimentado, que tenha sido transportado ou formado por intemperismo da rocha in loco. É geralmente constituído de minerais, rocha ou matéria orgânica, juntamente com qualquer gás ou liquido intersticial. Varnes (1978) denomina a sua descrição de solos como solo para a engenharia (Engineering soil), podendo ser divididos em:

i. Detritos: solo superficial que contém uma significativa proporção de material grosso. Pode definir materiais que possuem entre 20 e $80 \%$ de fragmentos maiores que $2 \mathrm{~mm}$.

ii. Terra: Solo com aproximadamente $80 \%$ ou mais de fragmentos menores que $2 \mathrm{~mm}$. Pode incluir materiais que variam de areias não plásticas a argilas altamente plásticas.

Segundo Cruden e Lan (2015), podem ser adicionadas mais algumas informações na classificação do material, levando em consideração a distinção de terra, solo orgânico e vulcânico, por exemplo. Camadas de partículas finas podem ser divididas em siltes e argilas observando sua plasticidade, dilatância e outras propriedades que caracterizam os materiais finos.

A descrição dos materiais foi modificada por Hungr, Leroueill e Picarelli (2014). Neste estudo o autor apresenta uma nova versão para a classificação de movimentos de massa gravitacionais. Esta nova divisão foi proposta tendo como 
objetivo utilizar os avanços geotécnicos e geológicos relacionados à definição dos materiais.

Assim, são apresentados os seguintes tipos de materiais: rocha, argila, lama, silte, areia, cascalho, pedregulho, detrito, turfa e gelo. Hungr, Leroueill e Picarelli (2014) ainda adiciona termos complementares para ajudar na descrição do movimento, como por exemplo os termos: dura e branda para rocha; bem como parâmetros do solo para melhor definir qual o tipo de material (Tabela 6).

O mesmo autor sugere que se deve ter cuidado na escolha dos tipos de materiais, buscando seguir um critério (textura, composição, parâmetros físicos, entre outros) que leve a um bom resultando, visando um estudo mais abrangente dos movimentos de massa gravitacionais. Por exemplo, quando o solo apresentar um conjunto com vários materiais, como areia e argila, deve-se escolher para denominar o movimento aquele material que domina o mecanismo de ruptura. No caso do termo lama, só deve ser usado para solos argilosos amolgados cuja matriz seja plástica e que o índice de liquidez durante o movimento seja maior que 0,5 (Tabela $6)$.

Tabela 6 - Tipos de solo e suas propriedades.

\begin{tabular}{|c|c|c|c|c|}
\hline \multicolumn{2}{|c|}{ Material } & \multirow{2}{*}{$\begin{array}{c}\text { Termos } \\
\text { complementares }\end{array}$} & \multirow{2}{*}{$\begin{array}{l}\text { Classificação } \\
\text { Unificada }\end{array}$} & \multirow{2}{*}{ Índices } \\
\hline Inglês & Português & & & \\
\hline \multirow{2}{*}{ Rock } & \multirow{2}{*}{ Rocha } & Dura & \multirow{2}{*}{ - } & $\mathrm{UCS}>25 \mathrm{MPa}$ \\
\hline & & Branda & & $2<\mathrm{UCS}<25 \mathrm{MPa}$ \\
\hline \multirow{3}{*}{ Clay } & \multirow{3}{*}{ Argila } & Dura & \multirow{3}{*}{$\begin{array}{c}\mathrm{GC}, \mathrm{SC}, \mathrm{CL} \\
\mathrm{MH}, \mathrm{CH}, \mathrm{OL} \mathrm{e} \\
\mathrm{OH}\end{array}$} & \multirow{3}{*}{$I_{\mathrm{P}}>0,05$} \\
\hline & & Mole & & \\
\hline & & Sensível & & \\
\hline Mud & Lama & Líquido & $\mathrm{CL}, \mathrm{CH}$ e $\mathrm{CM}$ & $I_{\mathrm{P}}>0,05$ e $I_{l}>0,5$ \\
\hline \multirow{3}{*}{$\begin{array}{c}\text { Silt, sand, } \\
\text { gravel, } \\
\text { boulders }\end{array}$} & \multirow{3}{*}{$\begin{array}{c}\text { Silte, areia, } \\
\text { cascalho, } \\
\text { pedregulho }\end{array}$} & Seco & $M L$ & \multirow{3}{*}{$I_{\mathrm{P}}<0,05$} \\
\hline & & Saturado & SW, SP e SM & \\
\hline & & Parcialmente saturado & GW, GP e GM & \\
\hline \multirow{3}{*}{ Debris } & \multirow{3}{*}{ Detritos } & Seco & SW-GW & \multirow{3}{*}{$I_{P}<0,05$} \\
\hline & & Saturado & SM-GM & \\
\hline & & Parcialmente saturado & $\mathrm{CL}, \mathrm{CH}$ e $\mathrm{CM}$ & \\
\hline Peat & Turfa & Orgânico & & - \\
\hline Ice & Gelo & Glacial & & - \\
\hline
\end{tabular}

Adaptado de Hungr, Leroueill e Picarelli (2014). 
Outras análises e recomendações podem ser vistas em Hungr, Leroueill e Picarelli (2014) e através da Tabela 6 que mostra os tipos de materiais e algumas propriedades de cada tipo.

\subsubsection{Comparação entre as classificações}

Rodrigues e Pejon (1998) apresentam uma comparação entre as classificações de MMG mais conhecidas até o ano de 1995, mostrando as principais características de cada uma delas e apontando vantagens e desvantagens da utilização de determinadas classificações.

Com o propósito de apresentar a classificação mais adequada, Rodrigues (1998) levou em consideração os seguintes aspectos:

1. Data em que a classificação foi proposta;

2. Tipos de materiais envolvidos na movimentação;

3. Atributos que são levados em consideração na classificação:

a) Processos geomorfológicos,

b) Velocidade;

c) Geometria;

d) Estruturas;

e) Landform;

f) Zona de transferência;

g) Superfície de ruptura;

4. Tipos de movimentos considerados;

5. Origem do movimento (natural ou induzido);

6. Detalhamento dos tipos de movimentos;

7. Subtipos e adaptações ou modificações posteriores;

8. Modificação desenvolvida para permitir aplicação em regiões especificas; 
9. Instituições e/ou associações que elaborou estudos baseados nas mesmas;

10. Consideração de processos associados.

A Tabela 7 reúne as informações obtidas por Rodrigues (1998) a partir do check-list mencionado. Esta tabela foi modificada por Amaral Jr. (2007) e por este trabalho para adição das classificações existentes após 1995, seguindo o mesmo critério de análise.

As classificações mais recentes foram desenvolvidas para atualizar, principalmente, a classificação de Varnes (1978). Cruden e Varnes (1996) propõem modificações e acréscimos em alguns termos já considerados por Varnes (1978). E Hungr, Leroueill e Picarelli (2014) propõe a atualização da divisão dos materiais a partir de uma caracterização mais detalhada. 
Tabela 7 - Características das principais classificações de MMG.

\begin{tabular}{|c|c|c|c|c|c|c|c|c|c|c|}
\hline Autores & 1 & 2 & 3 & 4 & 5 & 6 & 7 & 8 & 9 & 10 \\
\hline Sharpe & 1938 & $\begin{array}{l}\text { Solo, rocha, } \\
\text { gelo, } \\
\text { mistura }\end{array}$ & $\begin{array}{l}a \\
b\end{array}$ & 6 básicos & Natural & Sim & Não & - & - & Sim \\
\hline Terzaghi & 1928 & Solo, rocha & $\begin{array}{l}c \\
d \\
d\end{array}$ & Escorregamento & Natural & Não & 1950 & $\begin{array}{c}\text { Causas: } \\
\text { internas, } \\
\text { externas e } \\
\text { intermediárias }\end{array}$ & - & Não \\
\hline $\begin{array}{l}\text { Magalhães } \\
\text { Freire }\end{array}$ & 1965 & $\begin{array}{l}\text { Solo, rocha, } \\
\text { mistura }\end{array}$ & $\begin{array}{l}\mathrm{a} \\
\mathrm{b} \\
\mathrm{c}\end{array}$ & 6 básicos & Natural & Sim & Não & - & IPT & Sim \\
\hline Nemcok & 1972 & Solo, rocha & $\begin{array}{l}c \\
d\end{array}$ & $\begin{array}{c}\text { Quedas, fluxo, } \\
\text { rastejo, } \\
\text { escorregamento }\end{array}$ & Natural & Sim & Não & - & - & Não \\
\hline $\begin{array}{l}\text { Zaruba e } \\
\text { Mencl }\end{array}$ & 1976 & Solo, rocha & $c$ & - & Natural & Sim & - & - & - & - \\
\hline Varnes & 1978 & Solo, rocha & C & 6 básicos & Natural & Sim & $\begin{array}{l}1985 \\
1996 \\
2014\end{array}$ & $\begin{array}{l}\text { Velocidade } \\
\text { Subtipos } \\
\text { Detalhamento }\end{array}$ & WP/WLI & Não \\
\hline Hasengawa & 1985 & Solo, rocha & $\begin{array}{l}\mathrm{a}, \\
e_{1} \\
f_{1} \\
g\end{array}$ & $\begin{array}{l}\text { Quedas, fluxo, } \\
\text { rastejo, } \\
\text { escorregamento }\end{array}$ & Natural & Sim & Não & - & - & Não \\
\hline Sassa & 1985 & Solo, rocha & $\begin{array}{l}\mathrm{b} \\
\mathrm{c} \\
\mathrm{d}\end{array}$ & $\begin{array}{l}\text { Quedas, fluxo, } \\
\text { tombamento, } \\
\text { solifluxão }\end{array}$ & Natural & Sim & - & - & - & Não \\
\hline Hutchinson & 1988 & $\begin{array}{l}\text { Solo, rocha, } \\
\text { mistura }\end{array}$ & $\begin{array}{l}\mathrm{a} \\
\mathrm{b} \\
\mathrm{c} \\
\mathrm{d}\end{array}$ & $\begin{array}{l}6 \text { básicos + } \\
\text { recuo e ruptura }\end{array}$ & $\begin{array}{c}\text { Natural } \\
\text { e } \\
\text { induzido }\end{array}$ & Sim & - & - & - & Sim \\
\hline Yagi & 1993 & $\begin{array}{l}\text { Solo, rocha, } \\
\text { mistura }\end{array}$ & e & $\begin{array}{l}\text { Deslizamento, } \\
\text { abatimento }\end{array}$ & Natural & Sim & Não & - & - & Sim \\
\hline $\begin{array}{l}\text { Augusto } \\
\text { Filho }\end{array}$ & 1994 & $\begin{array}{l}\text { Solo, rocha, } \\
\text { mistura }\end{array}$ & $\begin{array}{l}a \\
b \\
d\end{array}$ & $\begin{array}{c}\text { Rastejo, } \\
\text { escorregamento, } \\
\text { quedas, } \\
\text { corridas. }\end{array}$ & Natural & Sim & Não & - & IPT & Não \\
\hline Lansheng & 1995 & Solo, rocha & $d$ & $\begin{array}{c}\text { Escorregamento, } \\
\text { acamamento, } \\
\text { fraturado, fluxo, } \\
\text { plástico- } \\
\text { fraturamento. }\end{array}$ & Natural & Sim & Não & - & - & Sim \\
\hline $\begin{array}{l}\text { Antoine \& } \\
\text { Giraud }\end{array}$ & 1995 & Solo, rocha & & $\begin{array}{c}\text { Esfoliação, } \\
\text { tombamento, } \\
\text { rolamento, } \\
\text { escorregamento, } \\
\text { escoamento, } \\
\text { subsidência. } \\
\end{array}$ & Natural & Sim & Não & - & $\begin{array}{l}\text { Nainville- } \\
\text { les } \\
\text { roches }\end{array}$ & Não \\
\hline $\begin{array}{l}\text { Cruden e } \\
\text { Varnes }\end{array}$ & 1996 & $\begin{array}{l}\text { Solo e } \\
\text { rocha }\end{array}$ & $\begin{array}{l}\mathrm{b} \\
\mathrm{c}\end{array}$ & 6 básicos & Natural & $\operatorname{Sim}$ & 2014 & $\begin{array}{l}\text { Detalhamento } \\
\text { dos materiais }\end{array}$ & WPNWLI & Não \\
\hline $\begin{array}{l}\text { Hungr, } \\
\text { Leroueill e } \\
\text { Picarelli }\end{array}$ & 2014 & $\begin{array}{c}\text { Rocha, } \\
\text { argila, lama, } \\
\text { silte, areia, } \\
\text { cascalho, } \\
\text { pedregulho, } \\
\text { detrito, } \\
\text { turfa e gelo }\end{array}$ & $\begin{array}{l}a \\
b \\
d \\
g\end{array}$ & $\begin{array}{l}5 \text { básicos } \\
\text { (exclusão do } \\
\text { movimento } \\
\text { complexo) }\end{array}$ & Natural & Sim & - & - & BGS* & Não \\
\hline
\end{tabular}


A Tabela 8 mostra as vantagens e desvantagens destas classificações e, também foi modificada de Rodrigues (1998) por Amaral Jr.(2007) e por este trabalho para adição de classificações mais recentes.

Rodrigues (1998) agrupa as classificações analisadas em 4 grupos:

i. Classificações adaptadas: classificações que mantiveram a base de outras e se adequaram às situações particulares de cada região;

ii. Classificações específicas: classificações que apresentam características para aplicação de condições especiais do meio físico;

iii. Classificações básicas: classificações que foram desenvolvidas a partir de condições próprias e serviram de fonte para as modificações,

iv. Classificações globais: classificações que apresentam como principal característica um conjunto de informações que podem ser aplicadas em praticamente todas as situações.

Por serem consideradas as classificações mais importantes e também por se tornarem mundialmente utilizadas por diversas organizações relacionadas ao estudo dos movimentos de massa gravitacionais, as classificações de Varnes (1978) e Hutchinson (1988) serão apresentadas de forma mais detalhada a seguir. Vale lembrar que a versão proposta por Hungr, Leroueill e Picarelli (2014) é muito recente e, por esse motivo, pode ainda não ter alcançado notoriedade no meio científico. Apesar disso, ela foi adicionada à seção da classificação de Varnes (1978). 
Tabela 8 - Vantagens e desvantagens das principais classificações dos movimentos de massa gravitacionais.

\begin{tabular}{|c|c|c|c|}
\hline $\begin{array}{c}\text { Tipo de } \\
\text { classificação } \\
\end{array}$ & Autores & Vantagens & Desvantagens \\
\hline Básica & Sharpe & $\begin{array}{c}\text { Número de processos; } \\
\text { Associação } \\
\text { velocidade/geologia }\end{array}$ & Difícil entendimento \\
\hline Específica & Terzaghi & $\begin{array}{l}\text { Detalhe de causas } \\
\text { mecânicas de } \\
\text { escorregamentos }\end{array}$ & $\begin{array}{c}\text { Destaca fenômenos } \\
\text { geológicos em termos } \\
\text { meramente mecânicos }\end{array}$ \\
\hline Adaptada & Magalhães Freire & $\begin{array}{l}\text { Detalhada; } \\
\text { Baseada em Sharpe e Varnes }\end{array}$ & Difícil entendimento \\
\hline Específica & Nemcok & Modelos dos tipos & $\begin{array}{c}\text { Não relaciona tipos e } \\
\text { mecanismos }\end{array}$ \\
\hline Básica & Zaruba e Mencl & Detalhada & $\begin{array}{l}\text { Considera os tipos de } \\
\text { movimentos basicamente } \\
\text { em função do tipo de } \\
\text { material, tornando-se } \\
\text { restrita às condições } \\
\text { locais semelhantes }\end{array}$ \\
\hline Global & Varnes & $\begin{array}{c}\text { Clareza; } \\
\text { Subdivisões; } \\
\text { Básica; } \\
\text { Mais adotado } \\
\text { mundialmente; } \\
\text { Associação velocidade/ } \\
\text { geologia } \\
\end{array}$ & $\begin{array}{l}\text { Não considera } \\
\text { movimentos induzidos; } \\
\text { Não apresenta } \\
\text { correlações }\end{array}$ \\
\hline Específica & Hasengawa & Atributos considerados & - \\
\hline Adaptada & Sassa & $\begin{array}{l}\text { Baseada em Varnes; } \\
\text { Modelo dos mecanismos }\end{array}$ & $\begin{array}{c}\text { Condições tectônicas e } \\
\text { sísmicas diferentes do } \\
\text { Brasil }\end{array}$ \\
\hline Global & Hutchinson & $\begin{array}{c}\text { Considera a origem natural } \\
\text { ou induzida e processos } \\
\text { correlatos; } \\
\text { Mais completa } \\
\end{array}$ & Classificação complexa \\
\hline Específica & Yagi & $\begin{array}{l}\text { Voltada para identificação e } \\
\text { fotografia aérea }\end{array}$ & $\begin{array}{l}\text { Baseada somente em } \\
\text { landforms }\end{array}$ \\
\hline Básica & Augusto Filho & $\begin{array}{l}\text { Fácil entendimento; } \\
\text { Fácil classificação em campo }\end{array}$ & $\begin{array}{c}\text { Baseada em eventos } \\
\text { ocorridos em uma região } \\
\text { específica }\end{array}$ \\
\hline Específica & Lansheng & $\begin{array}{c}\text { Relações estruturais do } \\
\text { maciço }\end{array}$ & $\begin{array}{c}\text { Meio predominantemente } \\
\text { rochoso }\end{array}$ \\
\hline Específica & Antonie \& Giraud & $\begin{array}{c}\text { Detalhamento do terreno e } \\
\text { litoestrutural }\end{array}$ & $\begin{array}{l}\text { Não considera } \\
\text { escorregamento em } \\
\text { cunha }\end{array}$ \\
\hline Global & Cruden e Varnes & $\begin{array}{l}\text { Atualização dos conceitos } \\
\text { relacionados a landslides }\end{array}$ & $\begin{array}{l}\text { Não apresenta grande } \\
\text { variações dos materiais }\end{array}$ \\
\hline Global & $\begin{array}{l}\text { Hungr, Leroueill e } \\
\text { Picarelli }\end{array}$ & $\begin{array}{c}\text { Subdivisões dos tipos de } \\
\text { movimentos; } \\
\text { Adição do material e da } \\
\text { velocidade na descrição da } \\
\text { classificação; } \\
\text { Mais completa }\end{array}$ & $\begin{array}{l}\text { Somente considera } \\
\text { movimentos naturais }\end{array}$ \\
\hline
\end{tabular}

Fonte - Adaptada de Rodrigues (1998). 


\subsubsection{Principais classificações}

\subsubsection{Classificação de Varnes (1978)}

A classificação de Varnes (1978) é uma das mais utilizadas e serve como base de vários estudos e instruções de organizações internacionais ligadas ao assunto, como a United States Geological Survey (USGS) e International Association for Engineering Geology and the Environment (IAEG).

Em 1996, Cruden e Varnes apresentaram mudanças e acréscimos ao vocabulário da classificação de Varnes (1978). Esta atualização passou a ser utilizada sem substituição à anterior. Atualmente, uma nova revisão da classificação de Varnes (1978) foi apresentada por Hungr, Leroueill e Picarelli (2014). Ela está sendo divulgada pela British Geological Survey (BGS) a fim de ser avaliada pela comunidade científica da área.

Um dos objetivos desta nova versão é adequar a classificação quanto aos avanços recentes na compreensão dos movimentos de massa gravitacionais, principalmente no que diz respeito às definições geotécnicas e geológicas dos materiais envolvidos, solo e rocha. Podem-se destacar duas outras mudanças: a exclusão do movimento complexo como um dos tipos da classificação e a definição de 32 tipos de movimentos oriundos dos 5 movimentos principais já descritos por Varnes (1978) - quedas, tombamentos, escorregamentos, espalhamentos e fluxos.

Entre os atributos utilizados por Varnes (1978) como critérios para identificação e classificação dos MMG tem-se: tipos de movimentos, natureza do material, velocidades do movimento, geometria da área de ruptura e a área de deposição resultante, entre outros relacionados ao local de ocorrência, relações com a litologia, etc.

A Tabela 9 apresenta a classificação proposta por Hungr, Leroueill e Picarelli (2014), subdividindo os movimentos pelo tipo de material envolvido: solo e rocha. Além dos já conhecidos, adicionou-se outro tipo de movimento denominado deformação da encosta. 
A classificação do movimento é formada pelo tipo de processo juntamente com material envolvido. De acordo com Hungr, Leroueill e Picarelli (2014) podem ser usados até dois tipos de materiais na formação do nome do movimento de massa.

Os tipos de movimento classificados por Varnes (1978) e também por Hungr, Leroueill e Picarelli (2014) são descritos a seguir:

Tabela 9 - Tipos de movimentos de massa gravitacionais classificados (Modificada de Hungr, Leroueill e Picarelli, 2014).

\begin{tabular}{|c|c|c|}
\hline \multirow{2}{*}{ Tipo de movimento } & \multicolumn{2}{|c|}{ Tipos de material } \\
\hline & Rocha & Solo \\
\hline Queda & Queda de rocha ou gelo & Queda de pedregulhos, detritos ou silte \\
\hline \multirow{2}{*}{ Tombamento } & Tombamento de blocos rochosos & \multirow{2}{*}{ Tombamento de cascalhos, areia ou silte } \\
\hline & Tombamento flexural de rocha & \\
\hline \multirow{5}{*}{ Escorregamento } & Escorregamento rotacional de rocha & Escorregamento rotacional de silte ou argila \\
\hline & Escorregamento planar de rocha & Escorregamento planar de silte ou argila \\
\hline & Escorregamento em cunha de rocha & Escorregamento de cascalhos, areia ou detritos \\
\hline & Escorregamento composto de rocha & Escorregamento composto de silte ou argila \\
\hline & Escorregamento irregular de rocha & \\
\hline \multirow{2}{*}{ Espalhamento } & \multirow{2}{*}{ Espalhamento de rocha } & Espalhamento de areia ou silte por liquefação \\
\hline & & Espalhamento de argila sensível \\
\hline \multirow{9}{*}{ Fluxo (escoamento) } & \multirow{9}{*}{ Avalanche de rocha ou gelo } & Fluxo de areia, silte ou detritos secos \\
\hline & & Fluxo de areia, silte ou detritos \\
\hline & & Fluxo de argila sensível \\
\hline & & Fluxo de detritos \\
\hline & & Fluxo de lama \\
\hline & & Inundação de detritos \\
\hline & & Avalanche de detritos \\
\hline & & Fluxo de terra \\
\hline & & Fluxo de turfa \\
\hline \multirow{3}{*}{ Deformação da encosta } & Deformação das encostas montanhosas & Deformação dos solos das encostas \\
\hline & & Rastejo de solo \\
\hline & Deformação das encostas rochosas & Solifluxão \\
\hline
\end{tabular}




\section{A. Quedas (falls)}

São movimentos onde fragmentos de materiais de qualquer tamanho, geralmente rochosos, se desprendem de uma encosta íngreme sem ocorrer cisalhamento ao longo da superfície. O desprendimento do material pode ser incitado simplesmente por intemperismo da parede e, consequentemente perda de sustentação do maciço (Figura 1). Estes movimentos são sempre rápidos ou extremamente rápidos, deslocando os blocos por queda livre (Figura 2), saltamento ou rolamento, e podem ou não serem precedidos por movimentos menores que geram a separação progressiva da massa.

Quando o tipo de material envolvido é o gelo, o mecanismo é idêntico ao da rocha, com exceção à baixa resistência do bloco movimentado (Hungr, Leroueill e Picarelli, 2014). Neste caso, pequenas quedas podem fragmentar o bloco transformando a queda em uma avalanche de gelo.

Para movimentos que envolvem solo, os fragmentos podem ser grandes blocos de depósitos de solo ou de solo coeso (cimentado e não saturado) e, assim como no gelo, os impactos podem reduzir o tamanho dos fragmentos devido a sua baixa resistência.

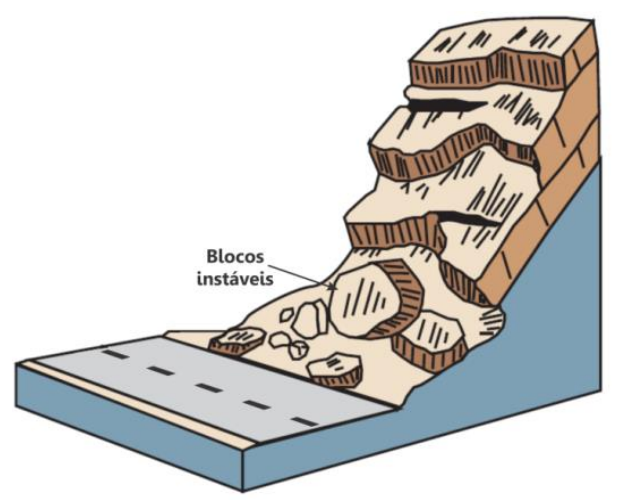

Figura 1 - Queda de rocha por queda livre (Fonte: USGS, 2004). 


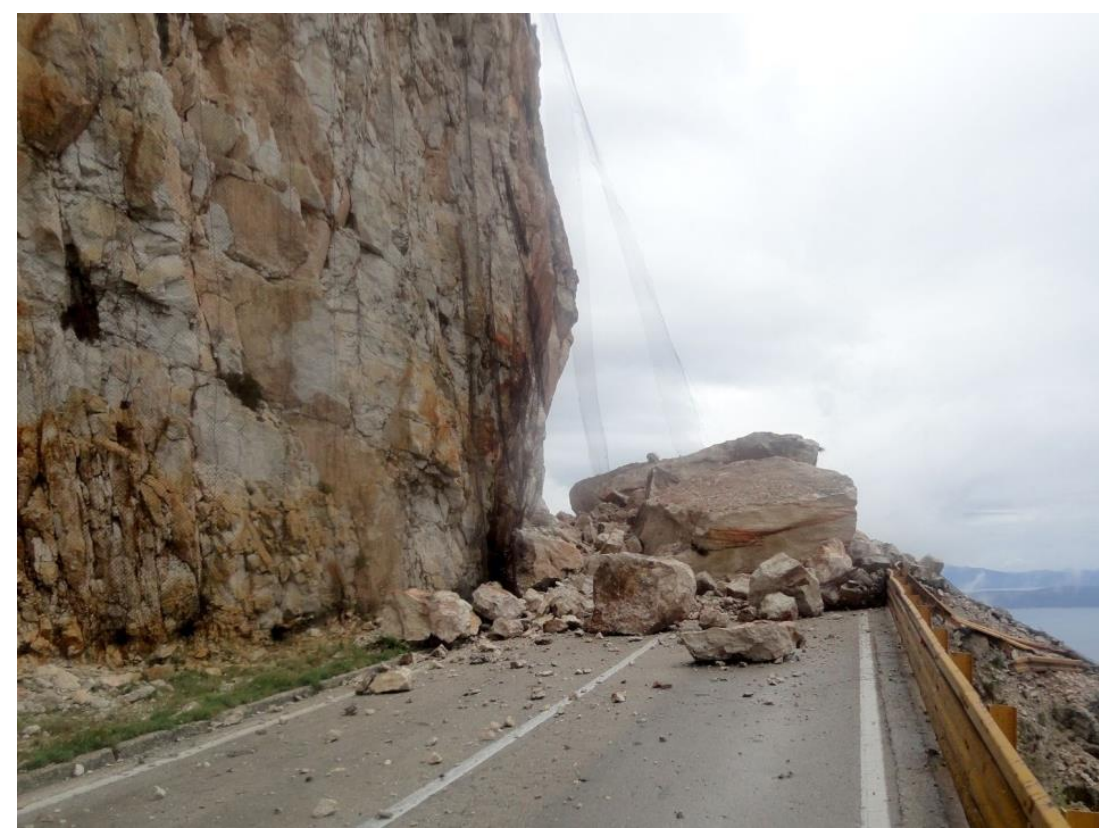

Figura 2 - Exemplo de queda de blocos de rocha ocorrido em Stupica na Croácia².

\section{B. Tombamento (topples)}

Caracteriza-se pela rotação do material (solo ou rocha) que se desloca para frente do declive a partir de um ponto de apoio, geralmente situado na base do bloco, abaixo do centro de gravidade da massa deslocada (Figura 3). Quando associados à rocha, esta deve ser relativamente maciça e a rotação ocorre em descontinuidades basais bem definidas (Hungr, Leroueill e Picarelli, 2014).

O tombamento pode ocorrer pela ação da gravidade, por forças exercidas pelos blocos vizinhos ou pela presença de água ou gelo nas descontinuidades, e, a sua velocidade pode variar de extremamente lenta a extremamente rápida. Dependendo da geometria do material e, da orientação e extensão das descontinuidades, os tombamentos podem culminar em quedas de blocos e escorregamentos. A Figura 4 mostra um exemplo de tombamento de rocha.

Sendo a rocha branda e físsil, existe a possibilidade de as descontinuidades basais não serem bem definidas, de modo que a rotação dos estratos seja facilitada pela flexão (Hungr, Leroueill e Picarelli, 2014). Neste caso, o maciço rochoso é

\footnotetext{
${ }^{2}$ Procedência da Figura 2:<http://galleryhip.com/rock-fall.html>
} 
caracterizado por descontinuidades pouco espaçadas e mergulho acentuado. Geralmente o movimento é lento e tende à auto estabilização.

O mecanismo de tombamento em solo é igual ao que acontece em rocha. $\mathrm{O}$ solo é geralmente coeso e separado por descontinuidades verticais, e não há a necessidade de descontinuidades horizontais, pois a fratura basal acontece como consequência dos esforços aplicados na coluna (Hungr, Leroueill e Picarelli, 2014).

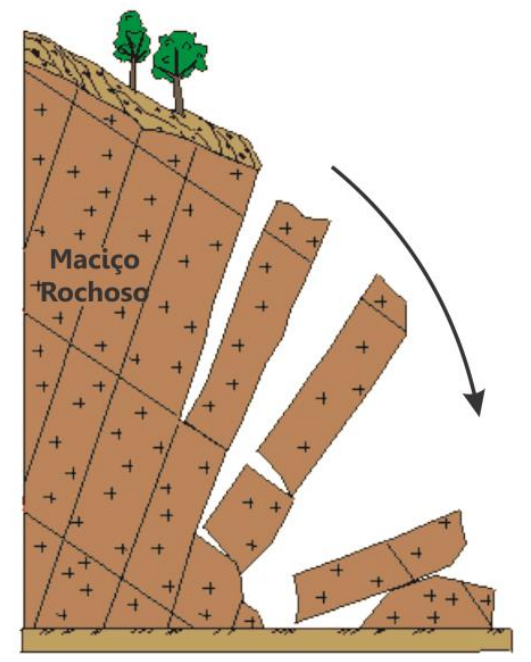

Figura 3 - Tombamento (Fonte: Geodinâmica, 2001).

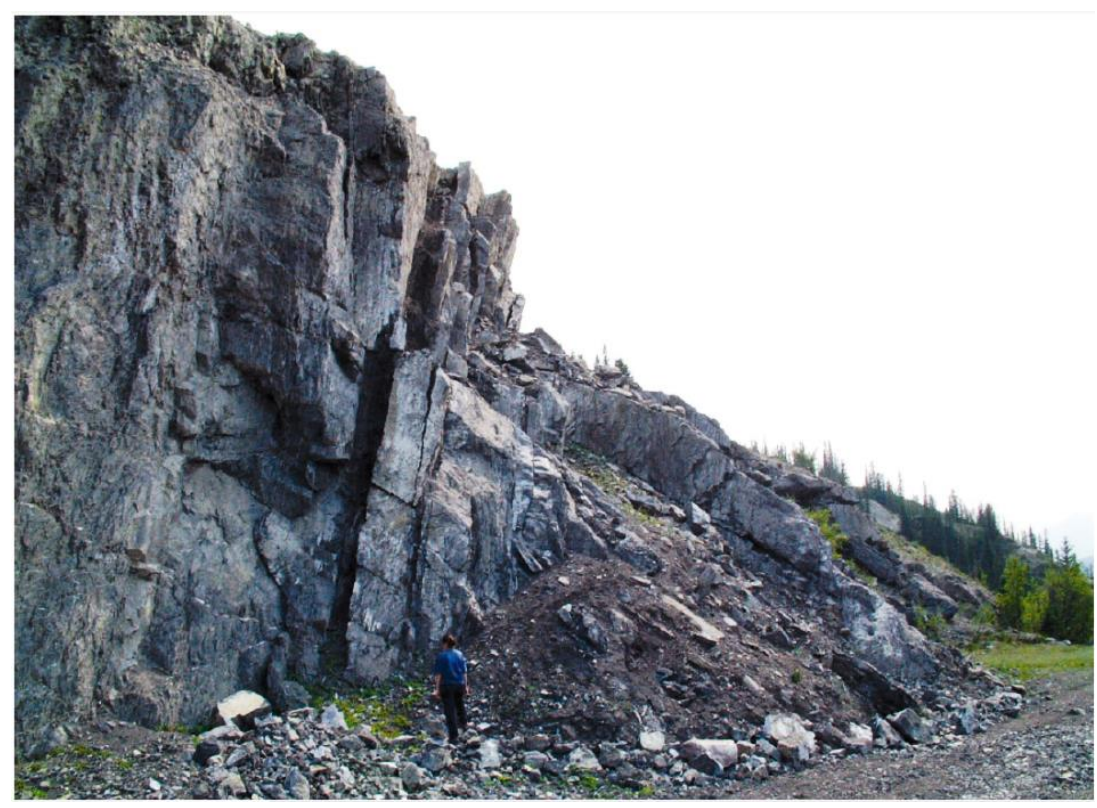

Figura 4 - Exemplo de tombamento de rocha ocorrido em Alberta/Canadá ${ }^{3}$.

${ }^{3}$ Procedência da Figura 4:<http://landslides.usgs.gov/dysi/form.php?landslide_id=15>. 


\section{Escorregamentos (slides)}

Abrange materiais rochosos e solos. É causado por uma deformação cisalhante que pode ocorrer ao longo de vários tipos de superfícies. Estas podem ser visíveis ou parcialmente visíveis. A massa deslocada pode deslizar por toda a extensão da superfície original de ruptura e acima da superfície do solo original formando um plano de separação. Muitas vezes, os primeiros sinais de movimentos no solo são fissuras em sua superfície.

Os escorregamentos são divididos em rotacionais e translacionais.

No subtipo rotacional, o material sofre pouca deformação e se desloca a partir de superfícies de ruptura internas (Figura 5). Este mecanismo gera degraus de abatimento na superfície apresentando rachaduras concêntricas ao longo do plano e côncavas ao longo da direção do movimento. Exibem uma superfície de escorregamento curva com a concavidade voltada para cima, embora ela raramente apresente uma curvatura uniforme. $O$ escorregamento rotacional ocorre frequentemente em materiais homogêneos e, por esse motivo, é o movimento que comumente acontece em aterros.

A Figura 6 mostra uma superfície de ruptura característica do movimento rotacional. Ela é nitidamente côncava, voltada para cima, como em forma de uma colher.

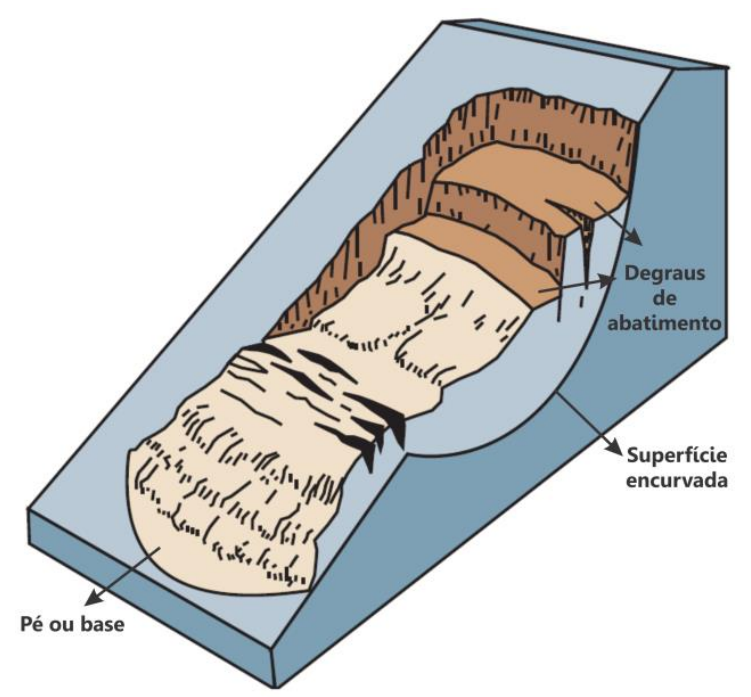

Figura 5 - Escorregamento rotacional (Fonte: USGS, 2004). 


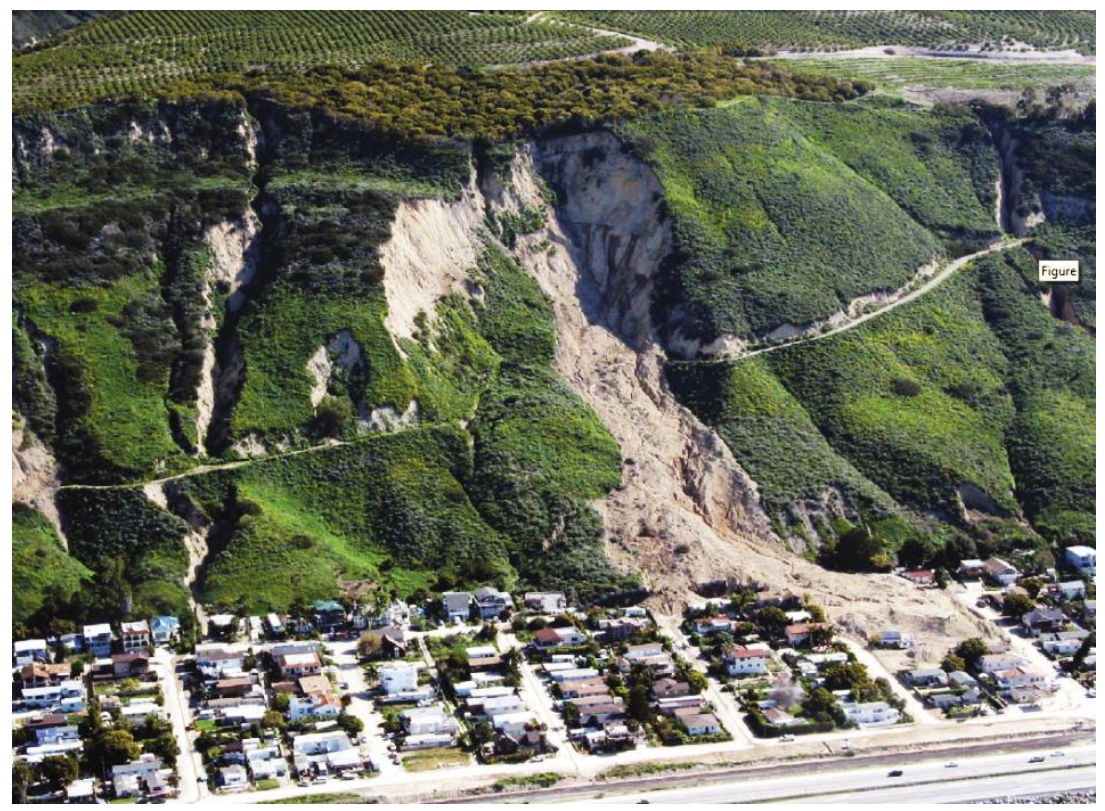

Figura 6 - Escorregamento rotacional de grandes dimensões ocorrido em La Conchita, Califórnia/EUA4.

Para o escorregamento rotacional, Hungr, Leroueill e Picarelli (2014) segue os mesmos conceitos adotados por Varnes (1978) e adiciona informações complementares quanto ao material envolvido.

O escorregamento rotacional em rochas acontece somente naquelas de baixa resistência e muitas vezes devido a sobrecarga de uma camada de rocha mais resistente. Usualmente é lento ou moderadamente lento. O escorregamento rotacional em solo é lento a rápido, entretanto, pode ser extremamente rápido quando em solos colapsíveis.

Nos escorregamentos translacionais, a massa em movimento se deforma enquanto desliza no sentido para fora e para baixo, ao longo de uma superfície aproximadamente plana com pouca rotação ou inclinação para trás (Figura 7). É controlado por estruturas de fraqueza, por exemplo: falhas, juntas, planos de acamamento, variações na resistência ao cisalhamento entre os estratos e nas superfícies entre diferentes tipos de materiais geológicos. Geralmente os escorregamentos translacionais são relativamente mais rasos do que os rotacionais.

\footnotetext{
${ }^{4}$ Procedência da Figura 6: <http://www.rc.unesp.br/igce/aplicada/ead/interacao/inter09c.html>.
} 
A Figura 8 mostra um escorregamento translacional ocorrido em Blumenau/SC em 2008. A superfície de ruptura planar se formou paralela à encosta íngreme, em meio à vegetação.

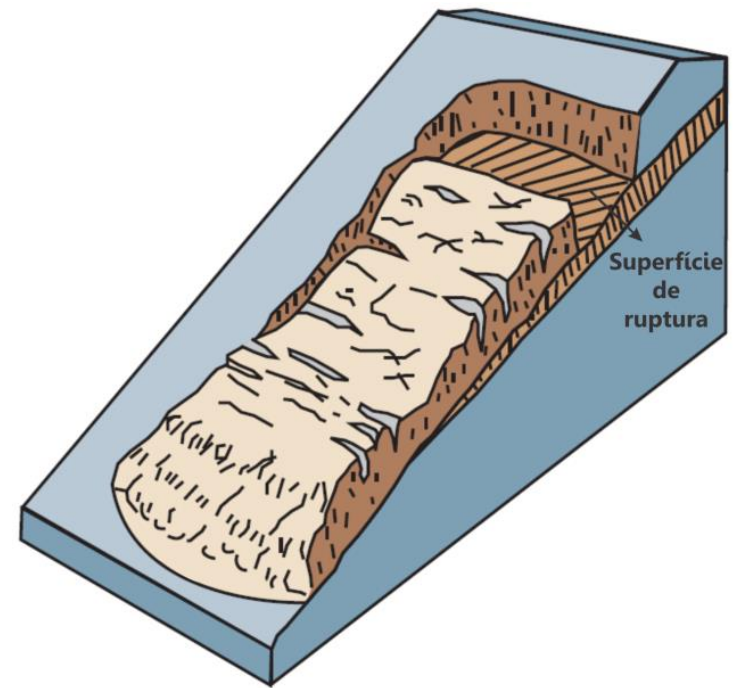

Figura 7 - Escorregamento translacional (Fonte: USGS, 2004).

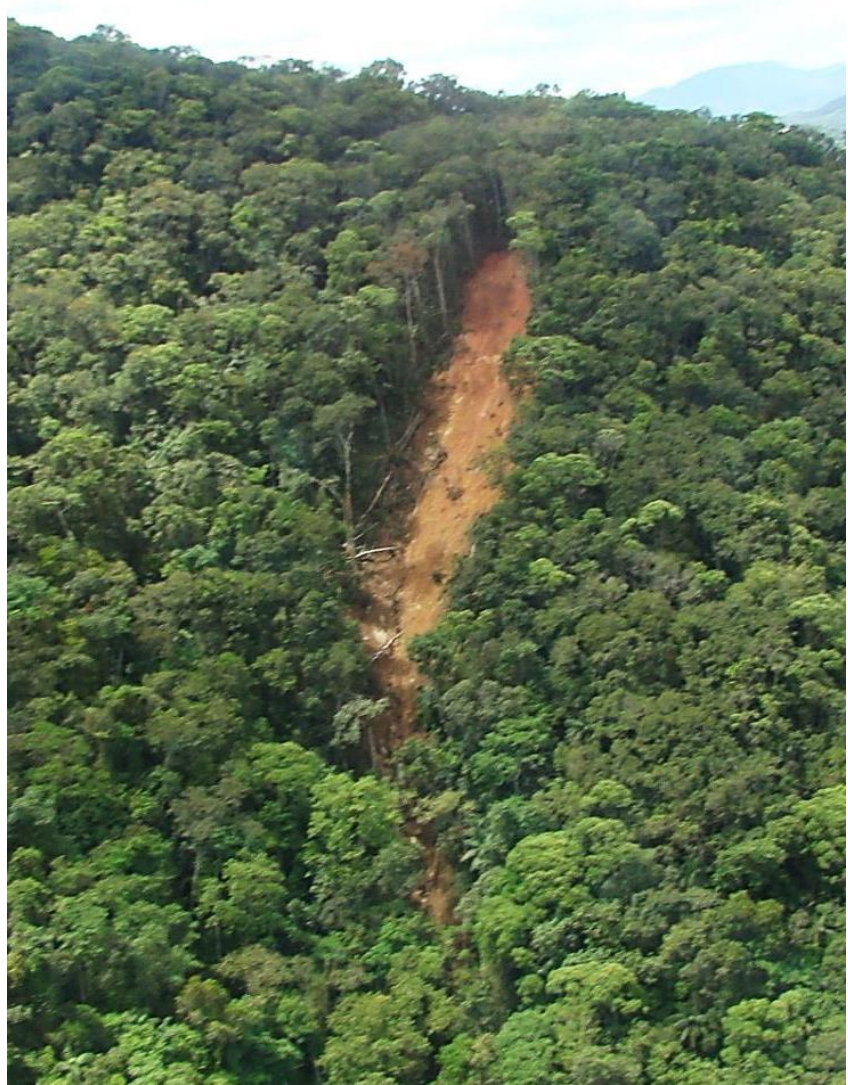

Figura 8 - Escorregamento translacional ocorrido em 2008 na cidade de Blumenau, Santa Catarina ${ }^{5}$.

${ }^{5}$ Procedência da Figura 8: Arquivo pessoal do Prof. Lázaro Valentin Zuquette. 
A geometria do escorregamento rotacional apresenta a superfície de deslizamento inclinada para o interior da curva de ruptura, assim, o movimento alcança o equilíbrio na região do pé do talude (Figura 5). Esta estabilidade somente acontece no escorregamento translacional quando as forças atuantes na massa diminuem em relação à resistência.

Hungr, Leroueill e Picarelli (2014) modifica a classificação de Varnes (1978) subdividindo os escorregamentos translacionais em planar, cunha e composto, como já posteriormente indicado por Cruden e Varnes (1996), e adiciona um novo tipo de movimento denominado irregular (somente para materiais rochosos).

Os escorregamentos planares em rochas e em solos ocorrem a partir de uma superfície de ruptura plana. São extremamente rápidos em rochas e, lentos ou rápidos em solos.

Hungr, Leroueill e Picarelli (2014) conceitua o escorregamento de materiais granulares, denominado escorregamento de cascalho, areia ou detritos. Este possui superfície de ruptura rasa, planar e paralela à superfície do terreno. Geralmente, a massa em movimento se trata de colúvios, solos intemperizados e depósitos piroclásticos, secos e homogêneos. Em alguns casos pode se transformar em uma avalanche de detritos extremamente rápida.

Os escorregamentos em cunha são formados por dois planos de ruptura tendo a linha interseção destes planos paralela ao mergulho da encosta. Este movimento ocorre em grande maioria em rochas, não possui deformação interna e é extremamente rápido.

O escorregamento irregular é o movimento de material rochoso sob superfície de ruptura irregular formada a partir de diversas descontinuidades orientadas aleatoriamente e separadas por porções de rocha intacta. Hungr, Leroueill e Picarelli (2014) comenta que esse mecanismo de ruptura é complexo e difícil de descrever, ocorrendo numa velocidade muito rápida a extremamente rápida. 


\section{Fluxo (flows)}

Pode também ser denominado escoamento. É o movimento espacialmente contínuo de uma massa que se desloca semelhante a um líquido viscoso. Um escorregamento, principalmente de detritos, pode evoluir para fluxo dependendo da quantidade de água, da mobilidade e da evolução do movimento.

Varnes (1978) divide este tipo em dois grupos: O fluxo de substrato rochoso e o de materiais inconsolidados, sendo este subdividido em fluxo de detritos, fluxo de terra e avalanche de detritos. Segundo USGS (2004) existem cinco categorias de fluxo, são elas: fluxo de detritos (debris flow), avalanche de detritos (debris avalanche), fluxo de terra (earthflow), fluxo de lama (mudflow) e rastejo (creep). As principais diferenças entre os tipos são: o material envolvido e a velocidade de movimentação.

Hungr, Leroueill e Picarelli (2014) apresenta 10 subdivisões para escoamento como mostrado na Tabela 9, sendo 9 específicos para solo. Nesta subdivisão foram considerados além da velocidade e do material, também a quantidade de água existente.

Abaixo segue a descrição sucinta dos tipos de fluxos e, para melhor detalhamento, indica-se a leitura do estudo de Hungr, Leroueill e Picarelli (2014).

Fluxo de detritos (debris flow): fluxo muito rápido a extremamente rápido que mobiliza detritos saturados, arrastando pela encosta a água e outros materiais como resíduos orgânicos e material erodido ao longo do trajeto. Fluxos de detritos são geralmente causados por intenso escoamento superficial de água, devido à forte precipitação ou rápido degelo. As áreas onde são originados frequentemente associam-se a vertentes íngremes. Pode ser iniciado por escorregamentos, avalanche de detritos ou quedas de rocha.

Quando há um aumento significativo da quantidade de água na qual a vazão pode ser comparada a uma inundação, este movimento é denominado inundação de detritos (debris flood). Ele percorre canais de drenagens de grandes bacias hidrográficas e é ampliado pela abundância de sedimentos acrescentados durante o caminho. 
A avalanche de detritos (debris avalanche) é um tipo de fluxo muito rápido a extremamente rápido e movimenta detritos parcialmente ou totalmente saturados por um canal não confinado da encosta. Por muitas vezes, a avalanche de detritos se inicia dispersa, como um escorregamento de detritos, percorrendo um caminho qualquer pela encosta, em seguida se concentra e desestabiliza parte do canal percorrido, se transformando em um fluxo de detritos.

Fluxo de lama (mud flow): fluxo muito rápido a extremamente rápido constituído por material plástico que contém água suficiente para fluir devido ao rápido degelo ou a precipitação intensa. Arrasta grande quantidade de material juntamente com água em canais íngremes. Hungr, Leroueill e Picarelli (2014) comenta que a interface entre fluxo de detritos e de lama é gradativo. $O$ índice de plasticidade dos materiais, neste caso, pode servir como parâmetro de controle. A Figura 9 mostra uma região de Blumenau/SC, atingida por vários movimentos de fluxos que carrearam grande quantidade de material, este sendo depositado nas planícies mais próximas.

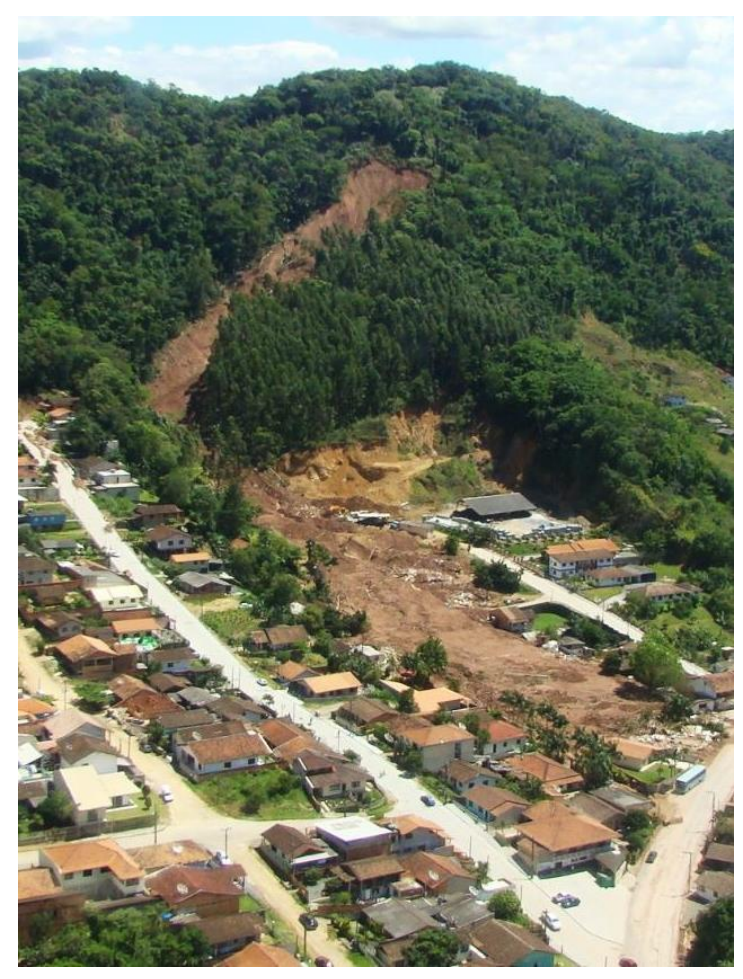

Figura 9 - Exemplo de fluxo de lama ocorrido em Blumenau, Santa Catarina em 2008. Observa-se que a lama atingiu várias casas no caminho da movimentação ${ }^{6}$.

${ }^{6}$ Procedência da Figura 9: Arquivo pessoal do Prof. Lázaro Valentin Zuquette. 
Fluxo de terra (earthflow): fluxo rápido ou lento de solos plásticos, argilosos, fluindo ao longo de múltiplas superfícies de cisalhamento em encostas de baixa inclinação, por volta de $12^{\circ}$. Os materiais devem ser facilmente deformados e essencialmente dúcteis. Pode apresentar longos períodos de dormência alternando a deslocamentos repentinos.

Fluxo de areia, silte ou detritos (Sand/silt/debris flowslide): fluxo rápido ou extremamente rápido de materiais granulares saturados (areias fofas, aterros ou resíduos de mineração, loess e silte) devido ao excesso de pressão na água ou liquefação. Quando este material é seco, úmido ou subaquoso, o movimento é chamado de fluxo seco (Sand/silt/debris dry flow) e não existe o aumento da pressão na água.

Fluxo de argila sensivel (sensitive clay flowslide): fluxo rápido a extremamente rápido de argila sensível. Acontece pela perda de resistência devido ao amolgamento da argila quando é submetida a uma tensão suficiente para ocorrer uma súbita mudança de fase de sólido para líquido. Este material também é chamado de "quick clays".

Fluxo de turfa (peat flow): fluxo rápido de matéria orgânica liquefeita, causada por cisalhamento não drenado.

Avalanche de rocha ou gelo (rock/ice avalanche): fluxo extremamente rápido que movimenta fragmentos de rocha a partir de um grande escorregamento ou queda. O material é predominantemente seco porque durante o movimento não existe possibilidade dos poros serem preenchidos por água devido ao curto tempo de movimento. A alta mobilidade do material possui muitas explicações propostas pela literatura, entretanto, nenhuma ganhou aceitação Hungr, Leroueill e Picarelli, 2014). 


\section{E. Espalhamentos laterais (lateral spreads)}

Este tipo de movimento geralmente acontece em encostas muito suaves ou em terreno plano. Ocorre através da expansão lateral do material acompanhada por fraturas de cisalhamento ou tração. Podem ser diferenciados em dois tipos:

i. Os que acontecem sem ter uma definição da superfície de cisalhamento ou da zona de plástica e ocorrem em formações rochosas espessas que se sobrepõem a material dúctil. Este tipo é chamando por Hungr, Leroueill e Picarelli (2014) por espalhamento de rocha. Segundo este autor, a deformação intensa do material subjacente de comportamento dúctil promove o estiramento da rocha rígida sobrejacente.

ii. Os que podem envolver fraturamento e expansão de materiais coesos, devido a liquefação do material basal (Figura 10). O material com mais alta coesão pode rotacionar, translacionar e desagregar.

De acordo com a atualização de Hungr, Leroueill e Picarelli (2014) o tipo (ii), descrito acima, é interpretado como dois movimentos distintos denominados: espalhamento de areia e silte por liquefação e de argila sensível.

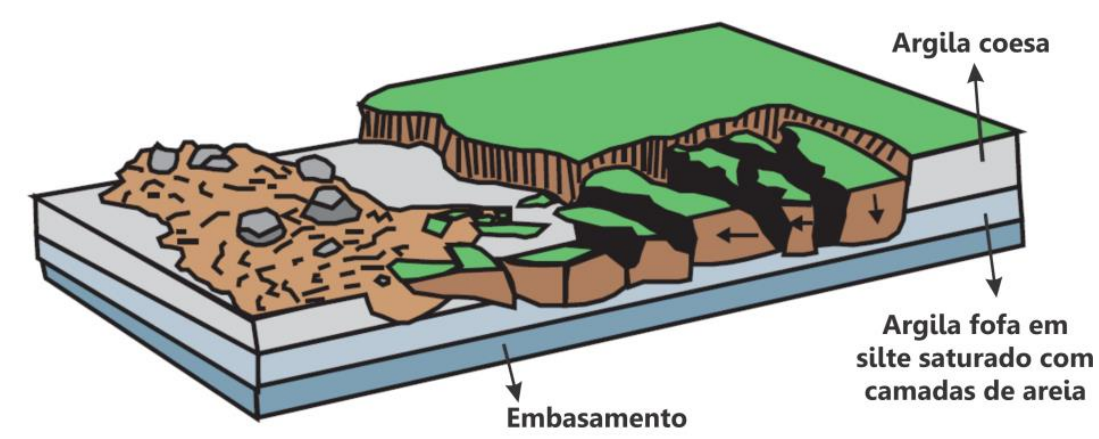

Figura 10 - Espalhamento lateral (Fonte: USGS, 2004).

O espalhamento por liquefação pode ser causado por terremotos ou espontaneamente, onde blocos de solo flutuam sobre material granular liquefeito caracterizando um movimento extremamente rápido. O espalhamento de argila 
sensível resulta da propagação de uma zona de cisalhamento horizontal a partir de uma camada de argila sensível que se transforma em fluido (perde a resistência) quando amolgada. Blocos de argila coesa intactos são deslocados como que flutuando sobre esta camada amolgada formando bancos de horst e grabens. A Figura 11 mostra o espalhamento lateral produzido pela liquefação do material sotoposto, ocorrido às margens de um lago em Manzanillo/México. Observa-se que a movimentação provocou distorção e rachaduras no piso da calçada.

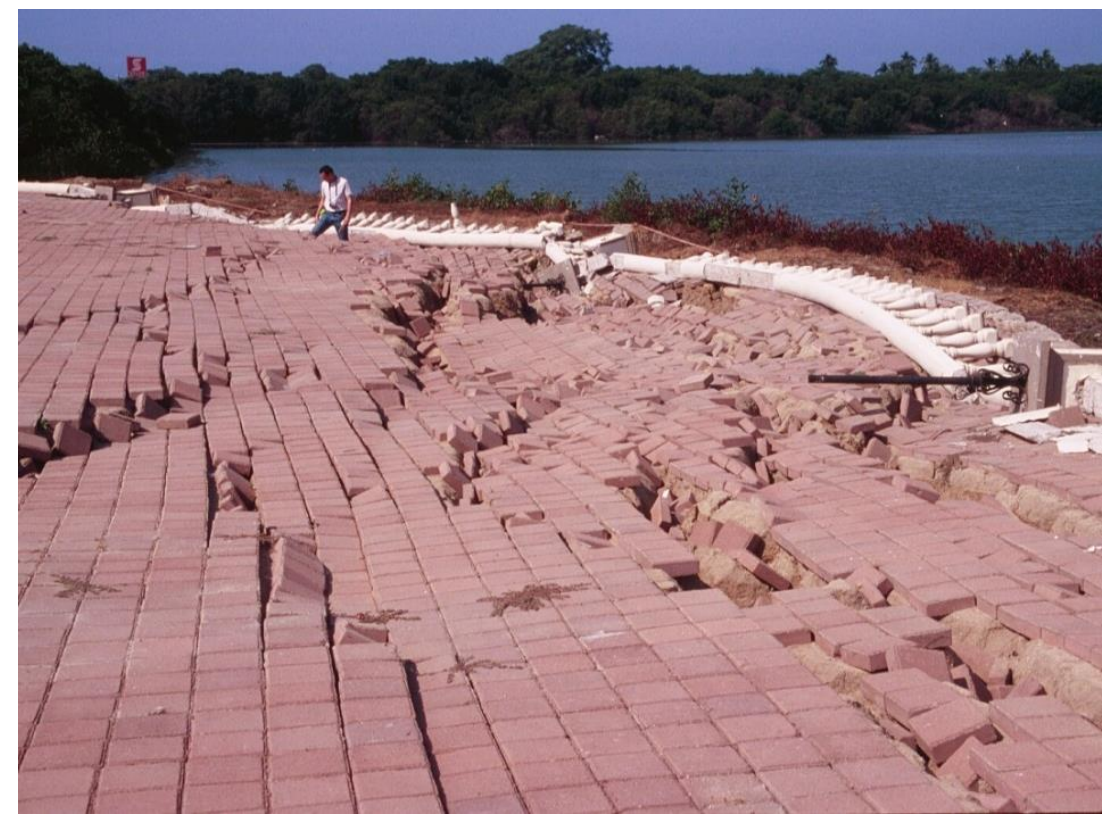

Figura 11 - Exemplo de espalhamento lateral. ${ }^{7}$.

\section{F. Deformação das encostas (Slope deformation)}

Os subtipos de deformação das encostas descritos a seguir, fazem parte da revisão do sistema de classificação de Varnes (1978) criada por Hungr, Leroueill e Picarelli (2014). Este tipo de movimento não foi considerado por Varnes (1978) e Cruden e Varnes (1996). Hutchinson (1988) cita alguns dos mecanismos posteriormente utilizados por Hungr, Leroueill e Picarelli (2014) para descrever a deformação em encostas, entretanto, não há uniformidade nos nomes definidos

\footnotetext{
${ }^{7}$ Procedência da Figura 11:< http://www.geerassociation.org/GEER_Post\%20EQ\%20Reports/Tecoman_2003/c-liq-
} 
pelos autores. A principal diferença é a inclusão do rastejo como um tipo de deformação da encosta e não mais como fluxo, como sugerido por Varnes (1978).

Rastejo (soil creep): é um movimento extremamente lento do solo em encostas, causado pela tensão de cisalhamento suficiente para produzir uma deformação, mas insuficiente para produzir ruptura (Figura 12). Este tipo de movimento é observado em campo por troncos de árvores e cercas curvas e tortos ou muros e postes inclinados, e pequenas ondulações do solo ou sulcos (Figura 13).

O movimento normalmente possui $1 \mathrm{~m}$ de profundidade e é o resultado da alteração volumétrica do solo devido a mudanças cíclicas do clima (úmido, seco e geada), ou atividades animal e vegetal (Hungr, Leroueill e Picarelli, 2014).

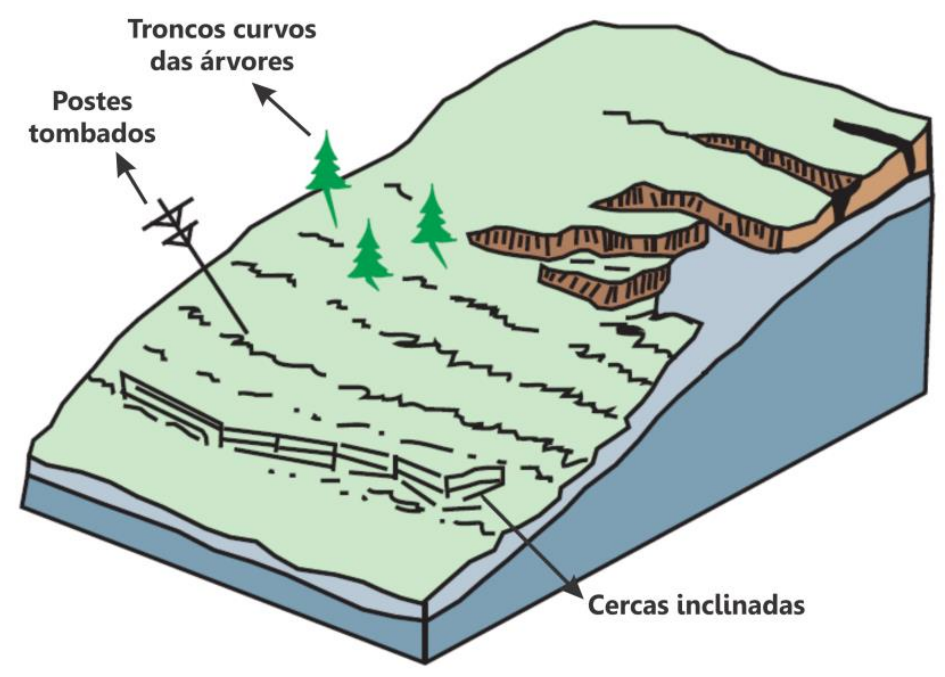

Figura 12 - Rastejo (Fonte: USGS, 2004). 


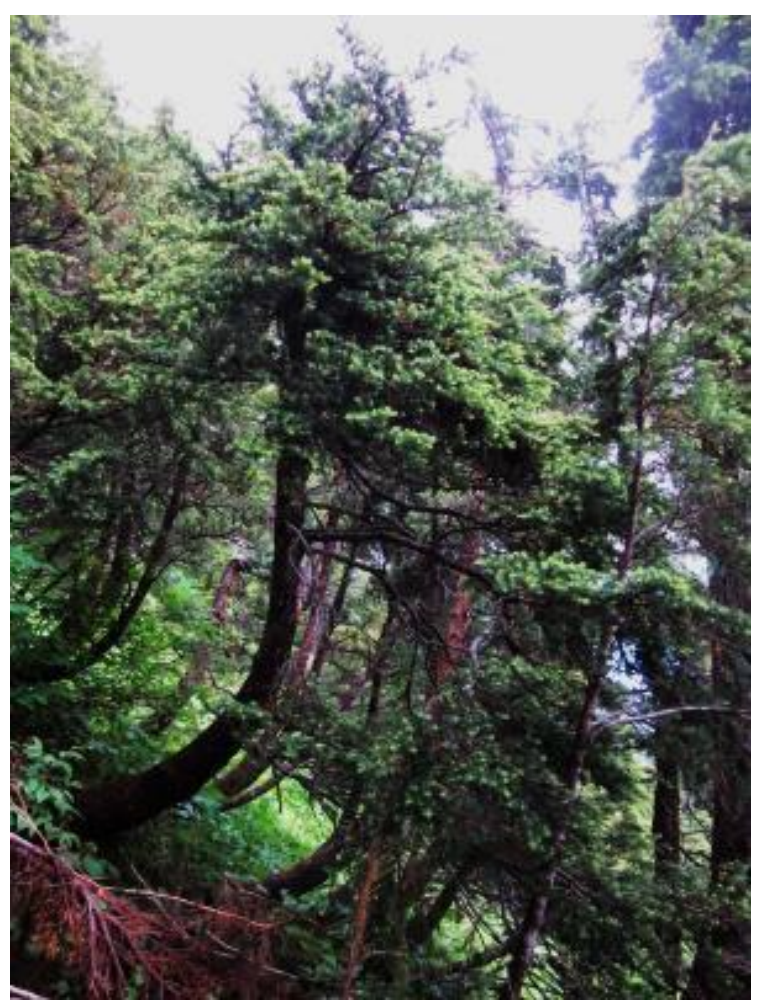

Figura 13 - Exemplo de rastejo em encosta cujos indícios são vistos através dos troncos curvos, buscando o crescimento vertical. ${ }^{8}$

Deformação das encostas montanhosas (mountain slope deformation): movimento extremamente lento com velocidades não mensuráveis, gerado pela deformação em grande escala de encostas rochosas muito íngremes em regiões montanhosas. Manifesta-se por rachaduras, saliências e valas vistas na superfície topográfica. Neste caso, não é possível a identificação de uma superfície de ruptura totalmente definida, e a deformação muitas vezes pode ser confundida como resultado de falhas tectônicas.

Deformação das encostas rochosas (rock slope deformation): deformação de vales ou encostas rochosas gerando flacidez das cristas e desenvolvimento de fissuras ou falhas, sem apresentar superfície de ruptura bem definida. O movimento é extremamente lento.

${ }^{8}$ Procedência da Figura 13: http://www.geomika.com/blog/2011/08/13/creep/ 
Deformação dos solos das encostas (Soil slope deformation): é um movimento lento a extremamente lento de vales e encostas formadas por solos coesivos e bastante presente em solos congelados de cristas (permafrost) com grande quantidade de gelo. Normalmente os deslocamentos são pequenos.

Solifluxão (solifluction): movimento muito lento, porém envolvendo intenso rastejo de solo congelado. Ocorre em regiões periglaciais como nos alpes e zonas polares. Com o degelo durante o verão, o solo fica saturado e, flui sobre material impermeável.

\section{G. Complexos (complex)}

Varnes (1978) define o movimento complexo como sendo a combinação de dois ou mais tipos principais. Eles podem ocorrer simultaneamente ou em diferentes estágios da evolução de um movimento. Cruden e Varnes (1996) reconhece o desuso deste termo como um tipo de movimento de massa gravitacional, sendo mantido para caracterizar o estilo da atividade de um movimento.

Hungr, Leroueill e Picarelli (2014) ressalta que classificar um movimento como complexo não é útil pois, a maioria dos tipos de movimentos de massa possuem uma certa complexidade. Por outro lado, as vezes é necessário a utilização de dois nomes de tipos de movimento para descrever um evento no qual um só termo não retrataria. Isto define uma terminologia composta que deve ser decidida pelo pesquisador, e não um novo tipo de movimento.

Como exemplo, tem-se um movimento que ocorreu em Canton Valais, sul da Suiça, descrito como escorregamento irregular de rocha e escorregamento de detritos (irregular rock slide-debris slide) (Hungr, Leroueill e Picarelli, 2014). Neste caso, o movimento se deu em dois estágios. Primeiro ocorreu um escorregamento irregular de rocha e o material se deslocou como uma avalanche de rocha recobrindo parte da encosta íngreme onde existia um depósito de tálus. Após alguns minutos, o depósito de tálus começou a se movimentar como um escorregamento translacional devido ao aumento da pressão nos poros (sobrecarga), e atingiu alta velocidade. 


\subsubsection{Classificação de Hutchinson (1988)}

A classificação de Hutchinson (1988) foi elaborada tendo como apoio os estudos anteriores do mesmo autor e o trabalho de Varnes (1978). A classificação se baseia, primeiramente, na morfologia do movimento da encosta, considerando também o mecanismo, o material e a taxa de movimentação. Aplica-se a movimentos que ocorrem nas áreas subsuperficiais da encosta, provocadas de forma natural ou pelo homem (Hutchinson, 1988). Para este autor a diversidade dos fatores interfere no processo, definindo uma variedade de tipos de movimento. Estes fatores são: litologia, estrutura geológica, hidrogeologia, topografia, clima, vegetação, sismicidade e erosão.

A descrição dos tipos de movimentos será apresentada a seguir, de forma reduzida. Para maiores detalhes, aconselha-se a leitura do tralhado de Hutchinson (1988) in extenso. Esta classificação está resumida na Tabela 10.

\section{A. Recuo (Rebound)}

O recuo acontece quando parte da superfície é desprendida seja por escavações antrópicas ou natural por erosões, o material responde a priori, elasticamente e depois por uma lenta expansão, com movimentos ascendentes e descendentes em sua base e nas laterais. Estes movimentos produzem fraturas e novas mudanças no material através do seu intemperismo acelerado. 
Tabela 10 - Tipos de movimentos de massa gravitacionais classificados por Hutchinson (1988).

\begin{tabular}{|c|c|c|}
\hline$\underset{\text { Recuo }}{\text { A }}$ & 1. & $\begin{array}{l}\text { Movimentos associados a escavações antrópicas. } \\
\text { Movimentos associados a vales naturalmente erodidos. }\end{array}$ \\
\hline $\begin{array}{c}\text { B } \\
\text { Rastejo }\end{array}$ & $\begin{array}{l}2 . \\
3 . \\
4 .\end{array}$ & $\begin{array}{l}\text { Rastejo superficial. } \\
\text { Rastejo profundamente assentado, contínuo e de massa. } \\
\text { Rastejo de pré-ruptura e progressivo. } \\
\text { Rastejo pós-ruptura. }\end{array}$ \\
\hline $\begin{array}{l}\text { C } \\
\text { Sagging of } \\
\text { mountain slopes }\end{array}$ & 3. & $\begin{array}{l}\text { Fraturamento unilateral associado aos estágios iniciais de } \\
\text { deslizamento. } \\
\text { Fraturamento bilateral associado aos estágios iniciais de } \\
\text { duplos deslizamentos, levando a propagação em direção à } \\
\text { crista. } \\
\text { Fraturamento associado à múltiplos colapsos. }\end{array}$ \\
\hline $\begin{array}{c}\text { D } \\
\text { Escorregamentos }\end{array}$ & $\begin{array}{l}1 . \\
2 . \\
3 . \\
4 .\end{array}$ & $\begin{array}{l}\text { Rupturas confinadas. } \\
\text { Rotacionais. } \\
\text { Compostos. } \\
\text { Translacionais. }\end{array}$ \\
\hline $\begin{array}{l}\text { E } \\
\text { Movimentos de } \\
\text { detritos em forma } \\
\text { de fluxo }\end{array}$ & $\begin{array}{l}1 . \\
2 . \\
3 . \\
4 . \\
5 .\end{array}$ & $\begin{array}{l}\text { Fluxo de lama. } \\
\text { Fluxo de lama periglacial. } \\
\text { Fluxo de terra. } \\
\text { Fluxo de detritos, fluxo extremamente rápido de detritos } \\
\text { úmidos. } \\
\text { Sturzstrom (avalanche de rocha), fluxo extremamente } \\
\text { rápido de detritos secos. }\end{array}$ \\
\hline $\begin{array}{c}\text { F } \\
\text { Tombamentos }\end{array}$ & 1. & $\begin{array}{l}\text { Tombamento delimitado por descontinuidades pré- } \\
\text { existentes. } \\
\text { Tombamento desprendido por tensões de falha na parte } \\
\text { traseira da massa. }\end{array}$ \\
\hline $\begin{array}{c}\text { G } \\
\text { Quedas }\end{array}$ & $\begin{array}{l}1 . \\
2 .\end{array}$ & $\begin{array}{l}\text { Primárias } \\
\text { Secundárias }\end{array}$ \\
\hline & & $\begin{array}{c}\text { H } \\
\text { vimentos complexos de vertentes }\end{array}$ \\
\hline
\end{tabular}

Fonte - Modificada de Hutchinson (1988).

\section{B. Rastejo (Creep)}

É um tipo de movimento extremamente lento e imperceptível, a não ser que sejam feitas medidas por um longo período. Os rastejos superficiais ocorrem devido a mudanças no teor de água e temperatura, variando o volume do solo, por isso são 
considerados predominantemente sazonais. O rastejo: ainda pode ser contínuo, profundos, de massa, pré-ruptura e pós-ruptura. O tipo superficial pode ser comparado ao rastejo descrito por Varnes (1978) e por Hungr, Leroueill e Picarelli (2014), entretanto para Hutchinson (1988), ele forma um tipo de movimento de massa separado dos outros.

\section{Sagging of mountain slopes (fraturamento de vertentes de montanhas)}

São deformações exibidas nas cristas e nas encostas íngremes das montanhas, formando uma variedade de horsts e grabens muitas vezes associadas a cristas duplas e pequenos lagos (Mahr \& Nemcok, $1977^{9}$ apud Hutchinson, 1988). Os deslocamentos em escarpas individuais geralmente variam de 1 a 2 metros e em casos mais severos pode chegar a dezenas de metros. Este tipo de movimento desenvolve-se melhor em rochas com forte anisotropia, principalmente em rochas metamórficas, como granulitos, xistos, gnaisses etc. e também são comuns em rochas ígneas, como em: granitos, dioritos e intrusões básicas. Possui baixa probabilidade de acontecer em rochas sedimentares.

A Figura 14 apresenta os tipos de movimentos de vertentes associados a movimento de fraturamento rotacional (a), fraturamento com superfície de ruptura lístrica (em forma de colher) (b) e fraturamento com escarpas múltiplas de deslizamentos biplanares (c).

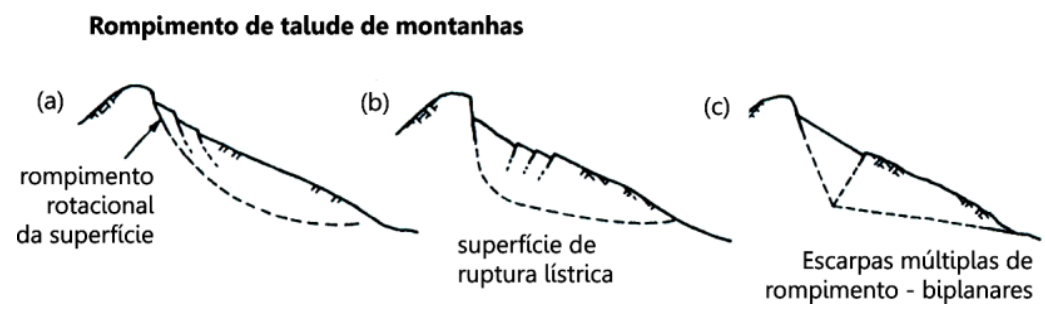

Figura 14 - Tipos de movimentos de vertentes de montanhas (Modificado de Hutchinson, 1988).

\footnotetext{
9 MAHR, T.\& NEMCOK, A. 1977. Deep-seated deformations in the crystaline cores of the Tatry Mountains. Boletin International Assoc. Eng. Geol. v. 16, p $104-106$.
} 
Também podem acontecer movimentos em montanhas que causam a partição bilateral das encostas associados aos estágios iniciais de duplos deslizamentos, e deformações associadas à múltiplos colapsos.

Para ilustrar o subtipo C2 (Tabela 10), tem-se a Figura 15 que mostra o resultado do movimento bilateral das encostas com propagação em direção à crista em uma montanha do Canadá, chamada Mission Ridge.

Este movimento de massa se relaciona à deformação das encostas apresentado por Hungr, Leroueill e Picarelli (2014).

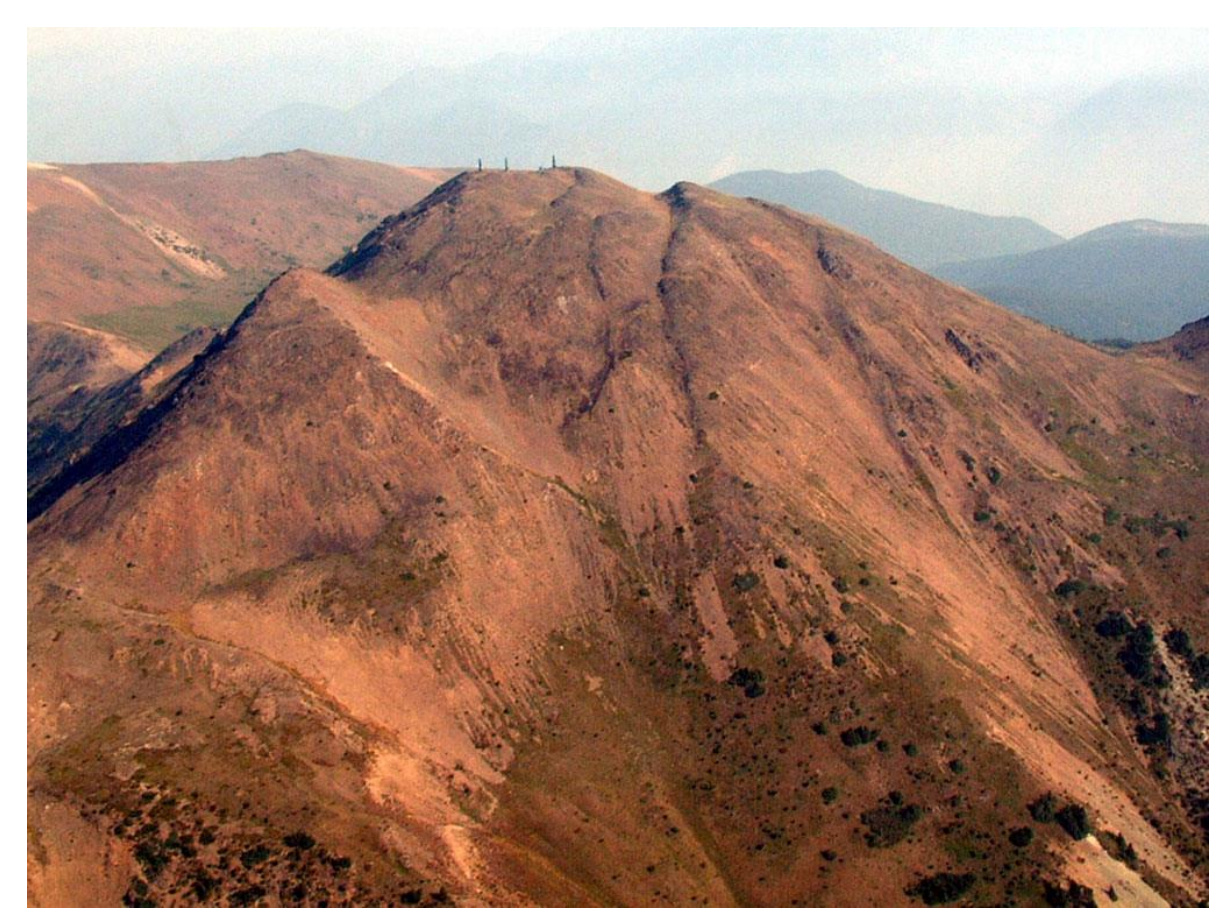

Figura 15 - Deformação da crista da montanha em fraturamento bilateral. Fonte: Hungr, Leroueill e Picarelli (2014).

\section{Escorregamentos (slides)}

São movimentos relativamente rápidos de solos e rochas que geram uma ou mais superfícies de deslizamento discretas. $O$ processo começa com o surgimento de fratura e é seguido pelo deslocamento da massa sendo o problema central da classificação definir qual é a importância que se deve dar a cada parte do movimento.

Existem os mais variados tipos de escorregamentos, por exemplo: 
i. Rupturas confinadas: surgem no estado inicial do processo de ruptura e podem acontecer em encostas naturais e em taludes artificiais;

ii. Rotacionais: acontecem em encostas que consistem de materiais grosseiros e homogêneos. Podem ser divididos em simples (Figura 16a), sucessivos (Figura 16b) e múltiplos (Figura 16c);

iii. Escorregamentos compostos: ocorrem entre rupturas translacionais e rotacionais e podem ser relacionados ao cisalhamento interno ou ao escorregamento progressivo;

iv. Translacionais: envolve ruptura por cisalhamento, divididos aqui em 6 subtipos: em lâminas (Figura 17a), em fatia (Figura 17b), em turfas, em rocha (Figura 17c), de detritos (Figura 17d) e em forma de espalhamento por falhas (Figura 17e).

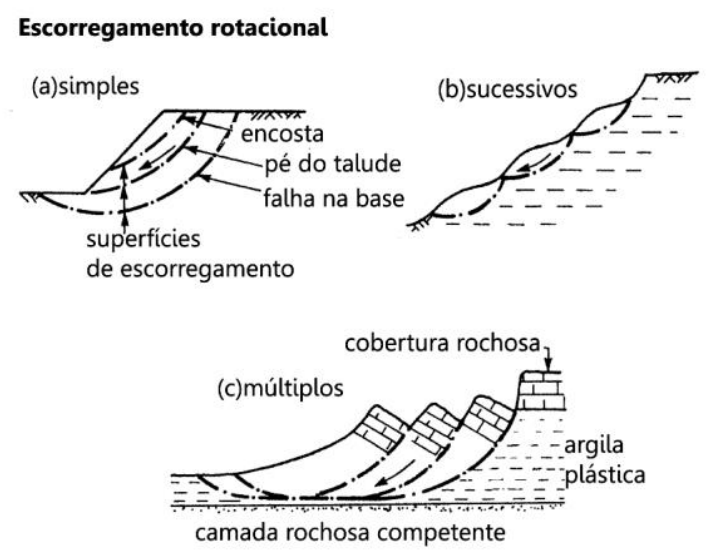

Figura 16 - Escorregamentos rotacionais (Modificado de Hutchinson, 1988).

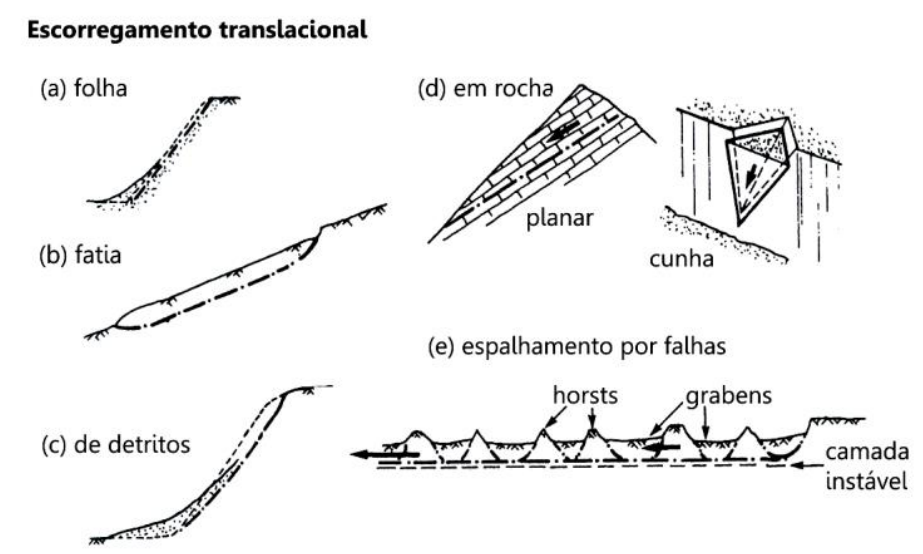

Figura 17 - Escorregamentos translacionais (Modificado de Hutchinson, 1988). 


\section{E. Movimento de detritos em forma de fluxo (debris movements of flow-like form)}

Neste tipo de movimento a morfologia é o principal fator de classificação. $O$ movimento de detritos em forma de fluxo pode ser dividido em: fluxo de lama, fluxo de lamas periglaciais, fluxo de terra, fluxo de detritos, avalanche de terra. Os fluxos de lama ocorrem em forma de lâminas e os fluxos de terra ocorrem em solos sem coesão e rochas de alta porosidade. Os fluxos possuem diferentes mecanismos: os de lama são movimentos que deslizam ao invés de fluir, sendo semelhante ao escorregamento translacional. O fluxo de lama e o fluxo de detritos (Figura 18a e Figura 18b) exibem variações entre o escorregamento e fluxo, respectivamente, enquanto a avalanche de terra é essencialmente fluxo (Figura 18c).

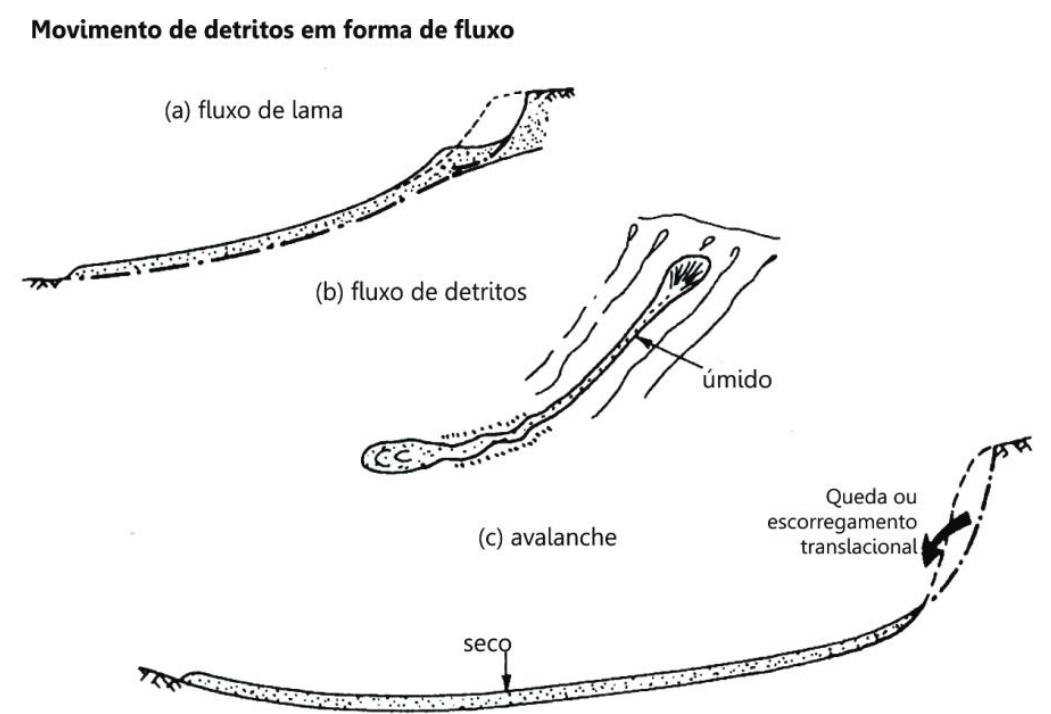

Figura 18 - Tipos de movimentos de detritos em forma de fluxo (Modificado de Hutchinson, 1988).

\section{F. Tombamento (topples)}

Este movimento ocorre quando o vetor resultante da força aplicada em um bloco rochoso provocando a queda do bloco a partir de um ponto de articulação na sua base. Isto é comum em maciços rochosos que apresentam descontinuidades quase verticais e pode envolver grandes volumes de material. Hutchinson (1988) 
citando Varnes (1978) diz que tombamentos em solos também existem e que uma boa revisão sobre este assunto foi feita por Goodman e Bray $\left(1976^{10}\right.$ apud Hutchinson, 1988). O mesmo autor divide os tombamentos em dois: os que ocorrem a partir de descontinuidades pré-existentes, sendo simples (Figura 19a) ou múltiplos (Figura 19b); e os que ocorrem por ruptura de tensão.

\section{Tombamento}

Descontinuidades pré-existentes

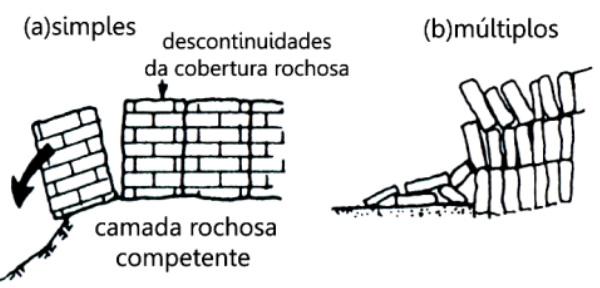

Descontinuidades por ruptura de tensão

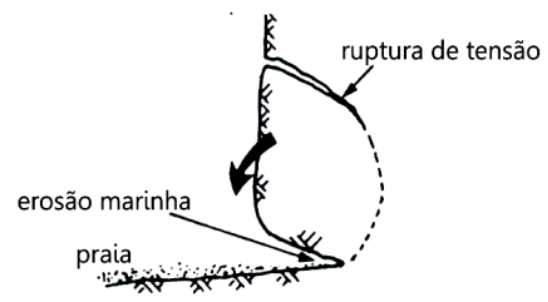

Figura 19 - Tipos de tombamentos (Modificado de Hutchinson, 1988).

\section{G. Quedas (falls)}

Compreende o rápido movimento descendente, em queda livre, de uma massa de solo ou rocha de qualquer tamanho que acontece em encostas muito íngremes ou em falésias. Elas podem se dividir em duas categorias:

a) Primária: são quedas de blocos de rocha ou solo envolvendo o desprendimento de uma parte constituinte da massa como mostra a Figura 20a. O processo de separação é geralmente progressivo e prolongado.

${ }^{0}$ GOODMAN.R.E. \& BRAY. J.W., 1976. Toppling of rock slopes. In Rock Engineering for foundations and slope, Special Conference, ASCE. Boulder, Colorado, v. 2, p. 201-234. 
b) Secundária: envolve a queda de um bloco de rocha ou matacões fisicamente separado da massa constituinte, e comumente solto sobre a encosta (Figura 20b).

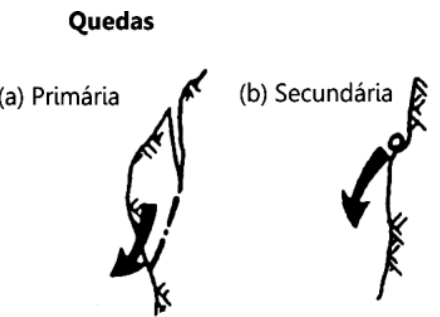

Figura 20 - Tipos de quedas de blocos (Modificado de Hutchinson, 1988).

\section{H. Movimentos Complexos (Complex slope movements)}

São movimentos originados pela combinação dois ou mais tipos de movimentos citados anteriormente. Os mais frequentes são: o soerguimento do fundo de vales; movimentos de encostas em blocos; encostas em material argiloso com alta declividade; escoamentos de lama ou fluxo na base das encostas, escorregamentos causados por erosão e escorregamentos de múltiplas camadas.

\subsubsection{Fatores que influenciam o MMG}

Os fatores que afetam a estabilidade de taludes são numerosos e variados e interagem entre si de formas complexas e muitas vezes sutis (Varnes, 1984). Muitos estudos são publicados com o intuito de definir, organizar e apresentar as principais causas, condicionantes e fatores deflagradores do movimento de massa gravitacional, são eles: Varnes (1984), Popescu (1994), Cruden e Varnes (1996), Sassa e Canuti (2009) e Cruden e Lan (2015).

Os fatores que produzem alterações desfavoráveis e podem levar ao movimento são chamados de condicionantes, sendo divididos em: predisponentes e 
deflagradores. Os fatores deflagradores foram subdivididos por Popescu (1994) como preparatórios e desencadeadores (ou efetivos).

Os fatores predisponentes são aqueles que se referem ao conjunto de características intrínsecas do terreno no qual vai ocorrer o movimento, e os deflagradores são aqueles que, de fato, causam o movimento, estando diretamente ligados à instabilização da encosta.

Os fatores deflagradores efetivos podem ser naturais e antrópicos. Os fatores naturais mais conhecidos são: chuvas intensas, rápido degelo, mudança no nível d'água, erupções vulcânicas, terremotos e mudanças na geometria da encosta (Sassa e Canuti, 2009). As formas de intervenção antrópica nas encostas podem ser cortes e aterros, concentração de água pluvial, lançamento de água servida, etc.

De acordo com Varnes (1978) os movimentos de massa acontecem pelo aumento ou redução das tensões cisalhantes. Desta forma, a adição de água ou a remoção de material através de cortes na encosta, podem contribuir para mudanças nos estados das tensões e causar a ruptura do material.

Cruden e Lan (2015) reúnem as principais causas de ocorrência de movimentos de massa gravitacionais em forma de check list (Tabela 11). Esta tabela é uma atualização da apresentada por Popescu (1994) e Cruden e Varnes (1984).

As causas podem ser divididas em 4 grupos, são eles:

i. Condições do material: são condições específicas do terreno no qual o movimento pode acontecer, relacionadas às propriedades do material, estrutura e descontinuidades presentes.

ii. Processos geomorfológicos: são processos relacionados a mudanças morfológicas no terreno. Podem ser documentados por mapas geológicos e topográficos, interpretação de fotografias aéreas, trabalhos de campo e observações feitas pela população local.

iii. Processos físicos: são mudanças no ambiente físico da encosta e podem ser documentadas por instrumentação como: pluviômetros, para estimativas de precipitação; sismógrafos, para registros de movimentação do terreno produzidos por terremotos, e piezômetros, 
para medir alterações na pressão da agua subterrânea ao longo do tempo.

iv. Processos artificiais: estão relacionados à intervenção humana nas encostas. Podem ser documentados por meio de mapas, fotografias aéreas e registros de construções e escavações. Para este processo, Cruden e Lan (2015) sugerem que sejam identificados, separadamente dos naturais, os movimentos de massa induzidos artificialmente.

Tabela 11 - Lista das causas que geram MMG (Cruden e Lan, 2015).

\begin{tabular}{|c|c|}
\hline Condições do material & Causas geomorfológicas \\
\hline Materiais de baixa resistência & Soerguimento tectónico \\
\hline Materiais sensíveis & Ajuste isostático glacial \\
\hline Materiais intemperizados & Erosão fluvial da base da encosta \\
\hline Materiais cisalhados & Erosão costeira da base da encosta \\
\hline Materiais fraturados & Erosão glacial da base da encosta \\
\hline $\begin{array}{l}\text { Descontinuidade da rocha orientada negativamente } \\
\text { (acamamento, xistosidade) }\end{array}$ & Erosão das margens laterais \\
\hline $\begin{array}{l}\text { Descontinuidade estrutural orientada negativamente } \\
\text { (angular, falha e contato) }\end{array}$ & Erosão subterrânea (dissolução e piping ) \\
\hline Contraste de permeabilidade & Deposição de carga sobre a encosta ou crista \\
\hline Contraste de rigidez & Remoção da vegetação (incêndios florestais, secas) \\
\hline Causas físicas & Causas artificiais \\
\hline Chuvas intensas & Escavação da encosta ou do pé da encosta \\
\hline Rápido degelo & Carregando da encosta ou crista \\
\hline Precipitação excepcional prolongada & Elevação de reservatórios \\
\hline Elevação rápida de inundações e marés & Desmatamento \\
\hline Terremoto & Irrigação \\
\hline Represamento de gelo & Mineração \\
\hline Descongelamento & Vibração artificial \\
\hline Intemperismo por congelamento e degelo & Vazamento de água de serviços públicos \\
\hline \multirow[t]{2}{*}{ Intemperismo por contração e dilatação } & Drenagem superficial com defeito \\
\hline & Lançamento de materiais soltos \\
\hline
\end{tabular}

A partir da identificação das condições e processos que promovem a instabilidade, podem ser estimadas a sua contribuição para a ocorrência de 
movimentos de massa. Para isso, são realizados estudos de susceptibilidade, perigo e risco do terreno com base nos dados levantados da área de pesquisa a depender do objetivo da sua avaliação.

A seguir, são apresentados os conceitos mais importantes relacionados ao estudo dos movimentos de massa gravitacionais e seus métodos de análise. 


\subsection{ESTUDO SOBRE MOVIMENTOS DE MASSA GRAVITACIONAIS}

\subsubsection{Conceitos gerais}

São apresentadas algumas definições relativas ao estudo dos movimentos de massa gravitacionais. Os termos usados neste estudo foram apresentados por Varnes (1984), Fell et al. (2008) e Crozier (2013).

Perigo (Hazard) - Ação com potencial de causar uma consequência indesejável. A descrição de perigo de movimento de massa deve incluir a localização, volume (ou área), classificação e a velocidade dos movimentos com potencial e/ou qualquer material desprendido resultante deste, e a probabilidade de sua ocorrência dentro de um determinado período de tempo.

Intensidade do movimento de massa - Um conjunto de parâmetros espacialmente distribuídos relacionadas ao poder destrutivo de um movimento de massa. Os parâmetros podem ser descritos quantitativa ou qualitativamente, podendo incluir a velocidade máxima do movimento, deslocamento total, deslocamento diferencial, a profundidade da massa em movimento, vazão de pico por unidade de largura, a energia cinética por unidade de área.

Elemento em risco - População, construções e obras de engenharia, atividades econômicas que, por exemplo, podem ser reduzidas devido à perda de uma estrada, equipamentos de serviços públicos, infraestrutura, além dos impactos ambientais na área que potencialmente pode ser afetada por movimentos de massa gravitacionais.

Risco - Medida da probabilidade e gravidade de um evento adverso à saúde, bens ou o ambiente. O risco é frequentemente estimado pelo produto da probabilidade do fenômeno pela magnitude das consequências. No entanto, uma interpretação mais geral de risco implica numa comparação da probabilidade e as consequências sem o uso do produto como aplicação. Para Fell et al. (2008) o risco é melhor definido como a probabilidade anual do elemento, seja ele uma pessoa ou uma propriedade em situação de risco, perder a vida ou sofrer algum dano, tendo 
em conta o perigo de um movimento de massa gravitacional, a probabilidade temporal e espacial, e a sua vulnerabilidade.

Risco - análise qualitativa: Análise que usa forma de texto, escalas descritivas ou numéricas para descrever a magnitude das consequências potenciais e a probabilidade dessas consequências ocorrerem.

Risco - análise quantitativa: Análise baseada em valores numéricos de probabilidade, a vulnerabilidade e consequências, e que resulta em um valor numérico de risco.

Vulnerabilidade - Grau de perda esperado para um determinado elemento ou conjunto de elementos dentro da área afetada pelo evento. Ela é expressa numa escala de 0 (sem perdas) a 1 (perda total). Para uma propriedade, a perda será o valor da avaria em relação ao valor da propriedade; para pessoas, será a probabilidade de uma vida em particular (o elemento em risco) ser perdida, dado que a pessoa seja afetada pelo movimento de massa gravitacional.

Zoneamento - Parcelamento da terra em áreas homogêneas ou domínios, cuja classificação se dá de acordo com os graus de suscetibilidade real ou potencial do movimento, perigo ou risco.

Tendo em vista todos estes conceitos, a próxima etapa é conhecer as suas formas de representação (cartas e mapas) que auxiliam na avaliação dos movimentos de massa, e os processos de pesquisa e elaboração de cada uma delas.

\subsubsection{Tipos de mapas e cartas de movimentos de massa gravitacionais}

Os estudos dos movimentos de massa gravitacionais são importantes no planejamento do uso da terra, obras de engenharia, programas de redução de risco e planejamento urbano (Sassa e Canuti, 2009). Vários pesquisadores (Guzzetti et al., 1999; Parise, 2001; Fell et al. 2008; Sassa e Canuti, 2009; Crozier, 2013) apresentam trabalhos sobre o modelo de representação e análise que podem ser feitos a partir da relação entre os movimentos de massa gravitacionais, os fatores predisponentes, os deflagradores e os elementos em risco. 
O modelo de aplicação clássico está associado à avaliações que geram subsídios para um novo estágio de pesquisa. Amaral Jr. (2007) e Silva (2009) abordam este assunto através de uma hierarquização das etapas do modelo (Figura 21). Estas etapas devem ser conduzidas em ordem lógica para uma melhor investigação das informações envolvidas.

Primeiramente é necessário estudar o passado da região, a fim de entender o processo de movimentação a partir das feições de movimentos de massa que já ocorreram e também registrar as ocorrências atuais. Esta etapa é chamada de inventário. Da mesma forma, é preciso investigar os fatores predisponentes da região, mapeá-los e, com base na análise de todos os fatores em conjunto, realizar o zoneamento de predisposição.

\section{INVENTÁRIO $\rightarrow$ PREDISPOSIÇÃO $\rightarrow$ SUSCETIBILIDADE $\rightarrow$ EVENTOS PERIGOSOS $\rightarrow$ RISCO}

Figura 21 - Etapas do modelo de avaliação dos movimentos de massa de uma área, organizados em ordem de pesquisa.

As próximas etapas devem ser a elaboração da carta de suscetibilidade e de eventos perigosos (hazard). Ambas necessitam do diagnóstico do agente deflagrador, que de fato provocará a movimentação. A diferença entre as duas cartas supracitadas é o cálculo da probabilidade de ocorrência de um ou mais eventos perigosos que deve ser realizado para elaboração de uma carta de eventos perigosos. A carta de risco adiciona a este grupo de informações os elementos em risco, analisando o potencial de risco da população, das propriedades, da economia e da componente ambiental.

Em seguida serão detalhadas as etapas citadas no modelo de avaliação dos movimentos de massa gravitacionais. 


\subsubsection{Inventário}

Um inventário é o registro da localização do evento e informações quanto ao tipo, data de ocorrência, atividade e velocidade (Guzzetti et al., 2012). Ele pode ser elaborado por diferentes técnicas que dependem do objetivo do inventário, do tamanho da área, da escala do trabalho, entre outros fatores. As metodologias mais utilizadas se baseiam principalmente em mapeamento de campo e interpretação de fotográficas aéreas ou imagens de satélites, em função da escala de trabalho e do tipo de mapeamento (Guzzetti, 2006). Geralmente, um mapa de inventário simples retrata diferentes tipos de movimentos de massa gravitacionais em uma área (Malamud et al., 2004). Entretanto, um grupo de mapas pode ser desenvolvido para retratar cada um dos diferentes tipos de movimentos (Guzzetti et al., 2012) ou diferenciá-los, por exemplo, em termos de materiais geológicos envolvidos, datas de ocorrência, entre outras características.

Um mapa de inventário pode ser classificado como inventário de registros e geomorfológico (Malamud et al., 2004; Guzzetti, 2006; Guzzetti et al., 2012).

O inventário de registros reúne as informações sobre os movimentos de massa gravitacionais a partir da literatura ou outros documentos como arquivos públicos ou privados, jornais, relatórios técnicos ou científicos e entrevistas (e.g., Guzzetti, Cardinali e Reichenbach, 1994; Salvati et al., 2003).

O inventário geomorfológico pode ser:

i. Histórico: Reúne informações em um determinado período de tempo, e.g., Cardinali et al., 2001 e Galli et al., 2008;

ii. de evento: Mostra feições ocorridas devido a um evento deflagrador, como um terremoto, e.g., Guzzetti et al., 2004 e Xu, 2014;

iii. Sazonal: registra feições ocorridas a partir de um único evento ou múltiplos durante um período temporal, e.g., Fiorucci et al., 2011 e Bauzys, 2012;

iv. Multitemporal: Reúne registros de ocorrências específicas em um longo período de tempo, e.g., Chau et al., 2004 e Duman et al., 2005. 
A partir do mapa de inventário, a maneira mais simples de obter a suscetibilidade é avaliar a porcentagem de área total de cada unidade geológicageotécnica está ocupada por feições de movimento de massa e classificar as unidades por este princípio (Parise, 2001). Para tanto, primeiramente é necessário definir as unidades geológico-geotécnicas a partir de um zoneamento de predisposição que analise todos os fatores predisponentes da região. E, desta forma, as unidades formadas por este zoneamento serão a base de análise da avaliação de suscetibilidade.

\subsubsection{Predisposição}

O zoneamento de predisposição está voltado para a identificação das características geológico-geotécnicas que influenciam à ocorrência de movimento de massa gravitacionais (Amaral Jr, 2007). Para isso, os fatores predisponentes ligados a geologia, geomorfologia, vegetação, aspectos climáticos e hidrológicos devem ser analisados em toda área de estudo. Eles são atributos que condicionam uma unidade a ter uma tendência a desenvolver um movimento de massa gravitacional.

Os atributos podem ser: material inconsolidado, textura e espessura do material, declividade, litologia, curvatura, índice de vegetação, uso e ocupação, entre outros.

Este tipo de carta apresenta as unidades classificadas de acordo com a sua predisposição. As categorias vão de unidade mais predisposta a se iniciar um movimento de massa até a categoria menos predisposta. 


\subsubsection{Suscetibilidade}

A suscetibilidade refere-se a propensão de uma área à ocorrência de movimentos de massa gravitacionais com base nas condições locais do terreno (Parise, 2001). Neste caso, a probabilidade de ocorrência não é considerada.

Fell et al. (2008) sugere que uma carta de suscetibilidade seja elaborada para cada tipo de movimento de massa, individualmente, e depois sejam combinadas para obter uma carta de suscetibilidade ao movimento de massa global. Isso também é válido para a carta de eventos perigosos.

Para elaboração de uma carta de suscetibilidade realiza-se um zoneamento que envolve a distribuição espacial e classificação das unidades de terreno de acordo com a sua predisposição ao evento (Fell et al., 2008). Na sua avaliação, devem ser considerados até mesmo os movimentos de massa que podem atingir a área de estudo, mesmo não estando dentro dela. Similarmente devem ser analisados todos os processos e atributos para hierarquizar as áreas sujeitas à ocorrência dos fenômenos a serem estudados. Por isso, ela está diretamente ligada a alguns fatores predisponentes como a declividade, geologia, clima, vegetação, propriedades geotécnicas e fatores antrópicos, através da predisposição.

A principal diferença entre susceptibilidade e perigo é que a avaliação de perigo considera o fator temporal para estimar a probabilidade de o evento ocorrer dentro de um determinado período de tempo (Varnes, 1984). Portanto, estes termos não devem ser usados como sinônimos.

\subsubsection{Eventos Perigosos (Hazard)}

Uma carta de eventos perigosos registra as diferentes probabilidades existentes de ocorrência de um ou mais eventos em uma área, num determinado período de tempo e com certo nível de intensidade (Varnes, 1984). É essencial que a 
carta de eventos perigosos apresente informações quanto à intensidade, probabilidade temporal e espacial (Zuquette e Gandolfi, 2004).

Os conceitos de magnitude, localização e recorrência estão diretamente relacionados à definição de carta de eventos perigosos (Guzzetti et al., 1999). A magnitude refere-se a intensidade do fenômeno natural quanto ao seu comportamento e seu poder destrutivo (volume e velocidade). A localização diz respeito a identificação do lugar onde ocorre o evento. E a recorrência faz menção à frequência temporal do evento.

Segundo Zuquette (1993) podem ser elaboradas cartas de previsão temporal, em que a avaliação se dá em relação a quando ocorrerá o evento; de previsão espacial, que busca prever o possível local de ocorrência; de previsão tipo, em que é antevisto quais os tipos de eventos podem acontecer.

A carta de eventos perigosos (hazard) é utilizada no estudo da previsão de riscos e desastres naturais como: terremotos, vulcões, movimentos de massa, inundações e tsunamis. Também são empregadas no estudo de contaminação de águas subterrâneas e solos, e, até mesmo, em atividades antrópicas (Zuquette, 1993).

A avaliação de perigo deve ter informações, por exemplo, sobre tempo de recorrência dos movimentos e estes dados são muito difíceis de serem adquiridos. Por isso, alguns pesquisadores preferem lidar com a falta destas informações e acabam produzindo uma análise de susceptibilidade e não de perigo (Parise, 2001).

\subsubsection{Risco}

O risco de ocorrência de movimentos de massa gravitacionais refere-se a danos ou perdas, incluindo vítimas, danos à propriedade e infraestrutura, interrupção de serviços públicos e atividades econômicas (Sassa e Canuti, 2009; Fell, et al., 2008) na área potencialmente afetada.

É recomendada a elaboração de um catálogo de informações sobre as consequências dos movimentos, a coleta de informações sobre a vulnerabilidade dos elementos; de dados de densidade populacional, localização das estruturas e áreas 
ambientais protegidas, e, a valoração econômica a todos os elementos em risco (Guzzetti, 2002). Para tanto, necessita-se da ajuda de profissionais como economistas, tomadores de decisões, políticos, entre outros que possam em conjunto preparar estas informações.

Quantitativamente, o risco pode ser analisado a fim de estimar as probabilidades objetivas, tais como: probabilidade de perda de vida, probabilidade de danos nas estruturas, ambas devido a ocorrência de movimentos de massa gravitacionais (Sassa e Canuti, 2009).

A estimativa do risco envolve a avaliação do perigo, dos elementos em risco e sua vulnerabilidade. $O$ valor do risco é gerado através da equação genérica adotada por Varnes (1984):

\section{RISCO = PERIGO $x$ ELEMENTOS EM RISCO $x$ VULNERABILIDADE}

Geralmente o perigo é dado em termos de probabilidade, os elementos em risco são expressos em termos da sua quantidade e custo, e a vulnerabilidade é expressa numa escala de 0 (ausência de danos) a 1 (perda total).

O zoneamento de risco é mais utilizado no planejamento urbano, onde os elementos em risco já existem ou está em fase de projeto, como por exemplo, estradas ou loteamento. Vale ressaltar que os elementos em risco muitas vezes variam com o tempo, de modo que o zoneamento precisa ser atualizado regularmente.

Como o objetivo deste trabalho é elaborar uma carta de eventos perigosos, dar-se-á maiores detalhes dos métodos para sua elaboração, além de exemplos para melhor entendimento da aplicação. 


\subsection{CARTA DE EVENTOS PERIGOSOS (HAZARD)}

\subsubsection{Métodos de elaboração}

Os métodos utilizados para avaliação dos eventos perigosos relacionados a movimentos de massa gravitacionais podem ser classificados como: qualitativos e quantitativos. Vários pesquisadores estudam estes métodos para além de elaborarem uma carta de eventos perigosos, também testarem a eficiência de cada um deles e, apresentar suas vantagens e desvantagens. Contudo, a escolha de uma metodologia depende do tamanho da região de estudo, da disponibilidade de tempo para a realização do trabalho, da disponibilidade de dados existentes e na possibilidade de elaboração destes, além de recursos financeiros disponíveis (Ahrendt, 2009).

Dentre os trabalhos que caracterizam as metodologias empregadas no estudo dos movimentos de massa gravitacionais e elaboração de carta de eventos perigosos, destaca-se: Aleotti e Chowdhury (1999), Guzzetti et al. (1999), Van Westen (2004), Sassa e Canuti (2009) e Pardeshi, Autade e Pardeshi (2013).

Os métodos qualitativos e quantitativos podem ser subdivididos de acordo com as técnicas de aplicação, conforme o enquadramento da Figura 22. 


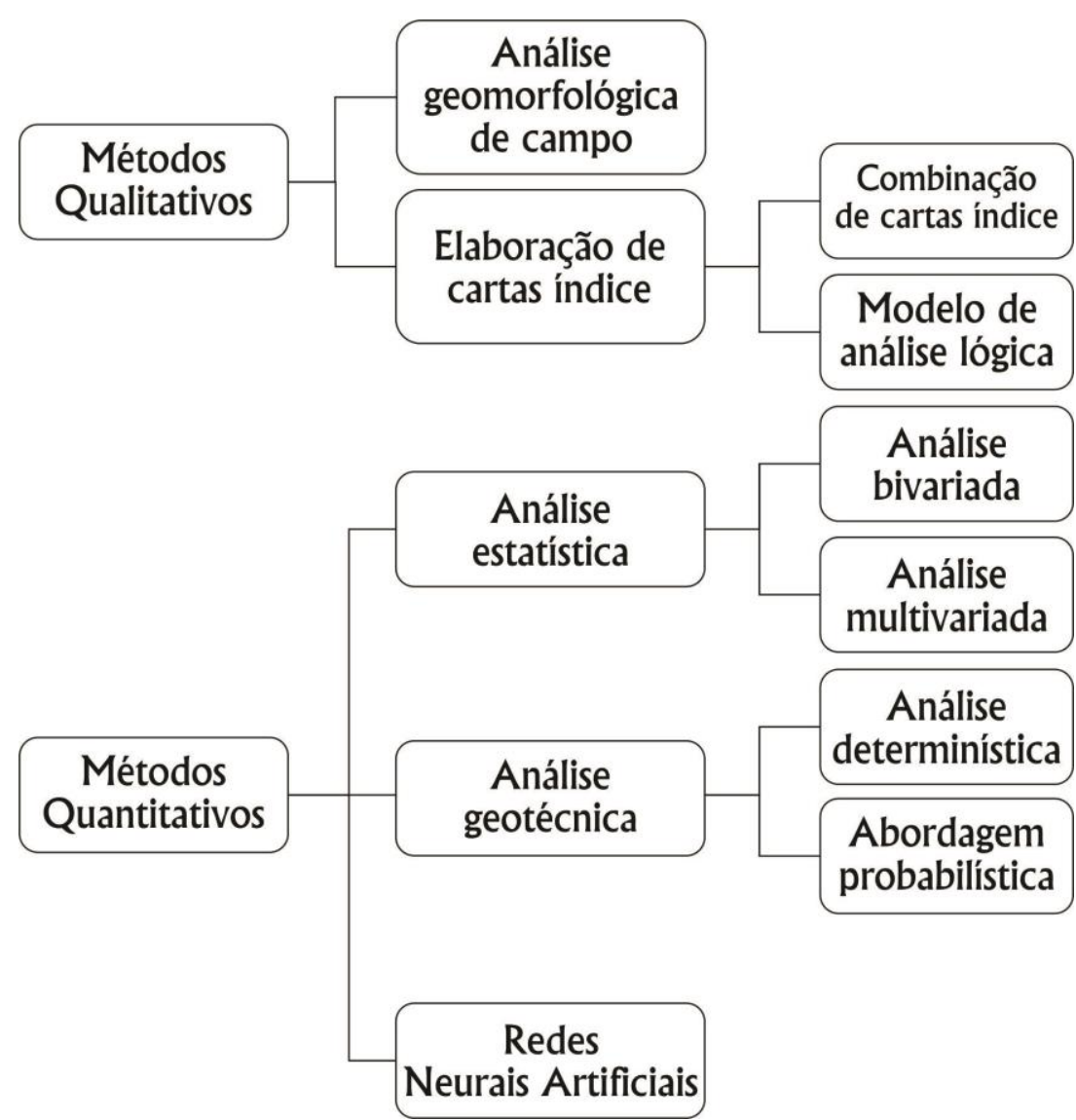

Figura 22 - Métodos de avaliação dos eventos perigosos relacionados a MMG. (Modificado de Aleotti e Chowdhury, 1999).

\subsubsection{Métodos qualitativos}

Os métodos qualitativos geralmente são baseados no julgamento/experiência do especialista que faz a avaliação. Essa avaliação é gerada a partir de trabalhos de campo e apoiado por interpretação de fotografias aéreas (Aleotti e Chowdhury, 1999). Podem ser divididos em análise geomorfológica de campo e combinação de mapas índice.

\section{A. Análise geomorfológica de campo}

Esta análise é a mais simples de ser aplicada dentre os métodos. É realizada através de trabalhos de campo onde a interpretação é baseada nas experiências dos 
pesquisadores adquiridas em outras situações semelhantes (Aleotti e Chowdhury, 1999). Os procedimentos de análise são difíceis de estabelecer, pois suas formas variam de lugar para lugar, pesquisador para pesquisador (Fell et al., 2008).

Historicamente, a técnica mais conhecida desta metodologia á a ZERMOS (Zones Exposed to Risk of Soil Movements) que foi bastante aplicada por vários pesquisadores na década de 70 (Varnes, 1984; Zuquette, 1993; Aleotti e Chowdhury, 1999). Este método combina a análise da configuração geomorfológica juntamente com os principais fatores predisponentes, a fim de avaliar o perigo. Posteriormente, a técnica pode ser extrapolada para áreas com condições geomorfológicas similares.

Uma das desvantagens da análise geomorfológica de campo é a subjetividade da avaliação dos fatores e elaboração da carta. Por este motivo, existe uma grande dificuldade em comparar cartas de eventos perigosos produzidas por diferentes pesquisadores. Além disso, a quantidade de especialistas envolvidos no projeto também pode alterar o resultado, apesar deste método ter a vantagem de ser de rápida elaboração (Aleotti e Chowdhury, 1999).

Um exemplo da utilização da análise geomorfológica de campo para produzir uma carta de eventos perigosos é dado pelo estudo de Hearn (1995). O autor elaborou uma carta de eventos perigosos relacionados a movimentos de massa gravitacionais e erosão da região de uma mina de cobre em Papua Nova Guiné. A área foi dividida em 245 zonas geomorfológicas e, em cada uma delas foi atribuído um valor de hazard a partir de dados de campo e interpretação de fotos aéreas. A caracterização de cada unidade foi feita por meio de fichas de campo na qual era cadastrado o mecanismo de ruptura, o tamanho, causa, o impacto atual, impacto potencial futuro e velocidade estimada de movimento. Sempre que possível, essas estimativas foram baseadas em investigação de solo, monitoramento e dados geológicos estruturais, embora na maioria dos casos, elas foram baseadas em evidências de superfície e inferência pessoal, e são, portanto, abertas à interpretação. O resultado do trabalho de Hearn (1995) é o mapa de eventos perigosos mostrado na Figura 23. 


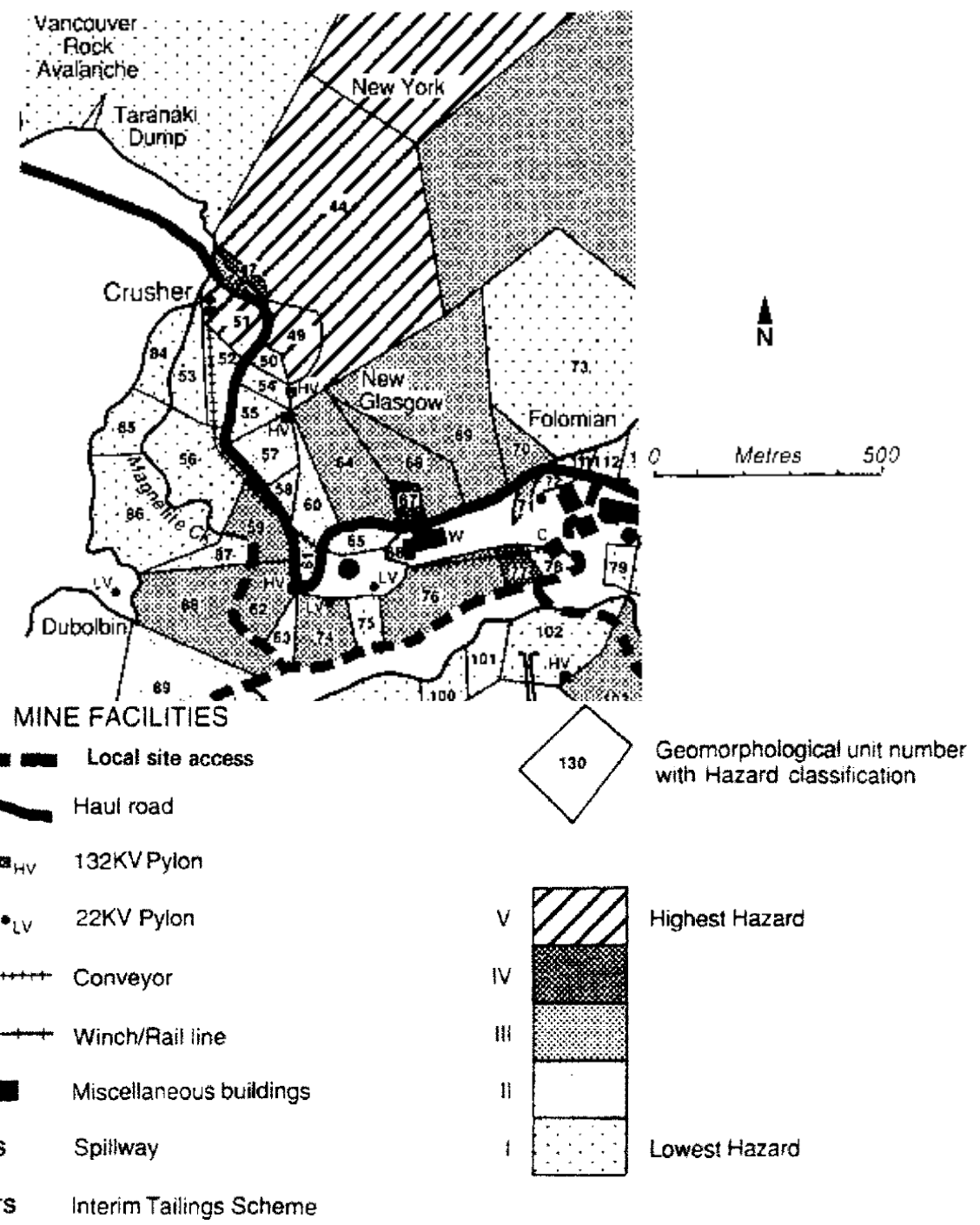

Figura 23 - Parte do mapa de eventos perigosos elaborado através da análise geomorfológica de campo (Hearn, 1995).

\section{B. Elaboração de cartas índice}

Nesta abordagem, a avaliação de eventos perigosos depende da investigação dos fatores que influenciam os movimentos de massa no local escolhido para o trabalho. Baseado na experiência dos próprios pesquisadores, esses fatores são selecionados e mapeados (mapa geológico, carta de declividade, mapa de material inconsolidado, entre outros). Em seguida, são atribuídos pesos de acordo 
com a importância de cada fator, ou seja, o valor do peso é proporcional à contribuição relativa esperada na geração do movimento.

Os mapas podem ser combinados/sobrepostos um a um, ou em conjunto que é o resultado de um primeiro passo da avaliação e depois de unirá a outros mapas nas próximas fases. Por exemplo, em uma primeira fase, são sobrepostos e somados os mapas: litológico e de declividade. O resultado desta sobreposição é sobreposto ao mapa geomorfológico, e mais uma vez somado (Aleotti e Chowdhury, 1999).

$\mathrm{Na}$ análise lógica, o modelo de aplicação inicia-se pelo exame da relação entre os fatores e seleção dos pesos de cada fator, fundamentados na experiência do especialista. Usando essa relação é possível prever os locais de movimentação e, este pode se comparado a dados de monitoramento existentes para definição do grau de concordância. Se o grau de concordância for bom, a avaliação preliminar pode ser usada para classificar as áreas de ocorrência de eventos perigosos, senão, deve ser novamente ponderada (Aleotti e Chowdhury, 1999).

A vantagem deste método é a redução considerável do problema quanto a subjetividade da avaliação e a automação de todo o processo através de ferramentas GIS, entretanto, a subjetividade ainda existente faz com que exista uma dificuldade de extrapolação do modelo desenvolvido em uma área particular para outras regiões.

Para exemplificar o método de elaboração de cartas índice aplicado no estudo dos movimentos de massa gravitacionais de uma determinada área, tem-se o trabalho de Perotto-Baldiviezo et al. (2004). Primeiramente foram mapeados 4 fatores predisponentes: declividade, curvatura, uso e ocupação e proximidade da drenagem (que foi criado a partir de linhas de contorno ao redor da drenagem de $100 \mathrm{~m}$ de distância). Com base na combinação de cada um dos fatores com o mapa de inventário, elaborou-se uma classificação de hazard decorrente da porcentagem de área afetada em cada uma das categorias dos fatores. Posteriormente, cada fator foi reclassificado e combinados entre si para formação da carta de eventos perigosos de uma região de Honduras. A Figura 24 mostra o resultado da análise de uma das regiões estudadas, Namasigue. 


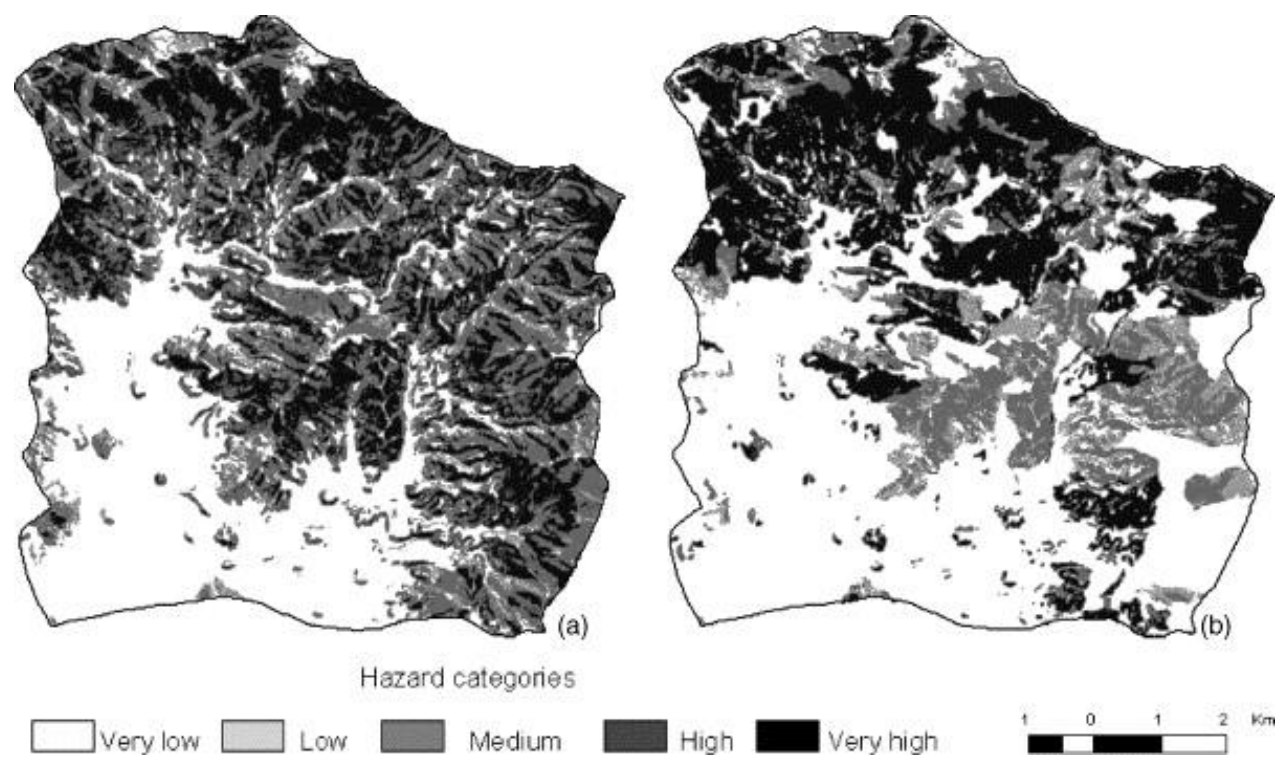

Figura 24 - Carta de eventos perigosos de Namasigue, Honduras: a) antes da adição do resultado do fator uso e ocupação e, b) depois da adição de todos os fatores (Perotto-Baldiviezo et al.,2004).

\subsubsection{Métodos quantitativos}

Os métodos quantitativos: envolvem a análise e descrição de um fenômeno através de valores numéricos, caracterizando matematicamente a avaliação dos eventos perigosos. Este método é dividido em três formas de análise: estatística, geotécnica e por redes neurais artificiais.

\section{A. Análise estatística}

O mais importante na análise estatística, é entender, a partir do inventário de MMG, que os fatores do passado e do presente que levaram aquela área a instabilização são os mesmos que irão causar movimentação de massa no futuro (Guzzetti et al., 1999).

Este tipo de método faz com que a subjetividade de se atribuir valores de pesos a fatores que governam a instabilidade, seja solucionada através da comparação entre a distribuição espacial dos movimentos de massa gravitacionais em relação aos parâmetros que estão sendo considerados. Uma das vantagens desse 
método é que o investigador pode validar a importância de cada fator e decidir o resultado desta avaliação de forma mais interativa (Aleotti e Chowdhury, 1999).

A análise estatística pode ser bivariada ou multivariada.

A estatística bivariada considera cada fator individualmente e o compara ao mapa de inventário (Aleotti e Chowdhury, 1999). O valor do peso, usado para categorizar todos os fatores, é determinado com base na densidade dos movimentos de massa em cada classe, individualmente. Esta metodologia é empregada por diversos pesquisadores e pode utilizar diferentes fatores como: litologia, declividade, altura da encosta, uso e ocupação, distância das maiores estruturas, densidade da drenagem, relevo, entre outras.

A análise multivariada necessita de uma malha de divisões espaciais baseada em unidades morfométricas. Nos trabalhos pioneiros (Carrara et al., 1978) sobre esta aplicação, as malhas eram quadradas de variados tamanhos, usualmente entre $100 \mathrm{e}$ $200 \mathrm{~m}$. Após a construção desta malha, são identificados os fatores mais relevantes e feitos os mapas oriundos desta primeira interpretação.

O próximo passo é a identificação da porcentagem de áreas onde ocorrem os movimentos de massa em todas as unidades e a classificação da unidade como instável ou estável, juntamente com a determinação da presença ou ausência de MMG em cada unidade morfométrica. A representação do mapa gera uma classificação de classes de suscetibilidade, se a intenção é gerar uma carta de hazard deve-se transformar as contagens da função em probabilidades. As análises mais usadas são a discriminante para variáveis contínuas e a regressão linear para variáveis nominais (Aleotti e Chowdhury, 1999).

Um exemplo da aplicação de análise estatística para elaboração de uma carta de eventos perigosos é o estudo de Pradhan (2010) em três regiões na Malásia. O autor utilizou o método de regressão logística multivariada. Os fatores predisponentes empregados foram: declividade, orientação, curvatura, distância da drenagem, litologia, distância dos lineamentos, tipo de solo, uso e ocupação do solo, precipitação da chuva e índice de vegetação. O mapa de inventário também foi elaborado e possui 25 anos de registros de movimentos de massa gravitacionais Para a análise foram estabelecidas as correlações espaciais entre a localização das feições e o fator predisponente relacionado. Os coeficientes de regressão foram calculados e 
utilizados para criar a carta de eventos perigosos. Além disso, foi feita uma validação cruzada entre dados obtidos nas três áreas estudadas, pois possuem condições geográficas, geológicas e geomorfológicas semelhantes. Para ilustrar o resultado, uma das cartas criadas pode ser observada pela Figura 25.

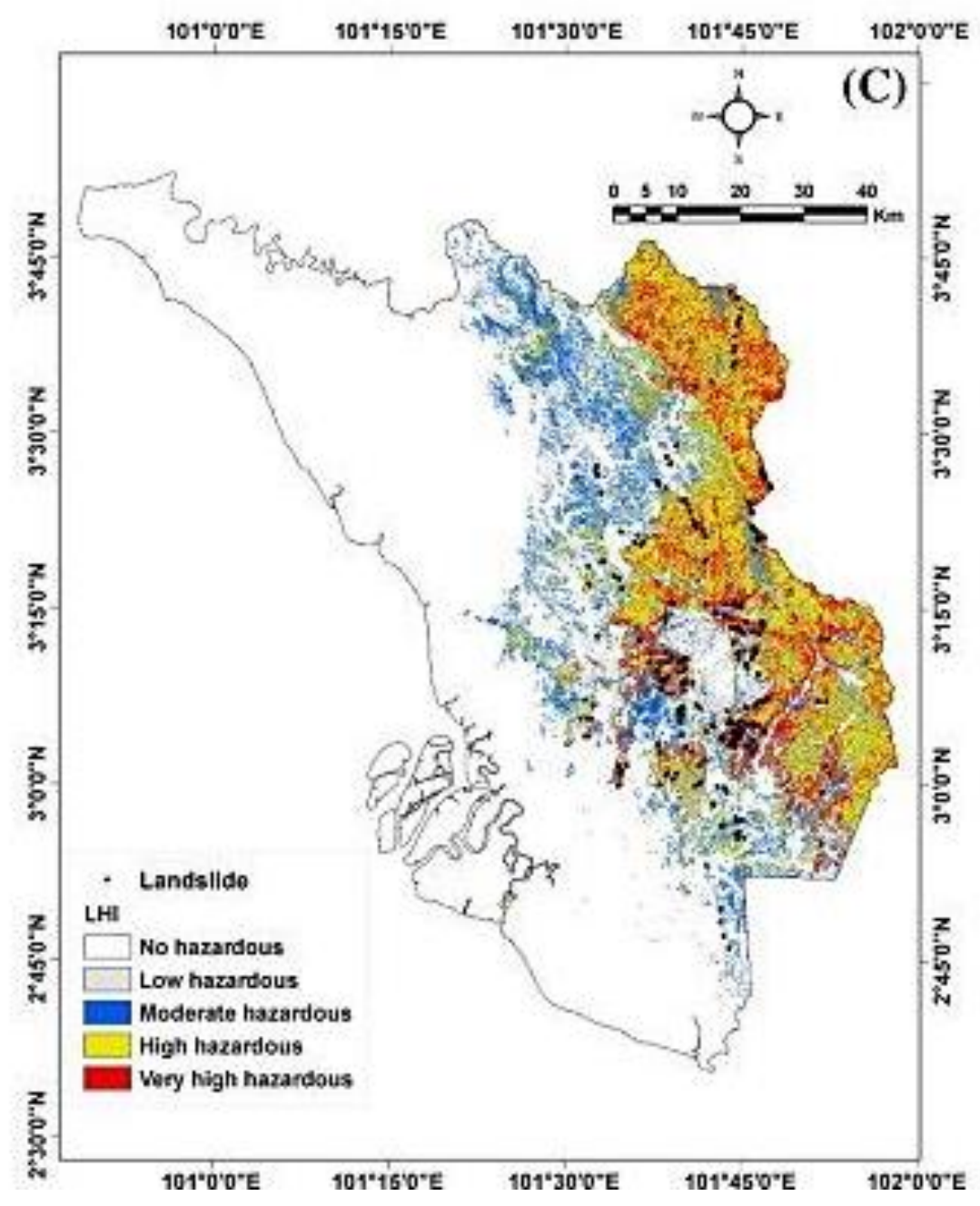

Figura 25 - Carta de eventos perigosos de Selangor, Malásia (Pradhan, 2010).

\section{B. Análise geotécnica}

O método de análise geotécnica é baseado nas leis da física que controlam a instabilidade da encosta e pode ser dividido em: determinística e a probabilística.

O método determinístico é comumente usado no estudo da estabilidade de taludes por meio do fator de segurança. Para o cálculo deste fator são necessários 
dados geométricos, parâmetros de resistência ao cisalhamento e informações quanto a pressão na água do material.

A análise determinística é fundamentada em leis da física de conservação da massa, energia e momento, e os parâmetros necessários para este estudo podem ser determinados em campo ou em laboratório. Calcula-se geralmente o fator de segurança para estabilidade de taludes por duas formas: a) análise de tensões, utilizando elementos finitos para o estudo da relação tensão versus deformação do material deslocado $e, b)$ estado de equilíbrio limite, que pode ser aplicado considerando a massa rompida como um corpo único e a superfície de ruptura de forma circular, planar, etc.

A análise probabilística permite determinar espacial e temporalmente a probabilidade de acontecer um evento relacionado a movimentos de massa gravitacionais. Segundo Pardeshi, Autade e Pardeshi (2013) eles possuem objetividade na atribuição dos pesos utilizando uma estrutura probabilística que pode ser: bayseana, função de favorabilidade, fator de segurança, entre outras. $O$ valor da relação entre cada fator predisponente e a distribuição das feições do inventário, é posteriormente transformado em um valor baseado na função de distribuição de probabilidade.

Para exemplificar a metodologia de análise geotécnica, apresenta-se o trabalho de Jelínek e Wagner (2007) que aplicaram o método determinístico baseado em fator de segurança no estudo de uma encosta de Vel'ká Čausa, Eslováquia. Os parâmetros de entrada foram preparados como mapas temáticos, são eles: nível d'água, pressão na água, superfície de ruptura, ângulo de atrito, coesão, declividade, peso específico e modelo digital de elevação. $O$ cálculo do fator de segurança foi realizado e o seu resultado foi dado para cada célula do mapa. Posteriormente os valores foram reclassificados para 5 intervalos de fator de segurança.

A carta de eventos perigosos (Figura 26) foi gerada para dois cenários. No cenário 1, o nível d'água foi considerado como o obtido entre março de 1995 e outubro de 1998, período entre a ativação do movimento e a sua remediação. No cenário 2, o nível de água foi considerado como o registrado entre novembro de 1998 a dezembro de 2004, o que corresponde a situação mais recente da feição. 
a

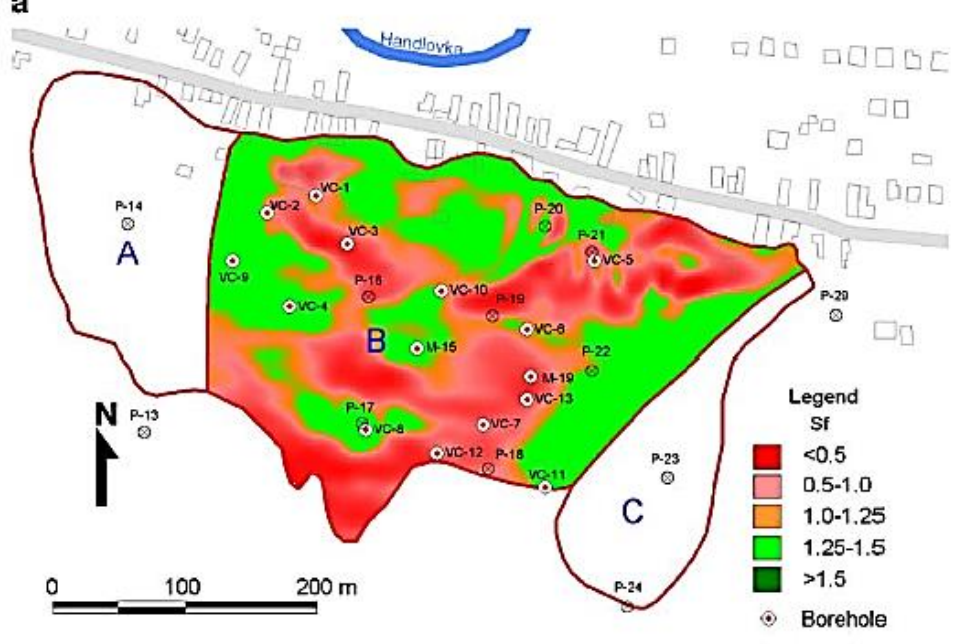

b

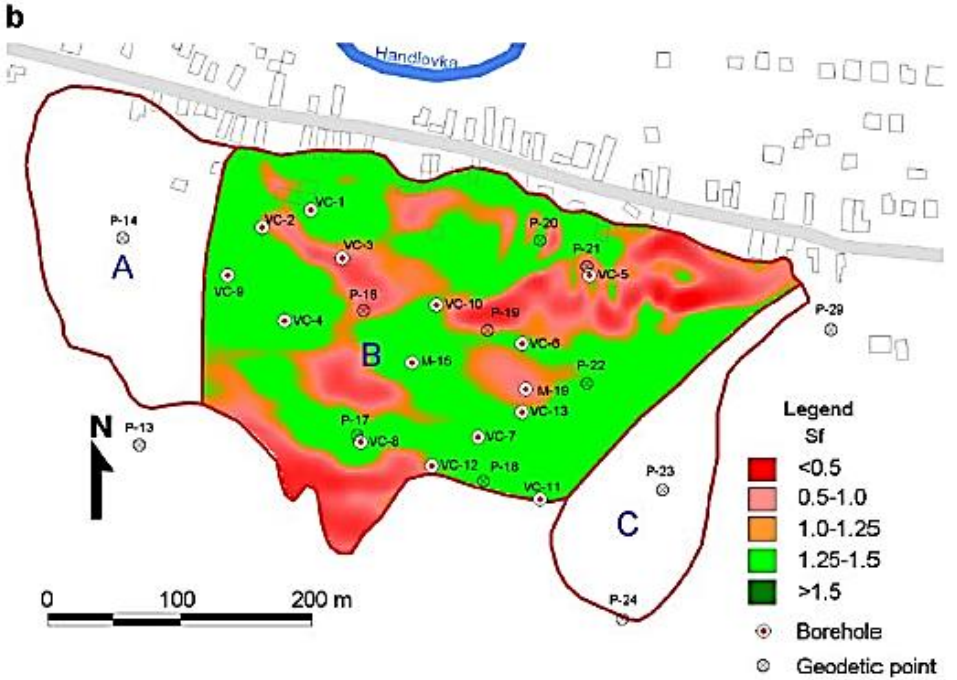

Figura 26 - Cartas de eventos perigosos de Vel'ká Čausa, Eslováquia, baseado em fator de segurança: a)cenário 1 e b)cenário 2 (Jelínek e Wagner, 2007).

\section{Redes Neurais Artificiais}

A rede neural artificial é um método que, a partir de um algoritmo de treinamento, é capaz de reagir e aprender com base em dados iniciais de entrada, formados pelos fatores predisponentes, que se alteram após o aprendizado.

A inter-relação entre os fatores e os movimentos de massa são naturalmente não-lineares e por isso, a aplicação deste modelo provou ser eficaz na avaliação dos movimentos de massa gravitacionais (Ercanglu,2005). De acordo com Pardeshi, 
Autade e Pardeshi (2013) uma das justificativas de se usar redes neurais artificiais é o fato de os fatores predisponentes serem interligados de forma complexa.

Os métodos probabilístico e redes neurais artificiais foram selecionados por este trabalho para serem os procedimentos de estudo e análise dos movimentos de massa através da carta de eventos perigosos. Por este motivo eles serão detalhados e exemplificados nas próximas seções 2.4 (Redes Neurais Artificiais) e 2.5 (Abordagem Probabilística), a fim de aprofundar o conhecimento destas metodologias e conhecer suas formas de aplicações. 


\subsection{REDES NEURAIS ARTIFICIAIS}

\subsubsection{Conceitos}

A rede neural artificial (RNA) é um sistema computacional estruturado para receber informações, interpretá-las e tomar decisões apropriadas a partir de um treinamento. $O$ estudo deste tema iniciou-se a partir da observação das atividades cerebrais humanas, onde as entidades básicas - neurônios, interconectados em redes permitem a troca de informação entre eles. A RNA é um modelo útil para a resolução de problemas de forma semelhante às características principais do cérebro humano do ponto de vista do processamento de informação.

Uma RNA possui a capacidade de adquirir, armazenar e administrar o conhecimento e é definida por Silva, Spatti e Flauzino (2010) como sendo "um conjunto de unidades de processamento, caracterizadas por neurônios artificiais, que são interligadas por sinapses artificiais". Este sistema de interconexões é representado por vetores e matrizes de pesos sinápticos.

Silva, Spatti e Flauzino (2010) e Matssunaga (2012) apresentam algumas características da rede neural como: a adaptação por experiência; capacidade de aprendizado; habilidade de generalização; organização dos dados; tolerância a falhas (devido ao elevado número de interconexões), armazenamento distribuído (o processo é realizado de forma distribuída entre as diversas sinapses).

Os elementos computacionais ou unidades processadoras, denominadas neurônios artificiais, são modelos simplificados dos neurônios biológicos. Os neurônios biológicos agrupados formam o nosso sistema nervoso e são encarregados por metabolizar e transmitir o impulso que chega ao seu corpo celular. $\mathrm{O}$ axônio transmite estes impulsos e os dendritos recebem os impulsos provenientes dos axônios de outros neurônios levando-os até o corpo celular para a integração.

Um neurônio típico é apresentado na Figura 27 destacando o sentido do impulso nervoso. As ramificações terminais do axônio são conectadas aos dendritos 
de outros neurônios através de neurotransmissores, onde ocorrem as sinapses nervosas (transmissão do impulso nervoso para os neurônios vizinhos).

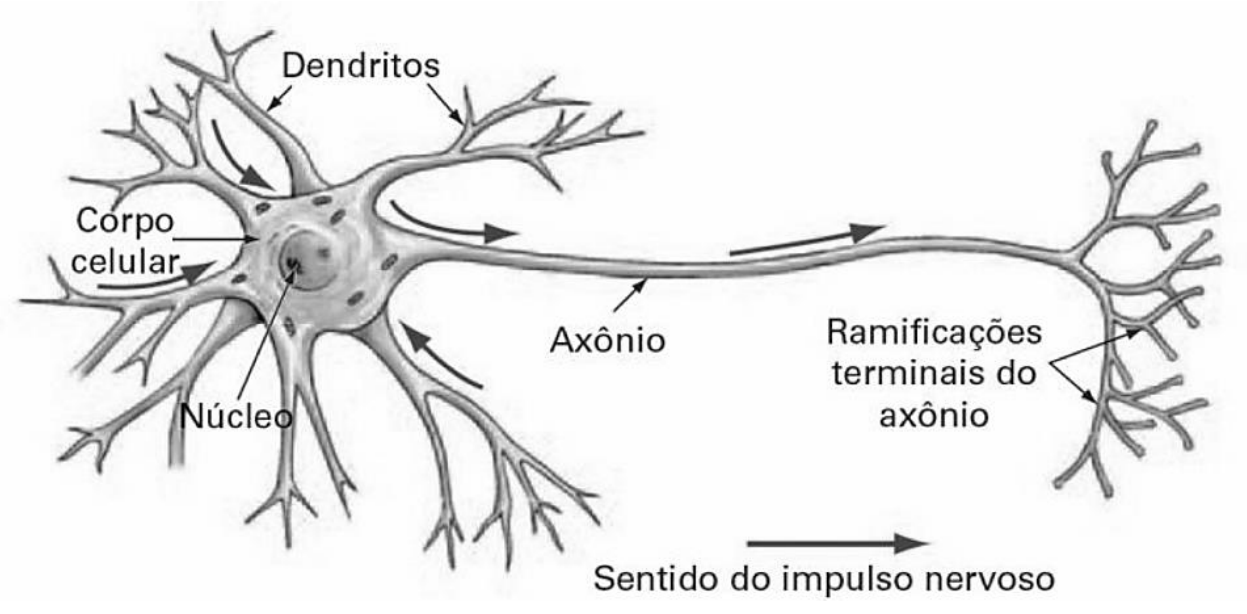

Figura 27 - Representação de um neurônio biológico.

O sistema nervoso controla as ações voluntárias e involuntárias do nosso corpo, como a nossa respiração, uma contração muscular, os batimentos cardíacos, o ato de comer, falar, etc. Uma das ações do cérebro de resposta a um estímulo (por mecanismo de defesa) é, por exemplo, quando nos engasgamos com algum alimento e automaticamente o cérebro codifica e responde a este estímulo com uma crise de tosse para expelir o que está impedindo a respiração.

Assim, a aprendizagem do cérebro humano é alcançada através do processo de mudança química em conexões sinápticas, e acontece a partir de restrições inatas e experiências adquiridas (Kasabov, 1998).

Uma rede neural é, portanto, uma técnica computacional que busca imitar o funcionamento do sistema nervoso do ser humano. Thomé (2003) ressalta que este tipo de sistema não é um programa onde o programador introduz e codifica a tática de solução do problema, ou seja, não possui uma sequência ordenada e definida de instruções; nem tão pouco que conduz o processo de resolução a partir de um conhecimento explicitamente armazenado, deve-se aprender a tarefa que será executada. A rede neural é dinâmica, não possui memória como arquivos de dados e a sua capacidade de aprender se faz com base na exposição de exemplos. 
A Figura 28 representa um modelo de neurônio artificial simples cuja função deve ser "coletar os sinais existentes de entrada, agregá-los de acordo com uma função operacional e produzir uma resposta, levando em consideração sua função de ativação inerente" (Silva, Spatti e Flauzino, 2010).

Assim, os sinais de entrada $\left(X_{1}, X_{2} \ldots X_{n}\right)$ são ponderados por seus pesos sinápticos $\left(W_{1}, W_{2} \ldots W_{n}\right)$ dando a eles uma relevância por meio de multiplicações. $A$ soma ponderada das entradas $(\Sigma)$ se transforma na saída do corpo celular artificial (u) após a introdução do limiar de ativação $(\theta)$. A função de ativação $(\mathrm{g})$ possui o objetivo de limitar a saída (y) dentro de um intervalo de valores a serem assumidos.

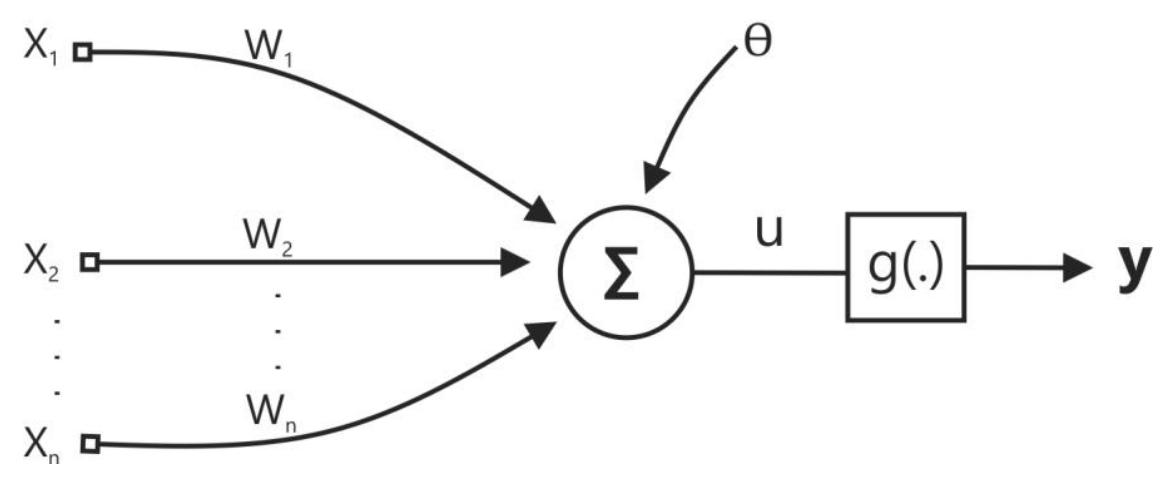

Figura 28 - Neurônio artificial simples.

A Tabela 12 apresenta a descrição, em resumo, dos elementos anteriormente citados que compõem um neurônio artificial. 
Tabela 12 - Descrição dos elementos que compõem um neurônio artificial.

\begin{tabular}{|c|c|}
\hline \multicolumn{2}{|r|}{ ELEMENTOS BÁSICOS DE UM NEURÔNIO ARTICIFIAL } \\
\hline $\begin{array}{l}\text { Sinais de } \\
\text { entrada }\end{array}$ & $\begin{array}{l}\text { São as variáveis assumidas para uma aplicação específica. Cada valor de entrada } \\
\text { é um tipo de dado associado à amostra. Ex: } \mathrm{X}_{1}=\text { valor de declividade. }\end{array}$ \\
\hline $\begin{array}{l}\text { Pesos } \\
\text { sinápticos }\end{array}$ & $\begin{array}{l}\text { São valores associados a cada variável de entrada a fim de ponderá-las, } \\
\text { permitindo quantificar as suas relevâncias. Os pesos se iniciam com valores } \\
\text { aleatórios entre } 0 \text { e } 1 \text {, e são ajustados durante o processo de cálculo da rede. }\end{array}$ \\
\hline $\begin{array}{l}\text { Combinador } \\
\text { linear }\end{array}$ & Tem a função de agrupar os produtos dos sinais de entrada e pesos sinápticos. \\
\hline $\begin{array}{l}\text { Limiar de } \\
\text { ativação }\end{array}$ & $\begin{array}{l}\text { Determina um valor que deve ser atingido pelo combinador linear de forma a } \\
\text { produzir um resultado pelo neurônio. }\end{array}$ \\
\hline $\begin{array}{l}\text { Potencial de } \\
\text { ativação }\end{array}$ & $\begin{array}{l}\text { É a diferença de valores entre o combinador linear e o limiar de ativação e } \\
\text { determina o comportamento do neurônio (excitatório ou inibitório). }\end{array}$ \\
\hline $\begin{array}{l}\text { Função de } \\
\text { ativação }\end{array}$ & Normaliza a saída do neurônio para valores que possam ser interpretados. \\
\hline $\begin{array}{l}\text { Sinal de } \\
\text { saída }\end{array}$ & $\begin{array}{l}\text { É o resultado final do processo de cálculo. Pode ser o produto final geral da } \\
\text { análise, bem como ser utilizado por outros neurônios da rede. }\end{array}$ \\
\hline
\end{tabular}

Fonte - Modificado de Medeiros (2013).

Os pesos sinápticos são determinados primeiramente de forma randômica. A partir do início do processo, os pesos sofrem um ajuste de acordo com alguma regra visando o aprimoramento da rede neural na execução da sua tarefa. Mais adiante (Seção 2.4.5.2), será exemplificada uma das regras utilizadas na atualização dos valores dos pesos sinápticos, o algoritmo backpropagation.

A representação matemática de um neurônio artificial é definida pelas equações 1 e 2 .

$$
\left\{\begin{array}{cc}
\boldsymbol{u}=\sum_{\boldsymbol{i}=1}^{n} \boldsymbol{w}_{\boldsymbol{i}} \cdot \boldsymbol{X}_{\boldsymbol{i}}-\boldsymbol{\theta} & \text { (Equação 1) } \\
\boldsymbol{y}=\boldsymbol{g}(\boldsymbol{u}) & \text { (Equação 2) }
\end{array}\right.
$$

As funções de ativação podem ser parcialmente diferenciáveis, quando possuem pontos cujas derivadas de primeira ordem são inexistentes e, totalmente diferenciáveis, quando as derivadas de segunda ordem são válidas e conhecidas em todo o domínio da função (Silva, Spatti e Flauzino, 2010). A Tabela 13 exibe os tipos de função de ativação aplicáveis em RNA. 
Tabela 13 - Funções de ativação em Redes Neurais Artificiais.

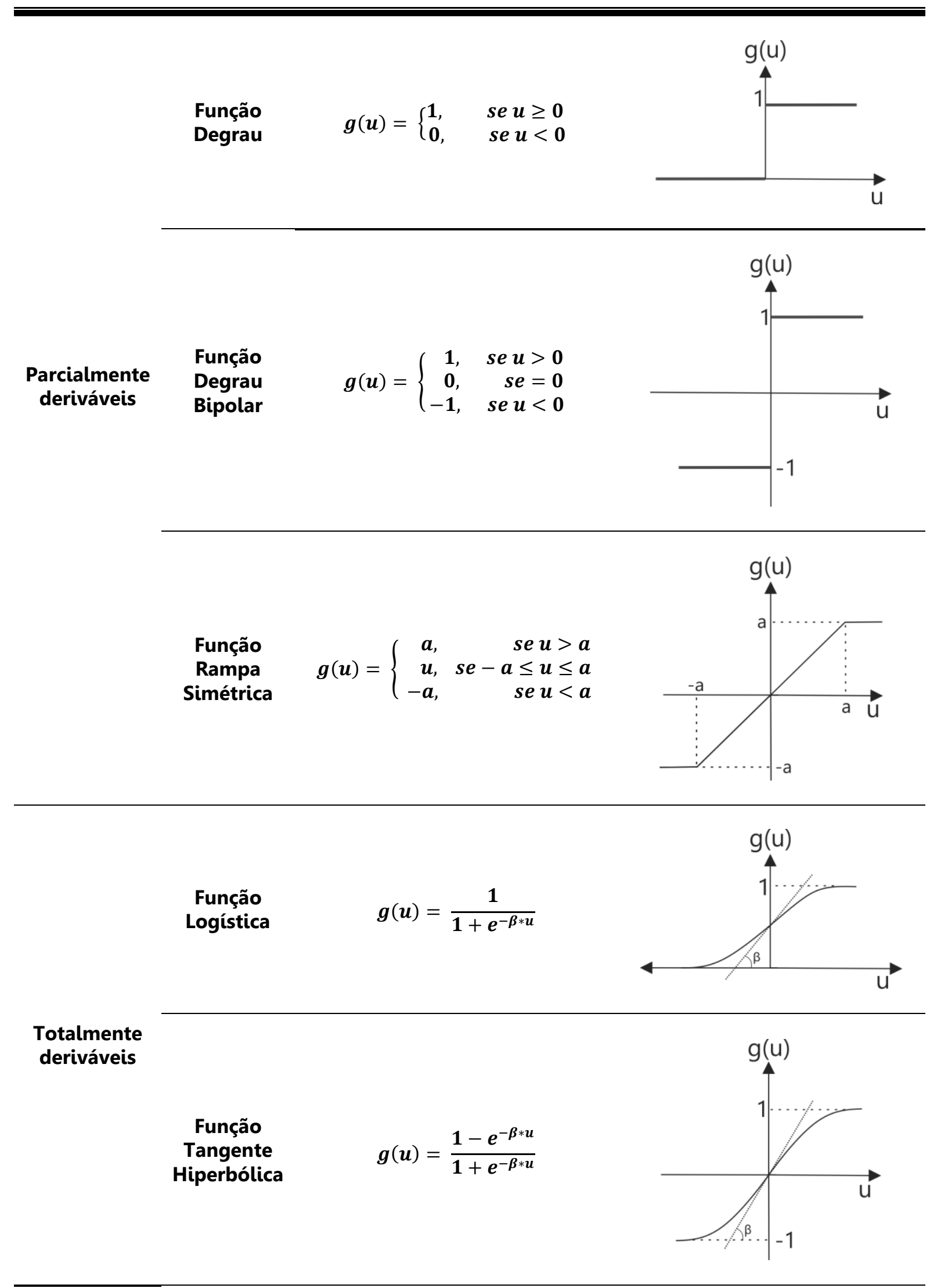


Tabela 13 - Funções de ativação em Redes Neurais Artificiais (continuação).

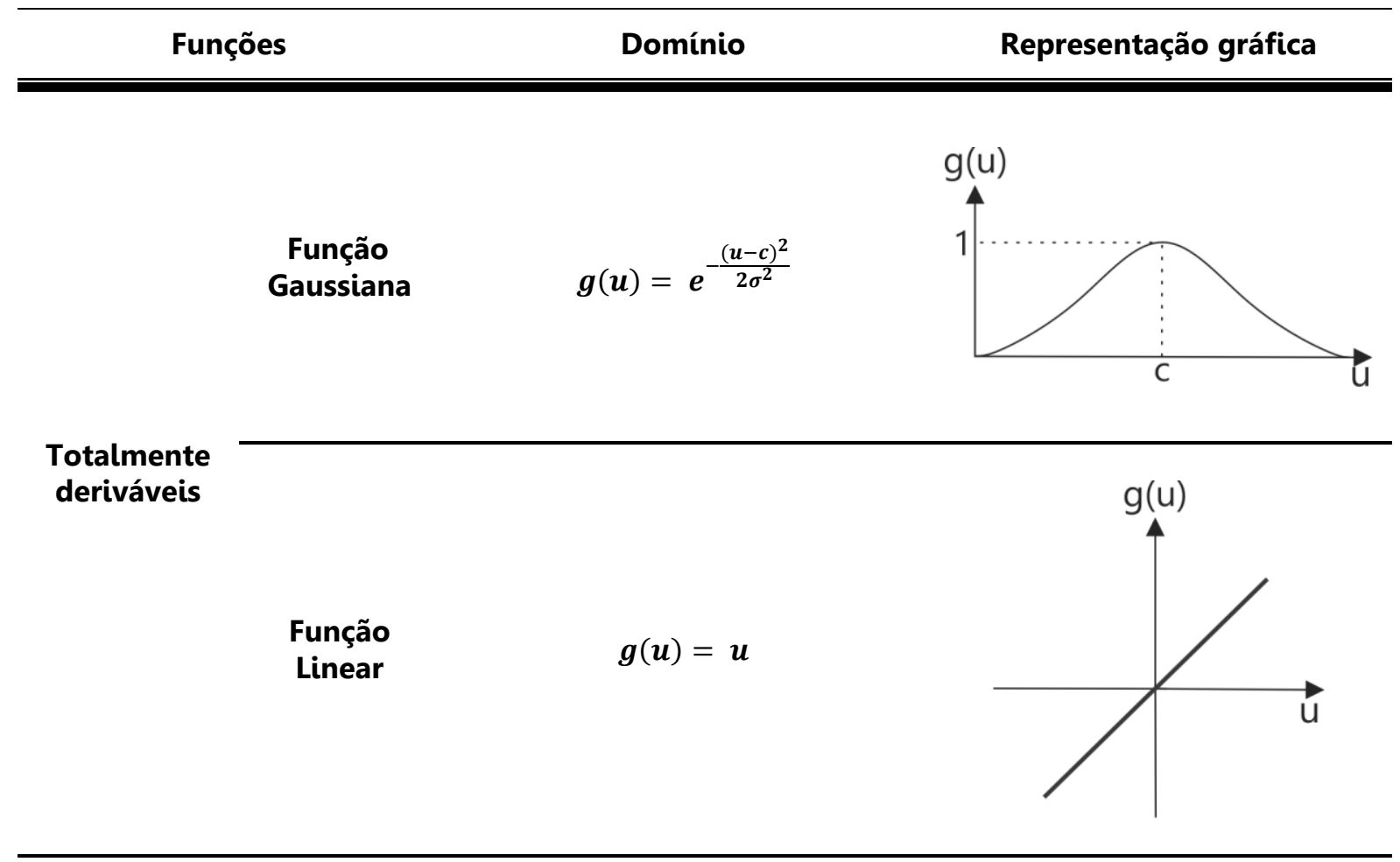

\subsubsection{Histórico}

Para desenvolver um sistema de rede neural artificial os pesquisadores buscaram alternativas para modelar o neurônio biológico, tanto na sua estrutura como na sua funcionalidade, na conectividade, na interatividade dos neurônios e, principalmente, na dinâmica operacional do sistema biológico (Thomé, 2003). Este tipo de rede que se espelha ao modelo biológico, necessita de arquiteturas paralelas, de algoritmos adequados na fase de aprendizado e alta capacidade de processamento.

Um histórico resumido sobre redes neurais artificiais se inicia com os pesquisadores McCulloch e Pitts que desenvolveram em 1943 um modelo matemático para o neurônio biológico, resultando numa primeira concepção de neurônio artificial (Kasabov, 1998). Neste momento os estudos estavam voltados 
para entender o funcionamento do cérebro e as aplicações estavam restritas à medicina e à psicologia (Thomé, 2003).

Donald Hebb em 1949 propôs algo inédito: uma lei de aprendizagem específica para as sinapses dos neurônios. A regra implica que a conexão é reforçada entre dois neurônios quando ambos são ativados ao mesmo tempo, sendo que a alteração na força é proporcional ao produto das duas atividades (Kriesel, 2005). Este foi o primeiro método de treinamento da rede neural artificial sendo denominado: regra de aprendizado de Hebb.

As atividades nessa linha de pesquisa culminaram na concepção do Perceptron por Frank Rosenblatt em 1958 e em um modelo parecido, o Adaline (Adaptive Linear Element) por Widrow e Hoff em 1960. Rosenblatt, Wightman e outros pesquisadores ainda desenvolveram o primeiro neurocomputador chamado Mark / Perceptron (Kriesel, 2005). Rauber (1997) expõe que o surgimento desta máquina causou grande euforia em relação a imaginação das capacidades de futuros robôs inteligentes. A rede Perceptron, desenvolvida neste período, possuía como uma das suas características principais um algoritmo de aprendizagem capaz de adaptar os pesos internos do neurônio, para resolver o problema de classificação linear, no caso em que esta separação existia entre as classes (Rauber, 1997).

Nos anos 60 e principalmente na década de 70 poucas publicações e pesquisas foram feitas. Isso aconteceu, em parte, devido ao trabalho de Minsky \& Papert que no ano de 1969 apresentaram as limitações das redes neurais artificiais constituídas por somente uma camada, como o Perceptron e Adelaine.

A partir deste trabalho, a popularidade e o investimento desta área de pesquisa diminuíram, pois o pensamento da época era que os modelos mais complexos poderiam mostrar exatamente os mesmos problemas apresentados por Minsky \& Papert. Assim, a especulação de que uma investigação neste campo estaria propensa ao fracasso, resultou em uma queda dos fundos de pesquisa nos 15 anos que se seguiram (Kriesel, 2005).

Silva, Spatti e Flauzino (2010) e Kriesel (2005) mencionam que o campo das redes neurais somente regressou ao destaque que tinha anteriormente após as publicações do pesquisador Hopfield, em 1982 e 1985, sobre a Rede Hopfiel que utiliza redes simétricas para otimização, além de Rumelhart, Hinton e Williams que, 
em 1986, publicaram o método backpropagation e, desta forma, problemas nãolinearmente separáveis poderiam ser resolvidos por Perceptron multicamadas.

O crescimento do estudo de redes neurais artificiais recentemente se dá através do desenvolvimento de novas aplicações em diferentes ramos do conhecimento e à proposição de aperfeiçoamentos de algoritmos e máquinas para incrementar a eficiência do processo de execução (Silva, Spatti e Flauzino, 2010). A Figura 29 retrata os principais pesquisadores na área.

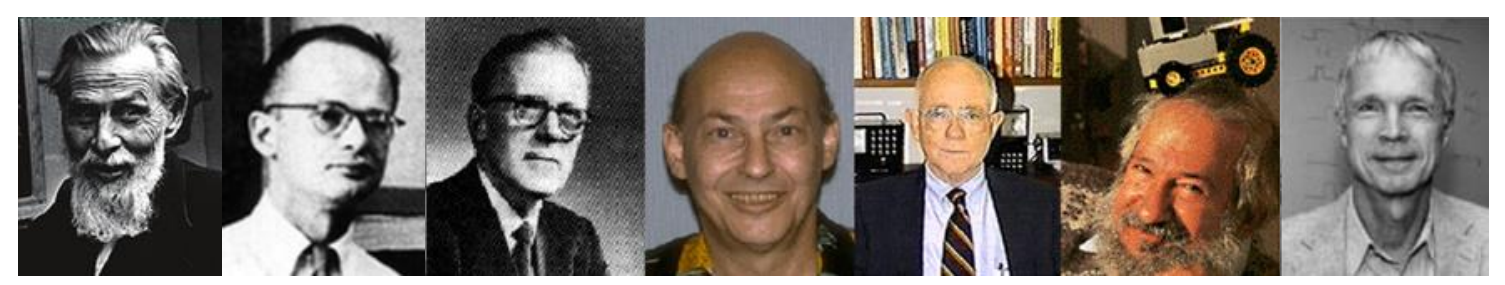

Figura 29 - Alguns pesquisadores no estudo das redes neurais artificiais. Da esquerda para direita: Warren McCulloch, Walter Pitts, Donald Hebb, Marvin Minsky, Bernard Widrow, Seymour Papert e John Hopfield (Adaptado de Kriesel 2005).

\subsubsection{Arquitetura de RNA}

A arquitetura de uma rede neural artificial é a maneira pela qual os neurônios de uma rede neural estão estruturados. Esta estrutura está intimamente ligada ao algoritmo de aprendizagem a ser usado para treinar a rede (Haykin, 2001). Pode-se, em geral, classificar três tipos de arquiteturas de rede fundamentalmente diferentes, como descritos a seguir.

Nas redes unidirecionais de uma única camada todas as conexões entre neurônios diferentes seguem a direção entrada $\rightarrow$ saída. Neste caso, a rede neural é organizada na forma mais simples: uma camada de entrada que se projeta para uma única camada de saída de camadas (Figura 30). Este tipo de rede também pode ser denominada como alimentada adiante ou acíclica ou feedforward de camada simples (Haykin, 2001 e Silva, Spatti e Flauzino, 2010). A designação de camada única referese à quantidade de camadas de nós computacionais. 
Ainda existem redes unidirecionais, ou seja, que seguem uma única direção, que possuem mais de uma camada de nós computacionais, são as chamadas redes de múltiplas camadas. As camadas são ocultas e a função dos neurônios ocultos é intervir entre a entrada externa e a saída da rede (Haykin, 2001). Os sinais de entrada (Figura 31) são inseridos nos neurônios da segunda camada (primeira camada oculta). Os sinais de saída desta camada são, então, utilizados como dados de entrada para a terceira camada e assim por diante até a finalização do processo.

Outro tipo de arquitetura é chamado de rede recorrente, que apresenta pelo menos uma realimentação durante o processo de execução da rede. A presença da realimentação tem um impacto significativo na capacidade de aprendizagem da rede e no seu desempenho (Matssunaga, 2012). Uma rede recorrente tem uma camada de entrada de neurônios que alimenta seu sinal de saída de volta para as entradas de todos os outros neurônios, podendo ter ou não auto-realimentação (Haykin, 2001). A Figura 32 apresenta uma rede com neurônios ocultos onde as conexões de realimentação se originam destes neurônios bem como dos neurônios de saída, e possuem uma memória de atraso, os operadores de atraso unitário, que operam sobre todas as entradas $x(n)$ produzindo uma versão atrasada (valores passados - $p$ ) da seguinte forma: $x(n-1), x(n-2), \ldots x(n-p)$. 

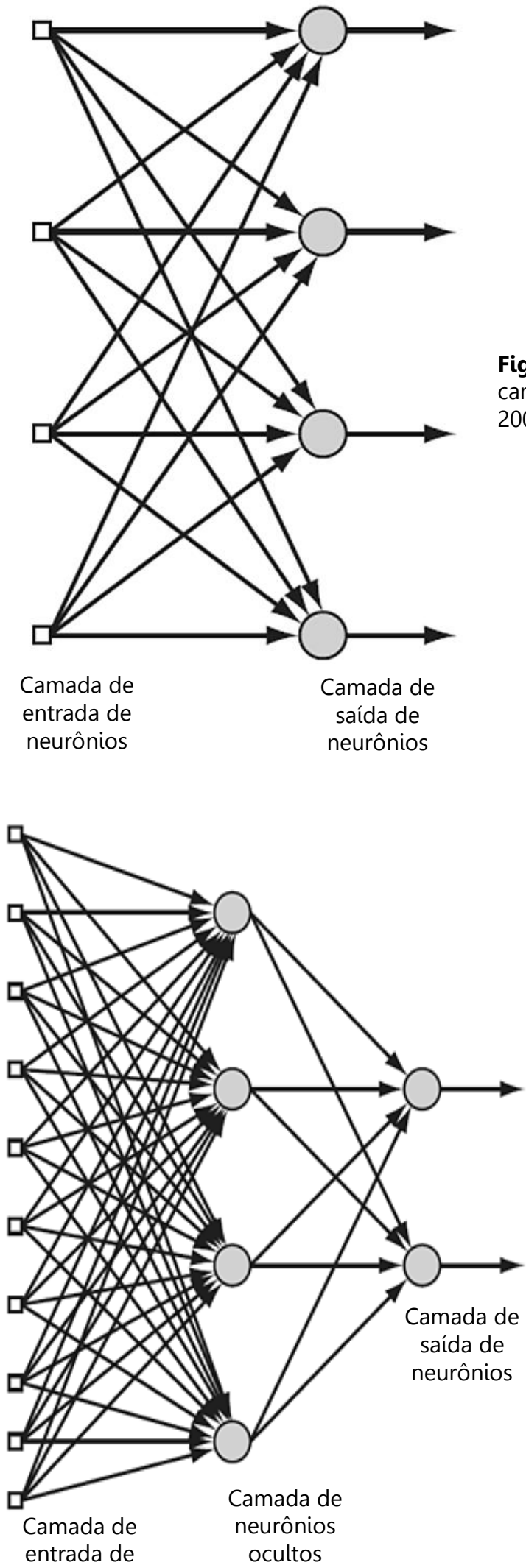

Figura 30 - Rede unidirecional com única camada de neurônios (Modificado de Haykin, 2001).

Figura 31 - Rede unidirecional com multicamadas de neurônios (Modificado de Haykin, 2001). 


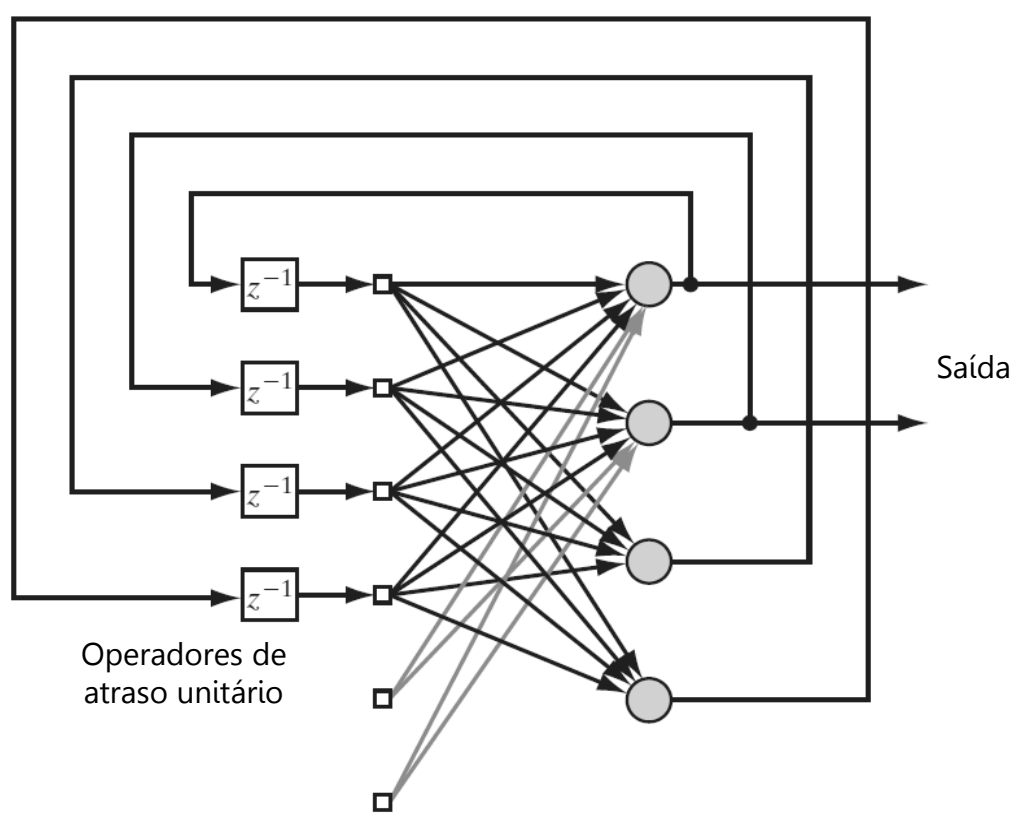

Entradas

Figura 32 - Rede recorrente com neurônios ocultos (Modificado de Haykin, 2001).

\subsubsection{Treinamento e aprendizagem}

De acordo com Haykin (2001) uma RNA possui "a habilidade de aprender a partir de seu ambiente e de melhorar o seu desempenho através da aprendizagem". A definição de aprendizagem de Mendel e McClaren (1970 ${ }^{11}$ apud Haykin, 2001) no contexto de redes neurais é:

[...] um processo pelo qual os parâmetros livres de uma rede neural são adaptados através de um processo de estimulação pelo ambiente no qual a rede está inserida. O tipo de aprendizagem é determinado pela maneira pela qual a modificação dos parâmetros ocorre.

Silva, Spatti e Flauzino (2010) expõe que após a rede ter aprendido o relacionamento entre as entradas e saídas, ela é capaz de generalizar soluções

\footnotetext{
${ }^{11}$ MENDEL. L.M. e MCLAREN, 1970. Reinforcement-learning control and pattern recognition systems. Adaptive, Learning and Pattern recognition Systems: Theory and Aplications. New York: Academic Press. V. 66., p.287 - 318.
} 
produzindo uma saída próxima daquela esperada a partir de quaisquer sinais inseridos em suas entradas.

Por exemplo, uma rede neural pode se tornar um sistema de auxílio no diagnóstico de doenças baseada nos conhecimentos prévios. Supondo que sejam introduzidos alguns dados de treinamento como os mostrados na Tabela 14. Estes dados foram obtidos através de pesquisa com pacientes passados com confirmação de diagnóstico por exames. Trata-se de 7 sintomas (dor de cabeça, febre, náuseas, etc) informados pelos pacientes através da resposta SIM ou NÃO, a fim de diagnosticar se eles estavam gripados ou com pneumonia. Após treinamento da rede com estes dados, ela estará preparada para presumir qual o diagnóstico dos próximos pacientes que possuem os sintomas (como exemplo):

- Paciente 1: S, N, S, N, S, N, S;

- Paciente 2: S, N, N, N, N, S, S.

Assim, a partir do treinamento, a rede neural aprende a relação entre os dados apresentados e a resposta esperada, e a partir deste momento ela é capaz de produzir uma saída satisfatória.

Tabela 14 - Dados de treinamento para diagnóstico de doenças.

\begin{tabular}{|c|c|c|c|c|c|c|c|}
\hline \multicolumn{7}{|c|}{ Questionário } & \multirow{2}{*}{ Diagnóstico } \\
\hline 1 & 2 & 3 & 4 & 5 & 6 & 7 & \\
\hline $\mathrm{S}$ & $\mathrm{S}$ & $S$ & S & $\mathrm{S}$ & $\mathrm{S}$ & $\mathrm{N}$ & Pneumonia \\
\hline $\mathrm{S}$ & $\mathrm{N}$ & S & $\mathrm{N}$ & $\mathrm{S}$ & $\mathrm{S}$ & S & Pneumonia \\
\hline $\mathrm{S}$ & $\mathrm{N}$ & $\mathrm{N}$ & $\mathrm{N}$ & $\mathrm{S}$ & $\mathrm{N}$ & S & Gripe \\
\hline $\mathrm{S}$ & $\mathrm{N}$ & S & $S$ & $\mathrm{~N}$ & $\mathrm{~N}$ & $\mathrm{~N}$ & Gripe \\
\hline
\end{tabular}


O conjunto de passos ordenados visando o treinamento da rede é denominado de algoritmo de aprendizagem e não há um único algoritmo para todas as redes neurais (Haykin, 2001). Eles diferem entre si pela forma como é formulado o ajuste de um peso sináptico de um neurônio. A forma mais simples da adequação de um peso sináptico $w(k)$, no instante de tempo $k$, o ajuste $\Delta w(k)$ é aplicado gerando o valor corrigido $w(k+1)$, na forma: $w(k+1)=w(k)+\Delta w(k)$.

Os modelos de redes neurais artificiais que têm capacidade de aprendizagem dividem-se em modelos que usam aprendizagem supervisionada e nãosupervisionada, dependendo se está disponível ou não a resposta desejada da rede (Rauber, 1997).

A aprendizagem supervisionada se baseia no erro entre a resposta desejada e a calculada pela rede para adaptar os pesos. Se os dados de saída gerados pela rede forem diferentes dos de saída desejado, o algoritmo de treinamento ajusta os pesos, segundo alguns critérios e, reduz o erro ocorrido (Thomé, 2003). Neste caso, o resultado dependerá do valor desejado, já conhecido a priori. $\mathrm{Na}$ aprendizagem não supervisionada a tarefa do aprendizado é descobrir correlações entre os exemplos dados para treinamento. Assim, a rede deve achar os atributos estatísticos que represente o conjunto de dados (Rauber, 1997).

\subsubsection{Tipos de redes}

Diversos são os modelos de rede propostos na literatura, cada qual advindo de uma linha de pesquisa diferente e visando um melhor desempenho na solução de um tipo específico de problema. Em seguida apresentar-se-á detalhadamente os três redes neurais artificiais mais conhecidos: Perceptron, que é o precursor do desenvolvimento de novas redes, e a Perceptron de Multicamadas que é a mais amplamente utilizada. Todavia, existem outros tipos de redes como: redes de função de base radial, Adaline, redes recorrentes de Hopfield, redes auto organizáveis de Kohonen, redes LVQ (Learning Vector Quantization) e counter-propagation e redes ART (Adaptive Resonance Theory). 


\subsubsection{Perceptron}

A rede Perceptron é a forma mais simples de configuração de uma rede neural artificial por ser constituída apenas de uma camada neural, tendo também somente um neurônio artificial nesta camada. Apesar de ser simples, esta rede atraiu diversos pesquisadores que aspiravam por esta área de estudo na época em que foi desenvolvida, principalmente os que estudavam a inteligência artificial (Silva, Spatti e Flauzino, 2010).

Perceptron é representada pela arquitetura classificada como feedforward, pois o sentido que flui as informações é unidirecional da entrada para a saída. (Hykin, 2009).

Seguindo seu princípio de funcionamento, cada uma das entradas $\left(X_{i}\right)$ é ponderada pelos pesos sinápticos $\left(w_{i}\right)$ para quantificar a importância quanto ao objetivo funcional atribuído ao neurônio. O valor resultante adicionado do limiar de ativação $(\theta)$ é repassado como argumento da função de ativação $(g(\cdot))$ cujo resultado é a saída $(y)$.

As funções de ativação normalmente usadas na rede Perceptron são a função degrau ou degrau bipolar, pelas quais existem duas possibilidades de saída: 0 ou 1 se utilizada a função degrau e 1 ou -1 se utilizada a função degrau bipolar.

Silva, Spatti e Flauzino (2010) apresenta uma tabela (Tabela 15) que reúne as características dos parâmetros importantes na dinâmica da rede. 
Tabela 15 - Aspectos dos parâmetros da rede Perceptron.

\begin{tabular}{cc}
\hline Parâmetro & Tipo característico \\
\hline Entradas & Reais ou binárias \\
\hline Pesos sinápticos & Reais \\
\hline Limiar & Real \\
\hline Saída & Binária \\
\hline Função de ativação & Degrau ou degrau bipolar \\
\hline Processo de treinamento & Supervisionado \\
\hline Regra de aprendizado & Regra de Hebb \\
\hline
\end{tabular}

Este tipo de rede é usualmente empregado em problemas de reconhecimento de padrões com o objetivo de dividir as classes adotadas como sinais de entrada que sejam linearmente separáveis. Para um Perceptron constituído de duas entradas a separação entre as classes é dada por uma reta, que no caso de a função de ativação ser degrau bipolar, separará a classe cujo dado de saída é -1 (que estarão abaixo da reta) da classe cuja saída é 1, que estará acima (Figura 33). Quando há muitas camadas a fronteira de separação é representada por um hiperplano.

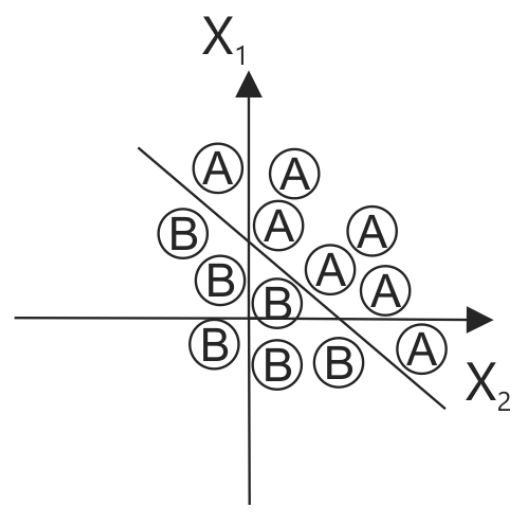

Figura 33 - Gráfico ilustrando a fronteira de separação entre as duas classes de saída (Modificado de Silva, Spatti e Flauzino, 2010).

O Perceptron é muito utilizado em problemas de classificação simples através de funções lineares. Um exemplo clássico que mostra o funcionamento desta 
rede é a representação das funções lógicas AND, OR ou XOR (exclusivamente OU) (Kovács, 2006).

Sabendo que a saída $\left(y_{i}\right)$ no neurônio para um vetor de dados $\left(x_{i}\right)$ pode ser representada pela equação:

$$
\boldsymbol{y}_{\boldsymbol{i}}=\boldsymbol{f}\left(\boldsymbol{w} * \boldsymbol{x}_{\boldsymbol{i}}+\boldsymbol{b}\right) \quad \text { (Equação 3) }
$$

onde, para quaisquer valores de pesos sinápticos $(w)$ e limiar de ativação $(b)$ a função separa as entradas em duas regiões por uma reta, tem-se que as funções lógicas AND e OR (entradas e saídas são mostradas na Tabela 16) podem ser linearmente separáveis e a função XOR não pode ser separada por uma reta. A Figura 34 apresenta as representações gráficas desta aplicação para AND, OR e XOR respectivamente.

Tabela 16 - Valores de entrada e saída para representação das funções AND, OR e XOR.

\begin{tabular}{cc|ccc}
\hline \multicolumn{2}{c|}{ Entradas } & AND & OR & XOR \\
\hline $\mathbf{X}_{\mathbf{1}}$ & $\mathbf{X}_{\mathbf{2}}$ & $\mathbf{X}_{\mathbf{1}}$ e $\mathbf{X}_{\mathbf{2}}$ & $\mathbf{X}_{1}$ ou $\mathbf{X}_{\mathbf{2}}$ & $\mathbf{X}_{1}$ xor $\mathbf{X}_{\mathbf{2}}$ \\
\hline \hline 0 & 0 & 0 & 0 & 0 \\
\hline 0 & 1 & 0 & 1 & 1 \\
\hline 1 & 0 & 0 & 1 & 1 \\
\hline 1 & 1 & 1 & 1 & 0 \\
\hline
\end{tabular}


a)

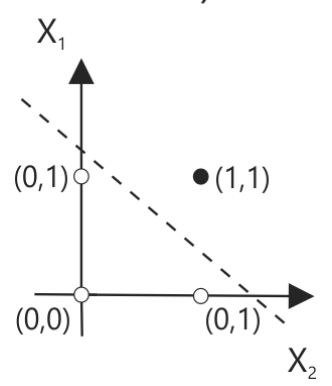

b)

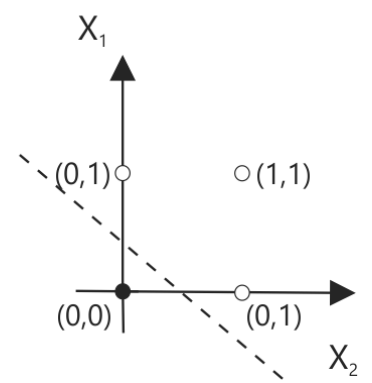

c)

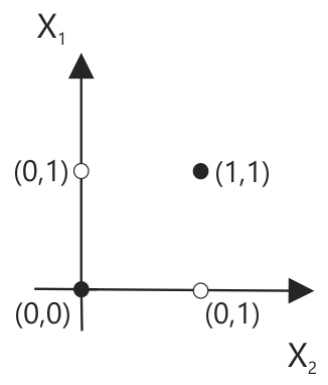

Figura 34 - Representações gráficas da separação linear dos dados usando Perceptron para: a) Função AND, b)Função OR e c)Função XOR.

O processo de treinamento ou aprendizagem pelo qual a rede deve passar é realizado por meio da regra de Hebb. Este aprendizado é o mais antigo e famoso de todas as regras e possui este nome em homenagem ao neuropsicólogo Hebb (1949 ${ }^{12}$ apud Hykin, 2001). Uma sinapse hebbiana é "um mecanismo dependente do tempo, altamente local e fortemente interativo para aumentar a eficiência sináptica como uma função da correlação entre as atividades pré-sinápticas e pós-sinápticas" (Hykin, 2009).

\subsubsection{Perceptron de Multicamadas}

As redes Perceptron de múltiplas camadas (Multilayer Perceptron - MLP) ou de retroprogradação do erro (Kovács, 2006) possuem como característica principal ter no mínimo uma camada intermediária de neurônios. Outra característica importante em relação a sua aplicação é o leque de possibilidades que elas alcançam em diferentes áreas do conhecimento, por isso é considerada uma das mais versáteis quanto à aplicabilidade.

Silva, Spatti e Flauzino (2010) discute que as redes MLP ficaram conhecidas após a publicação do livro de Rummelhart, Hinton e Williams em 1986 chamado

\footnotetext{
12 HEBB. D.O. 1949. The Organization of Behavior: A Neuropsychological Theory. New York, Wiley.
} 
Parallel Distributed Processing. Neste livro, os autores apresentam um algoritmo denominado backpropagation, fundamental no processo de aprendizagem da rede.

Este tipo de rede possui arquitetura de feedforward onde o sentido de seu funcionamento é entrada $\rightarrow$ saída. Os sinais são emitidos pela camada de entrada e as camadas intermediárias (Figura 35), por sua vez, extraem a maioria das informações referentes ao comportamento e as codificam por meio dos sinais sinápticos e os limiares de seus neurônios. A camada de saída recebe os sinais da última camada intermediária produzindo a resposta liberada pela rede.

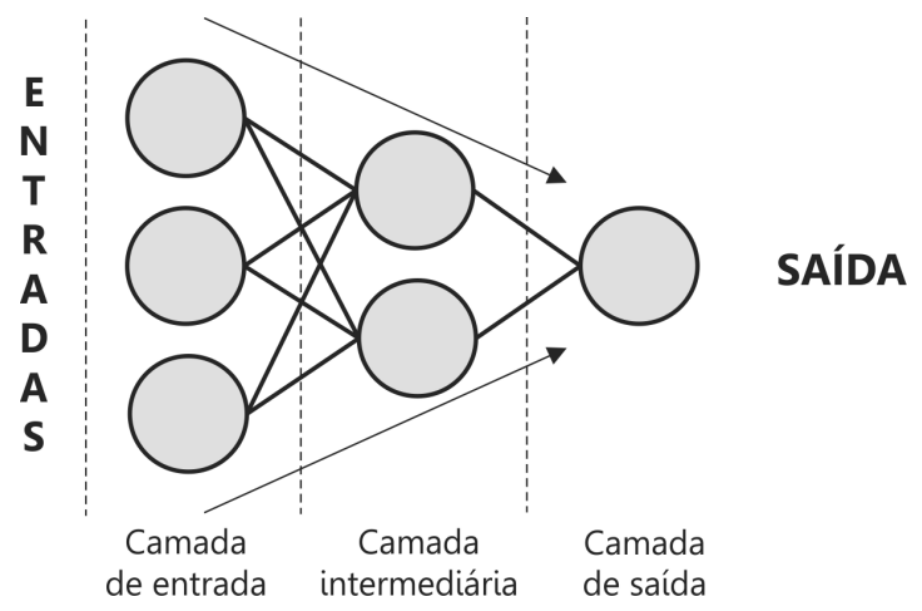

Figura 35 - Representação de uma rede simples do tipo MLP com camadas intermediárias ou ocultas.

Para treinar este tipo de rede é utilizada a regra Delta Generalizada (Duda, Hart e Stork, 2000), mais popularmente chamada de backpropagation ou algoritmo de retropropagação do erro através do treinamento de forma supervisionada (Haykin, 2001). O processo de treinamento é realizado por meio de duas fases bem específicas de aprendizado (Duda, Hart e Stork, 2000; Haykin, 2001; Silva, Spatti e Flauzino, 2010).

A primeira fase é denominada propagação adiante ou forward. Durante a sua execução os pesos sinápticos e os limiares dos seus neurônios permanecem inalterados, pois o objetivo é obter as respostas das redes levando em consideração os seus valores posteriormente modificados pelo processo de readequação. Assim, 
um conjunto de amostras de treinamento é inserido nas camadas de entrada e seu efeito se propaga, camada por camada, até a saída.

Usando o treinamento supervisionado, as respostas da rede são comparadas com as respostas desejadas e os erros produzidos pelos desvios entre as diferentes saídas são calculados e posteriormente utilizados para ajustar os pesos e limiares de todos os neurônios. Assim, os pesos sinápticos são ajustados de acordo com a regra de correção do erro (Haykin, 2001), ou seja, a resposta real é subtraída da resposta desejada para produzir um sinal de erro.

A segunda fase é denominada propagação reversa ou retroprogadação ou backward, onde o sinal de erro é propagado para trás através da rede. Assim, em função dos valores de erros produzidos na etapa anterior, são ajustados os pesos sinápticos. As aplicações sucessivas das duas fases fazem com que os pesos sinápticos sejam ajustados automaticamente em cada interação, consequentemente chegando a uma gradativa diminuição da soma dos erros produzidos pelas respostas a partir das desejadas. Em um sentido estatístico, os pesos sinápticos são ajustados para fazer com que a resposta real da rede se mova para mais perto da resposta desejada (Haykin, 2001).

Vale ressaltar que este sistema de interconexões é representado por vetores e matrizes de dados de entrada e pesos sinápticos e, geralmente as funções usadas no método backpropagation são a logística ou a tangente hiperbólica.

De maneira mais detalhada, tem-se um neurônio $(j)$, reproduzido pela Figura 36 , pertencente a uma camada $(L)$, cuja função de ativação $(g)$ deve ser contínua e diferenciável em torno do seu domínio. Os sinais de entrada são representados por $\left(X_{1}, X_{2} \ldots X_{n}\right)$ e os pesos sinápticos por $\left(W_{1}, W_{2} \ldots W_{n}\right)$, a soma ponderada das entradas $(\Sigma)$ se transforma na saída do corpo celular artificial (u) após a introdução do limiar de ativação $(\theta)$. 


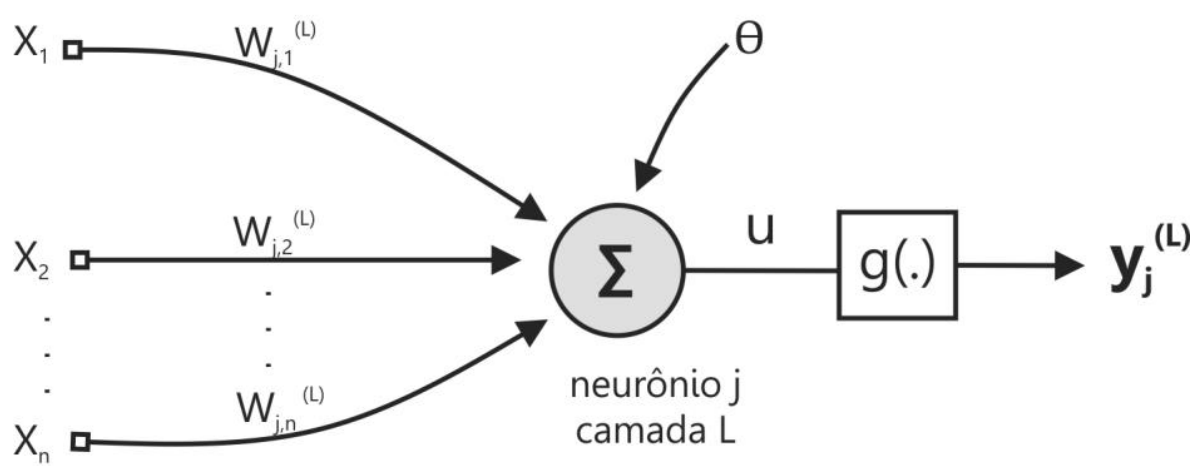

Figura 36 - Representação de um neurônio (j) da camada (L) de uma rede Perceptron multicamadas (Modificada de Silva, Spatti e Flauzino, 2010).

Se analisado somente um neurônio (j), representado pela Figura 36, a função representativa do erro de aproximação, cuja atribuição é medir o desvio entre o dado de saída e o valor desejado, é:

$$
\boldsymbol{e}_{j}(\boldsymbol{n})=\boldsymbol{d}_{\boldsymbol{j}}(\boldsymbol{n})-\boldsymbol{y}_{\boldsymbol{i}}(\boldsymbol{n}) \quad \text { (Equação 4) }
$$

onde $d_{j}(n)$ é o respectivo valor desejado e $n$ é a $n$-ésima interação. O erro total de todos os neurônios da camada de saída assume a função quadrática referida como:

$$
E(n)=\frac{1}{2} \sum_{j \in C}^{n_{3}}\left(d_{j}(n)-y_{i}(n)\right)^{2} \quad \text { (Equação 5) }
$$

A correção $\Delta w_{j}(n)$ a ser realizada ao peso sináptico $w_{j}(n)$, a partir do valor de saída daquela interação, deve ser proporcional à derivada parcial entre o erro total e o peso sináptico anteriormente usado:

$$
\Delta w_{j}(n)=-\eta \frac{\partial E(n)}{\partial w_{j}(n)} \quad \text { (Equação 6) }
$$


onde $\eta$ é o parâmetro da taxa de aprendizagem do algoritmo e o sinal negativo indica a descida do gradiente no espaço de pesos em busca do menor valor possível para o erro quadrático.

Silva, Spatti e Flauzino (2010) exemplifica a convergência para o menor erro possível $\left(w^{\star}\right)$ através de um gráfico (Figura 37 ) que corresponde a representação geométrica dos passos para atualização dos pesos rumo a otimização. Partindo de um valor $w^{0}$, o valor de $w^{1}$ é obtido a partir da direção oposta do vetor gradiente em relação ao valor do peso anterior, neste caso, $w^{0}$. Quando o processo se converge para $\mathrm{w}^{*}$, o valor de $\mathrm{E}$ é o menor em relação a qualquer outro calculado nos passos anteriores, em um total de $\mathrm{n}$ interações.

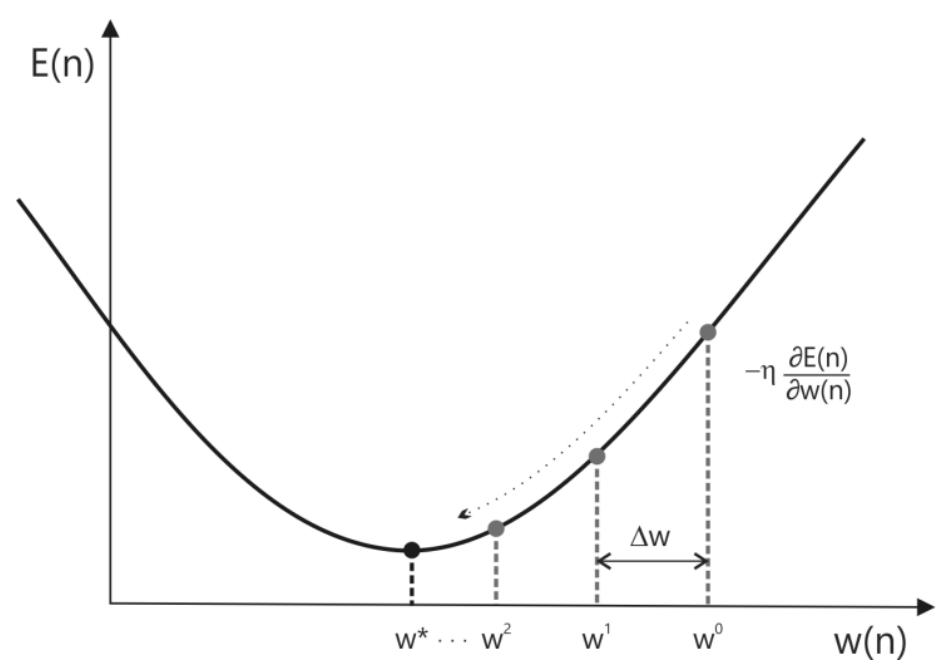

Figura 37 - Representação geométrica da obtenção do erro (Adaptada de Silva, Spatti e Flauzino, 2010).

No caso dos ajustes dos pesos para as camadas intermediárias, não existe uma forma de acessá-los diretamente, pois não se sabe a priori qual o valor desejado de saída para os neurônios destas camadas. Os ajustes, todavia, são feitos através dos erros de saída produzidos pelos neurônios da camada imediatamente posterior, que já foram ajustados. Assim, se faz necessário ter realizado o ajuste da camada de saída que servirá como estimativa de erro para a camada anterior, e daí por diante. 


\subsection{6 Área de aplicação}

Na década de 90, a utilização das redes neurais artificiais começou a ganhar forma e abriu-se um leque de aplicações ainda não preenchido por completo. Atualmente, podem ser observadas aplicações no setor financeiro principalmente devido ao comportamento não-linear característico desta área (Silva, Spatti e Flauzino, 2010). O estudo de Wong \& Selvi (1998), no qual encontra-se uma revisão das aplicações de RNA no setor financeiro, já elucidava uma crescente quantidade de esforços para se aplicar RNA entre os anos de 1990 e 1996.

Kalogirou (2000) apresentou várias aplicações no setor energético, entre elas: sistemas de aquecimento, ventilação e sistemas de ar condicionado, radiação solar, modelagem e controle de sistemas de geração de energia, previsão de carga e de refrigeração. Em um estudo sobre a previsão da performance de grandes sistemas solares, Kalogirou, Mathioulakis e Belessiotis (2014) descreveram as vantagens do método proposto como: a simplicidade na execução, mesmo quando as características dos componentes do sistema não são conhecidos, e o potencial para melhorar a capacidade da RNA para prever o desempenho do sistema de energia solar, através da adição contínua de novos dados recolhidos durante a operação do sistema.

Diversas são as áreas de aplicações, por exemplo, em controle, robótica, reconhecimento de padrões, previsão de eventos, energia, sistemas, fabricação, otimização, processamento de sinal e ciências sociais/psicologia (Kalogirou, 2000).

Silva, Spatti e Flauzino (2010) ainda incluiu nesta lista aplicações no ramo da biologia, ecologia, farmácia, acústica, no estudo da profundidade de poluentes (avaliação ambiental), na indústria de alimentos, no setor automotivo, entre outras. Além da área de medicina, que foi a precursora das aplicações. Nesta área pode-se exemplificar a aplicação em RNA com o trabalho de Lisboa \& Taktak (2006) que fizeram uma revisão sistemática para avaliar o benefício de redes neurais artificiais como ferramentas de tomada de decisão na área de câncer, e o trabalho de Saritas, Ozkan e Sert (2010) que estudaram a partir de redes neurais o prognóstico do câncer de próstata. 
Na área da Geotecnia também são utilizadas as redes neurais artificiais como forma de aplicação em diversos setores. Jeng, Cha e Blumenstein (2003) e Shahin, Jaksa e Majer (2008) citaram que esta técnica pode ser aplicada amplamente pois, ajuda a resolver problemas geotécnicos complexos e ainda não bem compreendidos, que por sua própria natureza apresentam grande variabilidade. Segundo Shahin et al. (2008), muitos modelos matemáticos não conseguem simular o comportamento complexo da maioria dos problemas de engenharia geotécnica e por isso a RNA pode ser um complemento para técnicas de computação convencionais. Contudo, ela ainda apresenta algumas deficiências quanto à transparência do processo, a extrapolação e as incertezas.

Propriedades geotécnicas do solo como a pressão de pré-adensamento (Çelik e Tan, 2005), a resistência ao cisalhamento (Kurup e Dudani, 2002) e a permeabilidade (Sinha e Wang, 2008), podem ser estimadas usando redes neurais. Das e Basudhar (2006) aplicaram redes neurais para estudar a capacidade lateral de estacas em argila. Na área ambiental, esta mesma técnica foi utilizada no mapeamento de solos ricos em sulfato ácido que constituem um problema ambiental grave (Beucher et al., 2013). Sanchez (2009) aplicou redes neurais para modelagem de subpressões das fundações da barragem de Itaipu. Outro trabalho executado com dados desta barragem avaliou os níveis piezométricos para determinação de supressões que atuam no maciço de fundação de Itaipu, visando a segurança da estrutura (Medeiros, 2013).

Dentro da área geotécnica, as redes neurais artificiais também são aplicadas no estudo dos movimentos de massa gravitacionais, buscando avaliar a susceptibilidade de áreas sujeitas a MMG, análise de eventos perigosos (hazard), o reconhecimento dos movimentos a partir de imagens, para previsão e monitoramento, dentre outros objetivos. A próxima seção (Seção 2.4.7) apresenta uma resenha desta aplicação. 


\subsubsection{Uso das redes neurais no estudo de MMG}

A abordagem de redes neurais artificiais na área de estudo de movimentos de massa, tem muitas vantagens quando comparado com métodos estatísticos. Como o método da rede neural artificial é independente da distribuição estatística dos dados, não há necessidade de variáveis estatísticas específicas. Redes neurais permitem que a integração de dados de sensoriamento remoto e dados GIS seja conveniente (Pradhan, Lee e Buchroithner, 2010).

Trabalhos relacionados à aplicação do método de redes neurais artificiais ao estudo de movimentos de massa gravitacionais para elaboração de carta de eventos perigosos foram investigados visando embasar esta pesquisa e examinar a resposta obtida pelos pesquisadores para uma correlação com o que é esperado após a execução do processo. Entre os pesquisados estão Arora, Das Gupta e Gupta (2004), Pradhan e Lee (2007), Wang e Sassa (2006), Pradhan e Lee (2011). Também foram pesquisados trabalhos que utilizaram RNA na elaboração de outras cartas que serviram de subsídio para o entendimento da técnica, destacam-se: Lee et al. (2004), Caniani et al. (2008), Choi, Joo Oh e Won. (2010), Ercanoglu (2005), Ermini, Catani e Casagli (2005), Melchiorre et al. (2008) e Pradhan e Lee (2010).

Em geral, os pesquisadores utilizam a rede neural artificial Perceptron de múltiplas camadas com camadas intermediárias de neurônios, de arquitetura feedforward e o treinamento supervisionado. O algoritmo mais utilizado é o backpropagation, embora alguns pesquisadores proponham algumas variações deste algoritmo (Chauhan et al., 2010; Kia et al., 2012; Gomez e Kavzoglu, 2005; Neaupane e Achet, 2004; Neaupane e Piantanakulchai, 2006; Yesilnacar e Topal, 2005).

As funções de transferência ou de ativação não são muito mencionadas, em alguns estudos cita-se que é sigmoidal, podendo ser hiperbólica ou logística (Lee et al., 2003).

A Figura 38 apresenta um diagrama de fluxo geral que exemplifica a técnica de aplicação de redes neurais no estudo de movimentos de massa. Foram citados apenas os temas, parâmetros de entrada e configurações mais usados, cuja finalidade 
é gerar uma carta de eventos perigosos dos movimentos de massa gravitacionais. Outros dados podem ser adicionados a este fluxograma dependendo do tipo e objetivo de estudo.

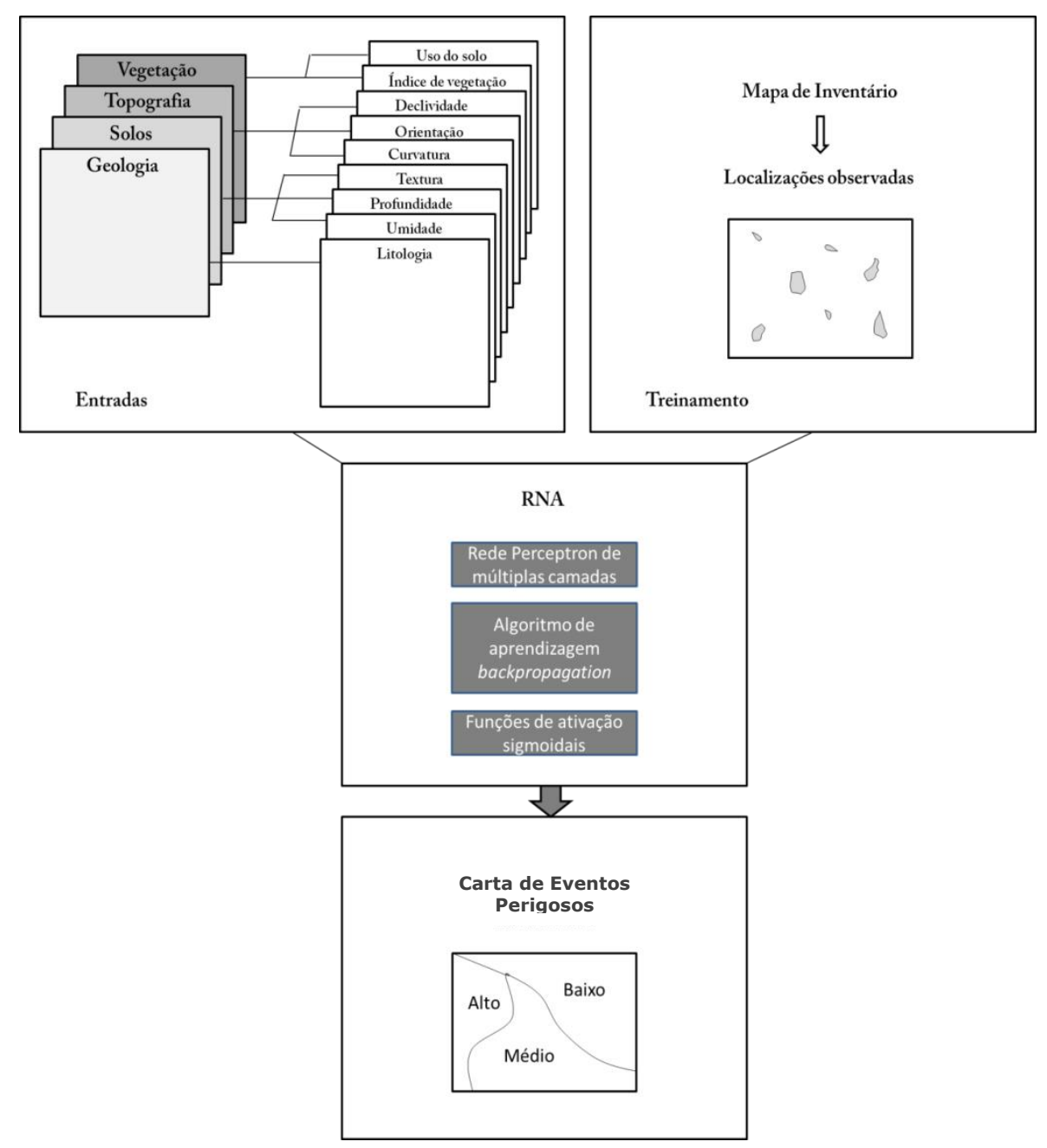

Figura 38 - Fluxograma de estudo.

Em relação à operação dos dados, habitualmente usa-se vetores e matrizes para a análise, sendo necessário um programa que execute as operações com esse tipo de formato. $O$ software mais usado é o MATLAB, embora alguns pesquisadores prefiram utilizar, por exemplo, o Trajan Software (Ermini, Catani e Casagli, 2005).

Diversos são os fatores para a entrada de dados utilizados, e também a quantidade de elementos. A média de utilização é de 7 a 10 fatores, embora alguns estudos como Pradhan, Lee e Buchroithner (2010) que utilizaram 15 atributos para análise 
Yesilnacar e Topal (2005) que utilizaram 19. Os mais empregados estão destacados na Figura 38. Ademais, existem autores que adicionam fatores como o diâmetro e as idades das árvores (Lee et al., 2004) e Yesilnacar e Topal (2005) que adicionaram dados de hidrologia, como: densidade de drenagem, bacias e energia de fluxo.

Após a extração de fatores a partir de mapas elaborados através de ferramentas do GIS, estes são convertidos para uma grade do tamanho do pixel escolhido para análise, e então repassados para o sistema de dados ASCII para serem usados na rede neural (Lee et al., 2003). Os valores de saída são novamente convertidos em gride para posterior elaboração da carta de eventos perigosos (Pradhan, Lee e Buchroithner, 2010). A geração da carta de eventos perigosos usualmente é feita por programas de sistemas de informações geográficas. O tamanho do pixel a ser analisado varia muito, encontram-se estudos que utilizam $10 \times 10 \mathrm{~m}, 25 \times 25 \mathrm{~m}$ e $30 \times 30 \mathrm{~m}$, não ultrapassando este último valor.

O mapa de inventário é uma chave de grande importância nos processos de avaliação do perigo quanto aos movimentos de massa gravitacionais, pois avalia a frequência e a distribuição dos movimentos de massa na área mapeada. $O$ inventário é a forma de obter os dados de treinamento mais usual.

O algoritmo de retropropagação treina a rede até atingir um valor mínimo de erro entre os valores de saída desejados e reais da rede. Uma vez que a aprendizagem é completa, a rede é utilizada como uma estrutura voltada para produzir o resultado a partir de outros dados (não mais de treinamento) com os pesos provenientes da etapa de aprendizagem.

Quase todos os trabalhos que exibem a adoção de valores para, por exemplo, a normalização, utilizam os dados de entrada normalizados para a escala de 0,1-0,9, a taxa de aprendizagem com ajuste para o valor de 0,01, e os pesos iniciais selecionados aleatoriamente. Os dados nominais e intervalo de grupos de classe são convertidos em valor contínuo entre 0,1 e 0,9 (Lee et al. 2004). 


\subsection{ABORDAGEM PROBABILÍSTICA}

\subsubsection{Principais conceitos}

A probabilidade está sempre presente na vida e na conversação diária das pessoas. Geralmente usam-se expressões típicas como "provavelmente vai chover" sem perceber que isto se relaciona ao conceito de probabilidade de um evento ocorrer. O estudo da probabilidade vem da necessidade de, em certas situações, prever a possibilidade de ocorrência de determinados fatos. Esta previsão deve ser feita em experimentos que apresentem resultados diferentes a cada ocorrência ou na análise de várias ocorrências sucessivas, ou seja, não apresentam um padrão, e em um espaço amostral no qual o conjunto de todos os resultados seja possível em um experimento aleatório (que não podem ser previstos com certeza). Segundo Ang \& Tang (2007), probabilidade pode ser considerada como sendo a possibilidade de ocorrência de um evento dentro de um espaço amostral composto por todos os possíveis acontecimentos.

A probabilidade possui propriedades e regras a serem seguidas. Estas propriedades são embasadas na teoria matemática de probabilidade. Algumas regras fundamentais, também chamadas axiomas, são (Pestana \& Velosa (2006), Ang e Tang (2007), Walpole et al.(2011)):

i. $\quad P(A) \geq 0$, (Equação 7)

para a probabilidade de um evento existir, o seu valor deve ser sempre maior que zero.

ii. $\quad P(\Omega)=1$, (Equação 8)

o espaço amostral $(\Omega)$, sempre é igual a 1 (hum). Isso significa que o somatório de todas as probabilidades envolvidas deve ser igual a 1 (hum). $\mathrm{O}$ caso mais simples é a probabilidade do evento $A$ acontecer, somado ao dele não 
acontecer, $\bar{A}$ (Figura 39). No cálculo da probabilidade de um ou mais eventos, o espaço amostral $(\Omega)$ é definido como sendo o conjunto completo de todas as possibilidades de um experimento. Por exemplo, no lançamento de um dado, o espaço amostral é: 1, 2, 3, 4, 5 e 6.

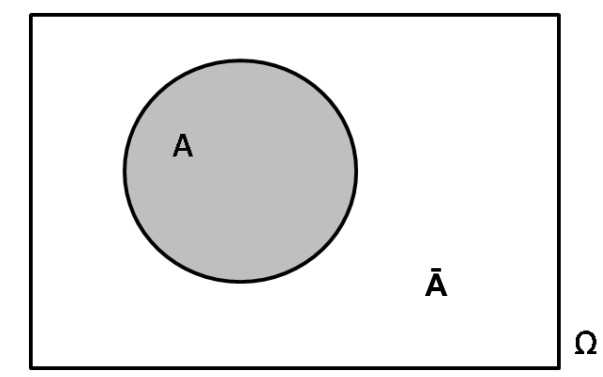

Figura 39 - Evento A e seu evento complementar $\bar{A}$ num espaço amostral $\Omega$.

iii. $P=(A \cup B) \leq P(A)+P(B)$,

(Equação 9)

a probabilidade de $\mathrm{A}$ acontecer somado à probabilidade de $\mathrm{B}$ também ocorrer é maior que a união de eventos (Figura 40), pois, deve-se respeitar a regra da adição (Seção 0) de probabilidades.

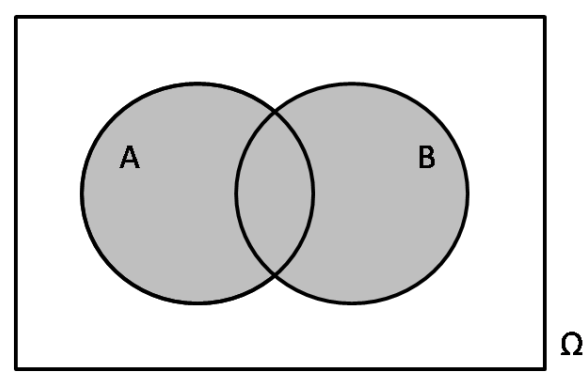

Figura 40 - Diagrama de Venn para $\boldsymbol{A} \cup \boldsymbol{B}$ num espaço amostral $\Omega$.

Se os eventos forem mutuamente exclusivos, verifica-se a igualdade no axioma iii. Os eventos mutuamente exclusivos são aqueles que não podem acontecer juntos, ou seja, a probabilidade dos dois eventos ocorrerem ao mesmo tempo é zero (Ang e Tang, 2007). 
Por exemplo, em um arremesso de uma moeda, não existe nenhuma chance de ocorrer cara e coroa numa mesma jogada, estes eventos são mutuamente exclusivos ou excludentes. Similarmente, três ou mais eventos são mutualmente exclusivos se a ocorrência de um evento impede a ocorrência de todos os outros eventos (Ang e Tang, 2007).

O diagrama de Venn ilustrado na Figura 41 representa os eventos A e B pertencentes ao mesmo espaço amostra $(\Omega)$, embora sejam mutualmente exclusivos. Conclui-se que não há interseção entre os dois eventos, entretanto a união pode ser calculada.

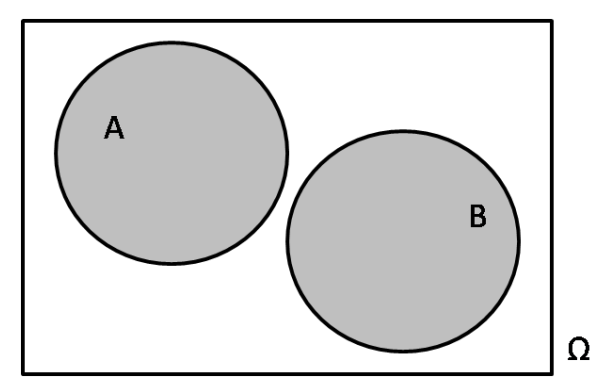

Figura 41 - Diagrama de Venn para eventos mutuamente exclusivos em um espaço amostral $\Omega$.

Estes axiomas fazem parte da teoria da probabilidade e, por serem premissas essenciais, não podem ser violadas (Ang e Tang, 2007). Outras propriedades de probabilidade podem ser deduzidas a partir dos axiomas mostrados anteriormente.

Algumas regras são provenientes dos axiomas e também fazem parte das relações que fundamentam a teoria matemática da probabilidade, são elas: regra da adição e regra da multiplicação. A regra da adição será demostrada na próxima sessão, entretanto, considerou-se mais pertinente apresentar a regra da multiplicação juntamente com a probabilidade condicional. 


\section{Regra da Adição}

A regra da adição origina-se da Equação 9 do axioma iii, no qual diz que: para dois eventos A e B de um mesmo espaço amostral, a soma das probabilidades é sempre maior que a sua união. Isto porque os eventos que acontecem em $A$ e $B$ simultaneamente são repetidos.

Se o evento A e seu complementar Ā são mutualmente exclusivos, com base na Equação 9, tem-se que:

$$
P(A \cup \overline{\mathrm{A}})=P(A)+P(\overline{\mathrm{A}})
$$

Se os eventos A e $\bar{A}$ representarem todo o espaço amostral, ou seja, $A \cup \overline{\mathrm{A}}=\Omega$, a partir da Equação 9 pode-se afirmar que:

$$
P(\overline{\mathrm{A}})=1-P(A)
$$

Entretanto, quando os eventos A e B não são mutualmente exclusivos, a regra da adição é proposta e válida, sendo:

$$
P(A \cup B)=P(A)+P(B)-P(A \cap B) \quad \text { (Equação 12) }
$$

A porção duplicada dos casos favoráveis a A e a B, simultaneamente, deve ser subtraída para se obter a probabilidade da união. Visualmente esta porção é representada pela área hachurada na Figura 42.

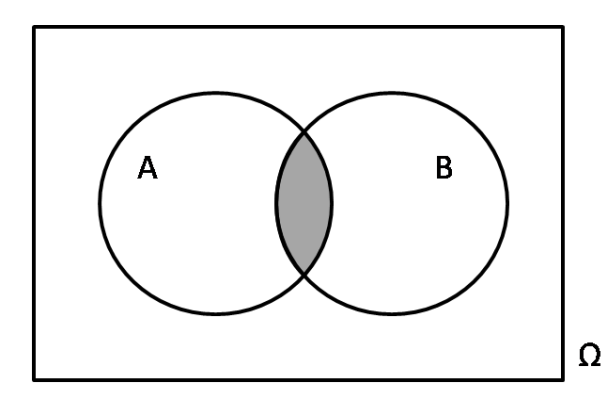

Figura 42 - Diagrama de Venn para os eventos A e B, cuja interseção, $A \cap B$, é representada pela área hachurada. 


\subsubsection{Abordagens probabilísticas}

Existem muitas formas de interpretação da probabilidade, isto é, existem várias maneiras de obter a probabilidade de um ou mais eventos. As mais conhecidas são: a abordagem clássica, a frequentista e a subjetiva.

\subsubsection{Abordagem clássica}

A abordagem clássica, também denominada de probabilidade laplaciana em mérito ao seu autor, Pierre Simon Laplace, admite que os acontecimentos são equiprováveis e, está restringida a situações de equilíbrio perfeito (Pestana \& Velosa, 2006). Esta abordagem só se ajusta a condições artificiais (moeda equilibrada, dados perfeitos e cartas bem embaralhadas) ou à modelação simplificada de situações reais (selecionar ao acaso uma pessoa do sexo masculino em uma sala de aula, por exemplo).

Apesar de sua aplicação ser simples e limitada às circunstâncias abstratas de equilíbrio usualmente empregadas em jogos de azar, a abordagem clássica é de grande importância teórica e prática quanto ao aprendizado da arte de enumerar acontecimentos favoráveis e possíveis (Pestana \& Velosa, 2006).

Os princípios que devem conduzir ao cálculo da probabilidade definem que a probabilidade de um acontecimento é o quociente entre os números de casos que são favoráveis e o número de casos possíveis (Walpole et al. 2011). Assim, a probabilidade de ocorrer um evento A é:

$$
\mathrm{P}(\mathrm{A})=\frac{\text { número de casos favoráveis a } A}{\text { número de casos possíveis }} \quad \text { (Equação 13) }
$$




\subsubsection{Abordagem frequentista}

A abordagem frequentista avalia a probabilidade de um evento como a frequência relativa da sua ocorrência em $n$ repetições independentes do experimento (James, 1996). A probabilidade relativa está baseada nos dados históricos acumulados, ou seja, naquilo que ocorreu no passado.

Observando as repetições do evento no qual a variável de interesse se encontra, podem-se levantar as informações de ocorrência dessa variável e para um número grande calcular a sua frequência relativa (Magalhães e Lima, 2002). A probabilidade avaliada pela frequência dos acontecimentos pode ser expressa pela Equação 14, genérica:

$$
\mathrm{P}(\mathrm{A})=\frac{\text { número de vezes que um evento ocorreu no passado }}{\text { número total de oportunidades para o evento ocorrer }} \text { (Equação 14) }
$$

Esta abordagem pode ser analisada a partir de dados observados de um conjunto de amostras. Por exemplo, em uma empresa há 57 funcionários, divididos por grau de instrução de acordo com a Tabela 17. Para este caso, qual a probabilidade de, ao selecionar aleatoriamente um funcionário para ganhar uma promoção, ele tenha no mínimo o ensino superior incompleto (evento A)?

Tabela 17 - Tabela de informações dos funcionários de uma empresa.

\begin{tabular}{cc}
\hline Grau de Instrução & $\begin{array}{c}\text { Número de } \\
\text { profissionais }\end{array}$ \\
\hline \hline Ensino Médio Incompleto & 7 \\
Ensino Médio Completo & 20 \\
Técnicos & 5 \\
Ensino Superior Incompleto & 15 \\
Ensino Superior Completo & 10 \\
\hline TOTAL & 57 \\
\hline
\end{tabular}


Os funcionários que possuem pelo menos o ensino superior incompleto são 15 com este grau de instrução e 10 que possuem ensino superior completo. $O$ valor destas duas possibilidades juntas é chamado frequência relativa. $O$ total de número de funcionários da empresa é a soma das frequências. Assim, utilizando os conceitos de probabilidade frequentista, tem-se que:

$$
\begin{array}{cc}
\mathrm{P}(\mathrm{A})=\frac{\text { número de funcionários com no mínimo o ensino superior incompleto }}{\text { número total de funcinários }} & \text { (Equação 15) } \\
\mathrm{P}(\mathrm{A})=\frac{25}{57} & \text { (Equação 16) } \\
\mathrm{P}(\mathrm{A}) \cong 0,44 & \text { (Equação 17) }
\end{array}
$$

\subsubsection{Abordagem subjetiva}

A probabilidade subjetiva é baseada na intuição, no julgamento pessoal, acúmulo de conhecimento e experiências (Walpole et al., 2011). Existem algumas situações que podem ser analisadas em um sentido probabilístico, mas não podem apresentar uma probabilidade certa em termos matemáticos. Um exemplo disso é o uso diariamente do conceito de probabilidade para prever eventos cotidianos, somente com base de observação do passado.

Em alguns casos a probabilidade frequentista pode ser usada, mas deve-se lembrar de que existem situações pelas quais é contestável calcular com base na frequência dos eventos (Magalhaes e Lima, 2002). Por exemplo, calcular a probabilidade de um time ganhar o campeonato não depende somente de quantas vezes ele já ganhou este campeonato, e nem mesmo se ele ganhou as últimas rodadas, porque esta nova situação não é exatamente idêntica a anterior. A cada ano novos jogadores são convocados, muda-se o treinador, os árbitros são substituídos, entre outras alterações. As informações sobre o desempenho anterior do time é importante, mas outros fatores também podem influenciar o resultado. 
Como foi dito anteriormente, a probabilidade frequentista pode ser usada para o cálculo da probabilidade subjetiva calculando-a a partir de experiências repetidas. Em muitas situações a probabilidade utilizando a frequência relativa não pode ser aplicada, como por exemplo, o cálculo da probabilidade de chover amanhã. Esta probabilidade pode ser diferente para cada pessoa.

Entretanto, uma abordagem bayseana tem sido empregada por esta se tratar de parâmetros aleatórios que regem o evento e por isso pode ser uma ferramenta para analisar a probabilidade subjetiva (Rychik e Rydén, 2006). O teorema de Bayes será apresentado na Sessão 2.5.7.

Para dar sequência à compreensão das regras e propriedades pelas quais é fundamentado o conceito de probabilidade, serão apresentados nas próximas sessões os tipos de eventos que podem compor o espaço amostral.

\subsubsection{Eventos dependentes e independentes}

Se a ocorrência ou não ocorrência de um evento não afetar a probabilidade de ocorrência de outro evento, os dois são estatisticamente independentes (Ang e Tang, 2007). Ou seja, a probabilidade de ocorrência de um evento não depende da ocorrência de outro.

Os eventos independentes e os mutualmente exclusivos podem erroneamente serem considerados iguais, entretanto, eles se diferem. Os eventos independentes podem acontecer simultaneamente, mas não podem afetar a probabilidade um do outro. Enquanto nos mutualmente exclusivos é impossível calcular a probabilidade deles ocorrerem juntos, pois a ocorrência de um evento $A$, impede a ocorrência do evento $B$.

Para os eventos independentes tem-se que:

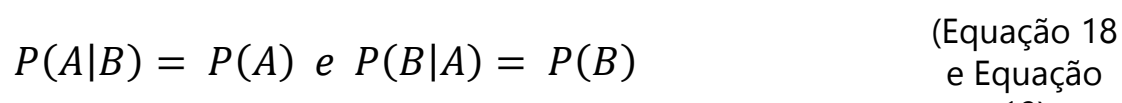


Para eventos mutualmente exclusivos:

$$
P(A \mid B)=0
$$

(Equação 20)

Por exemplo, como calcular a probabilidade do lançamento de um dado duas vezes, sabendo que o primeiro resultado foi impar (evento A) e o segundo foi o número 1 (evento B)? Os eventos são independentes, pois o segundo resultado não está vinculado ao acontecimento do primeiro.

$$
P(A \cap B)=P\{(1,1),(3,1),(5,1)\}=3 / 36=1 / 12 \quad \text { (Equação 21) }
$$

Se em um saco existem 5 bolas iguais, a não ser pela cor, pois há duas bolas vermelhas e três verdes, qual a probabilidade de retirar duas bolas verdes?

- Evento A: retirar uma bola verde;

- Evento B: retirar a segunda bola verde.

A probabilidade de retirar a primeira bola verde é :

$$
P(A)=3 / 5
$$

Agora, a probabilidade de se retirar as duas verdes é:

$$
\begin{gathered}
P(A \cap B)=P(A) * P(B \mid A) \\
P(A \cap B)=\frac{3}{5} * \frac{2}{4}=\frac{3}{10}
\end{gathered}
$$

Neste caso, A e B são dependentes, pois após retirar a primeira bola verde, há no saco somente duas bolas verdes. A probabilidade do evento $B$ depende do evento $\mathrm{A}$ acontecer.

O conceito de independência pode ser aplicado em todas as áreas da estatística aplicada e por isso é muito importante o seu conhecimento no estudo de probabilidades (Walpole et al. (2011), Magalhães e Lima, (2002)). 


\subsubsection{Eventos compostos}

Em probabilidade, um evento simples consiste em exatamente um resultado direto, sem equações complexas. Por exemplo, o cálculo da probabilidade de lançar um dado equilibrado e sair o número 6 é definido pela razão entre o número de resultados favoráveis (1) pelo número total de resultados possíveis (6), por meio da abordagem clássica da probabilidade. Um evento composto é a combinação de dois ou mais eventos simples.

Para organização do espaço amostral de um evento composto pode-se utilizar: uma lista, uma tabela, ou um diagrama de árvore.

\subsubsection{Lista}

O espaço amostral de um evento composto através de uma lista mostra todos os possíveis resultados como um check list (Pestana \& Velosa, 2006). Por exemplo:

Exemplo 1: Ao lançar um dado e uma moeda, qual a probabilidade do resultado ser um número maior que 4 e ser coroa?

O esquema a seguir representa uma lista com todas as possibilidades de resultados deste exemplo. 


$$
\begin{array}{ll}
\checkmark 1 \text { e CARA } & \checkmark 1 \text { e COROA } \\
\checkmark 2 \text { e CARA } & \checkmark 2 \text { e COROA } \\
\checkmark 3 \text { e CARA } & \checkmark 3 \text { e COROA } \\
\checkmark 4 \text { e CARA } & \checkmark 4 \text { e COROA } \\
\checkmark 5 \text { e CARA } & \checkmark 5 \text { e COROA } \\
\checkmark 6 \text { e CARA } & \checkmark 6 \text { e COROA }
\end{array}
$$

Depois de feita a lista, para o cálculo da probabilidade aplica-se a abordagem clássica:

$$
P(A)=2 / 12=1 / 6
$$

\subsubsection{Tabela}

A lista é a forma de organização mais utilizada quando existem poucos resultados possíveis. Entretanto, quando há uma maior quantidade de resultados que podem ocorrer, a melhor forma de organizá-los é por tabela.

Utilizando o Exemplo 1, a sua representação em forma de tabela pode ser ilustrada pela Tabela 18.

Tabela 18 - Resultados para lançamento de uma moeda e um dado.

\begin{tabular}{c|cccccc}
\hline & $\mathbf{1}$ & $\mathbf{2}$ & $\mathbf{3}$ & $\mathbf{4}$ & $\mathbf{5}$ & $\mathbf{6}$ \\
\hline CARA & 1-CARA & 2-CARA & 3-CARA & 4-CARA & 5-CARA & 6-CARA \\
COROA & 1-COROA & 2-COROA & 3-COROA & 4-COROA & 5-COROA & 6-COROA \\
\hline
\end{tabular}

\subsubsection{Diagrama de Árvore}

Outra maneira de representar o espaço amostral é utilizando o diagrama de árvore. Esta representação é comumente usada quando o evento composto é 
formado por muitos eventos simples e também para organizar informações de um conjunto de eventos condicionais. (Magalhães e Lima, 2002)

O diagrama de árvore de probabilidades deve ser ilustrado como a Figura 43. Nesta representação, a probabilidade de um ramo da árvore é o produto das probabilidades condicionais dispostas nos galhos que ligam os acontecimentos.

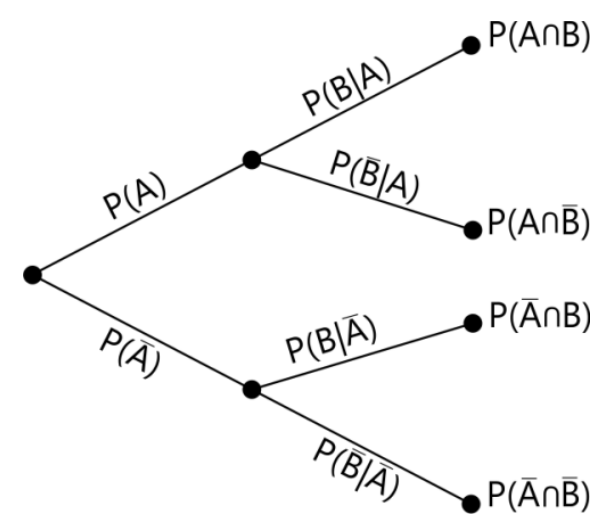

Figura 43 - Diagrama da árvore para probabilidade condicional.

O diagrama de árvore para o Exemplo 1 está demostrado na Figura 44. Em todas as representações vê-se 12 resultados possíveis, mas somente 2 são favoráveis. Assim, a probabilidade do número no lançamento de um dado ser maior que 4 e sair coroa é de $1 / 6$.

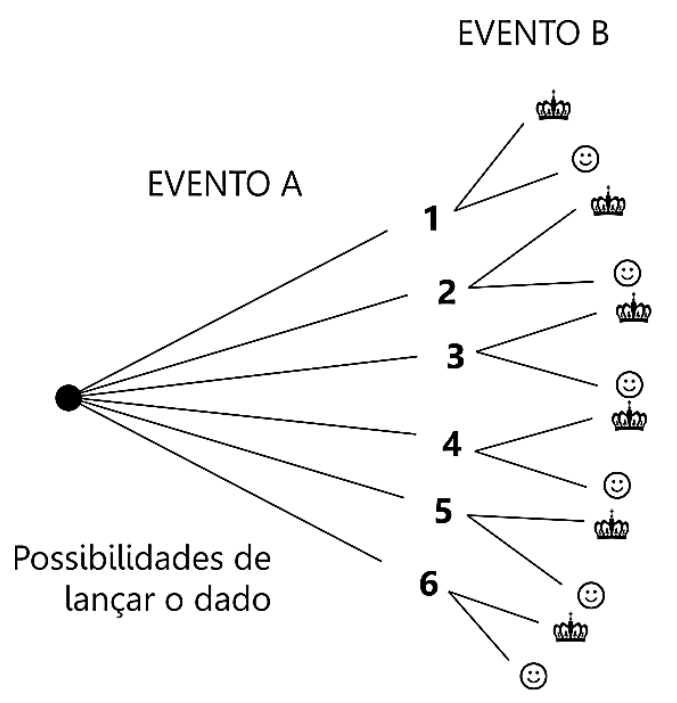

Possibilidades de lançar uma moeda

Figura 44 - Diagrama de árvore com as possibilidades existentes ao lançar um dado e uma moeda. 


\subsubsection{Probabilidade condicional}

Existem ocasiões onde a probabilidade de um evento pode depender da ocorrência (ou não ocorrência) de outro acontecimento. Se esta dependência se comprova, a probabilidade é condicional (Ang e Tang, 2007).

Um exemplo desta análise é o cálculo da probabilidade de se retirar uma carta de número 3, sabendo que a carta sorteada é de ouros. O conjunto de cartas de baralho deve estar completo, com 52 cartas.

A certificação de que este exemplo se trata de um caso de probabilidade condicional é a informação de que o naipe retirado é de ouros. Isso restringe a quantidade de chances para retirada de uma carta de número 3.

Havendo os eventos A e B no espaço amostral $\Omega$, a probabilidade de um evento A ocorrer (e.g. retirar uma carta de número 3) depende do evento B ocorrer (e.g. a carta ser de ouros) e pode ser expressa da seguinte forma:

$$
P(A \mid B) \rightarrow \text { probabilidade de } A \text {, tal que B ocorra }
$$

A probabilidade condicional pertence aos pontos amostrados de A relativos aos de $B$, pois existe um conjunto de amostras de $A$ que também pertence ao conjunto B (Ang e Tang, 2007), como mostra a Figura 45. A área hachurada da figura representa a interseção entre os dois conjuntos, ou seja, $A \cap B$.

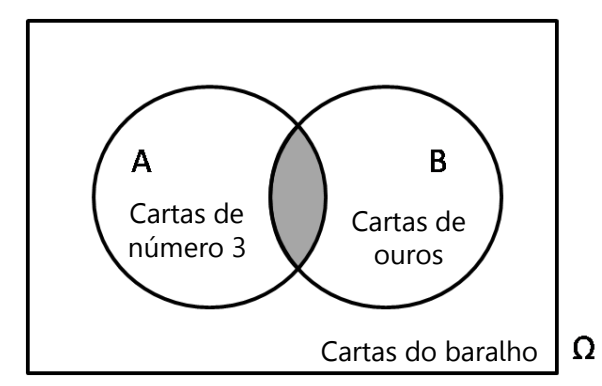

Figura 45 - Representação do espaço amostral do evento AกB. 
Para o cálculo da probabilidade condicional dos dois eventos, a interseção deve ser normalizada em relação a B, o evento que condiciona (Magalhães e Lima, 2002). Portanto:

$$
P(A \mid B)=\frac{P(A \cap B)}{P(B)}
$$

Assim, a probabilidade de retirar uma carta de número 3 (evento A) tal que ela seja de ouros (evento B) é:

$$
P(A \mid B)=\left(\frac{1 / 52}{13 / 52}\right) \rightarrow \frac{a \text { carta ser } 3 \text { e ser de ouros }}{\text { a carta } \text { ser de ouros }}=\frac{1}{13} \quad \text { (Equação 27) }
$$

Vale ressaltar que a $P(A \mid B)$ é diferente de $P(B \mid A)$ (Pestana \& Velosa, 2006). Pode-se entender esta distinção através do exemplo já comentado. Neste caso, pretende-se calcular qual a probabilidade da carta ser de ouros sabendo que a carta retirada é um 3.

$$
P(B \mid A)=\left(\frac{1 / 52}{4 / 52}\right) \rightarrow \frac{a \text { carta ser } 3 \text { e ser de ouros }}{a \text { carta } \operatorname{ser} \text { um } 3}=\frac{1}{4} \quad \text { (Equação 28) }
$$

Nas situações práticas, observando uma situação global, a informação de que ocorreu um determinado evento pode influenciar nas possibilidades de ocorrências dos eventos futuros (Magalhães e Lima, 2002). Desta forma, deve-se recalcular as probabilidades de interesse a partir do que foi mudado.

Com base nas definições de probabilidade condicional, pode-se determinar a regra da multiplicação.

\section{Regra da multiplicação}

A regra da multiplicação define que a probabilidade de que dois eventos ocorram é igual a probabilidade de um deles ocorrer multiplicado pela probabilidade de que o outro evento aconteça tal que o primeiro ocorreu. 
Sabendo que:

$$
P(A \cap B)=P(B \cap A)
$$

e partir da Equação 26, pode-se concluir que:

$$
P(A \mid B) * P(B)=P(B \mid A) * P(A)
$$

Para eventos independentes de acordo com as equações 18 e 19, a regra da multiplicação pode ser expressa da seguinte forma:

$$
P(A \cap B)=P(A) * P(B)
$$

A grande importância do teorema da multiplicação é que ele permite determinar a probabilidade da intersecção de dois ou mais eventos. Assim, é possível determinar as probabilidades condicionais de maneira simples e usá-las para definir a probabilidade de outros eventos (Rifo, 2014).

No caso de três eventos $A, B$ e $C$, a regra da multiplicação mostraria a seguinte combinação:

$$
\begin{aligned}
P(A \cap B \cap C) & =P(A \mid B \cap C) P(B \cap C) \\
& =P(A \mid B \cap C) P(B \mid C) P(C)
\end{aligned}
$$

Para eventos independentes seria:

$$
P(A \cap B \cap C)=P(A) * P(B) * P(C)
$$

Com esta explicação e todos os conceitos já estabelecidos a próxima sessão apresenta o Teorema da Probabilidade Total, também muito importante no estudo da probabilidade devido o seu alcance matemático. 


\subsubsection{Teorema da Probabilidade Total}

Se a probabilidade do evento $A$ não pode ser determinada diretamente, sua ocorrência ou não ocorrência depende de outros eventos e ainda depende de qual dos eventos ocorreu, a probabilidade de $A$ pode ser calculada pela probabilidade condicional e ponderada por cada evento do qual ela depende (Ang e Tang, 2007). Esta solução é apresentada pelo Teorema da Probabilidade Total.

Se os eventos $B_{1}, B_{2}, \ldots, B_{k}$ constituem uma partição do espaço amostral $\Omega$ tal que $P(B) \neq 0$ para todo $i=1,2, \ldots, k$, então, a probabilidade de qualquer evento $A$ de $\Omega$ é:

$$
\mathrm{P}(\mathrm{A})=\sum_{i=1}^{k} \mathrm{P}\left(\mathrm{B}_{i} \cap \mathrm{A}\right)=\sum_{i=1}^{k} \mathrm{P}\left(\mathrm{B}_{i}\right) \mathrm{P}\left(\mathrm{A} \mid \mathrm{B}_{i}\right)
$$

\subsubsection{Teorema de Bayes}

O teorema de Bayes é utilizado quando se conhece a probabilidade de $A_{i}$ para todo $i=1,2, \ldots, k$ e a probabilidade condicional de $B$ dado $A_{i}$, mas não se conhece a probabilidade direta de $B$ (James, 1996).

Utilizando os conceitos da regra da multiplicação e a partir da Equação 35, tem-se que:

$$
\mathrm{P}\left(\mathrm{A}_{i} \mid \mathrm{B}\right) \mathrm{P}(\mathrm{B})=\mathrm{P}\left(\mathrm{B} \mid \mathrm{A}_{i}\right) P\left(\mathrm{~A}_{i}\right)
$$

O teorema de Bayes diz que:

"Se $A_{1}, A_{2}, \ldots A_{k}$ são uma partição de $\Omega$, ou seja, são mutualmente exclusivos e coletivamente exaustivos, e o evento $B$ possui $P(B)>0$. "Então, 


$$
\mathrm{P}\left(\mathrm{A}_{i} \mid \mathrm{B}\right)=\frac{\mathrm{P}\left(\mathrm{B} \mid \mathrm{A}_{i}\right) P\left(\mathrm{~A}_{i}\right)}{\mathrm{P}(\mathrm{B})}=\frac{\mathrm{P}\left(\mathrm{A}_{i} \cap \mathrm{B}\right)}{\mathrm{P}(\mathrm{B})}
$$

A Equação 36 pode se expandida usando o teorema da probabilidade total, tornando-se a seguinte expressão:

$$
\mathrm{P}\left(\mathrm{A}_{i} \mid \mathrm{B}\right)=\frac{\mathrm{P}\left(\mathrm{B} \mid \mathrm{A}_{i}\right) P\left(\mathrm{~A}_{i}\right)}{\sum_{j=1}^{k} \mathrm{P}\left(\mathrm{B} \mid \mathrm{A}_{j}\right) P\left(\mathrm{~A}_{j}\right)}
$$

\subsubsection{Uso de análise probabilística no estudo de MMG}

Muitos trabalhos sobre análise probabilística são desenvolvidos a fim de calcular a possibilidade de ocorrência de movimentos de massa gravitacionais e gerar uma carta de eventos perigosos. Eles abordam o tema a partir de vários métodos dentro do amplo conjunto de análises probabilísticas. Nesta seção serão mostrados dois exemplos de utilização de probabilidade para o estudo dos movimentos de massa gravitacionais.

O primeiro exemplo se refere a aplicação da abordagem probabilística condicional que é baseada na observação da relação entre cada fator envolvido no processo e a ocorrência de movimentos de massa, assim como a relação entre os movimentos de massa gravitacionais do passado e do presente em uma determinada região. Assim a probabilidade condicional no estudo de movimentos de massa é dada pela probabilidade da ocorrência de um MMG, sabendo que outros eventos já ocorreram em um conjunto de atributos presente na região.

O estudo de Ozdemir (2009) mostra a aplicação da probabilidade condicional em uma área da cidade de Yaka na Turquia. O autor indicou alguns fatores condicionantes do movimento, sendo eles: litologia, declividade, aspecto, elevação, índice de umidade topográfica, índice de fluxo de energia. O teorema da probabilidade total foi então aplicado a partir da frequência dos movimentos de 
massa gravitacionais relacionada a cada classe de cada fator condicionante. Vale ressaltar que o autor considerou os eventos de ocorrer determinada classe como mutualmente exclusivos para o evento total que é a ocorrência do movimento de massa gravitacional.

O resultado do trabalho é a carta mostrada na Figura 46 que indica a susceptibilidade alta, média e baixa de a área ser atingida por movimentos de massa na região.

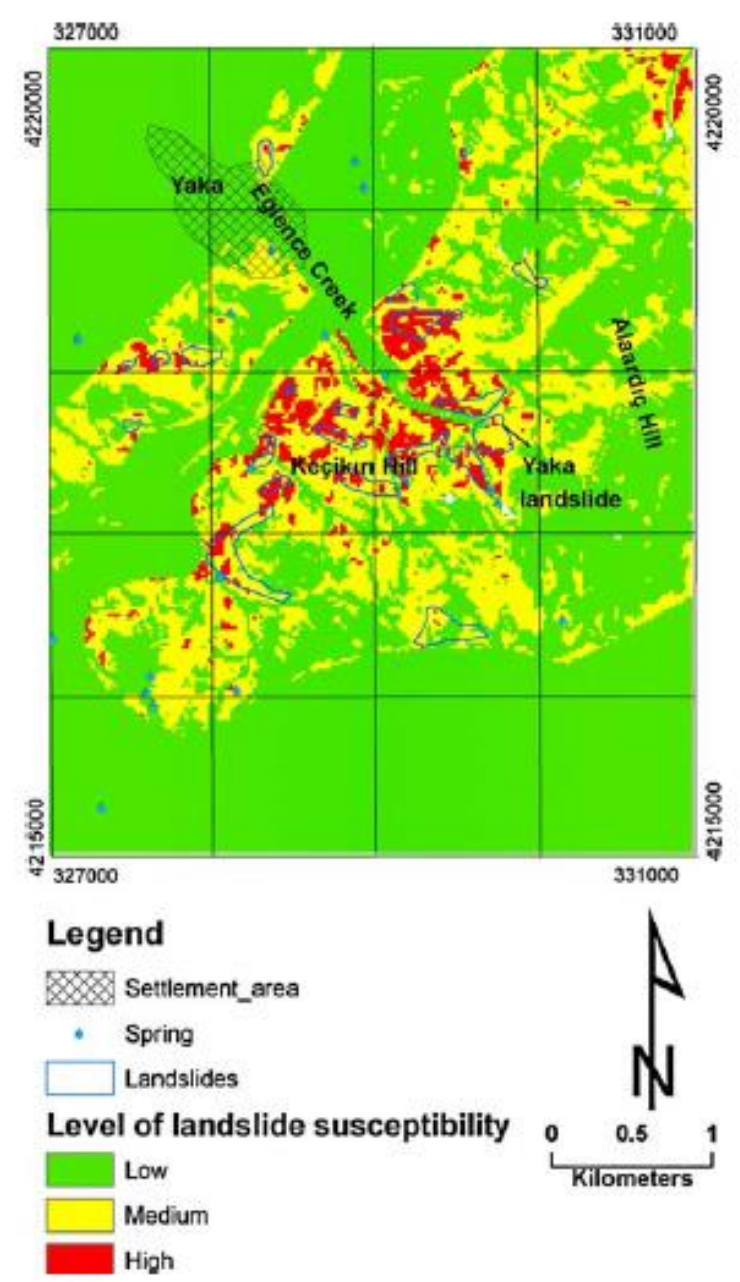

Figura 46 - Carta de susceptibilidade aos movimentos de massa gravitacionais (Ozdemir, 2009).

O estudo de Tongzhen, Shunan e Huiming (1997) utiliza Poisson e binomial para estudar a previsão de movimentos de massa gravitacionais em uma determinada região. Seu estudo se baseia em separar a área em células de mesmo tamanho e identificar quantos movimentos ocorreram em cada célula e, neste caso, 
não é necessário que a feição completa esteja representada dentro na célula. Desta maneira, a probabilidade é calculada a partir da probabilidade de Poisson tendo um $\lambda$ que representa $x f / f$ onde $x f$ é o número de células com movimento de massa gravitacional e $f$ é o número total de células.

Outros trabalhos também podem ser citados por realizarem o estudo dos movimentos de massa gravitacionais por meio de análise probabilística, a saber: Chung e Fabbri (1999), Jibson, Harp e Michael (2000), Guzzetti et al. (2005), Lee e Pradhan (2006), Lee, Choi e Min (2004) relacionados à elaboração de carta de eventos perigosos (hazard); Lee e Talib (2005) relacionado à elaboração de carta de susceptibilidade aos movimentos de massa gravitacionais, e Crovelli e Coe (2009) relacionado ao estudo do risco associado aos movimentos. 



\section{CARACTERIZAÇÃO DA ÁREA}

\subsection{CONSIDERAÇÕES GERAIS}

O sítio de aplicação deste estudo corresponde à área urbana de Ouro Preto/MG já contemplada por vários estudos referentes aos movimentos de massa gravitacionais, como os trabalhos de Souza (1996), Bonuccelli (1999), Zenóbio (2000), Carvalho (2001), Dias (2002), Rodrigues (2002), Castro (2006) e Fontes (2011).

A cidade de Ouro Preto situa-se no estado de Minas Gerais, numa região importante historicamente pelo Ciclo do Ouro, período em que a extração e exportação de ouro dominavam a economia do Brasil-Colônia. Isso ocorreu nos primeiros 60 anos do século XVIII e, atualmente, sua economia baseia-se na produção de minério de ferro e alumínio, indústrias metalúrgicas e no turismo.

A área de interesse foi considerada por Rodrigues (2002) como sendo palco de acidentes geológico-geotécnicos que coloca em risco a população da cidade e seu patrimônio histórico. Bonuccelli \& Zuquette (1999) ressaltam que os processos de movimentos de massa gravitacionais têm sido observados desde o início do povoamento da cidade, com a implantação de minerações e garimpos de ouro, e nas últimas décadas está mais concentrado na zona urbana. Sua importância, então, é justificada pelo desenvolvimento de diversas pesquisas, as quais geraram uma gama de informações que permitiram a composição do banco de dados necessário neste estudo.

\subsubsection{Localização}

Ouro Preto se distancia da capital mineira, Belo Horizonte, cerca de $90 \mathrm{~km}$ e possui como cidades limítrofes outros municípios importantes da região, como 
Congonhas, Mariana, Catas Altas e Itabirito. O acesso se dá, partindo de Belo Horizonte, pela rodovia BR-040 (Figura 47), sentido Rio de Janeiro, por aproximadamente $20 \mathrm{~km}$. Entrando em seguida no trevo que dá acesso a BR-356 (Rodovia dos Inconfidentes) chegando à zona urbana de Ouro Preto após passar por Itabirito, Amarantina e Cachoeira do Campo (nesta ordem).

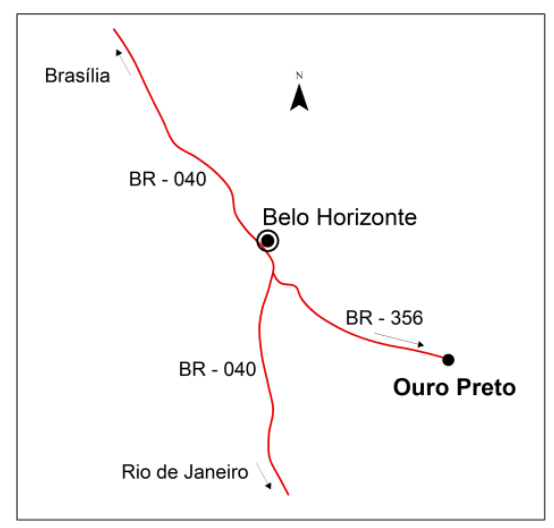

Figura 47 - Vias de acesso à cidade de Ouro Preto.

Selecionou-se, neste município, um campo de trabalho de $45 \mathrm{~km}^{2}$, englobando a zona urbana de Ouro Preto e parte da região limítrofe (o mesmo usado por Souza (1996) e Bonuccelli (1999)). As coordenadas dos vértices da área são UTM/23S: E654700/N7748000, E661000/N7748000, E661000/N7742000, E653000/N7742000,E653000/N7746400 e E654700/N7746400. A Figura 48 ilustra a localização da área escolhida em escala estadual e municipal.

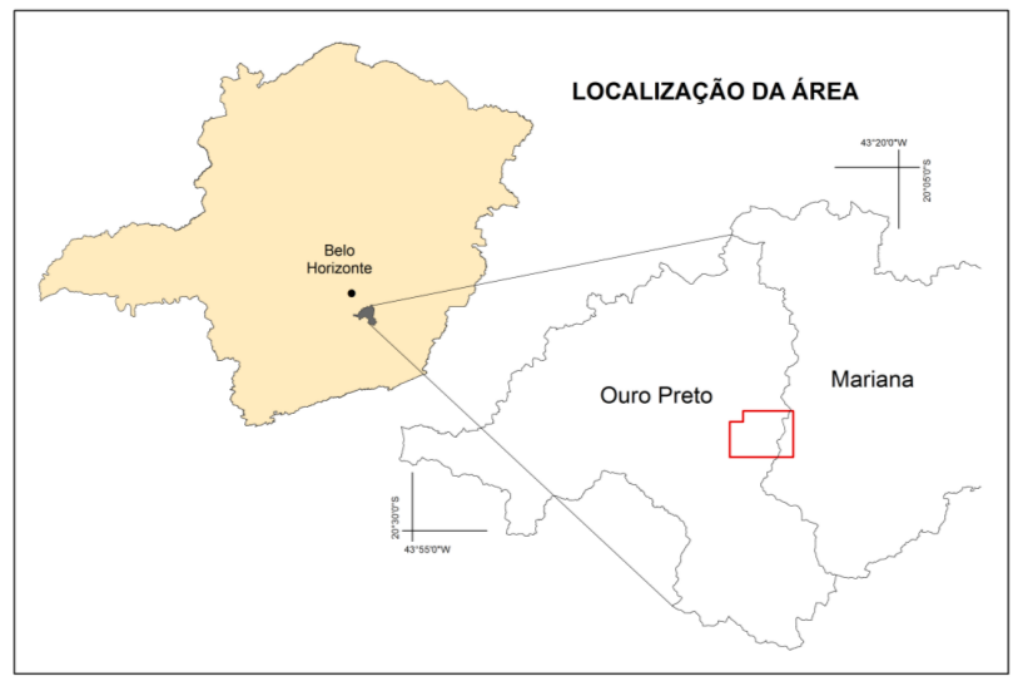

Figura 48 - Localização da área de estudo. 


\subsection{ASPECTOS GERAIS}

O clima do município de Ouro Preto é considerado tropical de altitude mesotérmico úmido com inverno seco e verão brando. Rodrigues (2002) utiliza a classificação de Kopen que indica para este tipo de clima a sigla Cwb. A temperatura em época mais quente é de $21,2^{\circ} \mathrm{C}$ (em janeiro) e a menor é de $15,5^{\circ} \mathrm{C}$ (em julho). A média anual gera em torno dos $18^{\circ} \mathrm{C}$.

O rio do Carmo ou ribeirão do Funil, como é chamado no município, é a principal drenagem da área e atravessa grande parte do centro urbano. Este rio é um dos tributários da bacia do rio Doce. O seu leito é principalmente rochoso, o que dificulta a infiltração rápida das águas pluviais, predominando o escoamento superficial e a retenção de água nas camadas superficiais (Rodrigues, 2002). A ocorrência de águas subterrâneas, quando acontece, está restrita ao sistema de fraturas (Zenóbio, 2000).

$\mathrm{O}$ alto índice pluviométrico é uma característica marcante da cidade. $\mathrm{O}$ período chuvoso se estende de outubro a março e a altitude elevada (entre 1070 a $1420 \mathrm{~m}$ ) é considerada um dos fatores responsáveis pelos máximos de precipitação (Rodrigues, 2002). Segundo IGA (1995 apud Rodrigues, 2002), existe uma relação entre a topografia elevada e os altos índices de umidade relativa, induzindo precipitações isoladas ou intensificando as chuvas já previstas.

\subsubsection{Geologia}

No que diz respeito ao contexto geológico local, Ouro Preto se insere no Quadrilátero Ferrífero, região com arcabouço litológico complexo e ocorrências minerais significantes, como por exemplo, o ouro e o minério de ferro. $O$ embasamento geológico é composto por rochas arqueanas como os mica-xistos do Grupo Nova Lima (Supergrupo Rio das Velhas). Filitos, quartzitos e xistos, itabiritos e formações ferríferas bandadas formam o substrato paleoproterozóico, onde inclui-se 
o Grupo Itabira, o Grupo Caraça, a formação Cercadinho e o Grupo Sabará. É comum a ocorrência de crosta laterítica (cangas) nos topos de morro e vertentes. Estas unidades litológicas estão descritas no Mapa Geológico de Ouro Preto e Mariana (Lobato et al., 2005).

\subsubsection{Geomorfologia}

A geomorfologia mostra dependência direta com a geologia local, caracterizando a área em altas montanhas, áreas aplainadas com altitudes diversas e vales alongados e por muitas vezes encaixados.

As atividades mineradoras antigas, da época do Ciclo do Ouro, alteraram a morfologia das escarpas com o acréscimo de materiais tecnógenos que foram abandonados de forma desordenada com o esgotamento dos veios auríferos seguido pelo fechamento das lavras.

As zonas escarpadas são comuns em toda área urbana (Gomes et al. 1998). Um exemplo é a Serra de Ouro Preto, limite norte da área urbana (Figura 49). Esta serra é um divisor de águas entre as bacias do Rio das Velhas e do Rio Doce e geologicamente representa o flanco sul do Anticlinal Mariana de direção aproximadamente leste-oeste e mergulho para sul na ordem de $30^{\circ}$.

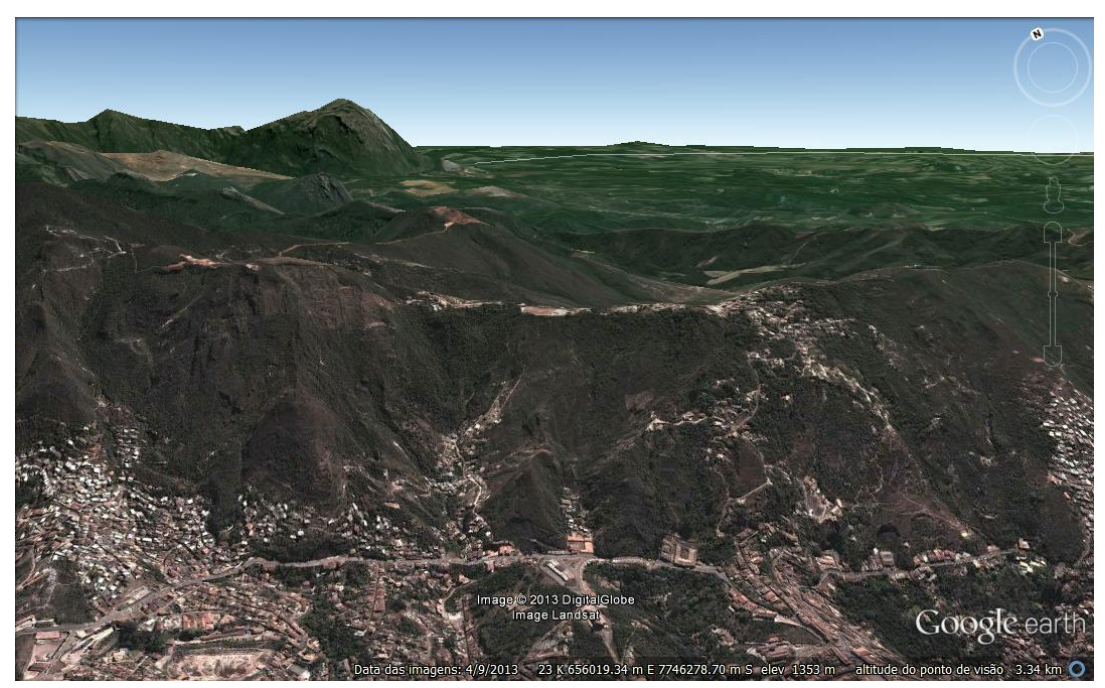

Figura 49 - Serra de Ouro Preto (visada NNE). (Google Earth, 2013). 
Fontes (2011) utiliza trabalhos de campos, fotointerpretações e um modelo digital de terreno (MDT) produzido por ele, para caracterizar cinco unidades morfológicas principais que formam o relevo da cidade de Ouro Preto:

$\rightarrow$ Relevo de serra: regiões com altitudes superiores a 1400m e encostas com declividades acentuadas (maiores que 100\%) formando cristas que se destacam na paisagem como a serra de Ouro Preto e a Serra do Itacolomi (Figura 50).

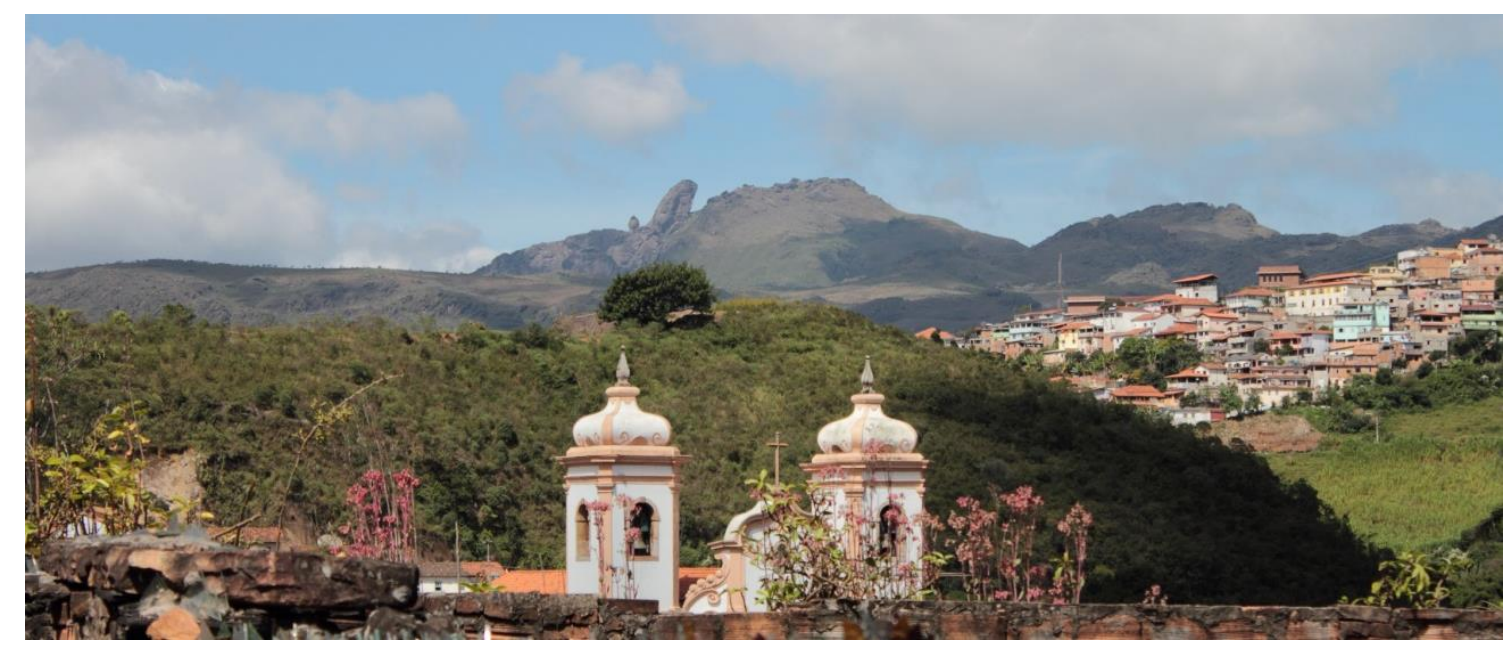

Figura 50 - Serra de Itacolomi ao fundo e ocupação urbana a direita da imagem.

> Relevo escarpado a montanhoso: regiões com altitudes entre $1400 \mathrm{e}$ $1200 \mathrm{~m}$, com desníveis dos topos para os fundos de vale entre 200 e $300 \mathrm{~m}$, caracterizada por elevações alongadas com vertentes íngremes.

$>$ Relevo ondulado: regiões com desníveis menores que os registrados no relevo escarpado com declividade entre 20 e $40 \%$ tomando valores menores em direção ao topo. Esta unidade morfológica é a mais representativa no território urbano da cidade.

$>$ Relevo suave-ondulado: conjunções de morros com vertentes mais suaves que as anteriormente citadas, refletindo as elevações típicas de um planalto dissecado. Predominam declives inferiores a $20 \%$ consequência de um desnivelamento entre o topo e os vales produzido pela erosão. 
$>$ Relevo de planalto: regiões de altitudes variadas e declividades inferiores a 10\%. Um exemplo desta unidade é o Morro do Cruzeiro que forma um platô com bordas suaves como resultado da exposição de rochas mais resistentes aos processos erosivos (chapadas de cangas).

O contexto geomorfológico da cidade é marcado por várias cicatrizes geradas por movimento de massa gravitacional. A Figura 51 e a Figura 52 mostram ocorrências de movimentação no terreno, ainda ativas. Ambas foram fotografadas em janeiro de 2015, sendo o deslizamento registrado em 2012. Desde 1975 estes movimentos são estudados (Castro, 2006) e existem relatos de movimentação a datar de 1814, quando um escorregamento matou o proprietário de uma lavra e todos os seus escravos em sua mina de ouro (Fontes, 2011). Em 1979, altos índices pluviométricos levaram a deflagração de MMG em muitas encostas da cidade afetando áreas habitadas, provocando grandes perdas materiais, obstruções de ruas e danos parciais ao patrimônio artístico e cultural da cidade. Dez anos depois, houve novamente movimentação de massa com $80 \%$ de reincidência dos casos anteriormente catalogados. Outros eventos foram registrados entre 1996 e 1997 com 13 perdas humanas e em 2006 houve 312 ocorrências, o maior número apontado até o ano de 2011 (Fontes, 2011).

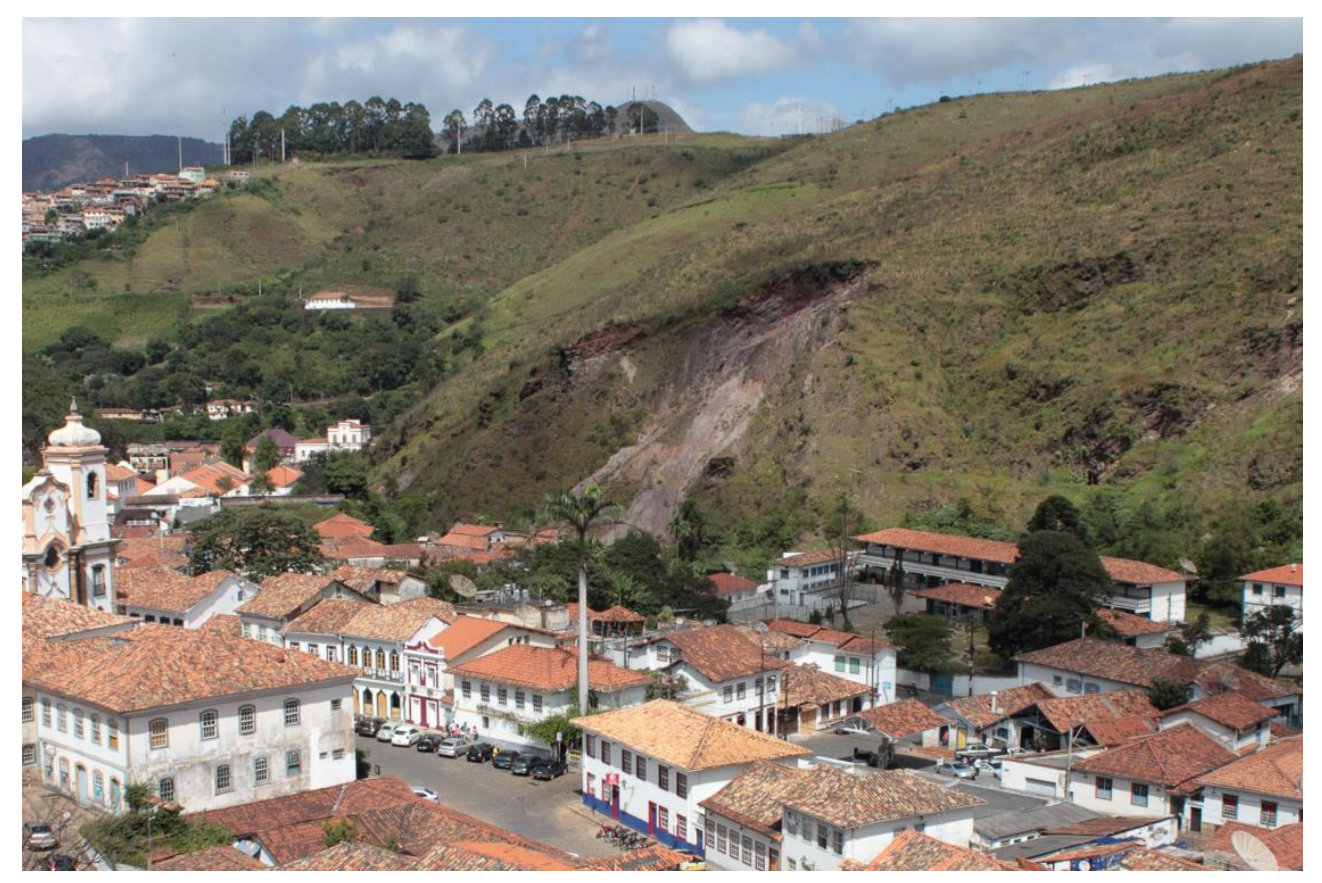

Figura 51 - Cicatrizes de movimentação de massa em encosta na cidade de Ouro Preto. 


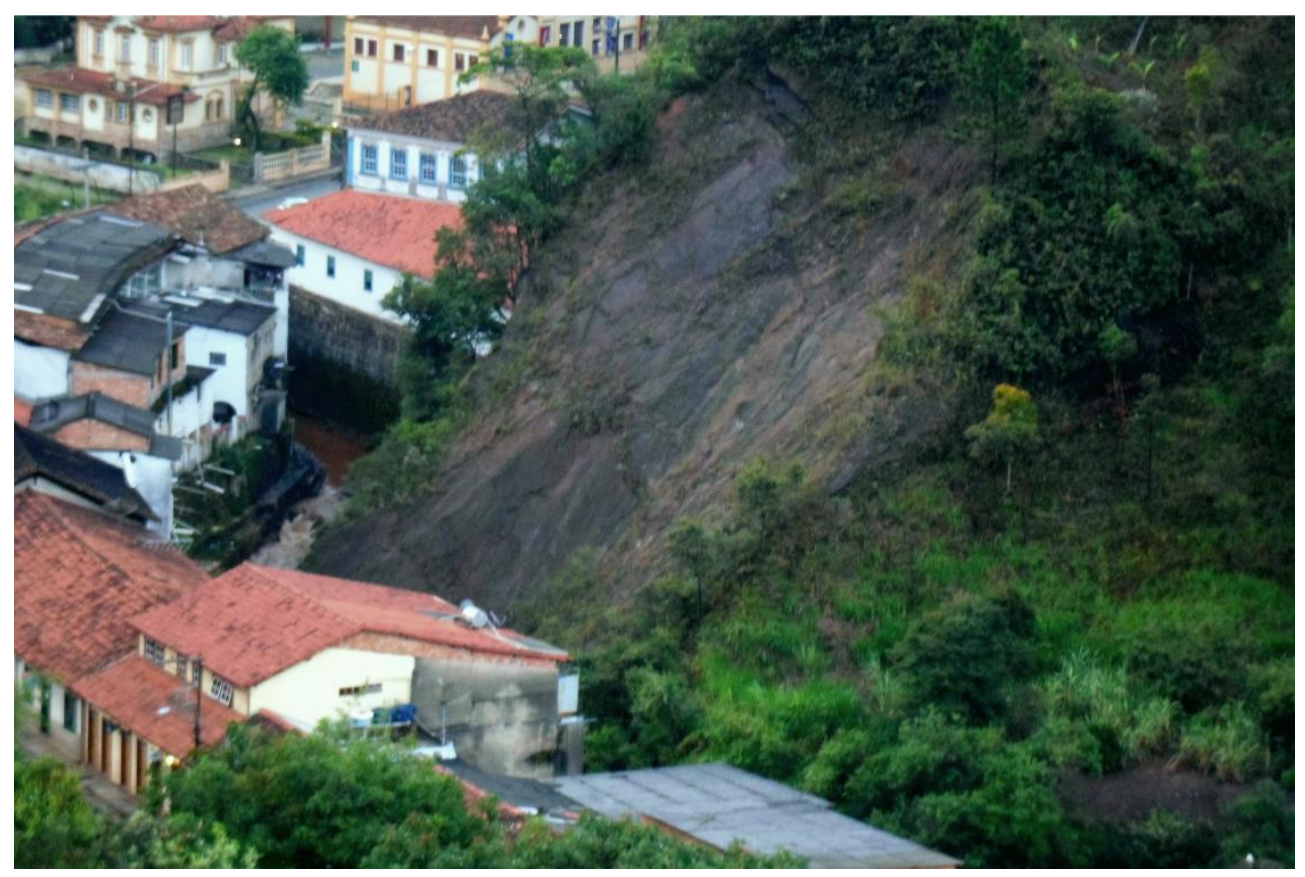

Figura 52 - Cicatriz de movimentação de massa próxima ao Morro do Cruzeiro na cidade de Ouro Preto.

\subsubsection{Uso e ocupação}

A ocupação urbana está inserida num vale limitado pelas serras de Ouro Preto e de Itacolomi, em relevo acidentado ocupando vertentes e encostas gerando cenários propícios a eventos geotécnicos críticos. Apresenta ocupação urbana com diferentes densidades, áreas habitadas por indústrias, centros acadêmicos, áreas de preservação ambiental, áreas de mineração ativa e inativa, e áreas vegetadas (Rodrigues, 2002).

A vegetação apresenta uma transição entre florestas de planalto e campos de planaltos, todavia estas áreas se encontram bastante degradadas pela ação antrópica existente desde meados no século XVIII (Bonuccelli, 1999).

A cidade se desenvolveu a partir de arraiais surgidos na época da mineração de ouro. Estes arraiais se formavam ao redor das áreas de extração de ouro que eram feitas nos vales, através do ouro aluvionar, e, posteriormente nas serras, neste caso, utilizando escavação das encostas e construção de túneis. Desta forma, os 
garimpeiros eram forçados a construir suas moradias próximas das minas a que tinham direito de explorarem, o que deu origem às ruas tortuosas e as ladeiras íngremes que caracterizam a ocupação do centro histórico da cidade de Ouro Preto.

Fontes (2011) cita que no final da década de 40, o desenvolvimento da cidade concentrava-se à volta da estação ferroviária. Nesta fase, o crescimento urbano foi reacendido a partir da recuperação do potencial mineral com a extração de alumínio em escala industrial. Este crescimento se estendeu até a década de 90 devido à implantação dos centros acadêmicos (técnico e superior) e da extração de ferro pela Companhia Vale do Rio Doce.

A expansão urbana da cidade está condicionada em terra pelas áreas de proteção ambiental, como: o Parque do Tripuí, o Parque do Itacolomi e a Área de Proteção Ambiental (APA) das Andorinhas. Outro fator que condiciona este processo é a garantia da manutenção das características arquitetônicas da cidade, visto que esta foi tombada pela UNESCO como Patrimônio Histórico e Cultural da Humanidade em 1982. Entretanto, o crescimento populacional gerado pela industrialização, potencialidade ao turismo e a expansão dos centros acadêmicos aumentou a ocupação das áreas periférica se transformou este processo em um cenário totalmente desordenado, ocupando encostas com edificações de baixos padrões construtivos (Castro, 2006).

As condições descritas acima, aliadas a outras complexidades da cidade como a ação antrópica (ocupação urbana desordenada), propiciam ao terreno grandes problemas geológico-geotécnicos, e a situação já existente se agrava em condições naturais adversas, surgindo várias situações de risco geológicogeotécnicos. 


\section{MATERIAIS E MÉTODOS}

Qualquer estudo que envolva a investigação e a caracterização dos movimentos de massa gravitacionais requer o levantamento de muitas informações que são intrínsecas à área estudada e também ao processo de movimentação. Devido à complexidade do processo de análise de todas as informações, elaborou-se um procedimento que se tornou um roteiro funcional de atividades para amparar a fase de interpretação e obtenção dos resultados. Para uma melhor visualização da organização desta dissertação, apresenta-se o fluxograma ilustrado na Figura 53.

Os procedimentos de análise vistos neste fluxograma podem ser agrupados em quatro conjuntos de atividades: os relacionados à fase inicial da pesquisa, à revisão bibliográfica, aos procedimentos de análise das informações e à aplicação nos métodos de RNA e abordagem probabilística. Este ordenamento gráfico serve como orientação e otimização das ações desenvolvidas para realização deste trabalho.

\subsection{PRIMEIRA ETAPA}

A primeira etapa da pesquisa se relaciona à definição da problemática a qual se pretende estudar, os objetivos e a justificativa da pesquisa. Inclui também o processo de busca por trabalhos anteriores realizados na região escolhida, a avaliação dos primeiros dados levantados e a definição do mapa básico que constitui um documento padrão para a elaboração dos resultados deste trabalho. 


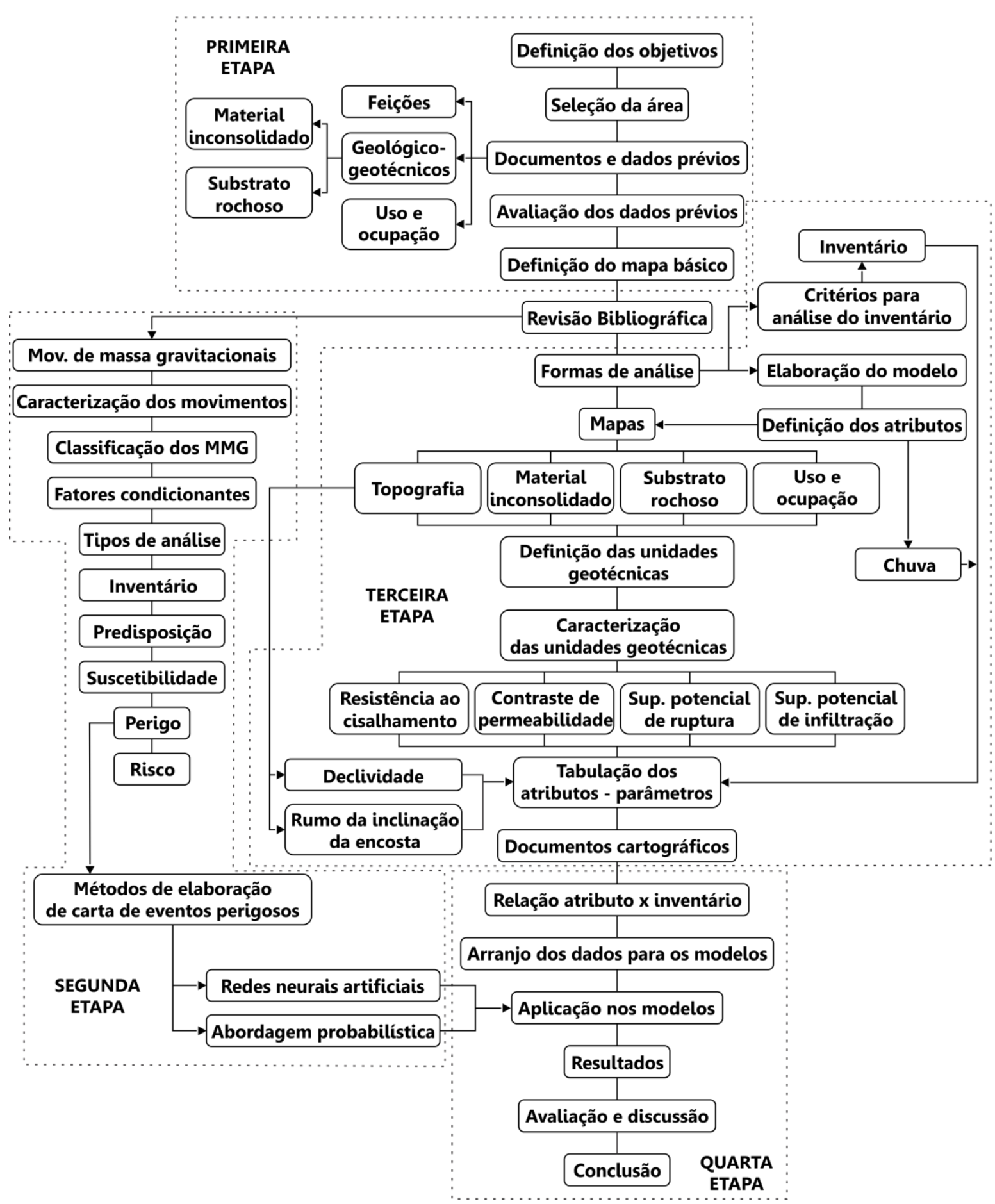

Figura 53 - Organização da dissertação. 


\subsubsection{Documentos e dados prévios}

Os trabalhos anteriores realizados na área de abrangência deste estudo forneceram subsídios para o levantamento das feições de ocorrências de MMG dos últimos anos, além de outros dados como: informações geológica-geotécnicas (substrato rochoso e material inconsolidado), e de uso e ocupação da área superficial. Estes dados foram selecionados dos trabalhos acadêmicos de:

4.1.1.1 Souza (1996)

O trabalho de Souza (1996) apresenta o mapeamento geotécnico de Ouro Preto/MG mostrando as áreas com suscetibilidade de ocorrência de movimentos de massa gravitacionais e processos correlatos. Entre os mapas e cartas apresentados por Souza (1996), foram selecionados:

i. Mapa das Feições dos Movimentos de Massa e Processos Correlatos;

ii. Mapa de Substrato Rochoso,

iii. Mapa dos Materiais Inconsolidados.

\subsubsection{Bonuccelli (1999)}

Bonuccelli (1999) estudou os movimentos de massa gravitacionais e processos correlatos na área urbana de Ouro Preto/MG, a partir do levantamento e discussão dos tipos de processos e atributos que influenciam na ocorrência dos movimentos. Entre os mapas e cartas apresentados por este trabalho foram selecionados: 
i. Mapa dos Movimentos de Massa Gravitacionais e Processos Correlatos; tipos de processos;

ii. Mapa de Substrato Rochoso;

iii. Mapa dos Materiais Inconsolidados,

iv. Mapa de Uso e Ocupação do Solo.

Dados do inventário de feições de movimentos de massa gravitacionais como: profundidade das feições, tipos de materiais e estado da atividade foram também utilizados deste trabalho.

\subsubsection{Zenóbio (2000)}

Zenóbio (2000) desenvolveu um estudo de caracterização dos maciços rochosos em encostas naturais na área urbana de Ouro Preto/MG, a partir do levantamento e da análise das descontinuidades presentes nos maciços, gerando cartas de zoneamento para cada sistema de classificação geomecânica. Deste trabalho foi selecionado para compor o banco de dados de feições, o Mapa de Feições dos Movimentos de Massa Gravitacionais e Processos Correlatos.

\subsubsection{Castro (2006)}

Castro (2006) estudou as correlações entre os movimentos de massa gravitacionais e a precipitação na cidade de Ouro Preto/MG, além de apresentar um zoneamento das áreas críticas de acordo com o número de registros de cada região. Deste trabalho foram coletados os dados relacionados às ocorrências de movimentos de massa gravitacionais levantados principalmente após 1998. Os documentos relacionados às ocorrências de movimentos de massa gravitacionais são: 
i. Mapa com Zoneamento das Áreas de Risco,

ii. Ocorrências Utilizadas para Análise de Correlação (tabela de dados).

\subsubsection{Fontes (2011)}

Fontes (2011) desenvolveu um trabalho de caracterização dos riscos geotécnicos relacionados aos movimentos de massa gravitacionais na área urbana do município de Ouro Preto/MG, a partir da investigação do solo e do mapeamento geológico-geotécnico das encostas. Deste trabalho foram selecionados para análise os documentos relacionados às ocorrências de movimentos de massa gravitacionais, são eles:

i. Mapa de Inventário de Ocorrências;

ii. Lista de Ocorrências Mapeadas,

iii. Fichas de campo.

\subsubsection{IGEO (2015)}

O Instituto Geotécnico (IGEO) promove a gestão de risco associado a processos de movimentação de massa gravitacional no município de Ouro Preto/MG a partir de uma iniciativa público-privada. Este instituto juntamente com a Coordenadoria Municipal de Defesa Civil de Ouro Preto cedeu um banco de dados de ocorrências cadastradas entre os anos de 2009 a 2013 e pareceres técnicos elaborados pela IGEO.

O banco de dados de feições, resultante deste levantamento, foi organizado em uma planilha eletrônica e as informações de cada trabalho foram avaliadas separadamente. Os documentos cartográficos geológico-geotécnicos e de uso e ocupação foram adaptados para o layout deste trabalho. 


\subsubsection{Definição do mapa básico}

O mapa básico constitui uma representação espacial de uma área de $45 \mathrm{~km}^{2}$ do município de Ouro Preto, ocupando na sua grande maioria a área urbana da cidade.

Os dados cartográficos que compõem este mapa básico, como a topografia e hidrografia, foram obtidos de Bonuccelli (1999). Conservou-se a escala 1:10.000, dos produtos cartográficos de Souza (1996) e Bonuccelli (1999), na elaboração dos mapas e das cartas. Na existência de dados em outras escalas, estes foram adaptados.

A projeção cartográfica utilizada para georeferenciamento dos dados, mapas e cartas deste trabalho corresponde ao sistema de coordenadas cartesianas: Universal Transversa de Mercator (UTM), zona 23S. O datum horizontal usado foi o Córrego Alegre. Os dados que estavam em sistema de coordenadas e datum diferentes foram reposicionados.

O arranjo dos dados de caracterização da área e, a confecção de novos

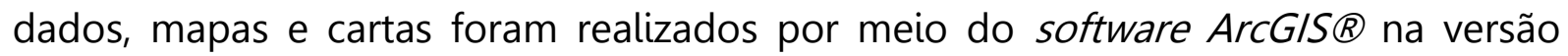

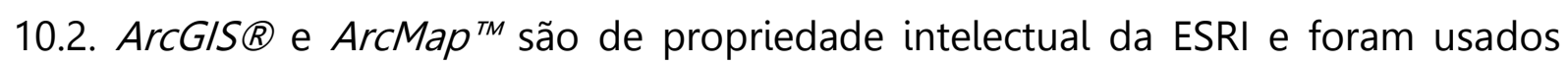
neste trabalho sob licença. Também utilizou-se o software AutoCAD Civil $\mathbb{R}$ produzido pela AutoDesk na versão 2013. Como editor de planilhas utilizou-se o software Microsoft Office Excel $\mathbb{R}$ produzido pela Microsoft na versão 12.0 de 2007. Desta mesma versão, fez-se uso do software Microsoft Office Word $\mathbb{R}$ como processador de texto.

\subsection{SEGUNDA ETAPA}

Esta etapa representa a revisão bibliográfica da pesquisa. Constituiu-se na reunião de trabalhos clássicos, acadêmicos e artigos sobre os assuntos que envolvem os temas: 
i. Movimentos de massa gravitacionais: caracterização, classificações, fatores condicionantes e tipos de análise;

ii. Métodos para elaboração de carta de eventos perigosos: redes neurais artificiais e abordagem probabilística.

Abordou-se os principais conceitos e técnicas adotados nos dois temas principais supracitados, além de uma pesquisa bibliográfica sobre os métodos de aplicação de RNA e abordagem probabilística no estudo dos movimentos de massa gravitacionais. Houve também pesquisa específica da área de estudo para o entendimento de como acontecem os movimentos de massa na região de Ouro Preto, os fatores envolvidos e as condições de ocorrência.

\subsection{TERCEIRA ETAPA}

Nesta etapa realizou-se a análise dos dados levantados, armazenamento, adequação e avaliação, visando gerar uma análise crítica quanto a viabilidade de aplicação das informações. Esta etapa pode ser dividida em algumas fases internas que culminaram na elaboração dos resultados preliminares desta pesquisa. Algumas fases que se destacam, são: a análise do inventário; elaboração do modelo e definição dos atributos; análise dos dados prévios; elaboração dos demais dados a partir dos dados prévios e tabulação dos atributos.

Os resultados oriundos desta etapa foram agrupados no apêndice desta dissertação de duas formas. O primeiro grupo são os resultados em formato de tabelas que foram nomeados por letras maiúsculas desta forma: Apêndice $A$, Apêndice $B$, Apêndice $C$ e assim por diante. $O$ segundo grupo é formado pelos mapas e cartas e foram nomeados por números romanos, assim: Apêndice I, Apêndice II, Apêndice III, etc. 


\subsubsection{Inventário}

Os trabalhos anteriores contendo dados sobre as feições foram levantados e as informações transferidas para um único documento cartográfico para o qual foi desenvolvido um sistema de identificação na forma de um código alfanumérico. Os dados existentes passaram por uma avaliação em termos da qualidade e do potencial de uso futuro da informação.

Os critérios para análise do inventário se basearam na averiguação da qualidade original das informações e, em vista disso, também foram analisados os seguintes aspectos:

i. quanto a forma que os dados foram obtidos: se existem mapas e tabelas que os apresentam;

ii. quanto ao formato de representação: se os dados são representados por pontos ou polígonos;

iii. quanto aos tipos e a sistemática de classificação;

iv. quanto às características registradas como localização, material envolvido, atividade, velocidade, volume, etc.;

v. quanto à distribuição espacial.

Considerados estes critérios, elaborou-se um mapa de inventário ligado ao banco de dados de registros de todas as informações pré e pós-análise.

Os dados válidos após a análise foram recodificados para um código alfanumérico criado especificamente por este trabalho. Este código foi desenvolvido do ponto de vista de reunir as principais informações de cada feição, assim como ter possibilidade de sofrer modificações no sentido de incrementar informações novas, conforme dados apresentados na Figura 54. O mesmo é composto de 3 informações, a saber:

i. autor de onde obteve as informações; 
ii. tipos de movimentos de massa envolvidos, que pode ser até 3, visto que acima deste número o mesmo é classificado como complexo;

iii. número da feição no banco de dados e no mapa de inventário.

$\mathrm{Na}$ condição de o movimento envolver mais de um processo, a letra do segundo tipo de movimento é simplesmente adicionada. Como não há simbologias duplicadas, o código mesmo que com uma letra a mais é facilmente decifrado. Por exemplo, o código BEC314 representa uma feição cadastrada por Bonuccelli (1999), cujo movimento de massa é do tipo escorregamento e corrida de material, e a numeração da feição é 314 .

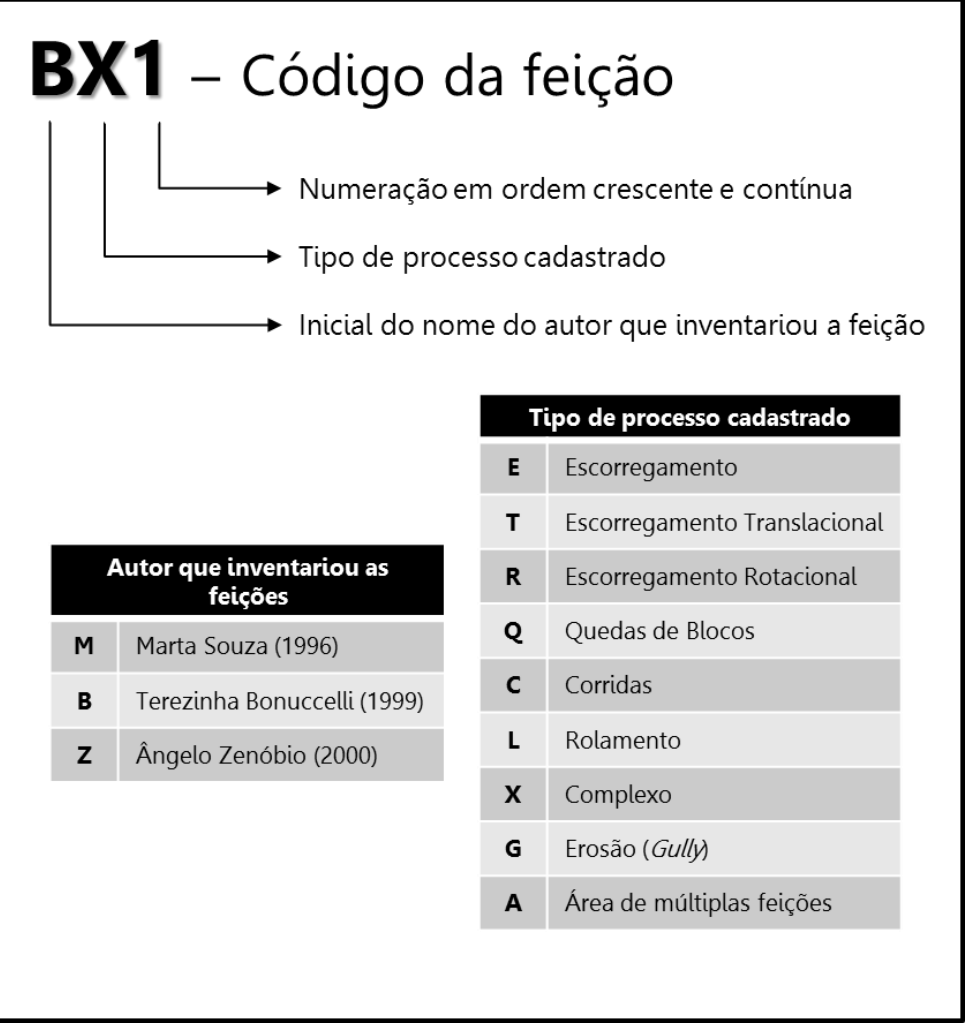

Figura 54 - Legenda utilizada para geração do código das feições. 


\subsubsection{Elaboração do modelo e definição dos atributos}

A proposta de um modelo físico e matemático teve como finalidade discriminar os fatores que interferem na estabilidade das encostas. Tendo em vista o método de aplicação, alguns fatores foram assumidos como ocorrentes impreterivelmente e outros foram dispensados.

Como cada tipo de movimento tem seu próprio modelo conceitual, físico e matemático de ocorrência, optou-se por representar neste trabalho somente o modelo do escorregamento translacional. $O$ escorregamento translacional é o tipo de movimento mais comum que ocorre na área estudada. A confirmação desta informação foi feita por meio das conclusões obtidas por Souza (1996), Bonuccelli (1999) e Dias (2002) em seus trabalhos.

A partir da definição do tipo de movimento a ser estudado e da elaboração do modelo, listou-se os atributos que devem ser verificados por ocasião dos movimentos de massa gravitacionais e que fazem parte da análise deste trabalho.

Esta fase auxiliou a análise dos dados prévios e à escolha das novas informações que deveriam ser geradas para aplicação do método proposto.

\subsubsection{Dados prévios}

Os dados prévios obtidos a partir do levantamento citado na Sessão 4.1.1. foram apresentados, são eles: os mapas de substrato rochoso, de material inconsolidado, uso e ocupação. Estes mapas foram reproduzidos sem alteração, sendo adaptados somente o layout de cada um deles.

O mapa topográfico foi elaborado a partir da topografia apresentada no trabalho de Bonuccelli (1999) a partir de curvas de nível com 10m de equidistância. 


\subsubsection{Dados gerados}

Os dados gerados foram elaborados com o auxílio dos documentos previamente levantados. As unidades geotécnicas foram definidas a partir dos mapas de substrato rochoso e material inconsolidado. Estas unidades com o apoio dos dados prévios formaram a base para interpretação das outras informações, a saber: domínios estruturais, resistência ao cisalhamento, contraste de permeabilidade, superfície potencial de ruptura e superfície potencial de infiltração. O mapa topográfico subsidiou a elaboração dos mapas de declividade e de rumo a inclinação da encosta.

\subsubsection{Tabulação dos atributos e parâmetros}

A determinação das classes a serem utilizadas para representação dos atributos constitui uma parte importante do trabalho. Realizou-se um levantamento tendo em consideração a análise da resistência, permeabilidade, estruturas geológicas e principalmente pela caracterização do perfil de alteração das unidades geológica-geotécnicas, através de trabalhos de campo e trabalhos anteriores que descrevem a região geológica e geotecnicamente. Nesta seção é apresentada a tabulação dos atributos que foram utilizados.

Para definição das classes representativas de cada atributo utilizou-se uma tabulação compilada de várias referências. Os trabalhos de Souza (1996) e Bonuccelli (1999) foram utilizados para determinar as classes dos atributos: declividade, rumo da inclinação da encosta e uso e ocupação que podem ser observadas na Tabela 19. Para os demais atributos, a definição das classes apresentou-se mais detalhada e é mostrada a seguir. 
Tabela 19 - Tabulação dos atributos e parâmetros utilizados.

\begin{tabular}{|c|c|c|}
\hline & Definição & Classes \\
\hline Declividade & $\begin{array}{l}- \\
- \\
- \\
- \\
- \\
- \\
-\end{array}$ & $\begin{array}{c}<3^{\circ} \\
3-6^{\circ} \\
6-11^{\circ} \\
11-16^{\circ} \\
16-24^{\circ} \\
24-36^{\circ} \\
>36^{\circ}\end{array}$ \\
\hline $\begin{array}{c}\text { Rumo da inclinação } \\
\text { da encosta }\end{array}$ & $\begin{array}{l}\text { Plano } \\
\text { Norte } \\
\text { Nordeste } \\
\text { Leste } \\
\text { Sudeste } \\
\text { Sul } \\
\text { Sudoeste } \\
\text { Oeste } \\
\text { Noroeste } \\
\text { Norte }\end{array}$ & $\begin{array}{c}-1^{\circ} \\
0-22,5^{\circ} \\
22,5-67,5^{\circ} \\
67,5-112,5^{\circ} \\
112,5-157,5^{\circ} \\
157,5-202,5^{\circ} \\
202,5-247,5^{\circ} \\
247,5-292,5^{\circ} \\
292,5-337,5^{\circ} \\
337,5-360,0^{\circ}\end{array}$ \\
\hline Uso e Ocupação & $\begin{array}{c}\text { Urbana com baixa densidade } \\
\text { Urbana com alta densidade } \\
\text { Urbana com média densidade } \\
\text { Mineração ativa } \\
\text { Mineração inativa } \\
\text { Preservação ambiental } \\
\text { Disposição de resíduos } \\
\text { Vegetação } \\
\text { Ocupação industrial } \\
\text { Ocupação escolar } \\
\text { Urbana alta com mineração inativa }\end{array}$ & $\begin{array}{l}- \\
- \\
- \\
- \\
- \\
- \\
- \\
- \\
- \\
-\end{array}$ \\
\hline
\end{tabular}

\section{A. Domínios Estruturais}

As estruturas geológicas de um maciço rochoso necessitam ser pesquisadas de forma a caracterizar todo o arranjo espacial do substrato. Deve-se procurar obter informações através de análise de literatura preexistente, fotointerpretação e trabalhos de campo. Qualquer estrutura geológica pode se tornar uma superfície potencial de ruptura se tratando de escorregamento translacional, desde que se caracterize de acordo com as orientações apresentadas no modelo conceitual e matemático do movimento.

Assim sendo, o levantamento deve descrever todas as estruturas tectônicas como: dobras, zonas de cisalhamento, foliações e lineações, diaclases; ou atectônicas, como: juntas de alívio e junta-falha, que ocorrerem na área de estudo. 
O indicado para a caracterização das descontinuidades é a obtenção da maior quantidade possível de dados quanto as suas propriedades, tais como: orientação espacial (direção e mergulho), espaçamento, persistência, preenchimento, abertura, rugosidade e conectividade das descontinuidades. Este levantamento pode seguir os procedimentos sugeridos por Ulusay e Hudson, 2007.

Sugere-se que as classes do atributo domínios estruturais sejam definidas através de um mapeamento das estruturas geológicas, dividindo a região em setores que representam as variações do estilo estrutural da região, como azimute e mergulho das descontinuidades.

\section{B. Resistência ao Cisalhamento}

Geralmente são necessários parâmetros de resistência ao cisalhamento: coesão e atrito, para classificar o material. Entretanto, existem formas indiretas de classificações mundialmente usadas: a classificação Brow (1983) e a URCS (Unified Classification Rock System) de Willianson \& Kuhn (1988). Estas avaliam a resistência em campo sem a necessidade de análises laboratoriais. Outro fator que influencia diretamente a resistência do material e, consequentemente na ocorrência de movimentos de massa, é o grau de alteração da rocha que também pode ser extraído pelas classificações supracitadas.

A resistência ao cisalhamento dos materiais foi definida a partir da escala apresentada por Matula (1981) para classificação das rochas em função da resistência à compressão simples (ou uniaxial) do material. Esta foi associada às classes de resistência apresentadas por Ulusay e Hudson (2007) e também à escala de graus de alteração do mesmo estudo. Os valores, correlações e características principais das classes podem ser vistas na Tabela 20. 
Tabela 20 - Classificação para as classes de resistência.

\begin{tabular}{|c|c|c|c|c|}
\hline $\begin{array}{l}\text { Classificação } \\
\text { (IAEG) }\end{array}$ & $\begin{array}{c}\text { Identificação em } \\
\text { campo }\end{array}$ & $\begin{array}{c}\text { Resistência à } \\
\text { compressão } \\
\text { uniaxial } \\
\text { (Matula, 1981) }\end{array}$ & $\begin{array}{c}\text { Classe de } \\
\text { resistência } \\
\text { (Ulusay e } \\
\text { Hudson, } \\
\text { 2007) } \\
\end{array}$ & $\begin{array}{c}\text { Grau de } \\
\text { alteração } \\
\text { (Ulusay e } \\
\text { Hudson, } \\
\text { 2007) } \\
\end{array}$ \\
\hline Rocha Branda & $\begin{array}{l}\text { Pode ser raspada por } \\
\text { canivete com } \\
\text { dificuldade. Pode ser } \\
\text { marcada por firme } \\
\text { pancada com a ponta } \\
\text { do martelo. }\end{array}$ & $1,5-15,0 \mathrm{MPa}$ & $\mathrm{R} 1$ e $\mathrm{R} 2$ & A5/A4 \\
\hline $\begin{array}{c}\text { Rocha } \\
\text { Moderadamente } \\
\text { Dura }\end{array}$ & $\begin{array}{l}\text { Não pode ser raspada } \\
\text { por canivete. Podem } \\
\text { ser fraturadas com um } \\
\text { único golpe do } \\
\text { martelo de geólogo. }\end{array}$ & $15,0-50,0 \mathrm{MPa}$ & R3 & A4/A3 \\
\hline Rocha Dura & $\begin{array}{c}\text { Amostras requerem } \\
\text { mais de um golpe de } \\
\text { martelo para fraturar- } \\
\text { se. }\end{array}$ & $50,0-120 \mathrm{MPa}$ & R4 & A3/A2 \\
\hline $\begin{array}{l}\text { Rocha Muito } \\
\text { Dura }\end{array}$ & $\begin{array}{l}\text { Amostras requerem } \\
\text { muitos golpes de } \\
\text { martelo de geólogo } \\
\text { para fraturar-se. } \\
\text { Amostras podem ser } \\
\text { somente lascadas } \\
\text { pelo martelo. }\end{array}$ & $120-230 \mathrm{MPa}$ & R5 & $\mathrm{A} 2 / \mathrm{A} 1$ \\
\hline
\end{tabular}

A classificação de rocha branda abrange também a classe R1 (rocha muito branda) apresentada por Ulusay e Hudson (2007). A rocha muito branda pode ser facilmente marcada pela unha, esmigalha quando sofre impacto da ponta do martelo de geólogo e raspada pelo canivete.

Os valores de compressão uniaxial para as classes de resistência apresentadas pela Ulusay e Hudson (2007) são semelhantes aos valores do Matula (1981), salvo uma leve diferença dos limites superior e inferior de cada classe, e também à união das classes R1 e R2.

O estudo de Matula (1981) ainda apresenta uma outra classe denominada extremamente dura (classe R6 para o Ulusay e Hudson, 2007), entretanto, esta não foi utilizada neste trabalho.

A descrição dos graus de alteração para apresentada por Ulusay e Hudson (2007) pode ser vista na Tabela 21. 
Tabela 21 - Classificação dos graus de alteração (Ulusay e Hudson, 2007).

\begin{tabular}{ccc}
\hline Classe & Grau de alteração & Descrição da alteração \\
\hline \hline A5 & $\begin{array}{c}\text { Completamente } \\
\text { alterada } \\
\text { Intensamente } \\
\text { alterada }\end{array}$ & $\begin{array}{r}\text { Todo o material rochoso está decomposto para solo. As estruturas } \\
\text { e texturas estão em grande parte preservadas. }\end{array}$ \\
A4 & $\begin{array}{r}\text { Mais da metade do material rochoso está decomposto pera solo. } \\
\text { Fragmentos de rocha fresca ou descolorida podem estar } \\
\text { presentes, como uma estrutura descontínua. }\end{array}$ \\
A3 & $\begin{array}{c}\text { Moderadamente } \\
\text { alterada }\end{array}$ & $\begin{array}{r}\text { Pouco menos da metade do material rochoso está decomposto } \\
\text { para solo. Fragmentos de rocha fresca ou descolorida podem estar } \\
\text { presentes, como estrutura contínua. }\end{array}$ \\
A2 & Levemente alterada & $\begin{array}{r}\text { intemperismo penetrado através de muitas descontinuidades e } \\
\text { somente um leve intemperismo no material rochoso. } \\
\text { Não são visíveis sinais de alteração no material rochoso, } \\
\text { intemperismo limitado nas superfícies das maiores } \\
\text { descontinuidades. }\end{array}$ \\
\hline
\end{tabular}

Neste caso, como a finalidade é a reprodução em mapa desta propriedade, o conjunto de unidades geológico-geotécnicas que apresentar semelhança quanto ao resultado do perfil podem ser unificadas, analogamente à setorização sugerida para representar o atributo domínios estruturais.

Para captação destes dados, realizou-se uma busca em trabalhos já existentes que classificaram as rochas e os solos da região. Quando não existem estas informações ou não estarem completas, pode haver a necessidade de trabalhos de campo para coletas de amostras (caso seja prevista a análise laboratorial) ou para descrição tátil visual do substrato rochoso e do material inconsolidado.

\section{Contraste de Permeabilidade}

A permeabilidade de um material é o que indica maior ou menor dificuldade com que a água percola pelos seus poros. Nos materiais granulares não coesivos como as areias, por exemplo, a alta porosidade facilita o fluxo de água através do solo, enquanto que nos materiais finos e coesivos, como as argilas, ocorre o inverso, o que torna este tipo pouco permeável.

Os dados sobre contraste de permeabilidade para a área de estudo foram construídos a começar pela elaboração de croquis que representam o perfil de alteração solo/rocha nos diversos contextos existentes na região. Este levantamento 
foi concebido a partir dos dados de material inconsolidado e de substrato rochoso elaborados por Souza (1996) e Bonuccelli (1999). Posteriormente, fez-se uma avaliação quanto ao material que apresentava menor permeabilidade ou maior, segundo o intervalo apresentado na Tabela 22.

\begin{tabular}{cc}
\hline Tabela 22 - Intervalos de permeabilidade dos materiais existentes na área de est \\
\hline Materiais & Permeabilidade \\
\hline Aluvião/ Colúvio/ Materiais tecnógenos & $<10^{-2} \mathrm{~m} / \mathrm{s}$ \\
Solo residual/ Saprólito de quartzito & $10^{-2}$ a $10^{-4} \mathrm{~m} / \mathrm{s}$ \\
Saprólito & $10^{-4}$ a $10^{-7} \mathrm{~m} / \mathrm{s}$ \\
Rocha & $>10^{-7} \mathrm{~m} / \mathrm{s}$ \\
\hline
\end{tabular}

Assim, elabora-se uma carta que apresente todos os conjuntos de unidades geológico-geotécnicas que se comportam de forma análogas quanto ao perfil apresentado para caracterizar a permeabilidade dos materiais.

\section{Superfície Potencial de Infiltração}

A água é o principal agente deflagrador do movimento de massa. O modo mais comum com que a ela chega à superfície é pela chuva, mas existem outros meios como lançamento de água servida ou o rompimento de uma tubulação, por exemplo. A chuva quando chega à superfície do solo pode infiltrar, escoar superficialmente e uma parcela desta água evapora. Ela pode se acumular no solo ou na rocha de duas formas: por saturação pelo topo ou saturação pela base (quando a água infiltrada em outro lugar, topograficamente mais alto, chega até uma região de menor altitude e aumenta o nível freático daquele local). A variação da saturação do meio pode reduzir a resistência ao cisalhamento, aumentar o peso do maciço e reduzir as condições de sucção.

Uma carta de superfície potencial de infiltração pode ser elaborada a partir das unidades geológico-geotécnicas distinguindo, por exemplo, a profundidade de 
um possível difrator hídrico gerando uma acumulação de água na camada mais permeável e provocando um aumento na pressão neutra deixando o solo instável.

\section{E. Superfície Potencial de Ruptura}

A superfície de ruptura pode ser representada por meio de um valor estimado para sua profundidade, que pode ser exposta através de intervalos, como por exemplo, até $2 \mathrm{~m}$, de 2 a $10 \mathrm{~m}$, e acima de $10 \mathrm{~m}$. Vale ressaltar que esta medida é apenas uma aproximação do valor, devido a dificuldade de se definir com precisão qual plano de ruptura está mais susceptível.

Neste trabalho, optou-se por apresentar possibilidades de superfície potencial de ruptura de todo o conjunto de materiais inconsolidados e substratos rochosos que formam as unidades geológico-geotécnicas. Pretendeu-se considerar como uma superfície potencial de ruptura o contato entre diferentes materiais como solo/rocha ou aterro/solo e os planos de descontinuidades que caracterizam alguns grupo de rochas, levando também em consideração à possibilidade de ocorrência destas superfícies em qualquer profundidade principalmente em solos com maior espessura.

\section{F. Chuva}

A chuva pode ser considerada um fator deflagrador do movimento de massa gravitacional, pois a quantidade de água precipitada e a sua distribuição na região possui relação direta com a instabilização das encostas, devido às mudanças nos parâmetros de resistência dos materiais e ao avanço da saturação provocando aumento nas pressões neutras.

Os movimentos de massa gravitacionais podem estar associados às chuvas acumuladas de vários dias ou de chuvas intensas de curta duração. Os dados de precipitação utilizados para analisar este fator devem ser levantados de estações pluviométricas locadas na região de estudo a partir da medição da altura da coluna de água precipitada. 
A representação deste atributo pode ser realizada através de medidas de intensidade pluviométrica, por exemplo, da chuva imediata de 3 dias ou acumulada de 15 dias, da precipitação média anual ou a precipitação média em períodos chuvosos. A escolha de qual representação utilizar dependerá do objetivo da carta de eventos perigosos. $\mathrm{Se}$, a título de exemplo, pretende-se estudar a probabilidade de ocorrência de movimentos de massa gravitacionais em um período chuvoso, deve-se utilizar dados pluviométricos que representem este período.

\subsection{QUARTA ETAPA}

Esta etapa constitui a preparação, análise e apresentação dos resultados da avaliação crítica quanto ao emprego dos dados elaborados nos métodos probabilísticos e redes neurais artificiais para elaboração de uma carta de eventos perigosos. Para cada uma das aplicações elaborou-se um roteiro que propõe um arranjo e também uma forma de uso dos dados nos modelos em análise.

Este roteiro foi elaborado visando desenvolver um passo a passo da aplicação a partir dos princípios básicos dos métodos probabilísticos e redes neurais artificiais. Para ambos, é necessário que as informações amostrais sejam representativas de todo o conjunto e que a aplicação de cada método esteja adequada para gerar resultados de boa qualidade.

\subsubsection{Aplicação em Redes Neurais Artificiais}

Para aplicação em RNA um tipo de rede é escolhido, neste trabalho a rede Perceptron de múltiplas camadas. Posteriormente, um conjunto de arquiteturas é sugerido para ser analisado. Antes da aplicação da rede em toda a área, esta é treinada e validada, se preciso por várias vezes para certificação. Este processo irá depender da escolha dos dados de entrada, pesos e funções utilizados na elaboração 
da rede. Um resultado insatisfatório pode ocorrer devido à escolha errada do tipo de rede e, como a escolha da arquitetura e das funções é subjetiva, talvez seja necessário a modificação destes parâmetros para se obter um resultado satisfatório.

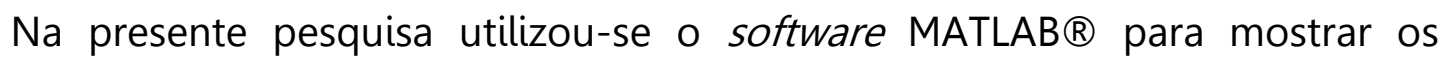
estágios da aplicação do método. Este é um software interativo voltado para o cálculo numérico que possui entre outras extensões de trabalho, a extensão Neural Network Toolbox. Esta extensão é destinada a fornecer funções e aplicativos para a modelagem de sistemas complexos não-lineares, com o objetivo de criar, formar, visualizar e simular redes neurais artificiais.

\subsubsection{Aplicação em Probabilidade}

Para aplicação em probabilidade foi utilizada a abordagem frequentista que avalia a possibilidade do evento ocorrência de movimento de massa gravitacional (Evento O) como a frequência relativa dos atributos independentes, ou seja, a relação entre as feições e os atributos mapeados como fatores predisponentes.

Os fatores que propiciam o movimento são os mesmos que levaram à instabilização das encostas no passado e que podem instabilizar também no futuro. Por isso, os estudos de movimentação de massa são apoiados na interpretação do que aconteceu no passado, assim como para a probabilidade relativa.

A probabilidade condicional foi utilizada para montar esta aplicação a partir da teoria de probabilidade total. Para definição da probabilidade dos eventos com os quais o Evento $\mathrm{O}$ é dependente, foi utilizada a área correspondente a cada atributo $\mathrm{e}$ também a área das feições de movimentos de massa gravitacionais.

Estas probabilidades foram calculados usando o software $\operatorname{ArcMap}^{T M} \mathrm{e}$

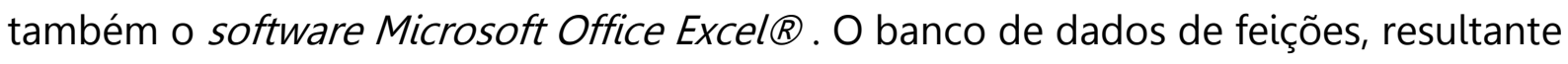
deste levantamento, foi organizado em uma planilha eletrônica. 



\section{APRESENTAÇÃO DOS DADOS OBTIDOS}

Neste capítulo são exibidos os dados necessários para a aplicação da metodologia anteriormente comentada. As seções que compõem este capítulo foram divididas em dados prévios e dados gerados.

\subsection{DADOS PRÉVIOS}

Os dados prévios são aqueles obtidos a partir de trabalhos anteriores. Eles formam um conjunto de mapas básicos fundamentais para a aplicação e também para obtenção dos dados gerados. Fazem parte deste grupo os mapas: topográfico, de substrato rochoso, de material inconsolidado e de uso e ocupação.

\subsubsection{Mapa topográfico}

A base de dados cartográficos através da qual elaborou-se o mapa topográfico deste estudo pertence ao trabalho de Bonuccelli (1999). A autora digitalizou as curvas de nível com 10m de equidistância em escala 1:10000. A delimitação das estradas principais e a drenagem também foram selecionadas a partir do trabalho de Bonuccelli (1999).

Do mapa geológico de Ouro Preto em escala 1:50000 (Lobato et al., 2005) obteve-se a mancha urbana. Esta se configurou a base mais recente obtida da delimitação do limite urbano, por este motivo e também por se tratar de um dado somente de cunho informativo, não foi considerada obrigatória a semelhança entre as escalas para sobreposição dos dados. 
O mapa topográfico representa adequadamente as variações no relevo na região de Ouro Preto mapeada. Ele encontra-se adequado para a escala deste trabalho, sendo empregado no mapa de inventário e também sendo a base da elaboração do mapa de declividade e rumo da inclinação da encosta.

O mapa topográfico pode ser visualizado no Apêndice I.

\subsubsection{Mapa de Substrato Rochoso}

Para representar o mapa de substrato rochoso avaliou-se os mapas de Souza (1996) e Bonuccelli (1999). Optou-se por apresentar o mapa de Bonuccelli (1999) por este ter melhor detalhamento quanto a descrição das unidades litológicas.

A elaboração do mapa foi realizada a partir de dados obtidos por meio de trabalhos de campo, fotointerpretação e, avaliação e uso de informações já existentes. A autora se baseou principalmente no mapa de substrato rochoso elaborado por Souza (1996), com alterações e subdivisões adicionais. Estas modificações foram feitas a partir da coleta de um maior número de informações de campo e fotointerpretação, fundamentadas na análise das litologias, grau de alteração da rocha e sua resistência.

Souza (1996) observa que mesmo que as litologias da região de Ouro Preto estejam geneticamente associadas, elas possuem comportamentos diferentes em um mesmo perfil apresentando os mais variados graus de alteração.

Para formar as 21 unidades descritas, primeiramente, as rochas foram separadas quanto a sua resistência em dois grupos: rochas brandas e rochas duras, utilizando as sugestões de Franklin e Dusseault (1989 apud Bonuccelli, 1999). Depois, separou-se por grau de alteração: rocha sã ou fracamente alterada, rocha levemente alterada, moderadamente alterada, e intensamente alterada, de acordo com a proposta da Brow (1983).

A Tabela 23 resume as descrições das unidades litológicas e suas principais características. Para mais informações sugere-se a leitura do trabalho de Bonuccelli (1999). 


\section{O Mapa de Substrato Rochoso encontra-se no Apêndice II.}

Tabela 23 - Características principais das unidades do substrato rochoso.

\begin{tabular}{|c|c|c|}
\hline Código & Litologia & Grau de alteração \\
\hline r1 & Xistos sericíticos e quartzosos brandos & Intensamente alterados \\
\hline r2 & Xistos sericíticos e quartzitos duros & $\begin{array}{l}\text { Levemente a moderadamente } \\
\text { alterados }\end{array}$ \\
\hline r3 & Filitos e xistos brandos associados a duros & Intensamente alterados \\
\hline r3D & Xistos duros & $\begin{array}{l}\text { Levemente a moderadamente } \\
\text { alterados }\end{array}$ \\
\hline r4 & Quartzitos e quartzitos sericíticos duros & $\begin{array}{l}\text { Levemente a moderadamente } \\
\text { alterados }\end{array}$ \\
\hline r5 & $\begin{array}{l}\text { Quartzitos e quartzo-sericita-xistos, brandos e duros } \\
\text { intercalados }\end{array}$ & $\begin{array}{l}\text { Levemente a moderadamente } \\
\text { alterados ou intensamente } \\
\text { alterados quando friáveis } \\
\end{array}$ \\
\hline r6 & $\begin{array}{l}\text { Quartzitos silicosos duros, quartzitos micáceos brandos, } \\
\text { xistos sericíticos brandos, ora intercalados ora associados }\end{array}$ & Intensamente alterados \\
\hline r7 & $\begin{array}{c}\text { Itabiritos intensamente aterados com canga e materiais } \\
\text { lateríticos }\end{array}$ & Intensamente alterados \\
\hline r8 & $\begin{array}{l}\text { Itabiritos e itabiritos dolomíticos duros e brandos } \\
\text { intercalados; presença de canga e materiais lateríticos } \\
\text { associados }\end{array}$ & Moderadamente alterados \\
\hline r9 & $\begin{array}{l}\text { Dolomitos e itabiritos dolomíticos duros ora intercalados e } \\
\text { ora associados com filitos e itabiritos dolomíticos brandos }\end{array}$ & $\begin{array}{l}\text { Levemente a moderadamente } \\
\text { alterados }\end{array}$ \\
\hline $\mathbf{r 1 0}$ & $\begin{array}{l}\text { Filitos brandos intercalados a quartzitos brandos; presença } \\
\text { em associação de quartzitos duros intercalados com filitos } \\
\text { sericíticos brandos. }\end{array}$ & Intensamente alterados \\
\hline $\mathbf{r 1 1}$ & Quartzitos e filitos duros & $\begin{array}{l}\text { Levemente a moderadamente } \\
\text { alterados }\end{array}$ \\
\hline $\mathbf{r 1 2}$ & $\begin{array}{l}\text { Quartzitos friáveis e filitos grafitosos brandos intercalados; } \\
\text { quartzitos brandos e duros intercalados com filitos } \\
\text { sericíticos brandos. Níveis ferruginosos e manganesíferos. }\end{array}$ & Intensamente alterados \\
\hline r13 & Quartzitos e filitos ferruginosos, brandos, intercalados & $\begin{array}{c}\text { Intensamente completamente a } \\
\text { alterados }\end{array}$ \\
\hline r14 & Filitos e xistos brandos, intercalados com filitos grafitosos & $\begin{array}{c}\text { Intensamente completamente a } \\
\text { alterados } \\
\end{array}$ \\
\hline $\mathbf{r 1 5}$ & Filitos e xistos brandos associados a filitos e xistos duros & Intensamente alterados \\
\hline $\mathbf{r 1 6}$ & $\begin{array}{c}\text { Filitos, xistos e quartzitos brandos, ferruginosos e } \\
\text { manganesíferos }\end{array}$ & Intensamente alterados \\
\hline r17 & Filitos grafitosos/sericíticos e quartzitos brandos & $\begin{array}{l}\text { Intensamente completamente a } \\
\text { alterados }\end{array}$ \\
\hline $\mathbf{r 1 8}$ & Filitos e xistos duros & $\begin{array}{l}\text { Levemente a moderadamente } \\
\text { alterados }\end{array}$ \\
\hline r19 & Quartzitos brandos & $\begin{array}{l}\text { Levemente a moderadamente } \\
\text { alterados }\end{array}$ \\
\hline r20 & Quartzitos brandos, friáveis & $\begin{array}{c}\text { Intensamente completamente a } \\
\text { alterados }\end{array}$ \\
\hline
\end{tabular}

Fonte - Adaptada de Bonuccelli (1999). 


\subsubsection{Mapa de Material Inconsolidado}

Optou-se pela utilização do mapa de material inconsolidado elaborado por Bonuccelli (1999), por este apresentar as mesmas características do mapa de substrato rochoso contido no trabalho, como: detalhamento na elaboração e descrição dos materiais levantados pelo mapeamento.

O mapa de material inconsolidado de Bonuccelli (1999) foi elaborado com dados obtidos por meio de trabalhos de campo, fotointerpretação e, referência bibliográfica de trabalhos já executados na região. A autora, assim como o mapa de substrato rochoso, se baseou principalmente no trabalho de Souza (1996), com alterações e subdivisões adicionais. Em consequência da grande diversidade litológica e a influência antrópica, os materiais foram analisados quanto a sua gênese, espessura das camadas, textura e perfil de alteração, para representar com clareza a heterogeneidade dos materiais.

Para este mapa, foram adotados os graus de alteração: completamente alterada e solo residual. Além destes, também foram incluídos na descrição: colúvio, aluvião, aterros não compactados, depósitos de rejeitos e resíduos.

Assim, o mapa de material inconsolidado apresenta 19 unidades levando em conta 3 classes relacionadas às espessuras do material: até $2 \mathrm{~m}$, entre 2 e $10 \mathrm{~m}$ e, acima de $10 \mathrm{~m}$.

A Tabela 24 resume as descrições das unidades de material inconsolidado e suas principais características. Para mais informações sugere-se a leitura do trabalho de Bonuccelli (1999).

O Mapa de Material Inconsolidado encontra-se no Apêndice III. 
Tabela 24 - Características principais das unidades do material inconsolidado.

\begin{tabular}{|c|c|c|}
\hline Código & Material inconsolidado & $\begin{array}{c}\text { Espessura do perfil de } \\
\text { solo }\end{array}$ \\
\hline i1 & Ausência de material inconsolidado & - \\
\hline i2 & Colúvio sobre rocha branda ou dura & $<2 m$ \\
\hline i2A & Colúvio sobre rocha branda & $<0,5 \mathrm{~m}$ \\
\hline i2B & Colúvio associado a blocos de rocha e canga & $<2 \mathrm{~m}$ \\
\hline i3 & Aterros não compactados e resíduos & $\begin{array}{l}\text { Entre } 2 \text { e } 10 \mathrm{~m}, \text { podendo } \\
\text { maiores que } 10 \mathrm{~m}\end{array}$ \\
\hline i4 & Aluvião & $<2 m$ \\
\hline i5 & $\begin{array}{c}\text { Colúvio, residuais de xistos/filitos, saprólitos } \\
\text { xistos/filitos }\end{array}$ & 2 a $10 m$ \\
\hline i6 & $\begin{array}{l}\text { Colúvio, residuais de xistos/filitos, saprólitos } \\
\text { xistos/filitos, presença de material laterítico }\end{array}$ & 2 a $10 m$ \\
\hline i7 & Colúvios e saprólitos xistos/filitos & 2 a $10 m$ \\
\hline i8 & Colúvios e saprólitos xistos/filitos & $<2 m$ \\
\hline i8B & Colúvios e saprólitos associados, blocos de rocha & $<2 m$ \\
\hline i9 & Residuais filitos/quartzitos, saprólitos filitos/quartzitos & 2 a $10 m$ \\
\hline i10 & Colúvios e saprólitos filitos/quartzitos & 2 a $10 m$ \\
\hline i11 & Colúvios, saprólitos quartzitos & 2 a $10 m$ \\
\hline i12 & Canga e material laterítico & 2 a $10 m$ \\
\hline i12A & Concreções e material laterítico poroso & 2 a $10 m$ \\
\hline i13 & $\begin{array}{l}\text { Endurecido, saprólito de quartzitos/xistos ferruginosos } \\
\text { friáveis }\end{array}$ & 2 a $10 m$ \\
\hline i14 & $\begin{array}{l}\text { Residuais e saprólito de quartzitos/xistos/filitos } \\
\text { ferruginosos friáveis }\end{array}$ & 2 a $10 m$ \\
\hline i15 & $\begin{array}{l}\text { Colúvios,residuais filitos/xistos, saprólito de } \\
\text { filito/xistos, material laterítico }\end{array}$ & $>10 \mathrm{~m}$ \\
\hline
\end{tabular}

Fonte - Adaptada de Bonuccelli (1999).

\subsubsection{Mapa de Uso de Ocupação}

O mapa de uso e ocupação foi reproduzido do trabalho de Bonuccelli (1999). Utilizou-se interpretação de fotos aéreas e ortofotos, trabalhos de campo e dados censitários do IBGE para sua elaboração. Para determinação das áreas vegetadas, quanto ao seu tipo, foi utilizado pela autora o trabalho de Silva \& Gontijo (1999 apud 
Bonuccelli, 1999). Este mapa, também produzido em escala 1:10000, recobre toda a área deste estudo com 11 unidades de uso e ocupação.

O mapa não foi atualizado, assumindo que as recentes mudanças ocorridas não são tão significativas e que as informações necessárias para influenciar o resultado deste estudo não foram ainda mapeadas. Tais modificações podem ser: inclusão de áreas de corte e aterro de estradas e encostas, estilo de ocupação em relação ao usufruto da área ocupada, disposição das fossas e destinação da água servida, por exemplo.

A Tabela 25 apresenta as unidades de uso e ocupação. Para as unidades cuja descrição é urbana, foram consideradas áreas de alta densidade aquelas que possuem 1 domicílio para áreas abaixo de $500 \mathrm{~m}^{2}$; urbana de média densidade possuem 1 domicílio para áreas entre 500 e 1500m²; e urbana de baixa densidade foram classificadas como 1 domicílio para áreas acima de $1500 \mathrm{~m}^{2}$.

Para mais informações sugere-se a leitura do trabalho de Bonuccelli (1999). O Mapa de Uso e Ocupação encontra-se no Apêndice IV.

Tabela 25 - Unidade de uso e ocupação.

\begin{tabular}{cc}
\hline Código & Litologia \\
\hline $\mathbf{u 1}$ & Urbana com baixa densidade \\
\hline $\mathbf{u 2}$ & Urbana com alta densidade \\
\hline $\mathbf{u 3}$ & Urbana com média densidade \\
\hline $\mathbf{u 4}$ & Mineração ativa \\
\hline $\mathbf{u 5}$ & Mineração inativa \\
\hline $\mathbf{u 6}$ & Preservação ambiental \\
\hline $\mathbf{u 7}$ & Disposição de resíduos \\
\hline $\mathbf{u 8}$ & Vegetação \\
\hline $\mathbf{u 9}$ & Ocupação industrial \\
\hline $\mathbf{u 1 0}$ & Ocupação escolar \\
\hline $\mathbf{u 1 1}$ & Urbana alta com mineração \\
\hline inativa
\end{tabular}

Fonte - Adaptada de Bonuccelli (1999). 


\subsection{DADOS GERADOS}

Os dados gerados foram formados a partir dos mapas prévios e da análise das informações de trabalhos anteriores. Eles também constituem um conjunto de cartas fundamentais para a aplicação e, fazem parte deste conjunto de dados os seguintes mapas e cartas: de inventário, de declividade, rumo da inclinação da encosta, carta geotécnica, mapa de domínios estruturais, de resistência ao cisalhamento, de contraste de permeabilidade, de superfície potencial de ruptura e de potencial de infiltração.

\subsubsection{Mapa de Inventário dos Movimentos de Massa Gravitacionais}

Os inventários desenvolvidos na região de Ouro Preto reúnem as feições presentes nos terrenos, produzidas por algum evento que nos últimos anos envolveu o movimento de massa gravitacional de forma natural, sem a ação antrópica como agente deflagrador. Neste caso, mesmo que retirada a ação antrópica, fez-se necessário a interpretação dos movimentos que envolvessem os materiais tecnógenos, pois estes se fazem presentes na área desde o século XVII e, além de já fazerem parte do contexto geomorfológico da cidade, são de difícil identificação.

Assim, foram consideradas as ocorrências inventariadas por diversos autores, são eles: Souza (1996), Bonuccelli (1999), Zenóbio (2000), Castro (2006), Fontes (2011). Além destes trabalhos, também foram analisados os dados obtidos do Instituto Geotécnico (IGEO) de Ouro Preto.

A seção denominada Completo (Seção 5.2.1.1) apresenta todos os dados elaborados pelos autores supracitados e a análise de viabilidade de aplicação das informações na elaboração do mapa de inventário dos movimentos de massa gravitacionais. A Seção 5.2.1.2 mostra os dados que foram considerados válidos para a elaboração do mapa pretendido e a análise detalhada de suas informações. 


\subsubsection{Completo}

Esta seção apresenta todos os dados de inventário elaborados por cada autor separadamente e a análise de sua aplicabilidade na formação do inventário de movimentos de massa gravitacionais.

\section{A. Trabalho de Souza (1996)}

Foram cadastrados 319 feições na mesma área de abrangência deste estudo. Retirados os processos correlatos como erosão, assoreamento, etc., os tipos de materiais envolvidos no MMG variam de rocha, detritos e solo. Adicionou-se outra categoria denominada Área de múltiplas feições que, como o próprio nome diz, representa uma região onde não é possível a individualização de um único movimento. Este grupo foi formado a partir de feições registradas como movimentos complexos.

Os tipos de movimentos de massa inventariados com suas respectivas quantidades de feições por processo estão apresentados na Tabela 26.

Souza (1996) inventariou estas feições com trabalhos de campo a partir de fichas de cadastramento e de interpretação de fotos aéreas na escala 1:10000 do ano de 1969, eventualmente com o apoio de aerofotos de 1:8000 (1978).

Tabela 26 - Feições inventariadas por Souza (1996).

\begin{tabular}{lc}
\hline Processos & $\begin{array}{c}\text { Quantidade } \\
\text { de feições }\end{array}$ \\
\hline Escorregamento rotacional & 1 \\
\hline Escorregamento translacional & 52 \\
\hline Quedas & 64 \\
\hline Corridas & 33 \\
\hline Complexo & 125 \\
\hline Área de múltiplas feições & 44 \\
\hline
\end{tabular}




\section{B. Trabalho de Bonuccelli (1999)}

Foram consideradas 335 feições, já retirados os processos correlatos como erosão, assoreamento, etc. O cadastramento foi realizado pela autora com base em verificações de campo e em fotointerpretação de fotos aéreas na escala de 1:10000 e 1:8000, dos anos de 1969 e 1978, respectivamente. Quanto ao tipo de material envolvido, os processos foram separados nas classes: blocos de rocha, detritos, solo, mistura de detritos e solo, mistura de detritos e rocha, e, mistura de rocha, detritos e solo. Ademais, a autora também mostra informações quanto a profundidade, área da feição e o seu estado de atividade. Assim como o cadastramento de Souza (1996), uma nova categoria chamada Área de múltiplas feições foi adicionada a partir de feições registradas como movimentos complexos. Elas representam regiões onde não é possível a individualização de um único movimento.

As quantidades de feições para cada processo levantadas por Bonuccelli (1999) podem ser observadas na Tabela 27.

Tabela 27 - Feições inventariadas por Bonuccelli (1999).

\begin{tabular}{lc}
\hline Processos & $\begin{array}{c}\text { Quantidade } \\
\text { de feições }\end{array}$ \\
\hline \hline Escorregamento & 79 \\
\hline Escorregamento translacional & 55 \\
\hline Quedas e rolamentos & 78 \\
\hline Escoamentos rápidos ou corridas & 10 \\
\hline Complexo & 24 \\
\hline Escorregamento e corrida & 12 \\
\hline Escorregamento e erosão & 14 \\
\hline Escorregamento translacional e corrida & 31 \\
\hline Corridas e rolamentos & 25 \\
\hline Área de múltiplas feições & 7 \\
\hline
\end{tabular}




\section{Trabalho de Zenóbio (2000)}

Foram registrados 64 feições e os tipos de materiais são rocha ou solo. 0 trabalho foi realizado em escala 1:5000 utilizando fotografias aéreas na escala 1:8000 de 1978. Para complementação, fez-se levantamento de campo e registro fotográfico das feições inventariadas. Das 64 feições cadastradas pelo autor, 39 foram utilizadas neste inventário por possuírem uma área definida para a feição.

As quantidades de feições cadastradas por Zenóbio (2000) para cada processo estão listadas na Tabela 28.

Tabela 28 - Feições inventariadas por Zenóbio (2000).

\begin{tabular}{lc}
\hline Processos & $\begin{array}{c}\text { Quantidade } \\
\text { de feições }\end{array}$ \\
\hline \hline Complexo & 1 \\
Escorregamento translacional & 36 \\
Quedas & 2 \\
\hline
\end{tabular}

\section{Trabalho de Castro (2006)}

O trabalho conta com o levantamento de 417 feições entre os anos de 1989 a 2003, entretanto somente 270 foram realmente utilizadas. Este número corresponde a quantidade total de movimentos de massa cadastrados do tipo escorregamento. Segundo Castro (2006) esta separação foi necessária, pois os escorregamentos sofrem maior influência da precipitação no seu desencadeamento, sendo este o objetivo do seu estudo.

Todos os dados apresentados na tabela denominada Ocorrências Utilizadas para Análise de Correlação (Anexo I), possuem informação quanto a data de ocorrência, tipo de processo e dados de pluviosidade, mas não existe informação quanto ao material envolvido. Os dados de localização se resumem ao logradouro e bairro, não possuindo coordenadas geográficas da feição em sua tabela. 
As ocorrências até 1998 foram obtidas através da tese de Bonuccelli (1999). A partir deste ano o cadastramento foi realizado por Castro (2006) a partir do levantamento das ocorrências atendidas pelo Corpo de Bombeiros de Ouro Preto, selecionando apenas aquelas relacionadas a movimentos de massa gravitacionais e erosões.

No mapa apresentado por Castro (2006) - Mapa com Zoneamento das Áreas de Risco - reproduzido em detalhe na Figura 55, há todos os escorregamentos analisados, entretanto não há nenhuma codificação através da qual exista a possibilidade de fazer uma associação destes pontos com a tabela apresentada em seu trabalho. O mapa original pode ser visualizado no Anexo II.

Desta forma, viu-se impossibilitada a utilização destes dados na composição do banco de dados deste trabalho. Além de se tratarem de registros pontuais, visto que a prioridade seria de registros com representação espacial, ou seja, possuíssem a representação da área de ocorrência por meio de um polígono.

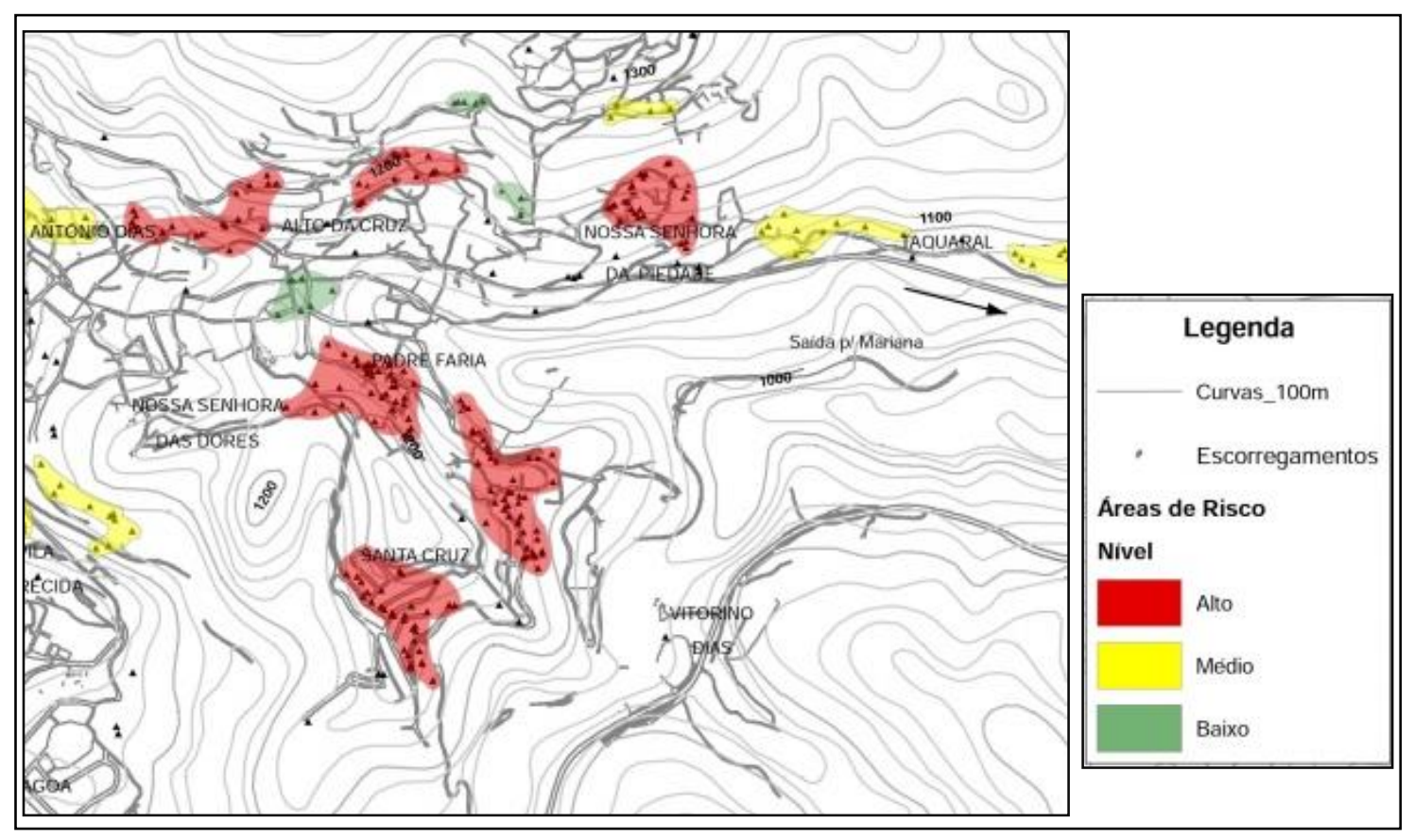

Figura 55 - Detalhe da porção leste do Mapa de Áreas de Risco e Registros de Escorregamento apresentado por Castro (2006). 


\section{E. Trabalho de Fontes (2011)}

Os dados de Fontes (2011) foram obtidos através das tabelas de dados contidos em sua dissertação e do mapa de ocorrências. Este autor também utiliza as ocorrências cadastradas por Castro (2006). A catalogação englobou 1029 ocorrências registradas entre os anos de 1988 a 2009.

Além do material técnico bibliográfico houve agrupamento de dados de relatórios do Arquivo Municipal, Cadastro de Registro da Prefeitura Municipal de Ouro Preto, Corpo de Bombeiros e Defesa Civil. De acordo com Fontes (2011) "as ocorrências foram sistematizadas, tomando-se como referência apenas o conjunto de eventos passíveis de contextualização completa, sendo descartadas àquelas que apresentavam dados insuficientes e/ou incompletos para uma caracterização plena".

Assim, das 1029 ocorrências somente 254 foram efetivamente listadas e correlacionadas com a natureza correspondente do evento geotécnico. Os tipos de movimentos de massa inventariados por Fontes (2011) estão apresentadas na Tabela 29.

Tabela 29 - Feições inventariadas por Fontes (2011).

\begin{tabular}{lc}
\hline Processos & $\begin{array}{c}\text { Quantidade } \\
\text { de feições }\end{array}$ \\
\hline \hline Escorregamento rotacional & 82 \\
Escorregamento translacional & 89 \\
Quedas e rolamentos & 31 \\
Escoamentos rápidos ou corridas & 8 \\
Complexo & 17 \\
\hline
\end{tabular}

O autor apresenta o seu banco de dados de duas formas:

i. através de uma tabela reproduzida no Anexo III denominada Lista de Ocorrências Mapeadas, na qual o autor mostra as ocorrências nomeadas por dois códigos. Um deles se inicia em E1 e finaliza em E254, número correspondente à quantidade de movimentos citados pelo autor como efetivamente utilizados. E outro código numérico que 
não possui uma sequência definida. Além destas informações, ela apresenta as coordenadas geográficas dos pontos, alguns possuem data de ocorrência e raramente alguma informação adicional. A Figura 56 ilustra uma parte desta tabela.

\begin{tabular}{|l|l|l|l|l|l|}
\hline Ponto & $\begin{array}{c}\text { Código da } \\
\text { Ocorrência }\end{array}$ & $\begin{array}{c}\text { Coordenada } \\
\mathbf{X}\end{array}$ & $\begin{array}{c}\text { Coordenada } \\
\mathbf{Y}\end{array}$ & $\begin{array}{c}\text { Data da } \\
\text { Ocorrência }\end{array}$ & $\begin{array}{l}\text { Eventos Geotécnicos } \\
\text { Observados }\end{array}$ \\
\hline E1 & 290 & 657289 & 7744134 & $04 / 11 / 1990$ & \\
\hline E2 & 291 & 657164 & 7744133 & & \\
\hline E3 & 292 & 657251 & 7744225 & $03 / 01 / 1997$ & $\begin{array}{l}\text { Demais ocorrências: } \\
23 / 12 / 1996 .\end{array}$ \\
\hline E4 & 293 & 657259 & 7744214 & & \\
\hline E5 & 294 & 657245 & 7744221 & & \\
\hline E6 & 295 & 657295 & 7744175 & $25 / 10 / 1993$ & \\
\hline E7 & 296 & 657529 & 7744161 & & \\
\hline E8 & 297 & 657353 & 7744003 & $21 / 11 / 1996$ & \\
\hline E9 & 298 & 657376 & 7743948 & $06 / 02 / 1998$ & \\
\hline E10 & 299 & 657422 & 7743916 & & \\
\hline
\end{tabular}

Figura 56 - Reprodução de parte da tabela de dados apresentada por Fontes(2011).

ii. Outro documento contido em uma separata denominada Fichas de Campo. Nesta base, o autor apresenta as fichas de campos de 160 pontos vistoriados. Entretanto, apesar de terem maior quantidade de informações sobre o ponto cadastrado, algumas fichas de campo não dispõem de coordenadas geográficas e a importância do cadastro está voltada para a avaliação das condições de risco do que à caracterização do movimento.

No mapa apresentado pelo autor - Mapa de Inventário de Ocorrênciasreproduzido em detalhe na Figura 57, há todos os movimentos de massa gravitacionais e processos correlatos analisados, entretanto não há nenhuma codificação através da qual exista a possibilidade de fazer uma associação destes pontos com as tabelas e fichas de campo apresentadas em seu trabalho. O mapa de inventário completo pode ser visto no Anexo IV desta dissertação.

Contudo, houve a tentativa de associação através do georreferenciamento deste mapa com as tabelas apresentadas por Fontes (2011) por meio das 
coordenadas geográficas. Entretanto, outros problemas foram diagnosticados, tais como:

- Há pontos sem correlação de posicionamento geográfico, ou seja, não há na tabela pontos que tenham o mesmo conjunto de coordenadas encontradas pelo georreferenciamento do Mapa de Inventário de Ocorrências;

- Existem pontos nas tabelas e fichas de campo que não possuem representação no mapa;

- Alguns pontos foram correlacionados, mas não correspondem ao mesmo tipo de movimento ou processo correlato cadastrado. Como exemplo: tem-se o ponto STC24 (E:657289,659/N:7744134,307) na ficha de campo diz ser escorregamento translacional e no mapa está representado como escorregamento rotacional. O ponto STC4 (E:657295,33/N:7744175,537) na ficha de campo é descrito como inundação e assoreamento e no mapa está representado como escorregamento rotacional. A ficha de campo do ponto STC4 está, como exemplo, reproduzida no Anexo V.

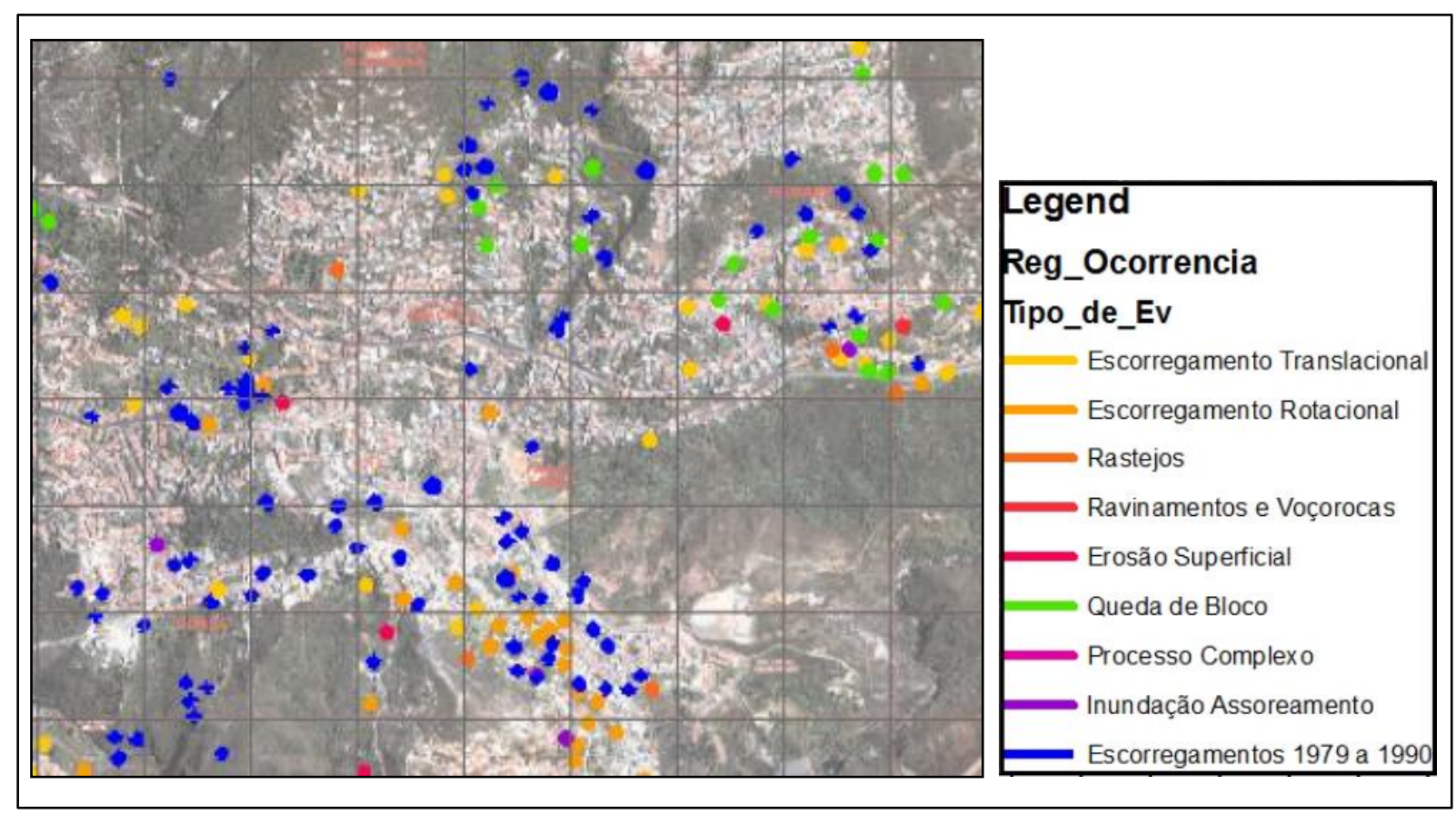

Figura 57 - Porção leste do Mapa de Inventário de Ocorrências apresentado por Fontes(2011). 
Desta forma, devido a incompatibilidade existente entre as bases de dados apresentadas e também às incertezas de se utilizar uma das bases partindo do pressuposto dela estar correta, chegou-se a conclusão de que não há possibilidade de utilizar estes dados na composição do banco de dados deste trabalho. Além de se tratarem de registros pontuais, assim como os dados de Castro (2006).

\section{F. Trabalhos de IGEO (2008-2014)}

Os dados cedidos pelo IGEO também foram analisados para posterior adição ao banco de dados deste trabalho. Estes documentos se tratam de algumas tabelas separadas por ano de ocorrência com pontos cadastrados a partir do que foi registrado pela Defesa Civil, Corpo de Bombeiros, população, etc.. Estes pontos são posteriormente inspecionados pelo instituto gerando um relatório técnico que é usado para avaliar geotecnicamente a ocorrência.

A Figura 58 apresenta parte da planilha de dados do ano de 2009, e foi aqui ilustrada a fim de representar a forma de cadastramento do instituto para os pontos oriundos das fontes anteriormente citadas.

Para o melhor aproveitamento destes documentos foram retirados os pontos cuja ocorrência não foi encontrada pela equipe de trabalho do IGEO. Da mesma forma, pontos que continham como descrição do tipo de movimento expressões como trincas, desabamento, queda de muro, entre outros também foram removidos.

Assim, a seleção se fez a partir do apresentado como deslizamento, queda de bloco, escorregamento rotacional e muro gabião, e o resultado final pode ser visualizado no Apêndice A. A tabela contida nesse apêndice contempla os anos de 2009 a 2013 com um total de 92 pontos armazenados. O ano com o maior número de ocorrências foi 2012 com 42 pontos inspecionados. 


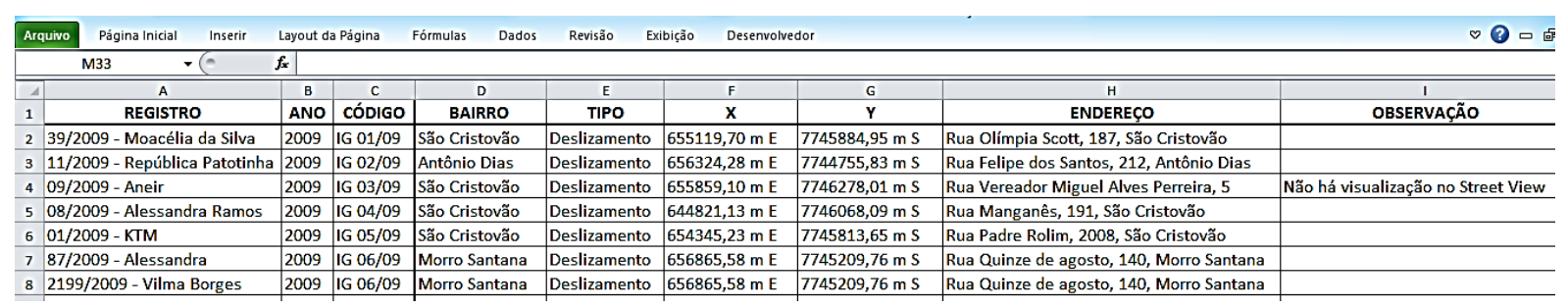

Figura 58 - Exemplo de uma das planilhas de dados concedidas pelo IGEO.

Os pareceres técnicos cedidos pelo IGEO não representam os pontos apresentados no Apêndice A. Ao todo são 15 relatórios datados de 2014 que foram analisados a fim de responder as seguintes questões:

i. É possível identificar qual o tipo de movimento?

ii. O movimento ocorreu por ação natural ou antrópica?

iii. Qual o tipo de material envolvido no movimento?

iv. Qual a atividade do movimento?

Ao fim da análise, constata-se que dificilmente é possível extrair dos pareceres técnicos as informações necessárias para elaboração do banco de dados de inventário de movimentos de massa gravitacionais.

Somente pela leitura dos relatórios, não há resposta para a maioria das questões levantadas na análise. Em alguns pareceres, é possível ter a informação do tipo de movimento, mas não há informação de que ele ocorreu naturalmente ou por interferência antrópica. O que dificulta ainda mais a sua utilização é a localização das ocorrências uma vez que elas estão sempre associadas à danificação de uma ocupação ou infraestrutura da cidade como: muros de pedra, ruas, casas e escolas.

Outro ponto importante a se discutir é a falta de uma delimitação da área em movimentação ou movimentada, pois, todos os relatórios avaliam uma região ou uma encosta como um todo e não se detêm à caracterização do movimento, mas sim à identificação do risco, avaliação das consequências e propostas de mitigação.

Para ilustrar os documentos cedidos pelo IGEO, consta no Anexo VI uma das cópias dos pareceres técnicos. Este parecer aborda a investigação geológicogeotécnica executada por membros do instituto para avaliação e remediação da 
instabilização da encosta situada na Rua Diogo de Vasconcelos, n 345 na cidade de Ouro Preto.

Vale aqui ressaltar que as informações que constam nos relatórios foram coletadas para fins específicos, não cabendo aqui qualquer análise correspondente a sua aplicabilidade, mas sim a possibilidade de incorporação destes na presente pesquisa.

Para representar espacialmente todos os dados elaborados por cada autor e a distribuição deles na área de estudo, apresenta-se, no Apêndice $V$, o Mapa Prévio dos Movimentos de Massa Gravitacionais. Este possui todos os dados catalogados sem nenhuma verificação de duplicação, incompatibilidade ou falta/insuficiência de informações, inclusive com os dados não validados neste estudo.

Tendo em vista as incertezas de identificação dos movimentos de massa quanto a sua origem: naturais ou relacionados a ação antrópica, as feições cadastradas por Castro(2006), Fontes (2011) e IGEO(2015) não foram consideradas em condições de serem utilizadas. Isto devido às dificuldades de validar o registro visto que são oriundos de defesa civil e, assim, não fazem parte do banco de dados deste estudo.

A partir dos resultados da análise dos trabalhos anteriores foi possível selecionar os dados que efetivamente podem ser incorporados à base deste trabalho, com a finalidade de elaborar um inventário dos movimentos de massa gravitacionais da área de estudo. Estes dados são tratados como válidos e serão melhor detalhados na próxima seção.

\subsubsection{Válidos}

Dentre todas as literaturas examinadas, foram escolhidos como válidos os conjuntos de informações inventariadas por Souza (1996), Bonuccelli (1999) e Zenóbio (2000), devido a estes levantamentos apresentarem melhor compatibilidade de dados. No Apêndice $B$ encontra-se a tabela denominada Banco de dados do 
inventário de movimentos de massa gravitacionais, com todos os dados válidos para as feições levantadas a partir da pesquisa mencionada anteriormente.

A partir da reunião destes dados para formação da base do inventário, elaborou-se o Mapa de Inventário dos Movimentos de Massa Gravitacionais, contido no Apêndice $\mathrm{Vl}$, que reúne todos os movimentos de massa gravitacionais cadastrados.

\section{A. Análise dos dados quanto às informações disponíveis}

Durante a pesquisa para o levantamento de dados, notou-se que algumas informações importantes para a caracterização dos movimentos de massa gravitacionais não foram relatadas pelos autores da literatura analisada.

Souza (1996) possui um mapa de documentação onde apresenta os pontos avaliados durante o seu trabalho de campo, entretanto, apesar de apresentar o levantamento das informações básicas quanto ao tipo de movimento e material envolvido, não existem dados quanto a atividade do movimento.

Zenóbio (2000), assim como Souza (1999), não apresenta informações mais sobre as feições, enquanto Bonuccelli (1999) contempla além da área, localização, classificação do tipo, dados sobre atividade e a profundidade da superfície de ruptura, em um banco de dados com todas as ocorrências cadastradas.

As informações mencionadas pelas referências mundiais como relevantes para a realização de um inventário, como: data da ocorrência, volume do material deslocado e velocidade - não foram obtidos pelos autores relacionados.

\section{B. Análise dos dados quanto às características das feições}

O banco de dados em sua base contempla as seguintes informações (Apêndice B): autoria, data do trabalho, código da ocorrência, código do processo, tipos, materiais geológicos envolvidos, coordenadas geográficas do centro geométrico das feições, área, atividade e profundidade da superfície de ruptura.

Ao todo, reuniu-se um total de 693 registros inventariados ilustrando 11 tipos de movimentos distintos (ou agrupamentos) de acordo com a classificação de 
Hutchinson (1988) e Cruden (1993). A distribuição de feições pode ser visualizada através da Tabela 30. A área total das feições registradas no mapa de inventário é de $2,23 \mathrm{~km}^{2}$, o que corresponde a aproximadamente $5 \%$ da área total

Tabela 30 - Número total de feições válidas.

\begin{tabular}{cc}
\hline Processos & $\begin{array}{c}\text { Quantidade de } \\
\text { feições }\end{array}$ \\
\hline \hline Escorregamento rotacional & 1 \\
Escorregamento translacional & 143 \\
Corridas & 43 \\
Complexo & 150 \\
Escorregamento* & 79 \\
Quedas e rolamentos & 144 \\
Escorregamento e corrida & 12 \\
Escorregamento e erosão & 14 \\
Escorregamento translacional e corrida & 31 \\
Corridas e rolamentos & 25 \\
Área de múltiplas feições & 51 \\
\hline${ }^{*}$ Não apresenta classificação quanto ao tipo de escorregamento.
\end{tabular}

As feições cadastradas não possuem padrão morfológico aparente. Nota-se que elas podem ser alongadas segundo a direção da encosta e, em sua grande maioria, alongadas no sentido da inclinação da encosta (Apêndice VI). As feições cadastradas como área de múltiplas feições podem ocorrer em topos de morro, encostas e vales.

Cerca de 45 feições ocupam área maior que $10.000 \mathrm{~m}^{2}$. A maior delas, com $74.942 \mathrm{~m}^{2}$, é classificada como área de múltiplas feições. 175 feições possuem área menor que $500 \mathrm{~m}^{2}$ e a menor ocupa $33,3 \mathrm{~m}^{2}$ da área total representando um escorregamento translacional. 


\section{Análise dos dados quanto à frequência das feições}

Para uma melhor visualização da distribuição de feições elaborou-se um gráfico de barras que exibe a frequência dos registros por tipo de movimento, conforme Figura 60. As feições classificadas como quedas e como quedas e rolamentos foram agrupadas. Os autores classificaram várias feições como do tipo complexo, porém não se encontram descrições dos subtipos envolvidos, e grande parte destas podem ser enquadradas como áreas de múltiplas feições. Estas correspondem a regiões onde não há como individualizar as feições existentes.

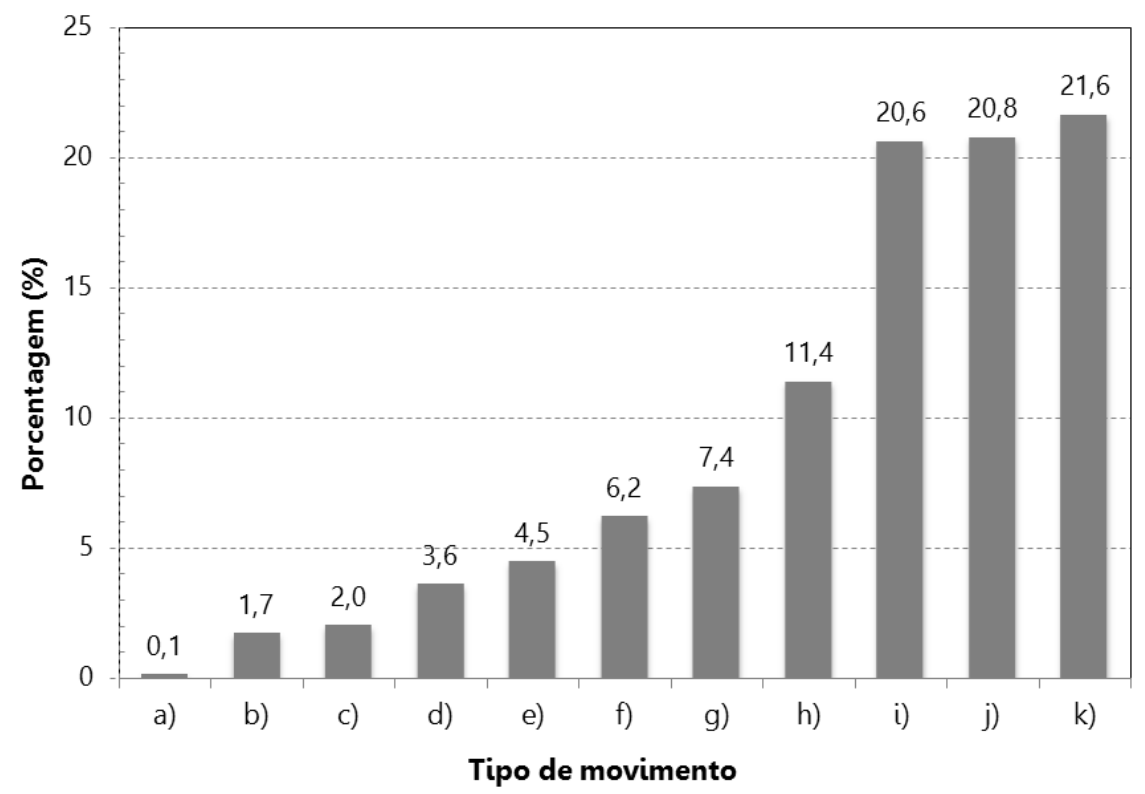

Figura 59 - Frequência das ocorrências quanto ao tipo de movimento, que são: a) Escorregamento rotacional;

b) Escorregamento e corrida; c) Escorregamento e erosão; d) Corridas e rolamentos; e) Escorregamento translacional e corrida; f) Corridas; g) Área de múltiplas feições; h) Escorregamento; i) Escorregamento translacional; j) Quedas e rolamentos; k) Complexo.

Dentre todos os tipos de processos classificados e apresentados no Banco de dados do inventário de movimentos de massa gravitacionais (Apêndice B), pode-se observar que o tipo de movimento que mais ocorre na região estudada é o movimento complexo (150 feições), seguido de quedas e rolamentos (144 feições), escorregamento translacional (143 feições) e escorregamento (79 feições). Demais tipos de processos somam $25,5 \%$ do total de feições inventariadas. 


\section{Análise quanto às informações do banco de dados}

Devido à ausência de informações nos diversos trabalhos não há condições de uma análise geral e comparativa em termos estatísticos. Entretanto, informações quanto à atividade, profundidade da superfície de ruptura e material geológico envolvido puderam ser analisados estatisticamente (Figura 60).
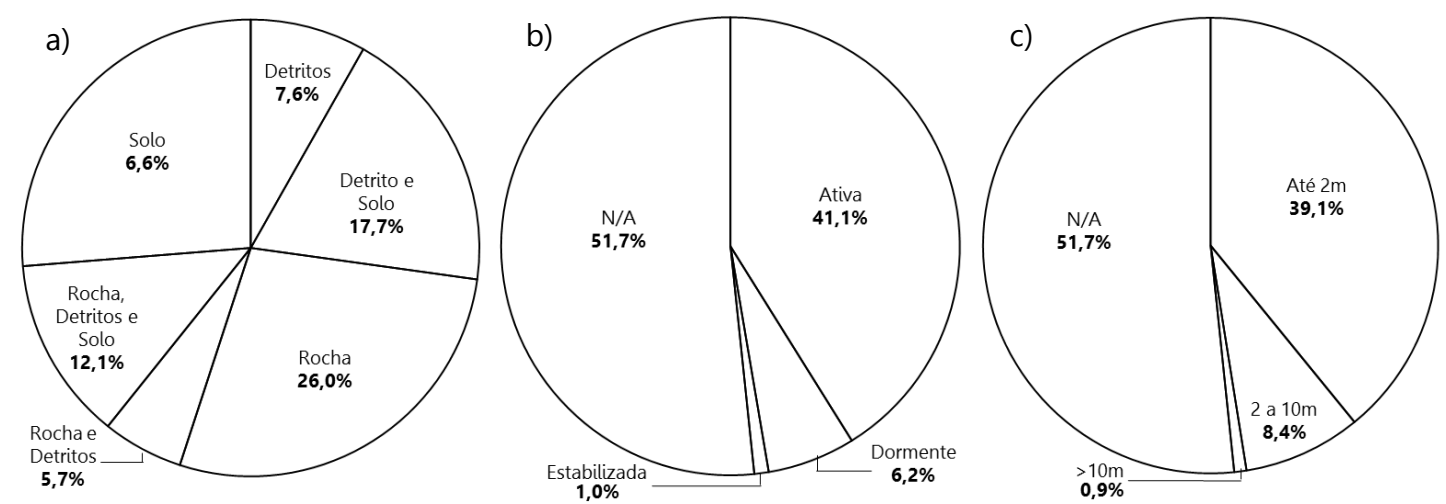

Figura 60 - Análise das feições inventariadas:

a)Tipo de material; b)Atividade; c)Profundidade da superfície de ruptura.

Observou-se que as feições cadastradas movimentam mais materiais rochosos quando comparado aos outros tipos citados no banco de dados $(26,0 \%)$, seguido da mistura detritos e solo com 17,7\% (Figura 60a). Como já referido, a classificação quanto à atividade e profundidade da ruptura do movimento não foi descrita por Souza (1996) e Zenóbio (2000) por isso, cerca de 52 \% dos dados inventariados não possuem estas informações (Figura 60b e Figura 60c), nomeado nos gráficos como N/A (Not Available). Em 1999, 41,1\% dos registros inventariados estavam ativos e somente $1,0 \%$ estabilizados. Quanto a profundidade da superfície de ruptura, 39\% dos dados mostram que a superfície de ruptura dos movimentos se forma em até $2 \mathrm{~m}$ de profundidade. Profundidades maiores que $10 \mathrm{~m}$ foram constatadas em $0,9 \%$ dos registros. 


\subsubsection{Mapa de Inventário dos escorregamentos translacionais}

Os movimentos de massa gravitacionais do tipo complexo são os que mais ocorrem na área de estudo. Este movimento é considerado composto por ser originado pela combinação de mais de um dos tipos de movimentos de massa. 0 movimento de queda não possui um simples entendimento e modelamento do processo que compreende a movimentação de massa neste contexto. Devido ao elucidado, o escorregamento translacional, que possui também grande ocorrência, foi selecionado para ser o movimento base do modelo de aplicação adotado neste trabalho.

Portanto, do banco de dados geral foram selecionadas as ocorrências do tipo escorregamento translacional formando um inventário específico para este movimento.

Do banco de dados elaborado por Bonuccelli (1999) foram adicionados os movimentos classificados como escorregamento translacional e corrida. Ao todo, 174 ocorrências formaram um novo banco de dados para avaliação específica deste tipo de processo.

O mapa de inventário dos escorregamentos translacionais produzido apenas apresenta os dados inventariados por Souza (1996), Bonuccelli (1999) e Zenóbio (2000) e pode ser visto no Apêndice VII.

\section{A. Análise dos dados quanto à sobreposição}

Após obtenção dos dados, observou-se que algumas feições se encontram sobrepostas, são elas:

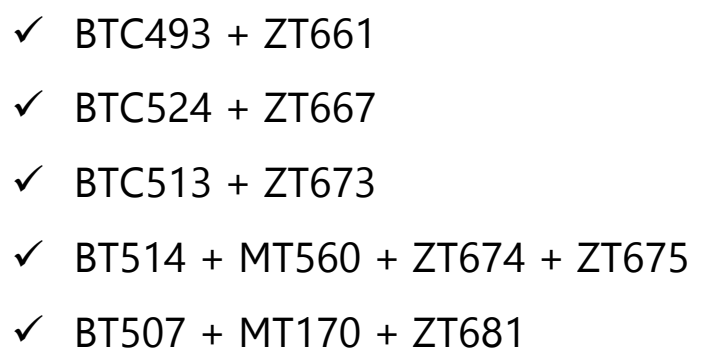




$$
\begin{array}{ll}
\checkmark & \text { BTC518 + MT69 } \\
\checkmark & \text { BT443 + MT102 }
\end{array}
$$

Estas sobreposições podem ser parciais ou completas e foram mantidas por significarem uma possível reativação do movimento observada em anos distintos.

\section{B. Análise quanto às informações do banco de dados}

Quanto ao material movimentado no escorregamento translacional, verificase que $28,2 \%$ envolveram rocha, seguido de detritos e solo com $21,8 \%$ e somente solo (20,1\%). A classificação quanto à atividade e profundidade de ruptura do escorregamento translacional, realizada por Bonuccelli (1999), mostra que 44,3\% das ocorrências estavam ativas em 1999 e somente uma feição estava estabilizada. Quanto a profundidade da superfície de ruptura, 40,8\% dos dados mostram que a superfície de ruptura dos movimentos se forma em até $2 \mathrm{~m}$ de profundidade. Profundidades maiores que $10 \mathrm{~m}$ não foram registradas em escorregamentos translacionais. De todos os escorregamentos cadastrados, 50,6\% não possuem estas informações.
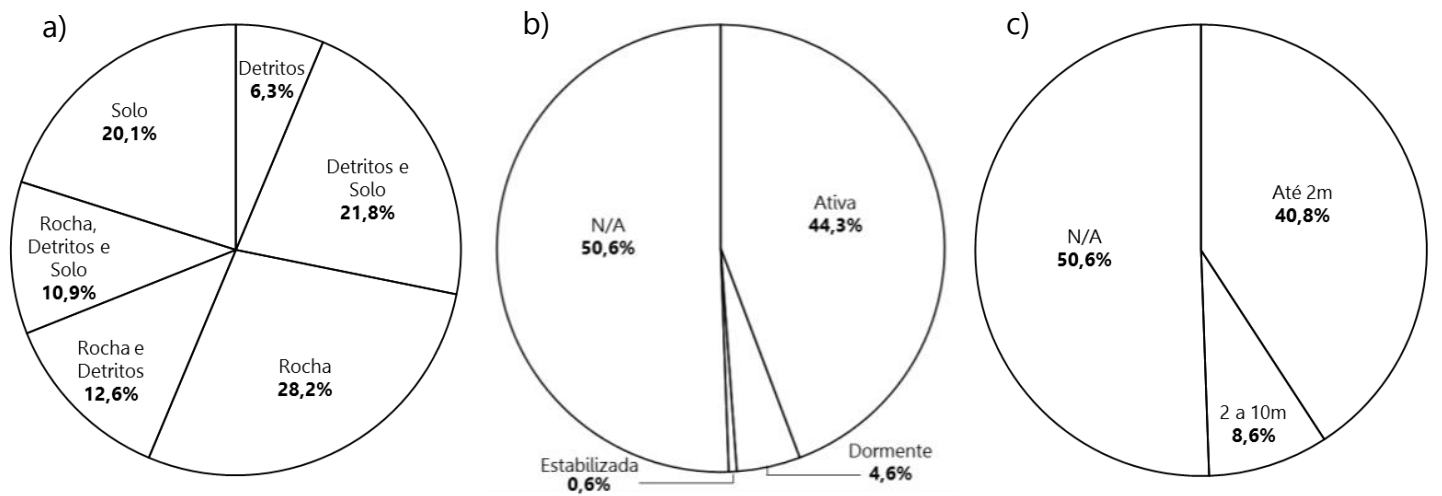

Figura 61 - Análise das feições classificadas como escorregamento translacional: a)Tipo de material; b)Atividade; c)Profundidade da superfície de ruptura.

Para representar espacialmente os escorregamentos translacionais a partir dos materiais envolvidos na movimentação foi elaborado um mapa de inventário dos 
escorregamentos translacionais representando o tipo de material envolvido, que pode ser visto no Apêndice VIII.

\subsubsection{Carta de Declividade}

A carta de declividade (Apêndice IX) foi produzida a partir da base topográfica em formato digital, com curvas de nível espaçadas de $10 \mathrm{~m}$ de

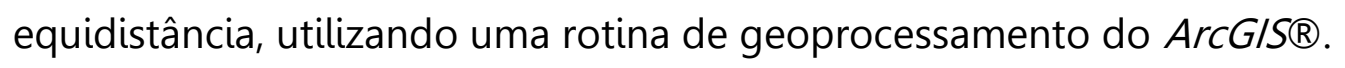

A declividade é a inclinação da uma encosta medida no alinhamento de seu máximo declive. Para este estudo, foram utilizados os intervalos em graus adotados por Souza (1996) como pode ser visualizado na Tabela 31. A porcentagem da área ocupada por cada classe em relação à área total foi também apresentada nesta tabela.

Tabela 31 - Classes de declividade e seus intervalos de inclinação

\begin{tabular}{ccc}
\hline Classes & Inclinações ( ${ }^{\circ}$ ) & Área (\%) \\
\hline \hline 1 & $<3$ & 3,61 \\
2 & $3-6$ & 5,51 \\
3 & $6-11$ & 14,15 \\
4 & $11-16$ & 20,19 \\
5 & $16-24$ & 33,45 \\
6 & $24-36$ & 20,78 \\
7 & $>36$ & 2,31 \\
\hline
\end{tabular}

Observa-se que a classe com declividades entre 16 e $24^{\circ}$ é a mais representativa, ocupando $33,45 \%$ da área total. Declividades maiores que $36^{\circ}$ somente acontece em 2,31\% da área, cerca de $6,48 \mathrm{~km}^{2}$. Ao todo, predominam declividades entre 6 e $36^{\circ}$, o que indica uma grande variação no relevo. 


\subsubsection{Carta de Rumo da Inclinação da Encosta}

A partir do mesmo raster criado para o atributo declividade, gerou-se a carta de rumo da inclinação da encosta usando a ferramenta Aspecto que está disponível

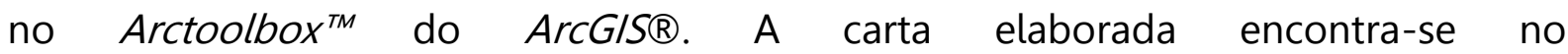
Apêndice $X$.

Este procedimento fornece o sentido da inclinação da encosta e está diretamente associada à declividade. Por exemplo, se uma determinada encosta possui sentido de inclinação para Leste $\left(67,5^{\circ}-112,5^{\circ}\right)$ e a mesma região foi mapeada como tendo declividade maior que $<45^{\circ}$ isto significa que esta parte da encosta mergulha mais que $45^{\circ}$ para leste.

As classes utilizadas estão apresentadas na Tabela 32 com seus respectivos intervalos de valores e com a porcentagem da área ocupada por cada uma em relação à área total.

Tabela 32 - Classes do rumo de inclinação das encostas e seus intervalos.

\begin{tabular}{ccc}
\hline Classes & Rumos $\mathbf{(}^{\circ}$ ) & Área (\%) \\
\hline Plano & -1 & 0 \\
Norte & $0-22,5$ & 7,63 \\
Nordeste & $22,5-67,5$ & 15,62 \\
Leste & $67,5-112,5$ & 12,64 \\
Sudeste & $112,5-157,5$ & 13,04 \\
Sul & $157,5-202,5$ & 16,29 \\
Sudoeste & $202,5-247,5$ & 10,38 \\
Oeste & $247,5-292,5$ & 8,96 \\
Noroeste & $292,5-337,5$ & 8,96 \\
Norte & $337,5-360,0$ & 6,48 \\
\hline
\end{tabular}

A classe que possui rumo da inclinação para Sul (entre 157,5 e $202,5^{\circ}$ ) é a que ocupa maior extensão, 16,29\% da área total. Entretanto, ressalta-se que os rumos 
para Nordeste e Norte também possuem valores próximos ao mencionado anteriormente, sendo que o rumo da inclinação das encostas para Norte possui dois intervalos que somados chegam ao valor de $14,11 \%$ da área total ocupada.

As classes menos representativas são das encostas de inclinação para Noroeste e Oeste, ambas acontecem em 8,96\% da área. Não houve representatividade da classe plana (sem inclinação). No geral, as encostas da região estudada estão voltadas para leste, entre os sentidos norte e sul.

\subsubsection{Carta Geotécnica - Unidades geológico-geotécnicas}

As unidades geológico-geotécnicas foram formadas pela sobreposição dos mapas de material inconsolidado e de substrato rochoso. Optou-se por individualizar cada conjunto formado da união das duas unidades sobrepostas e estabelecer outra unidade com características geotécnicas que remetessem a um perfil de caracterização do solo. Por exemplo, a unidade i2 do mapa de material inconsolidado está, dentre outras unidades do substrato rochoso, sobre a unidade denominada $r 2$. As duas juntas compõem a unidade geológico-geotécnicas IR3 (Ver Figura 62).

Desta forma, elaborou-se a Carta de Unidades Geológico-Geotécnicas que se encontra no Apêndice XII. Foram formadas 51 unidades que se distribuem por toda a região estudada. Cerca de 25 unidades ocupam, individualmente, menos que $1 \%$ da área total e somadas representam somente $4,5 \%$ da área de estudo. As duas unidades mais representativas são: IR2 e IR29 com 10,9\% e 11,1\% da área total, respectivamente. A unidade IR2 está localizada no extremo sudeste da área, na região da serra do Itacolomi, e caracteriza-se por afloramentos de quartzitos, quartzitos sericíticos e quartzo-sericita-xistos, sem material inconsolidado. A unidade IR29 trata-se de colúvio sobre solo residual e saprolito de xistos sericíticos e quartzosos, e está localizada na porção norte da área, escarpa sul da serra de Ouro Preto.

A unidade que mais possui subunidades distribuídas pela região é a IR17. Ao todo são 10 regiões representadas por alguns aterros não compactados, depósitos 
de entulhos e resíduos urbanos e de mineração que estão dispostos sobre filitos intercalados a quartzitos.

As informações passíveis de serem extraídas das características geológicogeotécnicas de cada unidade deram subsídio para a elaboração da Tabela de Caracterização das Unidades Geológico-Geotécnicas (Apêndice XI). Esta tabela descreve cada unidade separadamente e compreende a caracterização geral da maioria dos atributos utilizados neste trabalho. Uma parte deste apêndice pode ser observada através da Figura 62, onde são apresentados os seguintes dados:

- Código da unidade geológico-getécnica;

- Material inconsolidado e substrato rochoso que compõem a unidade;

- Perfil de alteração;

- Contraste de permeabilidade;

- Relevo respectivo da unidade;

- Perfil topográfico típico da unidade;

- Superfície potencial de ruptura;

- Resistência ao cisalhamento;

- Presença de matacões.

A representação espacial de todas as unidades pode ser visualizada através do Apêndice XII - Carta de Unidades Gológico-Geotécnicas. Os perfis topográficos exibidos na Tabela de Caracterização das Unidades Geológico-Geotécnicas foram locados sobre a carta geotécnica em um mapa à parte, denominado Mapa das Seções Típicas das Unidades Geológico-geotécnicas, e pode ser consultado no Apêndice XIII desta dissertação. 


\begin{tabular}{|c|c|c|c|c|c|c|c|c|c|c|c|c|}
\hline \multicolumn{2}{|c|}{$\begin{array}{c}\text { Material } \\
\text { Inconsolidado }\end{array}$} & \multicolumn{2}{|r|}{$\begin{array}{l}\text { Substrato } \\
\text { Rochoso }\end{array}$} & \multirow{2}{*}{$\begin{array}{l}\text { Unidade } \\
\text { IR1 }\end{array}$} & \multicolumn{2}{|c|}{ Perfil de alteração } & \multirow[t]{2}{*}{\begin{tabular}{c|} 
Contraste de \\
Permeabilidade
\end{tabular}} & \multirow[b]{2}{*}{ 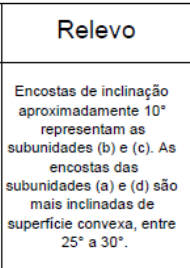 } & \multirow{2}{*}{ Perfil topográfico típico da unidade } & \multirow{2}{*}{\begin{tabular}{|c|}
$\begin{array}{c}\text { Superfície potencial } \\
\text { de ruptura }\end{array}$ \\
\\
Pode romper nos \\
panos de \\
descontiuidades \\
presentes na rocha.
\end{tabular}} & \multirow{2}{*}{$\begin{array}{c}\begin{array}{c}\text { Resistência ao } \\
\text { cisalhamento }\end{array} \\
\text { Rocha Dura }\end{array}$} & \multirow{2}{*}{$\begin{array}{c}\text { Matacões } \\
\text { PRESENCAAM } \\
\text { ROCHA }\end{array}$} \\
\hline \multirow{2}{*}{ i 1} & \multirow{2}{*}{$\begin{array}{l}\text { Ausência de material } \\
\text { inconsolidado. }\end{array}$} & r 4 & 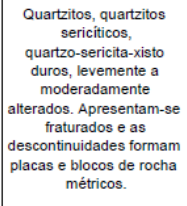 & & & $\begin{array}{l}\text { Rocha afforante } \\
\text { Quartititos equartzitos } \\
\text { sericiticos duros }\end{array}$ & & & & & & \\
\hline & & r 19 & \begin{tabular}{|l} 
Quartititos duros, \\
levementea \\
moderadamente \\
alterados. Filitos (duros \\
e brandos) ocorrem em \\
alguns locais. As \\
descontinuidades \\
formam placas elocos \\
de rocha métricos.
\end{tabular} & IR2 & & $\begin{array}{l}\text { Rocha afforante } \\
\text { Quartzitos duros e } \\
\text { filitos isoladamente }\end{array}$ & $<10^{7} \mathrm{~m} / \mathrm{s}$ & 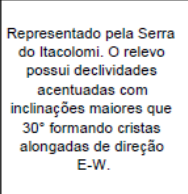 & 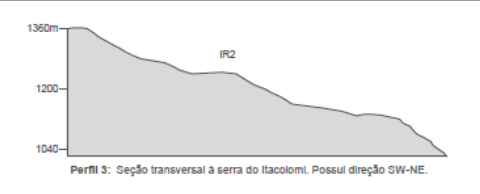 & 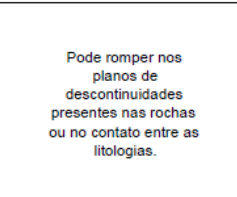 & Rocha Dura & $\begin{array}{l}\text { PRESENCA EM } \\
\text { ROCHA }\end{array}$ \\
\hline \multirow[t]{2}{*}{ i 2} & \multirow{2}{*}{ 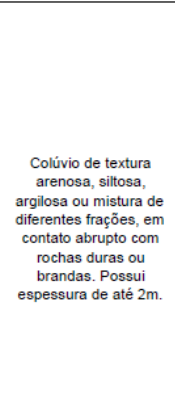 } & $r 2$ & 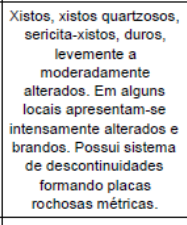 & IR3 & $\mathbb{M} \mathbb{M}$ & \begin{tabular}{|c|} 
Colúvio \\
\\
Xistos sericiticose \\
quartzosos brandos
\end{tabular} & $\begin{array}{l}>10^{2} \mathrm{~m} / \mathrm{s} \\
<10^{-7} \mathrm{~m} / \mathrm{s}\end{array}$ & 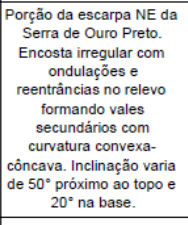 & 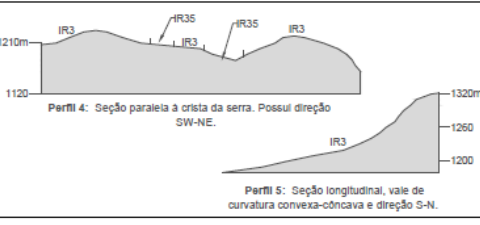 & 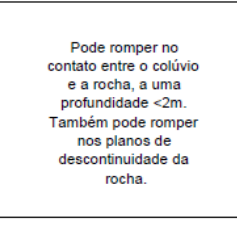 & $\begin{array}{l}\text { Solo Fime } \\
\text { Rocha Dura }\end{array}$ & $\begin{array}{l}\text { PRESENCA EM } \\
\text { ROCHA }\end{array}$ \\
\hline & & $r 3 D$ & $\begin{array}{l}\text { Xistos duros levemente a } \\
\text { moderadamente } \\
\text { atterasos, intercalados ou } \\
\text { associatos a filtos eu } \\
\text { xistos brandos. }\end{array}$ & IR4 & & \begin{tabular}{|c|c|c|} 
Colúvio \\
Xistos duros e filitos \\
brandos
\end{tabular} & $\begin{array}{l}>10^{2} \mathrm{~m} / \mathrm{s} \\
<10^{-7} \mathrm{~m} / \mathrm{s}\end{array}$ & $\begin{array}{l}\text { Área restrita à uma } \\
\text { porç̧ấf filetada ao norte } \\
\text { do mapa. Faz parte da } \\
\text { escarpa voltada para } \\
\text { norte da serra de Ouro } \\
\text { Preto. }\end{array}$ & 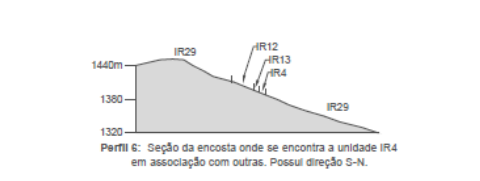 & 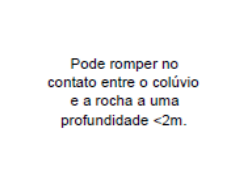 & $\begin{array}{l}\text { Solo Fime } \\
\text { Rocha Dura }\end{array}$ & AUSĖNCIA \\
\hline
\end{tabular}

Figura 62 - Parte da Tabela de Caracterização das Unidades Geológico-Geotécnicas. 


\subsubsection{Carta de Resistência ao Cisalhamento}

A resistência de um solo em um plano aleatório é a tensão de cisalhamento máxima que pode ser aplicada à estrutura do solo naquela direção. Quando este máximo é atingido, o solo não resiste e rompe. Em rochas pode-se pensar analogamente ao que acontece nos solos, salvo que, neste caso, pode-se tratar também da resistência à compressão uniaxial e puntiforme.

Analisou-se a resistência dos materiais inconsolidados e dos substratos rochosos ocorrentes na área, individualmente, e com estes dados foi produzido um perfil com a sequência das resistências dos materiais que constituem cada unidade geológico-geotécnica, segundo consta na metodologia.

Após a caracterização das unidades quanto à resistência dos materiais, elaborou-se a Carta de Resistência ao Cisalhamento que pode ser visualizada no Apêndice XIV. Foram formadas 93 regiões que representam as 28 classes de acordo com a Tabela 33.

A classe do conjunto de resistências que ocupa maior porção da área total é a RC13 com 15,3\%, seguida pela classe RC1 que ocupa 12,0\%. A classe RC13 representa o conjunto de resistências que variam, em profundidade, de Solo Firme $\rightarrow$ Firme/Rígido $\rightarrow$ Muito Branda $\rightarrow$ Rocha Moderadamente Dura. A classe RC1 representa rochas consideradas duras, sem a presença de material inconsolidado.

Separadamente, as classes RC6, RC7, RC8, RC9, RC10, RC11, RC12, RC19, RC26, RC27 e RC28 ocupam menos que $1 \%$ da área total e somadas representam aproximadamente $1,2 \%$ da área de estudo. 
Tabela 33 - Classes das resistências dos materiais.

\begin{aligned} & \hline Classes Descrição \\ & \hline RC1 Rocha Dura \\ & RC2 Solo Firme $\rightarrow$ Rocha Dura \\ & RC3 Solo Firme $\rightarrow$ Rocha Branda + Moderadamente Dura \\ & RC4 Solo Firme $\rightarrow$ Rocha Muito Dura + Moderadamente Dura \\ & RC5 Solo Firme $\rightarrow$ Rocha Moderadamente Dura \\ & RC6 Material Fofo $\rightarrow$ Rocha Moderadamente Dura \\ & RC7 Material Fofo $\rightarrow$ Rocha Dura \\ & RC8 Material Fofo $\rightarrow$ Rocha Muito Dura + Branda \\ & RC9 Material Fofo $\rightarrow$ Rocha Dura + Branda \\ & RC10 Material Fofo $\rightarrow$ Rocha Muito Dura + Moderadamente Dura \\ & RC11 Material Fofo $\rightarrow$ Rocha Branda + Moderadamente Dura \\ & RC12 Solo Firme $\rightarrow$ Rocha Branda \\ & RC13 Solo Firme $\rightarrow$ Firme $/$ Rígido $\rightarrow$ Muito Branda $\rightarrow$ Rocha Moderadamente Dura \\ & RC14 Muito Rígido $\rightarrow$ Firme $\rightarrow$ Firme/Rígido $\rightarrow$ Muito Branda $\rightarrow$ Rocha Dura + Moderadamente Dura \\ & RC15 Muito Rígido $\rightarrow$ Firme $\rightarrow$ Firme/Rígido $\rightarrow$ Muito Branda $\rightarrow$ Rocha Branda \\ & RC16 Solo Firme $\rightarrow$ Muito Branda $\rightarrow$ Rocha Branda + Moderadamente Dura \\ & RC17 Solo Firme $\rightarrow$ Muito Branda $\rightarrow$ Rocha Dura + Moderadamente Dura \\ & RC18 Solo Firme $\rightarrow$ Muito Branda $\rightarrow$ Rocha Muito Dura + Branda \\ & RC19 Solo Firme $\rightarrow$ Muito Branda $\rightarrow$ Rocha Branda \\ & RC20 Solo Firme $/$ Rígido $\rightarrow$ Muito Branda $\rightarrow$ Rocha Branda + Moderadamente Dura \\ & RC21 Solo Firme $\rightarrow$ Muito Branda $\rightarrow$ Rocha Moderadamente Dura \\ & RC22 Muito Rígido $\rightarrow$ Firme/Rígido $\rightarrow$ Rocha Moderadamente Dura \\ & RC23 Muito Rígido $\rightarrow$ Firme/Rígido $\rightarrow$ Rocha Dura + Moderadamente Dura \\ & RC24 Firme/Rígido $\rightarrow$ Muito Branda $\rightarrow$ Rocha Moderadamente Dura \\ & RC25 Solo Firme $\rightarrow$ Firme $/$ Rígido $\rightarrow$ Muito Branda $\rightarrow$ Rocha Branda + Moderadamente Dura \\ & RC26 Solo Firme $\rightarrow$ Firme/Rígido $\rightarrow$ Muito Branda $\rightarrow$ Rocha Dura + Moderadamente Dura \\ & RC27 Material Fofo $\rightarrow$ Rocha Dura + Moderadamente Dura \\ & RC28 Solo Firme $\rightarrow$ Rocha Dura + Moderadamente Dura \\ & \hline\end{aligned}




\subsubsection{Carta de Contraste de Permeabilidade}

A permeabilidade de um material é o que indica maior ou menor dificuldade com que a água percola pelos seus poros. Nos materiais granulares não coesivos como as areias, por exemplo, a alta porosidade facilita o fluxo de água através do solo, enquanto que nos materiais finos e coesivos, como as argilas, ocorre o inverso, o que torna este tipo pouco permeável.

A partir da analise do que foi exposto nos perfis de alteração solo/rocha e utilizando as classes definidas pela metodologia proposta (Tabela 34), foi elaborada a Carta de Contraste de Permeabilidade que pode ser visualizada no Apêndice XV. Foram formadas 60 regiões distribuídas por toda a área que representam as 6 classes propostas. Destas 60 regiões, 30 representam somente a classe K2 e ocupam aproximadamente $16,8 \%$ da área total.

A classe com maior extensão territorial é a K4 que descreve o conjunto de contraste de permeabilidade equivalente a Aluvião/Colúvio/Materiais tecnógenos sobre saprolitos e substratos rochosos variados. A classe $\mathrm{K} 4$ ocupa $26,5 \%$ da área total, seguida pela classe K3 com 22,3\%. As outras classes ocupam em média cerca de $11,5 \%$ da área total de estudo.

Tabela 34 - Classes dos contrastes de permeabilidade.

\begin{aligned} & \hline Classes Descrição \\ & \hline \hline K1 $<10^{-7} \mathrm{~m} / \mathrm{s} \\ &$ K2 $>10^{-2} \mathrm{~m} / \mathrm{s} \rightarrow<10^{-7} \mathrm{~m} / \mathrm{s} \\ &$ K3 $>10^{-2} \mathrm{~m} / \mathrm{s} \rightarrow 10^{-2}$ a $10^{-4} \mathrm{~m} / \mathrm{s} \rightarrow 10^{-4}$ a $10^{-7} \mathrm{~m} / \mathrm{s} \rightarrow<10^{-7} \mathrm{~m} / \mathrm{s} \\ &$ K4 $>10^{-2} \mathrm{~m} / \mathrm{s} \rightarrow 10^{-4}$ a $10^{-7} \mathrm{~m} / \mathrm{s} \rightarrow<10^{-7} \mathrm{~m} / \mathrm{s} \\ &$ K5 $10^{-2}$ a $10^{-4} \mathrm{~m} / \mathrm{s} \rightarrow 10^{-4}$ a $10^{-7} \mathrm{~m} / \mathrm{s} \rightarrow<10^{-7} \mathrm{~m} / \mathrm{s} \\ &$ K6 $10^{-2}$ a $10^{-4} \mathrm{~m} / \mathrm{s} \rightarrow<10^{-7} \mathrm{~m} / \mathrm{s} \\ &$\hline\end{aligned}

A classe de contraste de permeabilidade de cada unidade geológicogeotécnica pode ser observada através da Tabela de Caracterização das Unidades Geológico-Geotécnicas (Apêndice XI). 


\subsubsection{Carta de Superfície Potencial de Ruptura}

A superfície potencial de ruptura representa a localização de um possível plano de fraqueza na rocha, no solo ou no conjunto solo/rocha. Para o escorregamento translacional, a superfície potencial de ruptura deve ser planar podendo ser uma descontinuidade existente no maciço, ou um contato solo-rocha, um plano entre contraste de resistência ou entre contraste de permeabilidade e até mesmo camadas litológicas que se comportam como descontinuidades.

Tendo realizado as analises e abordadas na metodologia deste trabalho, foi elaborada a Carta de Superfície Potencial de Ruptura. Esta carta pode ser vista no Apêndice XVI.

Foram formadas 75 regiões que representam as 11 classes descritas na Tabela 35. A classe SR6 possui maior extensão territorial com 23,5\% da área total do mapa. Ela representa a superfície de ruptura que pode ocorrer entre o colúvio e o solo residual quando em profundidade próxima a $2 \mathrm{~m}$. Esta seria a superfície mais provável, entretanto, podem surgir outras superfícies em espessuras maiores (próximas a 10m) que acontecerá nos materiais inconsolidados sotopostos de forma indefinida.

Outra classe que se destaca é a SR8 com 18,0\% da área de estudo. As classes SR4 e SR11 ocupam menos de 1\% cada.

Através da Tabela de Caracterização das Unidades Geológico-Geotécnicas (Apêndice $\mathrm{XI}$ ) podem ser observadas as descrições da superfície potencial de ruptura para cada unidade geológico-geotécnica. 
Tabela 35 - Classes da superfície potencial de ruptura.

\section{Classes Descrição}

SR1 Pode romper nos planos de descontinuidades presentes na rocha. Quando existem intercalações entre litologias, a ruptura pode ocorrer também no contato entre elas.

Pode romper no contato entre o colúvio e a rocha, a uma profundidade $<2 \mathrm{~m}$. Também

SR2 pode romper nos planos mais superficiais de descontinuidade da rocha, ou no contato entre as litologias em unidades que possuem estas intercalações.

Pode romper no contato entre o colúvio e a rocha a uma profundidade $<0,5 \mathrm{~m}$. Pode

SR3 também romper no contato entre as litologias ou nas descontinuidades presentes nas rochas, quando ambas ocorrerem próximas à superfície.

Pode romper no contato entre os materiais tecnógenos e a rocha ou solo sotoposto a uma profundidade próxima a $2 \mathrm{~m}$. E também nos planos de descontinuidade presentes nas rochas quando estas estiverem próximas à superfície. Quando em espessuras maiores (próximas a $10 \mathrm{~m}$ ) a superfície de ruptura será definida por outros fatores.

SR5 Pode romper no contato entre o aluvião e a rocha a uma profundidade $<2 \mathrm{~m}$.

Pode romper no contato entre o colúvio e o solo residual quando em profundidade próxima a $2 \mathrm{~m}$. Quando em espessuras maiores (próximas a $10 \mathrm{~m}$ ) a superfície de ruptura será mais profunda e acontecerá nos materiais inconsolidados sotopostos de forma indefinida.

Pode romper no contato entre o colúvio e o saprolito quando em profundidade próxima a $2 \mathrm{~m}$. Quando em espessuras maiores (próximas a $10 \mathrm{~m}$ ) a superfície de ruptura será mais

SR7 profunda e acontecerá de forma indefinida no saprólito. Pode também romper nas descontinuidades presentes nas rochas/saprolitos, quando ocorrerem próximas à superfície.

Pode romper no contato entre o colúvio e o saprolito, a uma profundidade $<2 \mathrm{~m}$. Também pode romper no plano de descontinuidade da rocha.

Pode romper no contato entre o solo residual e o saprolito quando em profundidade próxima a $2 \mathrm{~m}$, ou em descontinuidades da rocha/saprolito. Quando em profundidades maiores (próximas a $10 \mathrm{~m}$ ) a superfície de ruptura será mais profunda e acontecerá nos materiais inconsolidados sotopostos de forma indefinida.

Pode romper no contato entre o solo laterítico e a rocha a uma profundidade próxima a $2 \mathrm{~m}$. Quando em espessuras maiores (próximas a $10 \mathrm{~m}$ ) a superfície de ruptura será mais profunda e acontecerá de forma indefinida no solo laterítico. Pode também romper nas descontinuidades presentes nas rochas, quando ocorrerem próximas à superfície.

SR11 Pode romper no saprolito a uma profundidade de ruptura de 2 a $10 \mathrm{~m}$. 


\subsubsection{Resultados ausentes}

A elaboração das cartas de domínios estruturais, superfície potencial de infiltração e chuva não foram concluídas pelas seguintes causas:

i. Para representar os domínios estruturais foram pesquisados principalmente dados de orientação espacial (direção e mergulho) das descontinuidades presentes nas rochas, como: atitudes de contatos entre litologias, xistosidade, juntas de alívio entre outras estruturas. Todavia as informações obtidas não abrangem toda a área de estudo e/ou não são suficientes para a caracterização prevista das descontinuidades a fim de formar setores de domínios estruturais.

ii. Para representar as superfícies potenciais de infiltração faltaram informações que caracterizassem os materiais para formação de classes distintas. Outro aspecto foi a elaboração da carta de superfície potencial de ruptura e a carta de contraste de permeabilidade, que de alguma forma, poderiam ser semelhantes ao resultado da análise das superfícies potenciais de infiltração, e, neste caso, não iria agregar informação adicional à aplicação das redes neurais artificiais. Também não foi possível uma interpretação em conjunto com os dados de uso e ocupação do solo.

iii. Na área de estudo, os registros disponíveis de chuva são oriundos de somente uma estação pluviométrica localizada na indústria NOVELIS. Para representar a intensidade e distribuição da chuva de forma a registrar a variação espacial deste atributo seriam necessárias outras estações pluviométricas que abrangessem toda a área de estudo. Entretanto, sabe-se que recentemente foram instaladas outras estações pluviométricas, iniciando a coleta de um banco de dados espacialmente mais amplo. 


\section{ANÁLISE CRÍTICA DOS DADOS PARA USO EM RNA E PROBABILIDADE}

\subsection{DEFINIÇÃO DO MODELO PARA ESTUDO DO MMG}

\subsubsection{Modelo conceitual adotado}

Em estudo feito para análise da previsão de movimentos de massa na Serra de Ouro Preto, Dias (2002) elabora um modelo conceitual para caracterizar diversos tipos de movimentos de massa. Segundo o mesmo autor, os movimentos mais comuns na região de Ouro Preto são os escorregamentos translacionais rasos, em rochas e em material inconsolidado. Por este motivo e confirmando esta afirmativa através da quantidade de feições deste tipo levantadas pelo mapa de inventário (143 feições), definiu-se o escorregamento translacional como sendo o movimento de massa a ser ilustrado e examinado nesta pesquisa.

Dias (2002) propõe uma abordagem de caráter geral, utilizando trabalhos clássicos sobre movimentos de massa, e outra como base em alguns trabalhos realizados em regiões montanhosas. As referências utilizadas para reunião dos condicionantes de cada um dos processos de movimentação de massa pode ser consultadas através da dissertação de Dias (2002).

Para cada tipo de movimento estudado, o autor considera na sua contextualização a definição no movimento, o tipo de material envolvido e as condições estabelecidas em cada processo para gerar os condicionantes para os processos de MMG.

Para o movimento de massa do tipo escorregamento translacional em rocha ou em material inconsolidado, Dias (2002) apresenta a seguinte definição retirada de (Hutchinson, 1988): Ruptura cisalhante numa superficie uniformemente planar em que a relação $d / L$ (relação entre a espessura e o comprimento da camada) seja tipicamente 0,1 ou menor, sem rotação da superfície de descontinuidade. 
Existe uma diferenciação, mostrada através da Tabela 36, quanto às condições levantadas pelas referências analisadas por Dias (2002) quando se trata do escorregamento translacional em material inconsolidado e em rocha.

Tabela 36 - Condições para ocorrência de escorregamento translacional.

\begin{tabular}{|c|c|}
\hline \multicolumn{2}{|c|}{ ESCORREGAMENTO TRANSLACIONAL } \\
\hline em material inconsolidado & em rocha \\
\hline $\begin{array}{l}\checkmark \text { Superfície de descontinuidade/junta bem } \\
\text { definida; }\end{array}$ & $\begin{array}{l}\checkmark \text { Superfície de descontinuidade/junta ou linha } \\
\text { de intersecção entre dois planos bem definida; }\end{array}$ \\
\hline $\begin{array}{l}\checkmark \text { Descontinuidades persistentes (acamamento. } \\
\text { Junta, clivagem, ou plano de foliação); }\end{array}$ & $\begin{array}{l}\checkmark \text { Descontinuidades persistentes (acamamento. } \\
\text { Junta, clivagem, ou plano de foliação); }\end{array}$ \\
\hline $\begin{array}{l}\checkmark \text { Direção aproximadamente paralela (por volta } \\
\text { de } 20^{\circ} \text { ) com o contorno da superfície do } \\
\text { terreno; }\end{array}$ & $\begin{array}{l}\checkmark \text { Direção aproximadamente paralela (por volta } \\
\text { de } 20^{\circ} \text { ) com o contorno da superfície do } \\
\text { terreno; }\end{array}$ \\
\hline $\begin{array}{l}\checkmark \text { Material inconsolidado com contraste de } \\
\text { permeabilidade. }\end{array}$ & $\begin{array}{l}\checkmark \text { A inclinação da descontinuidade deve ser } \\
\text { suficiente para promover o escorregamento. }\end{array}$ \\
\hline
\end{tabular}

A Tabela 37apresenta as condições para cada classe gerada a partir do tipo de material geológico envolvido.

Tabela 37 - Condições para ocorrência de escorregamento translacional.

\begin{tabular}{ll}
\hline \multicolumn{1}{c}{ Tipo de material envolvido } & \multicolumn{1}{c}{ Condições de cada processo } \\
\hline \hline & $\checkmark$ Baixos ângulos $\left(8-30^{\circ}\right) ;$ \\
& $\checkmark$ Pouco espesso $(>0,5 \mathrm{~m} \mathrm{e}<2 \mathrm{~m}) ;$ \\
ESCORREGAMENTO & $\checkmark$ Não coesivos; \\
TRANSLACIONAL & $\checkmark$ Taludes essencialmente secos; \\
EM MATERIAL & Em lajes $\quad \checkmark$ O mergulho do plano de ruptura deve ser maior que o \\
INCONSOLIDADO & ângulo de atrito; \\
& $\checkmark$ Desencadeado por chuva intensa e prolongada (se a \\
& infiltração for rápida) e chuva moderada e longa duração \\
& (se a infiltração for lenta). \\
\hline
\end{tabular}




\begin{tabular}{|c|c|c|}
\hline \multirow{13}{*}{$\begin{array}{l}\text { ESCORREGAMENTO } \\
\text { TRANSLACIONAL } \\
\text { EM MATERIAL } \\
\text { INCONSOLIDADO }\end{array}$} & \multirow{6}{*}{ Em placas } & $\checkmark$ Altos ângulos $\left(30-45^{\circ}\right) ;$ \\
\hline & & $\checkmark$ Pouco espesso $(<0,5 \mathrm{~m})$ \\
\hline & & $\checkmark$ Coesivos; \\
\hline & & $\checkmark$ Taludes essencialmente secos; \\
\hline & & $\begin{array}{l}\checkmark \text { O mergulho do plano de ruptura deve ser maior que o } \\
\text { ângulo de atrito; }\end{array}$ \\
\hline & & $\begin{array}{l}\checkmark \text { Desencadeado por chuva intensa e prolongada (se a } \\
\text { infiltração for rápida) e chuva moderada e longa duração } \\
\text { (se a infiltração for lenta). }\end{array}$ \\
\hline & \multirow{7}{*}{ De detritos } & $\checkmark$ Afeta o manto de detritos; \\
\hline & & $\begin{array}{l}\checkmark \text { Massa de material de baixa coesão que tende a sofrer } \\
\text { considerável distorção e partição durante o movimento; }\end{array}$ \\
\hline & & $\begin{array}{l}\checkmark \text { Velocidade aumenta com a declividade e diminui com a } \\
\text { quantidade de argila; }\end{array}$ \\
\hline & & $\checkmark$ Declividade de 25 a $45^{\circ}$; \\
\hline & & $\begin{array}{l}\checkmark \text { Baixa relação entre a espessura e o comprimento da } \\
\text { camada deve ser menor que } 0,05(\mathrm{~d} / \mathrm{L}) ;\end{array}$ \\
\hline & & $\begin{array}{l}\checkmark \text { Desencadeado por chuva intensa e prolongada (se a } \\
\text { infiltração for rápida) e chuva moderada e longa duração } \\
\text { (se a infiltração for lenta); }\end{array}$ \\
\hline & & $\checkmark$ Majorado com a destruição de vegetação. \\
\hline \multirow{11}{*}{$\begin{array}{l}\text { ESCORREGAMENTO } \\
\text { TRANSLACIONAL } \\
\text { EM ROCHA }\end{array}$} & \multirow{4}{*}{ Planar } & $\begin{array}{l}\checkmark \text { O mergulho do plano de ruptura deve ser menor que o } \\
\text { mergulho da face do talude; }\end{array}$ \\
\hline & & $\begin{array}{l}\checkmark \text { O mergulho do plano de ruptura deve ser maior que o } \\
\text { ângulo de atrito; }\end{array}$ \\
\hline & & $\checkmark$ Liberação das margens laterais de blocos; \\
\hline & & $\checkmark$ Desencadeado por chuva forte e prolongada. \\
\hline & \multirow{3}{*}{ Cunha } & $\begin{array}{l}\checkmark \text { O escorregamento é direcionado ao longo da linha de } \\
\text { intersecção de dois planos de descontinuidade; }\end{array}$ \\
\hline & & $\begin{array}{l}\checkmark \text { Mínimo de duas famílias de descontinuidades contínuas } \\
\text { e não paralelas; }\end{array}$ \\
\hline & & $\checkmark$ Desencadeado por chuva forte e prolongada. \\
\hline & \multirow{4}{*}{ Em degraus } & $\begin{array}{l}\checkmark \text { Descontinuidade/fratura/junta sem persistência e que } \\
\text { formam uma superfície de escorregamento contínua; }\end{array}$ \\
\hline & & $\begin{array}{l}\checkmark \text { Ângulo de superfície de ruptura é maior que da } \\
\text { descontinuidade e menor que a face do talude; }\end{array}$ \\
\hline & & $\begin{array}{l}\checkmark \text { Duas ou mais famílias de descontinuidades não paralelas } \\
\text { aproximadamente perpendiculares entre si; }\end{array}$ \\
\hline & & $\checkmark$ Desencadeado por chuva forte e prolongada. \\
\hline
\end{tabular}




\subsubsection{Modelo físico e matemático adotado}

Para estudar o escorregamento translacional a partir de seu modelo matemático, utilizou-se o método de estabilidade de Talude Infinito empregado para os casos nos quais o escorregamento é translacional e paralelo à face do talude.

Este modelo, desenvolvido por Taylor (1948), como outros que também estudam a estabilidade de taludes, procuram encontrar o valor do Fator de Segurança (FS) que consiste na relação entre as forças de resistência ao cisalhamento existente no solo e as tensões cisalhantes que atuam sobre ele. O método de Talude Infinito despreza os efeitos das extremidades e pode ser melhor visualizado através da Figura 63.

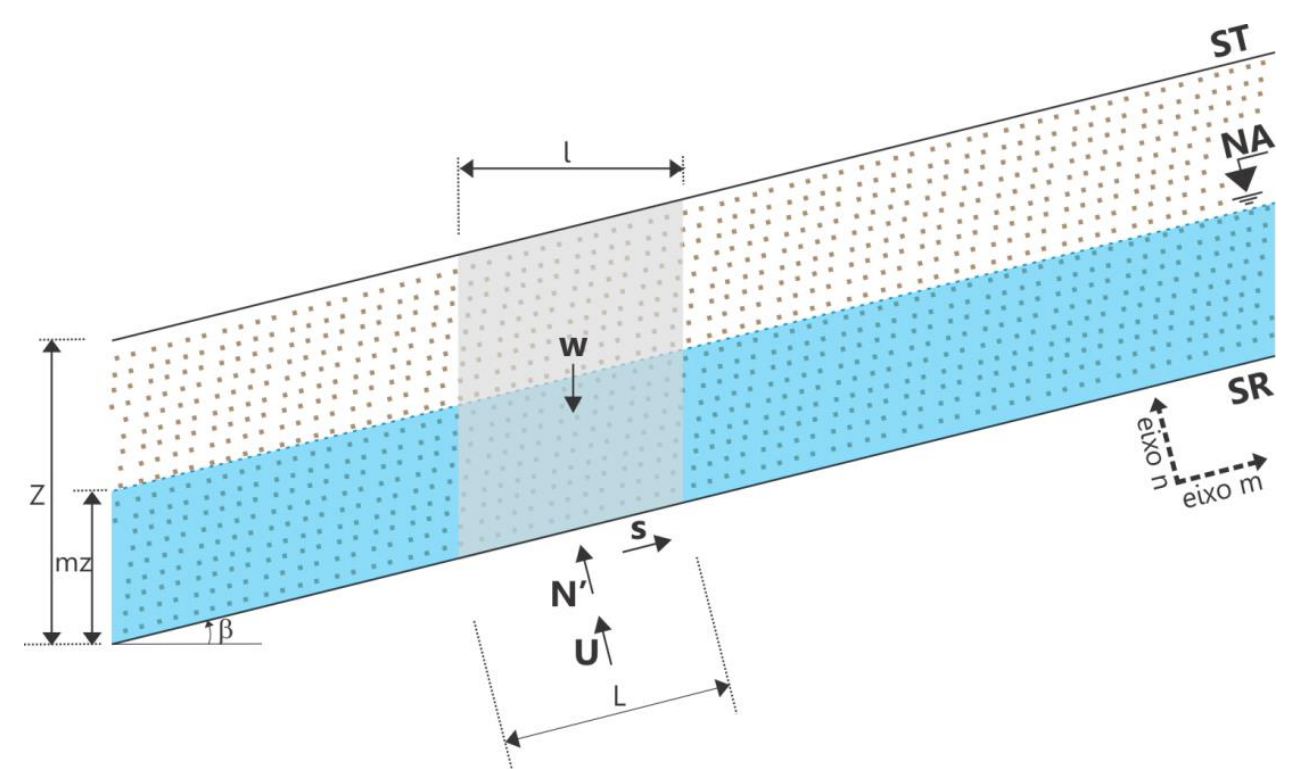

Figura 63 - Forças atuantes em uma fatia genérica, segundo o método de Talude Infinito. (Modificado de Gerscovich, 2012).

Nestas condições, existem as seguintes relações entre as variáveis:

$$
\begin{array}{cc}
b=l \cos \beta & (\text { Equação 38) } \\
U=u l & \text { (Equação 39) } \\
W=b h \gamma & \text { (Equação 40) }
\end{array}
$$




$$
s=\frac{c^{\prime} l}{F S}+N^{\prime} \frac{\operatorname{tg} \varphi^{\prime}}{F S}
$$

Ao assumir que as forças que atuam na fatia estão em equilíbrio nas direções paralela (eixo m) e perpendicular (eixo n) à superfície do talude, obtém-se as seguintes relações matemáticas:

$$
\begin{array}{ll}
\sum F_{m}=0 & W \operatorname{sen} \beta=s \rightarrow W \operatorname{sen} \beta=\frac{c^{\prime} l}{F S}+N^{\prime} \frac{\operatorname{tg} \varphi^{\prime}}{F S} \\
\sum F_{n}=0 & W \cos \beta=N^{\prime}+u l \rightarrow N^{\prime}=W \cos \beta-u l
\end{array}
$$

O cálculo do Fator de Segurança (FS), independente da dimensão da fatia, pode ser exposto em termos de tensões efetivas (Equação 44) e totais (Equação 45).

$$
\begin{gathered}
F S=\frac{c^{\prime}+\left(\gamma h \cos ^{2} \beta-u\right) \operatorname{tg} \varphi^{\prime}}{\gamma h \operatorname{sen} \beta \cos \beta} \quad \text { (Equação 44) } \\
F S=\frac{s_{u} l}{\gamma h \operatorname{sen} \beta \cos \beta} \quad \text { (Equação 45) }
\end{gathered}
$$

A condição de estabilidade do talude é indicada pelo valor de FS>1 e se o valor for $\mathrm{FS}<1$ indica que o talude está instável, ou fisicamente já tenha rompido. $\mathrm{O}$ valor de FS=1 é o limite entre a estabilidade e a instabilidade.

Levando em consideração esta explanação sobre o modelo conceitual, físico e matemático do escorregamento translacional definiu-se, dentre as condições para ocorrência do processo, os atributos que mais contribuem na instabilidade através dos quais se dará a elaboração da carta de eventos perigosos, a saber: unidades geológico-geotécnicas, declividade, rumo da inclinação da encosta, contraste de permeabilidade, resistência ao cisalhamento, superfície potencial de ruptura, uso e ocupação, domínios estruturais, superfície potencial de infiltração e chuva.

As próximas seções apresentarão a aplicação dos métodos redes neurais artificiais e probabilidade para elaboração de uma carta de eventos perigosos. 


\subsection{CONDIÇÕES PARA USO DOS DADOS EM REDES NEURAIS ARTIFICIAIS}

Após obtenção de todos os mapas e cartas que representam os fatores predisponentes à ocorrência de movimentos de massa gravitacionais, o próximo passo é a aplicação destes dados em redes neurais artificiais. Desta forma, são mostrados todos os procedimentos para chegar ao resultado esperado.

\subsubsection{Organização dos dados}

Esta fase se inicia pela transformação dos mapas e cartas em uma base de dados numérica para se tornarem elementos de entrada possíveis de serem lidos pelo programa utilizado para aplicação das redes neurais artificiais.

Foram produzidos dois formatos de dados espaciais, os matriciais em raster (declividade, por exemplo) e os vetoriais (resistência ao cisalhamento, por exemplo). Para os arquivos em formato raster usou-se, na sua criação, uma malha (grade ou grid) de células a partir de uma estrutura que abrangesse toda a área de estudo.

Cada mapa/carta foi dividido em células ou pixels de dimensão igual a $20 \times 20 \mathrm{~m}$. Este tamanho foi escolhido a partir da literatura estudada sabendo que ele deve representar o mais próximo do real possível àquela área, sem tampouco criar uma grande quantidade de dados que poderia dificultar e/ou interferir no resultado. Assim, chegou-se a uma malha com 116.000 pixels.

Para os dados em formato raster as células estão sempre associadas ao valor que representa uma das classes do atributo. Para os dados vetoriais foi necessário a sua conversão para matricial. Isto se deu através do software $\operatorname{ArcMap}^{T M}$ utilizando a ferramenta feature to raster. Esta ferramenta executa a transformação dos dados a partir das linhas vetoriais que separam as classes dos atributos. A escolha de qual classe representa a célula é definida como sendo a classe que possui maior representação dentro do pixel, como mostra a Figura 64. 


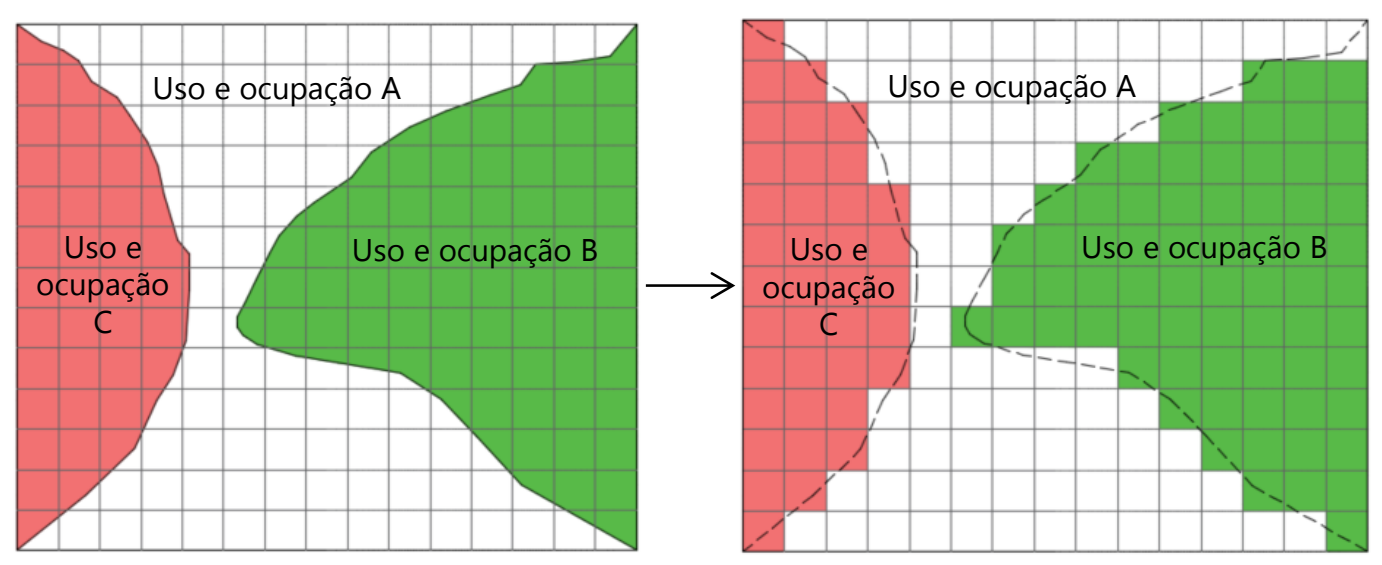

Figura 64 - Representação da conversão das classes de vetoriais para matriciais.

Ao final desta etapa, todos os mapas/cartas foram exportados como imagem e, optou-se por utilizar o próprio programa de execução da rede neural para esta transformação dos rasters em matrizes numéricas, o software MATLAB ${ }^{\circledR}$. Este procedimento também serve para tornar os dados não numéricos, como uso e ocupação, em dados numéricos.

Como exemplo é demonstrada a transformação da carta de declividade (Figura 65) a partir do algoritmo desenvolvido para executar as seguintes tarefas: entrada da imagem; transformação da imagem em tons de cinza utilizando o sistema de cores RGB; seleção da primeira matriz de cor; normalização dos dados da matriz para valores numéricos inteiros, e saída da matriz.

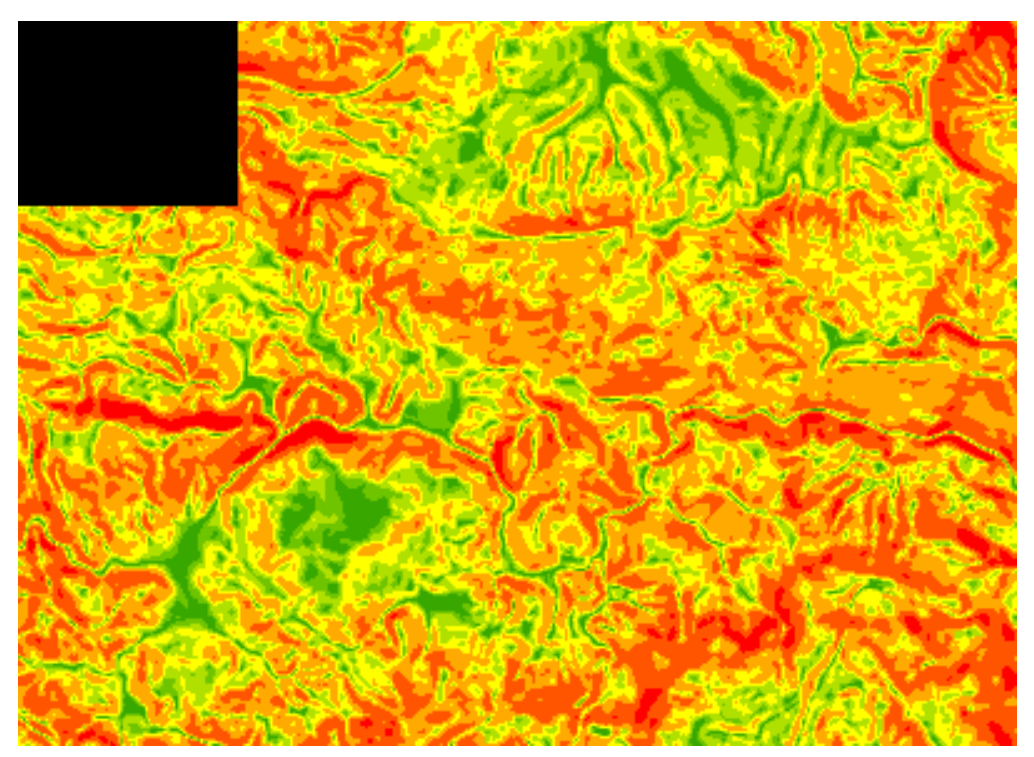

Figura 65 - Raster do atributo declividade. 
Para que não faltasse dados na matriz numérica, a porção da área de estudo que não possui informação, e por isso não completa o retângulo, foi colorida de preto, como pode ser visto na Figura 65. Ela será desconsiderada na fase da aplicação da rede.

O algoritmo proposto para execução das tarefas anteriormente mencionadas, ainda em fase de implantação na plataforma MATLAB $®$, é:

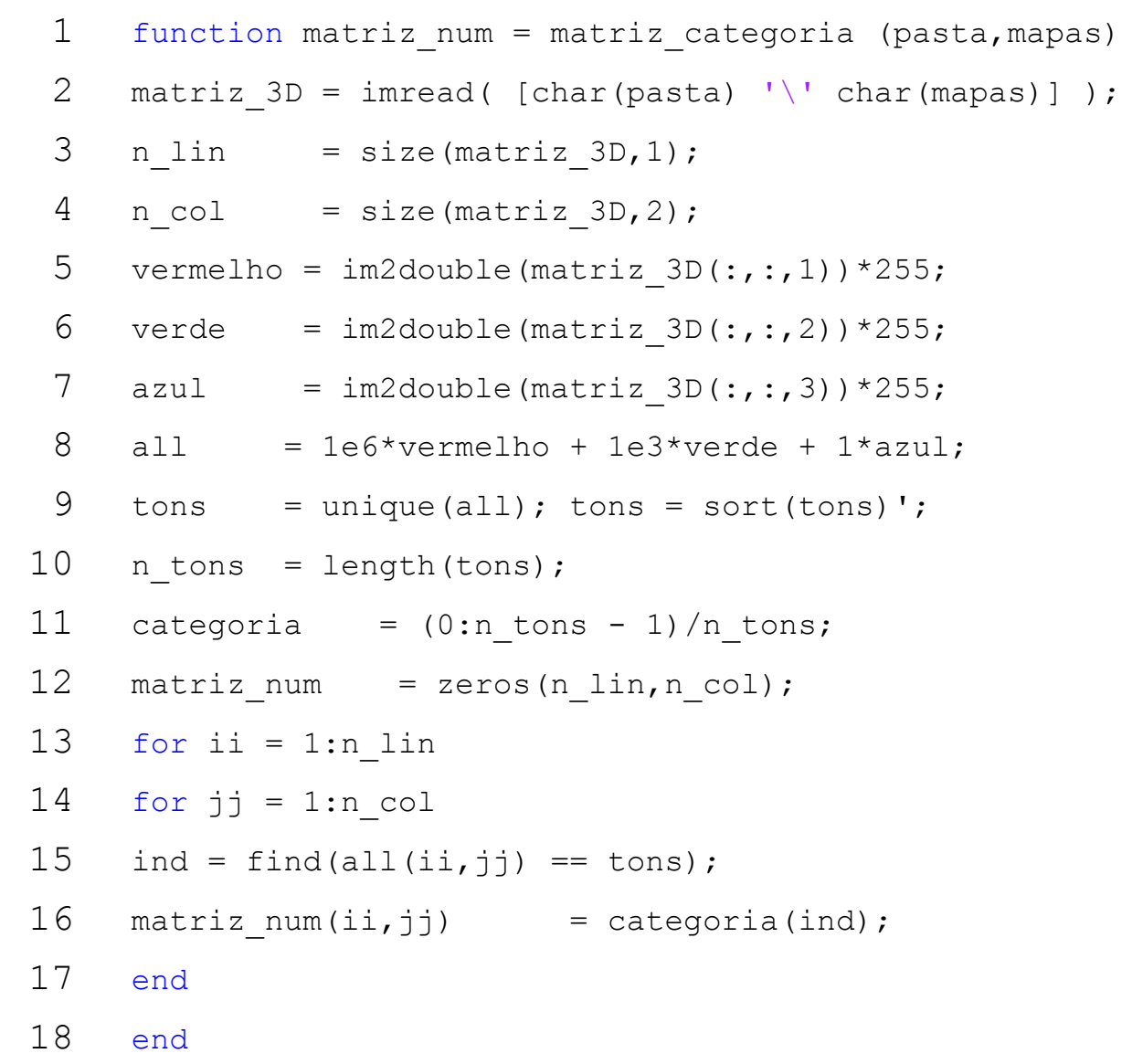

Os comandos mostrados no algoritmo podem ser explicados pelos passos a seguir:

\section{$1^{\circ}$ Define algumas variáveis}

1 Define a variável que será o resultado do algoritmo, neste caso, matriz_num

2 Busca a imagem e a define como matriz_3D

3 Mostra o número de linhas da matriz_3D e define este valor como n_lin

4 Mostra o número de linhas da matriz_3D e define este valor como n_col 


\section{$2^{\circ}$ Muda os valores do RGB da imagem para que eles não se repitam}

5 Obtém a componente de cor vermelha do RBG e a define como a variável vermelho

6 Obtém a componente de cor verde do RBG e a define como a variável verde

7 Obtém a componente de cor azul do RBG e a define como a variável azuI

8 Modifica os valores de RGB para que não se repitam em componentes diferentes, ou seja, cada combinação de RGB levará um valor único de all

9 Define como tons as diferentes cores da figura e coloca os valores em ordem crescente

10 Define como n_tons a quantidade de cores diferentes que tem a figura

\section{$3^{\circ}$ Construindo a matriz_num}

11 Define a variável categoria como um vetor formado por $n \_$tons normalizado entre os valores $[0,1[$

12 Define que a matriz_num deve ter a mesma quantidade de linhas e colunas da matriz_3D

13 Varre o número de linhas da matriz_num

14 Varre o número de colunas da matriz_num

15 Define como ind a posição do elemento i i e jj da matriz all dentro do vetor tons

16 Substitui o elemento $i i j j$ da matriz_num pelo elemento ind do vetor categoria

17 Fim

18 Fim

Depois da execução deste algoritmo cada mapa/carta, que representam os fatores predisponentes, são agora matrizes numéricas que possuem 290 linhas e 400 colunas, que juntas formam o conjunto de entradas na rede neural artificial de acordo com a Figura 66. Os elementos ij da mesma posição da malha formam um vetor de dados de entrada da rede neural. A execução deste algoritmo é feita em conjunto com o algoritmo de aplicação da rede neural. 


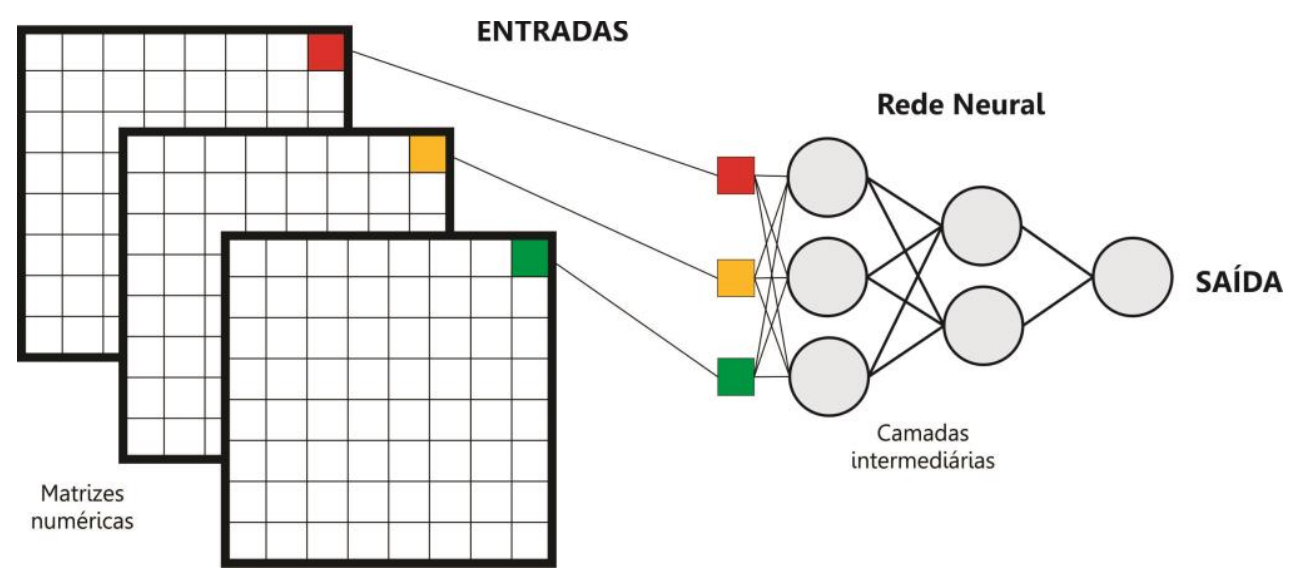

Figura 66 - Formação da rede neural artificial.

Esta fase da organização dos dados não foi executada para todos os mapas/cartas, pois, existem representações de alguns atributos que não foram elaborados. Os dados existentes para esta aplicação são:

- Unidades geológico-geotécnicas

- Declividade

- Rumo da inclinação da encosta

- Contraste de permeabilidade

- Resistência ao cisalhamento

- Superfície potencial de ruptura

- Uso e ocupação

E os dados ausentes, são:

- Domínios estruturais

- Superfície potencial de infiltração

- Chuva

Somente os dados existentes produziram um total de 123 classes diferentes, todavia a metodologia para a estruturação da RNA e seu treinamento foi elaborada levando em consideração os 10 fatores predisponentes, visto que se trata de uma avaliação da utilização dos dados e orientação para futuras aplicações. 


\subsubsection{Implementação de um modelo de RNA}

Nesta seção são apresentadas as principais características da rede neural proposta para aplicação dos dados deste trabalho. Desse modo são determinados: os parâmetros da rede, sua estrutura, arquitetura, treinamento e validação. Vale lembrar que esta aplicação não foi efetivamente executada, sendo apenas uma proposta de aplicação de redes neurais com base na literatura. Quando aplicado, este modelo poderá sofrem alterações baseadas na busca pela melhoria dos resultados.

\subsubsection{Estruturação da RNA}

Propõe-se que a rede neural artificial seja construída segundo a topologia Perceptron multicamadas, rede neural que possui camadas intermediárias de neurônios de arquitetura feedforward. As características da rede proposta são:

- Algoritmo de treinamento: Retro-propagação do erro (backpropagation);

- Função de ativação: Função logística;

- Camada de entrada: 10 neurônios na camada de entrada;

- Camadas intermediárias: 2 camadas ocultas;

- Camada de saída: 1 camada de saída.

A escolha dos parâmetros de uma rede neural é sempre subjetiva. Na maioria das vezes leva-se em consideração o problema em questão para determinar um arranjo e iniciar o processo de aplicação. Depois, algumas estruturas dentro do primeiro arranjo proposto podem ser alteradas se a rede não gerar resultados satisfatórios.

A topologia e o algoritmo de aprendizagem foram escolhidos com base no que é usual na literatura consultada. A função de ativação é dependente do valor 
esperado e da aplicação, por isso, sugere-se a função logística por apresentar valores de saída entre 0 e 1. A quantidade de dados de entrada determinou-se pela quantidade de fatores condicionantes a serem analisados. Para as camadas intermediárias optou-se por utilizar duas camadas, pode-se, nestes casos, treinar a rede com um ou mais camadas intermediárias e escolher para validação a arquitetura que mostrou melhor desempenho.

\subsubsection{Arquitetura da RNA}

A arquitetura da rede proposta é definida como sendo unidirecional de múltiplas camadas, esta escolha está ligada diretamente ao algoritmo de aprendizagem a ser usado. Definiu-se utilizar duas camadas intermediárias e a arquitetura de treinamento pode ser representada da seguinte forma: $10 \times[7-21] \times[7-21] \times 1$ de acordo com a Figura 67. Os valores entre colchetes indicam que as camadas intermediárias são treinadas para variar entre 7 e 21 neurônios no intuito de testar o desempenho das redes neurais e escolher a melhor.

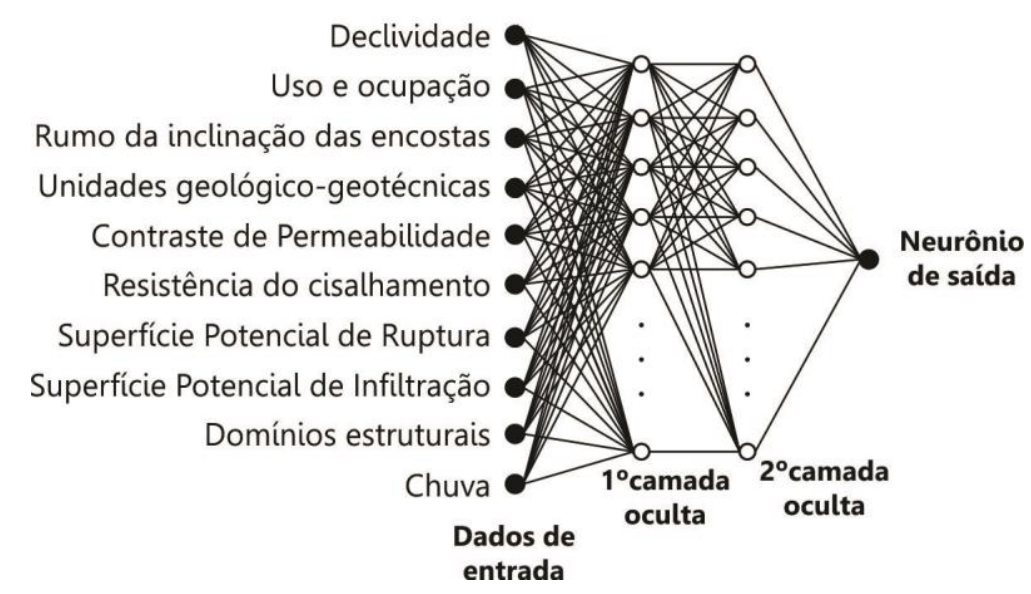

Figura 67 - Arquitetura da rede neural artificial. 


\subsubsection{Treinamento}

Do conjunto de dados existentes para treinamento, ou seja, dados que possuem o valor esperado, sugere-se separar aproximadamente 60\% para a etapa de treinamento da rede e, 40\% para validação da rede escolhida. O grupo de dados para cada etapa deve ser representativo de todo o conjunto.

O treinamento da rede no ambiente MATLAB@ pode ser realizado de duas formas: através da interface denominada NNTool ou por meio de linhas de comando. Optou-se, neste trabalho, em mostrar a aplicação em redes neurais através da utilização de linhas de comando para melhor visualizar as etapas e procedimentos a realizar. As etapas de entrada dos dados, definição da estrutura e arquitetura da rede, retirada da área sem informação (células que não possuem informação e foram substituídas pelo valor 0 no algoritmo de elaboração das matrizes numéricas), treinamento e validação formam a linguagem geral das linhas de comando.

Algumas funções básicas de criação que servem para aplicação de redes neurais utilizando $M A T L A B \circledR$ são mostradas no algoritmo proposto para execução da rede neural e podem ser descritas como:

- newff: cria uma rede MPL do tipo forward,

- logsig: função de transferência logística;

- traingdx: função de treinamento backpropagation;

- learngd: aprendizado supervisionado para ajustes dos pesos;

- train: aplica o treinamento na rede neural;

- sim: simula uma rede neural.

O algoritmo elaborado para aplicação do método de redes neurais é:

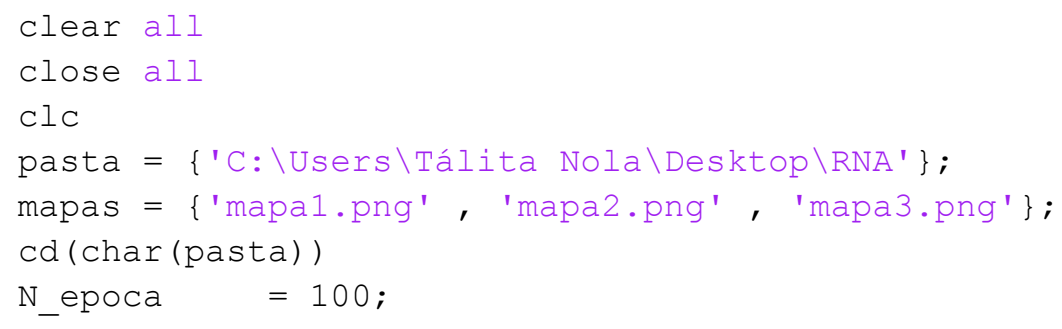




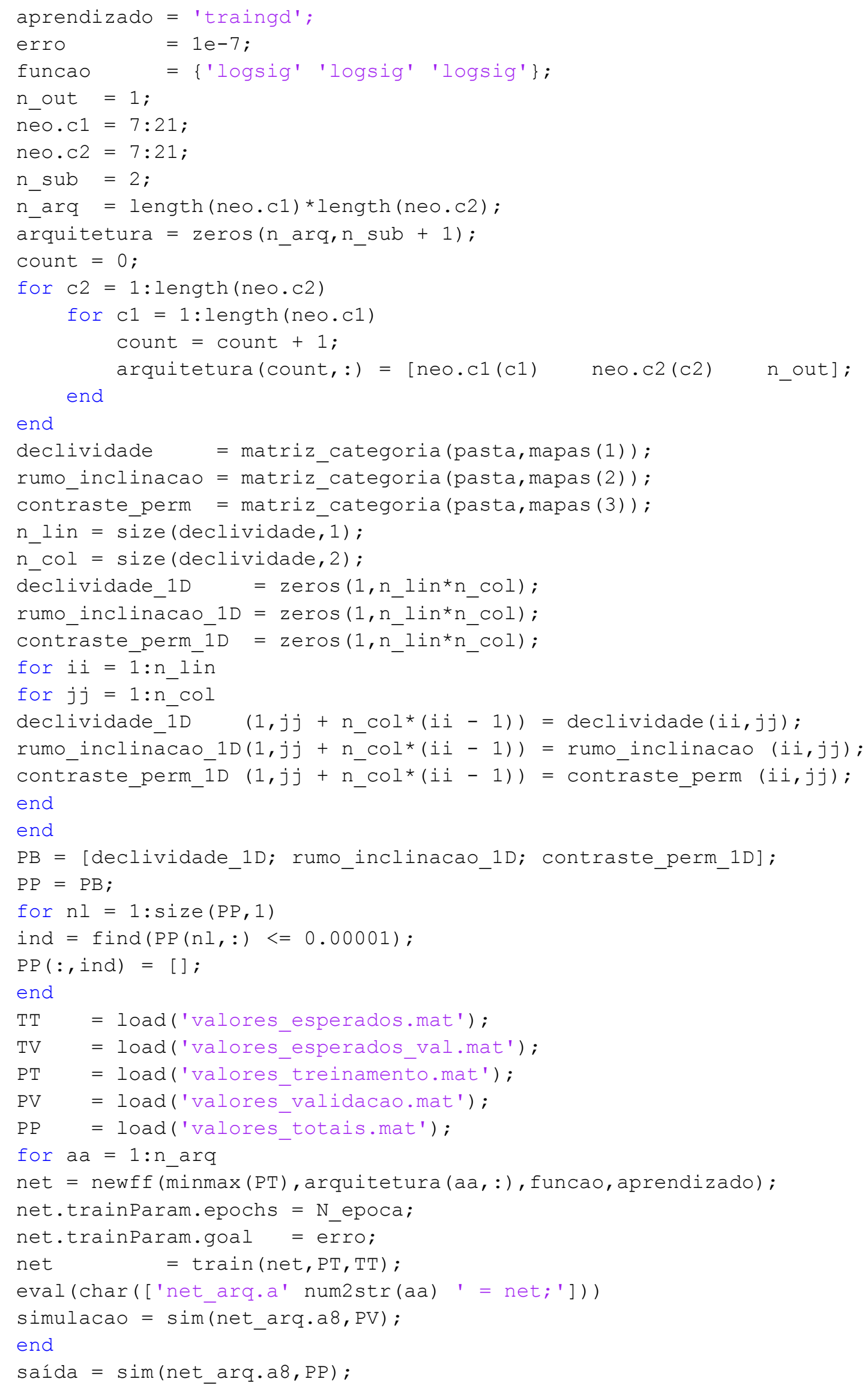


Os comandos mostrados no algoritmo podem ser explicados pelos passos a seguir:

\section{$1^{\circ}$ Limpa o ambiente e busca os arquivos}

1 Limpa a memória

2 Fecha todas as figuras

3 Limpa a janela de comandos

4 Define o local onde estão os dados

5 Define o nome dos dados que devem ser lidos

6 Define o local onde o MATLAB deve trabalhar

\section{$2^{\circ}$ Define as variáveis da aplicação}

7 Define o número de épocas

8 Define o método de aprendizado

9 Defino o valor do erro máximo a ser atingido

10 Define as funções de transferência

11 Define o número de neurônios na camada de saída

12 Define como será a variação do número de neurônios da primeira camada intermediária

13 Define como será a variação do número de neurônios da segunda camada intermediária

14 Define o número de camadas intermediárias

15 Define como n_arq as várias arquiteturas que serão treinadas

\section{$3^{\circ}$ Construindo a arquitetura da rede neural}

16 Define a dimensão da variável arquitetura

17 Define que count será um contador

18 Varre todos os elementos da variável neo.c2

19 Varre todos os elementos da variável neo.c1

20 A cada combinação de c1 e c2, count aumenta uma unidade

21 Define quais os dados que formam a variável arquitetura

22 Fim 
23 Fim

\section{$4^{\circ}$ Executando o algoritmo para construção da matriz numérica de cada atributo}

24 Define como declividade a matriz numérica gerada a partir do mapa 1

25 Define como rumo_inclinação a matriz numérica gerada a partir do mapa 2

26 Define como contraste_perm a matriz numérica gerada a partir do mapa 3

\section{$5^{\circ}$ Obtendo o número de linhas e colunas da matriz numérica}

27 Define $\mathrm{n}_{-}$lin como o número de linhas da matriz numérica

28 Define n_col como o número de linhas da matriz numérica

\section{$6^{\circ}$ Transformando as matrizes numéricas em vetores}

29 Define que a matriz declividade_1D deve ter a mesma quantidade de colunas que a matriz declividade

30 Define que a matriz rumo_inclinação_1D deve ter a mesma quantidade de colunas que a matriz declividade

31 Define que a matriz contraste_perm_1D deve ter a mesma quantidade de colunas que a matriz declividade

32 Varre o número de linhas das matrizes numéricas

33 Varre o número de colunas das matrizes numéricas

34 Transformando a matriz declividade em vetor

35 Transformando a matriz rumo_inclinação em vetor

36 Transformando a matriz contraste_perm em vetor

37 Fim

38 Fim 


\section{$7^{\circ}$ Retirando a parte da área sem informação}

39 Matriz $\mathrm{PB}$ é formada pelos vetores dos atributos

40 Define como PP a saída desta etapa

$41 \quad$ Varre todos os vetores

42 Procura todos os elementos $i j$ definidos como 0

43 Retira todos estes elementos

44 Fim

\section{$8^{\circ}$ Treinamento e validação da rede}

45 Busca o vetor TT dos resultados esperados para treinamento

46 Busca o vetor TV dos resultados esperados para validação

47 Busca a matriz PT dos dados de entrada referentes aos resultados esperados para treinamento

48 Busca a matriz PV dos dados de entrada referentes aos resultados esperados para validação

49 Busca a matriz PP dos dados de entrada da área total de estudo

50 Requer que o treinamento e validação sejam feitos para todas as arquiteturas previstas

51 Define a rede neural net

52 Entra com o parâmetro época

53 Entra com o parâmetro erro

54 Treina a rede neural e armazena o resultado na variável net

55 A variável net_arq armazena a rede neural net criada para cada arquitetura testada

56 Simula a rede neural com a melhor arquitetura usando PV como entrada

57 Fim

58 Simula a rede neural com a melhor arquitetura usando PP como entrada 


\section{OBSERVAÇÕES}

i. Na primeira etapa deve ser incluído o local específico dos dados em análise e todos eles devem ser também incluídos na leitura.

ii. A quarta, sexta e sétima etapas devem ser realizadas para todos os dados de entrada.

iii. A quinta, sexta e sétima etapas são necessárias apenas para retirada das células sem informação da área de estudo deste trabalho. Para entrada no algoritmo a imagem deve ser um polígono regular de 4 lados. No caso de a imagem ser retangular ou quadrada com todas as células preenchidas por informações, estas etapas podem ser excluídas do algoritmo.

iv. A quinta etapa é realizada para saber qual o número de linhas e colunas da matriz numérica. Como todas as matrizes são iguais, este procedimento pode ser realizado somente para uma das matrizes.

v. A simulação tanto da linha 56 quanto da linha 58 só deve ser feita depois de definida qual a arquitetura apresenta o melhor desempenho.

vi. Os critérios para parar o treinamento foram definidos como sendo a quantidade de épocas ou o erro máximo atingido.

vii. Este algoritmo encontra-se em fase de implantação na plataforma MATLABR.

\subsubsection{Validação e execução final}

Após o treinamento da rede neural e a definição de qual arquitetura usar, a fase de validação envolve testar a rede escolhida ocultando os resultados esperados. Desta forma as respostas apresentadas podem ser analisadas e comparadas aos valores reais. Este procedimento serve para confirmar a escolha da estrutura da rede neural, seus pesos e funções.

Nesta fase são inseridos no algoritmo da rede neural os $40 \%$ restantes dos dados de treinamento, no ambiente $M A T L A B \circledR$ esta etapa é denominada simulação. 
O resultado apresentado é uma tabela com os todos os valores obtidos. Faz-se, então, a avaliação dos erros apresentados entre os valores obtidos e os valores esperados. O cálculo do erro absoluto e do erro relativo pode ser feito diretamente

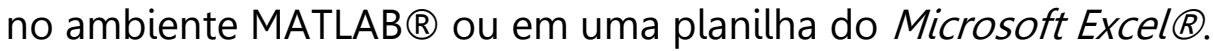

$\mathrm{Na}$ análise dos erros busca-se verificar se estes foram baixos o suficiente para comprovar a efetividade da rede neural escolhida e declará-la especialista nesta aplicação. Um procedimento para comprovação visual que pode ser realizado é comparar os dados obtidos (simulados) e os valores esperados por meio de um gráfico de sobreposição, que também pode ser feito facilmente no ambiente MATLAB®.

Por fim, a execução final é a etapa na qual são inseridos todos dos dados disponíveis para análise, ou seja, os dados que não possuem resposta e também os que possuem. Este conjunto de dados é inserido no mesmo algoritmo, e assim, são gerados os resultados para cada célula do mapa.

\subsubsection{Carta de Eventos Perigosos aplicando RNA}

A resposta da rede neural é um banco de dados com a quantidade total de células da área estudada, neste trabalho são 116.000 dados. Os valores do neurônio de saída foram projetados para estarem dentro de um intervalo entre 0 e 1 e podem ser posteriormente classificados de várias formas.

Levando em consideração o que é apresentado na literatura sobre esta aplicação, os dados de saída consistem, neste caso, nas diferentes representações das classes do zoneamento de eventos perigosos que podem ser interpretadas como um intervalo de valores dentro dos dados de saída da rede.

Por exemplo, valores de saída entre 0 e 0,2 podem representar um baixa probabilidade de ocorrência de eventos perigosos. Em torno de 3 a 5 classes são sugeridas pela literatura, a saber: zona de perigo muito baixo, zona de perigo baixo, zona de perigo moderado, zona de perigo alto e zona de perigo muito alto. 
Para que o vetor de dados de saída se transforme em uma representação espacial, o conjunto de resultados da rede neural artificial pode ser introduzido no software $\operatorname{ArCMap}^{T M}$ sendo elaborada a carta de eventos perigosos a partir da reclassificação dos intervalos de valores utilizando o mesmo programa.

Entretanto, sugere-se que a elaboração da carta de eventos perigosos não oculte os valores de probabilidade em classificações de intervalos. A proposta aqui apresentada é representar a probabilidade como sendo um valor representativo para uma determinada área que pode ser uma unidade geológico-geotécnica, um landform ou uma vertente.

Por exemplo, tendo como base um mapa de vertentes, como mostrado na Figura 68 , existirão " $n$ " pixels que possuem " $n$ " valores de probabilidade que estão representados em uma mesma vertente (Figura 68b). Pode-se, então, adotar um valor de probabilidade representativa daquela área.

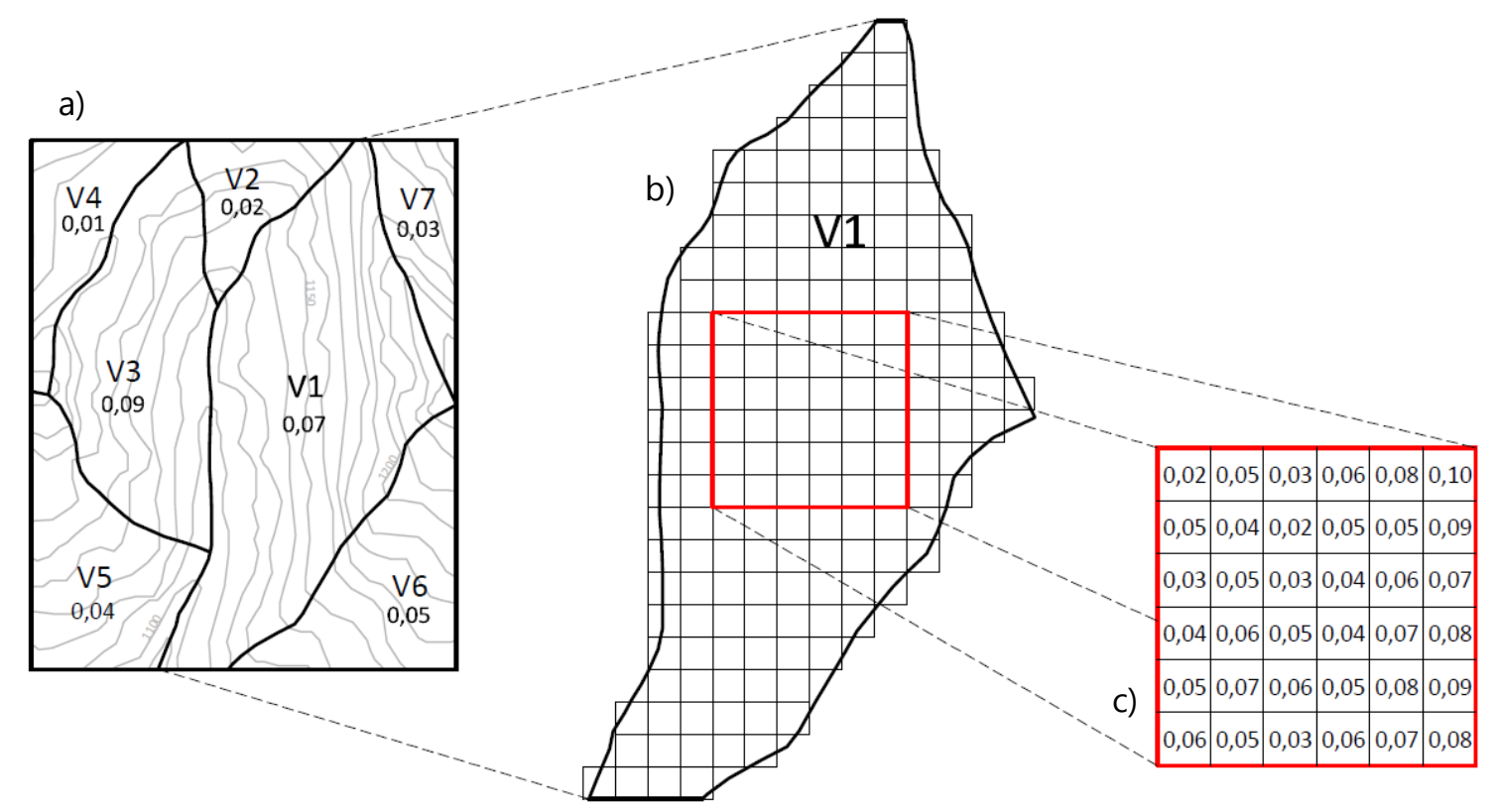

Figura 68 - Forma de representação da carta de eventos perigosos: a) mapa de vertentes, b)grade com valores de probabilidade sobre vertente $\mathrm{V} 1, \mathrm{c}$ ) detalhe dos valores de probabilidade. 
O valor de probabilidade, representado na Figura 68a, pode ser tomado como: a média dos valores que ocupam a vertente e seu desvio padrão; o menor ou o maior valor encontrado, e até mesmo o valor mais frequente. A Figura 68c mostra um detalhe dos resultados de probabilidades de parte dos pixels utilizados para definir o valor de probabilidade representativo da vertente $\mathrm{V} 1$.

Representar a carta de eventos perigosos desta maneira é uma forma mais simples de mostrar o seu significado e utilizá-la para outras aplicações. 


\subsection{CONDIÇÕES PARA USO DOS DADOS EM PROBABILIDADE}

Nesta seção, outro método de aplicação será testado, a abordagem probabilística dos dados para elaboração da carta de eventos perigosos. Da mesma forma com que foi descrito para seção 6.2, onde foi demonstrada a aplicação em redes neurais artificiais, esta fase ocorre após a obtenção de todos os mapas e cartas que representam os fatores predisponentes à ocorrência de movimentos de massa gravitacionais. Os procedimentos da aplicação serão descritos a seguir.

\subsubsection{Organização dos dados}

A organização dos dados para aplicação da abordagem probabilística utiliza, em partes, o que foi executado para aplicação em redes neurais artificiais. Também para este método é necessário que os mapas e cartas estejam em formato raster para facilitar a sua execução. Isto porque, para cada célula será calculado uma probabilidade de ocorrência de movimentos de massa gravitacionais a partir do conjunto de fatores condicionantes que ela apresenta.

Assim, esta fase se inicia pela transformação dos mapas e cartas em raster e reclassificação da imagem para uma forma única de representação, a partir de suas classes. Os mapas matriciais produzidos, cartas de declividade e rumo da inclinação da encosta já estão no formato desejado e, portanto são separados deste processo. Os mapas/cartas vetoriais foram transformados em matriciais com uma malha de células de dimensão igual a $20 \times 20 \mathrm{~m}$. Todo o procedimento para esta modificação pode ser consultado na seção 6.2.1.

Após esta etapa, os mapas e cartas estão prontos para a fase de reclassificação para os valores de probabilidade e execução do método. 


\subsubsection{Método probabilístico}

A abordagem probabilística escolhida para calcular a possibilidade de ocorrência de movimentos de massa gravitacionais na região de Ouro Preto é a Probabilidade Condicional, que se baseia na observação da relação entre cada fator envolvido no processo e a ocorrência de movimentos de massa gravitacionais, assim como a relação entre os movimentos de massa gravitacionais do passado e do presente em uma determinada região.

\subsubsection{Descrição do método}

A probabilidade condicional diz que, assumindo o evento " $O$ " como sendo a ocorrência de movimentos de massa gravitacionais e o evento " $A$ " como a ocorrência de um dos atributos que estão envolvidos no processo que desencadeia o movimento, a probabilidade do evento " $O$ " ocorrer dado que " $A$ " ocorreu é:

$$
P(O \mid A)=\frac{P(O \cap A)}{P(A)}
$$

Como,

$$
\begin{aligned}
& P(O \cap A)=P(A \cap O), \\
& \text { (Equação 47) } \\
& P(O \cap A)=P(O \mid A) P(A), \\
& \text { (Equação 48) } \\
& P(A \cap O)=P(A \mid O) P(O), \\
& \text { (Equação 49) }
\end{aligned}
$$

tem-se que,

$$
\begin{array}{ll}
P(O \mid A) P(A)=P(A \mid O) P(O) & \text { (Equação 50) } \\
\therefore P(A \cap O)=P(O \mid A) P(A) & \text { (Equação 51) }
\end{array}
$$


Se o evento " $O$ " é dependente de um número $n$ de eventos mutualmente exclusivos " $A_{1}, A_{2}, A_{3} \ldots A_{n}$." que formam um espaço amostral, $\Omega$, a probabilidade de ocorrência do evento " $O$ " pode ser calculado pelo Teorema da Probabilidade Total.

Por exemplo, o atributo declividade pode possuir 4 classes, a saber:

- Classe 1:0-15\%;

- Classe 2: $16-30^{\circ}$;

- Classe 3: 31 a $45^{\circ}$,

- Classe 4: $<45^{\circ}$.

Estas classes são mutualmente exclusivas, pois, quando acontece a classe 1 em uma determinada região de estudo não ocorre a classe 4, assim como quando ocorre a classe 2 não ocorre a 3, e, juntas elas formam o espaço amostral do atributo declividade. Cada uma das classes é um evento " $A_{n}$ " dos quais o evento " $O$ " é dependente. Se for analisado qualquer outro atributo, as classes que formam este grupo serão também mutualmente exclusivas entre si e serão representadas por um conjunto " $A_{1}, A_{2}, A_{3} \ldots A_{n}$ " de eventos (o numero $n$ é definido pela quantidade de classes que $\mathrm{o}$ atributo possui).

Desta forma, utilizando o Teorema da Probabilidade Total, tem-se que:

$$
\begin{gathered}
P(O)=P\left(A_{1} \cap O\right)+P\left(A_{2} \cap O\right)+\cdots+P\left(A_{n} \cap O\right)= \\
\sum_{i=1}^{n} P\left(\mathrm{~A}_{i}\right) \mathrm{P}\left(\mathrm{O} \mid \mathrm{A}_{i}\right)
\end{gathered}
$$

Ou seja, a probabilidade do evento " $O$ " ocorrer é igual ao somatório da probabilidade da intersecção dos eventos " $O$ " e " $A_{n}$ ".

Após a definição de qual abordagem probabilística utilizar e a descrição do método, a próxima fase é a implantação deste método com os dados deste trabalho a partir dos procedimentos citados a seguir. 


\subsubsection{Implementação do método}

No caso do estudo dos movimentos de massa gravitacionais, para a implantação deste método são necessários serem definidos os fatores predisponentes ao movimento. Estes fatores serão a base para o cálculo da probabilidade condicional.

A probabilidade condicional se baseia nos dados de frequência, como a área de movimentos de massa gravitacionais em relação à área total. Pode ser realizada por meio da área de cada variável ou pelo número de pixels que elas representam.

De acordo com o modelo definido na seção 6.1, os fatores que condicionam o escorregamento translacional foram selecionados, sendo:
A. Unidades geológico-geotécnicas
B. Declividade
C. Rumo da inclinação da encosta
D. Contraste de permeabilidade
E. Resistência ao Cisalhamento
F. Superfície Potencial de Ruptura
G. Uso e ocupação
H. Domínios estruturais
I. Superfície Potencial de infiltração
J. Chuva

Cada atributo de A - J corresponde ao evento do qual o evento " $O$ " é dependente. Assim, por exemplo, sendo o evento " $G$ " o atributo uso e ocupação do solo, independente do número de classes que este fator possui (neste caso,11 classes) a probabilidade condicional entre ele e o evento " $O$ " é:

$$
\begin{aligned}
& P\left(O \cap G_{1}\right)=P\left(O \mid G_{1}\right) P\left(G_{1}\right) \\
& \text { (Equação 53) } \\
& P\left(O \cap G_{2}\right)=P\left(O \mid G_{2}\right) P\left(G_{2}\right) \\
& \text { (Equação 54) }
\end{aligned}
$$




$$
P\left(O \cap G_{n}\right)=P\left(O \mid G_{n}\right) P\left(G_{n}\right)
$$

Pode se observar pelas equações 53, 54 e 55 que existe uma probabilidade condicional para classe de cada atributo, sendo:

$$
\begin{gathered}
P\left(O \mid G_{1}\right)=\frac{\text { área das feições que se encontram sobre a classe } G_{1}}{\text { área total da classe } G_{1}} \text { e } \\
P\left(G_{1}\right)=\frac{\text { área total da classe } G_{1}}{\text { área total da área de estudo }}
\end{gathered}
$$

Todos os atributos juntos devem formar o espaço amostral no qual o evento " $O$ " ocorre. O diagrama de Venn para este espaço amostral está demonstrado na Figura 69. Este diagrama representa um pixel da área estudada e cada atributo de A a J representa somente uma das suas classes.

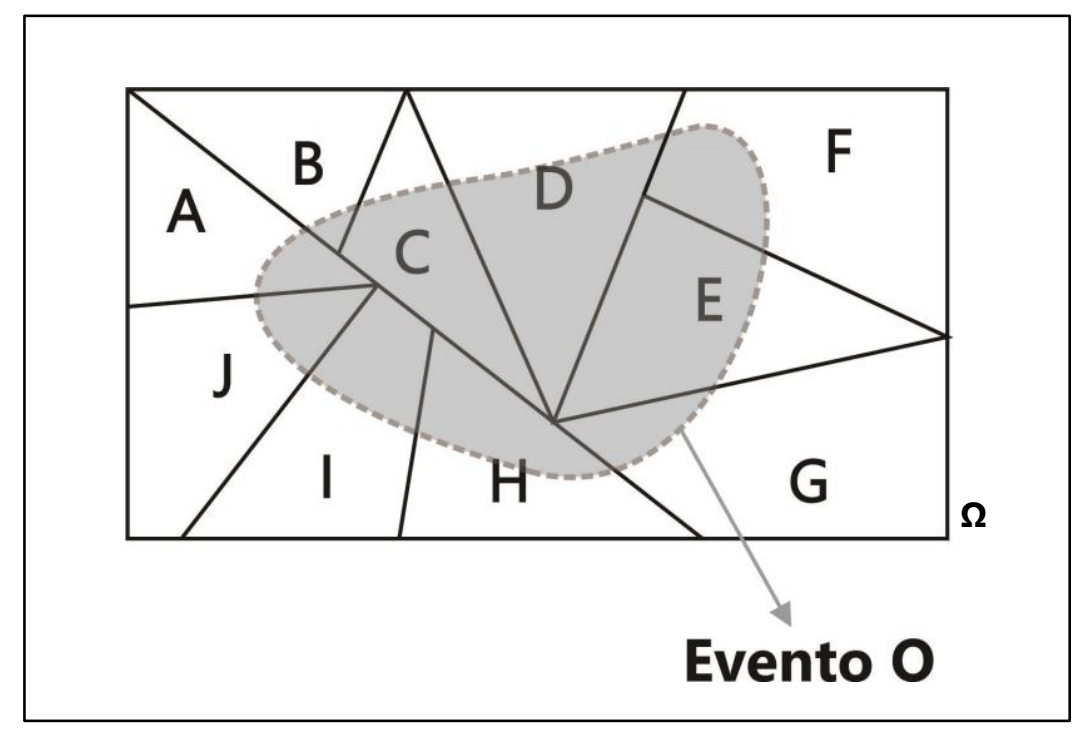

Figura 69 - Diagrama de Venn para o evento "O".

A probabilidade $P(O)$ de um determinado pixel é extraída do Teorema da Probabilidade Total gerando a equação representada na Figura 70 Figura 70 . A probabilidade de cada atributo simula a probabilidade da classe manifestada no pixel. 


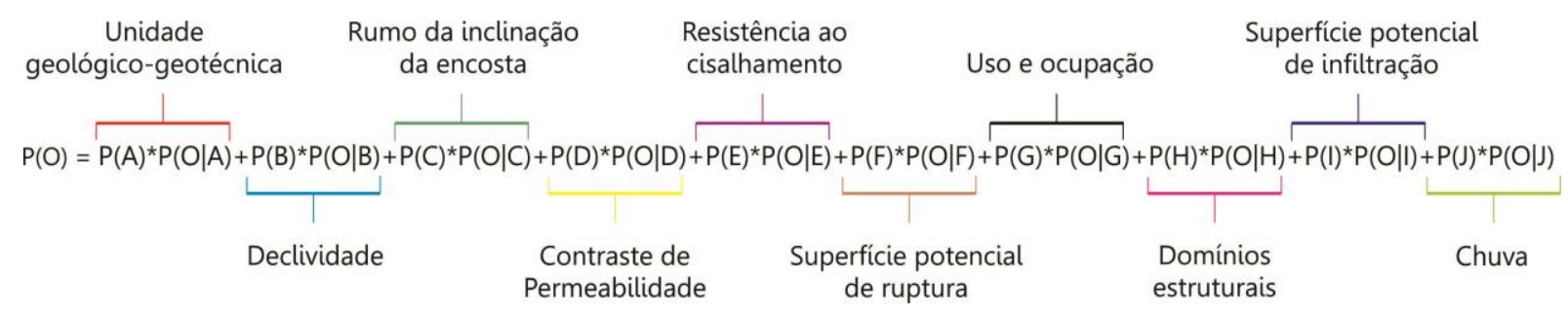

Figura 70 - Equação utilizada para cálculo da probabilidade $\boldsymbol{P}(\boldsymbol{O})$.

Para o cálculo das probabilidades condicionais é necessário o levantamento das frequências absolutas dos atributos em relação à área total de estudo e também a frequência absoluta dos movimentos de massa gravitacionais em relação à área de cada classe do atributo, como foi mostrado pelas equações 56 e 57. Esta análise será esclarecida na seção 6.3.3.1

\subsubsection{Relação atributo x inventário}

A análise da relação entre cada atributo e inventário dos movimentos de massa gravitacionais é realizada neste trabalho a partir da distribuição espacial de cada classe. Ou seja, obteve-se a frequência absoluta que é dada pela área do conjunto de feições em função da área da classe a qual ela ocupa. Também foi calculada a frequência absoluta de cada classe do atributo em relação à área total estudada. Ambos os valores são necessários para o cálculo da probabilidade condicional.

Os valores das áreas foram obtidos através da ferramenta calculate geometry do software $\operatorname{ArcMap}^{T M}$ para todos os atributos e feições. As frequências foram calculadas utilizando o software Microsoft Office Excel $\mathbb{R}$. Como exemplo, pode ser observado através da Tabela 38 o conjunto de valores calculados para o atributo unidades geológico-geotécnicas em relação à ocorrência de escorregamento translacional. 
Tabela 38 - Valores de probabilidade para as classes do atributo unidade geológico-geotécnicas.

\begin{tabular}{|c|c|c|c|c|c|}
\hline $\begin{array}{l}\text { Unidade } \\
\text { geológico- } \\
\text { geotécnica }\end{array}$ & $\begin{array}{c}\text { Área da } \\
\text { Unidade } \\
\left(\mathbf{k m}^{2}\right)\end{array}$ & $\begin{array}{c}\text { Área da } \\
\text { Feição } \\
\left(\mathbf{k m}^{2}\right)\end{array}$ & $P(A)$ & $P(O \mid A)$ & $P(A) * P(O \mid A)$ \\
\hline IR1 & 0,461199 & 0,004949 & 0,010526798 & 0,010730726 & 0,00011296 \\
\hline IR2 & 4,802600 & - & 0,10961862 & - & - \\
\hline IR3 & 0,644336 & - & 0,014706872 & - & - \\
\hline IR4 & 0,029735 & - & 0,000678697 & - & - \\
\hline IR5 & 0,086520 & - & 0,001974806 & - & - \\
\hline IR6 & 0,974162 & 0,023477 & 0,022235101 & 0,024099688 & 0,000535859 \\
\hline IR7 & 1,087369 & 0,011292 & 0,024819033 & 0,010384699 & 0,000257738 \\
\hline IR8 & 0,168923 & - & 0,003855642 & - & - \\
\hline IR9 & 1,651697 & 0,020332 & 0,037699735 & 0,012309764 & 0,000464075 \\
\hline IR10 & 0,617113 & 0,008145 & 0,014085511 & 0,013198555 & 0,000185908 \\
\hline IR11 & 0,561086 & - & 0,012806703 & - & - \\
\hline IR12 & 0,026737 & - & 0,000610268 & - & - \\
\hline IR13 & 0,006250 & - & 0,000142655 & - & - \\
\hline IR14 & 0,001977 & - & $4,51247 \mathrm{E}-05$ & - & - \\
\hline IR15 & 0,012786 & - & 0,000291839 & - & - \\
\hline IR16 & 0,002137 & - & 4,87767E-05 & - & - \\
\hline IR17 & 0,125720 & 0,004628 & 0,00286954 & 0,036811963 & 0,000105633 \\
\hline IR18 & 0,029829 & - & 0,000680842 & - & - \\
\hline IR19 & 0,008075 & - & 0,000184311 & - & - \\
\hline IR20 & 0,000789 & - & $1,80088 \mathrm{E}-05$ & - & - \\
\hline IR21 & 0,078290 & - & 0,001786957 & - & - \\
\hline IR22 & 0,426946 & - & 0,009744987 & - & - \\
\hline IR23 & 0,021857 & - & 0,000498883 & - & - \\
\hline IR24 & 0,057684 & - & 0,001316629 & - & - \\
\hline IR25 & 0,009168 & - & 0,000209258 & - & - \\
\hline IR26 & 0,041511 & - & 0,000947482 & - & - \\
\hline IR27 & 0,039282 & - & 0,000896606 & - & - \\
\hline IR28 & 0,002183 & - & 4,98266E-05 & - & - \\
\hline IR29 & 4,885670 & 0,013276 & 0,11151468 & 0,002717335 & 0,000303023 \\
\hline IR30 & 2,289792 & - & 0,052264157 & - & - \\
\hline IR31 & 1,346746 & 0,007371 & 0,030739274 & 0,005473192 & 0,000168242 \\
\hline IR32 & 0,490005 & 0,001805 & 0,01118429 & 0,003683636 & $4,11989 \mathrm{E}-05$ \\
\hline IR33 & 1,473015 & 0,007104 & 0,033621345 & 0,004822761 & 0,000162148 \\
\hline IR34 & 1,905298 & 0,004036 & 0,043488139 & 0,002118304 & $9,21211 \mathrm{E}-05$ \\
\hline IR35 & 1,496370 & 0,002004 & 0,034154419 & 0,001339241 & $4,5741 \mathrm{E}-05$ \\
\hline IR36 & 0,977244 & 0,032275 & 0,022305447 & 0,033026552 & 0,000736672 \\
\hline IR37 & 1,548042 & 0,019464 & 0,035333825 & 0,012573302 & 0,000444263 \\
\hline IR38 & 0,117803 & 0,000277 & 0,002688836 & 0,002351383 & 6,32248E-06 \\
\hline IR39 & 0,839573 & 0,000793 & 0,019163127 & 0,000944528 & $1,81001 \mathrm{E}-05$ \\
\hline IR40 & 0,747640 & 0,001479 & 0,01706477 & 0,001978225 & $3,3758 \mathrm{E}-05$ \\
\hline IR41 & 2,659160 & 0,069892 & 0,060694925 & 0,026283488 & 0,001595274 \\
\hline IR42 & 0,215669 & - & 0,004922612 & - & - \\
\hline IR43 & 0,176188 & 0,006298 & 0,004021464 & 0,035745908 & 0,000143751 \\
\hline
\end{tabular}




\begin{tabular}{|c|c|c|c|c|c|}
\hline $\begin{array}{l}\text { Unidade } \\
\text { geológico- } \\
\text { geotécnica }\end{array}$ & $\begin{array}{c}\text { Área da } \\
\text { Unidade } \\
\left(\mathbf{k m}^{2}\right)\end{array}$ & $\begin{array}{l}\text { Área da } \\
\text { Feição } \\
\left(\mathbf{k m}^{2}\right)\end{array}$ & $\mathbf{P}(\mathbf{A})$ & $P(O \mid A)$ & $P(A) * P(O \mid A)$ \\
\hline IR44 & 2,606070 & 0,027694 & 0,059483154 & 0,010626729 & 0,000632111 \\
\hline IR45 & 1,549270 & 0,000126 & 0,035361854 & $8,13286 \mathrm{E}-05$ & 2,87593E-06 \\
\hline IR46 & 0,750951 & - & 0,017140343 & - & - \\
\hline IR47 & 0,330891 & 0,002747 & 0,007552537 & 0,008301827 & $6,26999 \mathrm{E}-05$ \\
\hline IR48 & 0,516296 & 0,000555 & 0,011784378 & 0,001074965 & $1,26678 \mathrm{E}-05$ \\
\hline IR49 & 2,635422 & 0,00991 & 0,060153109 & 0,003760309 & 0,000226194 \\
\hline IR50 & 1,253890 & 0,000634 & 0,02861985 & 0,000505626 & $1,4471 \mathrm{E}-05$ \\
\hline IR51 & 0,017587 & - & 0,000401421 & - & - \\
\hline
\end{tabular}

Alguns valores de probabilidade não foram calculados devido à falta de feições de escorregamento translacional sobre certas classes do atributo unidades geológico-geotécnicas.

Os resultados são valores das probabilidades de cada pixel que devem ser armazenados e utilizados, posteriormente para elaboração da carta de eventos perigosos, como mostra a seção 6.3.4.

\subsubsection{Carta de Eventos Perigosos aplicando probabilidade}

Com todas as frequências calculadas o próximo passo é a elaboração da carta de eventos perigosos é a execução da equação mostrada na Figura 70.

Tanto o cálculo das frequências quanto a rotina completa para resolução da expressão da Figura 70 pode ser facilmente programada em planilhas eletrônicas como no software Microsoft Office Excel $\mathbb{R}$ ou em linguagem MATLAB, a depender do programador. A resposta é um valor de probabilidade representativo de cada pixel.

Da mesma forma com que foi abordada a elaboração da carta de eventos perigosos através da aplicação de redes neurais artificiais, o que é apresentado na literatura sobre a aplicação por meio de probabilidade também considera intervalos dos valores para formação das classes do zoneamento de eventos perigosos.

Contudo, também para a elaboração de uma carta de eventos perigosos por meio de probabilidade condicional, pode ser utilizada a mesma proposta descrita na 
aplicação de redes neurais artificiais, onde o resultado é um valor de probabilidade para, por exemplo, cada vertente (Ver seção 6.2.3). 


\section{CONCLUSÕES E RECOMENDAÇÕES}

Esta pesquisa foi realizada em área urbanizada do município de Ouro Preto, no estado de Minas Gerais, e apresenta o estudo dos movimentos de massa gravitacionais através de dados preexistentes e gerados, que foram avaliados quanto a sua aplicabilidade nos métodos de redes neurais artificiais e probabilidade condicional para elaboração de uma carta de eventos perigosos.

Os dados prévios se mostraram insuficientes para execução de ambos os métodos e também para gerar outros produtos de importância na elaboração da carta de eventos perigosos como, por exemplo, a carta de domínios estruturais.

Utilizando os mapas de material inconsolidado e de substrato rochoso, assim como as descrições de suas unidades, foi possível elaborar uma carta geotécnica apresentando as unidades geológico-geotécnicas que caracterizam a área. Esta carta deu origem à outros dados como: cartas de resistência ao cisalhamento, contraste de permeabilidade e superfície potencial de ruptura. Com o mapa topográfico foram geradas as cartas de declividade e rumo da inclinação da encosta e, o mapa de uso e ocupação do solo não foi alterado. Todas estas cartas e mapas encontram-se adequadas para a área.

Os atributos foram escolhidos para análise a partir do modelo físico, conceitual e matemático adotado. Optou-se por estudar os movimentos do tipo escorregamento translacional e para tal foram pesquisadas as condições para ocorrência deste movimento. Os 10 atributos selecionados foram aqueles que mostraram as diferentes condições para ocorrência do escorregamento translacional. Por exemplo, o atributo domínios estruturais apresenta as condições referentes aos padrões das descontinuidades que desempenham papel importante na geometria do movimento e, na infiltração e circulação da água.

Em relação aos atributos oriundos a partir dos dados preexistentes, notou-se que ainda faltam informações que possam, com maior clareza, caracterizar geotecnicamente os materiais, como determinar os parâmetros de resistência ao cisalhamento dos materiais inconsolidados e do substrato rochoso, pois a definição indireta deste atributo é apenas um indicativo do seu comportamento em campo. 
Isto vale também para a determinação da superfície potencial de ruptura, que deve ser associada à descrição das espessuras dos materiais, do contato entre litologias e das descontinuidades presentes nas rochas.

Quando avaliadas as condições geológico-geotécnicas em campo, a descrição dos materiais, solo e rocha, devem ser realizadas buscando descrever todas as informações que podem levar ao entendimento da interferência dos atributos na estabilidade do material. Entretanto, sabe-se que o levantamento ideal é oneroso, requer tempo e, as vezes instrumentos de análise que não estão disponíveis, promovendo a insuficiência de dados e prejudicando a realização de estudos secundários, como a elaboração de uma carta de suscetibilidade ou de eventos perigosos dos movimentos de massa gravitacionais.

As informações coletadas para formação do inventário de movimentos de massa gravitacionais permitiram a elaboração de um mapa de inventário com um total de 693 feições classificadas em 11 tipos de processos diferentes. Ressalta-se que pode existir um erro na classificação como complexos e que estas feições sejam na realidade áreas com múltiplas feições e não combinação de 3 tipos como preconizam as classificações.

Apesar da existência de inventários de diversos períodos, os trabalhos consultados apresentam registros com ausência de informações. Também existem diferenças quanto ao modo e forma dos registros procedentes dos trabalhos anteriores. Três deles, Souza (1996), Bonucceli(1999) e Zenóbio (2000), apresentaram feições poligonais representando a área de ocorrência enquanto os demais representam a ocorrência como pontos. Todavia, para aplicação de ambos os modelos propostos, o inventário de movimentos de massa gravitacionais deve apresentar feições representadas por uma área, o que dificultou a utilização dos dados de Castro (2006), Fontes (2011) e do IGEO. Outro empecilho foi a incompatibilidade dos dados apresentados por estes autores e a ausência de informações básicas (tipo de movimento, material geológico envolvido, coordenadas geográficas, entre outras) para caracterização dos movimentos de massa gravitacionais.

Mesmo para os dados considerados válidos, no geral, não existem dados quanto à velocidade, volume, condição de umidade e data de ocorrência dos 
movimentos de massa gravitacionais, sendo estas informações de grande relevância na elaboração de um mapa de inventário dos movimentos gravitacionais de massa.

Os inventários de movimentos de massa gravitacionais devem fazer parte de um programa contínuo e com obtenção de informações completas (localização, área, profundidade da superfície de ruptura e geometria, materiais geológicos envolvidos, data de ocorrências, atividade, velocidade, volume do material deslocado, etc). Sugere-se para pesquisas futuras que a elaboração dos mapas de inventário leve em consideração o que é esperado para um levantamento de inventário de feições resultantes de movimentos de massa gravitacionais.

Quanto à aplicação do método de redes neurais artificiais, conclui-se que seriam necessários maiores estudos para elaboração dos dados ausentes no sentido de compor o modelo escolhido para análise, assim como a definição dos valores esperados para saída, isto porque os dados obtidos não foram suficientes para execução do método.

A programação elaborada em linguagem MATLAB apresenta as principais funções de aplicação e, mesmo que em fase inicial, abrange os diversos processos envolvidos no método, desde a organização dos dados à execução da rede proposta. Devido à subjetividade envolvida na escolha da topologia, arquitetura e opções de parada, a análise ainda pode ser otimizada quando o algoritmo for implantado em ambiente $M A T L A B \otimes$. A depender do objetivo da pesquisa, as linhas de comando do algoritmo devem ser revistas ou adaptadas. Espera-se que quando implementado, os ajustes necessários para validação do algoritmo sejam para aperfeiçoamento da técnica.

Quanto à aplicação da probabilidade condicional para elaboração da carta de eventos perigosos, conclui-se que este método é de fácil execução desde que já obtidos todos os dados que levam ao cálculo das probabilidades condicionais das quais a ocorrência de movimentos gravitacionais de massa é dependente. A teoria da probabilidade total empregada nesta área de estudo, ajudou a entender, de maneira simples, a relação entre os fatores predisponentes e as feições de ocorrência de movimentos de massa gravitacionais através da frequência absoluta. No entanto, por mais que a equação seja matematicamente simples, a mesma necessita de recursos 
computacionais para sua execução devido à quantidade de dados processados durante o seu cálculo.

Vale ressaltar que além dos dados obtidos não serem suficientes para aplicação deste método, conforme foi observado, para algumas classes não foi possível a obtenção de um valor de probabilidade devido à ausência de feições de movimentos de massa gravitacionais sobre elas. Portanto, para estudos futuros, é indicado definir qual o valor mais adequado de probabilidade nestes casos. 


\section{REFERÊNCIAS BIBLIOGRÁFICAS}

AHRENDT, A. Movimentos de massa gravitacionais - proposta de um sistema de previsão: aplicação na área urbana de Campos do Jordão - SP. 2005. 390p. Tese (Doutorado em Geotecnia) - Escola de Engenharia de São Carlos, Universidade de São Paulo, São Carlos, 2005.

ALEOTTI, P.; CHOWDHURY, R. Landslide hazard assessment: summary review and new perspectives. Bulletin of Engineering Geology and the Environment, v.58, n.1, p.21-44, 1999.

AMARAL JR., A.F. Mapeamento geotécnico aplicado a análise de processos de movimentos de massa gravitacionais: Costa Verde - RJ - escala 1:10.000. 2007. 210p. Dissertação (Mestrado em Geotecnia) - Escola de Engenharia de São Carlos, Universidade de São Paulo, São Carlos, 2007.

ANG, A.H.S.; TANG, W.H. Probability concepts in engineering: emphasis on applications to civil and environmental engineering. $2^{\text {nd }}$ ed. New York: Wiley, 2007.

ARORA, M.K.; DAS GUPTA, A.S.; GUPTA, R.P. An Artificial neural network approach for landslide hazard zonation in the Bhagirathi (Ganga) Valley, Himalayas. International, Journal Remote Sensing, v.25, n.3, p.559-572, Feb. 2004.

BAUZYS, F. Mapa de inventário dos movimentos de massa ocorridos no alto da bacia do Ribeirão Belchior, Gaspar, Santa Catarina. Revista Geonorte, v.1, n.4, Edição Especial, p.788-799, 2012.

BEUCHER, A. et al. Artificial neural network for acid sulfate soil mapping: application to the Sirppujoki River catchment area, south-western Finland. Journal of Geochemical Exploration, v.125, p.46-55, Feb. 2013.

BONUCCELLI, T.J. Estudo dos movimentos de massa gravitacionais e processos erosivos em aplicação na área urbana de Ouro Preto (MG) - escala 1:10000. 1999. 208p. Tese (Doutorado em Geotecnia) - Escola de Engenharia de São Carlos, Universidade de São Paulo, São Carlos, 1999. 
BONUCCELLI, T.; ZUQUETTE, L.V. Movimentos gravitacionais de massa e erosões na cidade histórica de Ouro Preto, Brasil. Revista Portuguesa de Geotecnia, v.85, p.5980, 1999.

BROW, E.T. (Ed.). Suggested method for rock characterization testing and monitoring. Oxford: Pergamon Press, 1983.

CANIANI, D. et al. Neural networks and landslide susceptibility: a case study of the urban area of Potenza - Italy. Natural Hazards and Earth System Sciences, v.45, p.55-72, Apr. 2008.

CARDINALI, M. et al. Photo geological and landslide inventory map for the Upper Tiber River basin. Perugia: CNR, Gruppo Nazionale per la Difesa dalle Catastrofi Idrogeologiche, 2001. (Publication n 2116. Escala 1:100.000).

CARRARA, A. et al. Digital terrain analysis for land evaluation. Geologia Applicata e Idrogeologia, v.13, p.69-127, 1978.

CARVALHO, A. Hierarquização de áreas sucetíveis a movimentos gravitacionais de massa e processos erosivos no bairro Santa Cruz, em Ouro Preto - MG, na esc 1:2000. 2001. Dissertação (Mestrado em Engenharia Civil) - Universidade Federal de Ouro Preto, Ouro Preto, 2001.

CASTRO, J.M.G. Pluviosidade e movimentos de massa nas encostas de Ouro Preto. 2006. 110p. Dissertação (Mestrado em Engenharia Civil) - Escola de Minas, Universidade Federal de Ouro Preto, Ouro Preto, 2006.

ÇELIK, S.; TAN, Ö. Determination of preconsolidation pressure with artificial neural network. Civil Engineering and Environmental Systems, v.22, n.4, p.217-231, 2005.

CHAU, K.T. et al. Landslide hazard analysis for Hong Kong using landslide inventory and GIS. Computers \& Geosciences, v.3042, p.9-443, 2004.

CHAUHAN, S. et al. Landslide susceptibility zonation through ratings derived from artificial neural network. International Journal of Applied Earth Observation and Geoinformation, v.12, p.340-350, Apr. 2010. 
$\mathrm{CHOI}$, J.; $\mathrm{JOO} \mathrm{OH}, \mathrm{H}$.; WON, J.S. Validation of an artificial neural network model for landslide susceptibility mapping. Environmental Earth Sciences, v.60, p.473-483, Apr. 2010.

CHUNG, C.F.; FABBRI, A.G. Probabilistic prediction models for landslide hazard mapping. Photogrammetric Engineering and Remote Sensing, v.65, n.12, p.13891399, 1999.

CROVELLI, R.A.; COE, J.A. Probabilistic estimation of numbers and costs of future landslides in the San Francisco Bay region. Georisk, v.3, n.4, p.206-223, 2009.

CROZIER, M. Mass-movement hazards and risks. In: SHRODER, J. et al. Treatise on Geomorphology. San Diego: Academic Press, 2013. v.7, p.249-258.

CRUDEN, D. M. The multilingual landslide glossary. The International Geotechnical Societies UNESCO Working Party for World Landslide Inventory, Richmond: Bitech, v.5, 1993.

CRUDEN, D. M.; LAN, H.X. Using the working classification of landslides to assess the danger from a natural slope. In: LOLLINO, G. et al. (Ed.). Engineering geology for society and territory: landslide processes. Berlin: Springer International, 2015. v.2, p.3-12.

CRUDEN, D.M.; VARNES, D.J. Landslide types and processes. Landslides, Investigation and mitigation. Transportation Research Board, special report 247, p.36-75, 1996.

DAS, S.K.; BASUDHAR, P.K. Undrained lateral load capacity of piles in clay using artificial neural network. Computers and Geotechnics, v.33, n.8, p.454-459, 2006.

DIAS, E.C. Previsão de movimentos gravitacionais de massa na Serra de Ouro Preto com base em árvore de eventos. 2002. 191p. Dissertação (Mestrado em Geotecnia) - Escola de Engenharia de São Carlos, Universidade de São Paulo, São Carlos, 2002.

DUDA, R.O.; HART, P.E.; STORK, D.G. Pattern classification. New York: Stork-John Wiley, 2001. 
DUMAN, T.Y. et al. Landslide inventory of northwestern Anatolia, Turkey. Engineering Geology, v.77, p.99-114, 2005.

ERCANOGLU, M. Landslide susceptibility assessment of SE Bartin (West Black Sea region, Turkey) by artificial neural networks. Natural Hazards and Earth System Sciences, v.5, p.979-992, Dec. 2005.

ERMINI, L.; CATANI, F.; CASAGLI, N. Artificial Neural Networks applied to landslide susceptibility assessment. Geomorphology, v.66, p.327-343, 2005.

FELL, R. et al. Guidelines for landslide susceptibility, hazard and risk zoning for land use planning. Engineering Geology, v.102, p.85-98, Dec. 2008.

FIORUCCI, F. et al. Seasonal landslides mapping and estimation of landslide mobilization rates using aerial and satellite images. Geomorphology, v.129, p.59-70, 2011.

FONTES, M.M.M. Contribuição para o desenvolvimento da metodologia de análise, gestão e controle de riscos geotécnicos para a área urbana da cidade de Ouro Preto. 2011. 188p. Dissertação (Mestrado em Engenharia Civil) - Universidade Federal de Ouro Preto, Ouro Preto, 2011.

GALLI, M. et al. Comparing landslide inventory maps. Geomorphology, v.94. p.268289, 2008.

GEODINÂMICA externa - movimentos de massa: tombamento de blocos. Rio Claro: UNESP, 2001. Curso de Geologia ambiental Via Internet. Disponível em:<http://www.rc.unesp.br/ igce/aplicada/ead/interacao/inter09f.html>. Acesso em: 13 out. 2014.

GERSCOVICH, D.M.S. Estabilidade de taludes. São Paulo: Oficina de Textos, 2012.

GOMES, R.C. et al. Condicionantes geotécnicos do espaço urbano de Ouro Preto/MG. In: CONGRESSO BRASILEIRO DE MECÂNICA DOS SOLOS E ENGENHARIA GEOTÉCNICA, 11., 1998, Brasilía. Anais... São Paulo: Associação Brasileira de Mecânica dos Solos e Engenharia Geotécnica, 1998. p.363-370. 
GOMEZ, H.; KAVZOGLU, T. Assessment of shallow landslide susceptibility using artificial neural networks in Jabonosa River Basin, Venezuela. Engineering Geology, v.78, p.11-27, 2005.

GUTHRIE, R.H. Mass-movement: style, activity state and distribution. In: SHRODER, J. et al. Treatise on geomorphology. San Diego: Academic Press, 2013. v.7, p.230238.

GUZZETTI, F. Landslide hazard and risk assessment. 2006. 389p. Thesis (Ph.D.) Mathematisch-Naturwissenschaftlichen Fakultät der Rheinischen Friedrich-WilhelmsUniversität, University of Bonn, Bonn, Germany, 2006.2 Disponível em:<http://geomorphology.irpi.cnr.it/Members/fausto/PhD-dissertation>. Acesso em: 19 Jan. 2015.

Landslide hazard assessment and risk evaluation: limits and prospectives. In: EGS PLINIUS CONFERENCE HELD AT MALLORCA, 4., Spain. 2002. Proceedings... Spain: European Geophysical Society, 2012. Session 3.

GUZZETTI, F.; CARDINALI, M.; REICHENBACH, P. The AVI project: a bibliographical and archive inventory of landslides and floods in Italy. Environmental Management, v.18, n.4, p.623-633, 1994.

GUZZETTI, F. et al. Landslide hazard evaluation: a review of current techniques and their application in a multi-scale study, Central Italy. Geomorphology, v.31, n.1, p.181-216, 1999.

Landslides triggered by the 23 November 2000 rainfall event in the Imperia Province, Western Liguria, Italy. Engineering Geology, v.73, n.2, p.229-245, 2004.

Probabilistic landslide hazard assessment at the basin scale. Geomorphology, v.72, n.1, p.272-299, 2005.

Landslide inventory maps: new tools for and old problem. Earth-Science Reviews, v.112, p.42-66, 2012.

HAYKIN, S. Neural networks - a comprehensive foundation. $2^{\text {nd }}$ ed. Hamilton: Prentice Hall, 2001. 
HEARN, G.J. Landslide and erosion hazard mapping at Ok Tedi copper mine, Papua New Guinea. Quarterly Journal of Engineering Geology and Hydrogeology, v.28, n.1, p.47-60, 1995.

HUNGR, O. et al. A Review of the classification of the flow type. Environmental \& Engineering Geoscience, v.7, n.3, p.221-238, 2001.

HUNGR, O.; LEROUEILL, S.; PICARELLI, L. The Varnes classification of landslide types, an update. Landslides, v.11, n.2, p.167-194, 2014.

HUTCHINSON, J.N. General report: morphological and geotechnical parameters of landslides in relation to geology and hydrogeology. In: INTERNATIONAL SYMPOSIUM ON LANDSLIDES, 5., 1988, Rotterdam. Proceedings... Rotterdam: Bonnard C, 1988. p.3-35.

JAMES, B.R. Probabilidade: um curso em nível intermediário. Rio de Janeiro: LTC, 2009. (Coleção Projeto Euclides).

JELÍNEK, R.; WAGNER, P. Landslide hazard zonation by deterministic analysis (Vel'ká Čausa landslide area, Slovakia). Landslides, v.4, n.4, p.339-350, 2007.

JENG, D.S.; CHA, D.H.; BLUMENSTEIN, M. Application of neural network in civil engineering problems. In: INTERNATIONAL CONFERENCE ON ADVANCES IN THE INTERNET, 2003. Proceedings... 2003.

JIBSON, R.W.; HARP, E.L.; MICHAEL, J.A. A Method for producing digital probabilistic seismic landslide hazard maps. Engineering Geology, v.58, n.3, p.271-289, 2000.

KALOGIROU, S.A. Applications of artificial neural-networks for energy systems. Applied Energy, v.67, p.17-35, Sept. 2000.

KALOGIROU, S.A.; MATHIOULAKIS, E.; BELESSIOTIS, V. Artificial neural networks for the performance prediction of large solar systems. Renewable Energy, v.63, p.90-97, Mar. 2014.

KASABOV, N.K. Foundation of neural networks, fuzzy systems and knowledge engineering. $2^{\text {nd }}$ ed. Massachusetts: The MIT Press, 1998. 
KIA, M.B. et al. An Artificial neural network model for flood simulation using GIS: Johor River Basin, Malaysia. Environmental Earth Science, v.67, p.251-264, 2012.

KOVÁCS, Z.L. Redes neurais artificiais: fundamentos e aplicações. São Paulo: Livraria da Fisica, 2006.

KRIESEL, D. A Brief introduction to neural netwoks. University of Bonn in Germany, 2005. Disponível em:<www.dkriesel.com>. Acesso em: 29 Mar. 2014.

KURUP, P.U.; DUDANI, N.K. Neural networks for profiling stress history of clays from PCPT data. Journal of Geotechnical and Geoenvironmental Engineering, v.128, n.7, p.569-579, 2002.

LEE, S.; PRADHAN, B. Probabilistic landslide hazards and risk mapping on Penang Island, Malaysia. Journal of Earth System Science, v.115, n.6, p.661-672, 2006.

LEE, S.; TALIB, J.A. Probabilistic landslide susceptibility and factor effect analysis. Environmental Geology, v.47, n.7, p.982-990, 2005.

LEE, S.; CHOI, J.; MIN, K. Probabilistic landslide hazard mapping using GIS and remote sensing data at Boun, Korea. International Journal of Remote Sensing, v.25, n.11, p.2037-2052, 2004.

LEE, S. et al. Landslide susceptibility analysis using GIS and artificial neural network. Earth Surface Processes and Landforms, v.28, n.12, p.1361-1376, Nov. 2003.

- Determination and application of the weights for landslide susceptibility mapping using an artificial neural network. Engineering Geology, v.71, p.289-302, Feb. 2004.

LISBOA, P.J.; TAKTAK, A.F.G. The Use of artificial neural networks in decision support in cancer: a systematic review. Neural Networks, v.19, p.408-415, May 2006.

LOBATO, L.M. et al. Mapa geológico de Ouro Preto na escala 1:50.000. Belo Horizonte: CODEMIG, 2005. Projeto Geologia do Quadrilátero Ferrífero: Integração e Correção Cartográfica em SIG com nota explicativa. 
MAGALHÃES, M.N.; LIMA, A.C.P. Noções de probabilidade e estatística. São Paulo: EDUSP, 2002.

MALAMUD, B.D. et al. Landslide inventories and their statistical properties. Earth Surface Processes and Landforms, v.29, n.6, p.687-711, 2004.

MATSSUNAGA, V.Y. Curso de redes neurais utilizando o MATLAB. Belém, 2012. Apostila. Disponível em:<http://paginas.uepa.br/engprod/index.php?option=com_ rokdownloads\&view $=$ file\&task $=$ download \&id $=132 \% 3$ Aapostilaredesneurais \&ltemid $=67>$. Acesso em: 20 jan. 2014.

MATULA, M. et al. Rock and soil description and classification for engineering geological mapping report by the IAEG Commission on Engineering Geological Mapping. Bulletin of the International Association of Engineering Geology = Bulletin de l' Association Internationale de Geologie de L' Ingenieur, v.24, n.1, p.235-274, 1981.

MEDEIROS, B. Análise por meio de redes neurais artificiais dos dados de monitoramento dos piezômetros da barragem de concreto de ltaipu. 2013. 165p. Dissertação (Mestrado em Geotecnia) - Escola de Engenharia de São Carlos, Universidade de São Paulo, São Carlos, 2013.

MELCHIORRE, C. et al. Artificial neural networks and cluster analysis in landslide susceptibility zonation. Geomorphology, v.94, p.379-400, 2008.

NEAUPANE, K.M.; ACHET, S.H. Use of backpropagation neural network for landslide monitoring: a case study in the higher Himalaya. Engineering Geology, v.74, p.213226, 2004.

NEAUPANE, K.M.; PIANTANAKULCHAI, M. Analytic network process model for landslide hazard zonation. Engineering Geology, v.85, p.281-294, 2006.

OZDEMIR, A. Landslide susceptibility mapping of vicinity of Yaka Landslide (Gelendost, Turkey) using conditional probability approach in GIS. Environmental Geology, v.57, n.7, p.1675-1686, 2009.

PARDESHI, S.D.; AUTADE, S.E.; PARDESHI, S.S. Landslide hazard assessment: recent trends and techniques. SpringerPlus, v.2, n.1, p.523, 2013. 
PARISE, M. Landslide mapping techniques and their use in the assessment of the landslide hazard. Physics and Chemistry of the Earth, Part C: Solar, Terrestrial \& Planetary Science, v.26, n.9, p.697-703, 2001.

PEROTTO-BALDIVIEZO, H.L. et al. GIS-based spatial analysis and modeling for landslide hazard assessment in steeplands, southern Honduras. Agriculture, Ecosystems \& Environment, v.103, n.1, p.165-176, 2004.

PESTANA, D.; VELOSA, S. Introdução à probabilidade e estatística. Lisboa: Fundação Calouste Gulbenkian, 2006.

POPESCU, M. E. A suggested method for reporting landslide causes. Bulletin of the International Association of Engineering Geology = Bulletin de l'Association Internationale de Géologie de l'Ingénieur, v.50, n.1, p.71-74, 1994.

PRADHAN, B. Remote sensing and GIS-based landslide hazard analysis and crossvalidation using multivariate logistic regression model on three test areas in Malaysia. Advances in Space Research, v. 45, n. 10, p. 1244-1256, 2010.

PRADHAN, B.; LEE, S. Utilization of optical remote sensing data and GIS tools for regional landslide hazard analysis using an artificial neural network model. Earth Science Frontiers, v.14, n.6, p.143-151, 2007.

Landslide risk analysis using artificial neural network model focusing on different training sites. International Journal of Physical Sciences, v.3, p.1-15, 2009.

Regional landslide susceptibility analysis using back-propagation neural network model at Cameron Highland, Malaysia. Landslides, v.7, p.13-30, 2010.

. Delineation of landslide hazard areas on Penang Island, Malaysia, by using frequency ratio, logistic regression, and artificial neural network models. Environmental Earth Sciences, v.60, n.5, p.1037-1054, 2011.

PRADHAN, B.; LEE, S.; BUCHROITHNER, M.F. A GIS-based back-propagation neural network model and its cross application and validation for landslide susceptibility analyses. Computers Environment and Urban Systems, v.34, p.216-235, 2010. 
RAUBER, T.W. Redes neurais artificiais. Vitória, 1997. Apostila. Disponível em:<http://www.inf.ufes.br/ thomas/html/disc_rn.html>. Acesso em: 20 jan. 2014.

RIFO, L.L.R. Análise combinatória, probabilidade noções de estatística. [S.l]: UNESP, 2014. Apostila.

RODRIGUES, B.B. Inventário e análise de susceptibilidade aos movimentos de massa gravitacionais e erosões na região de Águas de Lindóia/SP - Escala 1:10000. 1998. 142p. Dissertação (Mestrado em Geotecnia) - Escola de Engenharia de São Carlos, Universidade de São Paulo, São Carlos, 1998.

RODRIGUES, B.B. Proposta de sistemática para tomada de decisão relativa a movimentos de massa gravitacionais: aplicação em Ouro Preto (MG). 2002. Tese (Doutorado) - Universidade Estadual Paulista, Instituto de Geociências e Ciências Exatas, 2002.

RODRIGUES, B.B.; PEJON, O.J. Inventário e análise de susceptibilidade aos movimentos de massa gravitacionais: aplicação em Águas de Lindóia/SP. In: SIMPÓSIO BRASILEIRO DE GEOTECNIA AMBIENTAL, 1998, São Paulo. Anais... São Paulo: ABMS, 1998. p.1-9.

RYCHLIK, I.; RYDÉN, J. Probability and risk analysis: an introduction for engineers. New York: Springer, 2006.

SALVATI, P. et al. Map of landslides and floods with human consequences in Italy. Perugia: CNR, Gruppo Nazionale per la Difesa dalle Catastrofi Idrogeologiche, 2003. (Publication $n^{\circ}$ 2822, Escala 1:1.200.000).

SANCHEZ, P.F. Mapeamento espaço-temporal e previsão de pressões piezométricas em maciços rochosos de fundações de grandes barragens estudo de caso de Itaipu. 2009. Dissertação (Mestrado em Construção Civil) Universidade Federal do Paraná, Curitiba, 2009.

SARITAS, I.; OZKAN, I.A.; SERT, I.U. Prognosis of prostate cancer by artificial neural networks. Expert Systems with Applications, v.37, p.6646-6650, Sept. 2010.

SASSA, K.; CANUTI, P. Landslides - disarter risk reduction. Berlin: Springer, 2009. 
SHAHIN, M.A.; JAKSA, M.B.; MAIER, H.R. State of the art of artificial neural networks in geotechnical engineering. Electronic Journal of Geotechnical Engineering, v.8, p.1-26, 2008.

SILVA, A.F. Estudo de previsão de escorregamento a partir do fator de segurança 3D: Campos do Jordão-SP. 2009. 353p. Dissertação (Mestrado em Geotecnia) Escola de Engenharia de São Carlos, Universidade de São Paulo, São Carlos, 2009.

SILVA, I.N.; SPATTI D.; FLAUZINO, R. Redes neurais artificiais para engenharia e ciências aplicadas: curso prático. São Paulo: Artliber, 2010.

SINHA, S.K.; WANG, M.C. Artificial neural network prediction models for soil compaction and permeability. Geotechnical Engineering Journal, v.26, n.1, p.47-64, 2008.

SOUZA, M.L. Mapeamento geotécnico da cidade de Ouro Preto-MG (Escala 1:10000) - susceptibilidade aos movimentos de massa e processos correlatos. 1996. Dissertação (Mestrado em Geotecnia) - Escola de Engenharia de São Carlos, Universidade de São Paulo, São Carlos, 1996.

TAYLOR, D.W. Fundamentals of soil mechanics. Soil Science, v.66, n.2, p.161, 1948.

TERRAIN, D. E. A suggested method for describing the rate of movement of a landslide. Bulletin of the International Association of Engineering Geology = Bulletin de l'Association Internationale de Géologie de l'Ingénieur, v.52, n.1, p.75-78, Oct. 1995.

THOMÉ, A.C.G. Redes neurais - uma ferramenta para KDD e data mining. Rio de Janeiro, 2003. Apostila. Disponível em:<http://equipe.nce.ufrj.br/thome/grad/nn/ mat_didatico/apostila_kdd_mbi.pdf>. Acesso em: 20 jan. 2014.

TONGZHEN, Y.; SHUNAN, Y.; HUIMING, T. "Easy sliding theory" and prognosis with poisson or binomial distribution of landslides. In: MARINOS, P.G. et al. (Ed.). Engineering Geology and the Environment. Rotterdam: A.A.Balkema, 1997. p.1137-1142. 
ULUSAY, R.; HUDSON, J.A. (Ed.). Suggested method for rock characterization testing and monitoring. In: __. The Complete ISRM suggested methods for rock characterization, testing and monitoring: 1974-2006. Ankara: ISRM Turkish National Group, 2007.

UNITED STATES GEOLOGICAL SURVEY. Landslide types and processes. Reston: U.S. Department of the Interior, 2004. Ficha informativa.

VAN WESTEN, C.J. Geo-information tools for landslide risk assessment: an overview of recent developments. In: INTERNATIONAL SYMPOSIUM ON LANDSLIDES, 9., 2004, Rio de Janeiro. Proceedings... Rotterdam: A.A.Balkema, 2004. p.39-56.

VARNES, D.J. Slope movement types and process. Landslides - analysis and control. Transportation Research Board, Special Report 176, p.11-13, 1978. $\frac{}{1984 .}$ Landslide hazard zonation: review of principle and practice. Paris: UNESCO,

WALPOLE, R.E. et al. Probabilidade e estatística para engenharia e ciências. Tradução de Luciane F. Pauleti Vianna. São Paulo: Pearson Prentice Hall, 2011.

WANG, H.B.; SASSA, K. Rainfall-induced landslide hazard assessment using artificial neural networks. Earth Surface Processes and Landforms, v.31, n.2, p.235-247, 2006.

WILLIAMSON, D.A.; KUHN, C.R. The Unified classification system. Rock engineneering systems for engineering purposcs. Philadelphia: American Society for Testing Materials, 1988. p.7-16. (ASTM STP 984).

WONG, B.K.; SELVI, Y. Neural network applications in finance: a review and analysis of literature (1990-1996). Information \& Management, v.34, p.129-139, Oct. 1998.

$X U, C$. Preparation of earthquake-triggered landslide inventory maps using remote sensing and GIS technologies: Principles and case studies. Geoscience Frontiers, v.30, p.1-12, 2014. 
YESILNACAR, E.; TOPAL, T. Landslide susceptibility mapping: a comparison of logistic regression and neural networks methods in a medium scale study, Hendek region (Turkey). Engineering Geology, v.79, p.251-266, 2005.

ZENÓBIO, A.A. Análise geológica-geotécnica de encostas naturais rochosas: área urbana de Ouro Preto (MG) - escala 1:50.000. 2000. Dissertação (Mestrado em Geotecnia) - Escola de Engenharia de São Carlos, Universidade de São Paulo, São Carlos, 2000.

ZUQUETTE, L.V. Algumas propostas metodológicas para elaboração de cartas de riscos e de hazards. In: CONGRESSO BRASILEIRO DE GEOLOGIA DE ENGENHARIA, 7. 1993, Poços de Caldas. Anais... São Paulo: ABGE, 1993. v.3, p.75-88.

ZUQUETTE, L.V.; GANDOLFI, N. Cartografia geotécnica. São Paulo: Oficina de Textos, 2004. 


\section{ANEXO I}

Ocorrências utilizadas para Análise de Correlação (Castro, 2006) 


\begin{tabular}{|c|c|c|c|c|c|c|c|c|c|c|c|}
\hline Data & $\begin{array}{c}\text { chuva } \\
(\mathrm{mm})\end{array}$ & AC2 & AC3 & AC4 & AC5 & AC6 & AC7 & Bairro & Logradouro & Nome & Tipo Processo \\
\hline 13-out-89 & 9,5 & 29,6 & 29,6 & 46,3 & \begin{tabular}{c|c}
46,3 \\
\end{tabular} & 62,3 & 62,3 & Piedade & Ladeira da Piedade, 170 & Terezinha Zacarias de Oliveira & Escorregamento \\
\hline 17-out-89 & 18,5 & 18,5 & 18,5 & 18,5 & 28,0 & 48,1 & 48,1 & Padre Faria & Desidério de Matos, 248 (alto da cruz) & João Pádua & Início de escorregamento \\
\hline 13-nov-89 & 32,6 & 44,4 & 62,8 & 64,1 & 64,1 & 64,1 & 65,2 & Padre Faria & Padre Martins, 43 (santa efigênia) & Avelino Augusto da Silva & Escorregamento \\
\hline 14-nov-89 & 12,0 & 44,6 & 56,4 & 74,8 & 76,1 & 76,1 & 76,1 & Santana & 15 de Agosto, 60 (logradouro) & Geralda Martinha Barbosa & Escorregamento \\
\hline 23-nov-89 & 19,6 & 30,6 & $\overline{34,4}$ & 36,6 & 53,4 & 55,6 & 55,6 & Padre Faria & Desíderio de Matos, 355 (alto da cruz) & |João Cláudio Nonato & Início de escorregamento \\
\hline 30-nov-89 & 16,8 & 17,5 & 37,7 & 37,7 & 37,7 & 73,1 & 73,1 & Alto da Cruz & Francisco Isaac, 68-A & Antônio Francisco & Escorregamento e erosão \\
\hline 11-dez-89 & 24,4 & 24,4 & 24,4 & 24,4 & 29,5 & 29,5 & 29,5 & Padre Faria & Padre Martins, 142 & Maria de Lourdes Pereira & Início de escorregamento \\
\hline 11-dez-89 & 24,4 & 24,4 & 24,4 & 24,4 & 29,5 & 29,5 & 29,5 & Taquaral & Águas Férreas, 889 & Marta Celeste da Silva & Início de escorregamento \\
\hline 13-dez-89 & 49,0 & 84,0 & 108,4 & 108,4 & 108,4 & 108,4 & 113,5 & Alto da Cruz & Francisco Isaac, 328 & Beatriz Ferreira Vieira & Escorregamento \\
\hline 13-dez-89 & 49,0 & 84,0 & 108,4 & 108,4 & 108,4 & 108,4 & 113,5 & Alto da Cruz & Francisco Isaac, 58 & Efigênia Lucia Anastácia da Paixão & Escorregamento \\
\hline 14-dez-89 & 78,5 & $\mid 127,5$ & 162,5 & 186,9 & $\mid 186,9$ & $\mid 186,9$ & $\mid 186,9$ & Centro & Salvador Trópia, 210 & José Luís da Cunha & Escorregamento \\
\hline 14-dez-89 & 78,5 & \begin{tabular}{|l|}
127,5 \\
\end{tabular} & 162,5 & 186,9 & 186,9 & \begin{tabular}{|l|}
186,9 \\
\end{tabular} & 186,9 & São Cristóvão & Candeias, 15D & Rodney Bráulio das Candeias & Escorregamento \\
\hline 14-dez-89 & 78,5 & 127,5 & 162,5 & 186,9 & 186,9 & 186,9 & 186,9 & São Cristóvão & Manganês, 1079 & Antônio José Lourenço & Escorregamento \\
\hline 14-dez-89 & 78,5 & 127,5 & 162,5 & 186,9 & 186,9 & 186,9 & \begin{tabular}{|l|}
186,9 \\
\end{tabular} & São Cristóvão & Pirita, 5 & Maria Auxiliadora dos Santos Silva & Escorregamento \\
\hline 14-dez-89 & 78,5 & 127,5 & 162,5 & 186,9 & 186,9 & 186,9 & 186,9 & São Cristóvão & Professor Alberto Barbosa, 84 & Maria Margarida Dias & Início de escorregamento \\
\hline 14-dez-89 & 78,5 & 127,5 & 162,5 & 186,9 & 186,9 & 186,9 & 186,9 & Taquaral & Águas Férreas, 182 & Edioclésio Gerônimo da Silva & Escorregamento \\
\hline 16-dez-89 & 46,0 & \begin{tabular}{|l|}
124,5 \\
\end{tabular} & 203,0 & 252,0 & 287,0 & 311,4 & 311,4 & Alto da Cruz & Francisco Isaac, $\mathrm{s} / \mathrm{n}$ & Amilcar Cirino de Vieira & Escorregamento \\
\hline 16-dez-89 & 46,0 & 124,5 & 203,0 & 252,0 & 287,0 & 311,4 & 311,4 & Padre Faria & Desidério de Matos, 750 (alto da cruz) & Ana Francisca Carneiro & Início de escorregamento \\
\hline 16-dez-89 & 46,0 & 124,5 & 203,0 & 252,0 & 287,0 & 311,4 & 311,4 & Padre Faria & Desidério de Matos, ao lado 750 (alto da cruz) & Geraldo Gomes & Início de escorregamento \\
\hline 15-jan-91 & 50,7 & 66,5 & 86,9 & 137,3 & 173,2 & 183,9 & 184,1 & Cabeças & Alvarenga, 219 & Roque Liberato Nolasco & Escorregamento \\
\hline 15-jan-91 & 50,7 & 66,5 & 86,9 & 137,3 & 173,2 & 183,9 & 184,1 & Padre Faria & Desiderio de Matos, 668 & Ester de Paula Borges & Início de escorregamento \\
\hline 15-jan-91 & 50,7 & 66,5 & 86,9 & 137,3 & 173,2 & 183,9 & 184,1 & Piedade & Abolição, 369 e 384 & Joaquim de Paula Moreira & Escorregamento \\
\hline 16-jan-91 & 20,5 & 71,2 & 87,0 & 107,4 & 157,8 & 193,7 & 204,4 & Santa Cruz & Rua 07, 115 (Santa Efigênia) & Maria de Lourdes Ramalho Alves & Escorregamento \\
\hline 17-jan-91 & 16,2 & 36,7 & 87,4 & 103,2 & 123,6 & 174,0 & 209,9 & Alto da Cruz & Francisco Isaac, 383 & Geuza Ribeiro Miriana & Escorregamento \\
\hline 17-jan-91 & 16,2 & 36,7 & 87,4 & 103,2 & 123,6 & 174,0 & 209,9 & Antônio Dias & Carlos Tomás, 120 & Sebastião Eustáquio Gonçalves & Escorregamento \\
\hline 17-jan-91 & 16,2 & 36,7 & 87,4 & 103,2 & 123,6 & 174,0 & 209,9 & Antônio Dias & Conselheiro Quintiliano, 760 (Alto da Cruz) & Celso Alves Moreira & Escorregamento \\
\hline 17-jan-91 & 16,2 & 36,7 & 87,4 & 103,2 & 123,6 & 174,0 & 209,9 & Centro & Padre Rolim, s/n, próximo ao Educandário & Antônio Dimas Mendes & Escorregamento \\
\hline 17-jan-91 & 16,2 & 36,7 & 87,4 & 103,2 & 123,6 & 174,0 & 209,9 & Santa Cruz & Rua Projetada Três, 221 (Santa Efigênia) & José Claro Ségala & Escorregamento \\
\hline 17-jan-91 & 16,2 & 36,7 & 87,4 & 103,2 & 123,6 & $\mid 174,0$ & 209,9 & Santa Cruz & Rua Projetada Três, 251 (Santa Efigênia) & Augusta Mesquita Silva & Escorregamento \\
\hline 17-jan-91 & 16,2 & 36,7 & 87,4 & 103,2 & 123,6 & 174,0 & 209,9 & São Cristóvão & São Miguel Arcanjo, 320 & Dulcineia Delfina Amâncio Pires & Escorregamento \\
\hline 17-jan-91 & 16,2 & 36,7 & 87,4 & 103,2 & 123,6 & 174,0 & 209,9 & Volta do Córrego & Padre Rolim, 58 (Logradouro, 236) & Geralda Hilária da Silva & Escorregamento \\
\hline 18-jan-91 & 115,2 & 131,4 & 151,9 & 202,6 & 218,4 & 238,8 & 289,2 & Alto da Cruz & Doutor João Veloso, 249 & Raimundo da Silva Filho & Escorregamento \\
\hline 18-jan-91 & 115,2 & 131,4 & 151,9 & 202,6 & 218,4 & 238,8 & 289,2 & Alto da Cruz & Logradouro, 198 & Francisco Araújo de Souza & Escorregamento \\
\hline 18-jan-91 & 115,2 & 131,4 & 151,9 & 202,6 & 218,4 & 238,8 & 289,2 & Padre Faria & Padre Faria, 274 & Reginaldo Cardoso Alves & Escorregamento \\
\hline 18-jan-91 & 115,2 & 131,4 & 151,9 & 202,6 & 218,4 & 238,8 & 289,2 & Padre Faria & Vereador José Teixeira, 312 e 314 (santa efigênia) & Maria das Graças Peres & Escorregamento \\
\hline 18-jan-91 & 115,2 & 131,4 & 151,9 & 202,6 & 218,4 & 238,8 & 289,2 & Santana & José Moreira Junior, 532 & Geraldo Ferreira da Silva & Início de escorregamento \\
\hline 18-jan-91 & 115,2 & \begin{tabular}{|c|}
131,4 \\
\end{tabular} & 151,9 & 202,6 & 218,4 & 238,8 & 289,2 & Santana & São Pedro, 151 & Djalma dos Reis & Escorregamento \\
\hline 19-jan-91 & 8,2 & 123,4 & 139,6 & 160,1 & 210,8 & 226,6 & 247,0 & Rosário & Getúlio Vargas, s/n & Nila Maria Almeida Oliveira Costa & Escorregamento \\
\hline 19-jan-91 & 8,2 & 123,4 & 139,6 & 160,1 & 210,8 & 226,6 & 247,0 & Vila Aparecida & Rodrigo Silva, 373 & Maria da Conceição Duarte & Escorregamento \\
\hline
\end{tabular}




\begin{tabular}{|c|c|c|c|c|c|c|c|c|c|c|c|}
\hline Data & $\begin{array}{c}\text { chuva } \\
(\mathrm{mm})\end{array}$ & AC2 & AC3 & AC4 & AC5 & AC6 & AC7 & Bairro & Logradouro & Nome & Tipo Processo \\
\hline 15-jan-92 & 6,6 & 48,8 & 79,3 & 79,3 & 79,3 & 114,8 & 118,6 & Santana & Travessa Santa Rita, 65-A & Maria Ângela de Azevedo & Escorregamento \\
\hline 16-jan-92 & 18,6 & 25,2 & 67,4 & 97,9 & 97,9 & 97,9 & 133,4 & Saramenha & Américo René Gianetti, 1877 & Silmara Maria Mendes & Início de escorregamento \\
\hline $20-$ jan-92 & 81,0 & 90,1 & 98,2 & 132,0 & 150,6 & 157,2 & 199,4 & São Cristóvão & Platina, 116 & José Luzia de Oliveira & Escorregamento \\
\hline 21-jan-92 & 19,8 & 100,8 & 109,9 & 118,0 & 151,8 & 170,4 & 177,0 & Água Limpa & Professor Antônio de Paula Ribas, 282 & Regina Celly de Carvalho & Escorregamento \\
\hline 22-jan-92 & 19,6 & 39,4 & 120,4 & 129,5 & 137,6 & 171,4 & 190,0 & Água Limpa & Augusto Correia de Magalhães, 143 & Geraldo Isaac & Início de escorregamento \\
\hline 23-jan-92 & 56,5 & 76,1 & 95,9 & 176,9 & 186,0 & 194,1 & 227,9 & Água Limpa & Elisa Gramigna Ferrari (São Cristóvão) & Marialva da Cruz Ramos & Início de escorregamento \\
\hline 23-jan-92 & 56,5 & 76,1 & 95,9 & 176,9 & 186,0 & 194,1 & 227,9 & Alto da Cruz & Francisco Isaac, 1 & Célia Maria dos Anjos & Escorregamento \\
\hline 23-jan-92 & 56,5 & 76,1 & 95,9 & 176,9 & 186,0 & 194,1 & 227,9 & Antônio Dias & Travessa das Lajes, 173 & Antônio Roberto Rodrigues & Escorregamento \\
\hline 23-jan-92 & 56,5 & 76,1 & 95,9 & 176,9 & 186,0 & 194,1 & 227,9 & Cabeças & Franklin Amâncio dos Santos, 120 & Anésia da Silva Nascimento & Escorregamento \\
\hline 23-jan-92 & 56,5 & 76,1 & 95,9 & 176,9 & 186,0 & 194,1 & 227,9 & Padre Faria & Pe Martins, 151 (caminho da fábrica) & Maria de Fátima Ferrar Guimaraes & Escorregamento \\
\hline 23-jan-92 & 56,5 & 76,1 & 95,9 & 176,9 & $\mid 186,0$ & 194,1 & 227,9 & Piedade & Abolição, 177 & Jorge de Paula Mendes & Início de escorregamento \\
\hline 23-jan-92 & 56,5 & 76,1 & 95,9 & 176,9 & 186,0 & 194,1 & 227,9 & Piedade & Ladeira da Piedade, 136 & Edna da Conceição Ramalho, & Escorregamento \\
\hline 23-jan-92 & 56,5 & 76,1 & 95,9 & 176,9 & 186,0 & 194,1 & 227,9 & Santana & 15 de Agosto, 608 & Quitéria Julía Alves & Escorregamento \\
\hline 23-jan-92 & 56,5 & 76,1 & 95,9 & 176,9 & 186,0 & 194,1 & 227,9 & Taquaral & Águas Férreas, 1029 & Irene Rosa Martins e Maria Luísa de Jesus & Escorregamento \\
\hline 23-jan-92 & 56,5 & 76,1 & 95,9 & 176,9 & 186,0 & 194,1 & 227,9 & Taquaral & Águas Férreas, 74 & Antônio Rodrigues de Sá & Início de escorregamento \\
\hline 23-jan-92 & 56,5 & 76,1 & 95,9 & 176,9 & 186,0 & 194,1 & 227,9 & Taquaral & Logradouro 06-85, 120; Águas Férreas & Carlos Alberto Cardoso Alves & Escorregamento \\
\hline 23-jan-92 & 56,5 & 76,1 & 95,9 & 176,9 & 186,0 & 194,1 & 227,9 & Tombadouro & Geraldo Jesus Gonçalves, 155 (caminho da Fábrica) & Osmar Pinto de Souza & Escorregamento \\
\hline 23-jan-92 & 56,5 & 76,1 & 95,9 & 176,9 & 186,0 & 194,1 & 227,9 & Volta do Córrego & Padre Rolim, s/n & PM de Ouro Preto & Escorregamento \\
\hline 24-jan-92 & 106,8 & \begin{tabular}{|c|}
163,3 \\
\end{tabular} & 182,9 & 202,7 & 283,7 & 292,8 & 300,9 & Bauxita & Perimetral, 464 & Maria de Jesus Carvalho Gomes & Escorregamento \\
\hline 24-jan-92 & 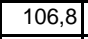 & 163,3 & 182,9 & 202,7 & 283,7 & 292,8 & 300,9 & São Cristóvão & Platina, 110 & Bento Teixeira do Nascimento & Escorregamento \\
\hline 24-jan-92 & 106,8 & 163,3 & 182,9 & 202,7 & 283,7 & 292,8 & 300,9 & Saramenha & Lima Júnior, 1542 & Clorides Catarina Pinto & Escorregamento \\
\hline 25 -jan-92 & 13,7 & $\mid 120,5$ & 177,0 & 196,6 & 216,4 & 297,4 & 306,5 & Rosário & Gabriel Santos, 200 & Maria Raimunda dos Santos Xavier & Início de escorregamento \\
\hline 25-jan-92 & 13,7 & 120,5 & 177,0 & 196,6 & 216,4 & 297,4 & 306,5 & Santa Cruz & Rua Projetada 3, 270 (Alto da Cruz) & Carlos Alberto da Silva & Escorregamento \\
\hline 29-jan-92 & 8,5 & 8,7 & 15,5 & 16,8 & 30,5 & 137,3 & 193,8 & N. Sra. do Carmo & 04 de Maio, 60 & |zabel Cristina dos Santos & Início de escorregamento \\
\hline 02-fev-92 & 11,2 & 46,6 & 91,8 & 98,8 & 107,3 & 107,5 & 114,3 & Antônio Dias & Chico Rei, 214 & Ivair Fabiano Silva & Escorregamento \\
\hline 02-fev-92 & 11,2 & 46,6 & 91,8 & 98,8 & 107,3 & 107,5 & 114,3 & Centro & Padre Rolim, s/n, igreja das Mercês de cima & Sargento Waldecir & Escorregamento \\
\hline 02-fev-92 & 11,2 & 46,6 & 91,8 & 98,8 & 107,3 & 107,5 & 114,3 & Volta do Córrego & Volta do Córrego, s/n & Rogério de Sales & Escorregamento \\
\hline 03-fev-92 & 60,0 & 71,2 & 106,6 & 151,8 & 158,8 & 167,3 & 167,5 & Água Limpa & Joaquim Fortes, 80 & Sinval Rodrigues de Irineu & Escorregamento \\
\hline 03-fev-92 & 60,0 & 71,2 & 106,6 & 151,8 & 158,8 & 167,3 & 167,5 & Centro & Praça Tiradentes, s/n, beco do Pilão, prox CAEM & Alberto Carlos Rietberg & Escorregamento \\
\hline 03-fev-92 & 60,0 & 71,2 & 106,6 & 151,8 & 158,8 & 167,3 & 167,5 & Padre Faria & Desidério de Matos, 980 & Sebastião Francisco de Jesus & Escorregamento \\
\hline 03-fev-92 & 60,0 & 71,2 & 106,6 & 151,8 & 158,8 & 167,3 & 167,5 & Santana & 15 de Agosto, 17, logradouro 5877 & Maria Sônia de Oliveira & Escorregamento \\
\hline $05-$ fev-92 & 27,6 & 53,0 & 113,0 & 124,2 & 159,6 & 204,8 & 211,8 & Alto da Cruz & 13 de Maio, 827 & José Conrado da Silva & Escorregamento \\
\hline $05-\mathrm{fev}-92$ & 27,6 & 53,0 & 113,0 & 124,2 & 159,6 & 204,8 & 211,8 & Taquaral & Rodovia dos Inconfidentes, Motel Sunny-day & Jarbas Soares Júnior (promotor) & Escorregamento \\
\hline 06-fev-92 & 42,3 & 69,9 & 95,3 & 155,3 & 166,5 & 201,9 & 247,1 & Alto da Cruz & 13 de Maio, 757 & João da Silva & Escorregamento e queda bloco \\
\hline 06-fev-92 & 42,3 & 69,9 & 95,3 & 155,3 & 166,5 & 201,9 & 247,1 & Piedade & José Anastácio & Nadir das Graças Lima Lopes & Escorregamento e queda de blocos \\
\hline 06-fev-92 & 42,3 & 69,9 & 95,3 & 155,3 & 166,5 & 201,9 & 247,1 & Piedade & Taquaral, s/n & Alfredo Ferreira Guimarães & Escorregamento \\
\hline 07-fev-92 & 8,0 & 50,3 & 77,9 & 103,3 & 163,3 & 174,5 & 209,9 & Santa Cruz & Rua Projetada, s/n (Santa Efigênia) & Maria do Socorro da Silva & Escorregamento \\
\hline 08-fev-92 & 18,3 & 26,3 & 68,6 & 96,2 & 121,6 & 181,6 & 192,8 & Vila São José & Doutor Albino Sartori, 265 & Vicente Heleno dos Anjos & Início de escorregamento \\
\hline 04-dez-95 & 11,6 & 11,6 & 19,1 & 32,5 & 35,3 & 35,3 & 35,3 & Padre Faria & Santa Rita, 820 & José Humberto Ibrahim & Escorregamento \\
\hline
\end{tabular}




\begin{tabular}{|c|c|c|c|c|c|c|c|c|c|c|c|}
\hline Data & $\begin{array}{c}\text { chuva } \\
(\mathrm{mm})\end{array}$ & AC2 & AC3 & AC4 & AC5 & AC6 & AC7 & Bairro & Logradouro & Nome & Tipo Processo \\
\hline 14-dez-95 & 97,9 & $\mid 127,4$ & 127,4 & 127,4 & 127,4 & 128,0 & 138,5 & Alto da Cruz & Francisco Isaac, 293 & Danilo Vidigal & Escorregamento \\
\hline 14-dez-95 & 97,9 & \begin{tabular}{|l|}
127,4 \\
\end{tabular} & 127,4 & 127,4 & 127,4 & 128,0 & 138,5 & Barra & Beco da Mãe Chica, s/n & Odilson (ou Adilson) dos Santos Neves & Início de escorregamento \\
\hline 14-dez-95 & 97,9 & 127,4 & 127,4 & 127,4 & 127,4 & 128,0 & 138,5 & Santa Cruz & das Orquídeas, s/n, a 100m da rua dos Girassois & Francisco Rosa, proximidades & Escorregamento \\
\hline 14-dez-95 & 97,9 & $\mid 127,4$ & 127,4 & 127,4 & 127,4 & 128,0 & 138,5 & Santa Cruz & dos Girassóis, s/n & Francisco Rosa & Escorregamento \\
\hline 14-dez-95 & 97,9 & $\mid 127,4$ & 127,4 & 127,4 & 127,4 & 128,0 & $\mid 138,5$ & Santana & José Moreira Junior, 750 & José Morato & Escorregamento \\
\hline 14-dez-95 & 97,9 & 127,4 & 127,4 & 127,4 & 127,4 & 128,0 & 138,5 & São Cristóvão & Padre Rolim, 06 & Tereza Canuta dos Santos & Escorregamento \\
\hline 14-dez-95 & 97,9 & 127,4 & 127,4 & 127,4 & 127,4 & 128,0 & 138,5 & Tombadouro & Geraldo Jesus Gonçalves, 748 (Alto da Cruz) & Rosemary Maria Silva & Escorregamento \\
\hline 15-dez-95 & 7,0 & 104,9 & 134,4 & 134,4 & 134,4 & 134,4 & 135,0 & Antônio Dias & José Diogo dos Santos, 58 & Orelina Alves de A. Silva & Escorregamento \\
\hline 15-dez-95 & 7,0 & \begin{tabular}{|l|}
104,9 \\
\end{tabular} & 134,4 & 134,4 & 134,4 & 134,4 & 135,0 & Dores & Doutor Antonio Ibrahim, 55 & José Aparecido da C. Gomes & Escorregamento \\
\hline 15-dez-95 & 7,0 & \begin{tabular}{|l|}
104,9 \\
\end{tabular} & 134,4 & 134,4 & 134,4 & 134,4 & 135,0 & Santa Cruz & das Orquídeas, s/n & Rogério Afonso Ferreira da Silva & Escorregamento \\
\hline 15-dez-95 & 7,0 & $\mid 104,9$ & 134,4 & 134,4 & $\mid 134,4$ & 134,4 & 135,0 & Santana & 24 de Junho, 519 & Otacílio Dias & Escorregamento \\
\hline 15-dez-95 & 7,0 & \begin{tabular}{|c|}
104,9 \\
\end{tabular} & 134,4 & 134,4 & 134,4 & 134,4 & 135,0 & Santana & 24 de Junho, 596 & Amanda Neves & Escorregamento \\
\hline 15-dez-95 & 7,0 & 104,9 & 134,4 & 134,4 & 134,4 & 134,4 & 135,0 & Taquaral & Águas Férreas, 48 & Jandira dos Anjos Corrêia & Escorregamento \\
\hline 25-dez-95 & 37,1 & 70,8 & 75,2 & 99,7 & 116,2 & 123,1 & 135,9 & Alto da Cruz & Francisco Isaac, 68-A & Antonio Francisco & Escorregamento \\
\hline 25-dez-95 & 37,1 & 70,8 & 75,2 & 99,7 & 116,2 & $\mid 123,1$ & 135,9 & Alto da Cruz & Francisco Isaac, 68-B & Maria Pereira da Silva & Escorregamento \\
\hline 25-dez-95 & 37,1 & 70,8 & 75,2 & 99,7 & 116,2 & $\mid 123,1$ & 135,9 & Tombadouro & Anacleto Faria, 22 (Santa Efigênia) & Jadir dos Reis Filho & Escorregamento \\
\hline 25-dez-95 & 37,1 & 70,8 & 75,2 & 99,7 & 116,2 & \begin{tabular}{|c|c|}
123,1 \\
\end{tabular} & 135,9 & Tombadouro & Anacleto Farias, 24 (Santa Efigênia) & José Fernandes da Costa & Escorregamento \\
\hline 26-dez-95 & 78,5 & \begin{tabular}{|l|}
115,6 \\
\end{tabular} & 149,3 & 153,7 & 178,2 & \begin{tabular}{ll|}
194,7 \\
\end{tabular} & 201,6 & Alto da Cruz & Francisco Isaac, 240 & Maria das Graças Santos & Escorregamento \\
\hline 26-dez-95 & 78,5 & \begin{tabular}{|c|}
115,6 \\
\end{tabular} & 149,3 & 153,7 & 178,2 & \begin{tabular}{|c|c|}
194,7 \\
\end{tabular} & 201,6 & Barra & Beco da Mãe Chica, s/n & Marlene Júlia Neves & Início de escorregamento \\
\hline 26-dez-95 & 78,5 & \begin{tabular}{|l|}
115,6 \\
\end{tabular} & 149,3 & \begin{tabular}{|c|}
153,7 \\
\end{tabular} & 178,2 & \begin{tabular}{|c|c|}
194,7 \\
\end{tabular} & 201,6 & Padre Faria & Padre Martins, 51 (alto da cruz) & Otaćílio Juliano Pereira & Escorregamento \\
\hline 26-dez-95 & 78,5 & \begin{tabular}{|l|}
115,6 \\
\end{tabular} & 149,3 & 153,7 & 178,2 & \begin{tabular}{|c|c|}
194,7 \\
\end{tabular} & 201,6 & Padre Faria & Santa Rita, 236 (Alto da Cruz) & Maria Eugênia Silva & Escorregamento \\
\hline 26-dez-95 & 78,5 & 115,6 & 149,3 & 153,7 & 178,2 & \begin{tabular}{|c|c|}
194,7 \\
\end{tabular} & \begin{tabular}{|l|}
201,6 \\
\end{tabular} & Santana & 15 de Agosto, 608 & Marcos Antonio da Costa & Escorregamento \\
\hline 26-dez-95 & 78,5 & 115,6 & 149,3 & 153,7 & 178,2 & \begin{tabular}{|c|}
194,7 \\
\end{tabular} & 201,6 & São Cristóvão & Padre Rolim, 47 & Rubens Silvestre & Escorregamento \\
\hline 26-dez-95 & 78,5 & \begin{tabular}{|c|}
115,6 \\
\end{tabular} & 149,3 & 153,7 & 178,2 & \begin{tabular}{|c|c|}
194,7 \\
\end{tabular} & 201,6 & Saramenha & Américo René Gianetti, 1846 & Maurício da Silva Mendes & Escorregamento \\
\hline 26-dez-95 & 78,5 & 115,6 & 149,3 & 153,7 & 178,2 & $\mid 194,7$ & 201,6 & Tombadouro & Anacleto Faria, 23 (Alto da Cruz) & Nádia Aparecida Santos & Escorregamento \\
\hline 27-dez-95 & 15,8 & 94,3 & 131,4 & 165,1 & 169,5 & 194,0 & 210,5 & Antônio Dias & Travessa das Lajes, 154 & José Aurélio de Paula & Escorregamento \\
\hline 27-dez-95 & 15,8 & 94,3 & 131,4 & 165,1 & 169,5 & $\mid 194,0$ & 210,5 & Rosário & Gabriel Santos, 60 & Ieda Maria Reis Lima & Escorregamento \\
\hline 28-dez-95 & 13,0 & 28,8 & 107,3 & 144,4 & 178,1 & 182,5 & 207,0 & São Cristóvão & Abelardo Braga, 256 & Marilene Aparecida Novaes & Início de escorregamento \\
\hline 30-dez-95 & 8,4 & 24,8 & 37,8 & 53,6 & 132,1 & 169,2 & 202,9 & Água Limpa & Professor Antonio de Paula Ribas, 161-B & Nair Alves & Escorregamento \\
\hline 03-nov-96 & 18,0 & 44,5 & 66,0 & 66,0 & 66,0 & 66,6 & 107,3 & Padre Faria & Padre Martins, 151 (tombadouro) & Maria de Fátima F. Guimarães & Escorregamento \\
\hline 18-nov-96 & 72,3 & 80,1 & 87,5 & 101,1 & 101,1 & $\mid 101,1$ & 103,9 & Santa Cruz & Rua 1 (das Orquídeas), 23 (Alto da Cruz) & Francisco Pinheiro da Cruz & Escorregamento \\
\hline 19-nov-96 & 49,1 & 121,4 & 129,2 & 136,6 & 150,2 & 150,2 & 150,2 & Bauxita & Acesso campus UFOP, 461 (morro do cruzeiro) & Eustáquio M. Bento & Escorregamento \\
\hline 19-nov-96 & 49,1 & \begin{tabular}{|l|}
121,4 \\
\end{tabular} & 129,2 & 136,6 & 150,2 & 150,2 & 150,2 & Piedade & Abolição, 383 e Logradouro 14174, n. 37 & Mauro César Goes e Raimundo S. Noé & Escorregamento e queda de bloco \\
\hline 19-nov-96 & 49,1 & 121,4 & 129,2 & 136,6 & 150,2 & 150,2 & 150,2 & Tombadouro & Anacleto Farias, 22 (caminho da Fábrica) & Dina Amélia dos Reis & Escorregamento \\
\hline 20-nov-96 & 11,8 & 60,9 & 133,2 & 141,0 & 148,4 & 162,0 & 162,0 & São Cristóvão & José Feliciano de Meira, 236 & João do Espirito Santo Fernandes & Escorregamento \\
\hline 21-nov-96 & 50,4 & 62,2 & 111,3 & 183,6 & 191,4 & 198,8 & 212,4 & Alto da Cruz & Francisco Isaac, 1 & Cristiano Rocha & Escorregamento \\
\hline 21-nov-96 & 50,4 & 62,2 & 111,3 & 183,6 & \begin{tabular}{|c|}
191,4 \\
\end{tabular} & 198,8 & 212,4 & Antônio Dias & Chico Rei, 286B (Alto da Cruz) & Aparecida Damasia & Escorregamento \\
\hline 21-nov-96 & 50,4 & 62,2 & 111,3 & 183,6 & 191,4 & 198,8 & 212,4 & Padre Faria & Cristo Operário, 41 (Alto da Cruz) & Sérgio Luís Moreira & Escorregamento e corrida de detritos \\
\hline 21-nov-96 & 50,4 & 62,2 & 111,3 & 183,6 & 191,4 & 198,8 & 212,4 & Padre Faria & Padre Martins, 143 & Maria Barbosa da Mota Correia & Escorregamento \\
\hline 21-nov-96 & 50,4 & 62,2 & 111,3 & 183,6 & 191,4 & 198,8 & 212,4 & Padre Faria & Padre Martins, 155 & Dulcineia Sabino Cesário & Início de escorregamento \\
\hline
\end{tabular}




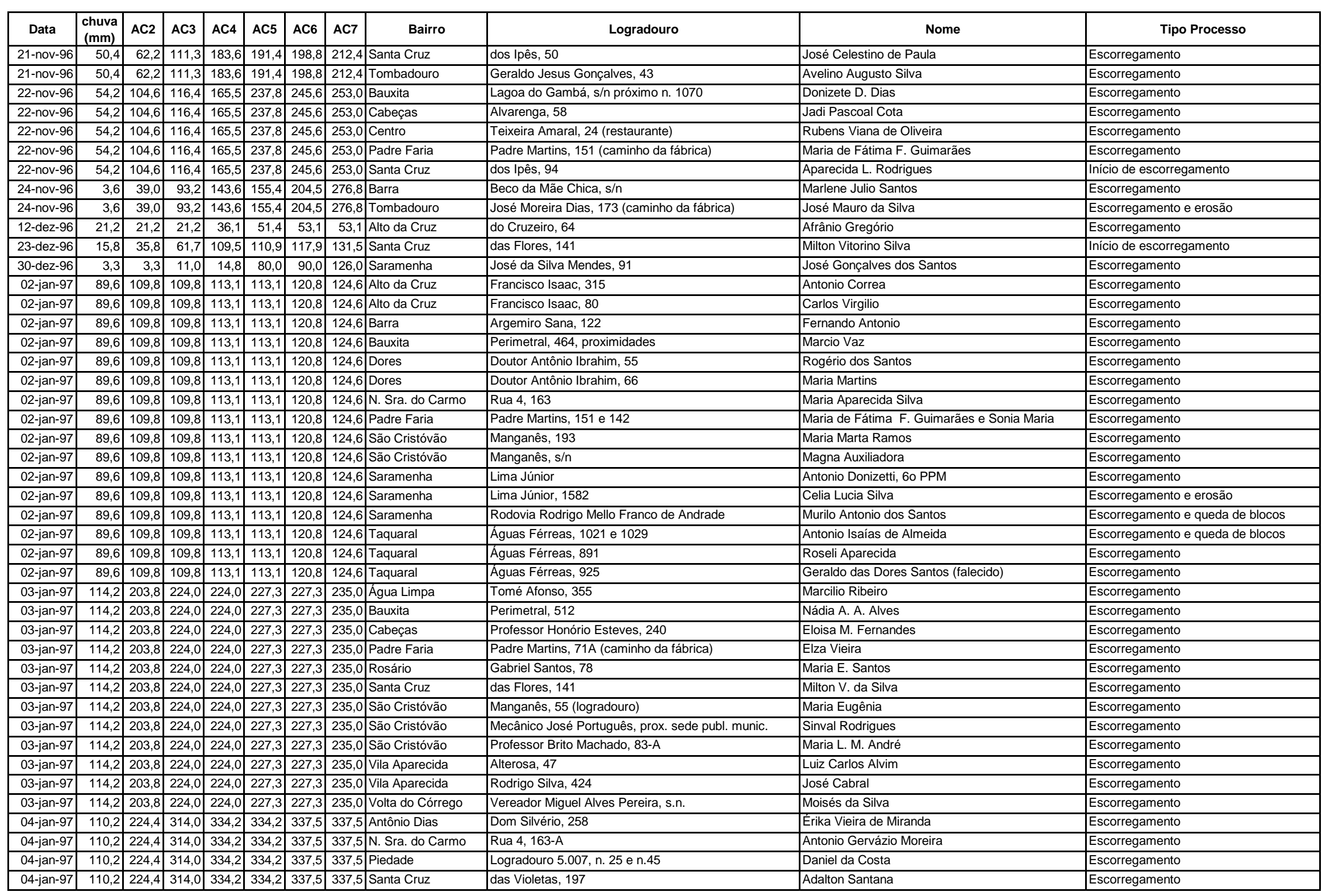




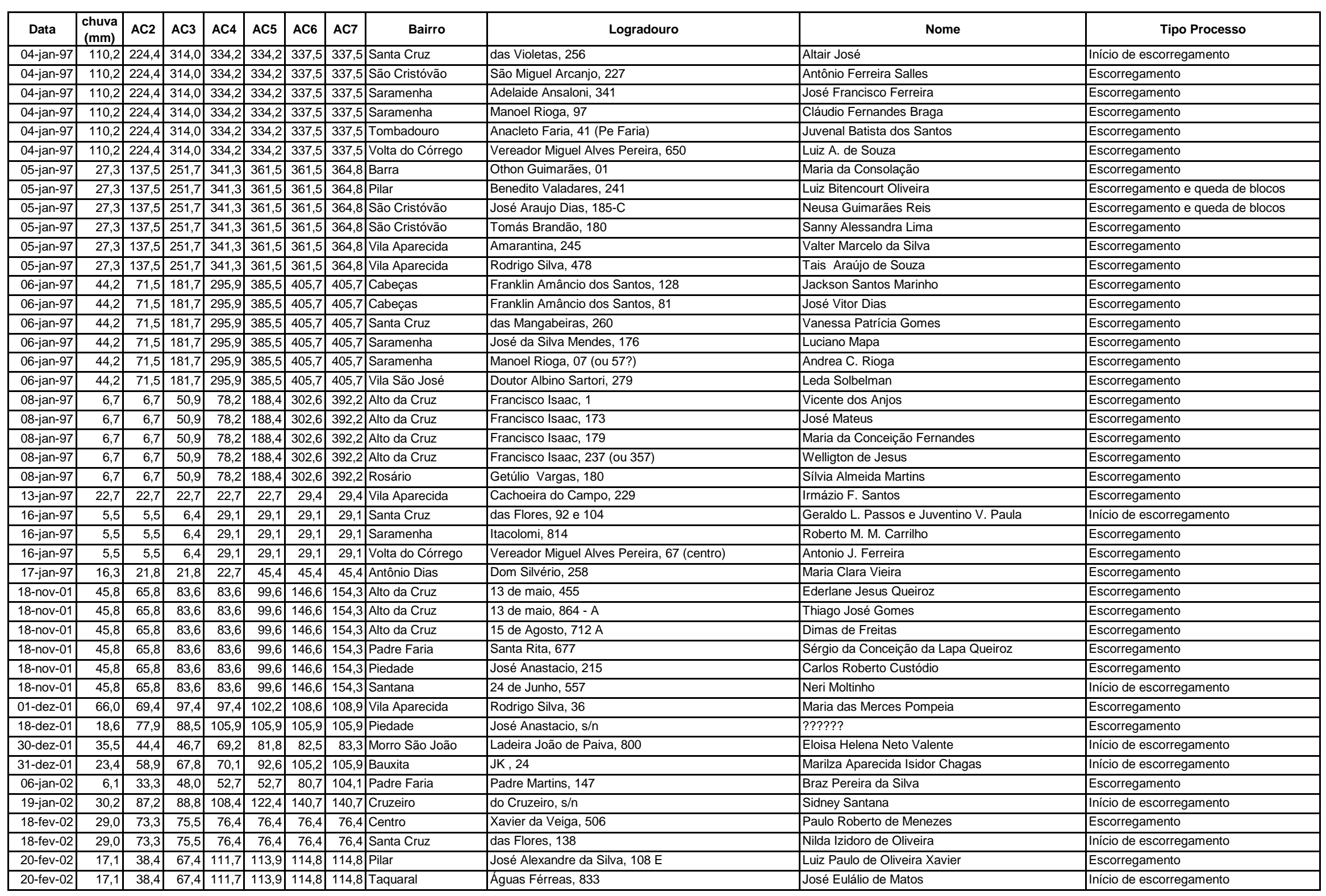




\begin{tabular}{|c|c|c|c|c|c|c|c|c|c|c|c|}
\hline Data & \begin{tabular}{|c|} 
chuva \\
$(\mathrm{mm})$
\end{tabular} & AC2 & AC3 & AC4 & AC5 & AC6 & AC7 & Bairro & Logradouro & Nome & Tipo Processo \\
\hline 17-nov-02 & 26,8 & 66,2 & 66,2 & 66,2 & 87,7 & 124,8 & 124,8 & São Cristóvão & Padre Rolim, 1129 & Nicia Cabral Danese & Início de escorregamento \\
\hline 18-nov-02 & 59,8 & 86,6 & 126,0 & 126,0 & 126,0 & $\mid 147,5$ & 184,6 & Água Limpa & Tomé de Vasconcelos, 270 & Atair Agostinho da Costa & Início de escorregamento \\
\hline 11-dez-02 & 29,4 & 45,4 & 50,6 & 69,2 & 91,0 & 100,0 & 100,0 & Caminho da Fábrica & Travessa Padre Martins, 166 & Marlene Faria Lima & Escorregamento \\
\hline 11-dez-02 & 29,4 & 45,4 & 50,6 & 69,2 & 91,0 & 100,0 & 100,0 & Padre Faria & Geraldo Jesus Gonçalves, 96 & Oromar Ladislau da Motta & Escorregamento \\
\hline 12-dez-02 & 62,8 & 92,2 & 108,2 & 113,4 & 132,0 & $\mid 153,8$ & 162,8 & Água Limpa & Benjamim Machado, 298 & Benedita Maria de Jesus Ribeiro & Escorregamento \\
\hline 12-dez-02 & 62,8 & 92,2 & 108,2 & 113,4 & 132,0 & 153,8 & 162,8 & Vila São José & Dr. Afonso Baeta, 102 & Paulo Roberto Borges & Escorregamento \\
\hline 13-dez-02 & 47,6 & 110,4 & 139,8 & 155,8 & 161,0 & $\mid 179,6$ & 201,4 & São Cristóvão & Professor Brito Machado, 49 & Rosilene Xavier Ribeiro & Início de escorregamento \\
\hline 13-dez-02 & 47,6 & \begin{tabular}{|l|}
110,4 \\
\end{tabular} & 139,8 & 155,8 & 161,0 & 179,6 & 201,4 & São Francisco & Vereador Miguel Alves Pereira, $441 \mathrm{~B}$ & Marta Costa Martins & Escorregamento \\
\hline 14-dez-02 & 5,7 & 53,3 & 116,1 & 145,5 & 161,5 & \begin{tabular}{|c|c|}
166,7 \\
\end{tabular} & 185,3 & Alto da Cruz & do Cruzeiro, 205 & Valdivino Geraldo da Silva & Escorregamento \\
\hline 26-dez-02 & 69,7 & 69,7 & 88,7 & 106,9 & 115,4 & 115,4 & 115,4 & Alto da Cruz & 13 de maio, 365 & Carmélio Francisco de Paula & Escorregamento \\
\hline 05-jan-03 & 17,0 & 32,2 & 73,8 & 74,2 & 90,8 & $\mid 112,2$ & 141,2 & São Cristóvão & José Pedro de Meira, 30 & Wellington César Ferreira de Souza & Escorregamento \\
\hline 07-jan-03 & 33,7 & 49,0 & 66,0 & 81,2 & 122,8 & 123,2 & 139,8 & Alto da Cruz & Chico Rei, 286 C & Giovana Elizabeth de Souza Barbosa & Escorregamento \\
\hline 07-jan-03 & 33,7 & 49,0 & 66,0 & 81,2 & 122,8 & 123,2 & 139,8 & Cabeças & Franklin Amâncio dos Santos, 120 & Davi Alberto Custódio & Escorregamento \\
\hline 07-jan-03 & 33,7 & 49,0 & 66,0 & 81,2 & 122,8 & 123,2 & 139,8 & Caminho da Fábrica & Anacleto Faria, 18 & Lurdes Rosa Silva & Escorregamento \\
\hline 07-jan-03 & 33,7 & 49,0 & 66,0 & 81,2 & 122,8 & 123,2 & 139,8 & Passa Dez & João Custódio, s/n & Adriana Clarett Guiriarde Cristina & Escorregamento \\
\hline 07-jan-03 & 33,7 & 49,0 & 66,0 & 81,2 & 122,8 & 123,2 & 139,8 & Pocinho & Rodovia Rodrigo Melo Franco de Andrade, s/n & Lurdes Bernado de Souza Rodrigues & Escorregamento \\
\hline 07-jan-03 & 33,7 & 49,0 & 66,0 & 81,2 & 122,8 & 123,2 & 139,8 & São Cristóvão & Logradouro 235, 75 & Carlos Maurício de Paula & Escorregamento \\
\hline 07-jan-03 & 33,7 & 49,0 & 66,0 & 81,2 & 122,8 & 123,2 & 139,8 & Saramenha & Felícia Mendes, 190 & Ângela de Fátima Pinto da Rocha & Escorregamento \\
\hline 16-jan-03 & 66,4 & 81,0 & 83,2 & 90,5 & 90,9 & 119,6 & 122,6 & Água Limpa & Professor Antônio de Paulo Ribas, 259 & Maria Marcelino & Escorregamento \\
\hline 16-jan-03 & 66,4 & 81,0 & 83,2 & 90,5 & 90,9 & 119,6 & 122,6 & Antônio Dias & Padre Tobias, 75 & Maria de Fátima Costa Reis Moutinho & Escorregamento \\
\hline 16-jan-03 & 66,4 & 81,0 & 83,2 & 90,5 & 90,9 & 119,6 & 122,6 & Bauxita & Perimetral, 464 & Maria de Jesus Carvalho Gomes & Escorregamento \\
\hline 16-jan-03 & 66,4 & 81,0 & 83,2 & 90,5 & 90,9 & 119,6 & 122,6 & Santana & Santa Marta, 86 & Luiz Gonzaga & Escorregamento e queda de blocos \\
\hline 16-jan-03 & 66,4 & 81,0 & 83,2 & 90,5 & 90,9 & 119,6 & 122,6 & Santana & Uberlândia, 35 & Anderson Carlos Santana & Escorregamento \\
\hline 16-jan-03 & 66,4 & 81,0 & 83,2 & 90,5 & 90,9 & 119,6 & 122,6 & Taquaral & Farmacêutico Duilo Passos, 1499 & Rafael Maciel Dutra & Escorregamento \\
\hline 16-jan-03 & 66,4 & 81,0 & 83,2 & 90,5 & 90,9 & 119,6 & 122,6 & Vila Aparecida & Rodrigo Silva, 32 & Mauro José Arlindo Gonçalves & Escorregamento e queda de blocos \\
\hline 17-jan-03 & 16,7 & 83,1 & 97,7 & 99,9 & 107,2 & 107,6 & 136,3 & Alto da Cruz & Francisco Isaac, 01 & Vicente dos Anjos & Escorregamento \\
\hline 17-jan-03 & 16,7 & 83,1 & 97,7 & 99,9 & 107,2 & 107,6 & 136,3 & Alto da Cruz & Francisco Isaac, 36 & Dayvid Richard da Cunha & Escorregamento \\
\hline $\begin{array}{ll}17-j a n-03 \\
\end{array}$ & 16,7 & 83,1 & 97,7 & 99,9 & 107,2 & 107,6 & 136,3 & Barra & dos Inconfidentes, 30 & Rosilene Cardoso da Silva & Escorregamento e queda de blocos \\
\hline 17-jan-03 & 16,7 & 83,1 & 97,7 & 99,9 & 107,2 & 107,6 & 136,3 & Barra & dos Inconfidentes, 67 & Maria do Carmo Santos & Escorregamento e queda de blocos \\
\hline 17-jan-03 & 16,7 & 83,1 & 97,7 & 99,9 & 107,2 & 107,6 & 136,3 & Córrego Seco & Uberlândia, 2058 & Carlos Ferreira Guimarães & Escorregamento \\
\hline 17-jan-03 & 16,7 & 83,1 & 97,7 & 99,9 & 107,2 & 107,6 & 136,3 & Piedade & da Abolição, 390 & Rosimery Cristina da Silva Moura & Escorregamento \\
\hline 17-jan-03 & 16,7 & 83,1 & 97,7 & 99,9 & 107,2 & 107,6 & 136,3 & Santana & 15 de Agosto, 265 & Maria Aparecida Borges Ferreira & Escorregamento \\
\hline $\begin{array}{l}17 \text {-jan-03 } \\
\end{array}$ & 16,7 & 83,1 & 97,7 & 99,9 & 107,2 & 107,6 & 136,3 & Santana & Santa Marta, 10 & Roberto Agustinho Mendes & Escorregamento e queda de blocos \\
\hline 17-jan-03 & 16,7 & 83,1 & 97,7 & 99,9 & 107,2 & 107,6 & 136,3 & Taquaral & Águas Férreas, 165 & Claudinei Rodrigues da Silva & Escorregamento e queda de blocos \\
\hline 17-jan-03 & 16,7 & 83,1 & 97,7 & 99,9 & 107,2 & 107,6 & 136,3 & Taquaral & Águas Férreas, 188 & Sueli Gomes Dias & Escorregamento \\
\hline 18-jan-03 & 15,4 & 32,1 & 98,5 & 113,1 & 115,3 & 122,6 & 123,0 & Água Limpa & Professor Antônio de Paulo Ribas, 229 & Sônia Maria Camilo & Escorregamento \\
\hline $\begin{array}{ll}18 \text {-jan-03 } \\
\end{array}$ & 15,4 & 32,1 & 98,5 & 113,1 & 115,3 & 122,6 & 123,0 & Santa Cruz & das Flores, 106 & Roberto Carlos de Souza & Escorregamento \\
\hline 19-jan-03 & 25,5 & 40,9 & 57,6 & 124,0 & 138,6 & 140,8 & 148,1 & Alto das Dores & Jair Afonso Inácio, 123 & Elma Aparecida de Almeida Morais & Escorregamento \\
\hline 19-jan-03 & 25,5 & 40,9 & 57,6 & 124,0 & 138,6 & 140,8 & 148,1 & Antônio Dias & Dr. João Veloso, 45 & Isabel Rioga André de Melo & Escorregamento \\
\hline
\end{tabular}




\begin{tabular}{|c|r|r|r|r|r|c|c|l|l|l|l|}
\hline Data & $\begin{array}{c}\text { chuva } \\
(\mathbf{m m})\end{array}$ & AC2 & AC3 & AC4 & AC5 & AC6 & AC7 & \multicolumn{1}{|c|}{ Bairro } & & \multicolumn{1}{|c|}{ Logradouro } & Nome \\
\hline 19 -jan-03 & 25,5 & 40,9 & 57,6 & 124,0 & 138,6 & 140,8 & 148,1 & Saramenha & Euclides Mapa, 124 & Margarida Marques Mendes \\
\hline 20-jan-03 & 3,2 & 28,7 & 44,1 & 60,8 & 127,2 & 141,8 & 144,0 & Antônio Dias & Padre Gabriel Carvalho, 61 & Ana Maria de Souza Silva Mendes \\
\hline 22-jan-03 & 37,3 & 48,3 & 51,5 & 77,0 & 92,4 & 109,1 & 175,5 & N. Sra. do Carmo & da Lagoa, 1135 A & Wanda Aparecida Moreira \\
\hline 22-jan-03 & 37,3 & 48,3 & 51,5 & 77,0 & 92,4 & 109,1 & 175,5 & São Cristóvão & Padre Carmelho, 100 & Vscorregamento \\
\hline 23-jan-03 & 19,3 & 56,6 & 67,6 & 70,8 & 96,3 & 111,7 & 128,4 & Santa Cruz & das Rosas, 35 & Vscente Barbosa Nolasco \\
\hline 23-jan-03 & 19,3 & 56,6 & 67,6 & 70,8 & 96,3 & 111,7 & 128,4 & Santa Cruz & dos Girassóis, 85 & Geraldo da Conceição dos Santos \\
\hline
\end{tabular}




\section{ANEXO II}

Mapa com Zoneamento das Áreas de Risco (Castro, 2006) 


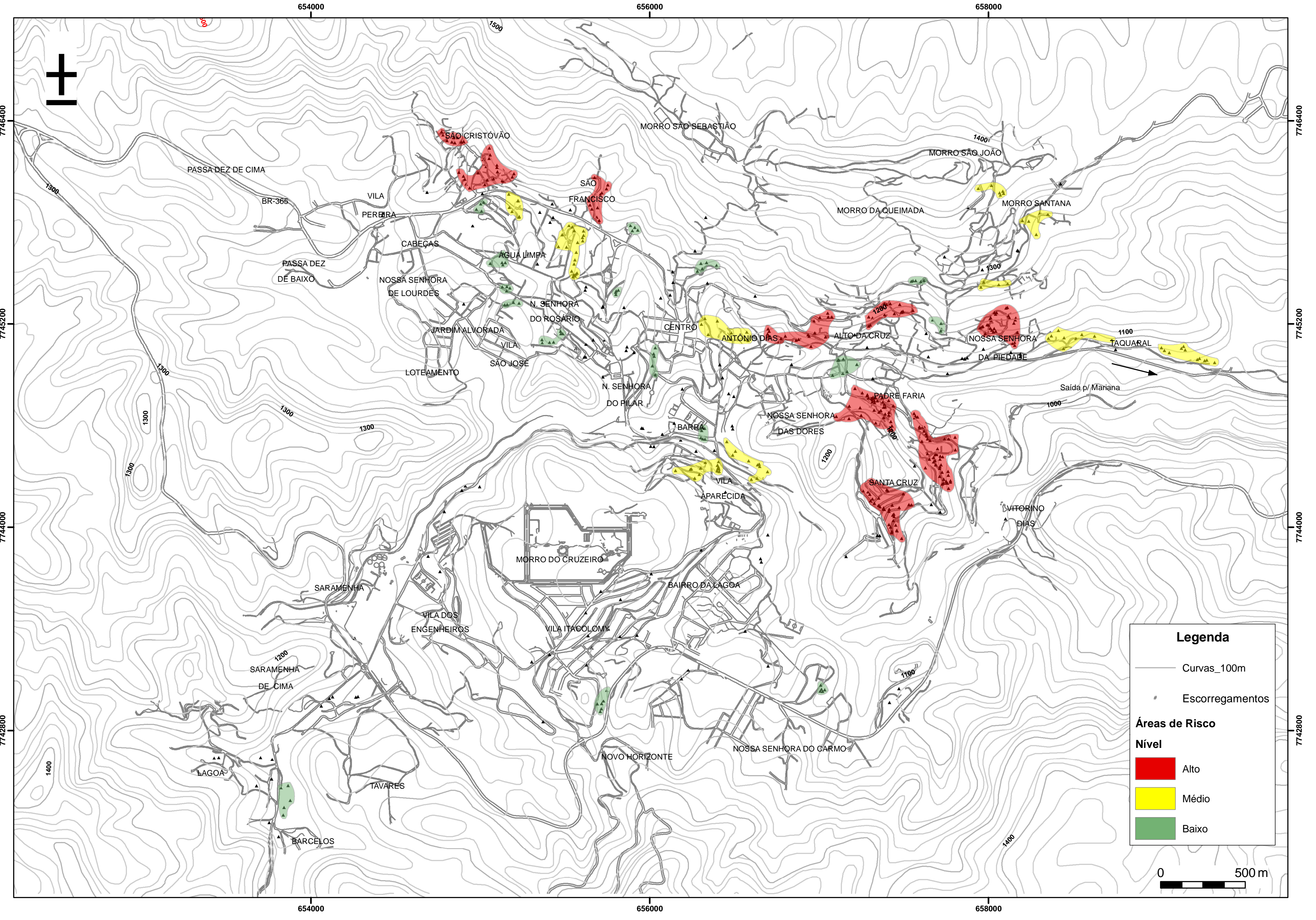


ANEXO III

Lista das Ocorrências Mapeadas (Fontes, 2011) 
Apresenta-se neste anexo a relação das ocorrências cadastradas e uma planilha modelo devidamente preenchida com as informações consideradas nas análises.

A Tabela a seguir sintetiza todas as ocorrências envolvendo processos geodinâmicos, devidamente compiladas e sistematizadas em Fontes (2011), as quais foram objetos de inspeções técnicas de campo e coleta de informações junto a moradores dos locais atingidos, para complementação dos dados e organização sistêmica do cadastro final.

Tabela Anexo I - Lista das Ocorrências Mapeadas

\begin{tabular}{|c|c|c|c|c|c|}
\hline Ponto & $\begin{array}{l}\text { Código da } \\
\text { Ocorrência }\end{array}$ & $\begin{array}{c}\text { Coordenada } \\
\text { X }\end{array}$ & $\begin{array}{c}\text { Coordenada } \\
\mathbf{Y} \\
\end{array}$ & $\begin{array}{c}\text { Data da } \\
\text { Ocorrência }\end{array}$ & $\begin{array}{l}\text { Eventos Geotécnicos } \\
\text { Observados }\end{array}$ \\
\hline E1 & 290 & 657289 & 7744134 & 04/11/1990 & \\
\hline E2 & 291 & 657164 & 7744133 & & \\
\hline E3 & 292 & 657251 & 7744225 & 03/01/1997 & $\begin{array}{l}\text { Demais ocorrências: } \\
\text { 23/12/1996. }\end{array}$ \\
\hline E4 & 293 & 657259 & 7744214 & & \\
\hline E5 & 294 & 657245 & 7744221 & & \\
\hline E6 & 295 & 657295 & 7744175 & 25/10/1993 & \\
\hline E7 & 296 & 657529 & 7744161 & & \\
\hline E8 & 297 & 657353 & 7744003 & 21/11/1996 & \\
\hline E9 & 298 & 657376 & 7743948 & 06/02/1998 & \\
\hline E10 & 299 & 657422 & 7743916 & & \\
\hline E11 & 324 & 657326 & 7744274 & & \\
\hline E12 & 301 & 657305 & 7744242 & & \\
\hline E13 & 303 & 657428 & 7744266 & & \\
\hline E14 & 304 & 657421 & 7744254 & & $\begin{array}{l}\text { Problema ao longo de toda a } \\
\text { Rua dos Bosques e Trilha } \\
\text { Paralela acima. }\end{array}$ \\
\hline E15 & 305 & 657566 & 7744248 & & \\
\hline E16 & 306 & 657396 & 7744232 & & \\
\hline E17 & 307 & 657443 & 7744238 & & \\
\hline E18 & 308 & 657411 & 774398 & 02/01/1996 & \\
\hline E19 & 309 & 657162 & 7743848 & & \\
\hline E20 & 310 & 657362 & 7743919 & & \\
\hline E21 & 311 & 657607 & 7744322 & 04/01/1997 & $\begin{array}{l}\text { Início de um processo erosivo } \\
\text { no lote vizinho, que pode } \\
\text { prejudicá-los. }\end{array}$ \\
\hline E22 & 312 & 657612 & 7744353 & 04/01/1997 & \\
\hline
\end{tabular}


Continuação da Tabela Anexo I - Lista das Ocorrências Mapeadas

\begin{tabular}{|c|c|c|c|c|c|}
\hline Ponto & $\begin{array}{l}\text { Código da } \\
\text { Ocorrência }\end{array}$ & $\begin{array}{c}\text { Coordenada } \\
\text { X }\end{array}$ & $\begin{array}{c}\text { Coordenada } \\
\text { Y }\end{array}$ & $\begin{array}{c}\text { Data da } \\
\text { Ocorrência }\end{array}$ & Eventos Geotécnicos Observados \\
\hline E23 & 313 & 657591 & 7744363 & & $\begin{array}{l}\text { Ao longo de toda a Rua das Violetas } \\
\text { existem erosões superficiais. }\end{array}$ \\
\hline E24 & 315 & 657406 & 7744108 & & \\
\hline E25 & 316 & 657434 & 7744121 & & $\begin{array}{l}\text { Nos fundos da Casa 113há entulhos } \\
\text { depositados, segurados por uma } \\
\text { barreira (paliçada) e pela vegetação. }\end{array}$ \\
\hline E26 & 317 & 657429 & 7744129 & 02/11/1996 & \\
\hline E27 & 314 & 657483 & 7744133 & & \\
\hline E28 & 318 & 657382 & 7744152 & & \\
\hline E29 & 319 & 657472 & 7744180 & & \\
\hline E30 & 320 & 657471 & 7744213 & & \\
\hline E31 & 321 & 657214 & 7744650 & 06/01/1997 & \\
\hline E32 & 322 & 657255 & 7744562 & & \\
\hline E33 & 323 & 658042 & 7746000 & 15/12/1995 & \\
\hline E34 & 325 & 657373 & 7744070 & 01/02/1997 & \\
\hline E35 & 337 & 657997 & 7746016 & & $\begin{array}{l}\text { Formou-se um grande bota-fora, no } \\
\text { qual encontra-se muito lixo, entulho, } \\
\text { material transportado, dentro de uma } \\
\text { drenagem natural. Todo esse } \\
\text { material escoa para jusante, } \\
\text { assoreando as casas próximas. Há } \\
\text { sinais de movimento de massa } \\
\text { (árvores inclinadas). }\end{array}$ \\
\hline E36 & 327 & 657718 & 7744175 & & \\
\hline E37 & 328 & 657622 & 7744132 & & $\begin{array}{l}\text { Dimensão da feição, } \\
\text { aproximadamente, } 10 \text { x 25m. }\end{array}$ \\
\hline E38 & 329 & 657168 & 7744132 & & \\
\hline E39 & 330 & 657251 & 7743807 & & $\begin{array}{l}\text { Feição muito grande ocasionada por } \\
\text { execução de taludes de mineração de } \\
\text { pirita. Observa-se várias trincas de } \\
\text { tração no solo de montante e } \\
\text { ocorrência de escorregamentos, em } \\
\text { função do descalçamento dos taludes } \\
\text { por ação das águas. }\end{array}$ \\
\hline $\mathrm{E} 40$ & 331 & 657419 & 7743955 & & \\
\hline E41 & 332 & 657544 & 7744240 & & \\
\hline E42 & 333 & 657479 & 7744147 & & \\
\hline E43 & 336 & 657648 & 7744251 & & \\
\hline E44 & 340 & 658004 & 7745987 & 01/04/1993 & $\begin{array}{l}\text { Demais datas de Ocorrência: } \\
\text { 15/12/95, 21/01/97 }\end{array}$ \\
\hline E45 & 341 & 658105 & 7745836 & & \\
\hline E46 & 342 & 657675 & 7745628 & & $\begin{array}{l}\text { Subsidência do Terreno devido a } \\
\text { existência de uma galeria, "sari", } \\
\text { dentro da qual é lançado o esgoto } \\
\text { das casas vizinhas. }\end{array}$ \\
\hline E47 & 343 & 657927 & 7745481 & & $\begin{array}{l}\text { Subsidência gerada pela presença } \\
\text { de galeria, com } \\
\text { aproximadamente } 5 \mathrm{~m} \text { de } \\
\text { profundidade. Há uma caixa } \\
\text { d'água muito próxima do local } \\
\text { onde houve a queda da laje da } \\
\text { galeria. }\end{array}$ \\
\hline
\end{tabular}


Continuação da Tabela Anexo I - Lista das Ocorrências Mapeadas

\begin{tabular}{|c|c|c|c|c|c|}
\hline Ponto & $\begin{array}{l}\text { Código da } \\
\text { Ocorrência } \\
\end{array}$ & $\begin{array}{c}\text { Coordenada } \\
\mathrm{X} \\
\end{array}$ & $\begin{array}{c}\text { Coordenada } \\
\text { Y } \\
\end{array}$ & $\begin{array}{c}\text { Data da } \\
\text { Ocorrência } \\
\end{array}$ & $\begin{array}{c}\text { Eventos Geotécnicos } \\
\text { Observados } \\
\end{array}$ \\
\hline E48 & 344 & 658150 & 7745604 & & \\
\hline E49 & 345 & 658395 & 7745775 & & \\
\hline E50 & 346 & 659271 & 7744980 & 17/06/1991 & \\
\hline E51 & 347 & 659166 & 7745006 & 02/01/1997 & \\
\hline E52 & 349 & 659072 & 7745029 & 02/01/1997 & $\begin{array}{l}\text { Presença de água, caracterizado } \\
\text { devido a presença de vegetação } \\
\text { típica como Bananeiras e } \\
\text { Mariazinhas. } \\
\end{array}$ \\
\hline E53 & 353 & 659042 & 7745042 & 21/11/1996 & $\begin{array}{l}\text { Presença de água, caracterizado } \\
\text { pela existência de vegetação } \\
\text { característica como Bananeiras } \\
\text { e Mariazinhas. Demais datas de } \\
\text { ocorrência: 28/11/89, 02/01/97. }\end{array}$ \\
\hline E54 & 351 & 659015 & 7745021 & 11/12/1989 & Presença de Bananeiras \\
\hline E55 & 354 & 658786 & 7745061 & 13/12/1989 & Presença de Entulho, lixo. \\
\hline E56 & 355 & 658439 & 7745089 & & \\
\hline E57 & 356 & 658477 & 7745078 & 14/12/1989 & $\begin{array}{l}\text { Existência de indicativos de } \\
\text { movimento, árvores tombadas, e } \\
\text { de presença de água, bananeiras. }\end{array}$ \\
\hline E58 & 357 & 658392 & 7745138 & & \\
\hline E59 & 359 & 658420 & 7745103 & 15/12/1995 & $\begin{array}{l}\text { Demais datas de Ocorrência: } \\
\text { 29/12/94 }\end{array}$ \\
\hline E60 & 367 & 658369 & 7745162 & 23/01/1992 & \\
\hline E61 & 365 & 658385 & 7745169 & & \\
\hline E62 & 364 & 658299 & 7745179 & & \\
\hline E63 & 363 & 658152 & 7745063 & 02/04/1998 & \\
\hline E64 & 361 & 658194 & 7745045 & 17/12/1996 & \\
\hline E65 & 360 & 658198 & 7745052 & & $\begin{array}{l}\text { Antes da Construção da } \\
\text { canaleta, existiam problemas } \\
\text { constantes. Entre a rua e a } \\
\text { Rodovia, ainda ocorrem } \\
\text { problemas devido a falta de } \\
\text { bueiros. Os cortes realizados na } \\
\text { Rodovia prejudicaram a rua. } \\
\end{array}$ \\
\hline E66 & 369 & 656975 & 7745280 & & $\begin{array}{l}\text { Foi encontrada uma mina nos } \\
\text { fundos da Residência, cujo salão } \\
\text { possui grandes dimensões } \\
\text { (alguns lugares com até } 6 \mathrm{~m} \text { de } \\
\text { altura). Uma grande quantidade } \\
\text { de água escoa pela mina. } \\
\text { Observa-se partes do teto } \\
\text { desmoronados. } \\
\end{array}$ \\
\hline E67 & 372 & 657369 & 7745377 & 23/01/1992 & $\begin{array}{l}\text { Observa-se um movimento de } \\
\text { massa no terreno, caracterizado } \\
\text { por árvores inclinadas. Demais } \\
\text { datas de ocorrência: 26/12/95, } \\
\text { 31/01/91, 24/01/92. }\end{array}$ \\
\hline E68 & 374 & 657460 & 7745396 & & $\begin{array}{l}\text { A casa foi construída dentro de } \\
\text { uma drenagem superficial (na } \\
\text { beira de um Córrego). }\end{array}$ \\
\hline E69 & 375 & 657571 & 7745416 & 24/10/1989 & \\
\hline
\end{tabular}


Continuação da Tabela Anexo I - Lista das Ocorrências Mapeadas

\begin{tabular}{|c|c|c|c|c|c|}
\hline Ponto & $\begin{array}{l}\text { Código da } \\
\text { Ocorrência }\end{array}$ & $\begin{array}{c}\text { Coordenada } \\
\text { X } \\
\end{array}$ & $\begin{array}{c}\text { Coordenada } \\
\text { Y } \\
\end{array}$ & $\begin{array}{c}\text { Data da } \\
\text { Ocorrência }\end{array}$ & $\begin{array}{c}\text { Eventos Geotécnicos } \\
\text { Observados } \\
\end{array}$ \\
\hline E70 & 377 & 657164 & 7745241 & & \\
\hline E71 & 376 & 657642 & 7745430 & & \\
\hline E72 & 378 & 658142 & 7745655 & & \\
\hline E73 & 379 & 658251 & 774386 & & \\
\hline E74 & 380 & 658226 & 7745420 & & \\
\hline E75 & 381 & 658229 & 7745507 & & $\begin{array}{l}\text { Ponto caracterizado por três } \\
\text { minas subterrâneas, uma delas } \\
\text { de enomes proporções ( } 3 \text { de } \\
\text { largura e } 5 \text { profundidade), } \\
\text { contendo um grande volume de } \\
\text { água. }\end{array}$ \\
\hline E76 & 383 & 658018 & 7745440 & 15/01/1992 & $\begin{array}{l}\text { Não foi possível descrever a } \\
\text { natureza do evento. }\end{array}$ \\
\hline E77 & 382 & 658051 & 7745441 & & $\begin{array}{l}\text { Subsidência de uma Mina } \\
\text { Subterrânea. }\end{array}$ \\
\hline E78 & 384 & 658171 & 7745421 & & \\
\hline E79 & 385 & 657204 & 7745389 & 25/11/1992 & \\
\hline E80 & 397 & 657824 & 7745053 & & \\
\hline E81 & 400 & 658141 & 7745115 & & \\
\hline E82 & 401 & 658124 & 7745092 & & \\
\hline E83 & 402 & 658110 & 7745073 & 22/11/1996 & \\
\hline E84 & 403 & 658106 & 7745084 & 23/01/1992 & $\begin{array}{l}\text { Foi construído um muro sem } \\
\text { drenos para conter os } \\
\text { escorregamentos. }\end{array}$ \\
\hline E85 & 404 & 658091 & 7745092 & 29/10/1989 & \\
\hline E86 & 405 & 658146 & 7745118 & & \\
\hline E87 & 406 & 657980 & 7745167 & 15/01/1991 & \\
\hline E88 & 407 & 658176 & 7745294 & & \\
\hline E89 & 399 & 657819 & 7745169 & & \\
\hline E90 & 398 & 657887 & 7745138 & 27/12/1995 & 04/03/1997 \\
\hline E91 & 390 & 657876 & 7745182 & $10 / 01 / 1992$ & \\
\hline E92 & 395 & 657969 & 7745176 & 21/11/1996 & Datas: 19/11/1996 e 27/02/1996 \\
\hline E93 & 394 & 658049 & 7745302 & & \\
\hline E94 & 392 & 658042 & 7745279 & 26/10/1989 & $\begin{array}{l}\text { Demais datas de ocorrência: } \\
\text { 29/11/89. }\end{array}$ \\
\hline E95 & 389 & 656592 & 7745351 & & \\
\hline E96 & 408 & 658102 & 7745285 & 21/12/1995 & \\
\hline E97 & 388 & 657906 & 7745252 & 15/12/1995 & $\begin{array}{l}\text { Os moradores da região captam } \\
\text { água de uma fenda atrás da casa } \\
\text { 41. Demais datas de ocorrência: } \\
\text { 27/08/97, 27/04/90. }\end{array}$ \\
\hline E98 & 393 & 657443 & 7745286 & & \\
\hline E99 & 418 & 654889 & 7746086 & 03/01/1997 & \\
\hline E100 & 417 & 654963 & 7746267 & $14 / 12 / 1989$ & \\
\hline E101 & 416 & 655152 & 7746060 & $16 / 01 / 1997$ & \\
\hline E102 & 415 & 655474 & 7745939 & $17 / 01 / 1991$ & \\
\hline E103 & 414 & 655474 & 7745939 & $16 / 01 / 1997$ & \\
\hline
\end{tabular}


Continuação da Tabela Anexo I - Lista das Ocorrências Mapeadas

\begin{tabular}{|c|c|c|c|c|c|}
\hline Ponto & $\begin{array}{l}\text { Código da } \\
\text { Ocorrência }\end{array}$ & $\begin{array}{c}\text { Coordenada } \\
\text { X } \\
\end{array}$ & $\begin{array}{c}\text { Coordenada } \\
\text { Y } \\
\end{array}$ & $\begin{array}{c}\text { Data da } \\
\text { Ocorrência }\end{array}$ & $\begin{array}{c}\text { Eventos Geotécnicos } \\
\text { Observados } \\
\end{array}$ \\
\hline E104 & 413 & 655656 & 7746072 & 03/01/1997 & \\
\hline E105 & 411 & 655859 & 7745788 & $14 / 01 / 1997$ & \\
\hline E106 & 410 & 655680 & 7746104 & 24/01/1992 & \\
\hline E107 & 409 & 655723 & 7746202 & 01/04/1997 & \\
\hline E108 & 426 & 654985 & 7746023 & $12 / 05 / 1996$ & 05/01/1997 e 30/01/1997. \\
\hline E109 & 424 & 655575 & 7745873 & $16 / 01 / 1997$ & \\
\hline E110 & 423 & 655666 & 7746095 & & \\
\hline E111 & 422 & 655720 & 7746228 & & \\
\hline E112 & 421 & 655792 & 7746236 & & \\
\hline E113 & 420 & 655749 & 7746167 & & \\
\hline E114 & 419 & 655313 & 7745825 & $16 / 02 / 1998$ & \\
\hline E115 & 412 & 655883 & 7745872 & $24 / 01 / 1992$ & \\
\hline E116 & 425 & 655646 & 7745842 & $09 / 03 / 1998$ & \\
\hline E117 & 427 & 654888 & 7746422 & & \\
\hline E118 & 428 & 654876 & 7746299 & & \\
\hline E119 & 490 & 654641 & 7746405 & 28/12/1995 & \\
\hline E120 & 430 & 655591 & 7746076 & $14 / 01 / 1991$ & \\
\hline E121 & 432 & 655165 & 7746048 & & \\
\hline E122 & 431 & 654944 & 7746073 & & \\
\hline E123 & 433 & 654776 & 7746010 & $02 / 01 / 1997$ & \\
\hline E124 & 434 & 654913 & 7746308 & 14/12/1995 & \\
\hline E125 & 435 & 654943 & 7746281 & $02 / 01 / 2000$ & 09/01/2000. \\
\hline E126 & 436 & 655043 & 7746162 & 05/01/1997 & $\begin{array}{l}\text { Observa-se árvores inclinadas } \\
\text { no terreno. }\end{array}$ \\
\hline E127 & 438 & 654943 & 7746073 & 03/01/1997 & \\
\hline E128 & 439 & 654813 & 7746044 & 20/01/1992 & \\
\hline E129 & 440 & 654787 & 7746048 & 02/01/1997 & $\begin{array}{l}\text { Presença de bananeiras e } \\
\text { mamonas. }\end{array}$ \\
\hline E130 & 441 & 654862 & 7746114 & 31/10/1989 & $\begin{array}{l}\text { Existem bananeiras no lote 194- } \\
\text { B. }\end{array}$ \\
\hline E131 & 442 & 654824 & 7746425 & 24/01/1992 & $\begin{array}{l}\text { Existência de afloramento de } \\
\text { água e árvores inclinadas. O } \\
\text { esgoto é lançado encosta abaixo. }\end{array}$ \\
\hline E132 & 443 & 654819 & 7746316 & 20/12/1988 & $\begin{array}{l}\text { Terreno totalmente construído, } \\
\text { impossibilitando a determinação } \\
\text { da litologia. }\end{array}$ \\
\hline E133 & 444 & 654939 & 7746026 & 27/12/1995 & $\begin{array}{l}\text { Movimento de massa } \\
\text { evidenciado por tronco de } \\
\text { árvores tombados. }\end{array}$ \\
\hline E134 & 445 & 654907 & 7746142 & 05/01/1997 & $\begin{array}{l}\text { A casa localiza-se em uma área } \\
\text { de drenagem. }\end{array}$ \\
\hline E135 & 446 & 655614 & 7746014 & & \\
\hline E136 & 447 & 655558 & 7745923 & 04/06/1993 & \\
\hline E137 & 448 & 6574444 & 7743883 & & $\begin{array}{l}\text { A voçoroca recebe um elevado } \\
\text { fluxo de água, que desemboca } \\
\text { em sulcos nas rochas a jusante. }\end{array}$ \\
\hline E138 & 449 & 657614 & 7744450 & 21/11/1996 & \\
\hline
\end{tabular}


Continuação da Tabela Anexo I - Lista das Ocorrências Mapeadas

\begin{tabular}{|c|c|c|c|c|c|}
\hline Ponto & $\begin{array}{l}\text { Código da } \\
\text { Ocorrência }\end{array}$ & $\begin{array}{c}\text { Coordenada } \\
\mathrm{X} \\
\end{array}$ & $\begin{array}{c}\text { Coordenada } \\
\text { Y } \\
\end{array}$ & $\begin{array}{c}\text { Data da } \\
\text { Ocorrência }\end{array}$ & $\begin{array}{c}\text { Eventos Geotécnicos } \\
\text { Observados } \\
\end{array}$ \\
\hline E139 & 451 & 657651 & 7744433 & 26/12/1995 & $\begin{array}{l}\text { Presença de ávores incinadas e } \\
\text { bananeiras. }\end{array}$ \\
\hline E140 & 452 & 657634 & 7744394 & 02/01/1997 & \\
\hline E141 & 453 & 657537 & 7744482 & 21/11/1996 & \\
\hline E142 & 454 & 657587 & 7744501 & 09/01/1997 & \\
\hline E143 & 456 & 657592 & 7744529 & $22 / 01 / 1997$ & \\
\hline E144 & 457 & 657542 & 7744552 & 23/01/1992 & \\
\hline E145 & 458 & 657282 & 7744758 & 02/02/1997 & \\
\hline E146 & 459 & 657315 & 774478 & 26/12/1995 & $\begin{array}{l}\text { Demais ocorrências: } \\
\text { 13/12/1989. }\end{array}$ \\
\hline E147 & 460 & 657383 & 7744653 & 23/01/1992 & $\begin{array}{l}\text { Demais ocorrências: } \\
\text { 08/01/1997. }\end{array}$ \\
\hline E148 & 461 & 657425 & 7744604 & 08/01/1997 & \\
\hline E149 & 462 & 657464 & 7744573 & $14 / 12 / 1995$ & \\
\hline E150 & 463 & 657449 & 7744537 & 08/01/1997 & \\
\hline E151 & 464 & 657387 & 7744571 & $17 / 01 / 1991$ & \\
\hline E152 & 465 & 657406 & 7744512 & & \\
\hline E153 & 466 & 657520 & 7744590 & 15/12/1995 & $\begin{array}{l}\text { Demais ocorrências: } \\
\text { 10/01/1992, 23/01/1992, } \\
\text { 15/01/1991. }\end{array}$ \\
\hline E154 & 467 & 657561 & 7744568 & 20/01/1992 & \\
\hline E155 & 468 & 657587 & 7744582 & 16/12/1989 & \\
\hline E156 & 469 & 657493 & 7744672 & 03/01/1997 & \\
\hline E157 & 470 & 657685 & 7744373 & $18 / 01 / 1991$ & \\
\hline E158 & 471 & 657992 & 7744025 & & $\begin{array}{l}\text { Abatimento do aterro de entrada } \\
\text { e saída da ponte. }\end{array}$ \\
\hline E159 & 472 & 657224 & 7744429 & & \\
\hline E160 & 473 & 657213 & 7744299 & & \\
\hline E161 & 474 & 657699 & 7744174 & & \\
\hline E162 & 476 & 656793 & 7745133 & $02 / 02 / 1992$ & \\
\hline E163 & 477 & 656779 & 7744987 & 24/02/1997 & \\
\hline E164 & 478 & 656524 & 7745289 & 23/01/2000 & \\
\hline E165 & 479 & 656556 & 7745268 & $27 / 12 / 1995$ & \\
\hline E166 & 480 & 656524 & 7745245 & $02 / 02 / 1992$ & \\
\hline E167 & 481 & 656466 & 7745143 & $04 / 08 / 1993$ & \\
\hline E168 & 482 & 656438 & 7745218 & 28/02/1995 & \\
\hline E169 & 483 & 656401 & 7744889 & $28 / 01 / 2000$ & \\
\hline E170 & 484 & 656996 & 7745075 & $21 / 11 / 1996$ & \\
\hline E171 & 485 & 656938 & 7744641 & $15 / 12 / 1995$ & \\
\hline E172 & 486 & 657062 & 7744992 & & \\
\hline E173 & 489 & 656826 & 7744727 & $09 / 04 / 1997$ & \\
\hline E174 & 488 & 656760 & 7745152 & 07/11/1989 & \\
\hline E175 & 491 & 656921 & 7744950 & $22 / 01 / 1991$ & Presença de lixo, entulho. \\
\hline E176 & 492 & 657288 & 7744624 & $10 / 02 / 1997$ & \\
\hline E177 & 493 & 656878 & 7745176 & $17 / 01 / 1991$ & \\
\hline
\end{tabular}


Continuação da Tabela Anexo I - Lista das Ocorrências Mapeadas

\begin{tabular}{|c|c|c|c|c|c|}
\hline Ponto & $\begin{array}{l}\text { Código da } \\
\text { Ocorrência }\end{array}$ & $\begin{array}{c}\text { Coordenada } \\
\text { X } \\
\end{array}$ & $\begin{array}{c}\text { Coordenada } \\
\text { Y } \\
\end{array}$ & $\begin{array}{c}\text { Data da } \\
\text { Ocorrência }\end{array}$ & $\begin{array}{c}\text { Eventos Geotécnicos } \\
\text { Observados } \\
\end{array}$ \\
\hline E178 & 494 & 656772 & 7745224 & 21/04/1997 & \\
\hline E179 & 496 & 655700 & 7744810 & & \\
\hline E180 & 500 & 658754 & 7745085 & & \\
\hline E181 & 499 & 659250 & 7744965 & & \\
\hline E182 & 498 & 659239 & 7745017 & & \\
\hline E183 & 497 & 658307 & 7745048 & & \\
\hline E184 & 507 & 658210 & 7745008 & & \\
\hline E185 & 506 & 658865 & 7745102 & & $\begin{array}{l}\text { Presença de grande sulco onde } \\
\text { toda a água pluvial escoa. }\end{array}$ \\
\hline E186 & 505 & 658259 & 7745027 & & \\
\hline E187 & 503 & 659247 & 7744988 & & \\
\hline E188 & 502 & 658942 & 7745098 & & \\
\hline E189 & 501 & 658223 & 7745133 & & $\begin{array}{l}\text { Observou-se que há junto ao } \\
\text { maciço dois blocos de canga, } \\
\text { aproximadamente } 2 \mathrm{~m} \text { de } \\
\text { diâmetro, descalçados na base. }\end{array}$ \\
\hline E190 & 508 & 657739 & 7744286 & $17 / 01 / 1991$ & \\
\hline E191 & 509 & 657754 & 7744453 & 27/12/1995 & \\
\hline E192 & 510 & 657234 & 7744228 & & $\begin{array}{l}\text { Bota-fora sendo formado } \\
\text { encosta abaixo. }\end{array}$ \\
\hline E193 & 511 & 655303 & 7745083 & 06/01/1997 & $\begin{array}{l}\text { Demais ocorrências: Casa 265: } \\
\text { 08/02/1995. Casa 272: } \\
\text { 28/10/1993. }\end{array}$ \\
\hline E194 & 512 & 655590 & 7744957 & 10/01/1997 & $\begin{array}{l}\text { Presença de árvores inclinadas. } \\
\text { Demais ocorrências: } \\
\text { 05/10/1993. }\end{array}$ \\
\hline E195 & 513 & 655519 & 7745480 & 25/01/1992 & $\begin{array}{l}\text { Segundo moradora o muro da } \\
\text { rua está suspenso, causando } \\
\text { preocupações aos moradores. }\end{array}$ \\
\hline E196 & 514 & 655678 & 7745390 & 08/01/1997 & $\begin{array}{l}\text { Árvores inclinadas e bananeiras } \\
\text { ao longo do terreno. Segundo a } \\
\text { propriétaria existe uma falha, } \\
\text { devido a uma galeria de água, } \\
\text { perpendicular ao sentido da rua, } \\
\text { que volta e meia funcionários da } \\
\text { prefeitura preenchem com } \\
\text { pedras e areia, reconstruindo a } \\
\text { rua. }\end{array}$ \\
\hline E197 & 515 & 655038 & 7745317 & 07/01/1997 & \\
\hline E198 & 516 & 655089 & 7745309 & 06/01/1997 & \\
\hline E199 & 517 & 655127 & 7745329 & 23/01/1992 & \\
\hline E200 & 519 & 655110 & 7745532 & 07/01/1997 & $\begin{array}{l}\text { As casas se encontram em uma } \\
\text { área de drenagem, onde observa- } \\
\text { se árvores tombadas, indicando } \\
\text { um movimento de massa. }\end{array}$ \\
\hline E201 & 520 & 655156 & 7745316 & 06/01/1997 & Presença de árvores inclinadas. \\
\hline E202 & 521 & 655089 & 7745347 & 07/01/1997 & $\begin{array}{l}\text { As árvores encontram-se } \\
\text { inclinadas, indicando um } \\
\text { movimento de massa no terreno. } \\
\text { Presença de muito lixo e } \\
\text { entulho. }\end{array}$ \\
\hline
\end{tabular}


Continuação da Tabela Anexo I - Lista das Ocorrências Mapeadas

\begin{tabular}{|c|c|c|c|c|c|}
\hline Ponto & $\begin{array}{l}\text { Código da } \\
\text { Ocorrência }\end{array}$ & $\begin{array}{c}\text { Coordenada } \\
\text { X }\end{array}$ & $\begin{array}{c}\text { Coordenada } \\
\text { Y }\end{array}$ & $\begin{array}{c}\text { Data da } \\
\text { Ocorrência }\end{array}$ & $\begin{array}{c}\text { Eventos Geotécnicos } \\
\text { Observados }\end{array}$ \\
\hline E203 & 523 & 654338 & 7745796 & & $\begin{array}{l}\text { Trata-se de uma área de } \\
\text { drenagem, onde o corrégo } \\
\text { encontra-se assoreado. No } \\
\text { terreno observa-se movimento } \\
\text { de massa indicado pelos platores } \\
\text { formados na encosta. Presença } \\
\text { de muito lixo e entulho. } \\
\end{array}$ \\
\hline E204 & 524 & 657620 & 7745288 & 06/02/1992 & \\
\hline E205 & 525 & 657429 & 7745357 & & \\
\hline E206 & 526 & 657337 & 7445216 & $13 / 11 / 1990$ & \\
\hline E207 & 522 & 658197 & 7745109 & & \\
\hline E208 & 527 & 655512 & 7745479 & $28 / 01 / 2000$ & \\
\hline E209 & 528 & 654999 & 7745624 & & $\begin{array}{l}\text { Aterro mal compactado, } \\
\text { causando o tombamento do } \\
\text { muro. }\end{array}$ \\
\hline E210 & 529 & 655556 & 7745752 & 21/01/1992 & $\begin{array}{l}\text { Observa-se que existe } \\
\text { movimento de massa no terreno } \\
\text { acima da casa, pois as árvores } \\
\text { encontram-se inclinadas. O solo } \\
\text { sobre o quartzito está descendo } \\
\text { até próximo ao muro de arrimo } \\
\text { construído no fundo da casa. } \\
\text { Demais datas de ocorrência: } \\
\text { Casa 288: 15/07/1991. } \\
\end{array}$ \\
\hline E211 & 530 & 655172 & 7745571 & 03/01/1997 & Existência de árvores inclinadas. \\
\hline E212 & 532 & 655974 & 7744927 & 14/12/1995 & $\begin{array}{l}\text { As árvores encontram-se } \\
\text { inclinadas, indicando um } \\
\text { movimento de massa. }\end{array}$ \\
\hline E213 & 533 & 656035 & 7745030 & 14/12/1989 & $\begin{array}{l}\text { Presença de bananeiras na divisa } \\
\text { do lote acima com a casa } 506 \text {. }\end{array}$ \\
\hline E214 & 534 & 656239 & 7745517 & 14/12/1989 & $\begin{array}{l}\text { Presença de uma mina de água } \\
\text { subterrânea. }\end{array}$ \\
\hline E215 & 535 & 655167 & 7745915 & & \\
\hline E216 & 536 & 656339 & 7744207 & & $\begin{array}{l}\text { Existência de árvores tombadas } \\
\text { e muito lixo e entulho. }\end{array}$ \\
\hline E217 & 537 & 656360 & 7744328 & & \\
\hline E218 & 538 & 656358 & 7744362 & 01/05/1993 & $\begin{array}{l}\text { Presença de muito lixo, entulho. } \\
\text { Demais ocorrências: } \\
\text { 14/01/1991. }\end{array}$ \\
\hline E219 & 539 & 656370 & 7744425 & 19/01/1991 & $\begin{array}{l}\text { Demais ocorrências: Casa n } \\
\text { 252, Rua Amarantina, em } \\
\text { 14011997. }\end{array}$ \\
\hline E220 & 540 & 656388 & 7744301 & 04/02/1997 & $\begin{array}{l}\text { Demais ocorrências: 30/01/1997 } \\
\text { e 05/01/1997. }\end{array}$ \\
\hline E221 & 541 & 656334 & 7744337 & 13/01/1997 & Presença de árvores inclinadas. \\
\hline E222 & 542 & 656264 & 7744580 & 02/12/1993 & $\begin{array}{l}\text { Demais ocorrências: 18/01/1991 } \\
\text { e 29/01/1991. }\end{array}$ \\
\hline E223 & 543 & 656612 & 7744351 & 20/01/1998 & \\
\hline E224 & 545 & 656688 & 7744302 & 02/01/1997 & $\begin{array}{l}\text { Demais ocorrências: } \\
\text { 26/12/1995, 24/11/1996, } \\
\text { 23/01/1992, 14/12/1995. } \\
\end{array}$ \\
\hline E225 & 546 & 656520 & 7744387 & & \\
\hline
\end{tabular}


Continuação da Tabela Anexo I - Lista das Ocorrências Mapeadas

\begin{tabular}{|c|c|c|c|c|c|}
\hline Ponto & $\begin{array}{l}\text { Código da } \\
\text { Ocorrência } \\
\end{array}$ & $\begin{array}{c}\text { Coordenada } \\
\mathrm{X} \\
\end{array}$ & $\begin{array}{c}\text { Coordenada } \\
\text { Y } \\
\end{array}$ & $\begin{array}{c}\text { Data da } \\
\text { Ocorrência } \\
\end{array}$ & $\begin{array}{c}\text { Eventos Geotécnicos } \\
\text { Observados } \\
\end{array}$ \\
\hline E226 & 548 & 656404 & 7744412 & 04/01/1997 & \\
\hline E227 & 547 & 656417 & 7744584 & 02/01/1997 & $\begin{array}{l}\text { Erosão causada pela força da } \\
\text { água do rio. Demais } \\
\text { ocorrências: } 13 / 03 / 1996 \text {. }\end{array}$ \\
\hline E228 & 549 & 656584 & 7744298 & 05/01/1997 & \\
\hline E229 & 550 & 655818 & 7744510 & 01/12/1993 & $\begin{array}{l}\text { Parte da água coletada pela } \\
\text { drenagem pluvial da rua acima } \\
\text { (Curva do Vento) escoa para } \\
\text { dentro do lote. }\end{array}$ \\
\hline E230 & 551 & 655684 & 7744561 & 30/01/1997 & $\begin{array}{l}\text { As margens do rio, lateral da } \\
\text { casa, estão sendo erodidas pela } \\
\text { força das águas do rio. }\end{array}$ \\
\hline E231 & 552 & 655732 & 7744564 & & $\begin{array}{l}\text { O solo localizado na frente e } \\
\text { lateral da casa está sendo } \\
\text { erodido pela água do rio. }\end{array}$ \\
\hline E232 & 553 & 656243 & 7744286 & 12/03/1989 & \\
\hline E233 & 556 & 656271 & 7744313 & 15/01/1991 & \\
\hline E234 & 557 & 657449 & 7744973 & 25/04/1991 & \\
\hline E235 & 558 & 657750 & 7744920 & 22/01/1997 & \\
\hline E236 & 559 & 659191 & 7745008 & & \\
\hline E237 & 560 & 659053 & 7745015 & & \\
\hline E238 & 561 & 658160 & 7745050 & & \\
\hline E239 & 564 & 653534 & 7742494 & 04/01/1997 & \\
\hline E240 & 565 & 653486 & 7742593 & 04/01/1997 & \\
\hline E241 & 566 & 653686 & 7742587 & 30/12/1996 & \\
\hline E242 & 567 & 653635 & 7742632 & 06/01/1997 & \\
\hline E243 & 568 & 653794 & 7742527 & 26/12/1995 & \\
\hline E244 & 569 & 65437 & 7743020 & 05/01/1997 & \\
\hline E245 & 570 & 654747 & 7742845 & 01/02/1997 & \\
\hline E246 & 571 & 654766 & 7744156 & & \\
\hline E247 & 572 & 65616 & 7743003 & 04/01/1998 & $\begin{array}{l}\text { Demais ocorrências: } \\
\text { 04/01/1998, 02/01/1997, } \\
\text { 24/01/1997. }\end{array}$ \\
\hline E248 & 573 & 657464 & 7743082 & 29/03/1997 & \\
\hline E249 & 574 & 656297 & 7743197 & 19/01/1998 & \\
\hline E250 & 563 & 655688 & 7742982 & 03/01/1997 & $\begin{array}{l}\text { Demais ocorrências: } \\
\text { 02/01/1997, 24/01/1992, } \\
\text { 26/12/1995, todas tendo } \\
\text { ocorrido na casa de número } 464 .\end{array}$ \\
\hline E251 & 562 & 6566426 & 7743378 & 20/12/1996 & \\
\hline E252 & 576 & 656622 & 7745331 & 20/01/1997 & \\
\hline E253 & 577 & 657024 & 7745025 & & \\
\hline E254 & 575 & 657364 & 7745417 & & \\
\hline
\end{tabular}

A Figura I a seguir sintetiza o modelo de planilha adotado e devidamente preenchida para a ocorrência de numero 290, ponto E1. 
ANEXO IV

Mapa de Inventário de Ocorrências (Fontes, 2011) 


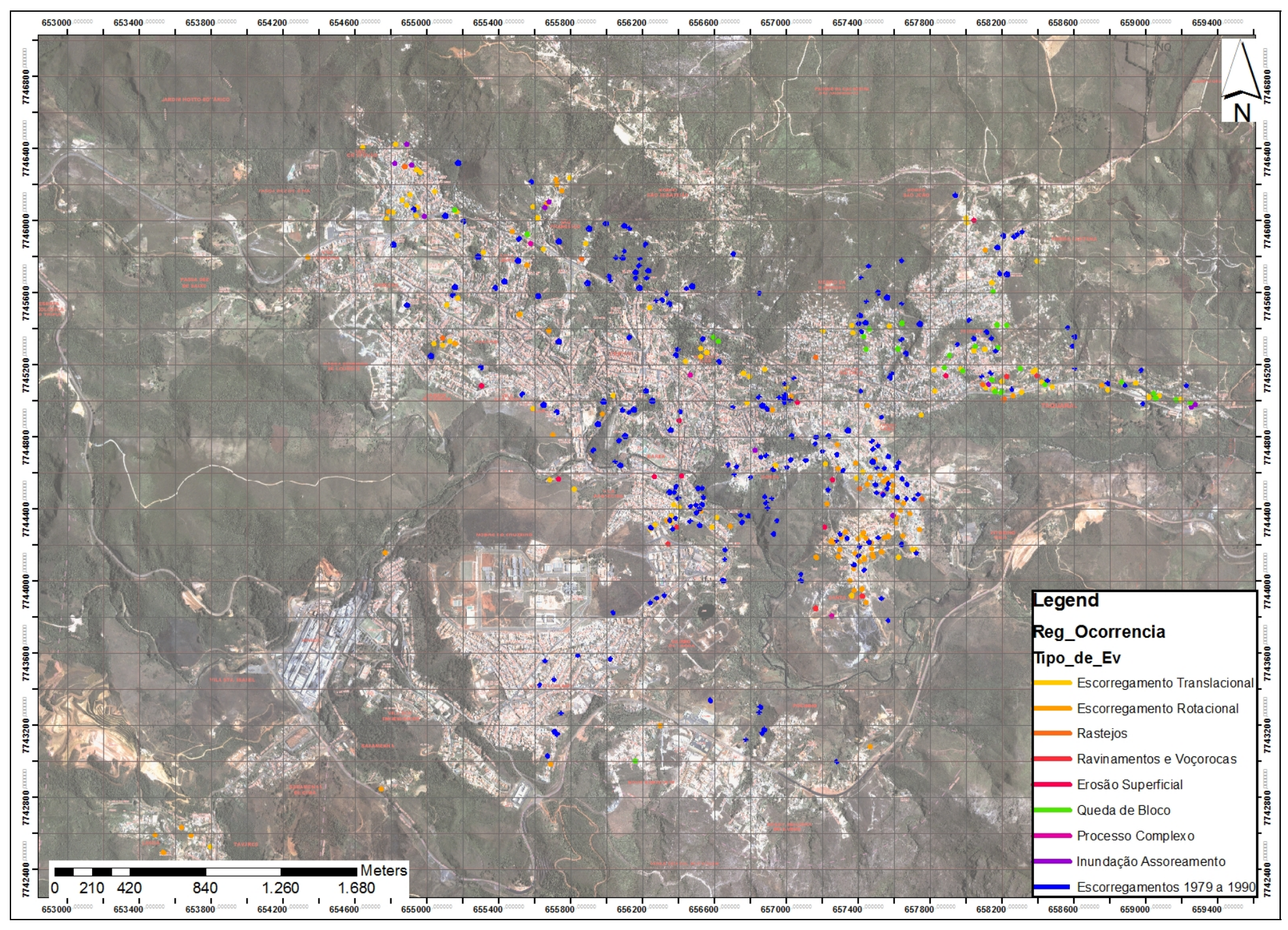

Figura 5.4 - Mapa de Inventário de Ocorrências registradas na área urbana da cidade de Ouro Preto/MG 
ANEXO V

Ficha de campo - STC4 (Fontes, 2011) 
Ficha de Campo - Vistoria Técnica

\begin{tabular}{|c|c|c|c|c|}
\hline Zoneamento & NumeroPonto & CoordenadaX & CoordenadaY & Data \\
\hline STC & 04 & 657295,33 & 7744175,537 & $20 / 01 / 2000$ \\
\hline \multicolumn{5}{|l|}{ Local } \\
\hline \multicolumn{5}{|c|}{ Residências 93 e 104} \\
\hline \multicolumn{2}{|l|}{ Rua } & \multicolumn{3}{|c|}{ Numero } \\
\hline \multicolumn{5}{|c|}{ Rua das Flores } \\
\hline \multicolumn{5}{|l|}{ Complemento } \\
\hline
\end{tabular}

\section{Diagnóstico da Condição Local}

\begin{tabular}{l|}
\hline \multicolumn{1}{c|}{ Situação } \\
\hline Alto de Encosta \\
$\square$ Meia Encosta \\
$\square$ Pé de Encosta \\
$\square$ Talude de Mineração \\
$\square$ Talude de Escavação \\
$\square$ Cortes \\
$\square$ Aterros \\
$\square$ Baixadas \\
$\square$ Outra
\end{tabular}

\begin{tabular}{|l|}
\hline \multicolumn{1}{c|}{ Drenagem } \\
$\square$ Natural \\
$\square$ Construída Superficial \\
$\square$ Construída Profunda \\
$\square$ Eficiente \\
$\square$ Parcialmente Obstruída \\
$\square$ Totalmente Obstruída \\
$\checkmark$ Inexistente
\end{tabular}

\begin{tabular}{l}
\hline \multicolumn{1}{c}{ Ocupação } \\
$\square$ Baixa \\
$\checkmark$ Média \\
$\square$ Elevada \\
$\square$ Controlada \\
$\square$ Desordenada \\
$\square$ Inexistente
\end{tabular}

\begin{tabular}{|l|}
\hline \multicolumn{1}{|c|}{ Vegetação } \\
$\square$ Esparsa \\
$\square$ Média \\
$\square$ Densa \\
$\square$ Rasteira \\
$\square$ Arbórea \\
$\square$ Inexistente
\end{tabular}

Natureza e Descrição de Evento Geotécnico

Data Ocorrência

\begin{tabular}{l}
\hline \multicolumn{1}{|c|}{ Naturez } \\
$\square$ Escorregamento Rotacional \\
$\square$ Escorregamento Translacional \\
$\square$ Queda e/ou Rolamento de Blocos \\
$\square$ Escoamentos (Rastejos e Corridas) \\
\hline Declividade da Encosta \\
$\square<30 \%$ \\
$\square 60 \%$ a $100 \%$ \\
\hline
\end{tabular}

\begin{tabular}{|c|c|}
\hline & Erosão Superficial \\
\hline & Ravinas e Voçorocas \\
\hline$\checkmark$ & Inundação Assoreamento \\
\hline
\end{tabular}

\begin{tabular}{|c|}
\hline Dimensão \\
$\checkmark$ Superficial $(<2,0 m)$ \\
$\square$ Média $(>2,0 m e<10,0 m$ \\
$\square$ Profunda $(>10,0 m)$
\end{tabular}

Estado de Atividades e Materiais

\begin{tabular}{c}
$\square$ Ativo \\
$\square$ Inativo Dormente $\checkmark$ Inativo Estabilizado \\
$\square$ Blocos $\square$ Detritos $\checkmark$ Solo $\square$ Misturas \\
\hline
\end{tabular}

\section{Litologia}

Solo e xisto

Xisto 


\section{Mecanismos Potenciais de Instabilização e Riscos Associados}

\begin{tabular}{|l|}
\hline Deficiência de Cobertura Vegetal \\
\hline Comprometimento da Rede de Água Pluvial \\
\hline Deficiência do Sistema de Drenagem Superficial \\
\hline Desestabilização por Desagregação Superficial \\
Fraturamento do Maciço Rochoso \\
\hline Fluxo de Água Subterrâneo \\
Descalçamento de Talude por Corte \\
Fundações com Baixa Capacidade de Carga \\
Execução de Botaforas ou Aterros Mal Compactados
\end{tabular}

Ocupação de Bacias Naturais de Drenagem

Inundação e Assoreamento

Ocupação Desordenada do Meio Físico

Natureza Inadequada das Construções

$\square$ Existência de Ravinas e/ou Voçorocas

$\square$ Ruptura de Obra de Contenção Inadequada

$\square$ Ruptura de Obra de Contenção Mal Executada

$\square$ Acumulação de Lixo ou Entulho

Outros (Especificar)

Danos Associados

Avaliação de Riscos

Existe Risco Potencial de Perda de Vida Humana Estimativa de Perdas de Vidas

Existe Risco Potencial de Perda de Danos Construtivos

Moradias Envolvidas

Existe Risco Potencial de Perda de Infraestrutura Urbana

Existe Risco Ambiental

Probabilidade de Danos Ocasionais

Probabilidade Remota de Danos

\section{Natureza e Descrição de Evento Geotécnico}

\begin{tabular}{|l|}
\hline \multicolumn{1}{c|}{ Prioridade de Intervenção } \\
$\square$ Imediata \\
$\square$ Médio Prazo Sem Evolução \\
$\square$ Médio Prazo Com Evolução \\
$\checkmark$ Observação a Longo Prazo \\
$\square$ Praticamente Nula \\
$\square$ Nenhuma
\end{tabular}

Soluções Recomendadas
$\square$ Manutenção do Sistema de Drenagem Existente
$\checkmark$ Execução de Drenagem Superficial
$\square$ Excecução de Drenagem Profunda
$\square$ Excução de Cobertura Vegetal
$\square$ Retaludamento
$\square$ Reconstrução do Aterro
$\square$ Estabilização de Blocos Isolados
$\checkmark$ Obras de Contenção
$\square$ Remoção de Construções / Realocação de Pessoal

Outra Solução (Especificar)

Problema aparentemente resolvido com a construção de muro, porém, devido a pequena profundidade da fundação, existe dúvida quanto a sua seguraça 
ANEXO VI

Parecer técnico - IG-1404-DEC-E-LT01-00 (IGEO, 2015) 
$\grave{A}$

\section{Coordenadoria Municipal de Defesa Civil}

Beco do Pilão - Centro, Ouro Preto - MG, 35400-000

$\mathrm{A} / \mathrm{C}$

Charles Romazâmu Murta

Engenheiro Geólogo

Referência: Contrato de Cooperação Técnica entre IGEO e PMOP

Local: $\quad$ Ouro Preto - MG

Prezado,

Este documento apresenta o parecer técnico a cerca dos processos deformacionais atuantes no muro de pedra seca, situado no beco do Pilão, e nas estruturas de concreto erguidas aos fundos do prédio do CAEM e do Cantinho do Pão de Queijo e Chopperia.

À disposição para esclarecimentos julgados necessários,

Ouro Preto, 22 de janeiro de 2014.

Atenciosamente, 


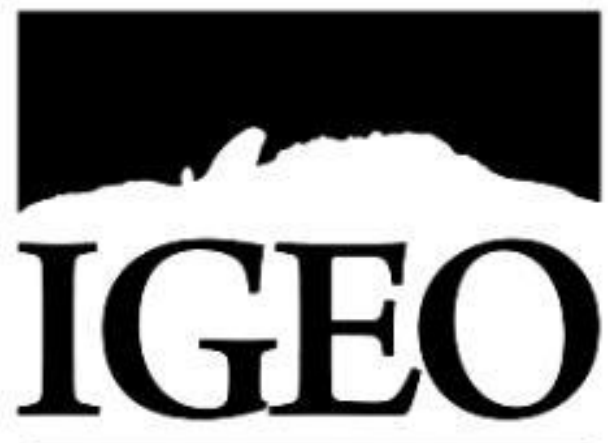

INSTITUTO GEOTE CN I CO

\section{LAUDO TÉCNICO}

IG-1404-DEC-E-LT-00

Janeiro/2014

\section{ESCOPO:}

Laudo Técnico Referente ao Muro de pedra seca.

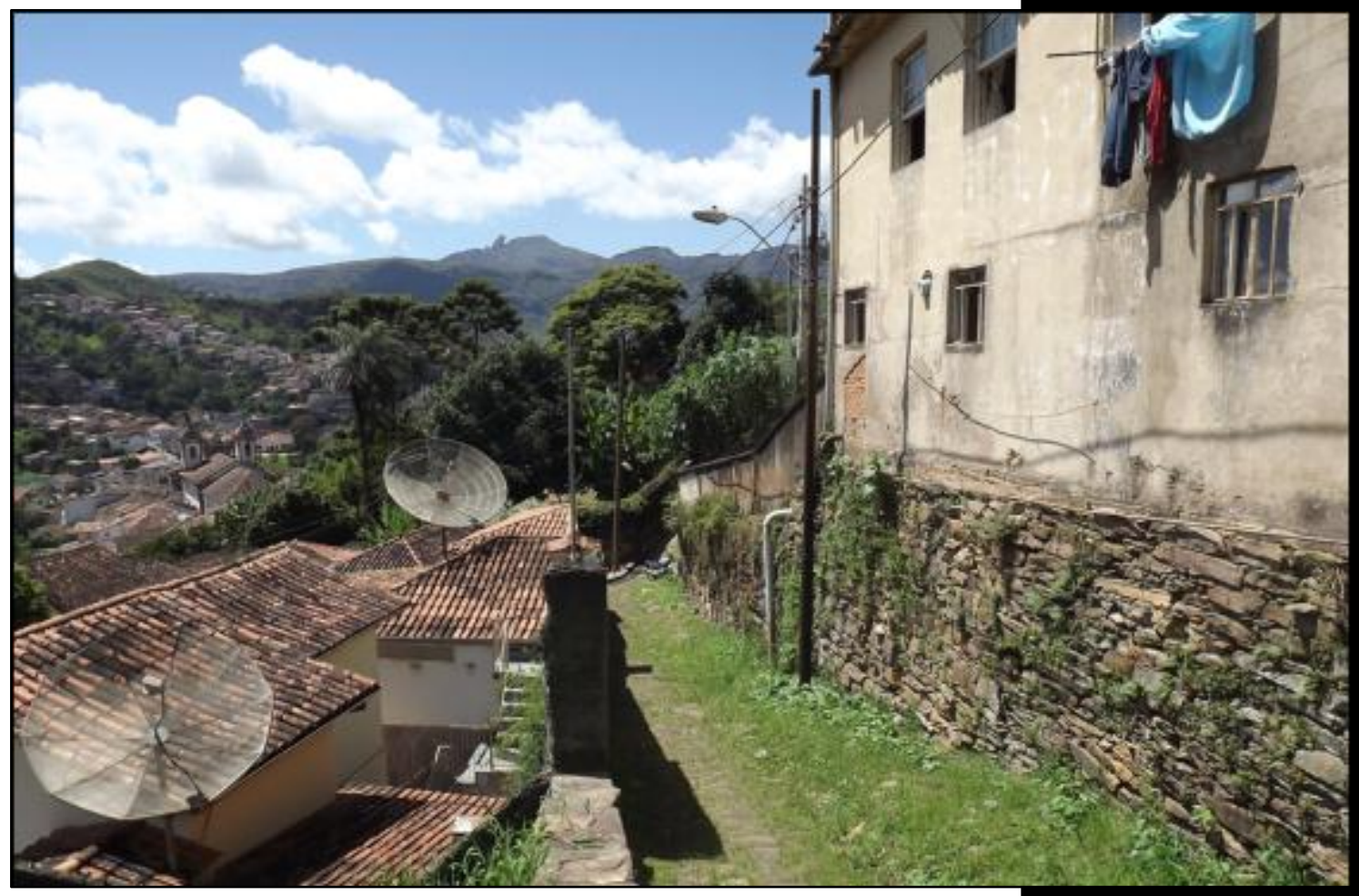




\section{SUMÁRIO}

1 INTRODUÇÃO

2 OBJETIVO

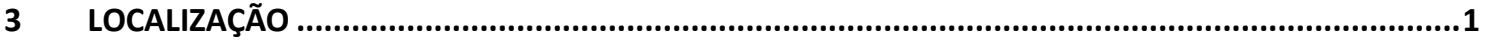

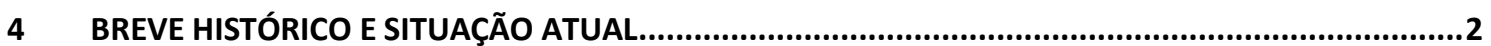

5 CARACTERIZAÇÃO DA ÁREA

6 CONDICIONANTES GEOLÓGICO E GEOTÉCNICO ......................................................................6

7 PARECER FINAL 


\section{INTRODUÇÃO}

O presente documento aborda as principais considerações a respeito das condições de estabilidade da encosta localizada no Beco do Pilão - Bairro Centro, mais precisamente, aos fundos do CAEM (Centro Acadêmico da Escola de Minas) e do Cantinho do pão de queijo e chopperia.

A visita técnica foi realizada no dia 15 de janeiro de 2014 pelo engenheiro Michel Fonntes, o geólogo Bruno Novais, e a estagiária Júlia Almeida, acompanhados pela equipe técnica da Defesa Civil do município de Ouro Preto, os geólogos, Charles Murta e Flávio, e a engenheira civil Cynara Gramigna, em cumprimento à solicitação deste órgão ao IGEO (Instituto Geotécnico).

Anexo a este laudo encontra-se a ficha de inspeção de campo devidamente preenchida. A referida ficha tem como referência o modelo sugerido pelo Instituto Geotécnico (IGEO), o qual preconiza as bases técnicas que fundamentam a identificação dos principais condicionantes de instabilidade de uma encosta, bem como a caracterização do meio físico.

\section{OBJETIVO}

Este estudo tem como objetivo apresentar as causas bem como os condicionantes geológico-geotécnicos responsáveis pela deformação e adernamento de cerca de $10^{\circ}$ do muro de pedra seca construído com blocos de quartzito localizado aos fundos do CAEM.

\section{LOCALIZAÇÃO}

A região de estudo está inserida na porção central do perímetro urbano do município de Ouro Preto, próximo a Praça Tiradentes (Figura 3.1), mais precisamente, aos fundos 


\section{INSTITUTO GEOTÉCNICO}

do CAEM e do Cantinho do Pão de Queijo, no Beco do Pilão. As coordenadas do local são $656217 \mathrm{~m} \mathrm{E} \mathrm{e} 7745221 \mathrm{~m}$ S.

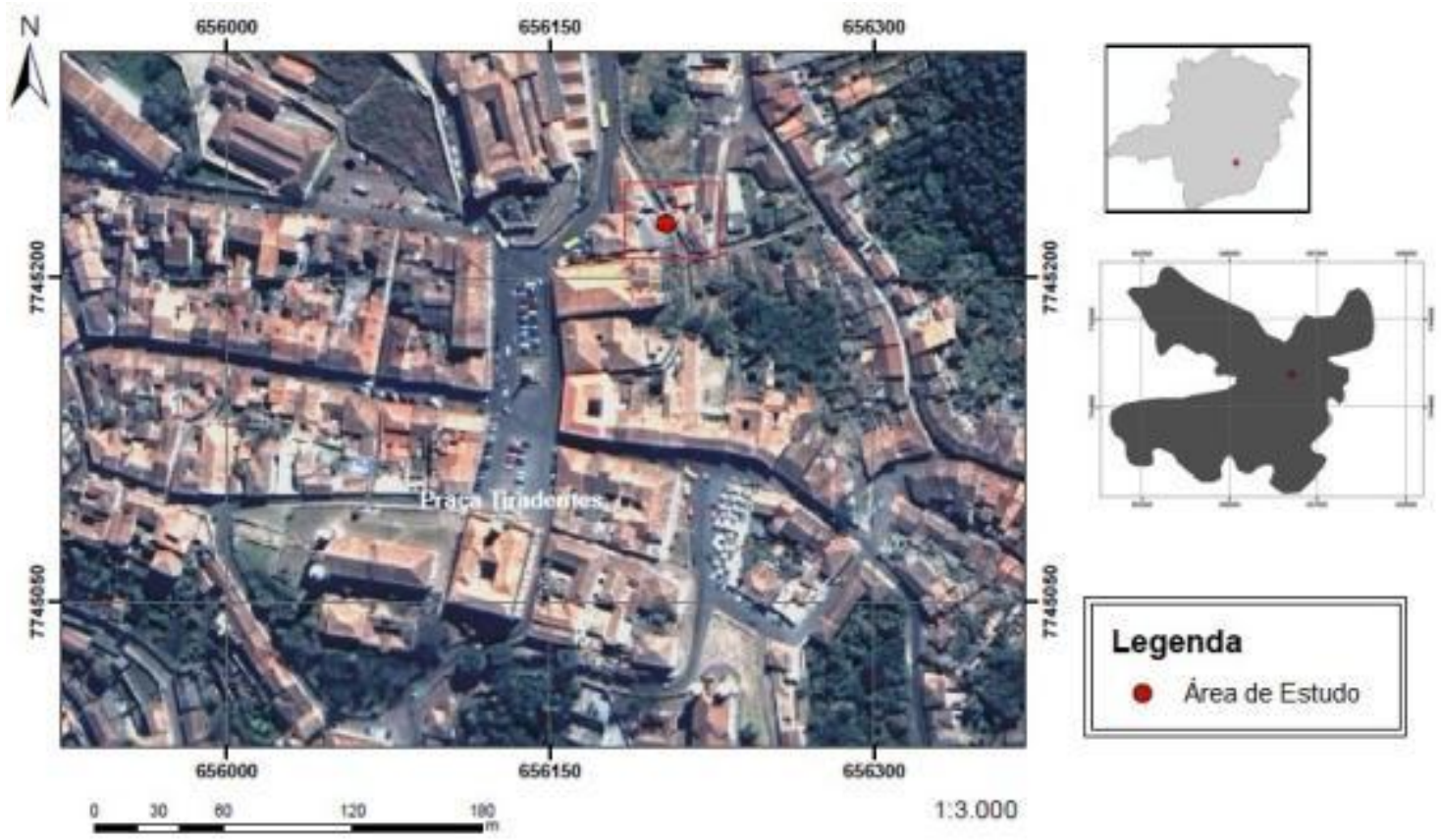

Figura 2.1- Mapa de localização da área de estudos.

\section{BREVE HISTÓRICO E SITUAÇÃO ATUAL}

Ouro Preto, cidade mineira histórica, famosa pelas suas riquezas minerais, bem como pela arquitetura barroca exibida nos casarões antigos e nas igrejas, foi e vem sendo povoada desde então ao longo de encostas íngremes e muito susceptíveis a movimentos gravitacionais de massa. Esta condição perigosa muitas vezes pode se agravar por meio de cortes e aterros realizados sem nenhum rigor técnico.

Em relação à área de estudos, esta se localiza no terço superior da encosta, caracterizada por apresentar declividade alta (cerca de $30^{\circ}$ ) e alinhamento segundo 0 azimute $150^{\circ}$. De acordo com o que foi observado em campo e relatado pelo morador apelidado de Cuia, grande parte da encosta e, inclusive a porção onde foram construídos o prédio do CAEM e o Cantinho do Pão de Queijo, foi aterrada e escorada por muros de pedra seca com até 3,5 $\mathrm{m}$ de altura. Em geral estes muros datam do 
início do século passado, e foram construídos a partir do empilhamento ordenado de blocos com formato tabular $(0,30 \times 0,50 \times 0,10)$ de quartzito duro. Os vãos entre um bloco e outro, via de regra, são preenchidos com blocos menores. À luz das características geotécnicas, estes muros se destacam por serem naturalmente drenantes e por oferecerem resistência ao empuxo promovido pelo aterro.

Atualmente, quando se caminha pelo Beco do Pilão, podem-se observar diversas interferências antrópicas à paisagem secular do muro de pedra seca e dos casarões. Dentre elas destacam-se:

A construção de um muro de alvenaria com cerca de $2 \mathrm{~m}$ de altura sobre o muro de pedra seca;

> Instalação de poste com transformador de distribuição de energia elétrica no terreno localizado atrás do prédio do CAEM. Estima-se que o conjunto possa pesar até $4.000 \mathrm{~kg}$;

> Lançamento de aterro misturado com entulho de construção formando patamar estimado em $4 \mathrm{~m}$ de altura sobre o antigo aterro;

> Ampliação das edificações do cantinho do pão de queijo a partir da construção de quiosque com cerca de $200 \mathrm{~m}^{2}$ em piso de concreto (cerca de $10 \mathrm{~cm}$ de espessura) e telhado sustentado por vigas de madeira;

$>$ Armazenamento de 6 mil litros de água em caixas de água instaladas sobre o aterro novo lançado sobre o velho;

Diante deste cenário de solicitações, nunca antes imaginado para o aterro bem como para o muro de gravidade à época de sua construção, promovido pelos diversos carregamentos aplicados, somado às vibrações provocadas pelo intenso trânsito de veículos que circulam todos os dias no centro de Ouro Preto, começaram a ocorrer deformações significativas no muro de pedra seca, as quais despertaram o interesse da população e das autoridades. 
Estas deformações foram e vem sendo evidenciadas, principalmente, através de danos estruturais provocados ao muro e às edificações apoiadas no aterro. Abaixo seguem os fatos observados em campo durante a visita.

$>$ Muro de pedra seca com deformações horizontais e verticais (embarrigado), trincado e adernado cerca de $10^{\circ}$ em região da encosta alinhada à porção onde foi instalado o poste com o transformador. Segundo o relato do Sr. Cuia, o embarrigamento do muro foi notado cerca de 6 meses após o término desta obra;

$>$ Trincas na edificação do cantinho do pão de queijo atestando o recalque produzido pelo provável adensamento do aterro induzido pelas diversas sobrecargas impostas;

D Existência de trincas de tração alinhadas à direção de menor largura do bloco de quartzito sugerindo provável adensamento do aterro e ou fundação deste;

$>$ Queda do muro de alvenaria construído sobre o muro de pedra seca alinhado aos fundos da CAEM;

$>$ Trinca com cerca de $2 \mathrm{~cm}$ de abertura no muro de alvenaria construído sobre o muro de pedra seca alinhado aos fundos do Cantinho do pão de queijo;

$>$ Embarrigamento do muro de pedra seca com cerca de $1,5 \mathrm{~m}$ de altura, implantado sobre o antigo aterro com a finalidade de suportar a nova camada de aterro lançado e as cargas impostas pelo quiosque construído aos fundos do prédio do Cantinho do pão de queijo. Infere-se que esta deformação seja reflexo da deformação no muro de pedra seca a jusante.

\section{CARACTERIZAÇÃO DA ÁREA}

A área de estudos, conforme pode-se observar no recorte do mapa geológico da folha de Ouro Preto, (escala 1:50.000), está inserida no domínio da Formação Cercadinho, pertencente ao Grupo Piracicaba (Figura 4.1). De uma maneira geral, esta formação geológica é composta por filito cinza-prateado, sericita xisto e por quartzito ferruginoso. 


\begin{tabular}{|c|}
\hline INSTITUTO GEOTÉCNICO \\
\hline amsirvio arotenteo \\
LAUDO TÉCNICO
\end{tabular}

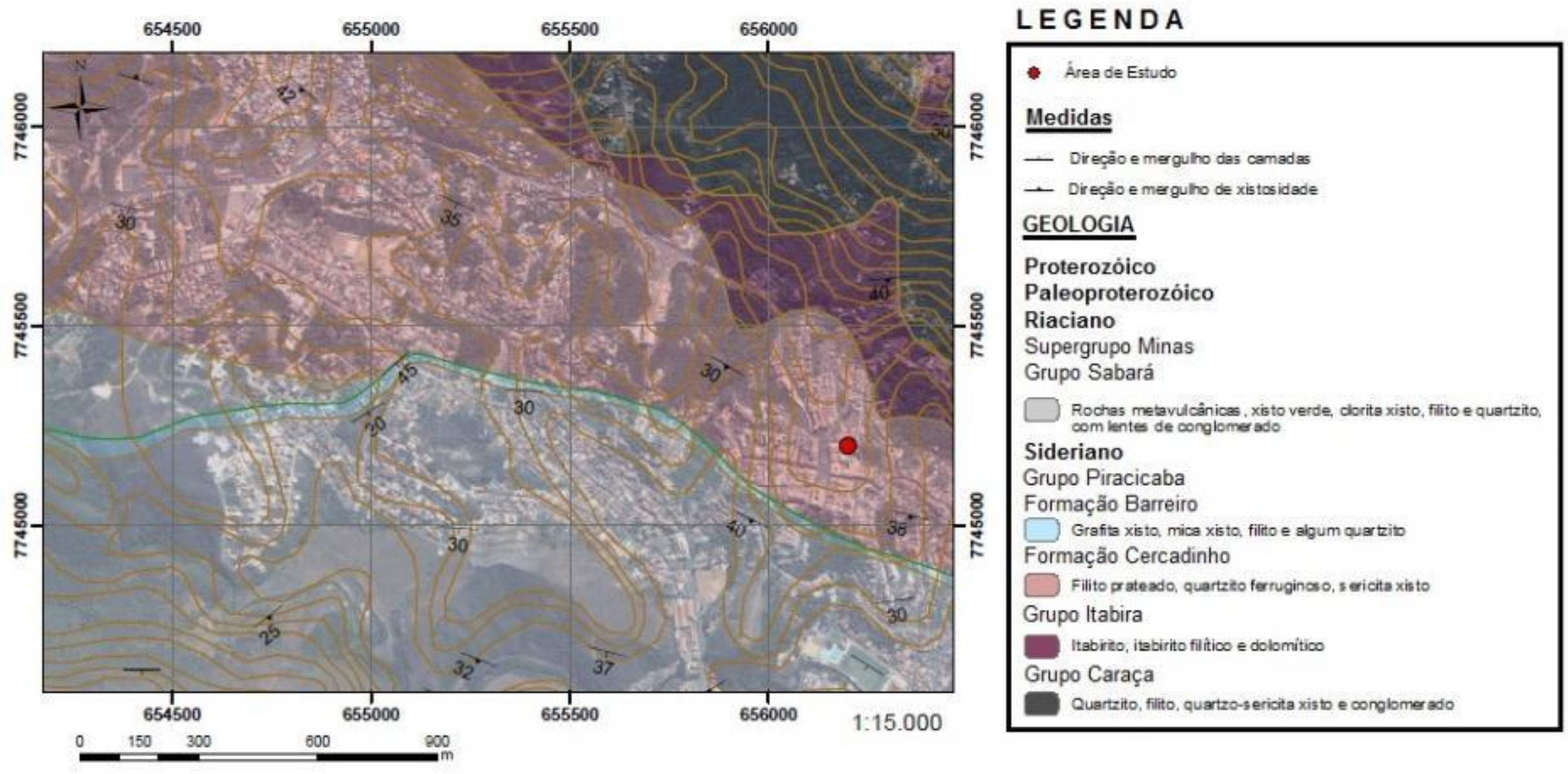

Figura 4.1: Recorte do mapa geológico folha Ouro Preto com escala 1:50.000 (Projeto geologia do Quadrilátero Ferrífero, CODEMIG 2005). A área de estudos está representada pelo círculo vermelho. 
Do ponto de vista geológico-geotécnico e, dada às intervenções antrópicas realizadas na encosta onde se insere a área de interesse, infere-se que o aterro construído no início do século passado, com o objetivo de regularizar e aplainar a encosta, tenha sido lançado sobre uma fina capa de solo coluvionar (talvez não superior a 1,50 m de espessura). Este por sua vez, possivelmente, esteja assentado sobre o filito sericítico muito alterado e com resistência extremamente branda.

De acordo com as atitudes do plano da foliação/xistosidade lançados no mapa geológico (vide figura 4.1) e, considerando que esta estrutura condiciona a maioria dos escorregamentos planares na região, infere-se que o potencial para a ocorrência deste mecanismo de ruptura é baixo, uma vez que o mergulho desta estrutura é contrário ao pendor da encosta. Todavia, não se pode desconsiderar a probabilidade de ocorrência de um escorregamento segundo o plano de contato entre o colúvio e o maciço rochoso alterado.

Com relação às espessuras dos aterros, estima-se que o mais antigo alcance uns 3,5 m e que o mais recente alcance uns $4 \mathrm{~m}$.

\section{CONDICIONANTES GEOLÓGICO E GEOTÉCNICO}

Com base no que foi explicitado acima, pode-se concluir que, de fato, o aterro construído no início do século passado e escorado com o muro de pedra seca não foi projetado para atender as novas solicitações de carga impostas pela instalação do transformador, lançamento de novas camadas de aterro e ampliação das edificações. Nesse sentido, infere-se que todas as deformações observadas em campo sejam o reflexo do processo, que é lento e gradual, do adensamento do aterro e, subordinadamente, do material presente na fundação deste.

A estrutura existente atua pela ação de seu peso próprio como principal elemento de estabilização da encosta, em contrapartida a ação de esforços instabilizantes, neste 
caso majorados pela imposição de elementos adicionais, tais como a implantação de um novo transformador de energia elétrica, caixas de água, bem como ampliações realizadas nas edificações.

$\mathrm{O}$ aterro existente a montante do muro, segundo relatos dos moradores locais ocorreram sem quaisquer controle tecnológico e em consequência disso, apresentam deformações acentuadas.

Localmente constatou-se a existência de um precário sistema de drenagem superficial que drena as águas de chuva advindas da cobertura da edificação anexa ao prédio do "Pão de Queijo" somada a área impermeabilizada por concreto (Foto 4). O subdimensionamento deste faz com que, sob a solicitação de eventos chuvosos extremos, o local funcione como um reservatório retendo a água que, por conseguinte infiltra nas trincas existentes no concreto saturando o aterro.

\section{PARECER FINAL}

Considerando o exposto neste documento, associado aos diversos indícios que elevam o índice de criticidade do risco existente no local, sugere-se preventivamente às intervenções físicas no local, a remoção da família as imediações do muro, em específico da residência do Sr. "Cuia", residência esta primordialmente afetada em consequência do escorregamento/tombamento do muro.

O IGEO entende que o cenário atual de deformação do aterro é crítico, necessitando, portanto, de uma intervenção urgente. Caso o muro de pedra seca venha a romper, estima-se que a energia potencial acumulada do sistema seja suficiente para projetar material até cerca de 30 metros a jusante. 
De maneira preventiva e emergencial sugere-se intervenção imediata com remoção das cargas adicionais (transformador e caixas de água) de maneira a reduzir significantemente as solicitações impostas a estrutura.

Implantar, pelo menos em período que anteceda as intervenções, sistema de monitoramento contínuo e diário dos deslocamentos observados na estrutura (muro) por meio de fixação de pinos em pedras específicas e amarração deste com referência externa.

Como solução de engenharia, sugere-se a remoção do aterro existente a montante do muro, promovendo o retaludamento da encosta de maneira escalonada sem afetar a fundação dos edifícios instalados também a montante do muro. Pretende-se desta maneira a remoção das cargas incidentes sobre o muro garantindo sua estabilidade e evitar o avanço dos deslocamentos e comprometimento das residências e do acervo histórico local.

Deverá ainda, ser constituído sistema de drenagem superficial devidamente projetado, associado a recuperação do concreto de cobertura do aterro (foto 4).

A seguir, é apresentada uma memória fotográfica da visita técnica ilustrando os principais aspectos abordados. 

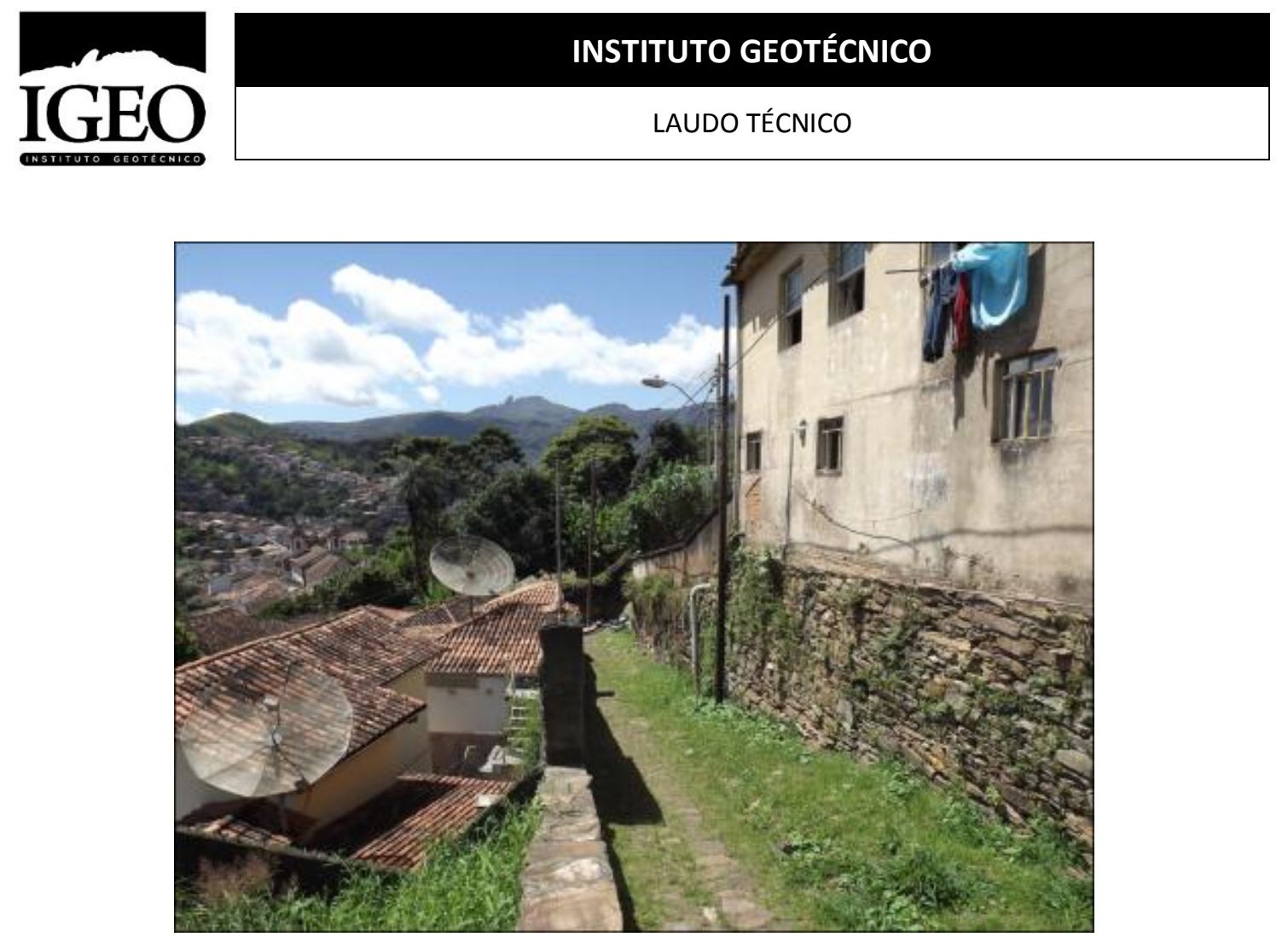

Foto 1: Vista geral do beco do Pilão, região alvo dos estudos. Notar ao final da arruela o muro adernado.

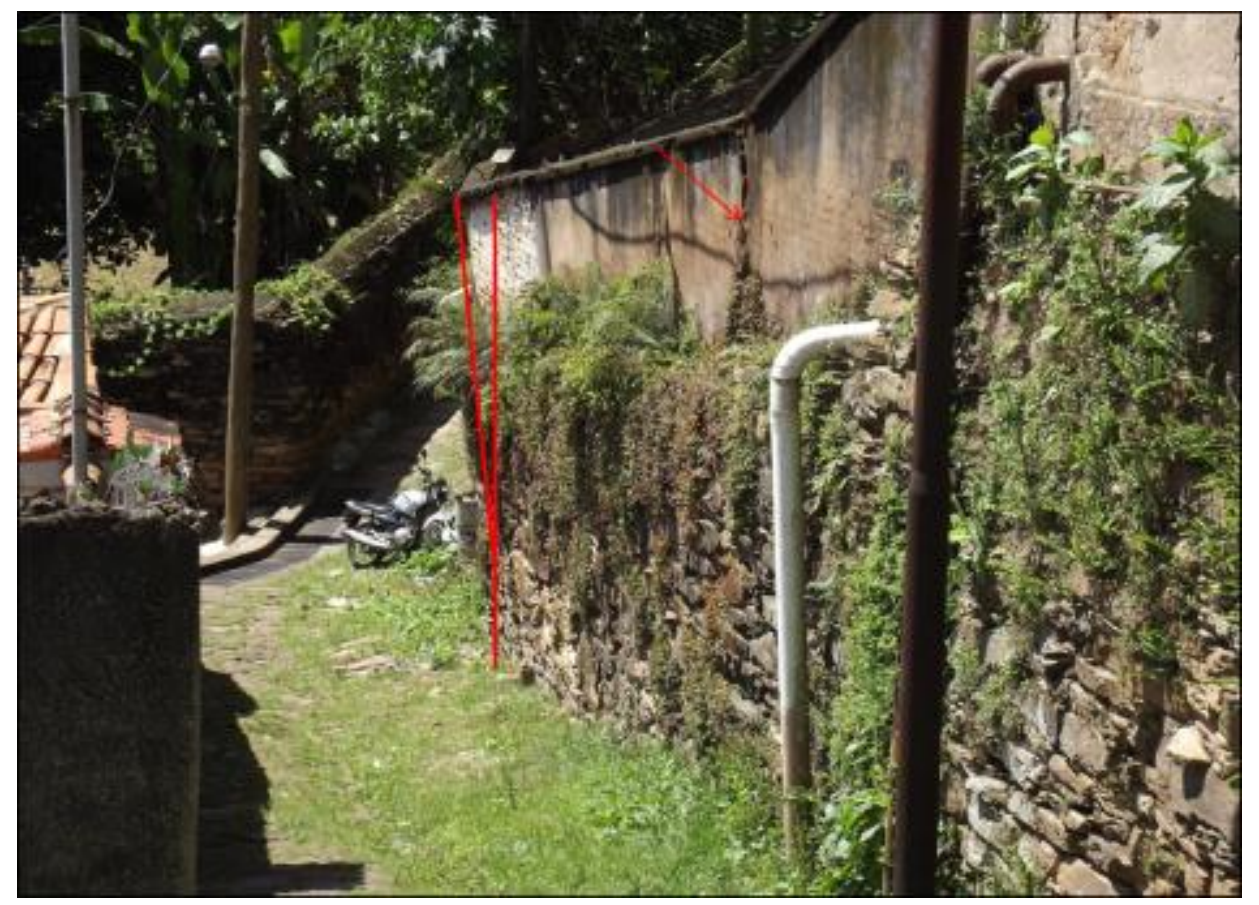

Foto 2: Detalhe do muro de alvenaria construído sobre o muro de pedra seca. Notar o adernamento deste e a presença de trincas (seta). 


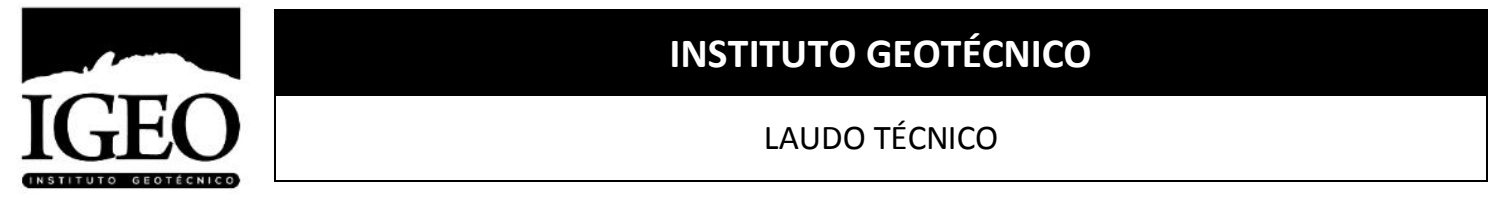

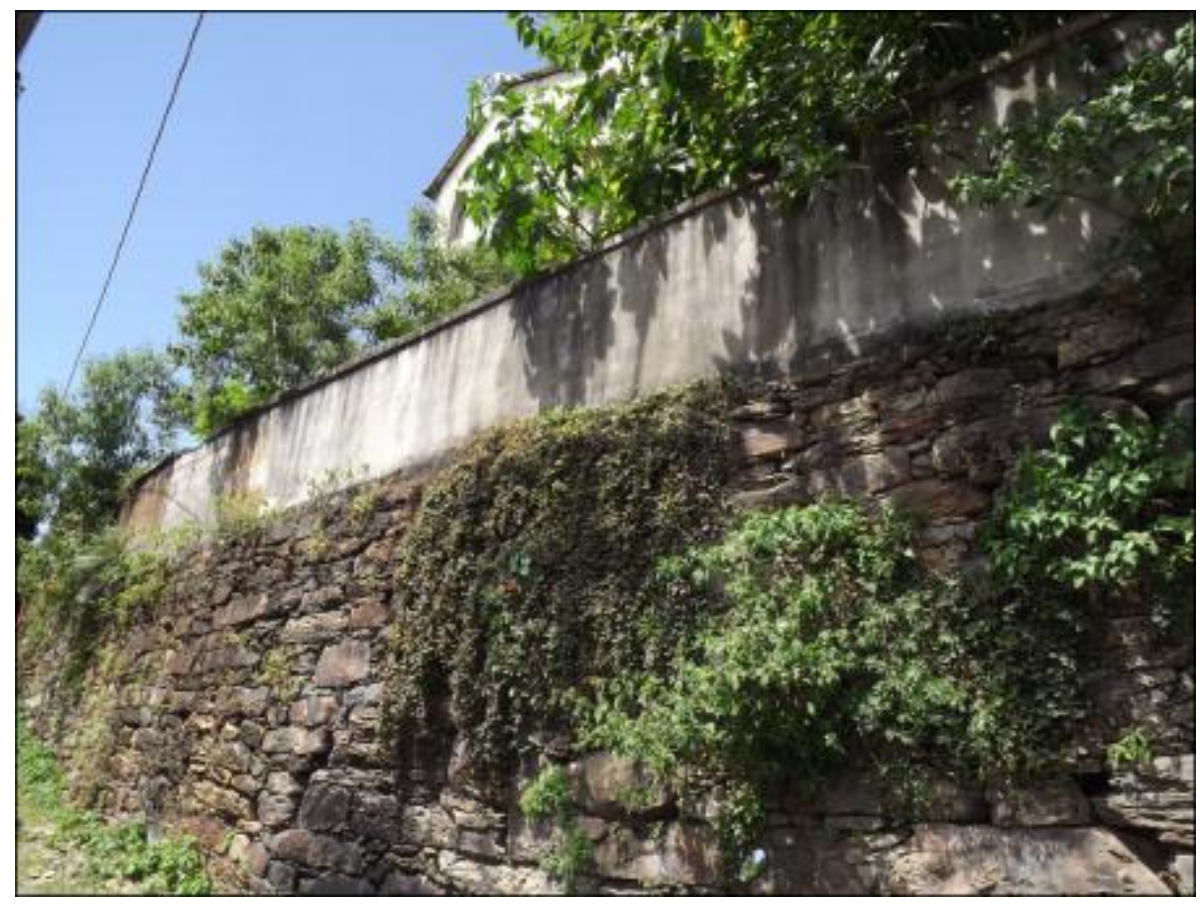

Foto 3: Vista para o muro de alvenaria localizado aos fundos do prédio do CAEM reconstruído.

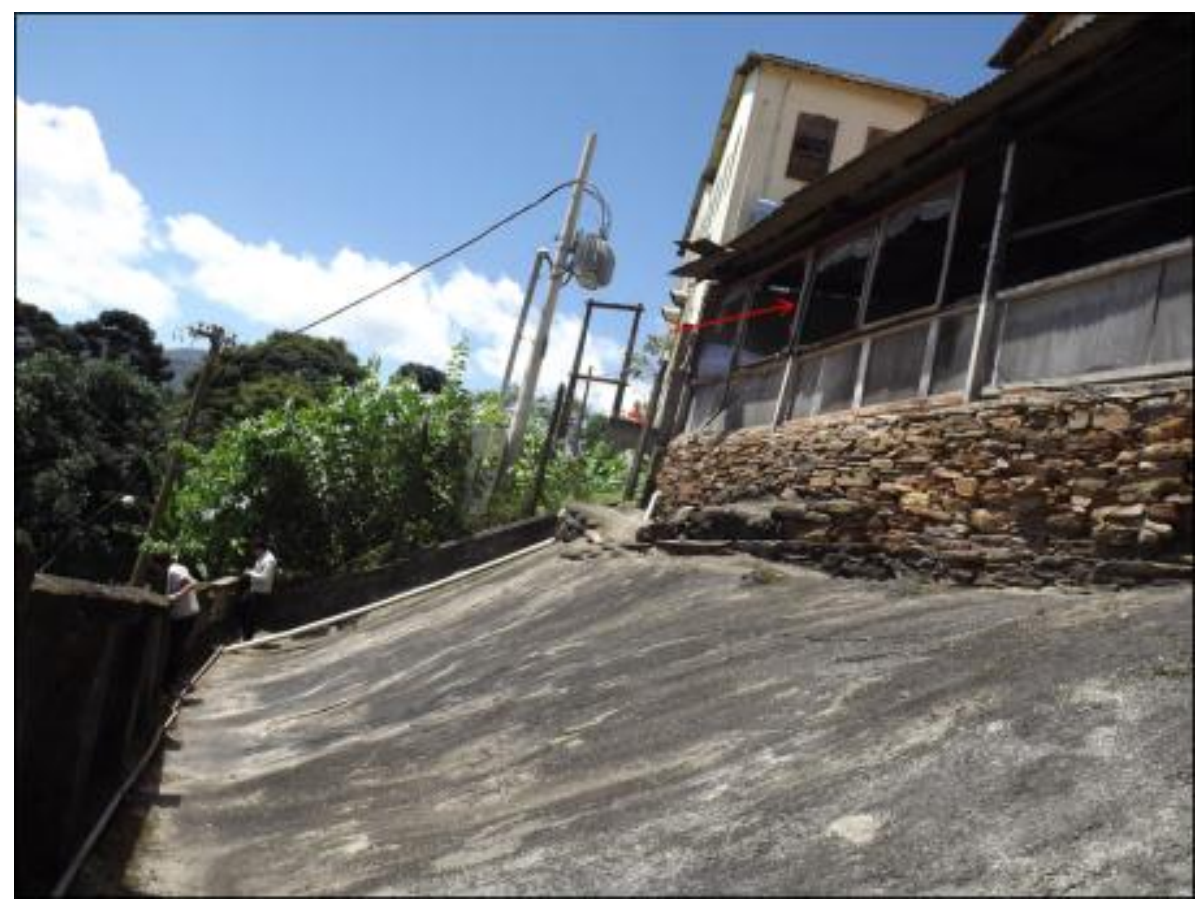

Foto 4:Vista geral para o patamar de aterro lançado sobre o antigo aterro de partida. Nota-se ainda a sobrecarga adicional promovida pelo conjunto do poste+transformador+sapata e do quiosque (seta) construído. 


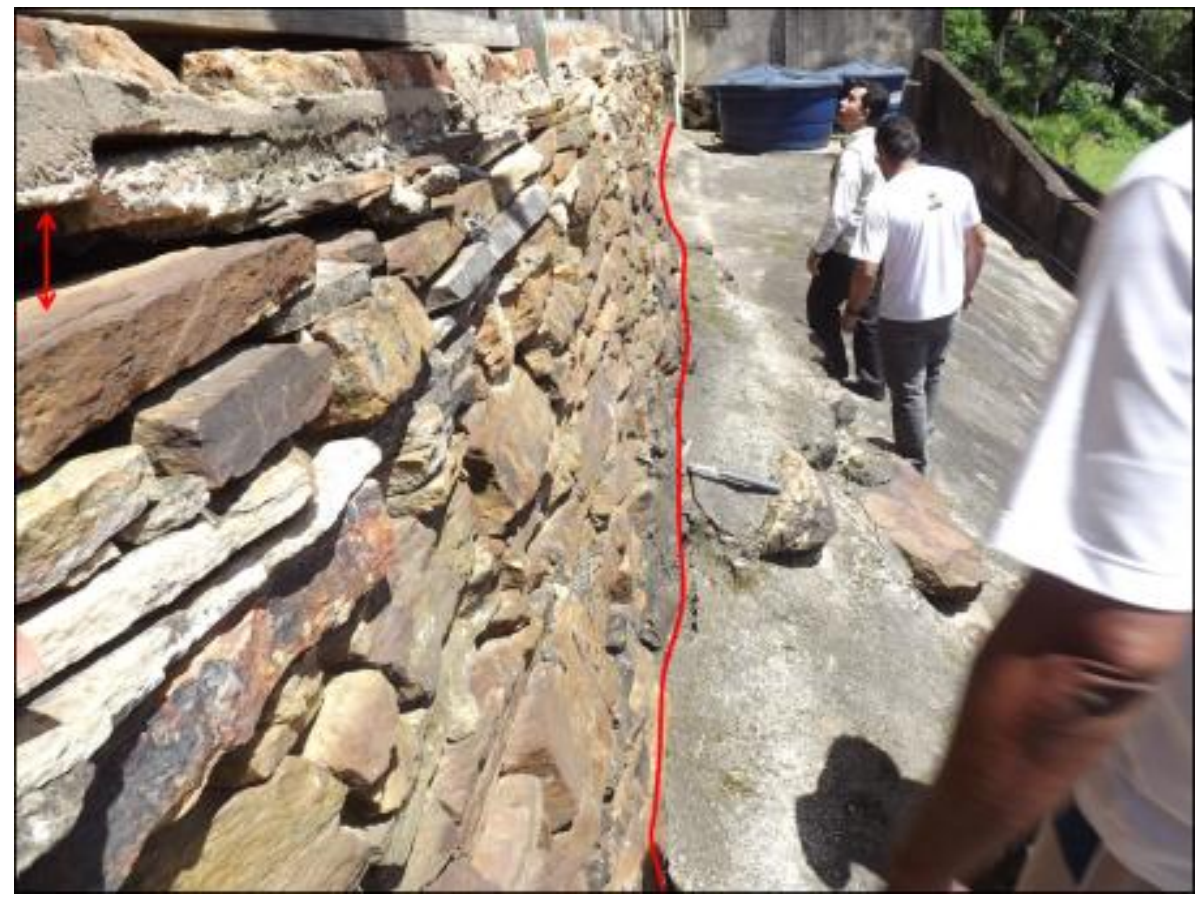

Foto 5: Detalhe do muro de pedra seca construído sobre camada de aterro nova. Notar o embarrigamento tanto no sentido longitudinal, quanto vertical, além do recalque centimétrico entre o muro e a base do quiosque.

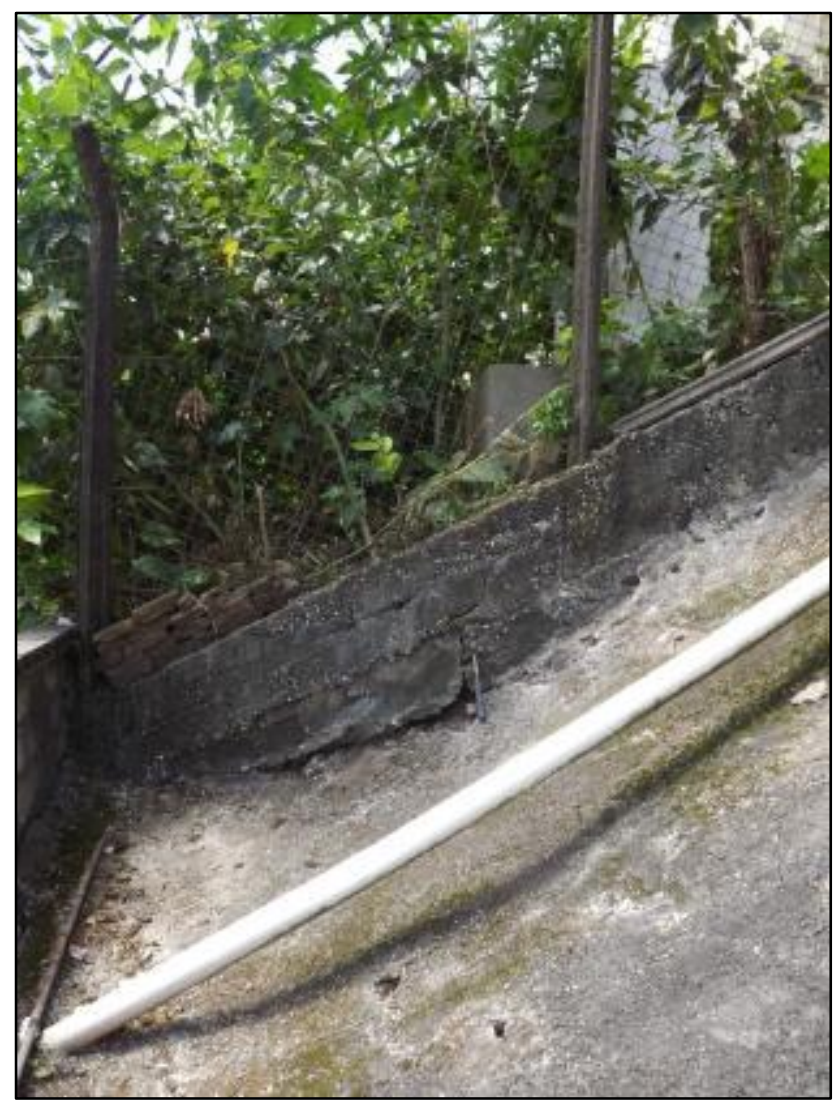

Foto 6: Detalhe da trinca de tração na sapata da cerca divisória indicando movimentação do aterro. 


\section{ANEXOS}

Fichas de Campo 


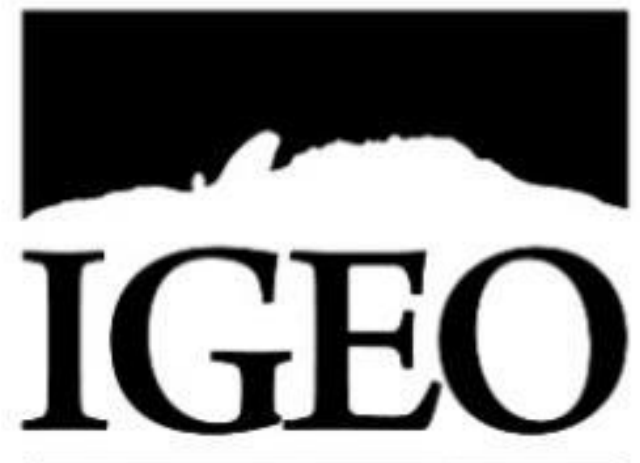

I NST I TUTO GEOTECN I CO

\section{WEBSITE}

www.igeo-op.com.br

\section{TELEFONES}

(31) 3582-9185

(31) $3582-9186$

\section{ENDEREÇO}

Rua Alberto Magalhães, no 245 - Sala 202

Bauxita, Ouro Preto - MG

CEP: $\mathbf{3 5 . 4 0 0 - 0 0 0}$ 


\section{APÊNDICE A}

Tabela de dados cedidos pelo IGEO 
Apêndice A: Tabela de dados cedidos pelo IGEO.

\begin{tabular}{|c|c|c|c|c|c|}
\hline CÓDIGO & ANO & TIPO DE PROCESSO & UTM E & UTM N & OBSERVAÇÃO \\
\hline IG 01/09 & 2009 & Deslizamento & 655119,7 & 7745885 & $\mathrm{~N} / \mathrm{A}$ \\
\hline IG 02/09 & 2009 & Deslizamento & 656324,3 & 7744755,8 & $\mathrm{~N} / \mathrm{A}$ \\
\hline IG 03/09 & 2009 & Deslizamento & 655859,1 & 7746278 & Não há visualização no Street View. \\
\hline IG 04/09 & 2009 & Deslizamento & 644821,1 & 7746068,1 & $\mathrm{~N} / \mathrm{A}$ \\
\hline IG 05/09 & 2009 & Deslizamento & 654345,2 & 7745813,7 & $\mathrm{~N} / \mathrm{A}$ \\
\hline IG 06/09 & 2009 & Deslizamento & 656865,6 & 7745209,8 & $\mathrm{~N} / \mathrm{A}$ \\
\hline IG 16/09 & 2009 & Deslizamento de rocha & 657366,5 & 7745231,7 & $\mathrm{~N} / \mathrm{A}$ \\
\hline IG 04/10 & 2010 & Deslizamento & 655012,8 & 7746106,9 & $\mathrm{~N} / \mathrm{A}$ \\
\hline IG 06/10 & 2010 & Deslizamento & 656589,7 & 7745908,7 & $\mathrm{~N} / \mathrm{A}$ \\
\hline IG 07/10 & 2010 & Deslizamento & 658033 & 7745062 & $\mathrm{~N} / \mathrm{A}$ \\
\hline IG 08/10 & 2010 & Deslizamento & 654796,2 & 7746113,9 & $\mathrm{~N} / \mathrm{A}$ \\
\hline IG 02/11 & 2011 & Deslizamento & 655183,9 & 7745865,4 & $\mathrm{~N} / \mathrm{A}$ \\
\hline IG 01/11 & 2011 & Deslizamento & 657377,3 & 7744631,1 & $\mathrm{~N} / \mathrm{A}$ \\
\hline IG 04/11 & 2011 & Deslizamento & 657356,7 & 7744661,6 & $N / A$ \\
\hline IG 09/11 & 2011 & Deslizamento & 657088,5 & 7744919 & $N / A$ \\
\hline IG 13/11 & 2011 & Deslizamento & 657804,4 & 7745000,1 & $\mathrm{~N} / \mathrm{A}$ \\
\hline $\mid \begin{array}{l}\text { IG } 14 / 11 \\
\end{array}$ & 2011 & Deslizamento & 657267,9 & 7744745,1 & $\mathrm{~N} / \mathrm{A}$ \\
\hline IG 03/11 & 2011 & Deslizamento & 657259,4 & 7745223 & N/A \\
\hline IG 05/11 & 2011 & Deslizamento & 656065,6 & 7745492 & $N / A$ \\
\hline IG 06/11 & 2011 & Deslizamento & 655591,3 & 7745998,7 & $\mathrm{~N} / \mathrm{A}$ \\
\hline $\mid \begin{array}{l}\text { IG } 12 / 11 \\
\end{array}$ & 2011 & Deslizamento & 654859 & 7746013,6 & $\mathrm{~N} / \mathrm{A}$ \\
\hline IG 10/11 & 2011 & Deslizamento & 656268,7 & 7744420 & $\mathrm{~N} / \mathrm{A}$ \\
\hline IG 02/12 & 2012 & Deslizamento & 657321,2 & 7744563,4 & $N / A$ \\
\hline IG 04/12 & 2012 & Deslizamento & 657226,4 & 7744774,3 & N/A \\
\hline $\mid \overline{I G ~ 06 / 12}$ & 2012 & Deslizamento & 657523,2 & 7744596,3 & $\mathrm{~N} / \mathrm{A}$ \\
\hline IG 22/12 & 2012 & Deslizamento & 657506,8 & 7744622,9 & N/A \\
\hline IG 09/12 & 2012 & Deslizamento & 657279,4 & 7744626,5 & N/A \\
\hline IG 26/12 & 2012 & Deslizamento & $\mathrm{N} / \mathrm{A}$ & $\mathrm{N} / \mathrm{A}$ & Endereço não encontrado. Próximo as coordenadas 657575,57 e 7744564,71. \\
\hline IG 33/12 & 2012 & Deslizamento & 657178,4 & 7744784,2 & N/A \\
\hline IG 34/12 & 2012 & Deslizamento & $\mathrm{N} / \mathrm{A}$ & $\mathrm{N} / \mathrm{A}$ & Endereço não encontrado. Próximo as coordenadas 657563,58 e 7744574,97. \\
\hline IG 51/12 & 2012 & Deslizamento & N/A & $\mathrm{N} / \mathrm{A}$ & Endereço não encontrado. Próximo as coordenadas 657178,00 e $7744784,00$. \\
\hline IG 55/12 & 2012 & Deslizamento & N/A & N/A & $\begin{array}{l}\text { Não visualizado pelo Street View. Localizado próximo às coordenadas } 657648,56 \mathrm{e} \\
7745061,50 \text {. }\end{array}$ \\
\hline IG 56/12 & 2012 & Deslizamento & $\mathrm{N} / \mathrm{A}$ & $\mathrm{N} / \mathrm{A}$ & Localizado próximo as coordenadas 657387,43 e $7744735,72$. \\
\hline
\end{tabular}

*CÓDIGO: Código de IGEO; ANO: Ano do cadastro da ocorrência; N/A: Not Available (Não disponível). 
Apêndice A: Tabela de dados cedidos pelo IGEO (continuação).

\begin{tabular}{|c|c|c|c|c|c|}
\hline CóDIGo & ANO & TIPO DE PROCESSO & UTM E & UTM N & OBSERVAÇÃO \\
\hline |IG 58/12 & 2012 & Deslizamento & N/A & N/A & $\begin{array}{l}\text { Não visualizado pelo Street View. Localizado próximo às coordenadas } 657239,23 \text { e } \\
7744655,24 \text {. }\end{array}$ \\
\hline IG 11/12 & 2012 & $\begin{array}{l}\begin{array}{l}\text { Deslizamento e queda de muro de } \\
\text { contenção }\end{array} \\
\end{array}$ & N/A & N/A & Não visualizado pelo street view. Endereço próximo as coordenadas 657560,64 e 7745398,45. \\
\hline IG 28/12 & 2012 & $\begin{array}{l}\text { Queda de muro de arrimo, } \\
\text { deslizamento }\end{array}$ & 657361,8 & 7745119,2 & Não visualizado pelo street view. \\
\hline IG 42/12 & 2012 & Risco de Deslizamento & & & Local próximo as coordenadas 657581,95 e $7744559,13$. \\
\hline IG $17 / 12$ & 2012 & Deslizamento & 655494,7 & 7745717,4 & $\mathrm{~N} / \mathrm{A}$ \\
\hline IG 20/12 & 2012 & Deslizamento & 656368,4 & 7744478,7 & N/A \\
\hline IG 01/12 & 2012 & Deslizamento & 654392,5 & 654392,5 & N/A \\
\hline IG 08/12 & 2012 & Deslizamento & 656057,2 & 7745252 & $\mathrm{~N} / \mathrm{A}$ \\
\hline IG 49/12 & 2012 & Deslizamento & N/A & $\mathrm{N} / \mathrm{A}$ & Local próximo as coordenadas 655786,20 e $7745076,52$. \\
\hline IG 30/12 & 2012 & Deslizamento & 655060,6 & 7745224,1 & $\mathrm{~N} / \mathrm{A}$ \\
\hline IG 12/12 & 2012 & Deslizamento & N/A & N/A & Não visualizado pelo Street View. Endereço próximo as coordenadas 658178,84 e 7745400,84 . \\
\hline IG 50/12 & 2012 & Queda de bloco & N/A & $\mathrm{N} / \mathrm{A}$ & Local próximo as coordenadas 657938,11 e $7745441,57$. \\
\hline IG 57/12 & 2012 & Deslizamento & N/A & N/A & Não visualizado pelo Street View. Localizado próximo às coordenadas $655063,637745337,18$ \\
\hline IG 60/12 & 2012 & Deslizamento & N/A & N/A & $\begin{array}{l}\text { Endereço não encontrado. Entorno da Capela do Bairro Nossa Senhora de Lourde. Próximo as } \\
\text { coordenadas } 654821,99 \text { e } 7745196,62 \text {. }\end{array}$ \\
\hline IG 19/12 & 2012 & Deslizamento & 657491,2 & 7744650,6 & $\mathrm{~N} / \mathrm{A}$ \\
\hline IG 24/12 & 2012 & Deslizamento & 655850,3 & 7744642,3 & Supermercado Varejão da Estação. \\
\hline IG 05/12 & 2012 & Deslizamento & 658067,6 & 7745277,4 & $\mathrm{~N} / \mathrm{A}$ \\
\hline $\mid \overline{I G ~ 27 / 12}$ & 2012 & Deslizamento & $\mathrm{N} / \mathrm{A}$ & $\mathrm{N} / \mathrm{A}$ & Endereço não encontrado. Próximo as coordenadas 657569,56 e 7745372,73. \\
\hline IG 07/12 & 2012 & Deslizamento & 657326,9 & 7743926,4 & N/A \\
\hline IG 15/12 & 2012 & Deslizamento & N/A & N/A & Não visualizado pelo Street View. Endereço próximo as coordenadas 657571,79 e $7744325,50$. \\
\hline IG 21/12 & 2012 & Deslizamento & 657317,2 & 7743946,2 & $\mathrm{~N} / \mathrm{A}$ \\
\hline IG 23/12 & 2012 & Deslizamento & 653862 & 7742813 & N/A \\
\hline IG 41/12 & 2012 & Deslizamento & N/A & N/A & Próximo à casa 441. Local próximo as coordenadas 655683,16 e 7746040,32. \\
\hline IG 54/12 & 2012 & Deslizamento & N/A & N/A & $\begin{array}{l}\text { Não visualizado pelo Street View. Localizado próximo às coordenadas } 655859,31 \text { e } \\
7746276,28 \text {. }\end{array}$ \\
\hline IG 18/12 & 2012 & Deslizamento & 655668 & 7745827 & N/A \\
\hline IG 43/12 & 2012 & Deslizamento & N/A & N/A & Local próximo as coordenadas 655702,09 e $7745758,43$. \\
\hline
\end{tabular}

*CÓDIGO: Código de IGEO; ANO: Ano do cadastro da ocorrência; N/A: Not Available (Não disponível). 
Apêndice A: Tabela de dados cedidos pelo IGEO (continuação).

\begin{tabular}{|c|c|c|c|c|c|}
\hline CÓDIGO & ANO & TIPO DE PROCESSO & UTME & UTM N & OBSERVAÇÃO \\
\hline IG 48/12 & 2012 & Risco de queda de bloco & 655679 & 7746020 & $\mathrm{~N} / \mathrm{A}$ \\
\hline IG 46/12 & 2012 & Deslizamento & 656699 & 7746068,5 & Não há visualização no Street View. \\
\hline IG 47/12 & 2012 & Deslizamento & 656704,5 & 7746074,4 & Não há visualização no Street View. \\
\hline IG 13/12 & 2012 & Deslizamento & N/A & N/A & Não visualizado pelo street view. Endereço próximo as coordenadas 658212,35 e 7745197,95 . \\
\hline IG 14/12 & 2012 & Deslizamento & N/A & $\mathrm{N} / \mathrm{A}$ & Endereço próximo as coordenadas 656244,07 e 7744428,38 . \\
\hline IG 03/13 & 2013 & Deslizamento & $\mathrm{N} / \mathrm{A}$ & $\mathrm{N} / \mathrm{A}$ & Endereço próximo as coordenadas 657915,25 e $7745433,18$. \\
\hline IG 03/13 & 2013 & Deslizamento & $\mathrm{N} / \mathrm{A}$ & $\mathrm{N} / \mathrm{A}$ & Endereço próximo as coordenadas 657915,25 e $7745433,18$. \\
\hline IG 04/13 & 2013 & Deslizamento & 655312 & 7745593,9 & $\mathrm{~N} / \mathrm{A}$ \\
\hline IG 05/13 & 2013 & Deslizamento & 655997,2 & 7744919,9 & $\mathrm{~N} / \mathrm{A}$ \\
\hline IG 06/13 & 2013 & Deslizamento & 656563,9 & 7744737,4 & $\mathrm{~N} / \mathrm{A}$ \\
\hline IG 07/13 & 2013 & Deslizamento & $\mathrm{N} / \mathrm{A}$ & $\mathrm{N} / \mathrm{A}$ & Endereço próximo as coordenadas 655798,01 e $7745254,18$. \\
\hline IG 08/13 & 2013 & Deslizamento & 654363,6 & 7745616,8 & Localizado na altura do número 38. \\
\hline IG 09/13 & 2013 & Deslizamento & $\mathrm{N} / \mathrm{A}$ & $\mathrm{N} / \mathrm{A}$ & Endereço próximo às coordenadas 657994,14 e 7745048,00 . \\
\hline IG 10/13 & 2013 & Deslizamento & N/A & $\mathrm{N} / \mathrm{A}$ & Endereço próximo às coordenadas 656196,00 e $7746560,00$. \\
\hline IG 11/13 & 2013 & Deslizamento & 655066 & 7745618 & Localizado ao lado do número 31. \\
\hline IG 12/13 & 2013 & Deslizamento & 656897 & 7744611 & Ficha de campo - 203. \\
\hline IG 13/13 & 2013 & Deslizamento & 657318 & 7744664 & Ficha de campo - 199. \\
\hline IG 14/13 & 2013 & Deslizamento & 654184 & 7745491 & Ficha de campo - 194. \\
\hline IG 15/13 & 2013 & Deslizamento & 656185 & 7744328 & Ficha de campo - 202. \\
\hline IG 16/13 & 2013 & Deslizamento & N/A & $\mathrm{N} / \mathrm{A}$ & Localizado próximo às coordenadas 657429,71 e 7745100,13. \\
\hline IG 17/13 & 2013 & Deslizamento & 657379 & 7744594 & Não há visualização no Street View - Ficha de campo - 198. \\
\hline IG 18/13 & 2013 & Deslizamento & N/A & $\mathrm{N} / \mathrm{A}$ & Local próximo às coordenadas 656699,00 e 7746068,00. \\
\hline IG 19/13 & 2013 & Deslizamento & 656965 & 7745070 & Ficha de campo - 195. \\
\hline IG 20/13 & 2013 & Deslizamento & 657590 & 7744962 & N/A \\
\hline IG 21/13 & 2013 & Deslizamento & $\mathrm{N} / \mathrm{A}$ & $\mathrm{N} / \mathrm{A}$ & Local próximo as coordenadas 656642,62 e 7746037,13. \\
\hline IG 22/13 & 2013 & Deslizamento & N/A & $\mathrm{N} / \mathrm{A}$ & Local próximo as coordenadas 658194,56 e $7745034,73$. \\
\hline IG 23/13 & 2013 & Deslizamento de talude & 655838,5 & 7745019,1 & $\mathrm{~N} / \mathrm{A}$ \\
\hline IG 24/13 & 2013 & Deslizamento/Corte & N/A & N/A & Local próximo as coordenadas 657587,90 e 7744553,40 . \\
\hline IG 26/13 & 2013 & Escorregamento Rotacional & 655151,2 & 7745396,4 & $\mathrm{~N} / \mathrm{A}$ \\
\hline IG 27/13 & 2013 & Instalação de muro de gabião & 655795 & 7745086 & Ficha de campo - 192. \\
\hline IG 33/13 & 2013 & Queda de bloco & 659102 & 7745089 & $\mathrm{~N} / \mathrm{A}$ \\
\hline IG 34/13 & 2013 & Queda de Bloco & 655913 & 7745641 & $\mathrm{~N} / \mathrm{A}$ \\
\hline IG 36/13 & 2013 & Rastejo/deslizamento de blocos & 657001,8 & 7744991,4 & $\mathrm{~N} / \mathrm{A}$ \\
\hline
\end{tabular}

*CÓDIGO: Código de IGEO; ANO: Ano do cadastro da ocorrência; N/A: Not Available (Não disponível). 


\section{APÊNDICE B}

Banco de dados do inventário de movimentos de massa gravitacionais 
Apêndice B: Banco de dados do inventário de movimentos de massa gravitacionais.

\begin{tabular}{|c|c|c|c|c|c|c|c|c|c|c|c|}
\hline AUTOR & ANO & 1 & 2 & TIPO DE PROCESSO & TIPO DE MATERIAL & COD.INV & UTM E & UTM N & ÁREA $\left(\mathbf{m}^{2}\right)$ & ATIVIDADE & PROF. \\
\hline Souza, M.L. & 1996 & $\mathrm{~N} / \mathrm{A}$ & $C x$ & Complexo & N/A & MX1 & 655405,382 & 7747086,890 & 15951,60 & N/A & N/A \\
\hline Souza, M.L. & 1996 & $\mathrm{~N} / \mathrm{A}$ & $\mathrm{Cd}$ & Corrida de material & Detritos & MC2 & 655634,034 & 7747158,187 & 2358,12 & $\mathrm{~N} / \mathrm{A}$ & $\mathrm{N} / \mathrm{A}$ \\
\hline Souza, M.L. & 1996 & $\mathrm{~N} / \mathrm{A}$ & $\mathrm{Cd}$ & Corrida de material & Detritos & MC3 & 655262,936 & 7746949,084 & 1736,39 & N/A & N/A \\
\hline Souza, M.L. & 1996 & N/A & $\mathrm{Qr}$ & Queda & Rocha & MQ4 & 655107,660 & 7746833,539 & 922,54 & $\mathrm{~N} / \mathrm{A}$ & $\mathrm{N} / \mathrm{A}$ \\
\hline Souza, M.L. & 1996 & $\mathrm{~N} / \mathrm{A}$ & $\mathrm{Qr}$ & Queda & Rocha & MQ5 & 655061,605 & 7746825,536 & 567,75 & N/A & N/A \\
\hline Souza, M.L. & 1996 & $\mathrm{~N} / \mathrm{A}$ & $\mathrm{Qr}$ & Queda & Rocha & MQ6 & 654984,261 & 7746710,001 & 1060,75 & $\mathrm{~N} / \mathrm{A}$ & $\mathrm{N} / \mathrm{A}$ \\
\hline Souza, M.L. & 1996 & $\mathrm{~N} / \mathrm{A}$ & $\mathrm{Qr}$ & Queda & Rocha & MQ7 & 655165,164 & 7746663,300 & 554,04 & N/A & N/A \\
\hline Souza, M.L. & 1996 & N/A & $C x$ & Complexo & N/A & MX8 & 655390,592 & 7746824,318 & 4513,07 & $\mathrm{~N} / \mathrm{A}$ & $\mathrm{N} / \mathrm{A}$ \\
\hline Souza, M.L. & 1996 & $\mathrm{~N} / \mathrm{A}$ & $\mathrm{Cd}$ & Corrida de material & Detritos & MC9 & 655559,810 & 7746834,247 & 2059,37 & N/A & N/A \\
\hline Souza, M.L. & 1996 & $\mathrm{~N} / \mathrm{A}$ & $\mathrm{Cd}$ & Corrida de material & Detritos & MC10 & 655564,985 & 7746711,024 & 1771,68 & $\mathrm{~N} / \mathrm{A}$ & $\mathrm{N} / \mathrm{A}$ \\
\hline Souza, M.L. & 1996 & $\mathrm{~N} / \mathrm{A}$ & $\mathrm{Qr}$ & Queda & Rocha & MQ11 & 655081,174 & 7746529,728 & 1175,74 & $\mathrm{~N} / \mathrm{A}$ & $\mathrm{N} / \mathrm{A}$ \\
\hline Souza, M.L. & 1996 & $\mathrm{~N} / \mathrm{A}$ & $\mathrm{Qr}$ & Queda & Rocha & MQ12 & 654921,395 & 7746395,352 & 2117,49 & N/A & N/A \\
\hline Souza, M.L. & 1996 & $\mathrm{~N} / \mathrm{A}$ & $C x$ & Complexo & N/A & MX13 & 655158,502 & 7746414,172 & 5219,42 & $\mathrm{~N} / \mathrm{A}$ & $\mathrm{N} / \mathrm{A}$ \\
\hline Souza, M.L. & 1996 & $\mathrm{~N} / \mathrm{A}$ & $C x$ & Complexo & N/A & MX14 & 655270,905 & 7746469,257 & 1883,67 & N/A & N/A \\
\hline Souza, M.L. & 1996 & $\mathrm{~N} / \mathrm{A}$ & $C x$ & Complexo & $\mathrm{N} / \mathrm{A}$ & MX15 & 655337,369 & 7746441,797 & 2742,18 & $\mathrm{~N} / \mathrm{A}$ & $\mathrm{N} / \mathrm{A}$ \\
\hline Souza, M.L. & 1996 & N/A & Ets & Escorregamento translacional & Solo & MT16 & 655201,178 & 7746610,036 & 4975,20 & N/A & $\mathrm{N} / \mathrm{A}$ \\
\hline Souza, M.L. & 1996 & $\mathrm{~N} / \mathrm{A}$ & Ets & Escorregamento translacional & Solo & MT17 & 655319,731 & 7746623,528 & 1323,32 & $\mathrm{~N} / \mathrm{A}$ & $\mathrm{N} / \mathrm{A}$ \\
\hline Souza, M.L. & 1996 & $\mathrm{~N} / \mathrm{A}$ & $\mathrm{Cd}$ & Corrida de material & Detritos & MC18 & 655812,158 & 7746506,156 & 2520,09 & N/A & $\mathrm{N} / \mathrm{A}$ \\
\hline Souza, M.L. & 1996 & $\mathrm{~N} / \mathrm{A}$ & $\mathrm{Cd}$ & Corrida de material & Detritos & MC19 & 655794,320 & 7746357,463 & 1319,94 & $\mathrm{~N} / \mathrm{A}$ & $\mathrm{N} / \mathrm{A}$ \\
\hline Souza, M.L. & 1996 & $\mathrm{~N} / \mathrm{A}$ & $C x$ & Complexo & N/A & MX20 & 655668,331 & 7746272,186 & 10327,60 & N/A & N/A \\
\hline Souza, M.L. & 1996 & $\mathrm{~N} / \mathrm{A}$ & $C x$ & Complexo & $\mathrm{N} / \mathrm{A}$ & MX21 & 655794,156 & 7746123,769 & 2769,90 & $\mathrm{~N} / \mathrm{A}$ & $\mathrm{N} / \mathrm{A}$ \\
\hline Souza, M.L. & 1996 & $\mathrm{~N} / \mathrm{A}$ & $C x$ & Complexo & N/A & MX22 & 655594,415 & 7745886,071 & 2267,68 & N/A & N/A \\
\hline Souza, M.L. & 1996 & $\mathrm{~N} / \mathrm{A}$ & $C x$ & Área de múltiplas feições & $\mathrm{N} / \mathrm{A}$ & MA23 & 655792,352 & 7745859,921 & 17396,80 & $\mathrm{~N} / \mathrm{A}$ & $\mathrm{N} / \mathrm{A}$ \\
\hline Souza, M.L. & 1996 & $\mathrm{~N} / \mathrm{A}$ & $\mathrm{Qr}$ & Queda & Rocha & MQ24 & 654620,753 & 7746486,206 & 1175,11 & N/A & N/A \\
\hline Souza, M.L. & 1996 & $\mathrm{~N} / \mathrm{A}$ & $\mathrm{Qd}$ & Queda & Detritos & MQ25 & 654731,433 & 7746360,922 & 1845,55 & $\mathrm{~N} / \mathrm{A}$ & $\mathrm{N} / \mathrm{A}$ \\
\hline Souza, M.L. & 1996 & $\mathrm{~N} / \mathrm{A}$ & $C x$ & Área de múltiplas feições & $\mathrm{N} / \mathrm{A}$ & MA26 & 654879,734 & 7746231,992 & 6615,91 & N/A & N/A \\
\hline Souza, M.L. & 1996 & $\mathrm{~N} / \mathrm{A}$ & $\mathrm{Cd}$ & Corrida de material & Detritos & MC27 & 654786,940 & 7746094,241 & 1718,12 & $\mathrm{~N} / \mathrm{A}$ & $\mathrm{N} / \mathrm{A}$ \\
\hline Souza, M.L. & 1996 & $\mathrm{~N} / \mathrm{A}$ & $\mathrm{Cd}$ & Corrida de material & Detritos & MC28 & 654861,757 & 7746013,800 & 1193,30 & N/A & N/A \\
\hline Souza, M.L. & 1996 & $\mathrm{~N} / \mathrm{A}$ & $C x$ & Área de múltiplas feições & $\mathrm{N} / \mathrm{A}$ & MA29 & 654735,334 & 7746006,349 & 14742,50 & $\mathrm{~N} / \mathrm{A}$ & $\mathrm{N} / \mathrm{A}$ \\
\hline Souza, M.L. & 1996 & $\mathrm{~N} / \mathrm{A}$ & $C x$ & Área de múltiplas feições & $\mathrm{N} / \mathrm{A}$ & MA30 & 654404,054 & 7746070,333 & 53748,10 & N/A & $\mathrm{N} / \mathrm{A}$ \\
\hline Souza, M.L. & 1996 & $\mathrm{~N} / \mathrm{A}$ & $\mathrm{Qr}$ & Queda & Rocha & MQ31 & 653137,160 & 7746332,811 & 1899,42 & $\mathrm{~N} / \mathrm{A}$ & $\mathrm{N} / \mathrm{A}$ \\
\hline Souza, M.L. & 1996 & $\mathrm{~N} / \mathrm{A}$ & $C x$ & Complexo & $\mathrm{N} / \mathrm{A}$ & MX32 & 653348,724 & 7746046,308 & 2891,26 & N/A & N/A \\
\hline Souza, M.L. & 1996 & $\mathrm{~N} / \mathrm{A}$ & $\mathrm{Qr}$ & Queda & Rocha & MQ33 & 653045,779 & 7745932,281 & 1681,82 & N/A & $\mathrm{N} / \mathrm{A}$ \\
\hline Souza, M.L. & 1996 & N/A & $\mathrm{Qr}$ & Queda & Rocha & MQ34 & 653334,240 & 7745881,934 & 775,74 & $\mathrm{~N} / \mathrm{A}$ & $\mathrm{N} / \mathrm{A}$ \\
\hline
\end{tabular}

*ANO: Data do trabalho; 1: Código da feição; 2: Código do processo; CÓD.INV: Código do inventário; PROF.: Profundidade do movimento, N/A: Not Available (Não disponível). 
Apêndice B: Banco de dados do inventário de movimentos de massa gravitacionais (continuação).

\begin{tabular}{|c|c|c|c|c|c|c|c|c|c|c|c|}
\hline AUTOR & ANO & 1 & 2 & TIPO DE PROCESSO & TIPO DE MATERIAL & COD.INV & UTM E & UTM N & ÁREA $\left(\mathbf{m}^{2}\right)$ & ATIVIDADE & PROF. \\
\hline Souza, M.L. & 1996 & $\mathrm{~N} / \mathrm{A}$ & Qr & Queda & Rocha & MQ35 & 653335,559 & 7745760,599 & 845,99 & N/A & N/A \\
\hline Souza, M.L. & 1996 & $\mathrm{~N} / \mathrm{A}$ & $C x$ & Área de múltiplas feições & $\mathrm{N} / \mathrm{A}$ & MA36 & 653754,565 & 7745466,940 & 11463,80 & $\mathrm{~N} / \mathrm{A}$ & $\mathrm{N} / \mathrm{A}$ \\
\hline Souza, M.L. & 1996 & $\mathrm{~N} / \mathrm{A}$ & Erot & Escorregamento rotacional & Solo & MR37 & 653931,796 & 7745949,936 & 816,85 & N/A & N/A \\
\hline Souza, M.L. & 1996 & N/A & $C x$ & Área de múltiplas feições & N/A & MA38 & 653966,855 & 7745419,671 & 27696,50 & $\mathrm{~N} / \mathrm{A}$ & $\mathrm{N} / \mathrm{A}$ \\
\hline Souza, M.L. & 1996 & $\mathrm{~N} / \mathrm{A}$ & $C x$ & Área de múltiplas feições & N/A & MA39 & 654115,702 & 7745447,493 & 4270,11 & N/A & N/A \\
\hline Souza, M.L. & 1996 & $\mathrm{~N} / \mathrm{A}$ & $C x$ & Área de múltiplas feições & N/A & MA40 & 653631,302 & 7743853,910 & 13875,00 & $\mathrm{~N} / \mathrm{A}$ & $\mathrm{N} / \mathrm{A}$ \\
\hline Souza, M.L. & 1996 & $\mathrm{~N} / \mathrm{A}$ & $C x$ & Complexo & $\mathrm{N} / \mathrm{A}$ & MX41 & 653784,074 & 7743387,449 & 2815,26 & $\mathrm{~N} / \mathrm{A}$ & $\mathrm{N} / \mathrm{A}$ \\
\hline Souza, M.L. & 1996 & $\mathrm{~N} / \mathrm{A}$ & $C x$ & Complexo & N/A & MX42 & 653622,257 & 7743332,034 & 1650,08 & $\mathrm{~N} / \mathrm{A}$ & $\mathrm{N} / \mathrm{A}$ \\
\hline Souza, M.L. & 1996 & $\mathrm{~N} / \mathrm{A}$ & $C x$ & Complexo & N/A & MX43 & 654158,088 & 7743267,784 & 1316,55 & N/A & N/A \\
\hline Souza, M.L. & 1996 & $\mathrm{~N} / \mathrm{A}$ & $C x$ & Complexo & N/A & MX44 & 654496,731 & 7743275,270 & 677,37 & N/A & $\mathrm{N} / \mathrm{A}$ \\
\hline Souza, M.L. & 1996 & $\mathrm{~N} / \mathrm{A}$ & $C x$ & Complexo & N/A & MX45 & 654699,830 & 7743148,291 & 2728,55 & $\mathrm{~N} / \mathrm{A}$ & $\mathrm{N} / \mathrm{A}$ \\
\hline Souza, M.L. & 1996 & $\mathrm{~N} / \mathrm{A}$ & $C x$ & Complexo & N/A & MX46 & 654682,630 & 7743070,499 & 1908,16 & N/A & N/A \\
\hline Souza, M.L. & 1996 & $\mathrm{~N} / \mathrm{A}$ & $C x$ & Área de múltiplas feições & N/A & MA47 & 654654,935 & 7743577,826 & 2172,93 & $\mathrm{~N} / \mathrm{A}$ & $\mathrm{N} / \mathrm{A}$ \\
\hline Souza, M.L. & 1996 & $\mathrm{~N} / \mathrm{A}$ & $C x$ & Área de múltiplas feições & N/A & MA48 & 653858,237 & 7743750,181 & 5963,58 & N/A & N/A \\
\hline Souza, M.L. & 1996 & $\mathrm{~N} / \mathrm{A}$ & Etr & Escorregamento translacional & Rocha & MT49 & 653969,838 & 7743610,761 & 790,47 & $\mathrm{~N} / \mathrm{A}$ & $\mathrm{N} / \mathrm{A}$ \\
\hline Souza, M.L. & 1996 & N/A & $C x$ & Complexo & N/A & MX50 & 654145,024 & 7743784,155 & 2024,40 & N/A & $\mathrm{N} / \mathrm{A}$ \\
\hline Souza, M.L. & 1996 & $\mathrm{~N} / \mathrm{A}$ & $C x$ & Complexo & $\mathrm{N} / \mathrm{A}$ & MX51 & 654214,739 & 7743806,431 & 2145,92 & $\mathrm{~N} / \mathrm{A}$ & $\mathrm{N} / \mathrm{A}$ \\
\hline Souza, M.L. & 1996 & $\mathrm{~N} / \mathrm{A}$ & Qd & Queda & Detritos & MQ52 & 654339,933 & 7743862,006 & 1889,81 & N/A & $\mathrm{N} / \mathrm{A}$ \\
\hline Souza, M.L. & 1996 & $\mathrm{~N} / \mathrm{A}$ & Ets & Escorregamento translacional & Solo & MT53 & 654724,523 & 7744029,833 & 1108,87 & $\mathrm{~N} / \mathrm{A}$ & $\mathrm{N} / \mathrm{A}$ \\
\hline Souza, M.L. & 1996 & $\mathrm{~N} / \mathrm{A}$ & Ets & Escorregamento translacional & Solo & MT54 & 654840,298 & 7743988,168 & 2050,08 & N/A & N/A \\
\hline Souza, M.L. & 1996 & $\mathrm{~N} / \mathrm{A}$ & Ets & Escorregamento translacional & Solo & MT55 & 654865,987 & 7743865,631 & 1312,61 & $\mathrm{~N} / \mathrm{A}$ & $\mathrm{N} / \mathrm{A}$ \\
\hline Souza, M.L. & 1996 & $\mathrm{~N} / \mathrm{A}$ & Ets & Escorregamento translacional & Solo & MT56 & 654779,738 & 7743858,663 & 3084,37 & N/A & N/A \\
\hline Souza, M.L. & 1996 & $\mathrm{~N} / \mathrm{A}$ & $C x$ & Área de múltiplas feições & $\mathrm{N} / \mathrm{A}$ & MA57 & 654532,011 & 7745896,747 & 18515,80 & $\mathrm{~N} / \mathrm{A}$ & $\mathrm{N} / \mathrm{A}$ \\
\hline Souza, M.L. & 1996 & $\mathrm{~N} / \mathrm{A}$ & $C x$ & Complexo & N/A & MX58 & 654419,652 & 7745782,908 & 5087,19 & N/A & N/A \\
\hline Souza, M.L. & 1996 & $\mathrm{~N} / \mathrm{A}$ & $C x$ & Área de múltiplas feições & $\mathrm{N} / \mathrm{A}$ & MA59 & 654627,443 & 7745778,315 & 10140,40 & $\mathrm{~N} / \mathrm{A}$ & $\mathrm{N} / \mathrm{A}$ \\
\hline Souza, M.L. & 1996 & $\mathrm{~N} / \mathrm{A}$ & $C x$ & Complexo & N/A & MX60 & 654761,149 & 7745804,459 & 2191,91 & N/A & N/A \\
\hline Souza, M.L. & 1996 & $\mathrm{~N} / \mathrm{A}$ & Ets & Escorregamento translacional & Solo & MT61 & 655103,347 & 7745420,272 & 647,68 & $\mathrm{~N} / \mathrm{A}$ & $\mathrm{N} / \mathrm{A}$ \\
\hline Souza, M.L. & 1996 & $\mathrm{~N} / \mathrm{A}$ & Etr & Escorregamento translacional & Rocha & MT62 & 655283,108 & 7745259,410 & 1952,97 & N/A & N/A \\
\hline Souza, M.L. & 1996 & $\mathrm{~N} / \mathrm{A}$ & $C x$ & Complexo & $\mathrm{N} / \mathrm{A}$ & MX63 & 655423,116 & 7745135,136 & 1939,66 & $\mathrm{~N} / \mathrm{A}$ & $\mathrm{N} / \mathrm{A}$ \\
\hline Souza, M.L. & 1996 & $\mathrm{~N} / \mathrm{A}$ & $C x$ & Complexo & $\mathrm{N} / \mathrm{A}$ & MX64 & 655462,483 & 7745009,116 & 433,78 & N/A & $\mathrm{N} / \mathrm{A}$ \\
\hline Souza, M.L. & 1996 & $\mathrm{~N} / \mathrm{A}$ & $C x$ & Complexo & $\mathrm{N} / \mathrm{A}$ & MX65 & 655299,833 & 7745006,242 & 1177,86 & $\mathrm{~N} / \mathrm{A}$ & $\mathrm{N} / \mathrm{A}$ \\
\hline Souza, M.L. & 1996 & $\mathrm{~N} / \mathrm{A}$ & $C x$ & Complexo & N/A & MX66 & 655115,738 & 7744924,604 & 2248,54 & N/A & N/A \\
\hline Souza, M.L. & 1996 & $\mathrm{~N} / \mathrm{A}$ & $C x$ & Área de múltiplas feições & N/A & MA67 & 655379,689 & 7744937,109 & 6343,42 & N/A & $\mathrm{N} / \mathrm{A}$ \\
\hline Souza, M.L. & 1996 & N/A & $C x$ & Área de múltiplas feições & $\mathrm{N} / \mathrm{A}$ & MA68 & 655463,892 & 7744865,725 & 5948,62 & $\mathrm{~N} / \mathrm{A}$ & $\mathrm{N} / \mathrm{A}$ \\
\hline
\end{tabular}

*ANO: Data do trabalho; 1: Código da feição; 2: Código do processo; CÓD.INV: Código do inventário; PROF.: Profundidade do movimento, N/A: Not Available (Não disponível). 
Apêndice B: Banco de dados do inventário de movimentos de massa gravitacionais (continuação).

\begin{tabular}{|c|c|c|c|c|c|c|c|c|c|c|c|}
\hline AUTOR & ANO & 1 & 2 & TIPO DE PROCESSO & TIPO DE MATERIAL & COD.INV & UTM E & UTM N & ÁREA $\left(\mathbf{m}^{2}\right)$ & ATIVIDADE & PROF. \\
\hline Souza, M.L. & 1996 & $\mathrm{~N} / \mathrm{A}$ & Etr & Escorregamento translacional & Rocha & MT69 & 655436,914 & 7744696,662 & 1632,28 & N/A & N/A \\
\hline Souza, M.L. & 1996 & $\mathrm{~N} / \mathrm{A}$ & $C x$ & Complexo & $\mathrm{N} / \mathrm{A}$ & MX70 & 655400,687 & 7744598,805 & 4219,23 & $\mathrm{~N} / \mathrm{A}$ & $\mathrm{N} / \mathrm{A}$ \\
\hline Souza, M.L. & 1996 & $\mathrm{~N} / \mathrm{A}$ & $C x$ & Complexo & N/A & MX71 & 655214,678 & 7744492,489 & 9429,20 & N/A & N/A \\
\hline Souza, M.L. & 1996 & $\mathrm{~N} / \mathrm{A}$ & $\mathrm{Cd}$ & Corrida de material & Detritos & MC72 & 654909,992 & 7744308,187 & 2106,94 & $\mathrm{~N} / \mathrm{A}$ & $\mathrm{N} / \mathrm{A}$ \\
\hline Souza, M.L. & 1996 & $\mathrm{~N} / \mathrm{A}$ & Etr & Escorregamento translacional & Rocha & MT73 & 655835,161 & 7744746,266 & 2733,91 & N/A & N/A \\
\hline Souza, M.L. & 1996 & $\mathrm{~N} / \mathrm{A}$ & $\mathrm{Cd}$ & Corrida de material & Detritos & MC74 & 654721,572 & 7744276,657 & 2311,86 & $\mathrm{~N} / \mathrm{A}$ & N/A \\
\hline Souza, M.L. & 1996 & $\mathrm{~N} / \mathrm{A}$ & Ets & Escorregamento translacional & Solo & MT75 & 656083,534 & 7745766,669 & 9294,69 & N/A & N/A \\
\hline Souza, M.L. & 1996 & $\mathrm{~N} / \mathrm{A}$ & $\mathrm{Cd}$ & Corrida de material & Detritos & MC76 & 655925,446 & 7745455,751 & 1517,53 & $\mathrm{~N} / \mathrm{A}$ & $\mathrm{N} / \mathrm{A}$ \\
\hline Souza, M.L. & 1996 & $\mathrm{~N} / \mathrm{A}$ & Etd & Escorregamento translacional & Detritos & MT77 & 655991,448 & 7745442,889 & 1685,83 & N/A & N/A \\
\hline Souza, M.L. & 1996 & $\mathrm{~N} / \mathrm{A}$ & Etr & Escorregamento translacional & Rocha & MT78 & 656037,378 & 7745353,782 & 1581,96 & N/A & $\mathrm{N} / \mathrm{A}$ \\
\hline Souza, M.L. & 1996 & $\mathrm{~N} / \mathrm{A}$ & $\mathrm{Cd}$ & Corrida de material & Detritos & MC79 & 655821,879 & 7745421,143 & 2150,33 & $\mathrm{~N} / \mathrm{A}$ & $\mathrm{N} / \mathrm{A}$ \\
\hline Souza, M.L. & 1996 & $\mathrm{~N} / \mathrm{A}$ & $C x$ & Complexo & N/A & MX80 & 655778,846 & 7745293,315 & 1658,27 & N/A & N/A \\
\hline Souza, M.L. & 1996 & $\mathrm{~N} / \mathrm{A}$ & Ets & Escorregamento translacional & Solo & MT81 & 655661,222 & 7745271,764 & 3114,14 & $\mathrm{~N} / \mathrm{A}$ & $\mathrm{N} / \mathrm{A}$ \\
\hline Souza, M.L. & 1996 & $\mathrm{~N} / \mathrm{A}$ & Etr & Escorregamento translacional & Rocha & MT82 & 656000,696 & 7745025,734 & 1486,82 & N/A & N/A \\
\hline Souza, M.L. & 1996 & $\mathrm{~N} / \mathrm{A}$ & $C x$ & Complexo & $\mathrm{N} / \mathrm{A}$ & MX83 & 655349,019 & 7745633,465 & 2553,01 & $\mathrm{~N} / \mathrm{A}$ & $\mathrm{N} / \mathrm{A}$ \\
\hline Souza, M.L. & 1996 & N/A & $C x$ & Complexo & N/A & MX84 & 655484,988 & 7745640,215 & 2264,53 & N/A & $\mathrm{N} / \mathrm{A}$ \\
\hline Souza, M.L. & 1996 & $\mathrm{~N} / \mathrm{A}$ & Qd & Queda & Detritos & MQ85 & 653087,376 & 7742668,397 & 2243,26 & $\mathrm{~N} / \mathrm{A}$ & $\mathrm{N} / \mathrm{A}$ \\
\hline Souza, M.L. & 1996 & $\mathrm{~N} / \mathrm{A}$ & Etd & Escorregamento translacional & Detritos & MT86 & 653278,063 & 7742801,644 & 2030,39 & N/A & $\mathrm{N} / \mathrm{A}$ \\
\hline Souza, M.L. & 1996 & $\mathrm{~N} / \mathrm{A}$ & Cs & Corrida de material & Solo & MC87 & 653660,171 & 7742370,649 & 2203,02 & $\mathrm{~N} / \mathrm{A}$ & $\mathrm{N} / \mathrm{A}$ \\
\hline Souza, M.L. & 1996 & $\mathrm{~N} / \mathrm{A}$ & $C x$ & Complexo & N/A & MX88 & 653728,759 & 7742045,672 & 1167,23 & N/A & N/A \\
\hline Souza, M.L. & 1996 & $\mathrm{~N} / \mathrm{A}$ & Etd & Escorregamento translacional & Detritos & MT89 & 653651,600 & 7742092,047 & 2426,84 & $\mathrm{~N} / \mathrm{A}$ & $\mathrm{N} / \mathrm{A}$ \\
\hline Souza, M.L. & 1996 & $\mathrm{~N} / \mathrm{A}$ & Cs & Corrida de material & Solo & MC90 & 653938,854 & 7742137,461 & 1576,99 & N/A & N/A \\
\hline Souza, M.L. & 1996 & $\mathrm{~N} / \mathrm{A}$ & Ets & Escorregamento translacional & Solo & MT91 & 654201,686 & 7742870,300 & 3052,16 & $\mathrm{~N} / \mathrm{A}$ & $\mathrm{N} / \mathrm{A}$ \\
\hline Souza, M.L. & 1996 & $\mathrm{~N} / \mathrm{A}$ & Ets & Escorregamento translacional & Solo & MT92 & 654128,560 & 7742792,759 & 813,86 & N/A & N/A \\
\hline Souza, M.L. & 1996 & $\mathrm{~N} / \mathrm{A}$ & $\mathrm{Qr}$ & Queda & Rocha & MQ93 & 654560,004 & 7742733,461 & 1893,04 & $\mathrm{~N} / \mathrm{A}$ & $\mathrm{N} / \mathrm{A}$ \\
\hline Souza, M.L. & 1996 & $\mathrm{~N} / \mathrm{A}$ & $C x$ & Complexo & N/A & MX94 & 654680,565 & 7742822,567 & 2091,50 & N/A & N/A \\
\hline Souza, M.L. & 1996 & $\mathrm{~N} / \mathrm{A}$ & $C x$ & Área de múltiplas feições & $\mathrm{N} / \mathrm{A}$ & MA95 & 655157,785 & 7743208,920 & 6983,85 & $\mathrm{~N} / \mathrm{A}$ & $\mathrm{N} / \mathrm{A}$ \\
\hline Souza, M.L. & 1996 & $\mathrm{~N} / \mathrm{A}$ & $C x$ & Complexo & N/A & MX96 & 655102,541 & 7743091,719 & 1794,99 & N/A & N/A \\
\hline Souza, M.L. & 1996 & $\mathrm{~N} / \mathrm{A}$ & Ets & Escorregamento translacional & Solo & MT97 & 655723,994 & 7742989,379 & 2024,95 & $\mathrm{~N} / \mathrm{A}$ & $\mathrm{N} / \mathrm{A}$ \\
\hline Souza, M.L. & 1996 & $\mathrm{~N} / \mathrm{A}$ & $C x$ & Complexo & N/A & MX98 & 655494,685 & 7742759,964 & 1645,46 & N/A & $\mathrm{N} / \mathrm{A}$ \\
\hline Souza, M.L. & 1996 & $\mathrm{~N} / \mathrm{A}$ & Ets & Escorregamento translacional & Solo & MT99 & 655024,748 & 7742318,010 & 2011,17 & $\mathrm{~N} / \mathrm{A}$ & $\mathrm{N} / \mathrm{A}$ \\
\hline Souza, M.L. & 1996 & $\mathrm{~N} / \mathrm{A}$ & $C x$ & Complexo & $\mathrm{N} / \mathrm{A}$ & MX100 & 655350,584 & 7742246,919 & 1892,57 & N/A & N/A \\
\hline Souza, M.L. & 1996 & $\mathrm{~N} / \mathrm{A}$ & Etr & Escorregamento translacional & Rocha & MT101 & 655685,150 & 7742053,296 & 1150,46 & $\mathrm{~N} / \mathrm{A}$ & $\mathrm{N} / \mathrm{A}$ \\
\hline Souza, M.L. & 1996 & $\mathrm{~N} / \mathrm{A}$ & Etr & Escorregamento translacional & Rocha & MT102 & 655715,570 & 7742182,844 & 1309,70 & $\mathrm{~N} / \mathrm{A}$ & $\mathrm{N} / \mathrm{A}$ \\
\hline
\end{tabular}

*ANO: Data do trabalho; 1: Código da feição; 2: Código do processo; CÓD.INV: Código do inventário; PROF.: Profundidade do movimento, N/A: Not Available (Não disponível). 
Apêndice B: Banco de dados do inventário de movimentos de massa gravitacionais (continuação).

\begin{tabular}{|c|c|c|c|c|c|c|c|c|c|c|c|}
\hline AUTOR & ANO & 1 & 2 & TIPO DE PROCESSO & TIPO DE MATERIAL & COD.INV & UTM E & UTM N & ÁREA $\left(\mathbf{m}^{2}\right)$ & ATIVIDADE & PROF. \\
\hline Souza, M.L. & 1996 & $\mathrm{~N} / \mathrm{A}$ & Qr & Queda & Rocha & MQ103 & 656016,309 & 7743160,645 & 1897,45 & N/A & N/A \\
\hline Souza, M.L. & 1996 & $\mathrm{~N} / \mathrm{A}$ & $\mathrm{Qr}$ & Queda & Rocha & MQ104 & 656099,784 & 7742338,662 & 1517,14 & $\mathrm{~N} / \mathrm{A}$ & $\mathrm{N} / \mathrm{A}$ \\
\hline Souza, M.L. & 1996 & $\mathrm{~N} / \mathrm{A}$ & $\mathrm{Qr}$ & Queda & Rocha & MQ105 & 656376,955 & 7742301,410 & 2350,29 & N/A & N/A \\
\hline Souza, M.L. & 1996 & $\mathrm{~N} / \mathrm{A}$ & $\mathrm{Qr}$ & Queda & Rocha & MQ106 & 656187,958 & 7742523,485 & 2219,64 & $\mathrm{~N} / \mathrm{A}$ & $\mathrm{N} / \mathrm{A}$ \\
\hline Souza, M.L. & 1996 & $\mathrm{~N} / \mathrm{A}$ & $\mathrm{Qr}$ & Queda & Rocha & MQ107 & 656252,678 & 7742721,437 & 1531,63 & N/A & N/A \\
\hline Souza, M.L. & 1996 & $\mathrm{~N} / \mathrm{A}$ & $C x$ & Área de múltiplas feições & N/A & MA108 & 656568,382 & 7742967,467 & 53582,70 & $\mathrm{~N} / \mathrm{A}$ & $\mathrm{N} / \mathrm{A}$ \\
\hline Souza, M.L. & 1996 & $\mathrm{~N} / \mathrm{A}$ & $C x$ & Área de múltiplas feições & N/A & MA109 & 656836,731 & 7743109,226 & 51226,30 & N/A & N/A \\
\hline Souza, M.L. & 1996 & $\mathrm{~N} / \mathrm{A}$ & $\mathrm{Qr}$ & Queda & Rocha & MQ110 & 656629,610 & 7742463,887 & 1900,52 & $\mathrm{~N} / \mathrm{A}$ & $\mathrm{N} / \mathrm{A}$ \\
\hline Souza, M.L. & 1996 & $\mathrm{~N} / \mathrm{A}$ & $\mathrm{Qr}$ & Queda & Rocha & MQ111 & 656798,025 & 7742581,147 & 1789,24 & N/A & N/A \\
\hline Souza, M.L. & 1996 & $\mathrm{~N} / \mathrm{A}$ & $\mathrm{Qr}$ & Queda & Rocha & MQ112 & 656599,167 & 7742656,000 & 1837,99 & $\mathrm{~N} / \mathrm{A}$ & $\mathrm{N} / \mathrm{A}$ \\
\hline Souza, M.L. & 1996 & $\mathrm{~N} / \mathrm{A}$ & $\mathrm{Qr}$ & Queda & Rocha & MQ113 & 656680,282 & 7742771,772 & 1908,00 & $\mathrm{~N} / \mathrm{A}$ & $\mathrm{N} / \mathrm{A}$ \\
\hline Souza, M.L. & 1996 & $\mathrm{~N} / \mathrm{A}$ & $C x$ & Complexo & N/A & MX114 & 656733,932 & 7742849,606 & 3148,95 & $\mathrm{~N} / \mathrm{A}$ & $\mathrm{N} / \mathrm{A}$ \\
\hline Souza, M.L. & 1996 & $\mathrm{~N} / \mathrm{A}$ & $\mathrm{Qr}$ & Queda & Rocha & MQ115 & 657020,664 & 7742703,779 & 1900,99 & $\mathrm{~N} / \mathrm{A}$ & $\mathrm{N} / \mathrm{A}$ \\
\hline Souza, M.L. & 1996 & $\mathrm{~N} / \mathrm{A}$ & $\mathrm{Qr}$ & Queda & Rocha & MQ116 & 657079,327 & 7742625,045 & 1927,30 & $\mathrm{~N} / \mathrm{A}$ & $\mathrm{N} / \mathrm{A}$ \\
\hline Souza, M.L. & 1996 & $\mathrm{~N} / \mathrm{A}$ & $\mathrm{Qr}$ & Queda & Rocha & MQ117 & 657184,673 & 7742540,250 & 1763,80 & $\mathrm{~N} / \mathrm{A}$ & $\mathrm{N} / \mathrm{A}$ \\
\hline Souza, M.L. & 1996 & $\mathrm{~N} / \mathrm{A}$ & $\mathrm{Qr}$ & Queda & Rocha & MQ118 & 657315,056 & 7742549,310 & 1756,08 & $\mathrm{~N} / \mathrm{A}$ & $\mathrm{N} / \mathrm{A}$ \\
\hline Souza, M.L. & 1996 & $\mathrm{~N} / \mathrm{A}$ & $\mathrm{Qr}$ & Queda & Rocha & MQ119 & 657297,426 & 7742396,039 & 2626,17 & $\mathrm{~N} / \mathrm{A}$ & $\mathrm{N} / \mathrm{A}$ \\
\hline Souza, M.L. & 1996 & $\mathrm{~N} / \mathrm{A}$ & $\mathrm{Qr}$ & Queda & Rocha & MQ120 & 657094,963 & 7742461,261 & 1705,84 & $\mathrm{~N} / \mathrm{A}$ & $\mathrm{N} / \mathrm{A}$ \\
\hline Souza, M.L. & 1996 & $\mathrm{~N} / \mathrm{A}$ & $\mathrm{Qr}$ & Queda & Rocha & MQ121 & 657167,341 & 7742355,235 & 1787,66 & $\mathrm{~N} / \mathrm{A}$ & $\mathrm{N} / \mathrm{A}$ \\
\hline Souza, M.L. & 1996 & $\mathrm{~N} / \mathrm{A}$ & $\mathrm{Qr}$ & Queda & Rocha & MQ122 & 657244,912 & 7742265,777 & 1580,22 & N/A & N/A \\
\hline Souza, M.L. & 1996 & $\mathrm{~N} / \mathrm{A}$ & $\mathrm{Qr}$ & Queda & Rocha & MQ123 & 657038,648 & 7742257,215 & 1676,86 & $\mathrm{~N} / \mathrm{A}$ & $\mathrm{N} / \mathrm{A}$ \\
\hline Souza, M.L. & 1996 & $\mathrm{~N} / \mathrm{A}$ & $C x$ & Complexo & N/A & MX124 & 657321,282 & 7742705,219 & 1647,40 & N/A & N/A \\
\hline Souza, M.L. & 1996 & $\mathrm{~N} / \mathrm{A}$ & $\mathrm{Qr}$ & Queda & Rocha & MQ125 & 657417,043 & 7742811,294 & 1441,06 & $\mathrm{~N} / \mathrm{A}$ & $\mathrm{N} / \mathrm{A}$ \\
\hline Souza, M.L. & 1996 & $\mathrm{~N} / \mathrm{A}$ & $\mathrm{Qr}$ & Queda & Rocha & MQ126 & 657515,969 & 7742896,605 & 1875,63 & N/A & N/A \\
\hline Souza, M.L. & 1996 & $\mathrm{~N} / \mathrm{A}$ & $\mathrm{Qd}$ & Queda & Detritos & MQ127 & 657707,860 & 7743057,428 & 1954,47 & $\mathrm{~N} / \mathrm{A}$ & $\mathrm{N} / \mathrm{A}$ \\
\hline Souza, M.L. & 1996 & $\mathrm{~N} / \mathrm{A}$ & $C x$ & Área de múltiplas feições & $\mathrm{N} / \mathrm{A}$ & MA128 & 657331,069 & 7743068,811 & 28564,40 & N/A & N/A \\
\hline Souza, M.L. & 1996 & $\mathrm{~N} / \mathrm{A}$ & $C x$ & Área de múltiplas feições & $\mathrm{N} / \mathrm{A}$ & MA129 & 657599,501 & 7743248,254 & 13133,00 & $\mathrm{~N} / \mathrm{A}$ & $\mathrm{N} / \mathrm{A}$ \\
\hline Souza, M.L. & 1996 & $\mathrm{~N} / \mathrm{A}$ & $C x$ & Área de múltiplas feições & N/A & MA130 & 657350,231 & 7743436,562 & 43135,30 & N/A & N/A \\
\hline Souza, M.L. & 1996 & $\mathrm{~N} / \mathrm{A}$ & Qd & Queda & Detritos & MQ131 & 657071,183 & 7743339,839 & 1796,25 & $\mathrm{~N} / \mathrm{A}$ & $\mathrm{N} / \mathrm{A}$ \\
\hline Souza, M.L. & 1996 & $\mathrm{~N} / \mathrm{A}$ & $C x$ & Complexo & $\mathrm{N} / \mathrm{A}$ & MX132 & 656272,330 & 7743178,263 & 2763,36 & N/A & $\mathrm{N} / \mathrm{A}$ \\
\hline Souza, M.L. & 1996 & $\mathrm{~N} / \mathrm{A}$ & $C x$ & Complexo & $\mathrm{N} / \mathrm{A}$ & MX133 & 656410,254 & 7743266,414 & 1226,69 & $\mathrm{~N} / \mathrm{A}$ & $\mathrm{N} / \mathrm{A}$ \\
\hline Souza, M.L. & 1996 & $\mathrm{~N} / \mathrm{A}$ & $C x$ & Complexo & N/A & MX134 & 656237,241 & 7743339,253 & 1838,07 & N/A & N/A \\
\hline Souza, M.L. & 1996 & $\mathrm{~N} / \mathrm{A}$ & $C x$ & Complexo & N/A & MX135 & 656115,149 & 7743409,225 & 1784,36 & N/A & $\mathrm{N} / \mathrm{A}$ \\
\hline Souza, M.L. & 1996 & $\mathrm{~N} / \mathrm{A}$ & $C x$ & Complexo & $\mathrm{N} / \mathrm{A}$ & MX136 & 656328,345 & 7743481,068 & 1757,26 & $\mathrm{~N} / \mathrm{A}$ & $\mathrm{N} / \mathrm{A}$ \\
\hline
\end{tabular}

*ANO: Data do trabalho; 1: Código da feição; 2: Código do processo; CÓD.INV: Código do inventário; PROF.: Profundidade do movimento, N/A: Not Available (Não disponível). 
Apêndice B: Banco de dados do inventário de movimentos de massa gravitacionais (continuação).

\begin{tabular}{|c|c|c|c|c|c|c|c|c|c|c|c|}
\hline AUTOR & ANO & 1 & 2 & TIPO DE PROCESSO & TIPO DE MATERIAL & COD.INV & UTM E & UTM N & ÁREA $\left(\mathrm{m}^{2}\right)$ & ATIVIDADE & PROF. \\
\hline Souza, M.L. & 1996 & N/A & $C x$ & Complexo & $\mathrm{N} / \mathrm{A}$ & MX137 & 656266,846 & 7743553,918 & 2094,89 & $\mathrm{~N} / \mathrm{A}$ & $\mathrm{N} / \mathrm{A}$ \\
\hline Souza, M.L. & 1996 & $\mathrm{~N} / \mathrm{A}$ & $C x$ & Complexo & $\mathrm{N} / \mathrm{A}$ & MX138 & 656335,070 & 7743693,191 & 1909,18 & $\mathrm{~N} / \mathrm{A}$ & $\mathrm{N} / \mathrm{A}$ \\
\hline Souza, M.L. & 1996 & $\mathrm{~N} / \mathrm{A}$ & Qd & Queda & Detritos & MQ139 & 656658,079 & 7743716,751 & 2597,03 & $\mathrm{~N} / \mathrm{A}$ & $\mathrm{N} / \mathrm{A}$ \\
\hline Souza, M.L. & 1996 & $\mathrm{~N} / \mathrm{A}$ & Qd & Queda & Detritos & MQ140 & 656980,568 & 7743660,955 & 1510,92 & $\mathrm{~N} / \mathrm{A}$ & $\mathrm{N} / \mathrm{A}$ \\
\hline Souza, M.L. & 1996 & N/A & $\mathrm{Cd}$ & Corrida de material & Detritos & MC141 & 657472,978 & 7743853,862 & 1433,11 & $\mathrm{~N} / \mathrm{A}$ & $\mathrm{N} / \mathrm{A}$ \\
\hline Souza, M.L. & 1996 & $\mathrm{~N} / \mathrm{A}$ & $\mathrm{Cd}$ & Corrida de material & Detritos & MC142 & 657499,142 & 7743960,879 & 1931,00 & $\mathrm{~N} / \mathrm{A}$ & $\mathrm{N} / \mathrm{A}$ \\
\hline Souza, M.L. & 1996 & $\mathrm{~N} / \mathrm{A}$ & Ets & Escorregamento translacional & Solo & MT143 & 657774,640 & 7743927,488 & 1958,72 & $\mathrm{~N} / \mathrm{A}$ & $\mathrm{N} / \mathrm{A}$ \\
\hline Souza, M.L. & 1996 & $\mathrm{~N} / \mathrm{A}$ & $C x$ & Complexo & $\mathrm{N} / \mathrm{A}$ & MX144 & 657676,900 & 7744050,060 & 1702,77 & $\mathrm{~N} / \mathrm{A}$ & $\mathrm{N} / \mathrm{A}$ \\
\hline Souza, M.L. & 1996 & $\mathrm{~N} / \mathrm{A}$ & $C x$ & Complexo & $\mathrm{N} / \mathrm{A}$ & MX145 & 657865,118 & 7744218,492 & 11319,20 & $\mathrm{~N} / \mathrm{A}$ & $\mathrm{N} / \mathrm{A}$ \\
\hline Souza, M.L. & 1996 & $\mathrm{~N} / \mathrm{A}$ & $C x$ & Complexo & $\mathrm{N} / \mathrm{A}$ & MX146 & 657670,155 & 7744378,303 & 1880,44 & $\mathrm{~N} / \mathrm{A}$ & $\mathrm{N} / \mathrm{A}$ \\
\hline Souza, M.L. & 1996 & N/A & Etd & Escorregamento translacional & Detritos & MT147 & 657757,823 & 7744543,446 & 2491,50 & $\mathrm{~N} / \mathrm{A}$ & $\mathrm{N} / \mathrm{A}$ \\
\hline Souza, M.L. & 1996 & $\mathrm{~N} / \mathrm{A}$ & Etd & Escorregamento translacional & Detritos & MT148 & 657594,961 & 77446551,487 & 1666,62 & $\mathrm{~N} / \mathrm{A}$ & $\mathrm{N} / \mathrm{A}$ \\
\hline Souza, M.L. & 1996 & N/A & Etd & Escorregamento translacional & Detritos & MT149 & 657708,156 & 7744687,797 & 2805,97 & $\mathrm{~N} / \mathrm{A}$ & $\mathrm{N} / \mathrm{A}$ \\
\hline Souza, M.L. & 1996 & $\mathrm{~N} / \mathrm{A}$ & Ets & Escorregamento translacional & Solo & MT150 & 657368,512 & 7744523,830 & 996,33 & $\mathrm{~N} / \mathrm{A}$ & $\mathrm{N} / \mathrm{A}$ \\
\hline Souza, M.L. & 1996 & $\mathrm{~N} / \mathrm{A}$ & $C x$ & Complexo & $\mathrm{N} / \mathrm{A}$ & MX151 & 657437,633 & 7744566,301 & 1887,60 & $\mathrm{~N} / \mathrm{A}$ & $\mathrm{N} / \mathrm{A}$ \\
\hline Souza, M.L. & 1996 & $\mathrm{~N} / \mathrm{A}$ & $C x$ & Área de múltiplas feições & $\mathrm{N} / \mathrm{A}$ & MA152 & 657595,015 & 7744515,356 & 14969,90 & $\mathrm{~N} / \mathrm{A}$ & $\mathrm{N} / \mathrm{A}$ \\
\hline Souza, M.L. & 1996 & $\mathrm{~N} / \mathrm{A}$ & Etd & Escorregamento translacional & Detritos & MT153 & 657245,133 & 7744681,306 & 3216,52 & $\mathrm{~N} / \mathrm{A}$ & $\mathrm{N} / \mathrm{A}$ \\
\hline Souza, M.L. & 1996 & $\mathrm{~N} / \mathrm{A}$ & $\mathrm{Cd}$ & Corrida de material & Detritos & MC154 & 657255,156 & 7744735,506 & 1428,54 & $\mathrm{~N} / \mathrm{A}$ & $\mathrm{N} / \mathrm{A}$ \\
\hline Souza, M.L. & 1996 & $\mathrm{~N} / \mathrm{A}$ & $C x$ & Complexo & $\mathrm{N} / \mathrm{A}$ & MX155 & 657341,024 & 7744782,535 & 834,10 & $\mathrm{~N} / \mathrm{A}$ & $\mathrm{N} / \mathrm{A}$ \\
\hline Souza, M.L. & 1996 & $\mathrm{~N} / \mathrm{A}$ & $\mathrm{Cd}$ & Corrida de material & Detritos & MC156 & 656946,350 & 7744784,138 & 1381,44 & $\mathrm{~N} / \mathrm{A}$ & $\mathrm{N} / \mathrm{A}$ \\
\hline Souza, M.L. & 1996 & $\mathrm{~N} / \mathrm{A}$ & Etd & Escorregamento translacional & Detritos & MT157 & 657056,958 & 7744683,865 & 901,12 & $\mathrm{~N} / \mathrm{A}$ & $\mathrm{N} / \mathrm{A}$ \\
\hline Souza, M.L. & 1996 & N/A & Etr & Escorregamento translacional & Rocha & MT158 & 657095,175 & 7744764,804 & 2007,63 & $\mathrm{~N} / \mathrm{A}$ & $\mathrm{N} / \mathrm{A}$ \\
\hline Souza, M.L. & 1996 & $\mathrm{~N} / \mathrm{A}$ & $C x$ & Complexo & $\mathrm{N} / \mathrm{A}$ & MX159 & 656986,209 & 7744553,431 & 4469,75 & $\mathrm{~N} / \mathrm{A}$ & $\mathrm{N} / \mathrm{A}$ \\
\hline Souza, M.L. & 1996 & N/A & $\mathrm{Cd}$ & Corrida de material & Detritos & MC160 & 656894,602 & 7744437,467 & 1283,39 & $\mathrm{~N} / \mathrm{A}$ & $\mathrm{N} / \mathrm{A}$ \\
\hline Souza, M.L. & 1996 & $\mathrm{~N} / \mathrm{A}$ & $C x$ & Área de múltiplas feições & $\mathrm{N} / \mathrm{A}$ & MA161 & 656923,110 & 7744348,423 & 4348,55 & $\mathrm{~N} / \mathrm{A}$ & $\mathrm{N} / \mathrm{A}$ \\
\hline Souza, M.L. & 1996 & N/A & Etr & Escorregamento translacional & Rocha & MT162 & 656600,784 & 7744566,820 & 1348,29 & $\mathrm{~N} / \mathrm{A}$ & $\mathrm{N} / \mathrm{A}$ \\
\hline Souza, M.L. & 1996 & $\mathrm{~N} / \mathrm{A}$ & Etr & Escorregamento translacional & Rocha & MT163 & 656616,273 & 7744396,147 & 1870,59 & $\mathrm{~N} / \mathrm{A}$ & $\mathrm{N} / \mathrm{A}$ \\
\hline Souza, M.L. & 1996 & N/A & $C x$ & Complexo & $\mathrm{N} / \mathrm{A}$ & MX164 & 656231,013 & 7744254,601 & 2663,34 & $\mathrm{~N} / \mathrm{A}$ & $\mathrm{N} / \mathrm{A}$ \\
\hline Souza, M.L. & 1996 & $\mathrm{~N} / \mathrm{A}$ & $C x$ & Complexo & $\mathrm{N} / \mathrm{A}$ & MX165 & 656053,324 & 7744785,524 & 1352,07 & $\mathrm{~N} / \mathrm{A}$ & $\mathrm{N} / \mathrm{A}$ \\
\hline Souza, M.L. & 1996 & N/A & Qr & Queda & Rocha & MQ166 & 656075,373 & 7744864,733 & 1213,70 & $\mathrm{~N} / \mathrm{A}$ & $\mathrm{N} / \mathrm{A}$ \\
\hline Souza, M.L. & 1996 & $\mathrm{~N} / \mathrm{A}$ & $C x$ & Complexo & $\mathrm{N} / \mathrm{A}$ & MX167 & 656173,945 & 7744806,935 & 1044,06 & $\mathrm{~N} / \mathrm{A}$ & $\mathrm{N} / \mathrm{A}$ \\
\hline Souza, M.L. & 1996 & N/A & Ets & Escorregamento translacional & Solo & MT168 & 656383,733 & 7744886,511 & 1694,10 & $\mathrm{~N} / \mathrm{A}$ & $\mathrm{N} / \mathrm{A}$ \\
\hline Souza, M.L. & 1996 & $\mathrm{~N} / \mathrm{A}$ & $\mathrm{Qr}$ & Queda & Rocha & MQ169 & 656369,071 & 7745031,094 & 1878,23 & $\mathrm{~N} / \mathrm{A}$ & $\mathrm{N} / \mathrm{A}$ \\
\hline Souza, M.L. & 1996 & N/A & Ets & Escorregamento translacional & Solo & MT170 & 656192,260 & 7745451,698 & 1659,29 & $\mathrm{~N} / \mathrm{A}$ & $\mathrm{N} / \mathrm{A}$ \\
\hline
\end{tabular}

*ANO: Data do trabalho; 1: Código da feição; 2: Código do processo; CÓD.INV: Código do inventário; PROF.: Profundidade do movimento, N/A: Not Available (Não disponível). 
Apêndice B: Banco de dados do inventário de movimentos de massa gravitacionais (continuação).

\begin{tabular}{|c|c|c|c|c|c|c|c|c|c|c|c|}
\hline AUTOR & ANO & 1 & 2 & TIPO DE PROCESSO & TIPO DE MATERIAL & COD.INV & UTM E & UTM N & ÁREA $\left(\mathbf{m}^{2}\right)$ & ATIVIDADE & PROF. \\
\hline Souza, M.L. & 1996 & $\mathrm{~N} / \mathrm{A}$ & Ets & Escorregamento translacional & Solo & MT171 & 656226,381 & 7745619,403 & 638,63 & $\mathrm{~N} / \mathrm{A}$ & $\mathrm{N} / \mathrm{A}$ \\
\hline Souza, M.L. & 1996 & $\mathrm{~N} / \mathrm{A}$ & $\mathrm{Qr}$ & Queda & Rocha & MQ172 & 656420,070 & 7745569,404 & 1911,78 & $\mathrm{~N} / \mathrm{A}$ & $\mathrm{N} / \mathrm{A}$ \\
\hline Souza, M.L. & 1996 & $\mathrm{~N} / \mathrm{A}$ & $C x$ & Área de múltiplas feições & N/A & MA173 & 656676,838 & 7745403,884 & 4168,91 & $\mathrm{~N} / \mathrm{A}$ & $\mathrm{N} / \mathrm{A}$ \\
\hline Souza, M.L. & 1996 & $\mathrm{~N} / \mathrm{A}$ & $C x$ & Complexo & N/A & MX174 & 657002,075 & 7745424,752 & 967,82 & $\mathrm{~N} / \mathrm{A}$ & $\mathrm{N} / \mathrm{A}$ \\
\hline Souza, M.L. & 1996 & $\mathrm{~N} / \mathrm{A}$ & $C x$ & Complexo & N/A & MX175 & 656919,245 & 7745444,550 & 1376,64 & $\mathrm{~N} / \mathrm{A}$ & $\mathrm{N} / \mathrm{A}$ \\
\hline Souza, M.L. & 1996 & $\mathrm{~N} / \mathrm{A}$ & $\mathrm{Qr}$ & Queda & Rocha & MQ176 & 656632,051 & 7745810,575 & 2236,10 & $\mathrm{~N} / \mathrm{A}$ & N/A \\
\hline Souza, M.L. & 1996 & $\mathrm{~N} / \mathrm{A}$ & $\mathrm{Cd}$ & Corrida de material & Detritos & MC177 & 656739,376 & 7746370,121 & 623,43 & $\mathrm{~N} / \mathrm{A}$ & $\mathrm{N} / \mathrm{A}$ \\
\hline Souza, M.L. & 1996 & $\mathrm{~N} / \mathrm{A}$ & $\mathrm{Cd}$ & Corrida de material & Detritos & MC178 & 656841,792 & 7746482,771 & 845,20 & $\mathrm{~N} / \mathrm{A}$ & $\mathrm{N} / \mathrm{A}$ \\
\hline Souza, M.L. & 1996 & $\mathrm{~N} / \mathrm{A}$ & $\mathrm{Cd}$ & Corrida de material & Detritos & MC179 & 656772,399 & 7746552,241 & 1504,85 & $\mathrm{~N} / \mathrm{A}$ & $\mathrm{N} / \mathrm{A}$ \\
\hline Souza, M.L. & 1996 & $\mathrm{~N} / \mathrm{A}$ & $\mathrm{Cd}$ & Corrida de material & Detritos & MC180 & 656874,122 & 7746570,725 & 3580,84 & $\mathrm{~N} / \mathrm{A}$ & $\mathrm{N} / \mathrm{A}$ \\
\hline Souza, M.L. & 1996 & $\mathrm{~N} / \mathrm{A}$ & $\mathrm{Cd}$ & Corrida de material & Detritos & MC181 & 656653,700 & 7746730,178 & 4559,53 & $\mathrm{~N} / \mathrm{A}$ & $\mathrm{N} / \mathrm{A}$ \\
\hline Souza, M.L. & 1996 & $\mathrm{~N} / \mathrm{A}$ & $\mathrm{Cd}$ & Corrida de material & Detritos & MC182 & 656744,982 & 7746629,176 & 4704,76 & $\mathrm{~N} / \mathrm{A}$ & N/A \\
\hline Souza, M.L. & 1996 & $\mathrm{~N} / \mathrm{A}$ & $C x$ & Área de múltiplas feições & N/A & MA183 & 656553,368 & 7747117,537 & 15375,90 & $\mathrm{~N} / \mathrm{A}$ & $\mathrm{N} / \mathrm{A}$ \\
\hline Souza, M.L. & 1996 & $\mathrm{~N} / \mathrm{A}$ & $C x$ & Área de múltiplas feições & N/A & MA184 & 656413,723 & 7747383,378 & 34265,60 & N/A & N/A \\
\hline Souza, M.L. & 1996 & $\mathrm{~N} / \mathrm{A}$ & $C x$ & Área de múltiplas feições & N/A & MA185 & 656619,466 & 7747437,717 & 74942,00 & N/A & N/A \\
\hline Souza, M.L. & 1996 & N/A & $C x$ & Área de múltiplas feições & N/A & MA186 & 656866,135 & 7747477,678 & 27287,70 & N/A & $\mathrm{N} / \mathrm{A}$ \\
\hline Souza, M.L. & 1996 & $\mathrm{~N} / \mathrm{A}$ & $C x$ & Complexo & $\mathrm{N} / \mathrm{A}$ & MX187 & 657001,205 & 7744944,886 & 1316,55 & $\mathrm{~N} / \mathrm{A}$ & $\mathrm{N} / \mathrm{A}$ \\
\hline Souza, M.L. & 1996 & $\mathrm{~N} / \mathrm{A}$ & $C x$ & Complexo & N/A & MX188 & 657815,674 & 7746834,257 & 14256,70 & N/A & N/A \\
\hline Souza, M.L. & 1996 & $\mathrm{~N} / \mathrm{A}$ & $C x$ & Complexo & N/A & MX189 & 658222,536 & 7746976,291 & 2733,99 & N/A & N/A \\
\hline Souza, M.L. & 1996 & $\mathrm{~N} / \mathrm{A}$ & $C x$ & Complexo & N/A & MX190 & 658559,588 & 7746999,722 & 4114,80 & N/A & N/A \\
\hline Souza, M.L. & 1996 & $\mathrm{~N} / \mathrm{A}$ & Ets & Escorregamento translacional & Solo & MT191 & 660163,939 & 7746844,954 & 1590,22 & $\mathrm{~N} / \mathrm{A}$ & $\mathrm{N} / \mathrm{A}$ \\
\hline Souza, M.L. & 1996 & $\mathrm{~N} / \mathrm{A}$ & Etd & Escorregamento translacional & Detritos & MT192 & 660105,050 & 7746710,710 & 1625,27 & $\mathrm{~N} / \mathrm{A}$ & $\mathrm{N} / \mathrm{A}$ \\
\hline Souza, M.L. & 1996 & $\mathrm{~N} / \mathrm{A}$ & Ets & Escorregamento translacional & Solo & MT193 & 659955,454 & 7746581,005 & 861,98 & N/A & N/A \\
\hline Souza, M.L. & 1996 & $\mathrm{~N} / \mathrm{A}$ & Ets & Escorregamento translacional & Solo & MT194 & 660250,063 & 7746381,743 & 1141,87 & N/A & N/A \\
\hline Souza, M.L. & 1996 & $\mathrm{~N} / \mathrm{A}$ & $C x$ & Complexo & $\mathrm{N} / \mathrm{A}$ & MX195 & 660166,805 & 7746405,957 & 3251,49 & $\mathrm{~N} / \mathrm{A}$ & $\mathrm{N} / \mathrm{A}$ \\
\hline Souza, M.L. & 1996 & $\mathrm{~N} / \mathrm{A}$ & $\mathrm{Qr}$ & Queda & Rocha & MQ196 & 658420,729 & 7743263,248 & 3433,57 & $\mathrm{~N} / \mathrm{A}$ & N/A \\
\hline Souza, M.L. & 1996 & $\mathrm{~N} / \mathrm{A}$ & Ets & Escorregamento translacional & Solo & MT197 & 658621,650 & 7743581,612 & 3979,82 & N/A & N/A \\
\hline Souza, M.L. & 1996 & $\mathrm{~N} / \mathrm{A}$ & $C x$ & Complexo & N/A & MX198 & 658163,210 & 7744258,154 & 3450,74 & N/A & N/A \\
\hline Souza, M.L. & 1996 & $\mathrm{~N} / \mathrm{A}$ & $C x$ & Complexo & $\mathrm{N} / \mathrm{A}$ & MX199 & 658047,096 & 77444402,444 & 1460,59 & $\mathrm{~N} / \mathrm{A}$ & $\mathrm{N} / \mathrm{A}$ \\
\hline Souza, M.L. & 1996 & $\mathrm{~N} / \mathrm{A}$ & $C x$ & Área de múltiplas feições & N/A & MA200 & 657911,601 & 7744374,987 & 5826,78 & $\mathrm{~N} / \mathrm{A}$ & N/A \\
\hline Souza, M.L. & 1996 & $\mathrm{~N} / \mathrm{A}$ & $C x$ & Complexo & N/A & MX201 & 658151,523 & 7744492,333 & 2457,48 & $\mathrm{~N} / \mathrm{A}$ & $\mathrm{N} / \mathrm{A}$ \\
\hline Souza, M.L. & 1996 & $\mathrm{~N} / \mathrm{A}$ & $C x$ & Área de múltiplas feições & N/A & MA202 & 657875,673 & 7744644,004 & 10555,00 & N/A & N/A \\
\hline Souza, M.L. & 1996 & $\mathrm{~N} / \mathrm{A}$ & Etd & Escorregamento translacional & Detritos & MT203 & 657701,675 & 7744765,303 & 1668,98 & $\mathrm{~N} / \mathrm{A}$ & $\mathrm{N} / \mathrm{A}$ \\
\hline Souza, M.L. & 1996 & $\mathrm{~N} / \mathrm{A}$ & Etd & Escorregamento translacional & Detritos & MT204 & 657940,331 & 77444799,997 & 1023,35 & N/A & N/A \\
\hline
\end{tabular}

*ANO: Data do trabalho; 1: Código da feição; 2: Código do processo; CÓD.INV: Código do inventário; PROF.: Profundidade do movimento, N/A: Not Available (Não disponível). 
Apêndice B: Banco de dados do inventário de movimentos de massa gravitacionais (continuação).

\begin{tabular}{|c|c|c|c|c|c|c|c|c|c|c|c|}
\hline AUTOR & ANO & 1 & 2 & TIPO DE PROCESSO & TIPO DE MATERIAL & COD.INV & UTM E & UTM N & ÁREA $\left(\mathbf{m}^{2}\right)$ & ATIVIDADE & PROF. \\
\hline Souza, M.L. & 1996 & $\mathrm{~N} / \mathrm{A}$ & Qr & Queda & Rocha & MQ205 & 657959,720 & 7744850,974 & 1554,71 & N/A & N/A \\
\hline Souza, M.L. & 1996 & $\mathrm{~N} / \mathrm{A}$ & $\mathrm{Qr}$ & Queda & Rocha & MQ206 & 658175,023 & 7744880,051 & 1752,07 & $\mathrm{~N} / \mathrm{A}$ & $\mathrm{N} / \mathrm{A}$ \\
\hline Souza, M.L. & 1996 & $\mathrm{~N} / \mathrm{A}$ & $\mathrm{Qr}$ & Queda & Rocha & MQ207 & 658474,185 & 7744811,684 & 1758,76 & N/A & N/A \\
\hline Souza, M.L. & 1996 & N/A & $C x$ & Área de múltiplas feições & N/A & MA208 & 658466,847 & 7744551,392 & 33861,00 & $\mathrm{~N} / \mathrm{A}$ & $\mathrm{N} / \mathrm{A}$ \\
\hline Souza, M.L. & 1996 & $\mathrm{~N} / \mathrm{A}$ & $C x$ & Complexo & N/A & MX209 & 659187,654 & 7744217,964 & 2873,07 & N/A & N/A \\
\hline Souza, M.L. & 1996 & $\mathrm{~N} / \mathrm{A}$ & $\mathrm{Qr}$ & Queda & Rocha & MQ210 & 659107,444 & 7743772,887 & 2285,00 & $\mathrm{~N} / \mathrm{A}$ & $\mathrm{N} / \mathrm{A}$ \\
\hline Souza, M.L. & 1996 & $\mathrm{~N} / \mathrm{A}$ & $\mathrm{Qr}$ & Queda & Rocha & MQ211 & 659391,395 & 7743667,926 & 2229,48 & N/A & N/A \\
\hline Souza, M.L. & 1996 & $\mathrm{~N} / \mathrm{A}$ & $\mathrm{Qr}$ & Queda & Rocha & MQ212 & 659555,674 & 7743081,779 & 1908,16 & $\mathrm{~N} / \mathrm{A}$ & $\mathrm{N} / \mathrm{A}$ \\
\hline Souza, M.L. & 1996 & $\mathrm{~N} / \mathrm{A}$ & $\mathrm{Qr}$ & Queda & Rocha & MQ213 & 659922,725 & 7743202,321 & 1979,59 & N/A & N/A \\
\hline Souza, M.L. & 1996 & $\mathrm{~N} / \mathrm{A}$ & $C x$ & Complexo & N/A & MX214 & 658271,919 & 7744357,732 & 9284,21 & N/A & $\mathrm{N} / \mathrm{A}$ \\
\hline Souza, M.L. & 1996 & $\mathrm{~N} / \mathrm{A}$ & $C x$ & Complexo & N/A & MX215 & 658645,745 & 7744662,777 & 1487,29 & $\mathrm{~N} / \mathrm{A}$ & $\mathrm{N} / \mathrm{A}$ \\
\hline Souza, M.L. & 1996 & $\mathrm{~N} / \mathrm{A}$ & Ets & Escorregamento translacional & Solo & MT216 & 658929,173 & 7744439,619 & 2343,99 & N/A & N/A \\
\hline Souza, M.L. & 1996 & $\mathrm{~N} / \mathrm{A}$ & Ets & Escorregamento translacional & Solo & MT217 & 658992,436 & 7744433,742 & 3501,46 & $\mathrm{~N} / \mathrm{A}$ & $\mathrm{N} / \mathrm{A}$ \\
\hline Souza, M.L. & 1996 & $\mathrm{~N} / \mathrm{A}$ & $C x$ & Complexo & N/A & MX218 & 659135,531 & 7744371,598 & 2142,93 & N/A & N/A \\
\hline Souza, M.L. & 1996 & $\mathrm{~N} / \mathrm{A}$ & Ets & Escorregamento translacional & Solo & MT219 & 659095,530 & 77444516,371 & 5023,87 & $\mathrm{~N} / \mathrm{A}$ & $\mathrm{N} / \mathrm{A}$ \\
\hline Souza, M.L. & 1996 & N/A & $C x$ & Complexo & N/A & MX220 & 659205,618 & 7744710,612 & 3212,19 & N/A & $\mathrm{N} / \mathrm{A}$ \\
\hline Souza, M.L. & 1996 & $\mathrm{~N} / \mathrm{A}$ & $C x$ & Complexo & $\mathrm{N} / \mathrm{A}$ & MX221 & 658934,466 & 7744676,611 & 1658,82 & $\mathrm{~N} / \mathrm{A}$ & $\mathrm{N} / \mathrm{A}$ \\
\hline Souza, M.L. & 1996 & N/A & $C x$ & Complexo & N/A & MX222 & 658753,615 & 7744844,066 & 13111,50 & N/A & $\mathrm{N} / \mathrm{A}$ \\
\hline Souza, M.L. & 1996 & $\mathrm{~N} / \mathrm{A}$ & $C x$ & Área de múltiplas feições & $\mathrm{N} / \mathrm{A}$ & MA223 & 658751,119 & 7744983,454 & 10119,70 & $\mathrm{~N} / \mathrm{A}$ & $\mathrm{N} / \mathrm{A}$ \\
\hline Souza, M.L. & 1996 & $\mathrm{~N} / \mathrm{A}$ & $C x$ & Complexo & N/A & MX224 & 658793,417 & 7745097,834 & 1369,55 & N/A & N/A \\
\hline Souza, M.L. & 1996 & $\mathrm{~N} / \mathrm{A}$ & $C x$ & Complexo & $\mathrm{N} / \mathrm{A}$ & MX225 & 658786,204 & 7745193,782 & 581,84 & $\mathrm{~N} / \mathrm{A}$ & $\mathrm{N} / \mathrm{A}$ \\
\hline Souza, M.L. & 1996 & $\mathrm{~N} / \mathrm{A}$ & $C x$ & Complexo & N/A & MX226 & 658704,272 & 7745222,021 & 2622,55 & N/A & N/A \\
\hline Souza, M.L. & 1996 & $\mathrm{~N} / \mathrm{A}$ & $C x$ & Complexo & N/A & MX227 & 658535,656 & 7745133,196 & 5185,64 & N/A & N/A \\
\hline Souza, M.L. & 1996 & $\mathrm{~N} / \mathrm{A}$ & $C x$ & Complexo & N/A & MX228 & 658173,880 & 7745111,675 & 2017,31 & N/A & N/A \\
\hline Souza, M.L. & 1996 & $\mathrm{~N} / \mathrm{A}$ & $C x$ & Área de múltiplas feições & $\mathrm{N} / \mathrm{A}$ & MA229 & 658247,418 & 7745184,664 & 50759,50 & $\mathrm{~N} / \mathrm{A}$ & $\mathrm{N} / \mathrm{A}$ \\
\hline Souza, M.L. & 1996 & $\mathrm{~N} / \mathrm{A}$ & $C x$ & Complexo & $\mathrm{N} / \mathrm{A}$ & MX230 & 658585,969 & 7745456,165 & 2092,76 & N/A & N/A \\
\hline Souza, M.L. & 1996 & $\mathrm{~N} / \mathrm{A}$ & $C x$ & Complexo & $\mathrm{N} / \mathrm{A}$ & MX231 & 658641,427 & 7745594,025 & 517,11 & $\mathrm{~N} / \mathrm{A}$ & $\mathrm{N} / \mathrm{A}$ \\
\hline Souza, M.L. & 1996 & N/A & $C x$ & Complexo & N/A & MX232 & 658574,132 & 7745625,266 & 1415,86 & N/A & $\mathrm{N} / \mathrm{A}$ \\
\hline Souza, M.L. & 1996 & $\mathrm{~N} / \mathrm{A}$ & Qd & Queda & Detritos & MQ233 & 657841,034 & 7745187,073 & 2216,80 & $\mathrm{~N} / \mathrm{A}$ & $\mathrm{N} / \mathrm{A}$ \\
\hline Souza, M.L. & 1996 & N/A & $C x$ & Complexo & $\mathrm{N} / \mathrm{A}$ & MX234 & 657361,817 & 7745156,581 & 464,50 & N/A & N/A \\
\hline Souza, M.L. & 1996 & $\mathrm{~N} / \mathrm{A}$ & $C x$ & Complexo & $\mathrm{N} / \mathrm{A}$ & MX235 & 657182,613 & 7745410,265 & 554,59 & $\mathrm{~N} / \mathrm{A}$ & $\mathrm{N} / \mathrm{A}$ \\
\hline Souza, M.L. & 1996 & N/A & $C x$ & Complexo & N/A & MX236 & 657130,841 & 7745446,702 & 861,03 & N/A & N/A \\
\hline Souza, M.L. & 1996 & $\mathrm{~N} / \mathrm{A}$ & $C x$ & Complexo & N/A & MX237 & 657079,047 & 7745427,367 & 718,41 & N/A & $\mathrm{N} / \mathrm{A}$ \\
\hline Souza, M.L. & 1996 & N/A & $C x$ & Complexo & $\mathrm{N} / \mathrm{A}$ & MX238 & 657115,984 & 7745347,280 & 953,49 & $\mathrm{~N} / \mathrm{A}$ & $\mathrm{N} / \mathrm{A}$ \\
\hline
\end{tabular}

*ANO: Data do trabalho; 1: Código da feição; 2: Código do processo; CÓD.INV: Código do inventário; PROF.: Profundidade do movimento, N/A: Not Available (Não disponível). 
Apêndice B: Banco de dados do inventário de movimentos de massa gravitacionais (continuação).

\begin{tabular}{|c|c|c|c|c|c|c|c|c|c|c|c|}
\hline AUTOR & ANO & 1 & 2 & TIPO DE PROCESSO & TIPO DE MATERIAL & COD.INV & UTM E & UTM N & ÁREA $\left(\mathbf{m}^{2}\right)$ & ATIVIDADE & PROF. \\
\hline Souza, M.L. & 1996 & $\mathrm{~N} / \mathrm{A}$ & $C x$ & Complexo & $\mathrm{N} / \mathrm{A}$ & MX239 & 657220,176 & 7745347,025 & 2251,77 & $\mathrm{~N} / \mathrm{A}$ & $\mathrm{N} / \mathrm{A}$ \\
\hline Souza, M.L. & 1996 & $\mathrm{~N} / \mathrm{A}$ & $C x$ & Área de múltiplas feições & $\mathrm{N} / \mathrm{A}$ & MA240 & 657367,902 & 7746112,153 & 49075,40 & $\mathrm{~N} / \mathrm{A}$ & $\mathrm{N} / \mathrm{A}$ \\
\hline Souza, M.L. & 1996 & $\mathrm{~N} / \mathrm{A}$ & $C x$ & Complexo & $\mathrm{N} / \mathrm{A}$ & MX241 & 658570,879 & 7745761,151 & 2648,69 & $\mathrm{~N} / \mathrm{A}$ & $\mathrm{N} / \mathrm{A}$ \\
\hline Souza, M.L. & 1996 & N/A & $C x$ & Complexo & N/A & MX242 & 658354,529 & 7745933,246 & 2025,90 & $\mathrm{~N} / \mathrm{A}$ & $\mathrm{N} / \mathrm{A}$ \\
\hline Souza, M.L. & 1996 & $\mathrm{~N} / \mathrm{A}$ & $C x$ & Complexo & $\mathrm{N} / \mathrm{A}$ & MX243 & 658275,547 & 7745922,538 & 4822,89 & N/A & $\mathrm{N} / \mathrm{A}$ \\
\hline Souza, M.L. & 1996 & $\mathrm{~N} / \mathrm{A}$ & $C x$ & Complexo & N/A & MX244 & 658104,242 & 7745851,895 & 3238,81 & $\mathrm{~N} / \mathrm{A}$ & $\mathrm{N} / \mathrm{A}$ \\
\hline Souza, M.L. & 1996 & $\mathrm{~N} / \mathrm{A}$ & $C x$ & Complexo & $\mathrm{N} / \mathrm{A}$ & MX245 & 658123,066 & 7745792,914 & 3296,22 & $\mathrm{~N} / \mathrm{A}$ & $\mathrm{N} / \mathrm{A}$ \\
\hline Souza, M.L. & 1996 & N/A & $C x$ & Complexo & $\mathrm{N} / \mathrm{A}$ & MX246 & 658644,726 & 7746027,031 & 2325,56 & $\mathrm{~N} / \mathrm{A}$ & $\mathrm{N} / \mathrm{A}$ \\
\hline Souza, M.L. & 1996 & $\mathrm{~N} / \mathrm{A}$ & $C x$ & Complexo & $\mathrm{N} / \mathrm{A}$ & MX247 & 657655,296 & 7746284,237 & 15067,40 & $\mathrm{~N} / \mathrm{A}$ & $\mathrm{N} / \mathrm{A}$ \\
\hline Souza, M.L. & 1996 & $\mathrm{~N} / \mathrm{A}$ & $\mathrm{Qr}$ & Queda & Rocha & MQ248 & 657824,143 & 7746312,678 & 7814,80 & $\mathrm{~N} / \mathrm{A}$ & $\mathrm{N} / \mathrm{A}$ \\
\hline Souza, M.L. & 1996 & $\mathrm{~N} / \mathrm{A}$ & $C x$ & Complexo & $\mathrm{N} / \mathrm{A}$ & MX249 & 657837,494 & 7746096,345 & 7746,99 & N/A & N/A \\
\hline Souza, M.L. & 1996 & $\mathrm{~N} / \mathrm{A}$ & $C x$ & Área de múltiplas feições & $\mathrm{N} / \mathrm{A}$ & MA250 & 657995,459 & 7746123,743 & 12260,60 & $\mathrm{~N} / \mathrm{A}$ & N/A \\
\hline Souza, M.L. & 1996 & $\mathrm{~N} / \mathrm{A}$ & $C x$ & Complexo & $\mathrm{N} / \mathrm{A}$ & MX251 & 657610,599 & 7746099,540 & 5298,89 & $\mathrm{~N} / \mathrm{A}$ & $\mathrm{N} / \mathrm{A}$ \\
\hline Souza, M.L. & 1996 & $\mathrm{~N} / \mathrm{A}$ & $C x$ & Complexo & $\mathrm{N} / \mathrm{A}$ & MX252 & 657254,086 & 7745772,622 & 339,91 & N/A & N/A \\
\hline Souza, M.L. & 1996 & $\mathrm{~N} / \mathrm{A}$ & $C x$ & Complexo & $\mathrm{N} / \mathrm{A}$ & MX253 & 657220,942 & 7745770,477 & 325,62 & N/A & N/A \\
\hline Souza, M.L. & 1996 & N/A & $C x$ & Complexo & N/A & MX254 & 657283,114 & 7745684,577 & 642,93 & N/A & $\mathrm{N} / \mathrm{A}$ \\
\hline Souza, M.L. & 1996 & $\mathrm{~N} / \mathrm{A}$ & $C x$ & Complexo & $\mathrm{N} / \mathrm{A}$ & MX255 & 657135,111 & 7745894,640 & 2858,69 & $\mathrm{~N} / \mathrm{A}$ & $\mathrm{N} / \mathrm{A}$ \\
\hline Souza, M.L. & 1996 & $\mathrm{~N} / \mathrm{A}$ & $C x$ & Complexo & $\mathrm{N} / \mathrm{A}$ & MX256 & 657227,299 & 7745893,361 & 5280,77 & N/A & N/A \\
\hline Souza, M.L. & 1996 & $\mathrm{~N} / \mathrm{A}$ & $C x$ & Complexo & $\mathrm{N} / \mathrm{A}$ & MX257 & 657347,087 & 77445823,835 & 534,91 & N/A & N/A \\
\hline Souza, M.L. & 1996 & N/A & $C x$ & Complexo & $\mathrm{N} / \mathrm{A}$ & MX258 & 657383,678 & 7745648,026 & 649,89 & N/A & N/A \\
\hline Souza, M.L. & 1996 & $\mathrm{~N} / \mathrm{A}$ & $C x$ & Complexo & $\mathrm{N} / \mathrm{A}$ & MX259 & 657528,469 & 7745611,518 & 299,43 & $\mathrm{~N} / \mathrm{A}$ & $\mathrm{N} / \mathrm{A}$ \\
\hline Souza, M.L. & 1996 & N/A & $C x$ & Complexo & $\mathrm{N} / \mathrm{A}$ & MX260 & 657526,623 & 7745541,012 & 344,16 & N/A & N/A \\
\hline Souza, M.L. & 1996 & $\mathrm{~N} / \mathrm{A}$ & $C x$ & Complexo & $\mathrm{N} / \mathrm{A}$ & MX261 & 657465,495 & 77445487,141 & 293,13 & N/A & N/A \\
\hline Souza, M.L. & 1996 & N/A & $C x$ & Complexo & $\mathrm{N} / \mathrm{A}$ & MX262 & 657555,366 & 7745396,736 & 2103,63 & N/A & N/A \\
\hline Souza, M.L. & 1996 & $\mathrm{~N} / \mathrm{A}$ & $C x$ & Complexo & $\mathrm{N} / \mathrm{A}$ & MX263 & 657595,312 & 7745455,449 & 1081,07 & $\mathrm{~N} / \mathrm{A}$ & $\mathrm{N} / \mathrm{A}$ \\
\hline Souza, M.L. & 1996 & N/A & $C x$ & Complexo & $\mathrm{N} / \mathrm{A}$ & MX264 & 657672,589 & 7745586,173 & 357,39 & $\mathrm{~N} / \mathrm{A}$ & N/A \\
\hline Souza, M.L. & 1996 & $\mathrm{~N} / \mathrm{A}$ & $C x$ & Complexo & $\mathrm{N} / \mathrm{A}$ & MX265 & 657687,465 & 7745731,693 & 423,47 & $\mathrm{~N} / \mathrm{A}$ & $\mathrm{N} / \mathrm{A}$ \\
\hline Souza, M.L. & 1996 & N/A & $C x$ & Complexo & $\mathrm{N} / \mathrm{A}$ & MX266 & 657718,075 & 7745667,367 & 499,31 & N/A & N/A \\
\hline Souza, M.L. & 1996 & $\mathrm{~N} / \mathrm{A}$ & $C x$ & Complexo & $\mathrm{N} / \mathrm{A}$ & MX267 & 657475,398 & 7745840,470 & 1769,31 & $\mathrm{~N} / \mathrm{A}$ & $\mathrm{N} / \mathrm{A}$ \\
\hline Souza, M.L. & 1996 & N/A & $C x$ & Complexo & $\mathrm{N} / \mathrm{A}$ & MX268 & 657563,141 & 7745827,373 & 2571,67 & $\mathrm{~N} / \mathrm{A}$ & N/A \\
\hline Souza, M.L. & 1996 & N/A & $C x$ & Complexo & $\mathrm{N} / \mathrm{A}$ & MX269 & 657629,113 & 77445767,564 & 2085,52 & $\mathrm{~N} / \mathrm{A}$ & $\mathrm{N} / \mathrm{A}$ \\
\hline Souza, M.L. & 1996 & N/A & $C x$ & Complexo & $\mathrm{N} / \mathrm{A}$ & MX270 & 657772,206 & 7745759,132 & 3656,21 & N/A & N/A \\
\hline Souza, M.L. & 1996 & $\mathrm{~N} / \mathrm{A}$ & $C x$ & Complexo & $\mathrm{N} / \mathrm{A}$ & MX271 & 657862,660 & 7745852,071 & 3949,65 & $\mathrm{~N} / \mathrm{A}$ & $\mathrm{N} / \mathrm{A}$ \\
\hline Souza, M.L. & 1996 & N/A & $C x$ & Complexo & $\mathrm{N} / \mathrm{A}$ & MX272 & \begin{tabular}{|l}
657959,063 \\
\end{tabular} & 77445550,111 & 2917,49 & N/A & N/A \\
\hline
\end{tabular}

*ANO: Data do trabalho; 1: Código da feição; 2: Código do processo; CÓD.INV: Código do inventário; PROF.: Profundidade do movimento, N/A: Not Available (Não disponível). 
Apêndice B: Banco de dados do inventário de movimentos de massa gravitacionais (continuação).

\begin{tabular}{|c|c|c|c|c|c|c|c|c|c|c|c|}
\hline AUTOR & ANO & 1 & 2 & TIPO DE PROCESSO & TIPO DE MATERIAL & COD.INV & UTM E & UTM N & ÁREA $\left(\mathbf{m}^{2}\right)$ & ATIVIDADE & PROF. \\
\hline Souza, M.L. & 1996 & $\mathrm{~N} / \mathrm{A}$ & $C x$ & Complexo & N/A & MX273 & 657847,221 & 7745431,367 & 5185,56 & N/A & N/A \\
\hline Souza, M.L. & 1996 & $\mathrm{~N} / \mathrm{A}$ & $\mathrm{Cd}$ & Corrida de material & Detritos & MC274 & 659732,868 & 7746174,483 & 1285,21 & $\mathrm{~N} / \mathrm{A}$ & $\mathrm{N} / \mathrm{A}$ \\
\hline Souza, M.L. & 1996 & $\mathrm{~N} / \mathrm{A}$ & $\mathrm{Cd}$ & Corrida de material & Detritos & MC275 & 659887,777 & 7745982,398 & 3059,72 & N/A & N/A \\
\hline Souza, M.L. & 1996 & $\mathrm{~N} / \mathrm{A}$ & $C x$ & Complexo & N/A & MX276 & 659407,364 & 7745851,481 & 5192,49 & $\mathrm{~N} / \mathrm{A}$ & $\mathrm{N} / \mathrm{A}$ \\
\hline Souza, M.L. & 1996 & $\mathrm{~N} / \mathrm{A}$ & $\mathrm{Cd}$ & Corrida de material & Detritos & MC277 & 659253,073 & 7745735,479 & 2339,27 & N/A & N/A \\
\hline Souza, M.L. & 1996 & $\mathrm{~N} / \mathrm{A}$ & $C x$ & Área de múltiplas feições & N/A & MA278 & 659341,580 & 7745587,750 & 4345,63 & $\mathrm{~N} / \mathrm{A}$ & N/A \\
\hline Souza, M.L. & 1996 & $\mathrm{~N} / \mathrm{A}$ & $C x$ & Complexo & $\mathrm{N} / \mathrm{A}$ & MX279 & 659113,917 & 7745528,409 & 5931,61 & $\mathrm{~N} / \mathrm{A}$ & $\mathrm{N} / \mathrm{A}$ \\
\hline Souza, M.L. & 1996 & $\mathrm{~N} / \mathrm{A}$ & Ets & Escorregamento translacional & Solo & MT280 & 659326,792 & 7745377,734 & 6728,84 & $\mathrm{~N} / \mathrm{A}$ & $\mathrm{N} / \mathrm{A}$ \\
\hline Souza, M.L. & 1996 & $\mathrm{~N} / \mathrm{A}$ & $C x$ & Área de múltiplas feições & N/A & MA281 & 659085,058 & 7745360,436 & 25666,10 & N/A & N/A \\
\hline Souza, M.L. & 1996 & $\mathrm{~N} / \mathrm{A}$ & $\mathrm{Cd}$ & Corrida de material & Detritos & MC282 & 658992,336 & 7745236,110 & 1476,90 & N/A & $\mathrm{N} / \mathrm{A}$ \\
\hline Souza, M.L. & 1996 & $\mathrm{~N} / \mathrm{A}$ & $C x$ & Complexo & N/A & MX283 & 659094,125 & 7745214,135 & 1838,30 & $\mathrm{~N} / \mathrm{A}$ & $\mathrm{N} / \mathrm{A}$ \\
\hline Souza, M.L. & 1996 & $\mathrm{~N} / \mathrm{A}$ & $C x$ & Complexo & N/A & MX284 & 659088,041 & 7745148,049 & 4390,52 & N/A & N/A \\
\hline Souza, M.L. & 1996 & $\mathrm{~N} / \mathrm{A}$ & $C x$ & Complexo & N/A & MX285 & 659237,780 & 7745119,915 & 2428,65 & $\mathrm{~N} / \mathrm{A}$ & $\mathrm{N} / \mathrm{A}$ \\
\hline Souza, M.L. & 1996 & $\mathrm{~N} / \mathrm{A}$ & Ets & Escorregamento translacional & Solo & MT286 & 659237,731 & 7744968,633 & 7540,57 & N/A & N/A \\
\hline Souza, M.L. & 1996 & $\mathrm{~N} / \mathrm{A}$ & $C x$ & Área de múltiplas feições & $\mathrm{N} / \mathrm{A}$ & MA287 & 658992,706 & 7745028,062 & 9401,40 & $\mathrm{~N} / \mathrm{A}$ & $\mathrm{N} / \mathrm{A}$ \\
\hline Souza, M.L. & 1996 & N/A & $\mathrm{Qr}$ & Queda & Rocha & MQ288 & 659350,430 & 7745256,320 & 4383,04 & N/A & $\mathrm{N} / \mathrm{A}$ \\
\hline Souza, M.L. & 1996 & $\mathrm{~N} / \mathrm{A}$ & $C x$ & Área de múltiplas feições & $\mathrm{N} / \mathrm{A}$ & MA289 & 659578,061 & 7745277,447 & 16354,40 & $\mathrm{~N} / \mathrm{A}$ & $\mathrm{N} / \mathrm{A}$ \\
\hline Souza, M.L. & 1996 & $\mathrm{~N} / \mathrm{A}$ & $\mathrm{Cd}$ & Corrida de material & Detritos & MC290 & 659712,117 & 7745394,776 & 5195,40 & N/A & $\mathrm{N} / \mathrm{A}$ \\
\hline Souza, M.L. & 1996 & $\mathrm{~N} / \mathrm{A}$ & $\mathrm{Qr}$ & Queda & Rocha & MQ291 & 659554,140 & 7745455,877 & 907,81 & $\mathrm{~N} / \mathrm{A}$ & $\mathrm{N} / \mathrm{A}$ \\
\hline Souza, M.L. & 1996 & $\mathrm{~N} / \mathrm{A}$ & $\mathrm{Cd}$ & Corrida de material & Detritos & MC292 & 659596,408 & 7745539,467 & 1545,65 & N/A & N/A \\
\hline Souza, M.L. & 1996 & $\mathrm{~N} / \mathrm{A}$ & $\mathrm{Cd}$ & Corrida de material & Detritos & MC293 & 659561,298 & 7745627,946 & 2668,38 & $\mathrm{~N} / \mathrm{A}$ & $\mathrm{N} / \mathrm{A}$ \\
\hline Souza, M.L. & 1996 & $\mathrm{~N} / \mathrm{A}$ & $\mathrm{Qr}$ & Queda & Rocha & MQ294 & 659692,907 & 7745636,911 & 2106,70 & N/A & N/A \\
\hline Souza, M.L. & 1996 & $\mathrm{~N} / \mathrm{A}$ & Ets & Escorregamento translacional & Solo & MT295 & 659211,956 & 7744863,284 & 2438,89 & N/A & $\mathrm{N} / \mathrm{A}$ \\
\hline Souza, M.L. & 1996 & $\mathrm{~N} / \mathrm{A}$ & Ets & Escorregamento translacional & Solo & MT296 & 659284,688 & 7744776,098 & 1578,88 & N/A & N/A \\
\hline Souza, M.L. & 1996 & $\mathrm{~N} / \mathrm{A}$ & $C x$ & Complexo & $\mathrm{N} / \mathrm{A}$ & MX297 & 659389,663 & 7744799,198 & 3063,10 & $\mathrm{~N} / \mathrm{A}$ & $\mathrm{N} / \mathrm{A}$ \\
\hline Souza, M.L. & 1996 & $\mathrm{~N} / \mathrm{A}$ & $C x$ & Área de múltiplas feições & N/A & MA298 & 659446,793 & 7744499,570 & 7066,07 & N/A & N/A \\
\hline Souza, M.L. & 1996 & $\mathrm{~N} / \mathrm{A}$ & $C x$ & Área de múltiplas feições & $\mathrm{N} / \mathrm{A}$ & MA299 & 659616,412 & 7744472,687 & 21035,10 & $\mathrm{~N} / \mathrm{A}$ & $\mathrm{N} / \mathrm{A}$ \\
\hline Souza, M.L. & 1996 & $\mathrm{~N} / \mathrm{A}$ & Ets & Escorregamento translacional & Solo & MT300 & 659541,631 & 7744148,114 & 5238,64 & N/A & N/A \\
\hline Souza, M.L. & 1996 & $\mathrm{~N} / \mathrm{A}$ & $\mathrm{Cd}$ & Corrida de material & Detritos & MC301 & 660092,194 & 7744507,354 & 1916,51 & $\mathrm{~N} / \mathrm{A}$ & $\mathrm{N} / \mathrm{A}$ \\
\hline Souza, M.L. & 1996 & $\mathrm{~N} / \mathrm{A}$ & $C x$ & Complexo & N/A & MX302 & 659737,694 & 7744891,555 & 2065,43 & N/A & $\mathrm{N} / \mathrm{A}$ \\
\hline Souza, M.L. & 1996 & $\mathrm{~N} / \mathrm{A}$ & $C x$ & Complexo & $\mathrm{N} / \mathrm{A}$ & MX303 & 659830,066 & 7744886,689 & 1758,21 & $\mathrm{~N} / \mathrm{A}$ & $\mathrm{N} / \mathrm{A}$ \\
\hline Souza, M.L. & 1996 & $\mathrm{~N} / \mathrm{A}$ & $C x$ & Complexo & N/A & MX304 & 659930,909 & 7744886,249 & 2342,57 & N/A & N/A \\
\hline Souza, M.L. & 1996 & $\mathrm{~N} / \mathrm{A}$ & $\mathrm{Qr}$ & Queda & Rocha & MQ305 & 660074,886 & 7744835,480 & 1969,04 & N/A & $\mathrm{N} / \mathrm{A}$ \\
\hline Souza, M.L. & 1996 & N/A & $C x$ & Complexo & $\mathrm{N} / \mathrm{A}$ & MX306 & 659851,604 & 7745006,044 & 6771,37 & $\mathrm{~N} / \mathrm{A}$ & $\mathrm{N} / \mathrm{A}$ \\
\hline
\end{tabular}

*ANO: Data do trabalho; 1: Código da feição; 2: Código do processo; CÓD.INV: Código do inventário; PROF.: Profundidade do movimento, N/A: Not Available (Não disponível). 
Apêndice B: Banco de dados do inventário de movimentos de massa gravitacionais (continuação).

\begin{tabular}{|c|c|c|c|c|c|c|c|c|c|c|c|}
\hline AUTOR & ANO & 1 & 2 & TIPO DE PROCESSO & TIPO DE MATERIAL & COD.INV & UTM E & UTM N & ÁREA $\left(\mathbf{m}^{2}\right)$ & ATIVIDADE & PROF. \\
\hline Souza, M.L. & 1996 & $\mathrm{~N} / \mathrm{A}$ & $C x$ & Área de múltiplas feições & N/A & MA307 & 660312,190 & 7745078,439 & 5700,62 & $\mathrm{~N} / \mathrm{A}$ & N/A \\
\hline Souza, M.L. & 1996 & $\mathrm{~N} / \mathrm{A}$ & $C x$ & Complexo & $\mathrm{N} / \mathrm{A}$ & MX308 & 660167,270 & 7744755,035 & 1310,33 & $\mathrm{~N} / \mathrm{A}$ & $\mathrm{N} / \mathrm{A}$ \\
\hline Souza, M.L. & 1996 & $\mathrm{~N} / \mathrm{A}$ & $\mathrm{Qd}$ & Queda & Detritos & MQ309 & 660299,793 & 7744788,687 & 5263,52 & $\mathrm{~N} / \mathrm{A}$ & $\mathrm{N} / \mathrm{A}$ \\
\hline Souza, M.L. & 1996 & $\mathrm{~N} / \mathrm{A}$ & $\mathrm{Qr}$ & Queda & Rocha & MQ310 & 660396,107 & 7744615,214 & 4352,64 & $\mathrm{~N} / \mathrm{A}$ & $\mathrm{N} / \mathrm{A}$ \\
\hline Souza, M.L. & 1996 & $\mathrm{~N} / \mathrm{A}$ & $C x$ & Área de múltiplas feições & N/A & MA311 & 660426,773 & 7744487,482 & 15396,00 & $\mathrm{~N} / \mathrm{A}$ & $\mathrm{N} / \mathrm{A}$ \\
\hline Souza, M.L. & 1996 & $\mathrm{~N} / \mathrm{A}$ & Qd & Queda & Detritos & MQ312 & 660512,811 & 7744738,312 & 6779,33 & $\mathrm{~N} / \mathrm{A}$ & $\mathrm{N} / \mathrm{A}$ \\
\hline Souza, M.L. & 1996 & $\mathrm{~N} / \mathrm{A}$ & Qd & Queda & Detritos & MQ313 & 660577,359 & 77448599,764 & 1064,69 & N/A & N/A \\
\hline Souza, M.L. & 1996 & $\mathrm{~N} / \mathrm{A}$ & Qs & Queda & Solo & MQ314 & 660743,257 & 7744589,671 & 1524,70 & $\mathrm{~N} / \mathrm{A}$ & $\mathrm{N} / \mathrm{A}$ \\
\hline Souza, M.L. & 1996 & $\mathrm{~N} / \mathrm{A}$ & $\mathrm{Qr}$ & Queda & Rocha & MQ315 & 660897,321 & 7744580,680 & 2086,23 & $\mathrm{~N} / \mathrm{A}$ & $\mathrm{N} / \mathrm{A}$ \\
\hline Souza, M.L. & 1996 & $\mathrm{~N} / \mathrm{A}$ & $C x$ & Área de múltiplas feições & N/A & MA316 & 660966,465 & 7744435,670 & 5586,26 & $\mathrm{~N} / \mathrm{A}$ & $\mathrm{N} / \mathrm{A}$ \\
\hline Souza, M.L. & 1996 & $\mathrm{~N} / \mathrm{A}$ & $C x$ & Complexo & $\mathrm{N} / \mathrm{A}$ & MX317 & 660963,675 & 7744097,486 & 2439,13 & $\mathrm{~N} / \mathrm{A}$ & $\mathrm{N} / \mathrm{A}$ \\
\hline Souza, M.L. & 1996 & $\mathrm{~N} / \mathrm{A}$ & Qr & Queda & Rocha & MQ318 & 660447,876 & 7745460,008 & 809,29 & $\mathrm{~N} / \mathrm{A}$ & N/A \\
\hline Souza, M.L. & 1996 & $\mathrm{~N} / \mathrm{A}$ & $C x$ & Área de mú & N/A & MA319 & 660467,856 & 7745318,451 & 25818,40 & $\mathrm{~N} / \mathrm{A}$ & $\mathrm{N} / \mathrm{A}$ \\
\hline Bonuccelli, T.J. & 1999 & 13 & 8 & Complexo & rocha, detritos e solo & BX320 & 653070,214 & 7743113,293 & 19513,70 & ativa & 2 a $10 m$ \\
\hline Bonuccelli, T.J. & 1999 & 132 & 2 & Escorregamento translacional & rocha e detritos & BT321 & 653038,629 & 7744681,058 & 653,72 & ativa & até $2 \mathrm{~m}$ \\
\hline Bonuccelli, T.J. & 1999 & 128 & 2 & Escorregamento translacional & rocha e detritos & BT322 & 653058,589 & 7746157,053 & 5915,10 & ativa & até $2 \mathrm{~m}$ \\
\hline Bonuccelli, T.J. & 1999 & 45 & 2 & Escorregamento translacional & solo & BT323 & 653185,679 & 7743905,592 & 876,83 & dormente & até $2 \mathrm{~m}$ \\
\hline Bonuccelli, T.J. & 1999 & 44 & 2 & Escorregamento translacional & solo & BT324 & 653075,632 & 7743887,605 & 745,39 & dormente & até $2 \mathrm{~m}$ \\
\hline Bonuccelli, T.J. & 1999 & 43 & 2 & Escorregamento translacional & rocha & BT325 & 653012,009 & 7743738,822 & 890,39 & ativa & 2 a $10 m$ \\
\hline Bonuccelli, T.J. & 1999 & 14 & 8 & Complexo & rocha, detritos e solo & BX326 & 653079,249 & 7743266,151 & 1532,44 & ativa & 2 a $10 m$ \\
\hline Bonuccelli, T.J. & 1999 & 443 & 2 & Escorregamento translacional & detritos e solo & BT327 & 658405,584 & 7747563,298 & 2167,33 & ativa & até $2 \mathrm{~m}$ \\
\hline Bonuccelli, T.J. & 1999 & 176 & 4 & Escoamentos rápidos ou corrida & detritos e solo & BC328 & 656542,928 & 7745157,448 & 645,00 & ativa & até $2 \mathrm{~m}$ \\
\hline Bonuccelli, T.J. & 1999 & 175 & 4 & Escoamentos rápidos ou corrida & detritos e solo & BC329 & 656379,896 & 7745212,276 & 329,39 & ativa & até $2 \mathrm{~m}$ \\
\hline Bonuccelli, T.J. & 1999 & 156 & 11 & Escorregamento translacional e & rocha, detritos e solo & BTC330 & 656156,659 & 7745612,843 & 1806,22 & ativa & até $2 \mathrm{~m}$ \\
\hline Bonuccelli, T.J. & 1999 & 212 & 3 & Quedas e rolamentos & rocha & BQL331 & 654873,558 & 7746386,226 & 320,33 & ativa & até $2 \mathrm{~m}$ \\
\hline Bonuccelli, T.J. & 1999 & 211 & 3 & Quedas e rolamentos & rocha & BQL332 & 654995,868 & 7746255,692 & 326,55 & ativa & até $2 \mathrm{~m}$ \\
\hline Bonuccelli, T.J. & 1999 & 217 & 3 & Quedas e rolamentos & rocha & BQL333 & 655013,823 & 7746695,367 & 144,55 & dormente & até $2 \mathrm{~m}$ \\
\hline Bonuccelli, T.J. & 1999 & 232 & 3 & Quedas e rolamentos & rocha & BQL334 & 656595,552 & 7745503,942 & 368,17 & dormente & até $2 \mathrm{~m}$ \\
\hline Bonuccelli, T.J. & 1999 & 231 & 3 & Quedas e rolamentos & rocha & BQL335 & 656595,442 & 77455899,734 & 193,83 & dormente & até $2 \mathrm{~m}$ \\
\hline Bonuccelli, T.J. & 1999 & 1 & 11 & Escorregamento translacional e & detritos e solo & BTC336 & 655897,013 & 7744624,218 & 489,44 & ativa & até $2 \mathrm{~m}$ \\
\hline Bonuccelli, T.J. & 1999 & 393 & 1 & Escorregamento & rocha, detritos e solo & BE337 & 656769,997 & 7745113,609 & 116,39 & ativa & até $2 \mathrm{~m}$ \\
\hline Bonuccelli, T.J. & 1999 & 439 & 3 & Quedas e rolamentos & rocha & BQL338 & 657387,048 & 7745245,867 & 679,66 & ativa & até $2 \mathrm{~m}$ \\
\hline Bonuccelli, T.J. & 1999 & 402 & 11 & Escorregamento translacional e & rocha, detritos e solo & BTC339 & 657255,082 & 7745307,520 & 894,22 & ativa & 2 a $10 m$ \\
\hline Bonuccelli, T.J. & 1999 & 268 & 3 & Quedas e rolamentos & rocha & BQL340 & 659169,322 & 7745263,106 & 490,67 & dormente & até $2 \mathrm{~m}$ \\
\hline
\end{tabular}

*ANO: Data do trabalho; 1: Código da feição; 2: Código do processo; CÓD.INV: Código do inventário; PROF.: Profundidade do movimento, N/A: Not Available (Não disponível). 
Apêndice B: Banco de dados do inventário de movimentos de massa gravitacionais (continuação).

\begin{tabular}{|c|c|c|c|c|c|c|c|c|c|c|c|}
\hline AUTOR & ANO & 1 & 2 & TIPO DE PROCESSO & TIPO DE MATERIAL & COD.INV & UTM E & UTM N & ÁREA $\left(\mathrm{m}^{2}\right)$ & ATIVIDADE & PROF. \\
\hline Bonuccelli, T.J. & 1999 & 240 & 3 & Quedas e rolamentos & rocha & BQL341 & 657068,186 & 7747778,809 & 673,00 & dormente & até $2 \mathrm{~m}$ \\
\hline$\overline{\text { Bonuccelli, T.J. }}$ & 1999 & 241 & 3 & Quedas e rolamentos & rocha & BQL342 & 656074,110 & 7747609,843 & 436,61 & ativa & até $2 \mathrm{~m}$ \\
\hline Bonuccelli, T.J. & 1999 & 288 & 3 & Quedas e rolamentos & rocha & BQL343 & 657194,634 & 7742234,823 & 311,39 & ativa & até $2 \mathrm{~m}$ \\
\hline Bonuccelli, T.J. & 1999 & 442 & 1 & Escorregamento & detritos e solo & BE344 & 658324,328 & 7745855,198 & 716,00 & ativa & até $2 \mathrm{~m}$ \\
\hline Bonuccelli, T.J. & 1999 & 441 & 1 & Escorregamento & rocha, detritos e solo & BE345 & 656939,017 & 7745153,809 & 431,55 & ativa & até $2 \mathrm{~m}$ \\
\hline Bonuccelli, T.J. & 1999 & 440 & 1 & Escorregamento & rocha, detritos e solo & BE346 & 657022,651 & 7745242,829 & 382,22 & ativa & até $2 \mathrm{~m}$ \\
\hline Bonuccelli, T.J. & 1999 & 438 & 1 & Escorregamento & detritos e solo & BE347 & 657576,398 & 7745460,328 & 840,39 & ativa & até $2 \mathrm{~m}$ \\
\hline Bonuccelli, T.J. & 1999 & 437 & 1 & Escorregamento & rocha, detritos e solo & BE348 & 657970,688 & 7745296,713 & 200,61 & dormente & até $2 \mathrm{~m}$ \\
\hline Bonuccelli, T.J. & 1999 & 434 & 1 & Escorregamento & rocha e detritos & BE349 & 658116,884 & 7745070,139 & 161,55 & dormente & até $2 \mathrm{~m}$ \\
\hline Bonuccelli, T.J. & 1999 & 435 & 1 & Escorregamento & rocha, detritos e solo & BE350 & 659254,278 & 7745060,793 & 247,83 & ativa & até $2 \mathrm{~m}$ \\
\hline Bonuccelli, T.J. & 1999 & 433 & 3 & Quedas e rolamentos & rocha & BQL351 & 656410,764 & 7742059,057 & 583,94 & ativa & até $2 \mathrm{~m}$ \\
\hline Bonuccelli, T.J. & 1999 & 431 & 11 & Escorregamento translacional e & rocha, detritos e solo & BTC352 & 655944,811 & 7742274,764 & 308,05 & ativa & até $2 \mathrm{~m}$ \\
\hline Bonuccelli, T.J. & 1999 & 430 & 8 & Complexo & rocha, detritos e solo & BX353 & 656986,468 & 7745642,097 & 2313,83 & ativa & 2 a $10 m$ \\
\hline Bonuccelli, T.J. & 1999 & 429 & 8 & Complexo & rocha, detritos e solo & BX354 & 656799,052 & 7745602,692 & 11593,80 & ativa & até $2 \mathrm{~m}$ \\
\hline Bonuccelli, T.J. & 1999 & 428 & 8 & Complexo & rocha, detritos e solo & BX355 & 656859,966 & 7745823,462 & 2093,77 & ativa & até $2 \mathrm{~m}$ \\
\hline Bonuccelli, T.J. & 1999 & 427 & 4 & Escoamentos rápidos ou corrida & detritos e solo & BC356 & 658635,458 & 7745973,647 & 436,17 & ativa & até $2 \mathrm{~m}$ \\
\hline Bonuccelli, T.J. & 1999 & 424 & 4 & Escoamentos rápidos ou corrida & detritos e solo & BC357 & 657899,067 & 7746020,657 & 1446,72 & ativa & até $2 \mathrm{~m}$ \\
\hline Bonuccelli, T.J. & 1999 & 426 & 3 & Quedas e rolamentos & rocha & BQL358 & 658128,161 & 7745893,985 & 358,83 & ativa & até $2 \mathrm{~m}$ \\
\hline Bonuccelli, T.J. & 1999 & 421 & 1 & Escorregamento & detritos e solo & BE359 & 657990,458 & 7746058,704 & 295,78 & ativa & até $2 \mathrm{~m}$ \\
\hline Bonuccelli, T.J. & 1999 & 416 & 3 & Quedas e rolamentos & rocha & BQL360 & 658833,772 & 7745245,103 & 538,89 & ativa & até $2 \mathrm{~m}$ \\
\hline Bonuccelli, T.J. & 1999 & 414 & 3 & Quedas e rolamentos & rocha & BQL361 & 658340,360 & 7745539,488 & 1757,72 & ativa & até $2 \mathrm{~m}$ \\
\hline Bonuccelli, T.J. & 1999 & 411 & 3 & Quedas e rolamentos & rocha & BQL362 & 658530,554 & 7745316,305 & 713,22 & ativa & até $2 \mathrm{~m}$ \\
\hline Bonuccelli, T.J. & 1999 & 410 & 3 & Quedas e rolamentos & rocha & BQL363 & 658478,081 & 7745400,230 & 814,55 & ativa & até $2 \mathrm{~m}$ \\
\hline Bonuccelli, T.J. & 1999 & 413 & 9 & Escorregamento e corrida & detritos e solo & BEC364 & 658474,850 & 7745713,709 & 1462,05 & ativa & até $2 \mathrm{~m}$ \\
\hline Bonuccelli, T.J. & 1999 & 408 & 3 & Quedas e rolamentos & rocha & BQL365 & 658413,297 & 7745225,876 & 277,05 & ativa & 2 a $10 m$ \\
\hline Bonuccelli, T.J. & 1999 & 409 & 3 & Quedas e rolamentos & rocha & BQL366 & 658283,988 & 7745210,795 & 349,89 & ativa & até $2 \mathrm{~m}$ \\
\hline Bonuccelli, T.J. & 1999 & 406 & 1 & Escorregamento & rocha, detritos e solo & BE367 & 658813,696 & 7745088,042 & 487,00 & ativa & 2 a $10 m$ \\
\hline Bonuccelli, T.J. & 1999 & 405 & 9 & Escorregamento e corrida & detritos e solo & BEC368 & 658520,472 & 7745130,232 & 254,17 & ativa & até $2 \mathrm{~m}$ \\
\hline Bonuccelli, T.J. & 1999 & 404 & 1 & Escorregamento & detritos & BE369 & 658320,773 & 7745134,469 & 364,50 & ativa & até $2 \mathrm{~m}$ \\
\hline Bonuccelli, T.J. & 1999 & 403 & 12 & Corridas e rolamentos & rocha, detritos e solo & BCL370 & 657667,163 & 7745247,423 & 751,83 & ativa & até $2 \mathrm{~m}$ \\
\hline Bonuccelli, T.J. & 1999 & 401 & 11 & Escorregamento translacional e & rocha, detritos e solo & BTC371 & 657612,696 & 7745256,686 & 793,44 & ativa & 2 a $10 m$ \\
\hline Bonuccelli, T.J. & 1999 & 400 & 1 & Escorregamento & rocha, detritos e solo & BE372 & 657953,959 & 7745161,225 & 395,05 & ativa & até $2 \mathrm{~m}$ \\
\hline Bonuccelli, T.J. & 1999 & 399 & 3 & Quedas e rolamentos & rocha, detritos e solo & BQL373 & 658084,323 & 7745290,400 & 1718,55 & dormente & até $2 \mathrm{~m}$ \\
\hline Bonuccelli, T.J. & 1999 & 398 & 1 & Escorregamento & rocha, detritos e solo & BE374 & 658229,443 & 7745035,696 & 1723,72 & ativa & 2 a $10 m$ \\
\hline
\end{tabular}

*ANO: Data do trabalho; 1: Código da feição; 2: Código do processo; CÓD.INV: Código do inventário; PROF.: Profundidade do movimento, N/A: Not Available (Não disponível). 
Apêndice B: Banco de dados do inventário de movimentos de massa gravitacionais (continuação).

\begin{tabular}{|c|c|c|c|c|c|c|c|c|c|c|c|}
\hline AUTOR & ANO & 1 & 2 & TIPO DE PROCESSO & TIPO DE MATERIAL & COD.INV & UTM E & UTM N & ÁREA $\left(\mathbf{m}^{2}\right)$ & ATIVIDADE & PROF. \\
\hline Bonuccelli, T.J. & 1999 & 395 & 1 & Escorregamento & detritos e solo & BE375 & 656793,438 & 7745092,203 & 106,33 & ativa & até $2 \mathrm{~m}$ \\
\hline Bonuccelli, T.J. & 1999 & 394 & 1 & Escorregamento & rocha, detritos e solo & BE376 & 656895,346 & 7745130,234 & 103,00 & ativa & até $2 \mathrm{~m}$ \\
\hline Bonuccelli, T.J. & 1999 & 392 & 1 & Escorregamento & rocha, detritos e solo & BE377 & 656651,830 & 7745151,957 & 76,44 & ativa & até $2 \mathrm{~m}$ \\
\hline Bonuccelli, T.J. & 1999 & 391 & 9 & Escorregamento e corrida & detritos e solo & BEC378 & 657011,218 & 7744763,044 & 292,67 & ativa & até $2 \mathrm{~m}$ \\
\hline Bonuccelli, T.J. & 1999 & 390 & 1 & Escorregamento & detritos e solo & BE379 & 656926,460 & 7744554,260 & 183,94 & ativa & até $2 \mathrm{~m}$ \\
\hline Bonuccelli, T.J. & 1999 & 385 & 1 & Escorregamento & detritos e solo & BE380 & 657401,091 & 7743997,131 & 140,83 & ativa & até $2 \mathrm{~m}$ \\
\hline Bonuccelli, T.J. & 1999 & 384 & 10 & Escorregamento e erosão & detritos e solo & BEG381 & 657343,127 & 7743904,596 & 775,83 & ativa & até $2 \mathrm{~m}$ \\
\hline Bonuccelli, T.J. & 1999 & 387 & 1 & Escorregamento & detritos e solo & BE382 & 657328,186 & 7744117,225 & 126,44 & ativa & até $2 \mathrm{~m}$ \\
\hline Bonuccelli, T.J. & 1999 & 388 & 1 & Escorregamento & detritos e solo & BE383 & 657496,374 & 7744126,660 & 158,05 & ativa & até $2 \mathrm{~m}$ \\
\hline Bonuccelli, T.J. & 1999 & 386 & 1 & Escorregamento & detritos e solo & BE384 & 657403,951 & 7744066,671 & 65,50 & ativa & até $2 \mathrm{~m}$ \\
\hline Bonuccelli, T.J. & 1999 & 381 & 1 & Escorregamento & solo & BE385 & 658129,162 & 7743996,001 & 91,61 & ativa & até $2 \mathrm{~m}$ \\
\hline Bonuccelli, T.J. & 1999 & 380 & 10 & Escorregamento e erosão & detritos e solo & BEG386 & 657511,406 & 7743916,922 & 552,55 & ativa & até $2 \mathrm{~m}$ \\
\hline Bonuccelli, T.J. & 1999 & 378 & 1 & Escorregamento & detritos e solo & BE387 & 657303,794 & 7744150,965 & 479,11 & ativa & até $2 \mathrm{~m}$ \\
\hline Bonuccelli, T.J. & 1999 & 368 & 9 & Escorregamento e corrida & detritos e solo & BEC388 & 657674,523 & 7744672,047 & 430,39 & ativa & 2 a $10 m$ \\
\hline Bonuccelli, T.J. & 1999 & 365 & 11 & Escorregamento translacional $\mathrm{e}$ & detritos e solo & BTC389 & 657226,042 & 7744743,116 & 718,66 & ativa & até $2 \mathrm{~m}$ \\
\hline Bonuccelli, T.J. & 1999 & 371 & 1 & Escorregamento & detritos e solo & BE390 & 657361,370 & 7744666,417 & 144,22 & ativa & até $2 \mathrm{~m}$ \\
\hline Bonuccelli, T.J. & 1999 & 372 & 1 & Escorregamento & detritos e solo & BE391 & 657378,369 & 7744629,313 & 245,89 & ativa & até $2 \mathrm{~m}$ \\
\hline Bonuccelli, T.J. & 1999 & 369 & 1 & Escorregamento & detritos e solo & BE392 & 657267,791 & 7744731,599 & 305,55 & ativa & até $2 \mathrm{~m}$ \\
\hline Bonuccelli, T.J. & 1999 & 370 & 8 & Complexo & detritos e solo & BX393 & 657322,647 & 7744706,957 & 196,28 & ativa & 2 a $10 \mathrm{~m}$ \\
\hline Bonuccelli, T.J. & 1999 & 374 & 8 & Complexo & detritos e solo & BX394 & 657640,287 & 7744500,003 & 1810,00 & ativa & até $2 \mathrm{~m}$ \\
\hline Bonuccelli, T.J. & 1999 & 375 & 1 & Escorregamento & detritos e solo & BE395 & 657695,352 & 7744225,662 & 340,28 & ativa & até $2 \mathrm{~m}$ \\
\hline Bonuccelli, T.J. & 1999 & 364 & 10 & Escorregamento e erosão & solo & BEG396 & 6575 & 7744609,044 & 102,28 & ativa & até $2 \mathrm{~m}$ \\
\hline Bonuccelli, T.J. & 1999 & 363 & 1 & Escorregamento & rocha, detritos e solo & BE397 & 657460,042 & 7744681,180 & 395,39 & ativa & até $2 \mathrm{~m}$ \\
\hline Bonuccelli, T.J. & 1999 & 366 & 2 & Escorregamento translacional & rocha e detritos & BT398 & 657158,447 & 7744758,048 & 366,33 & ativa & até $2 \mathrm{~m}$ \\
\hline Bonuccelli, T.J. & 1999 & 362 & 1 & Escorregamento & detritos e solo & BE399 & 657723,069 & 7744166,037 & 274,78 & ativa & até $2 \mathrm{~m}$ \\
\hline Bonuccelli, T.J. & 1999 & 373 & 8 & Complexo & detritos e solo & BX400 & 657540,110 & 7744502,656 & 194,83 & ativa & até $2 \mathrm{~m}$ \\
\hline Bonuccelli, T.J. & 1999 & 385 & 1 & Escorregamento & detritos e solo & BE380 & 657401,091 & 7743997,131 & 140,83 & ativa & até $2 \mathrm{~m}$ \\
\hline Bonuccelli, T.J. & 1999 & 275 & 3 & Quedas e rolamentos & rocha & BQL402 & 659098,751 & 7743161,492 & 288,94 & ativa & até $2 \mathrm{~m}$ \\
\hline Bonuccelli, T.J. & 1999 & 274 & 3 & Quedas e rolamentos & rocha & BQL403 & 659099,730 & 7743249,482 & 675,83 & ativa & até $2 \mathrm{~m}$ \\
\hline Bonuccelli, T.J. & 1999 & 354 & 11 & Escorregamento translacional $\mathrm{e}$ & rocha, detritos e solo & BTC404 & 658132,601 & 7744096,666 & 496,83 & ativa & até $2 \mathrm{~m}$ \\
\hline Bonuccelli, T.J. & 1999 & 353 & 11 & Escorregamento translacional e & detritos e solo & BTC405 & 657549,343 & 7744116,795 & 2207,44 & ativa & até $2 \mathrm{~m}$ \\
\hline Bonuccelli, T.J. & 1999 & 352 & 2 & Escorregamento translacional & rocha, detritos e solo & BT406 & 657451,463 & 7744036,443 & 522,00 & ativa & até $2 \mathrm{~m}$ \\
\hline Bonuccelli, T.J. & 1999 & 361 & 2 & Escorregamento translacional & rocha, detritos e solo & BT407 & 657707,547 & 7744104,999 & 693,72 & ativa & até $2 \mathrm{~m}$ \\
\hline Bonuccelli, T.J. & 1999 & 349 & 2 & Escorregamento translacional & rocha e detritos & BT408 & 657783,240 & 7744395,017 & 531,67 & ativa & até $2 \mathrm{~m}$ \\
\hline
\end{tabular}

*ANO: Data do trabalho; 1: Código da feição; 2: Código do processo; CÓD.INV: Código do inventário; PROF.: Profundidade do movimento, N/A: Not Available (Não disponível). 
Apêndice B: Banco de dados do inventário de movimentos de massa gravitacionais (continuação).

\begin{tabular}{|c|c|c|c|c|c|c|c|c|c|c|c|}
\hline AUTOR & ANO & 1 & 2 & TIPO DE PROCESSO & TIPO DE MATERIAL & COD.INV & UTM E & UTM N & ÁREA $\left(\mathrm{m}^{2}\right)$ & ATIVIDADE & PROF. \\
\hline Bonuccelli, T.J. & 1999 & 350 & 1 & Escorregamento & detritos e solo & BE409 & 657679,486 & 7744435,048 & 293,83 & ativa & até $2 \mathrm{~m}$ \\
\hline$\overline{\text { Bonuccelli, T.J. }}$ & 1999 & 351 & 11 & Escorregamento translacional e & rocha, detritos e solo & BTC410 & 658065,443 & 7744112,720 & 3181,44 & ativa & 2 a $10 m$ \\
\hline Bonuccelli, T.J. & 1999 & 348 & 1 & Escorregamento & detritos e solo & BE411 & 657885,672 & 7744395,232 & 162,94 & ativa & até $2 \mathrm{~m}$ \\
\hline Bonuccelli, T.J. & 1999 & 347 & 1 & Escorregamento & rocha, detritos e solo & BE412 & 657832,437 & 7744312,931 & 3482,16 & ativa & 2 a $10 m$ \\
\hline Bonuccelli, T.J. & 1999 & 345 & 1 & Escorregamento & rocha, detritos e solo & BE413 & 657873,718 & 7744096,801 & 839,83 & ativa & 2 a $10 m$ \\
\hline Bonuccelli, T.J. & 1999 & 343 & 2 & Escorregamento translacional & detritos e solo & BT414 & 658683,987 & 7743294,577 & 1263,50 & ativa & até $2 \mathrm{~m}$ \\
\hline Bonuccelli, T.J. & 1999 & 341 & 2 & Escorregamento translacional & rocha e detritos & BT415 & 658663,323 & 7743542,399 & 1859,72 & ativa & até $2 \mathrm{~m}$ \\
\hline Bonuccelli, T.J. & 1999 & 340 & 8 & Complexo & rocha, detritos e solo & BX416 & 658829,311 & 7743667,457 & 7536,71 & ativa & 2 a $10 m$ \\
\hline Bonuccelli, T.J. & 1999 & 19 & 8 & Complexo & rocha, detritos e solo & BX417 & 657861,054 & 7743539,217 & 312,22 & ativa & 2 a $10 m$ \\
\hline Bonuccelli, T.J. & 1999 & 337 & 1 & Escorregamento & detritos e solo & BE418 & 657106,865 & 7743958,909 & 259,11 & ativa & até $2 \mathrm{~m}$ \\
\hline Bonuccelli, T.J. & 1999 & 336 & 8 & Complexo & rocha, detritos e solo & BX419 & 658772,185 & 7744386,435 & 7865,76 & ativa & 2 a $10 m$ \\
\hline Bonuccelli, T.J. & 1999 & 332 & 8 & Complexo & detritos e solo & BX420 & 658979,190 & 7744473,027 & 1079,83 & ativa & 2 a $10 m$ \\
\hline Bonuccelli, T.J. & 1999 & 331 & 8 & Complexo & detritos e solo & BX421 & 658996,484 & 7744418,971 & 2835,88 & ativa & 2 a $10 m$ \\
\hline Bonuccelli, T.J. & 1999 & 324 & 12 & Corridas e rolamentos & rocha e detritos & $\mathrm{BCL} 422$ & 659307,596 & 7744816,314 & 609,89 & ativa & até $2 \mathrm{~m}$ \\
\hline Bonuccelli, T.J. & 1999 & 323 & 12 & Corridas e rolamentos & rocha e detritos & BCL423 & 659461,421 & 77444817,412 & 566,94 & ativa & até $2 \mathrm{~m}$ \\
\hline Bonuccelli, T.J. & 1999 & 321 & 9 & Escorregamento e corrida & detritos e solo & BEC424 & 658486,497 & 7745020,415 & 2242,00 & ativa & até $2 \mathrm{~m}$ \\
\hline Bonuccelli, T.J. & 1999 & 318 & 12 & Corridas e rolamentos & rocha e detritos & $\mathrm{BCL} 425$ & 658525,433 & 7744834,827 & 3790,21 & ativa & até $2 \mathrm{~m}$ \\
\hline Bonuccelli, T.J. & 1999 & 317 & 12 & Corridas e rolamentos & rocha e detritos & $\mathrm{BCL} 426$ & 658673,803 & 7744835,196 & 2490,88 & ativa & até $2 \mathrm{~m}$ \\
\hline Bonuccelli, T.J. & 1999 & 320 & 3 & Quedas e rolamentos & rocha & BQL427 & 658344,272 & 7744828,639 & 443,89 & dormente & até $2 \mathrm{~m}$ \\
\hline Bonuccelli, T.J. & 1999 & 319 & 3 & Quedas e rolamentos & rocha & BQL428 & 658401,685 & 7744859,406 & 629,94 & dormente & até $2 \mathrm{~m}$ \\
\hline Bonuccelli, T.J. & 1999 & 355 & 3 & Quedas e rolamentos & rocha & BQL429 & 659397,107 & 7743664,294 & 853,39 & ativa & até $2 \mathrm{~m}$ \\
\hline Bonuccelli, T.J. & 1999 & 308 & 8 & Complexo & rocha, detritos e solo & BX430 & 659199,371 & 7744287,287 & 8604,15 & ativa & 2 a $10 m$ \\
\hline Bonuccelli, T.J. & 1999 & 307 & 8 & Área de múltiplas feições & rocha, detritos e solo & BA431 & 659425,734 & 7744298,824 & 42422,00 & ativa & 2 a $10 m$ \\
\hline Bonuccelli, T.J. & 1999 & 305 & 2 & Escorregamento translacional & rocha e detritos & BT432 & 655924,985 & 7742103,183 & 1495,89 & ativa & 2 a $10 m$ \\
\hline Bonuccelli, T.J. & 1999 & 306 & 2 & Escorregamento translacional & detritos e solo & BT433 & 655710,775 & 7742198,926 & 1047,89 & ativa & até $2 \mathrm{~m}$ \\
\hline Bonuccelli, T.J. & 1999 & 271 & 3 & Quedas e rolamentos & rocha & BQL434 & 659561,852 & 7743034,157 & 705,22 & ativa & até $2 \mathrm{~m}$ \\
\hline Bonuccelli, T.J. & 1999 & 273 & 3 & Quedas e rolamentos & rocha & BQL435 & 659628,002 & 7743464,809 & 1031,83 & ativa & até $2 \mathrm{~m}$ \\
\hline Bonuccelli, T.J. & 1999 & 277 & 3 & Quedas e rolamentos & rocha & BQL436 & 658806,439 & 7742641,915 & 797,55 & ativa & até $2 \mathrm{~m}$ \\
\hline Bonuccelli, T.J. & 1999 & 276 & 3 & Quedas e rolamentos & rocha & BQL437 & 658878,768 & 7742855,132 & 625,11 & ativa & até $2 \mathrm{~m}$ \\
\hline Bonuccelli, T.J. & 1999 & 278 & 3 & Quedas e rolamentos & rocha & BQL438 & 658542,169 & 7742844,128 & 726,61 & ativa & até $2 \mathrm{~m}$ \\
\hline Bonuccelli, T.J. & 1999 & 280 & 3 & Quedas e rolamentos & rocha & BQL439 & 658049,484 & 7742660,573 & 631,61 & ativa & até $2 \mathrm{~m}$ \\
\hline Bonuccelli, T.J. & 1999 & 279 & 3 & Quedas e rolamentos & rocha & BQL440 & 658269,308 & 7742663,720 & 432,67 & ativa & até $2 \mathrm{~m}$ \\
\hline Bonuccelli, T.J. & 1999 & 282 & 3 & Quedas e rolamentos & rocha & BQL441 & 657708,088 & 7742008,919 & 792,94 & ativa & até $2 \mathrm{~m}$ \\
\hline Bonuccelli, T.J. & 1999 & 283 & 3 & Quedas e rolamentos & rocha & BQL442 & 657526,062 & 7742098,684 & 752,61 & ativa & até $2 \mathrm{~m}$ \\
\hline
\end{tabular}

*ANO: Data do trabalho; 1: Código da feição; 2: Código do processo; CÓD.INV: Código do inventário; PROF.: Profundidade do movimento, N/A: Not Available (Não disponível). 
Apêndice B: Banco de dados do inventário de movimentos de massa gravitacionais (continuação).

\begin{tabular}{|c|c|c|c|c|c|c|c|c|c|c|c|}
\hline AUTOR & ANO & 1 & 2 & TIPO DE PROCESSO & TIPO DE MATERIAL & COD.INV & UTM E & UTM N & ÁREA $\left(\mathrm{m}^{2}\right)$ & ATIVIDADE & PROF. \\
\hline Bonuccelli, T.J. & 1999 & 284 & 3 & Quedas e rolamentos & rocha & BQL443 & 657631,528 & 7742291,222 & 1132,33 & ativa & até $2 \mathrm{~m}$ \\
\hline Bonuccelli, T.J. & 1999 & 281 & 3 & Quedas e rolamentos & rocha & BQL444 & 657964,290 & 7742206,457 & 843,33 & ativa & até $2 \mathrm{~m}$ \\
\hline Bonuccelli, T.J. & 1999 & 291 & 3 & Quedas e rolamentos & rocha & BQL445 & 656929,349 & 7742436,710 & 829,33 & ativa & até $2 \mathrm{~m}$ \\
\hline Bonuccelli, T.J. & 1999 & 285 & 3 & Quedas e rolamentos & rocha & BQL446 & 657342,948 & 7742363,927 & 946,00 & ativa & até $2 \mathrm{~m}$ \\
\hline Bonuccelli, T.J. & 1999 & 286 & 3 & Quedas e rolamentos & rocha & BQL447 & 657333,496 & 7742498,457 & 498,67 & ativa & até $2 \mathrm{~m}$ \\
\hline Bonuccelli, T.J. & 1999 & 287 & 3 & Quedas e rolamentos & rocha & BQL448 & 657264,215 & 7742273,847 & 473,55 & ativa & até $2 \mathrm{~m}$ \\
\hline Bonuccelli, T.J. & 1999 & 289 & 3 & Quedas e rolamentos & rocha & BQL449 & 657186,416 & 7742317,773 & 469,17 & ativa & até $2 \mathrm{~m}$ \\
\hline Bonuccelli, T.J. & 1999 & 290 & 3 & Quedas e rolamentos & rocha & BQL450 & 657089,391 & 7742412,283 & 1482,00 & ativa & até $2 \mathrm{~m}$ \\
\hline Bonuccelli, T.J. & 1999 & 298 & 3 & Quedas e rolamentos & rocha & BQL451 & 656502,991 & 7742609,539 & 1333,72 & ativa & até $2 \mathrm{~m}$ \\
\hline Bonuccelli, T.J. & 1999 & 292 & 3 & Quedas e rolamentos & rocha & BQL452 & 656728,246 & 7742321,726 & 732,94 & ativa & até $2 \mathrm{~m}$ \\
\hline Bonuccelli, T.J. & 1999 & 299 & 3 & Quedas e rolamentos & rocha & BQL453 & 656596,220 & 7742424,899 & 800,83 & ativa & até $2 \mathrm{~m}$ \\
\hline Bonuccelli, T.J. & 1999 & 300 & 3 & Quedas e rolamentos & rocha & BQL454 & 656763,315 & 7742538,470 & 1449,44 & ativa & até $2 \mathrm{~m}$ \\
\hline Bonuccelli, T.J. & 1999 & 295 & 3 & Quedas e rolamentos & rocha & BQL455 & 656472,125 & 7742355,691 & 925,78 & ativa & até $2 \mathrm{~m}$ \\
\hline Bonuccelli, T.J. & 1999 & 294 & 3 & Quedas e rolamentos & rocha & BQL456 & 656272,456 & 7742290,118 & 885,16 & ativa & até $2 \mathrm{~m}$ \\
\hline Bonuccelli, T.J. & 1999 & 293 & 3 & Quedas e rolamentos & rocha & BQL457 & 656403,774 & 77422257,983 & 517,55 & ativa & até $2 \mathrm{~m}$ \\
\hline Bonuccelli, T.J. & 1999 & 297 & 3 & Quedas e rolamentos & rocha & BQL458 & 656297,023 & 7742649,294 & 924,55 & ativa & até $2 \mathrm{~m}$ \\
\hline Bonuccelli, T.J. & 1999 & 296 & 3 & Quedas e rolamentos & rocha & BQL459 & 656332,600 & 7742521,855 & 1313,05 & ativa & até $2 \mathrm{~m}$ \\
\hline Bonuccelli, T.J. & 1999 & 303 & 3 & Quedas e rolamentos & rocha & BQL460 & 656135,118 & 7742484,604 & 447,17 & ativa & até $2 \mathrm{~m}$ \\
\hline Bonuccelli, T.J. & 1999 & 397 & 9 & Escorregamento e corrida & rocha, detritos e solo & BEC461 & 657780,919 & 7745223,346 & 3860,99 & ativa & $>10 \mathrm{~m}$ \\
\hline Bonuccelli, T.J. & 1999 & 417 & 8 & Complexo & rocha, detritos e solo & BX462 & 658778,287 & 7745478,680 & 13054,30 & ativa & 2 a $10 m$ \\
\hline Bonuccelli, T.J. & 1999 & 264 & 12 & Corridas e rolamentos & rocha, detritos e solo & BCL463 & 659199,283 & 7745843,181 & 1780,50 & ativa & até $2 \mathrm{~m}$ \\
\hline Bonuccelli, T.J. & 1999 & 265 & 12 & Corridas e rolamentos & rocha, detritos e solo & BCL464 & 659679,916 & 7745556,670 & 1573,33 & ativa & até $2 \mathrm{~m}$ \\
\hline Bonuccelli, T.J. & 1999 & 249 & 3 & Quedas e rolamentos & rocha & BQL465 & 659555,737 & 7747089,122 & 1670,22 & ativa & até $2 \mathrm{~m}$ \\
\hline Bonuccelli, T.J. & 1999 & 248 & 3 & Quedas e rolamentos & rocha & BQL466 & 658593,873 & 7747653,679 & 1987,88 & dormente & até $2 \mathrm{~m}$ \\
\hline Bonuccelli, T.J. & 1999 & 238 & 3 & Quedas e rolamentos & rocha & BQL467 & 656068,498 & 7747005,288 & 1915,77 & dormente & até $2 \mathrm{~m}$ \\
\hline Bonuccelli, T.J. & 1999 & 237 & 3 & Quedas e rolamentos & rocha & BQL468 & 655867,933 & 77446915,711 & 2093,55 & ativa & até $2 \mathrm{~m}$ \\
\hline Bonuccelli, T.J. & 1999 & 216 & 3 & Quedas e rolamentos & rocha & BQL469 & 654975,775 & 7746638,064 & 492,55 & dormente & até $2 \mathrm{~m}$ \\
\hline Bonuccelli, T.J. & 1999 & 234 & 3 & Quedas e rolamentos & rocha & BQL470 & 655016,698 & 7747413,615 & 388,00 & dormente & até $2 \mathrm{~m}$ \\
\hline Bonuccelli, T.J. & 1999 & 236 & 3 & Quedas e rolamentos & rocha & BQL471 & 654929,138 & 7747509,715 & 569,55 & ativa & 2 a $10 m$ \\
\hline Bonuccelli, T.J. & 1999 & 235 & 3 & Quedas e rolamentos & rocha & BQL472 & 654996,743 & 7747551,658 & 672,89 & ativa & até $2 \mathrm{~m}$ \\
\hline Bonuccelli, T.J. & 1999 & 233 & 3 & Quedas e rolamentos & rocha & BQL473 & 654935,875 & 7747446,413 & 550,67 & ativa & até $2 \mathrm{~m}$ \\
\hline Bonuccelli, T.J. & 1999 & 209 & 1 & Escorregamento & rocha, detritos e solo & BE474 & 654800,951 & 7745712,947 & 107,67 & dormente & 2 a $10 m$ \\
\hline Bonuccelli, T.J. & 1999 & 208 & 1 & Escorregamento & rocha, detritos e solo & BE475 & 654977,655 & 7746052,382 & 123,00 & ativa & até $2 \mathrm{~m}$ \\
\hline Bonuccelli, T.J. & 1999 & 206 & 1 & Escorregamento & rocha & BE476 & 655004,379 & 7746172,541 & 223,22 & ativa & até $2 \mathrm{~m}$ \\
\hline
\end{tabular}

*ANO: Data do trabalho; 1: Código da feição; 2: Código do processo; CÓD.INV: Código do inventário; PROF.: Profundidade do movimento, N/A: Not Available (Não disponível). 
Apêndice B: Banco de dados do inventário de movimentos de massa gravitacionais (continuação).

\begin{tabular}{|c|c|c|c|c|c|c|c|c|c|c|c|}
\hline AUTOR & ANO & 1 & 2 & TIP & IATERIAL & COD & UTM E & UTM N & ÁREA $\left(\mathrm{m}^{2}\right)$ & ATIVIDADE & PROF. \\
\hline Bonuccelli, T.J. & 1999 & 205 & 1 & Escorregamento & rocha, detritos e solo & BE477 & 654873,409 & 7746222,944 & 238,83 & dormente & até $2 \mathrm{~m}$ \\
\hline Bonuccelli, T.J. & 1999 & 204 & 1 & Escorregamento & rocha, detritos e solo & BE478 & 654798,543 & 7746175,181 & 494,22 & ativa & até $2 \mathrm{~m}$ \\
\hline Bonuccelli, T.J. & 1999 & 202 & 1 & Escorregamento & rocha, detritos e solo & BE479 & 654598,773 & 7746309,739 & 167,50 & dormente & até $2 \mathrm{~m}$ \\
\hline Bonuccelli, T.J. & 1999 & 203 & 1 & Escorregamento & rocha, detritos e solo & BE480 & 654805,373 & 7746011,322 & 201,28 & ativa & até $2 \mathrm{~m}$ \\
\hline Bonuccelli, T.J. & 1999 & 210 & 3 & Quedas e rolamentos & rocha & BQL481 & 655414,163 & 7746408,556 & 241,94 & ativa & até $2 \mathrm{~m}$ \\
\hline Bonuccelli, T.J. & 1999 & 214 & 3 & Quedas e rolamentos & rocha & BQL482 & 655026,770 & 7746491,872 & 307,05 & ativa & até $2 \mathrm{~m}$ \\
\hline Bonuccelli, T.J. & 1999 & 215 & 3 & Quedas e rolamentos & rocha & BQL483 & 655101,283 & 7746584,318 & 595,39 & ativa & até $2 \mathrm{~m}$ \\
\hline Bonuccelli, T.J. & 1999 & 213 & 3 & Quedas e rolamentos & rocha & BQL484 & 655165,160 & 7746540,943 & 520,67 & ativa & 2 a $10 m$ \\
\hline Bonuccelli, T.J. & 1999 & 201 & 11 & Escorregamento translacional e & detritos e solo & BTC485 & 655994,608 & 7745988,182 & 2090,22 & ativa & até $2 \mathrm{~m}$ \\
\hline Bonuccelli, T.J. & 1999 & 199 & 11 & Escorregamento translacional e & detritos e solo & BTC486 & 655799,587 & 7745898,541 & 1464,33 & ativa & até $2 \mathrm{~m}$ \\
\hline Bonuccelli, T.J. & 1999 & 200 & 11 & Escorregamento translacional e & detritos e solo & BTC487 & 655887,132 & 7745837,176 & 991,22 & ativa & até $2 \mathrm{~m}$ \\
\hline Bonuccelli, T.J. & 1999 & 198 & 3 & Quedas e rolamentos & rocha & BQL488 & 655856,894 & 7745783,257 & 210,50 & ativa & até $2 \mathrm{~m}$ \\
\hline Bonuccelli, T.J. & 1999 & 197 & 3 & Quedas e rolamentos & rocha & BQL489 & 655855,701 & 7745734,874 & 231,39 & dormente & até $2 \mathrm{~m}$ \\
\hline Bonuccelli, T.J. & 1999 & 196 & 1 & Escorregamento & detritos e solo & BE490 & 655478,415 & 7745741,951 & 388,00 & ativa & até $2 \mathrm{~m}$ \\
\hline Bonuccelli, T.J. & 1999 & 191 & 2 & Escorregamento translacional & rocha & BT491 & 655509,951 & 7745893,095 & 196,55 & ativa & até $2 \mathrm{~m}$ \\
\hline Bonuccelli, T.J. & 1999 & 190 & 9 & Escorregamento e corrida & detritos e solo & BEC492 & 655621,118 & 7745951,267 & 305,22 & ativa & até $2 \mathrm{~m}$ \\
\hline Bonuccelli, T.J. & 1999 & 195 & 11 & Escorregamento translacional e & detritos e solo & BTC493 & 655553,599 & 7746155,161 & 565,83 & ativa & até $2 \mathrm{~m}$ \\
\hline Bonuccelli, T.J. & 1999 & 194 & 11 & Escorregamento translacional e & rocha e detritos & BTC494 &, 094 & 3,675 & 1509,94 & ativa & até $2 \mathrm{~m}$ \\
\hline Bonuccelli, T.J. & 1999 & 187 & 2 & Escorregamento translacional & rocha e detritos & BT495 & 655455,524 & 7745995,366 & 812,66 & ativa & até $2 \mathrm{~m}$ \\
\hline Bonuccelli, T.J. & 1999 & 186 & 11 & Escorregamento translacional e & rocha e detritos & BTC496 & 655516,393 & 7746036,058 & 3349,99 & ativa & 2 a $10 m$ \\
\hline Bonuccelli, T.J. & 1999 & 185 & 11 & Escorregamento translacional e & rocha e detritos & BTC497 & 655514,707 & 7746117,442 & 911,00 & ativa & até $2 \mathrm{~m}$ \\
\hline Bonuccelli, T.J. & 1999 & 184 & 1 & Escorregamento & rocha, detritos e solo & BE498 & 655272,112 & 7745 & 471,17 & ativa & até $2 \mathrm{~m}$ \\
\hline Bonuccelli, T.J. & 1999 & 181 & 9 & Escorregamento e corrida & detritos e solo & BEC499 & 655224,865 & 7745766,388 & 499,33 & ativa & até $2 \mathrm{~m}$ \\
\hline Bonuccelli, T.J. & 1999 & 180 & 9 & Escorregamento e corrida & detritos e solo & BEC500 & 655156,348 & 7745772,916 & 440,67 & ativa & até $2 \mathrm{~m}$ \\
\hline Bonuccelli, T.J. & 1999 & 182 & 1 & Escorregamento & rocha, detritos e solo & BE501 & 655508,326 & 7745624,601 & 859,83 & estabilizada & 2 a $10 m$ \\
\hline Bonuccelli, T.J. & 1999 & 179 & 3 & Quedas e rolamentos & rocha & BQL502 & 6564 & 7745557,172 & 609,50 & dormente & até $2 \mathrm{~m}$ \\
\hline Bonuccelli, T.J. & 1999 & 178 & 4 & Escoamentos rápidos ou corrida & detritos e solo & BC503 & 656005,525 & 7745034,659 & 487,44 & dormente & até $2 \mathrm{~m}$ \\
\hline Bonuccelli, T.J. & 1999 & 177 & 2 & Escorregamento translacional & detritos e solo & BT504 & 655826,060 & 7745061,974 & 256,55 & ativa & até $2 \mathrm{~m}$ \\
\hline Bonuccelli, T.J. & 1999 & 173 & 1 & Escorregamento & rocha, detritos e solo & BE505 & 656237,381 & 7745545,247 & 226,78 & ativa & até $2 \mathrm{~m}$ \\
\hline Bonuccelli, T.J. & 1999 & 171 & 1 & Escorregamento & detritos e solo & BE506 & 656009,121 & 7745431,298 & 352,11 & dormente & até $2 \mathrm{~m}$ \\
\hline Bonuccelli, T.J. & 1999 & 172 & 2 & Escorregamento translacional & rocha & BT507 & 656 & 7745 & 457,28 & estabilizada & até $2 \mathrm{~m}$ \\
\hline Bonuccelli, T.J. & 1999 & 169 & 1 & Escorregamento & rocha, detritos e solo & BE508 & 656925,868 & 7744939,057 & 435,39 & estabilizada & 2 a $10 m$ \\
\hline Bonuccelli, T.J. & 1999 & 170 & 4 & Escoamentos rápidos ou corrida & detritos e solo & BC509 & 657000,109 & 7744969,194 & 357,55 & ativa & até $2 \mathrm{~m}$ \\
\hline Bonuccelli, T.J. & 1999 & 168 & 11 & Escorregamento translacional e & rocha, detritos e solo & BTC510 & 656973,157 & 7744942,376 & 1295,72 & ativa & 2 a $10 m$ \\
\hline
\end{tabular}

*ANO: Data do trabalho; 1: Código da feição; 2: Código do processo; CÓD.INV: Código do inventário; PROF.: Profundidade do movimento, N/A: Not Available (Não disponível). 
Apêndice B: Banco de dados do inventário de movimentos de massa gravitacionais (continuação).

\begin{tabular}{|c|c|c|c|c|c|c|c|c|c|c|c|}
\hline AUTOR & ANO & 1 & 2 & TIPO DE PROCESSO & TIPO DE MATERIAL & COD.INV & UTM E & UTM N & ÁREA $\left(\mathbf{m}^{2}\right)$ & ATIVIDADE & PROF. \\
\hline Bonuccelli, T.J. & 1999 & 166 & 11 & Escorregamento translacional e & rocha, detritos e solo & BTC511 & 655044,340 & 7746107,673 & 344,50 & ativa & até $2 \mathrm{~m}$ \\
\hline Bonuccelli, T.J. & 1999 & 165 & 11 & Escorregamento translacional e & rocha, detritos e solo & BTC512 & 655130,647 & 7746051,537 & 472,39 & ativa & até $2 \mathrm{~m}$ \\
\hline Bonuccelli, T.J. & 1999 & 164 & 11 & Escorregamento translacional e & detritos e solo & BTC513 & 656029,380 & 7745944,363 & 1679,39 & ativa & até $2 \mathrm{~m}$ \\
\hline Bonuccelli, T.J. & 1999 & 153 & 2 & Escorregamento translacional & rocha, detritos e solo & BT514 & 655996,846 & 7745727,662 & 391,11 & ativa & 2 a $10 \mathrm{~m}$ \\
\hline Bonuccelli, T.J. & 1999 & 162 & 11 & Escorregamento translacional e & detritos e solo & BTC515 & 656278,561 & 7745949,257 & 2022,83 & ativa & até $2 \mathrm{~m}$ \\
\hline Bonuccelli, T.J. & 1999 & 161 & 2 & Escorregamento translacional & rocha, detritos e solo & BT516 & 656109,268 & 7745901,783 & 1891,83 & ativa & até $2 \mathrm{~m}$ \\
\hline Bonuccelli, T.J. & 1999 & 154 & 3 & Quedas e rolamentos & rocha e detritos & BQL517 & 656229,367 & 7745884,743 & 736,83 & ativa & até $2 \mathrm{~m}$ \\
\hline Bonuccelli, T.J. & 1999 & 160 & 9 & Escorregamento e corrida & detritos e solo & BEC518 & 655853,782 & 7745396,534 & 566,78 & ativa & até $2 \mathrm{~m}$ \\
\hline Bonuccelli, T.J. & 1999 & 159 & 9 & Escorregamento e corrida & detritos e solo & BEC519 & 655857,933 & 7745454,449 & 426,67 & ativa & até $2 \mathrm{~m}$ \\
\hline Bonuccelli, T.J. & 1999 & 158 & 4 & Escoamentos rápidos ou corrida & solo & BC520 & 655821,524 & 7745525,372 & 582,44 & ativa & até $2 \mathrm{~m}$ \\
\hline Bonuccelli, T.J. & 1999 & 157 & 1 & Escorregamento & detritos e solo & BE521 & 654868,658 & 7745915,614 & 2001,77 & estabili & até $2 \mathrm{~m}$ \\
\hline Bonuccelli, T.J. & 1999 & 188 & 8 & Complexo & rocha, detritos e solo & BX522 & 655778,125 & 7746039,201 & 9194,26 & ativa & 2 a $10 \mathrm{~m}$ \\
\hline Bonuccelli, T.J. & 1999 & 192 & 11 & Escorregamento translacional e & detritos e solo & BTC523 & 655669,772 & 7745896,290 & 1994,16 & ativa & até $2 \mathrm{~m}$ \\
\hline Bonuccelli, T.J. & 1999 & 163 & 11 & Escorregamento translacional e & detritos e solo & BTC524 & 655858,541 & 7745996,245 & 4101,88 & ativa & 2 a $10 \mathrm{~m}$ \\
\hline Bonuccelli, T.J. & 1999 & 155 & 2 & Escorregamento translacional & rocha, detritos e solo & BT525 & 655679,135 & 7745773,372 & 4302,10 & dorme & 2 a $10 \mathrm{~m}$ \\
\hline Bonuccelli, T.J. & 1999 & 151 & 1 & Escorregamento & rocha, detritos e solo & BE526 & 655493,581 & 7745466,750 & 1348,16 & ativa & 2 a $10 \mathrm{~m}$ \\
\hline Bonuccelli, T.J. & 1999 & 150 & 1 & Escorregamento & detritos e solo & BE527 & 655614,505 & 7745293,956 & 299,22 & ativa & até $2 \mathrm{~m}$ \\
\hline Bonuccelli, T.J. & 1999 & 149 & 1 & Escorregamento & detritos e solo & $\mathrm{BE}$ & 65566 & 7745349,491 & 679,33 & ativa & até $2 \mathrm{~m}$ \\
\hline Bonuccelli, T.J. & 1999 & 148 & 1 & Escorregamento & detritos e solo & BE529 & 655737,226 & 7745270,422 & 499,61 & ativa & até $2 \mathrm{~m}$ \\
\hline Bonuccelli, T.J. & 1999 & 147 & 1 & Escorregamento & detritos e solo & BE530 & 656021,938 & 7745347,721 & 544,33 & ativa & até $2 \mathrm{~m}$ \\
\hline Bonuccelli, T.J. & 1999 & 146 & 1 & Escorregamento & rocha e detritos & BE531 & 656095,766 & 7745263,717 & 1205,89 & estabilizada & 2 a $10 \mathrm{~m}$ \\
\hline Bonuccelli, T.J. & 1999 & 152 & 2 & Escorregamento translacional & detritos e solo & $\mathrm{BT}$ & 6559 & 7745641,616 & 7606,98 & ativa & 2 a $10 \mathrm{~m}$ \\
\hline Bonuccelli, T.J. & 1999 & 145 & 11 & Escorregamento translacional e & rocha e detritos & BTC533 & 654573,483 & 7745888,686 & 25547,60 & dormente & até $2 \mathrm{~m}$ \\
\hline Bonuccelli, T.J. & 1999 & 133 & 11 & Escorregamento translacional e & detritos e solo & BTC534 & 654609,082 & 7746024,111 & 869,11 & ativa & até $2 \mathrm{~m}$ \\
\hline Bonuccelli, T.J. & 1999 & 121 & 2 & Escorregamento translacional & rocha e detritos & BT535 & 654778,699 & 7745486,327 & 323,83 & ativa & até $2 \mathrm{~m}$ \\
\hline Bonuccelli, T.J. & 1999 & 120 & 2 & Escorregamento translacional & rocha e detritos & & 655 & 7745129,829 & 87,94 & ativa & até $2 \mathrm{~m}$ \\
\hline Bonuccelli, T.J. & 1999 & 116 & 10 & Escorregamento e erosão & detritos e solo & BEG537 & 6550 & 7745780,708 & 4180,21 & ativa & até $2 \mathrm{~m}$ \\
\hline Bonuccelli, T.J. & 1999 & 114 & 1 & Escorregamento & detritos e solo & BE538 & 655127,854 & 7745706,481 & 337,39 & ativa & até $2 \mathrm{~m}$ \\
\hline Bonuccelli, T.J. & 1999 & 113 & 10 & Escorregamento e erosão & detritos e solo & BEG539 & 654754,130 & 7745784,894 & 3715,55 & ativa & até $2 \mathrm{~m}$ \\
\hline Bonuccelli, T.J. & 1999 & 98 & 2 & Escorregamento translacional & rocha e detritos & BT540 & 655342,585 & 7745136,160 & 573,89 & ativa & até $2 \mathrm{~m}$ \\
\hline Bonuccelli, T.J. & 1999 & 112 & 2 & Escorregamento translacional & rocha e detritos & & 839 & 7745 & 379,17 & ativa & até $2 \mathrm{~m}$ \\
\hline Bonuccelli, T.J. & 1999 & 95 & 1 & Escorregamento & detritos e solo & BE542 & 655525,235 & 7744958,730 & 435,05 & ativa & até $2 \mathrm{~m}$ \\
\hline Bonuccelli, T.J. & 1999 & 115 & 1 & Escorregamento & detritos e solo & BE543 & 655043,366 & 7745589,364 & 453,67 & ativa & até $2 \mathrm{~m}$ \\
\hline Bonuccelli, T.J. & 1999 & 117 & 2 & Escorregamento translacional & rocha, detritos e solo & BT544 & 655064,254 & 7745510,969 & 1152,22 & ativa & até $2 \mathrm{~m}$ \\
\hline
\end{tabular}

*ANO: Data do trabalho; 1: Código da feição; 2: Código do processo; CÓD.INV: Código do inventário; PROF.: Profundidade do movimento, N/A: Not Available (Não disponível). 
Apêndice B: Banco de dados do inventário de movimentos de massa gravitacionais (continuação).

\begin{tabular}{|c|c|c|c|c|c|c|c|c|c|c|c|}
\hline AUTOR & ANO & 1 & 2 & TIPO DE PROCESSO & TIPO DE MATERIAL & COD.INV & UTM E & UTM N & ÁREA $\left(\mathbf{m}^{2}\right)$ & ATIVIDADE & PROF. \\
\hline Bonuccelli, T.J. & 1999 & 111 & 2 & Escorregamento translacional & rocha e detritos & BT545 & 655169,000 & 7744872,823 & 900,72 & ativa & até $2 \mathrm{~m}$ \\
\hline Bonuccelli, T.J. & 1999 & 110 & 10 & Escorregamento e erosão & rocha, detritos e solo & BEG546 & 654668,650 & 7745121,693 & 233,00 & ativa & até $2 \mathrm{~m}$ \\
\hline Bonuccelli, T.J. & 1999 & 109 & 10 & Escorregamento e erosão & rocha, detritos e solo & BEG547 & 654550,272 & 7745289,156 & 3165,77 & ativa & 2 a $10 m$ \\
\hline Bonuccelli, T.J. & 1999 & 108 & 10 & Escorregamento e erosão & rocha, detritos e solo & BEG548 & 654647,607 & 7745229,303 & 2746,38 & ativa & 2 a $10 \mathrm{~m}$ \\
\hline Bonuccelli, T.J. & 1999 & 119 & 2 & Escorregamento translacional & detritos e solo & BT549 & 654822,426 & 7745298,568 & 438,11 & dormente & até $2 \mathrm{~m}$ \\
\hline Bonuccelli, T.J. & 1999 & 107 & 2 & Escorregamento translacional & detritos e solo & BT550 & 655047,882 & 7745314,589 & 108,83 & ativa & até $2 \mathrm{~m}$ \\
\hline Bonuccelli, T.J. & 1999 & 105 & 1 & Escorregamento & detritos e solo & BE551 & 655137,287 & 7745314,909 & 47,44 & dormente & até $2 \mathrm{~m}$ \\
\hline Bonuccelli, T.J. & 1999 & 106 & 1 & Escorregamento & detritos e solo & BE552 & 655154,116 & 7745304,772 & 47,67 & ativa & até $2 \mathrm{~m}$ \\
\hline Bonuccelli, T.J. & 1999 & 104 & 1 & Escorregamento & detritos e solo & BE553 & 655103,612 & 7745293,949 & 83,00 & ativa & até $2 \mathrm{~m}$ \\
\hline Bonuccelli, T.J. & 1999 & 103 & 2 & Escorregamento translacional & rocha, detritos e solo & BT554 & 655044,401 & 7745291,060 & 482,67 & ativa & 2 a $10 \mathrm{~m}$ \\
\hline Bonuccelli, T.J. & 1999 & 97 & 2 & Escorregamento translacional & detritos e solo & BT555 & 655588,896 & 7744910,859 & 320,67 & ativa & até $2 \mathrm{~m}$ \\
\hline Bonuccelli, T.J. & 1999 & 99 & 10 & Escorregamento e erosão & rocha, detritos e solo & BEG556 & 655285,480 & 7745090,133 & 3813,55 & ativa & até $2 \mathrm{~m}$ \\
\hline Bonuccelli, T.J. & 1999 & 94 & 8 & Complexo & detritos e solo & BX557 & 655441,090 & 7744985,765 & 5230,27 & estabilizada & $>10 \mathrm{~m}$ \\
\hline Bonuccelli, T.J. & 1999 & 96 & 2 & Escorregamento translacional & rocha e detritos & BT558 & 655681,493 & 7744856,202 & 2326,50 & ativa & 2 a $10 \mathrm{~m}$ \\
\hline Bonuccelli, T.J. & 1999 & 90 & 2 & Escorregamento translacional & detritos e solo & BT559 & 656585,755 & 7744301,707 & 33,28 & ativa & até $2 \mathrm{~m}$ \\
\hline Bonuccelli, T.J. & 1999 & 89 & 2 & Escorregamento translacional & detritos e solo & BT560 & 656253,882 & 7744464,278 & 153,50 & ativa & até $2 \mathrm{~m}$ \\
\hline Bonuccelli, T.J. & 1999 & 81 & 10 & Escorregamento e erosão & detritos e solo & BEG561 & 657233,380 & 7743177,903 & 1877,00 & dormente & 2 a $10 \mathrm{~m}$ \\
\hline Bonuccelli, T.J. & 1999 & 82 & 10 & Escorregamento e erosão & detritos e solo & BEG562 & 6571 & 7743230,833 & 5175,77 & ativa & $>10 \mathrm{~m}$ \\
\hline Bonuccelli, T.J. & 1999 & 83 & 8 & Complexo & detritos e solo & BX563 & 657115,563 & 7743245,297 & 4901,77 & ativa & 2 a $10 \mathrm{~m}$ \\
\hline Bonuccelli, T.J. & 1999 & 80 & 8 & Área de múltiplas feições & detritos e solo & BA564 & 657358,934 & 7743117,728 & 26947,20 & ativa & 2 a $10 \mathrm{~m}$ \\
\hline Bonuccelli, T.J. & 1999 & 75 & 1 & Escorregamento & detritos e solo & BE565 & 656631,181 & 7743537,695 & 1052,39 & ativa & até $2 \mathrm{~m}$ \\
\hline Bonuccelli, T.J. & 1999 & 76 & 1 & Escorregamento & detritos e solo & BE566 & 6566 & 7743 & 317,22 & ativa & até $2 \mathrm{~m}$ \\
\hline Bonuccelli, T.J. & 1999 & 77 & 1 & Escorregamento & detritos e solo & BE567 & 656711,762 & 7743675,122 & 1728,27 & ativa & até $2 \mathrm{~m}$ \\
\hline Bonuccelli, T.J. & 1999 & 71 & 8 & Complexo & detritos e solo & BX568 & 657564,700 & 7743850,666 & 7384,32 & ativa & $>10 \mathrm{~m}$ \\
\hline Bonuccelli, T.J. & 1999 & 72 & 4 & Escoamentos rápidos ou corrida & solo & BC569 & 657731,443 & 7744031,343 & 764,72 & ativa & até $2 \mathrm{~m}$ \\
\hline Bonuccelli, T.J. & 1999 & 66 & 2 & Escorregamento translacional & detritos e solo & BT570 & 657037,197 & 7744130,258 & 1154,00 & ativa & até $2 \mathrm{~m}$ \\
\hline Bonuccelli, T.J. & 1999 & 65 & 2 & Escorregamento translacional & detritos e solo & BT571 & 6569 & 7744096,186 & 989,83 & ativa & até $2 \mathrm{~m}$ \\
\hline Bonuccelli, T.J. & 1999 & 64 & 2 & Escorregamento translacional & detritos e solo & BT572 & 656904,482 & 7744193,981 & 502,78 & ativa & até $2 \mathrm{~m}$ \\
\hline Bonuccelli, T.J. & 1999 & 63 & 2 & Escorregamento translacional & detritos e solo & BT573 & 656868,842 & 7744189,382 & 133,55 & ativa & até $2 \mathrm{~m}$ \\
\hline Bonuccelli, T.J. & 1999 & 62 & 2 & Escorregamento translacional & detritos e solo & BT574 & 656341,532 & 7744325,448 & 171,11 & ativa & até $2 \mathrm{~m}$ \\
\hline Bonuccelli, T.J. & 1999 & 38 & 2 & Escorregamento translacional & detritos e solo & BT575 & 655704,803 & 7744622,311 & 2174,33 & ativa & até $2 \mathrm{~m}$ \\
\hline Bonuccelli, T.J. & 1999 & 59 & 11 & Escorregamento translacional $\mathrm{e}$ & rocha, detritos e solo & BTC576 & 655299,632 & 7744639,545 & 264,05 & ativa & até $2 \mathrm{~m}$ \\
\hline Bonuccelli, T.J. & 1999 & 58 & 11 & Escorregamento translacional e & rocha, detritos e solo & BTC577 & 655633,821 & 7744587,416 & 539,67 & ativa & até $2 \mathrm{~m}$ \\
\hline Bonuccelli, T.J. & 1999 & 57 & 11 & Escorregamento translacional e & rocha, detritos e solo & BTC578 & 655445,564 & 7744664,051 & 1328,83 & ativa & até $2 \mathrm{~m}$ \\
\hline
\end{tabular}

*ANO: Data do trabalho; 1: Código da feição; 2: Código do processo; CÓD.INV: Código do inventário; PROF.: Profundidade do movimento, N/A: Not Available (Não disponível). 
Apêndice B: Banco de dados do inventário de movimentos de massa gravitacionais (continuação).

\begin{tabular}{|c|c|c|c|c|c|c|c|c|c|c|c|}
\hline AUTOR & ANO & 1 & 2 & TIPO DE PROCESSO & TIPO DE MATERIAL & COD.INV & UTM E & UTM N & ÁREA $\left(\mathbf{m}^{2}\right)$ & ATIVIDADE & PROF. \\
\hline Bonuccelli, T.J. & 1999 & 51 & 2 & Escorregamento translacional & detritos e solo & BT579 & 654774,900 & 7744063,520 & 1383,66 & ativa & até $2 \mathrm{~m}$ \\
\hline Bonuccelli, T.J. & 1999 & 48 & 2 & Escorregamento translacional & detritos e solo & BT580 & 654848,354 & 7744350,657 & 5848,38 & ativa & até $2 \mathrm{~m}$ \\
\hline Bonuccelli, T.J. & 1999 & 49 & 2 & Escorregamento translacional & detritos e solo & BT581 & 654769,406 & 7744234,781 & 715,89 & ativa & até $2 \mathrm{~m}$ \\
\hline Bonuccelli, T.J. & 1999 & 55 & 2 & Escorregamento translacional & detritos e solo & BT582 & 656137,798 & 7744538,922 & 83,33 & ativa & até $2 \mathrm{~m}$ \\
\hline Bonuccelli, T.J. & 1999 & 54 & 8 & Complexo & detritos e solo & BX583 & 656428,222 & 7744401,716 & 314,50 & ativa & até $2 \mathrm{~m}$ \\
\hline Bonuccelli, T.J. & 1999 & 52 & 2 & Escorregamento translacional & rocha e detritos & BT584 & 656367,589 & 7744426,497 & 568,61 & ativa & até $2 \mathrm{~m}$ \\
\hline Bonuccelli, T.J. & 1999 & 40 & 11 & Escorregamento translacional e & detritos e solo & BTC585 & 656030,989 & 7744686,004 & 389,61 & ativa & até $2 \mathrm{~m}$ \\
\hline Bonuccelli, T.J. & 1999 & 39 & 11 & Escorregamento translacional e & detritos e solo & BTC586 & 655959,852 & 7744645,955 & 1100,89 & ativa & até $2 \mathrm{~m}$ \\
\hline Bonuccelli, T.J. & 1999 & 32 & 1 & Escorregamento & detritos e solo & BE587 & 654694,080 & 7743872,483 & 250,72 & dormente & até $2 \mathrm{~m}$ \\
\hline Bonuccelli, T.J. & 1999 & 33 & 1 & Escorregamento & detritos e solo & BE588 & 654682,906 & 7743735,402 & 760,66 & dormente & até $2 \mathrm{~m}$ \\
\hline Bonuccelli, T.J. & 1999 & 37 & 1 & Escorregamento & detritos e solo & BE589 & 656067,328 & 7743740,360 & 316,50 & ativa & até $2 \mathrm{~m}$ \\
\hline Bonuccelli, T.J. & 1999 & 34 & 1 & Escorregamento & detritos e solo & BE590 & 655765,286 & 7743562,411 & 356,89 & ativa & até $2 \mathrm{~m}$ \\
\hline Bonuccelli, T.J. & 1999 & 36 & 1 & Escorregamento & detritos e solo & BE591 & 655626,521 & 7743154,413 & 544,22 & dormente & até $2 \mathrm{~m}$ \\
\hline Bonuccelli, T.J. & 1999 & 35 & 1 & Escorregamento & detritos e solo & BE592 & 655584,157 & 7743371,154 & 425,67 & dormente & até $2 \mathrm{~m}$ \\
\hline Bonuccelli, T.J. & 1999 & 28 & 9 & Escorregamento e corrida & solo & BEC593 & 655351,555 & 7742754,534 & 925,50 & ativa & até $2 \mathrm{~m}$ \\
\hline Bonuccelli, T.J. & 1999 & 47 & 2 & Escorregamento translacional & rocha & BT594 & 654958,153 & 7744383,372 & 1581,44 & ativa & até $2 \mathrm{~m}$ \\
\hline Bonuccelli, T.J. & 1999 & 30 & 10 & Escorregamento e erosão & solo & BEG595 & 655726,614 & 7742944,265 & 6016,38 & ativa & 2 a $10 \mathrm{~m}$ \\
\hline Bonuccelli, T.J. & 1999 & 68 & 8 & Área de múltiplas feições & detritos e solo & BA596 & 657347,265 & 7743626,057 & 71203,30 & ativa & $>10 \mathrm{~m}$ \\
\hline Bonuccelli, T.J. & 1999 & 219 & 12 & Corridas e rolamentos & rocha e detritos & BCL597 & 654884,985 & 7746983,737 & 913,44 & ativa & até $2 \mathrm{~m}$ \\
\hline Bonuccelli, T.J. & 1999 & 228 & 8 & Complexo & rocha, detritos e solo & BX598 & 655628,492 & 7746850,050 & 5651,60 & dormente & até $2 \mathrm{~m}$ \\
\hline Bonuccelli, T.J. & 1999 & 221 & 12 & Corridas e rolamentos & rocha e detritos & BCL599 & 655268,534 & 7747029,040 & 320,94 & ativa & até $2 \mathrm{~m}$ \\
\hline Bonuccelli, T.J. & 1999 & 222 & 12 & Corridas e rolamentos & rocha e detritos & BCL600 & 6553 & 7747050,732 & 723,39 & ativa & até $2 \mathrm{~m}$ \\
\hline Bonuccelli, T.J. & 1999 & 220 & 8 & Complexo & rocha, detritos e solo & BX601 & 655315,226 & 7746960,199 & 12936,20 & ativa & 2 a $10 \mathrm{~m}$ \\
\hline Bonuccelli, T.J. & 1999 & 223 & 12 & Corridas e rolamentos & rocha e detritos & BCL602 & 655550,949 & 7747041,253 & 204,22 & ativa & até $2 \mathrm{~m}$ \\
\hline Bonuccelli, T.J. & 1999 & 224 & 12 & Corridas e rolamentos & rocha e detritos & BCL603 & 655574,557 & 7747039,349 & 176,67 & ativa & até $2 \mathrm{~m}$ \\
\hline Bonuccelli, T.J. & 1999 & 225 & 12 & Corridas e rolamentos & rocha e detritos & BCL604 & 655559,332 & 7746960,777 & 144,67 & ativa & 2 a $10 \mathrm{~m}$ \\
\hline Bonuccelli, T.J. & 1999 & 226 & 12 & Corridas e rolamentos & rocha e detritos & BCL605 & 655648,778 & 7746881,936 & 1120,72 & ativa & até $2 \mathrm{~m}$ \\
\hline Bonuccelli, T.J. & 1999 & 227 & 12 & Corridas e rolamentos & rocha e detritos & BCL606 & 655726,759 & 7746834,190 & 973,05 & ativa & até $2 \mathrm{~m}$ \\
\hline Bonuccelli, T.J. & 1999 & 230 & 8 & Área de múltiplas feições & rocha, detritos e solo & BA607 & 655747,486 & 7747073,139 & 5195,99 & dormente & até $2 \mathrm{~m}$ \\
\hline Bonuccelli, T.J. & 1999 & 258 & 12 & Corridas e rolamentos & rocha, detritos e solo & BCL608 & 659325,826 & 7745671,075 & 841,50 & ativa & até $2 \mathrm{~m}$ \\
\hline Bonuccelli, T.J. & 1999 & 261 & 12 & Corridas e rolamentos & rocha, detritos e solo & BCL609 & 659311,795 & 3,620 & 1462,66 & ativa & até $2 \mathrm{~m}$ \\
\hline Bonuccelli, T.J. & 1999 & 142 & 2 & Escorregamento translacional & detritos e solo & BT610 & 653992,605 & 7746165,320 & 554,67 & ativa & até $2 \mathrm{~m}$ \\
\hline Bonuccelli, T.J. & 1999 & 141 & 2 & Escorregamento translacional & detritos e solo & BT611 & 654128,877 & 7745778,240 & 3022,88 & ativa & até $2 \mathrm{~m}$ \\
\hline Bonuccelli, T.J. & 1999 & 138 & 4 & Escoamentos rápidos ou corrida & detritos e solo & BC612 & 653978,172 & 7743954,834 & 410,94 & ativa & até $2 \mathrm{~m}$ \\
\hline
\end{tabular}

*ANO: Data do trabalho; 1: Código da feição; 2: Código do processo; CÓD.INV: Código do inventário; PROF.: Profundidade do movimento, N/A: Not Available (Não disponível). 
Apêndice B: Banco de dados do inventário de movimentos de massa gravitacionais (continuação).

\begin{tabular}{|c|c|c|c|c|c|c|c|c|c|c|c|}
\hline AUTOR & ANO & 1 & 2 & TIPO DE PROCESSO & TIPO DE MATERIAL & COD.INV & UTM E & UTM N & ÁREA $\left(\mathbf{m}^{2}\right)$ & ATIVIDADE & PROF. \\
\hline Bonuccelli, T.J. & 1999 & 137 & 2 & Escorregamento translacional & rocha e detritos & BT613 & 654158,923 & 7743768,266 & 1014,55 & dormente & até $2 \mathrm{~m}$ \\
\hline Bonuccelli, T.J. & 1999 & 136 & 8 & Complexo & rocha, detritos e solo & BX614 & 653721,264 & 7743967,579 & 2609,05 & ativa & 2 a $10 \mathrm{~m}$ \\
\hline Bonuccelli, T.J. & 1999 & 135 & 2 & Escorregamento translacional & rocha e detritos & BT615 & 653446,635 & 7745969,341 & 2747,27 & ativa & até $2 \mathrm{~m}$ \\
\hline Bonuccelli, T.J. & 1999 & 129 & 1 & Escorregamento & detritos e solo & BE616 & 653966,414 & 7745872,250 & 699,28 & ativa & 2 a $10 \mathrm{~m}$ \\
\hline Bonuccelli, T.J. & 1999 & 144 & 3 & Quedas e rolamentos & rocha & BQL617 & 653348,741 & 7745592,796 & 862,66 & dormente & até $2 \mathrm{~m}$ \\
\hline Bonuccelli, T.J. & 1999 & 130 & 1 & Escorregamento & detritos e solo & BE618 & 654042,014 & 7745602,292 & 3071,66 & dormente & até $2 \mathrm{~m}$ \\
\hline Bonuccelli, T.J. & 1999 & 41 & 2 & Escorregamento translacional & detritos e solo & BT619 & 653905,582 & 7743385,952 & 6906,32 & ativa & até $2 \mathrm{~m}$ \\
\hline Bonuccelli, T.J. & 1999 & 17 & 1 & Escorregamento & detritos e solo & BE620 & 653636,786 & 7742435,631 & 101,00 & ativa & até $2 \mathrm{~m}$ \\
\hline Bonuccelli, T.J. & 1999 & 11 & 8 & Área de múltiplas feições & rocha, detritos e solo & BA621 & 653487,300 & 7742889,724 & 7220,71 & ativa & 2 a $10 m$ \\
\hline Bonuccelli, T.J. & 1999 & 12 & 8 & Área de múltiplas feições & rocha, detritos e solo & BA622 & 653437,191 & 7743107,339 & 38270,50 & ativa & 2 a $10 \mathrm{~m}$ \\
\hline Bonuccelli, T.J. & 1999 & 10 & 1 & Escorregamento & detritos e solo & BE623 & 653553,441 & 7742572,275 & 636,78 & ativa & até $2 \mathrm{~m}$ \\
\hline Bonuccelli, T.J. & 1999 & 7 & 1 & Escorregamento & rocha, detritos e solo & BE624 & 653488,095 & 7742676,179 & 1224,94 & ativa & até $2 \mathrm{~m}$ \\
\hline Bonuccelli, T.J. & 1999 & 8 & 1 & Escorregamento & rocha, detritos e solo & BE625 & 653785,883 & 7742343,521 & 407,33 & ativa & até $2 \mathrm{~m}$ \\
\hline Bonuccelli, T.J. & 1999 & 15 & 1 & Escorregamento & detritos e solo & BE626 & 653735,361 & 7742580,943 & 329,83 & ativa & até $2 \mathrm{~m}$ \\
\hline Bonuccelli, T.J. & 1999 & 16 & 1 & Escorregamento & detritos e solo & BE627 & 653662,642 & 7742623,417 & 120,11 & ativa & até $2 \mathrm{~m}$ \\
\hline Bonuccelli, T.J. & 1999 & 6 & 2 & Escorregamento translacional & rocha e detritos & BT628 & 653698,379 & 7742274,424 & 359,33 & ativa & até $2 \mathrm{~m}$ \\
\hline Bonuccelli, T.J. & 1999 & 3 & 2 & Escorregamento translacional & solo & BT629 & 653663,704 & 7742028,194 & 319,61 & dormente & até $2 \mathrm{~m}$ \\
\hline Bonuccelli, T.J. & 1999 & 2 & 10 & Escorregamento e erosão & solo & BEG630 & 653748,355 & 7742012,049 & 801,16 & dormente & 2 a $10 \mathrm{~m}$ \\
\hline Bonuccelli, T.J. & 1999 & 4 & 11 & Escorregamento translacional e & detritos e solo & BTC631 & 653761,943 & 7742162,180 & 600,00 & ativa & 2 a $10 \mathrm{~m}$ \\
\hline Bonuccelli, T.J. & 1999 & 140 & 10 & Escorregamento e erosão & detritos e solo & BEG632 & 654280,847 & 7745773,100 & 2225,05 & ativa & 2 a $10 \mathrm{~m}$ \\
\hline Bonuccelli, T.J. & 1999 & 24 & 8 & Complexo & detritos e solo & BX633 & 654251,312 & 7742284,399 & 3427,44 & dormente & até $2 \mathrm{~m}$ \\
\hline Bonuccelli, T.J. & 1999 & 313 & 3 & Quedas e rolamentos & rocha & BQL634 & 6609 & 7744226,936 & 610,11 & ativa & até $2 \mathrm{~m}$ \\
\hline Bonuccelli, T.J. & 1999 & 312 & 2 & Escorregamento translacional & rocha & BT635 & 660963,583 & 7744454,381 & 1396,28 & dormente & 2 a $10 \mathrm{~m}$ \\
\hline Bonuccelli, T.J. & 1999 & 252 & 12 & Corridas e rolamentos & rocha, detritos e solo & BCL636 & 660271,045 & 7746478,411 & 2626,49 & estabilizada & até $2 \mathrm{~m}$ \\
\hline Bonuccelli, T.J. & 1999 & 419 & 3 & Quedas e rolamentos & rocha & BQL637 & 660075,848 & 7744877,876 & 865,66 & dormente & até $2 \mathrm{~m}$ \\
\hline Bonuccelli, T.J. & 1999 & 418 & 3 & Quedas e rolamentos & rocha & BQL638 & 659796,581 & 7744855,996 & 1020,83 & dormente & até $2 \mathrm{~m}$ \\
\hline Bonuccelli, T.J. & 1999 & 322 & 12 & Corridas e rolamentos & rocha, detritos e solo & BCL639 & 659931,432 & 7744551,686 & 1941,22 & ativa & até $2 \mathrm{~m}$ \\
\hline Bonuccelli, T.J. & 1999 & 311 & 3 & Quedas e rolamentos & rocha & BQL640 & 660457,282 & 7744691,006 & 1076,61 & ativa & até $2 \mathrm{~m}$ \\
\hline Bonuccelli, T.J. & 1999 & 269 & 3 & Quedas e rolamentos & rocha & BQL641 & 660268,629 & 7742802,624 & 1137,61 & ativa & até $2 \mathrm{~m}$ \\
\hline Bonuccelli, T.J. & 1999 & 270 & 3 & Quedas e rolamentos & rocha & BQL642 & 659854,359 & 7742868,552 & 1516,11 & ativa & até $2 \mathrm{~m}$ \\
\hline Bonuccelli, T.J. & 1999 & 272 & 3 & Quedas e rolamentos & rocha & BQL643 & 659969,935 & 7743399,954 & 528,55 & ativa & até $2 \mathrm{~m}$ \\
\hline Bonuccelli, T.J. & 1999 & 267 & 12 & Corridas e rolamentos & rocha, detritos e solo & BCL644 & 660477,937 & 7745569,353 & 2225,27 & ativa & até $2 \mathrm{~m}$ \\
\hline Bonuccelli, T.J. & 1999 & 266 & 12 & Corridas e rolamentos & rocha, detritos e solo & BCL645 & 660370,155 & 7745877,356 & 6833,04 & ativa & até $2 \mathrm{~m}$ \\
\hline Bonuccelli, T.J. & 1999 & 250 & 3 & Quedas e rolamentos & rocha & BQL646 & 660487,330 & 7746724,501 & 1244,22 & ativa & até $2 \mathrm{~m}$ \\
\hline
\end{tabular}

*ANO: Data do trabalho; 1: Código da feição; 2: Código do processo; CÓD.INV: Código do inventário; PROF.: Profundidade do movimento, N/A: Not Available (Não disponível). 
Apêndice B: Banco de dados do inventário de movimentos de massa gravitacionais (continuação).

\begin{tabular}{|c|c|c|c|c|c|c|c|c|c|c|c|}
\hline AUTOR & ANO & 1 & 2 & TIPO DE PROCESSO & TIPO DE MATERIAL & COD.INV & UTM E & UTM N & ÁREA $\left(\mathbf{m}^{2}\right)$ & ATIVIDADE & PROF. \\
\hline Bonuccelli, T.J. & 1999 & 251 & 3 & Quedas e rolamentos & rocha & BQL647 & 660650,764 & 7746606,868 & 994,78 & ativa & 2 a $10 \mathrm{~m}$ \\
\hline Bonuccelli, T.J. & 1999 & 253 & 12 & Corridas e rolamentos & rocha, detritos e solo & BCL648 & 660343,616 & 7745981,675 & 5356,49 & ativa & até $2 \mathrm{~m}$ \\
\hline Bonuccelli, T.J. & 1999 & 255 & 12 & Corridas e rolamentos & rocha, detritos e solo & BCL649 & 660448,343 & 7745674,892 & 3649,66 & ativa & 2 a $10 \mathrm{~m}$ \\
\hline Bonuccelli, T.J. & 1999 & 254 & 12 & Corridas e rolamentos & rocha, detritos e solo & $\mathrm{BCL} 650$ & 660595,947 & 7745774,564 & 5081,71 & ativa & 2 a $10 m$ \\
\hline Bonuccelli, T.J. & 1999 & 256 & 12 & Corridas e rolamentos & rocha, detritos e solo & BCL651 & 659966,541 & 77454955,934 & 3371,94 & ativa & até $2 \mathrm{~m}$ \\
\hline Bonuccelli, T.J. & 1999 & 257 & 8 & Área de múltiplas feições & rocha, detritos e solo & BA652 & 660562,875 & 7745276,748 & 55819,40 & ativa & $>10 \mathrm{~m}$ \\
\hline Bonuccelli, T.J. & 1999 & 436 & 1 & Escorregamento & rocha, detritos e solo & BE653 & 659116,742 & 7745035,682 & 208,98 & ativa & até $2 \mathrm{~m}$ \\
\hline Bonuccelli, T.J. & 1999 & 193 & 4 & Escoamentos rápidos ou corrida & detritos e solo & BC654 & 655888,217 & 7746311,110 & 2264,16 & ativa & até $2 \mathrm{~m}$ \\
\hline Zenóbio, A.A. & 2000 & $\mathrm{~N} / \mathrm{A}$ & Etr & Escorregamento translacional & Rocha & ZT655 & 655552,035 & 7746575,389 & 52,12 & N/A & $\mathrm{N} / \mathrm{A}$ \\
\hline Zenóbio, A.A. & 2000 & $\mathrm{~N} / \mathrm{A}$ & Etr & Escorregamento translacional & Rocha & ZT656 & 655224,938 & 7746550,667 & 85,48 & $\mathrm{~N} / \mathrm{A}$ & $\mathrm{N} / \mathrm{A}$ \\
\hline Zenóbio, A.A. & 2000 & $\mathrm{~N} / \mathrm{A}$ & Etr & Escorregamento translacional & Rocha & ZT657 & 655309,749 & 7746524,944 & 90,80 & N/A & $\mathrm{N} / \mathrm{A}$ \\
\hline Zenóbio, A.A. & 2000 & $\mathrm{~N} / \mathrm{A}$ & Etr & Escorregamento translacional & Rocha & ZT658 & 655335,272 & 7745958,846 & 540,40 & $\mathrm{~N} / \mathrm{A}$ & $\mathrm{N} / \mathrm{A}$ \\
\hline Zenóbio, A.A. & 2000 & $\mathrm{~N} / \mathrm{A}$ & Etr & Escorregamento translacional & Rocha & ZT659 & 655182,864 & 7746060,162 & 76,83 & N/A & $\mathrm{N} / \mathrm{A}$ \\
\hline Zenóbio, A.A. & 2000 & $\mathrm{~N} / \mathrm{A}$ & Etr & Escorregamento translacional & Rocha & ZT660 & 655476,641 & 7746144,537 & 47,60 & $\mathrm{~N} / \mathrm{A}$ & $\mathrm{N} / \mathrm{A}$ \\
\hline Zenóbio, A.A. & 2000 & $\mathrm{~N} / \mathrm{A}$ & Etr & Escorregamento translacional & Rocha & ZT661 & 655566,306 & 7746174,421 & 106,34 & N/A & $\mathrm{N} / \mathrm{A}$ \\
\hline Zenóbio, A.A. & 2000 & $\mathrm{~N} / \mathrm{A}$ & Etr & Escorregamento translacional & Rocha & ZT662 & 655589,781 & 7746108,554 & 229,68 & $\mathrm{~N} / \mathrm{A}$ & $\mathrm{N} / \mathrm{A}$ \\
\hline Zenóbio, A.A. & 2000 & $\mathrm{~N} / \mathrm{A}$ & Etr & Escorregamento translacional & Rocha & ZT663 & 655640,515 & 7746152,032 & 64,93 & N/A & $\mathrm{N} / \mathrm{A}$ \\
\hline Zenóbio, A.A. & 2000 & $\mathrm{~N} / \mathrm{A}$ & Etr & Escorregamento translacional & Rocha & ZT664 & 655667,121 & 7745998,594 & 72,52 & $\mathrm{~N} / \mathrm{A}$ & $\mathrm{N} / \mathrm{A}$ \\
\hline Zenóbio, A.A. & 2000 & $\mathrm{~N} / \mathrm{A}$ & Etr & Escorregamento translacional & Rocha & ZT665 & 655828,391 & 7746089,744 & 559,58 & N/A & $\mathrm{N} / \mathrm{A}$ \\
\hline Zenóbio, A.A. & 2000 & $\mathrm{~N} / \mathrm{A}$ & Etr & Escorregamento translacional & Rocha & ZT666 & 655855,195 & 7746056,907 & 236,72 & N/A & $\mathrm{N} / \mathrm{A}$ \\
\hline Zenóbio, A.A. & 2000 & $\mathrm{~N} / \mathrm{A}$ & Etr & Escorregamento translacional & Rocha & ZT667 & 655887,650 & 7746010,120 & 305,05 & N/A & $\mathrm{N} / \mathrm{A}$ \\
\hline Zenóbio, A.A. & 2000 & $\mathrm{~N} / \mathrm{A}$ & Etr & Escorregamento translacional & Rocha & ZT668 & 655980,849 & 7746073,401 & 58,70 & $\mathrm{~N} / \mathrm{A}$ & $\mathrm{N} / \mathrm{A}$ \\
\hline Zenóbio, A.A. & 2000 & $\mathrm{~N} / \mathrm{A}$ & Etr & Escorregamento translacional & Rocha & ZT669 & 655992,952 & 7746102,273 & 88,31 & $\mathrm{~N} / \mathrm{A}$ & $\mathrm{N} / \mathrm{A}$ \\
\hline Zenóbio, A.A. & 2000 & $\mathrm{~N} / \mathrm{A}$ & Etr & Escorregamento translacional & Rocha & ZT670 & 656071,147 & 7746313,103 & 207,49 & $\mathrm{~N} / \mathrm{A}$ & $\mathrm{N} / \mathrm{A}$ \\
\hline Zenóbio, A.A. & 2000 & $\mathrm{~N} / \mathrm{A}$ & Etr & Escorregamento translacional & Rocha & ZT671 & 656124,613 & 7746264,025 & 81,70 & $\mathrm{~N} / \mathrm{A}$ & $\mathrm{N} / \mathrm{A}$ \\
\hline Zenóbio, A.A. & 2000 & $\mathrm{~N} / \mathrm{A}$ & Etr & Escorregamento translacional & Rocha & ZT672 & 656190,039 & 7745883,882 & 104,90 & $\mathrm{~N} / \mathrm{A}$ & $\mathrm{N} / \mathrm{A}$ \\
\hline Zenóbio, A.A. & 2000 & $\mathrm{~N} / \mathrm{A}$ & Etr & Escorregamento translacional & Rocha & ZT673 & 656037,508 & 7745931,742 & 79,84 & $\mathrm{~N} / \mathrm{A}$ & $\mathrm{N} / \mathrm{A}$ \\
\hline Zenóbio, A.A. & 2000 & $\mathrm{~N} / \mathrm{A}$ & Etr & Escorregamento translacional & Rocha & ZT674 & 656127,504 & 7745775,929 & 68,88 & N/A & $\mathrm{N} / \mathrm{A}$ \\
\hline Zenóbio, A.A. & 2000 & $\mathrm{~N} / \mathrm{A}$ & Ets & Escorregamento translacional & Solo & ZT675 & 655984,477 & 7745712,675 & 136,09 & $\mathrm{~N} / \mathrm{A}$ & $\mathrm{N} / \mathrm{A}$ \\
\hline Zenóbio, A.A. & 2000 & $\mathrm{~N} / \mathrm{A}$ & Ets & Escorregamento translacional & Solo & ZT676 & 655956,700 & 7745688,343 & 520,20 & $\mathrm{~N} / \mathrm{A}$ & $\mathrm{N} / \mathrm{A}$ \\
\hline Zenóbio, A.A. & 2000 & $\mathrm{~N} / \mathrm{A}$ & Etr & Escorregamento translacional & Rocha & ZT677 & 656401,748 & 7746108,624 & 151,77 & $\mathrm{~N} / \mathrm{A}$ & $\mathrm{N} / \mathrm{A}$ \\
\hline Zenóbio, A.A. & 2000 & $\mathrm{~N} / \mathrm{A}$ & Etr & Escorregamento translacional & Rocha & ZT678 & 656510,892 & 7746100,486 & 48,58 & $\mathrm{~N} / \mathrm{A}$ & $\mathrm{N} / \mathrm{A}$ \\
\hline Zenóbio, A.A. & 2000 & $\mathrm{~N} / \mathrm{A}$ & Etr & Escorregamento translacional & Rocha & ZT679 & 656313,218 & 7745753,303 & 49,56 & $\mathrm{~N} / \mathrm{A}$ & $\mathrm{N} / \mathrm{A}$ \\
\hline Zenóbio, A.A. & 2000 & $\mathrm{~N} / \mathrm{A}$ & Etr & Escorregamento translacional & Rocha & ZT680 & 656241,892 & 7745657,204 & 140,64 & N/A & $\mathrm{N} / \mathrm{A}$ \\
\hline
\end{tabular}

*ANO: Data do trabalho; 1: Código da feição; 2: Código do processo; CÓD.INV: Código do inventário; PROF.: Profundidade do movimento, N/A: Not Available (Não disponível). 
Apêndice B: Banco de dados do inventário de movimentos de massa gravitacionais (continuação).

\begin{tabular}{|c|c|c|c|c|c|c|c|c|c|c|c|}
\hline AUTOR & ANO & 1 & 2 & TIPO DE PROCESSO & TIPO DE MATERIAL & COD.INV & UTM E & UTM N & ÁREA $\left(\mathbf{m}^{2}\right)$ & ATIVIDADE & PROF. \\
\hline Zenóbio, A.A. & 2000 & $\mathrm{~N} / \mathrm{A}$ & Etr & Escorregamento translacional & Rocha & ZT681 & 656207,950 & 7745484,476 & 142,84 & $\mathrm{~N} / \mathrm{A}$ & $\mathrm{N} / \mathrm{A}$ \\
\hline Zenóbio, A.A. & 2000 & $\mathrm{~N} / \mathrm{A}$ & Etr & Escorregamento translacional & Rocha & ZT682 & 656274,124 & 7745394,048 & 324,65 & $\mathrm{~N} / \mathrm{A}$ & $\mathrm{N} / \mathrm{A}$ \\
\hline Zenóbio, A.A. & 2000 & $\mathrm{~N} / \mathrm{A}$ & Etr & Escorregamento translacional & Rocha & ZT683 & 656557,262 & 7745777,621 & 107,28 & $\mathrm{~N} / \mathrm{A}$ & $\mathrm{N} / \mathrm{A}$ \\
\hline Zenóbio, A.A. & 2000 & $\mathrm{~N} / \mathrm{A}$ & Etr & Escorregamento translacional & Rocha & ZT684 & 656584,825 & 7745803,105 & 67,27 & $\mathrm{~N} / \mathrm{A}$ & $\mathrm{N} / \mathrm{A}$ \\
\hline Zenóbio, A.A. & 2000 & $\mathrm{~N} / \mathrm{A}$ & Etr & Escorregamento translacional & Rocha & ZT685 & 656586,041 & 7745830,062 & 62,51 & $\mathrm{~N} / \mathrm{A}$ & $\mathrm{N} / \mathrm{A}$ \\
\hline Zenóbio, A.A. & 2000 & $\mathrm{~N} / \mathrm{A}$ & Etr & Escorregamento translacional & Rocha & ZT686 & 656612,986 & 7745909,603 & 91,01 & $\mathrm{~N} / \mathrm{A}$ & $\mathrm{N} / \mathrm{A}$ \\
\hline Zenóbio, A.A. & 2000 & $\mathrm{~N} / \mathrm{A}$ & Etr & Escorregamento translacional & Rocha & ZT687 & 656778,888 & 7746016,822 & 45,43 & $\mathrm{~N} / \mathrm{A}$ & $\mathrm{N} / \mathrm{A}$ \\
\hline Zenóbio, A.A. & 2000 & $\mathrm{~N} / \mathrm{A}$ & Etr & Escorregamento translacional & Rocha & ZT688 & 656622,779 & 7745830,627 & 231,12 & $\mathrm{~N} / \mathrm{A}$ & $\mathrm{N} / \mathrm{A}$ \\
\hline Zenóbio, A.A. & 2000 & $\mathrm{~N} / \mathrm{A}$ & $C x$ & Complexo & $\mathrm{N} / \mathrm{A}$ & ZX689 & 656780,503 & 7745626,284 & 828,43 & $\mathrm{~N} / \mathrm{A}$ & $\mathrm{N} / \mathrm{A}$ \\
\hline Zenóbio, A.A. & 2000 & $\mathrm{~N} / \mathrm{A}$ & Etr & Escorregamento translacional & Rocha & ZT690 & 656721,524 & 7745442,792 & 47,08 & $\mathrm{~N} / \mathrm{A}$ & $\mathrm{N} / \mathrm{A}$ \\
\hline Zenóbio, A.A. & 2000 & $\mathrm{~N} / \mathrm{A}$ & Etr & Escorregamento translacional & Rocha & ZT691 & 656756,125 & 7745425,516 & 64,51 & $\mathrm{~N} / \mathrm{A}$ & $\mathrm{N} / \mathrm{A}$ \\
\hline Zenóbio, A.A. & 2000 & $\mathrm{~N} / \mathrm{A}$ & $\mathrm{B}$ & Queda & Rocha & ZQ692 & 656793,377 & 7745730,214 & 988,43 & $\mathrm{~N} / \mathrm{A}$ & $\mathrm{N} / \mathrm{A}$ \\
\hline Zenóbio, A.A. & 2000 & $\mathrm{~N} / \mathrm{A}$ & $B$ & Queda & Rocha & ZQ693 & 656386,525 & 7745837,378 & 732,32 & $\mathrm{~N} / \mathrm{A}$ & $\mathrm{N} / \mathrm{A}$ \\
\hline
\end{tabular}

*ANO: Data do trabalho; 1: Código da feição; 2: Código do processo; CÓD.INV: Código do inventário; PROF.: Profundidade do movimento, N/A: Not Available (Não disponível). 


\section{APÊNDICE I}

Mapa Topográfico 


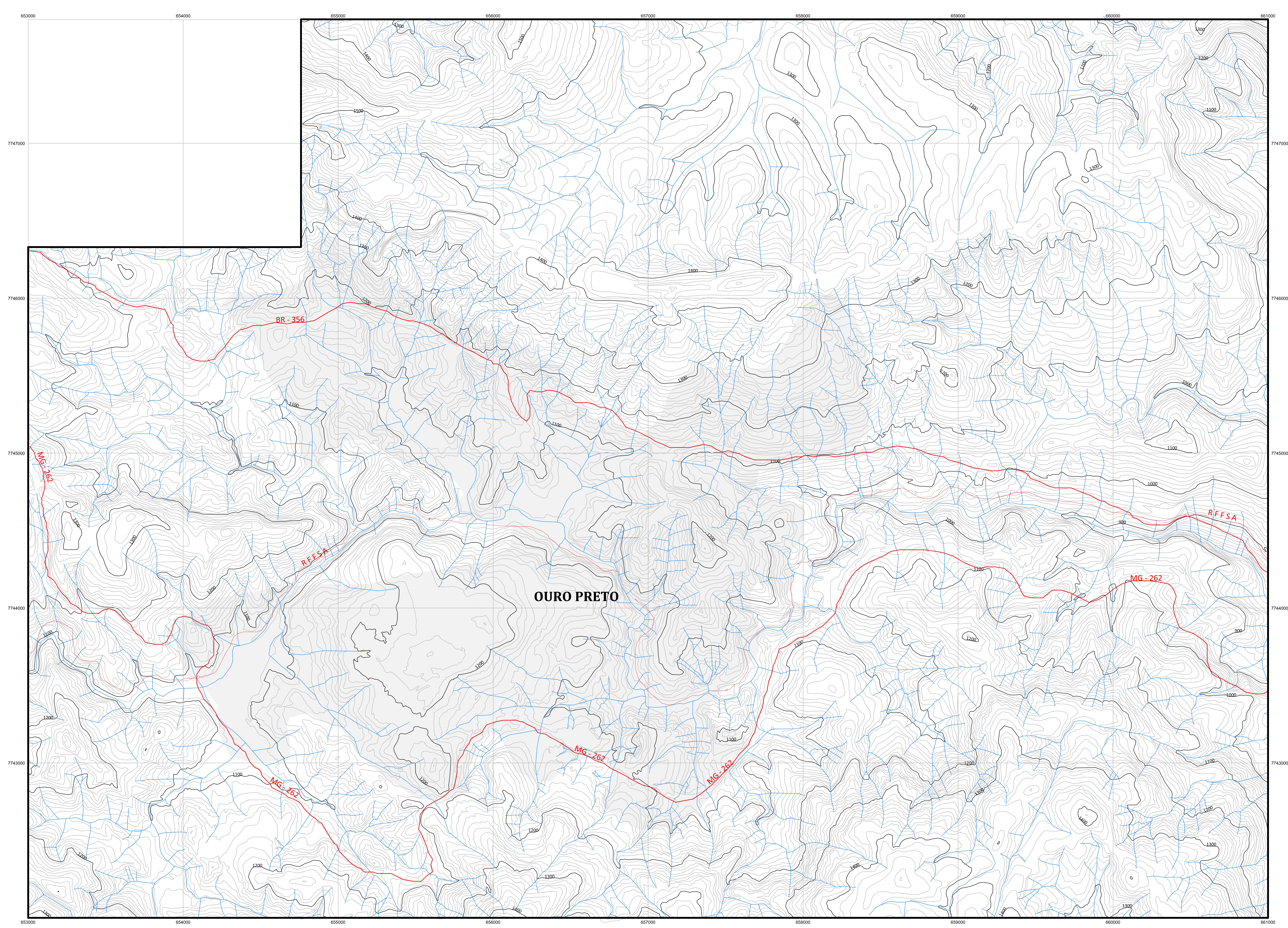

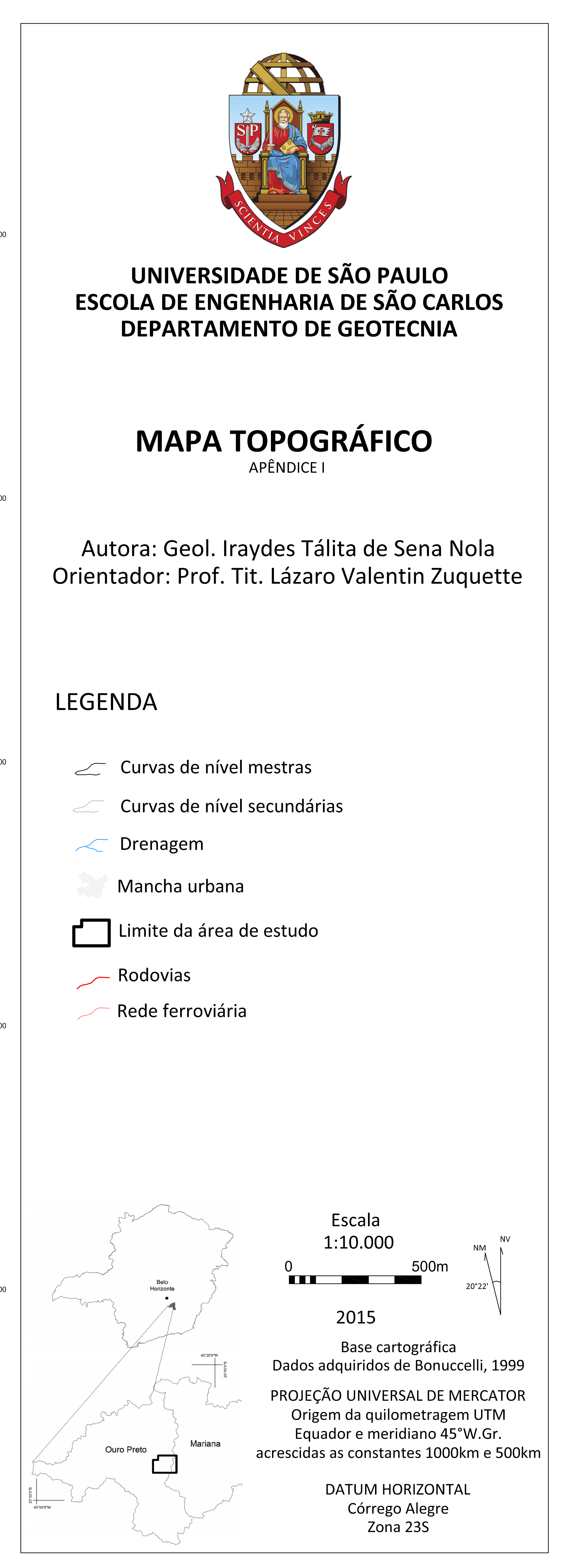




\section{APÊNDICE II}

Mapa de Substrato Rochoso 

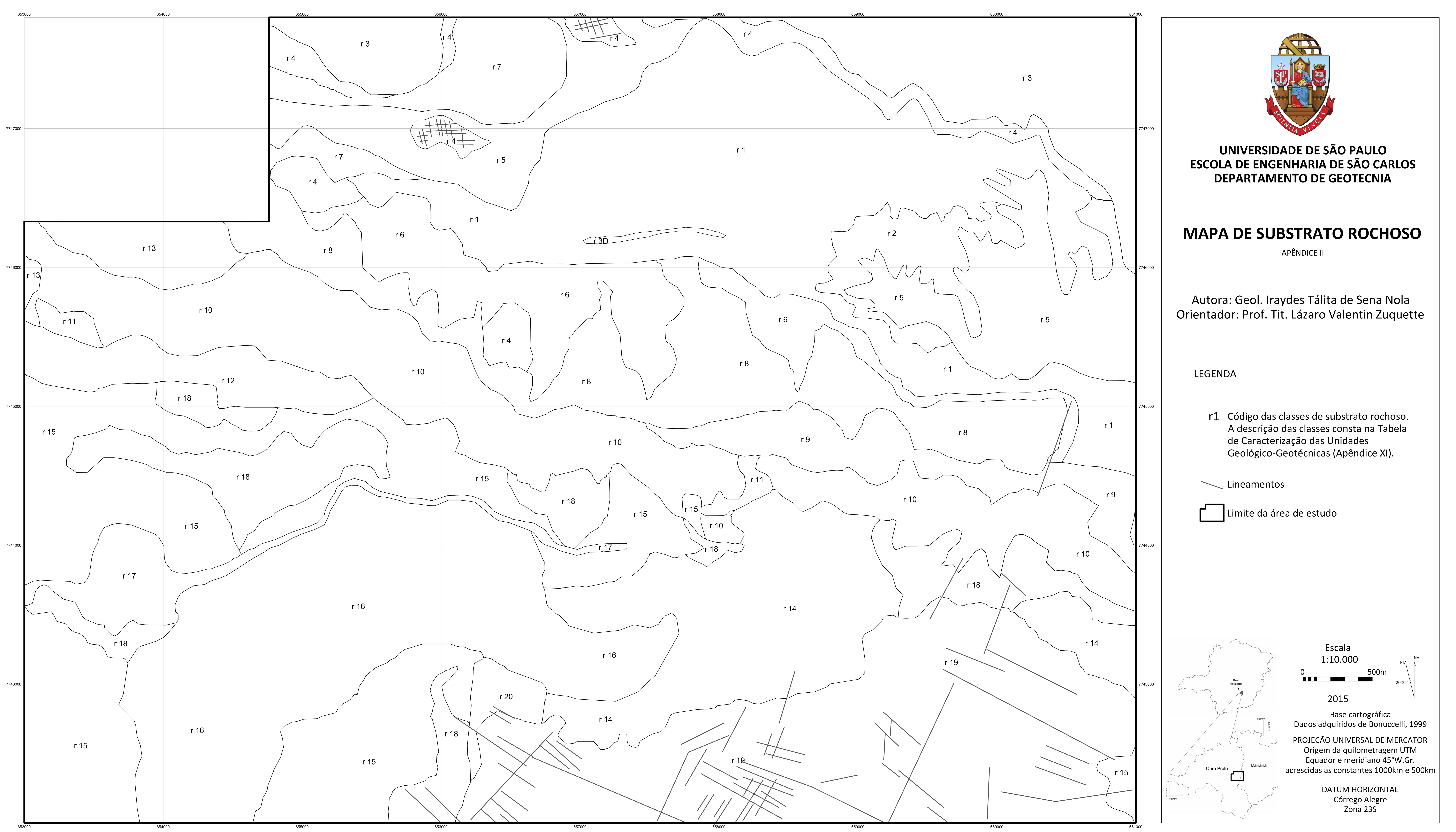


\section{APÊNDICE III}

Mapa de Material Inconsolidado 

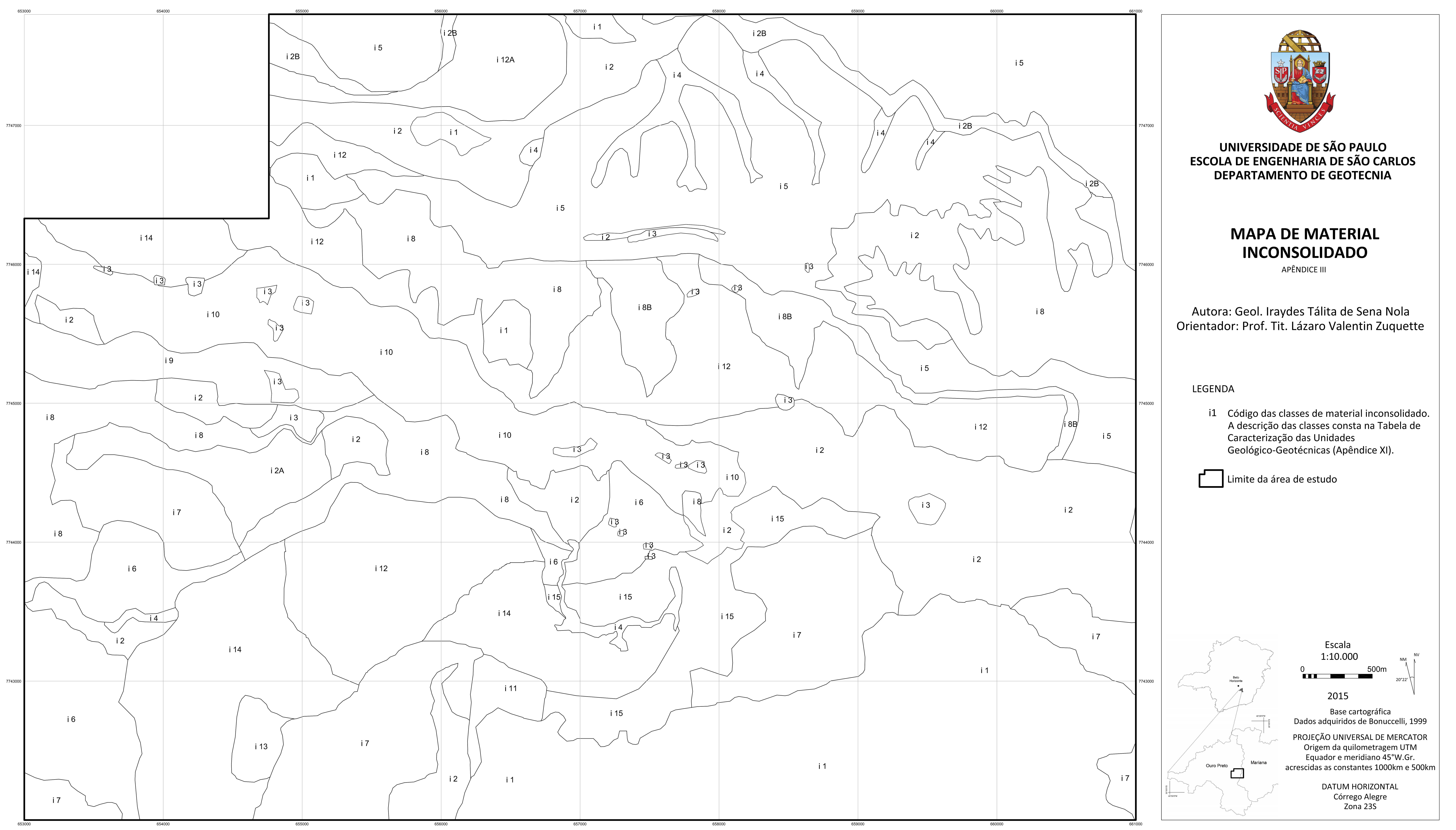


\section{APÊNDICE IV}

Mapa de Uso e Ocupação 

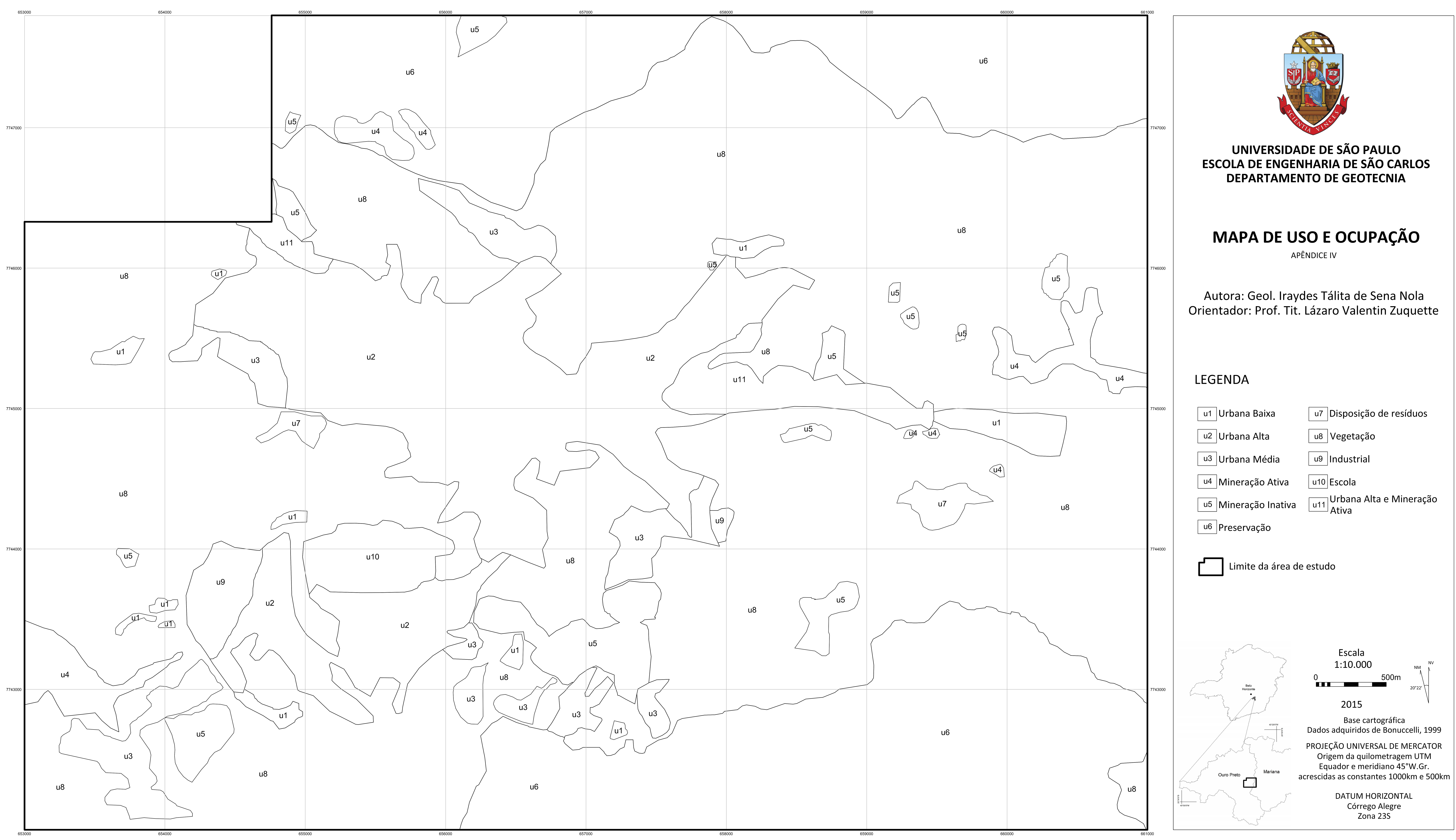


\section{APÊNDICE V}

Mapa das Ocorrências Inventariadas 

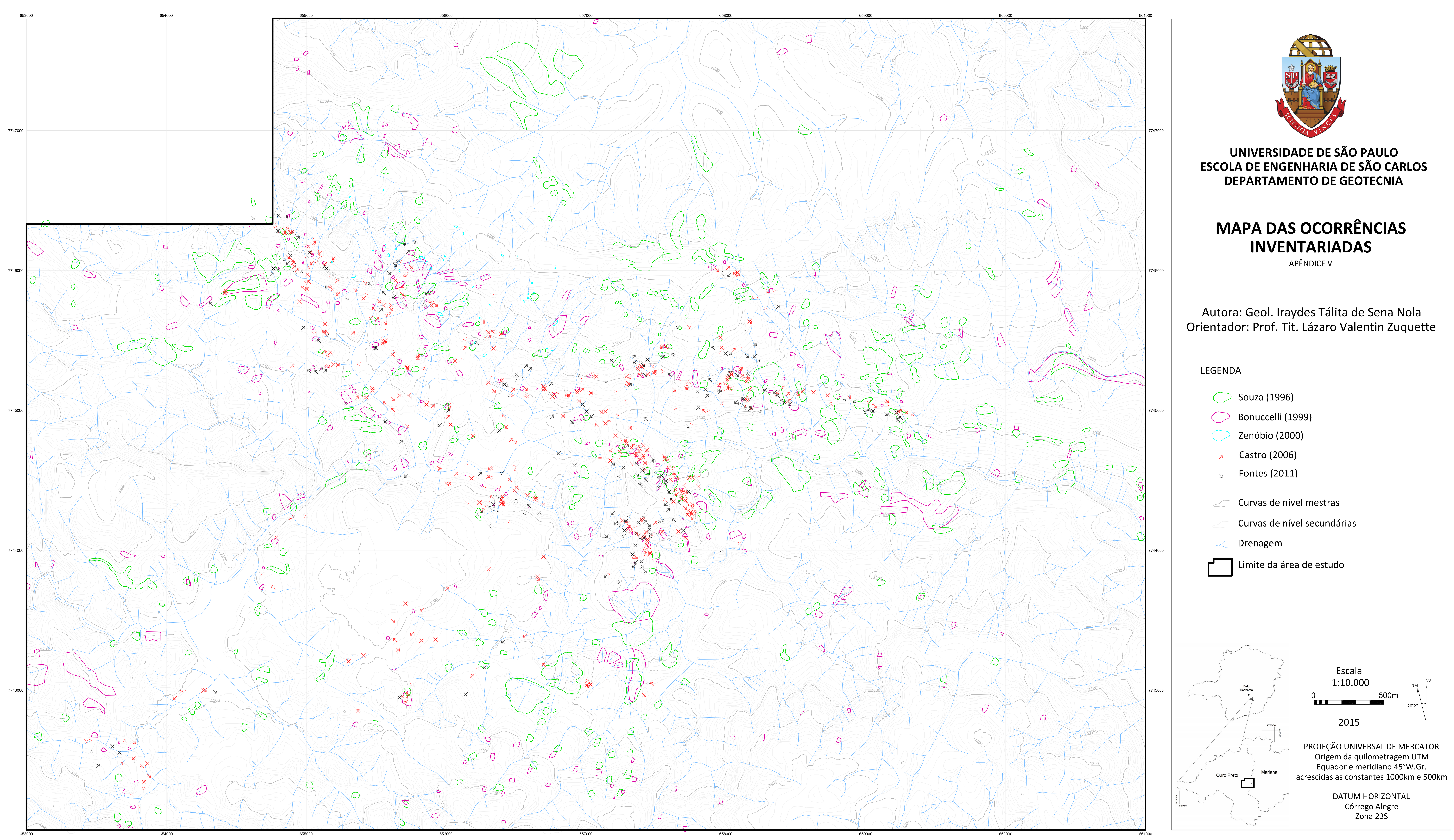


\section{APÊNDICE VI}

Mapa de Inventário dos Movimentos de Massa Gravitacionais 

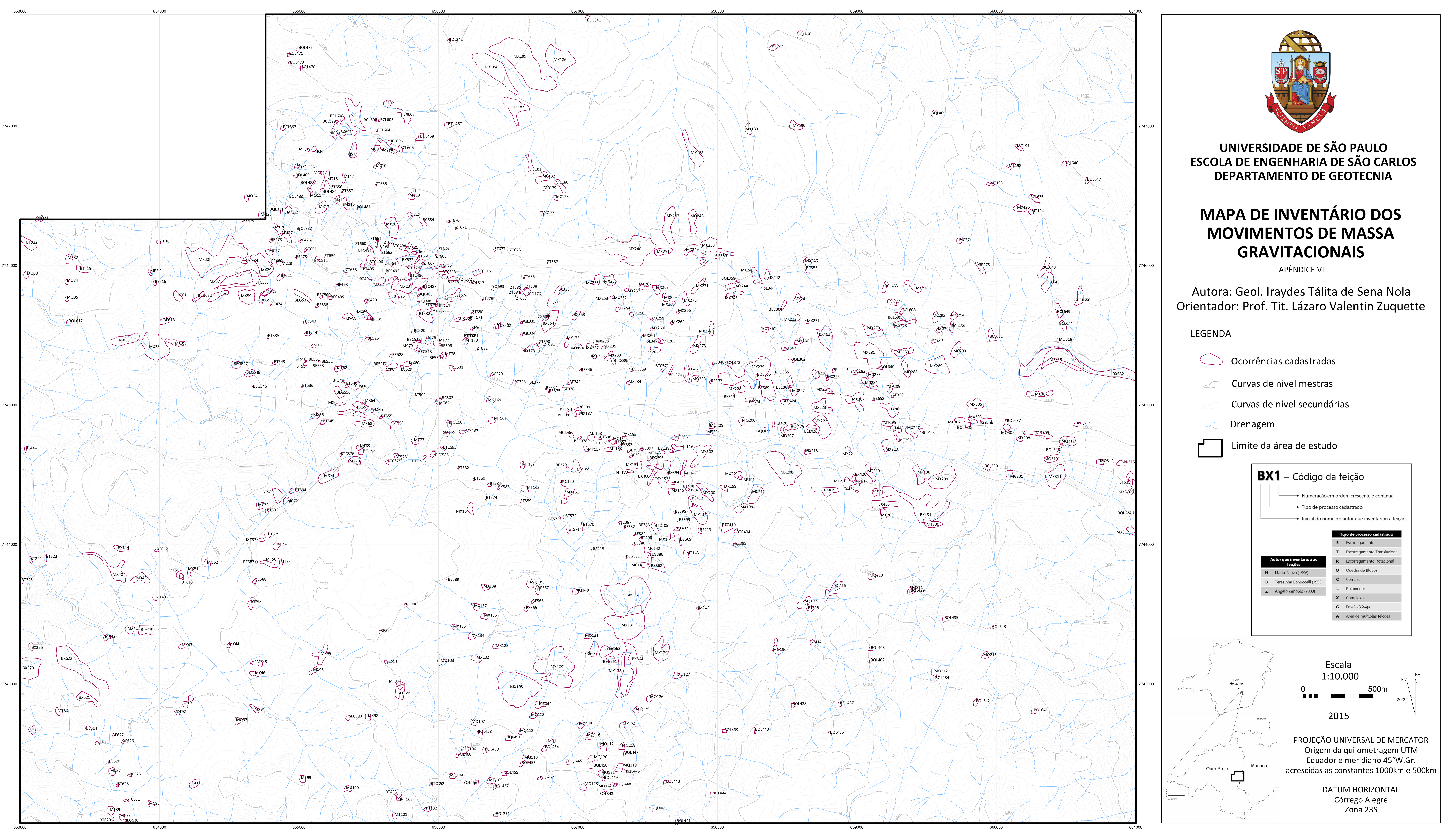


\section{APÊNDICE VII}

Mapa de Inventário dos Escorregamentos Translacionais 

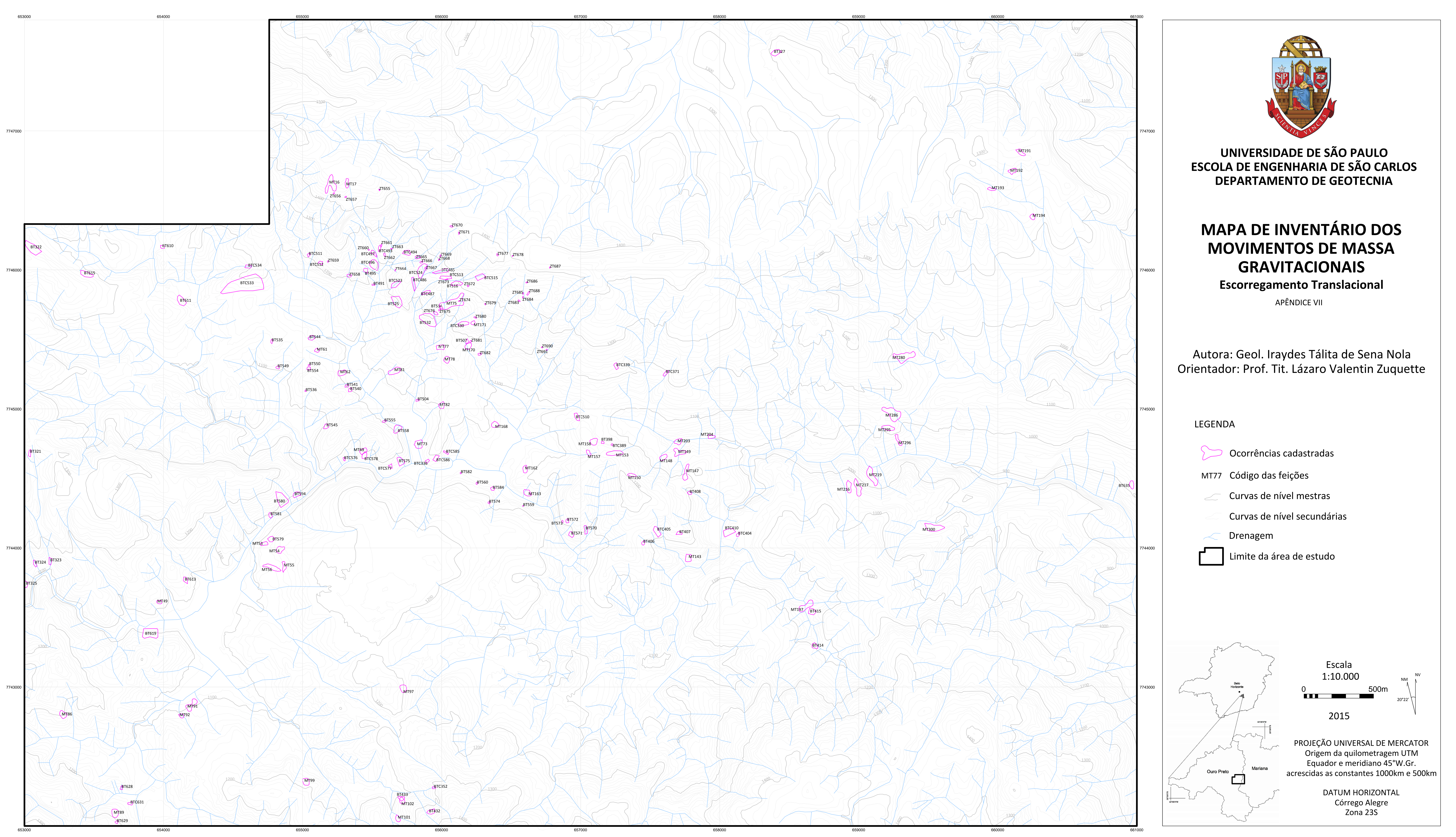


\section{APÊNDICE VIII \\ Mapa de Inventário dos Escorregamentos Translacionais - Tipo de Material}



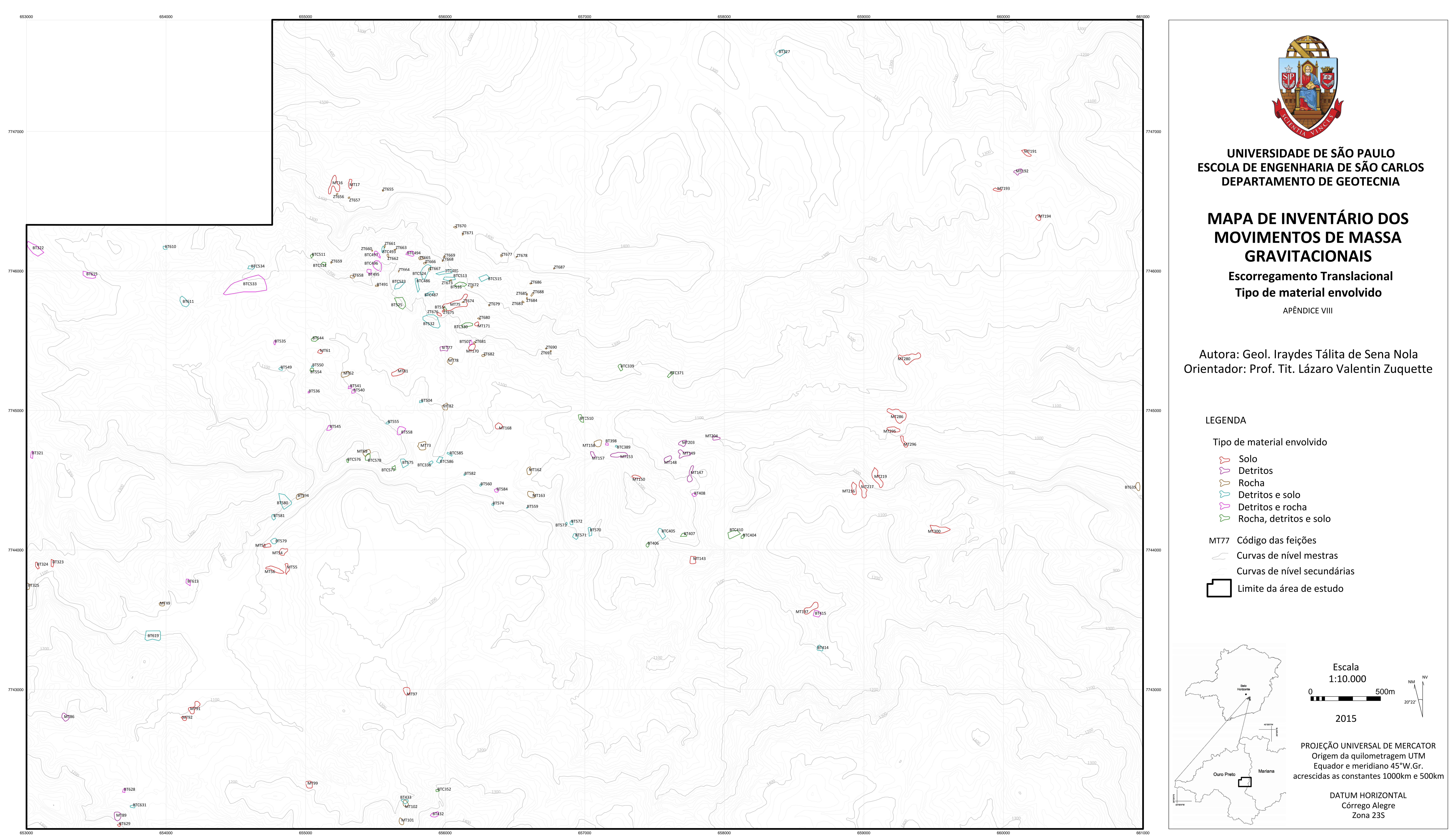


\section{APÊNDICE IX}

Carta de declividade 

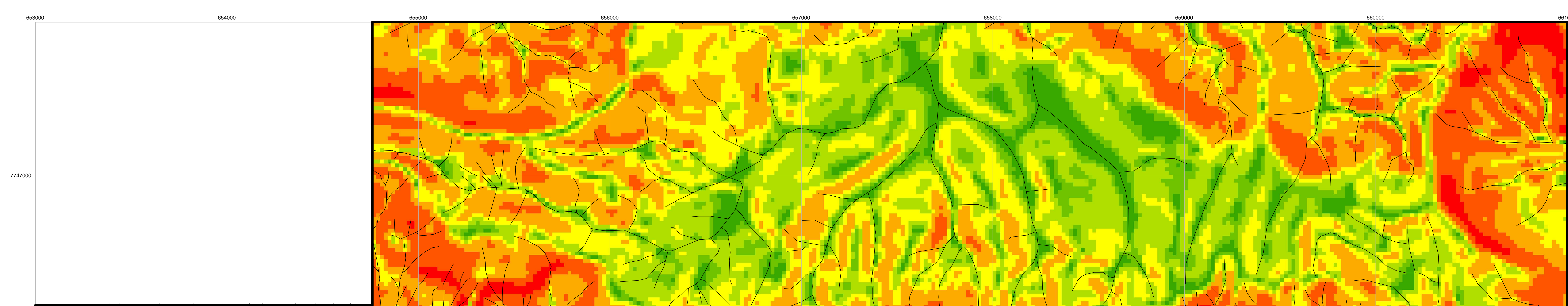

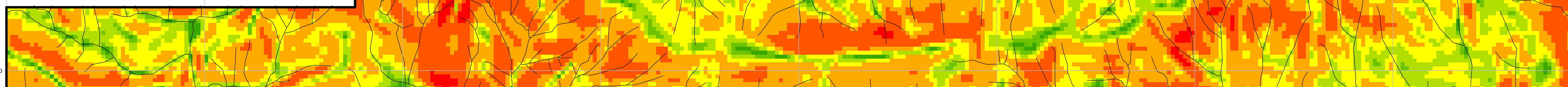

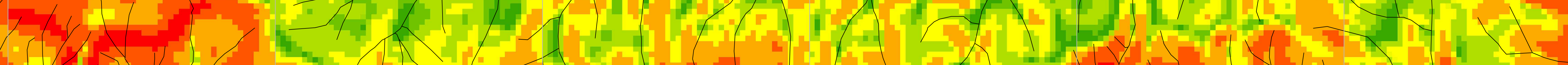

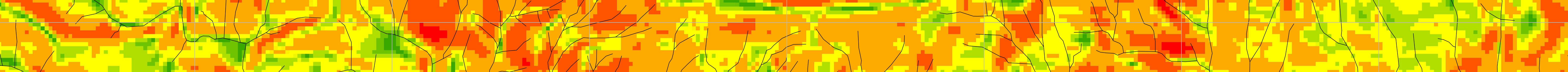

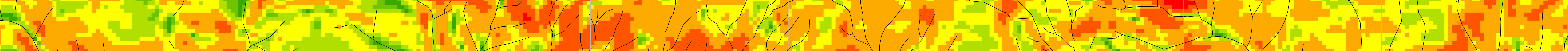

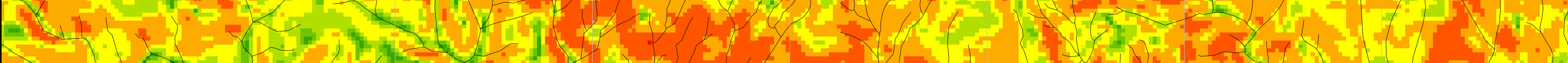

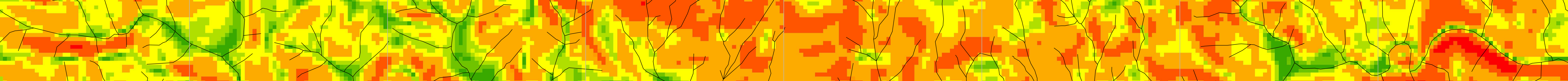

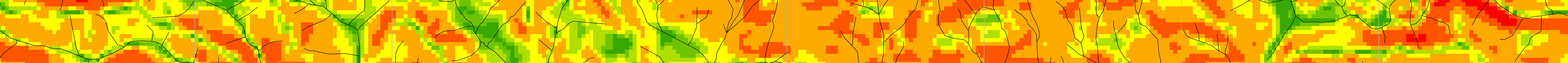

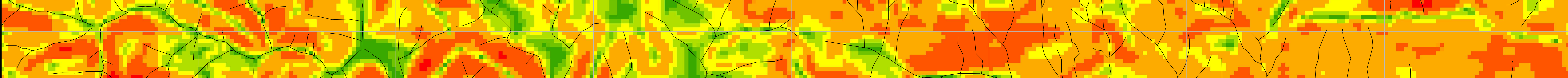

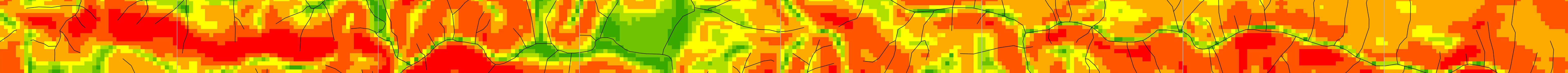

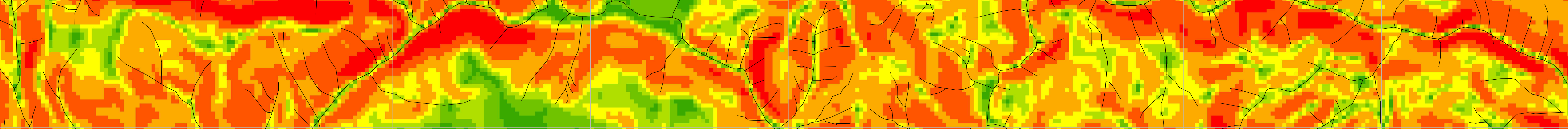

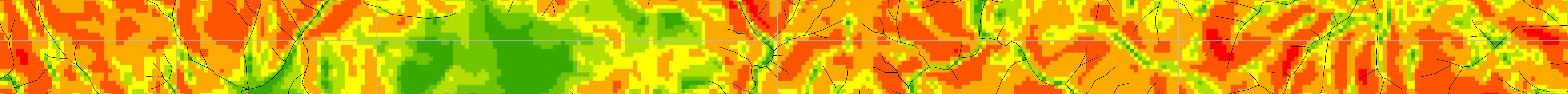

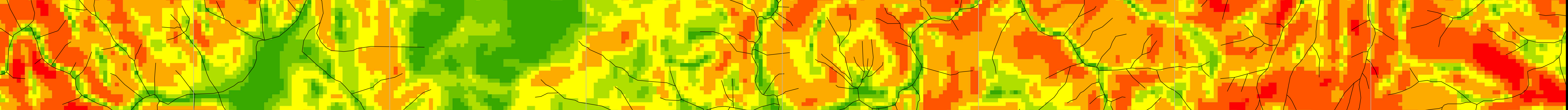

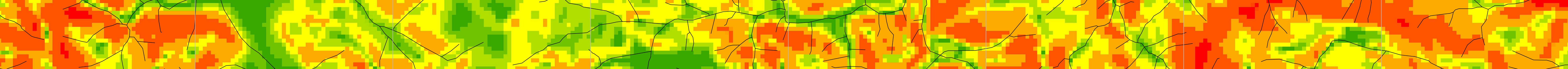

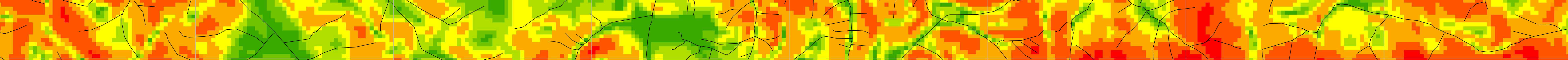

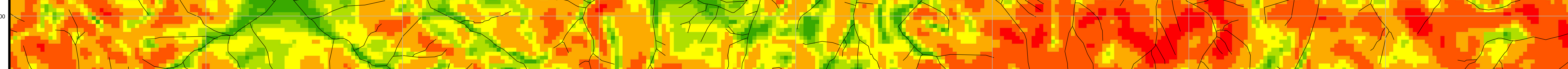

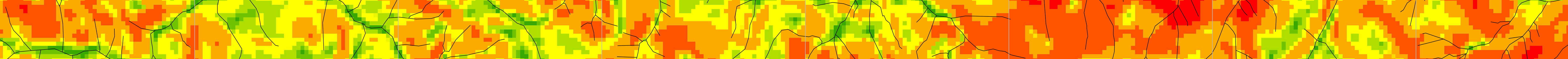

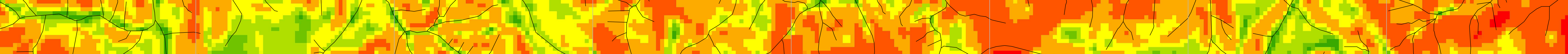

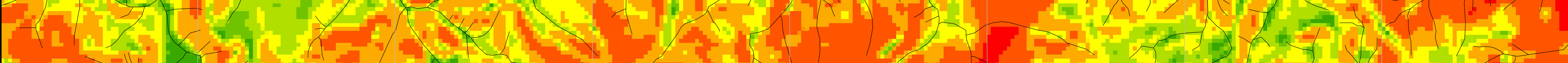

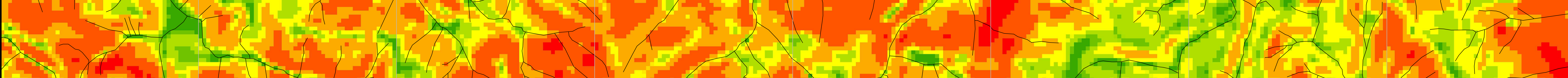

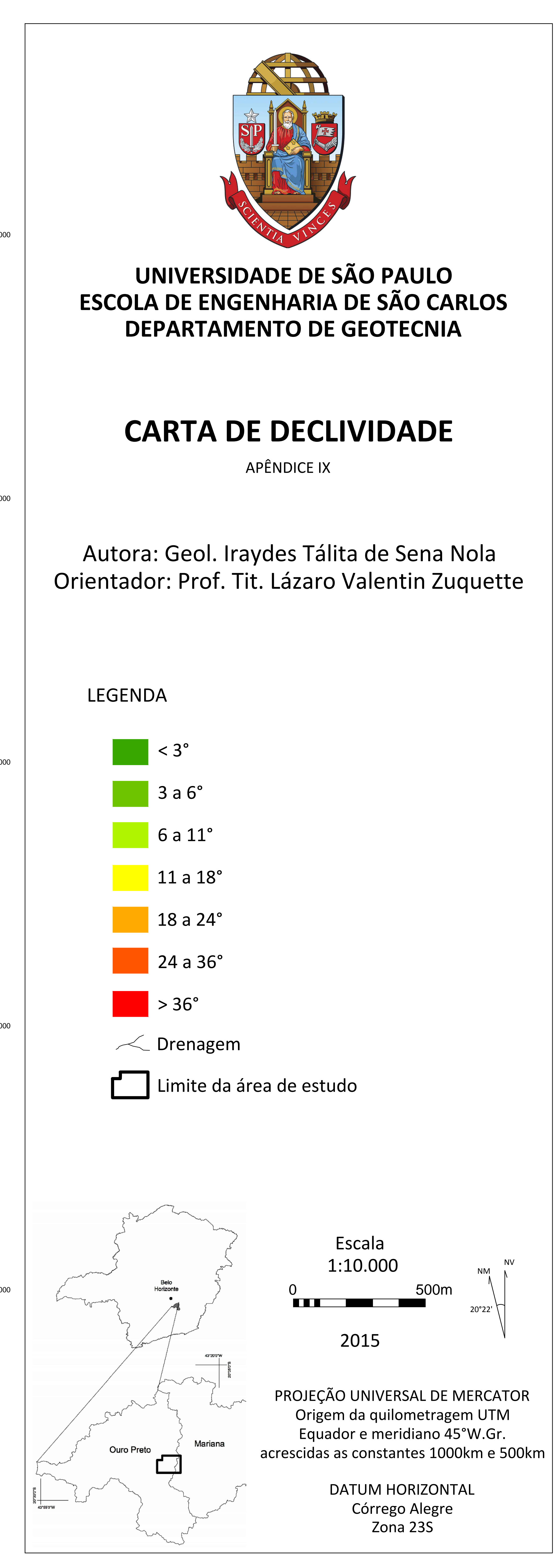




\section{APÊNDICE X}

Carta do Rumo da Inclinação das Encostas 

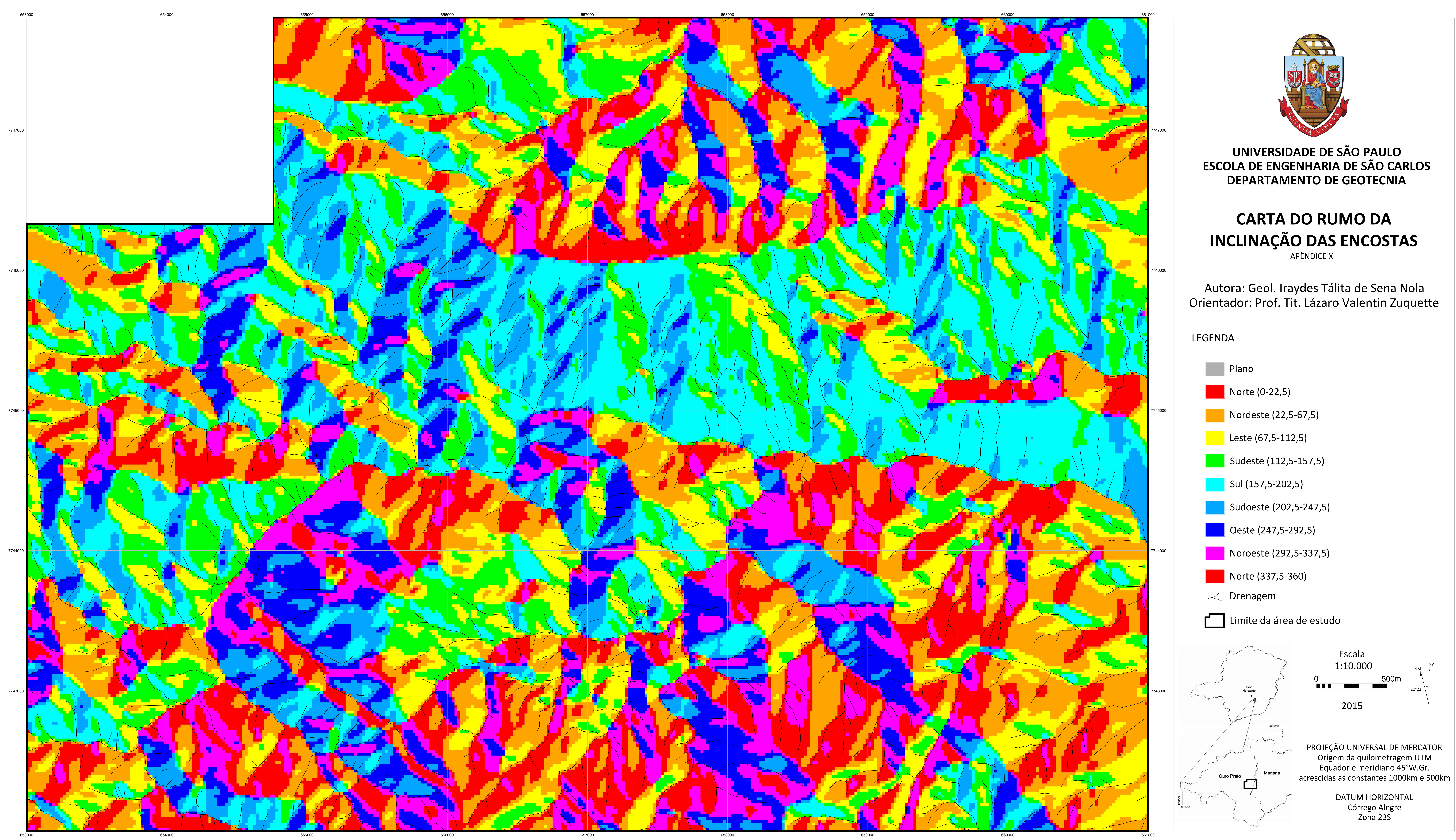


\section{APÊNDICE XI}

Tabela de Caracterização das Unidades Geológico-Geotécnicas 


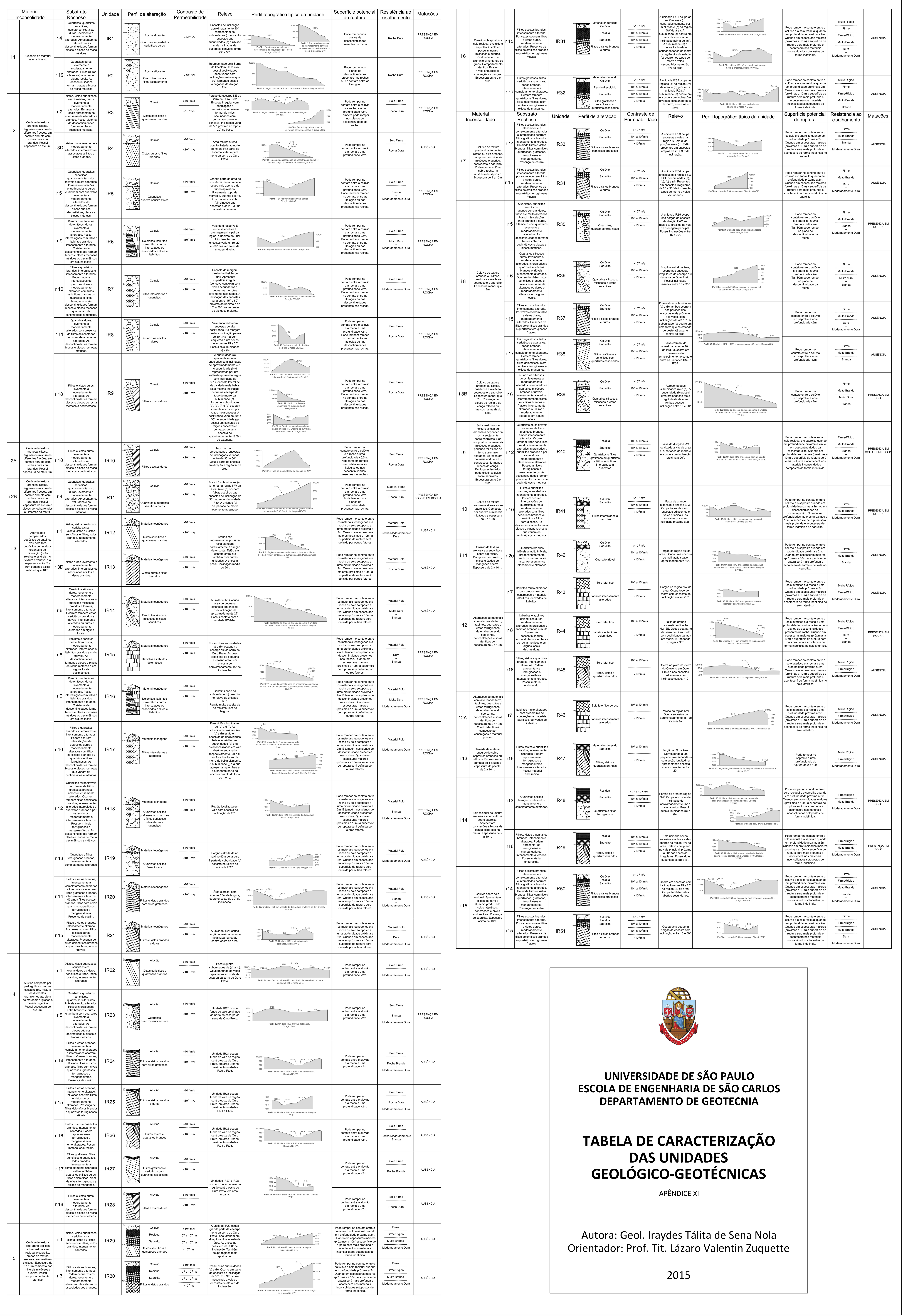




\section{APÊNDICE XII}

Carta das Unidades Geológico-Geotécnicas 

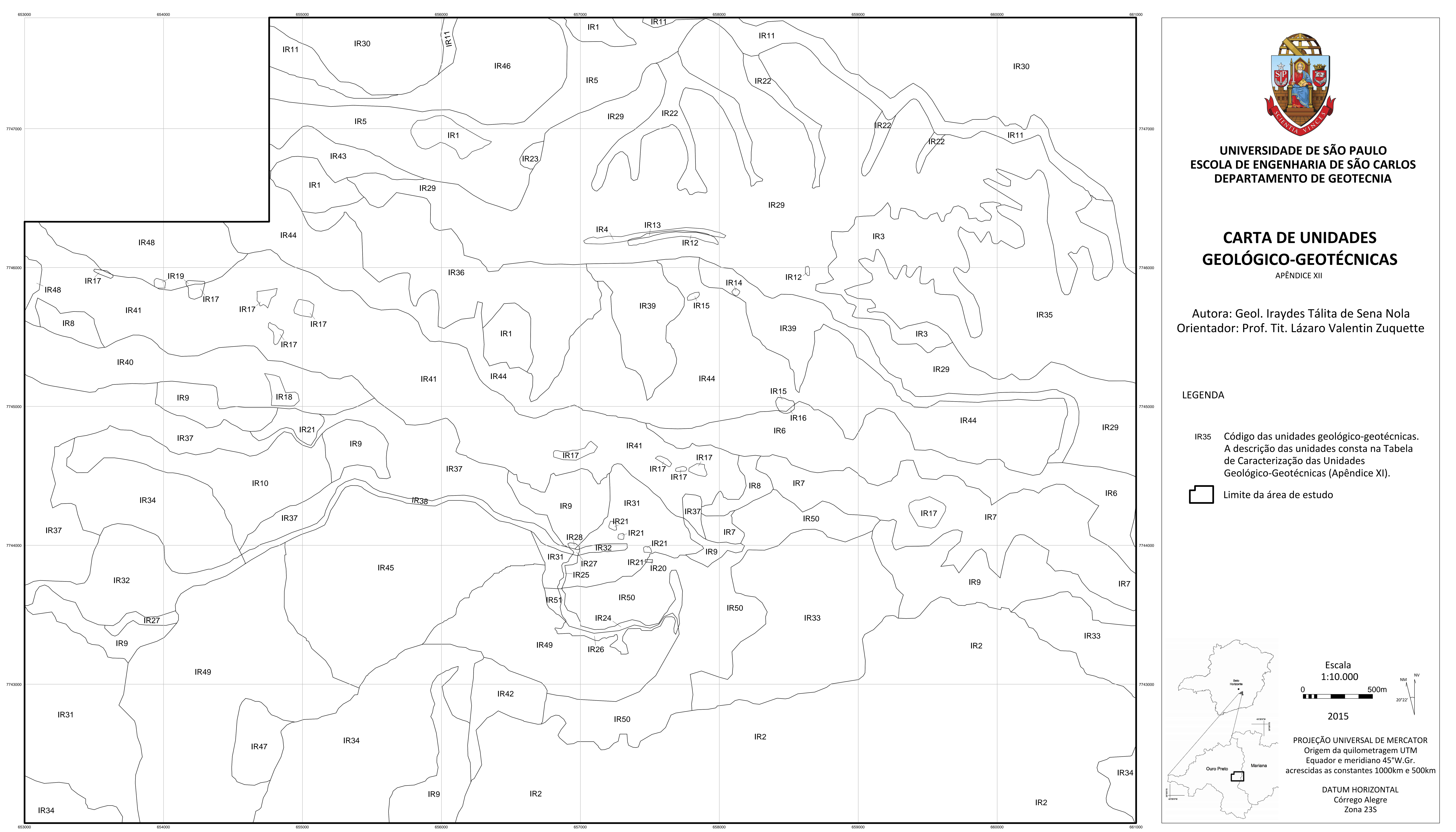


\section{APÊNDICE XIII}

Mapa das Seções Típicas das Unidades Geológico-Geotécnicas 

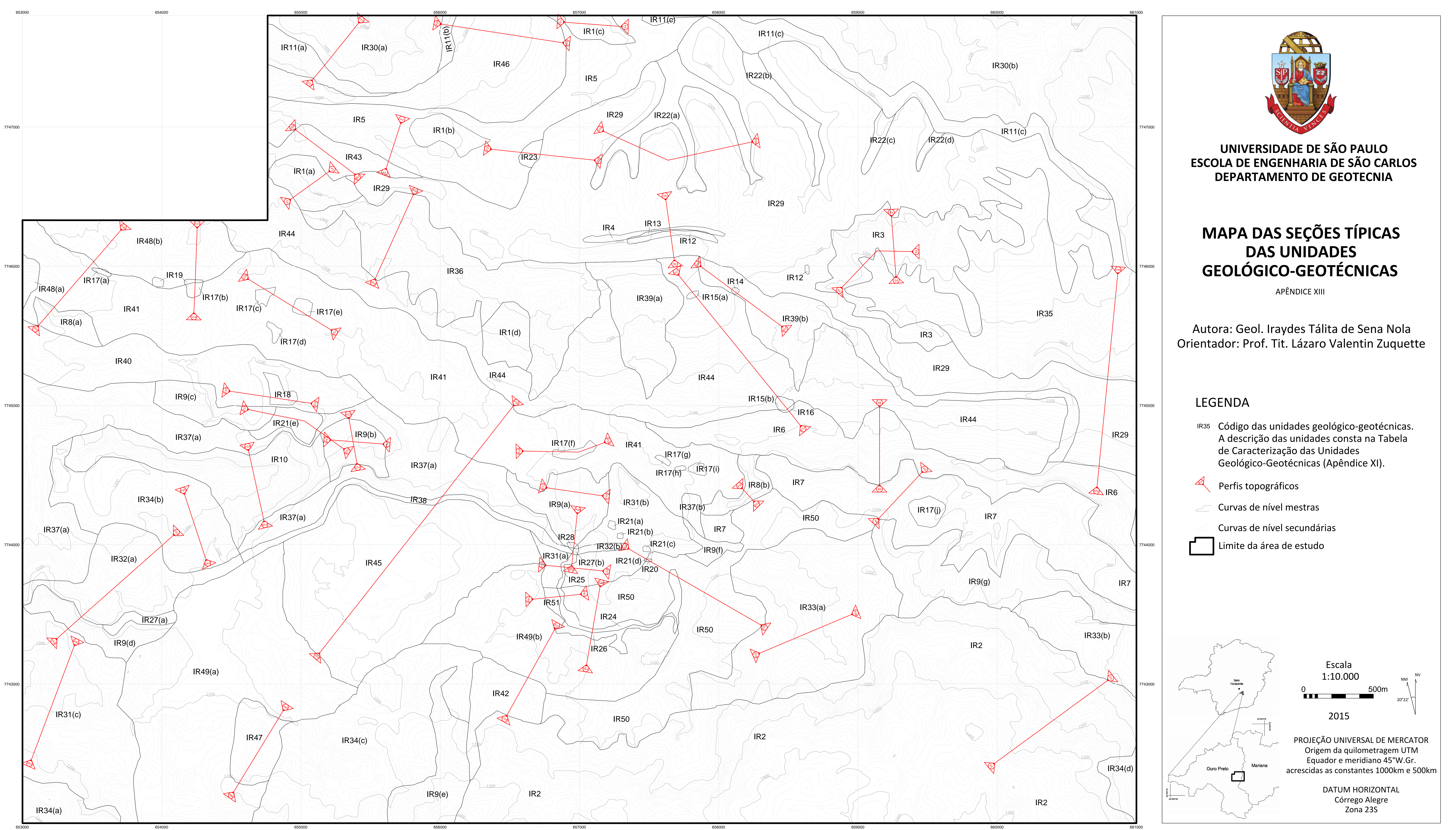


\section{APÊNDICE XIV}

Carta da Resistência ao Cisalhamento 

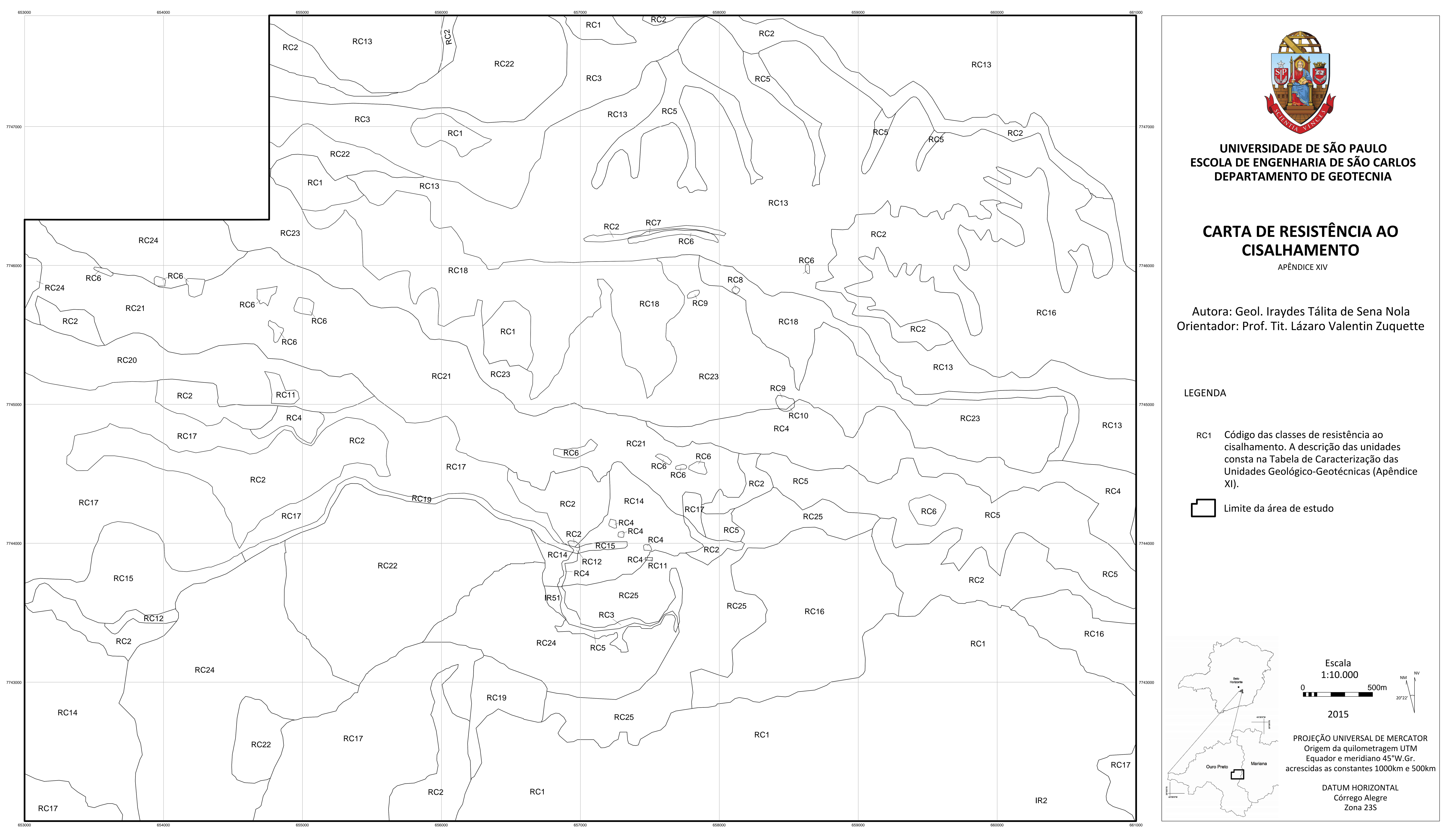


\section{APÊNDICE XV}

Carta de Contraste de Permeabilidade 

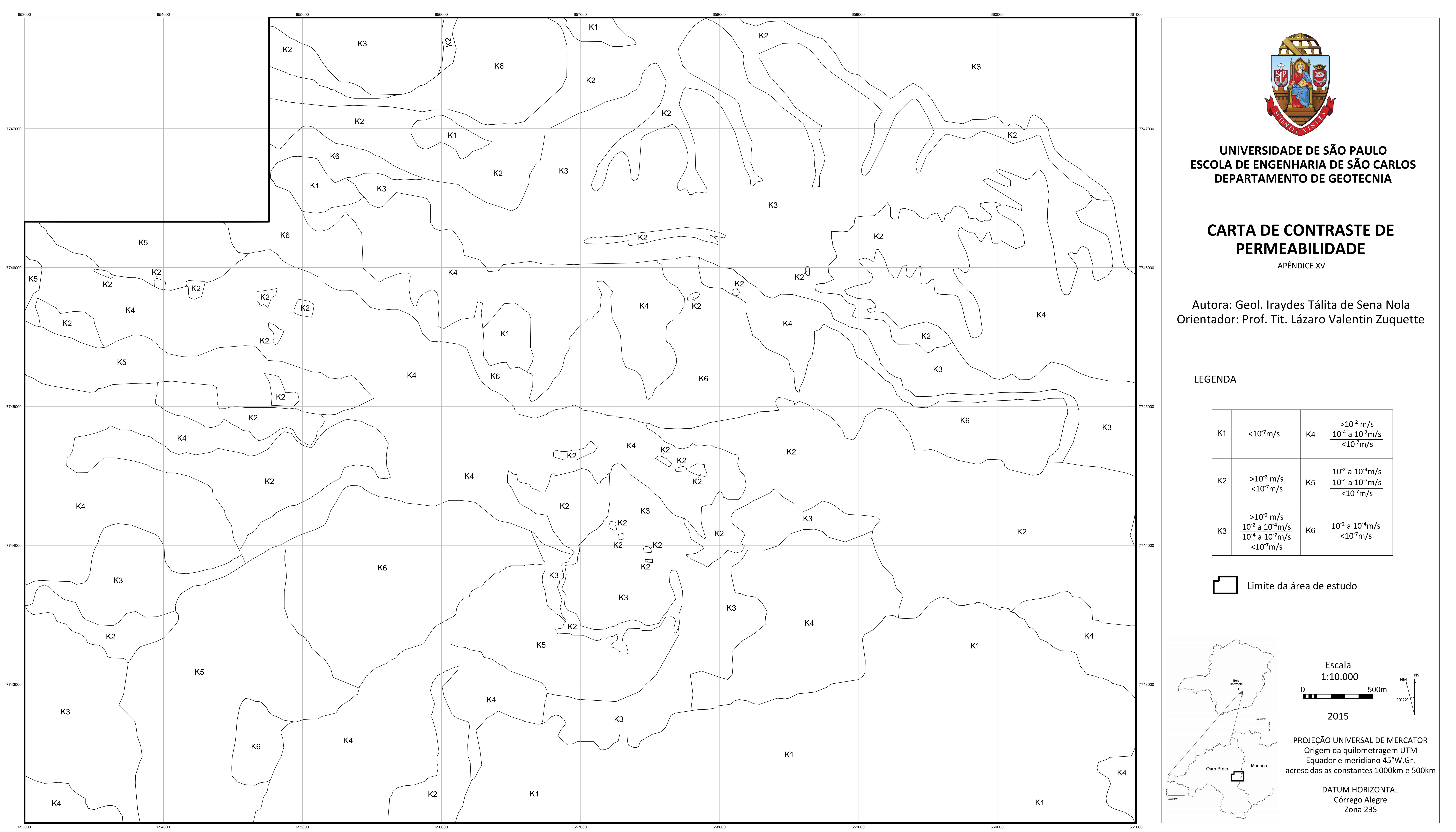


\section{APÊNDICE XVI}

Carta de Superfície Potencial de Ruptura 

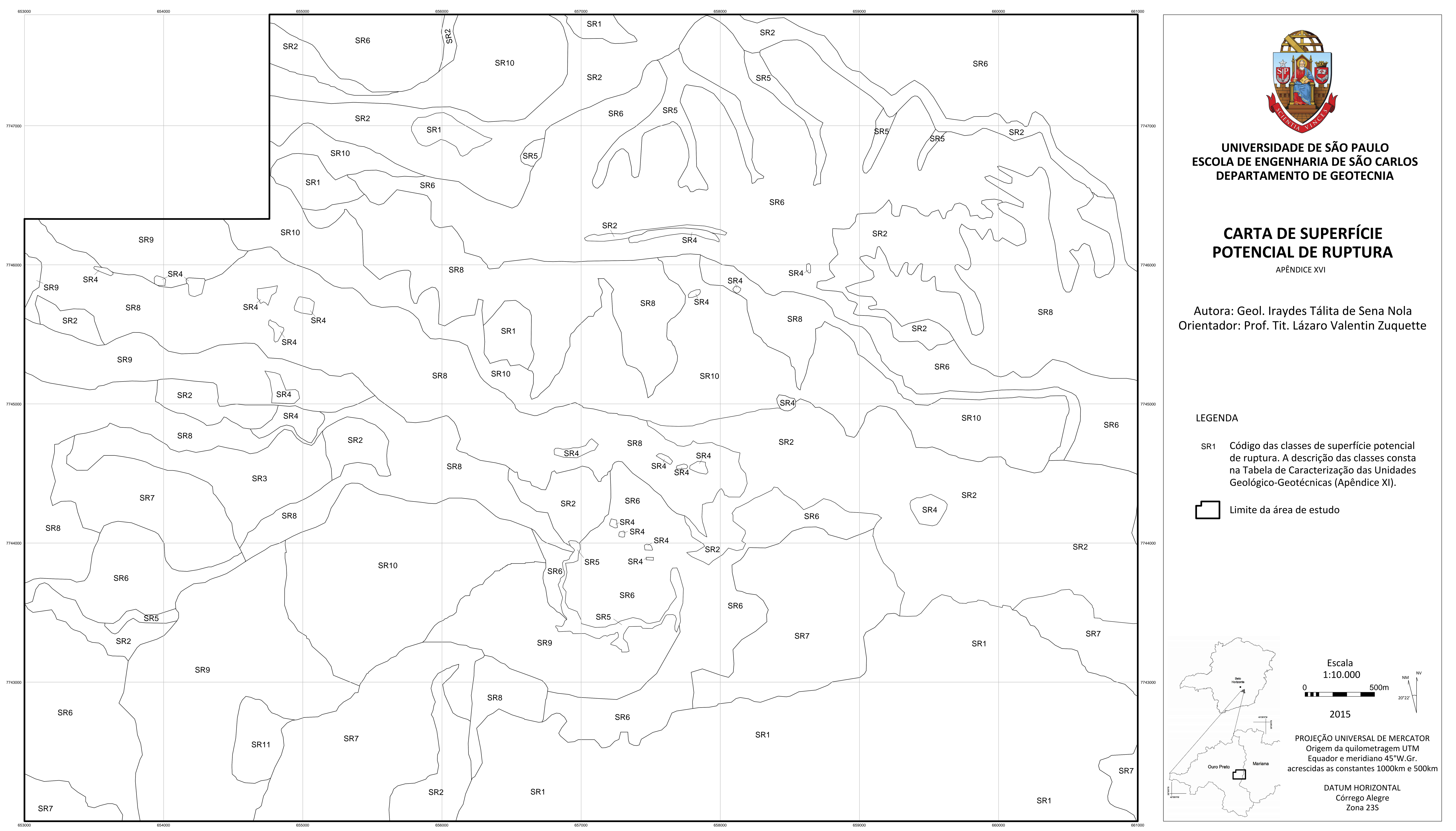